UNIVERSIDAde DE SÃo PaUlo

INSTITUTO DE FíSICA

\title{
Moléculas em Aglomerados e em Meio Líquido
}

Eudes Eterno Fileti

OrIEntador: Prof. Dr. Sylvio Canuto

Comissão Examinadora:

Prof. Dr. Sylvio Canuto - (USP)

Prof. Dr. José Antônio Roque da Silva - (USP)

Prof. Dr. José Manuel Riveros Nigra - (USP)

Prof. Dr. Rogério Custodio - (USP)

Prof. Dr. Marcos Antônio de Castro - (UFG)

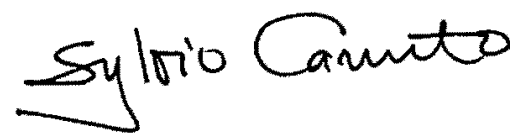

Tese de doutoramento apresentada ao Instituto de Física para a obtenção do título de Doutor em Ciências

\section{SB!-IFUSP}
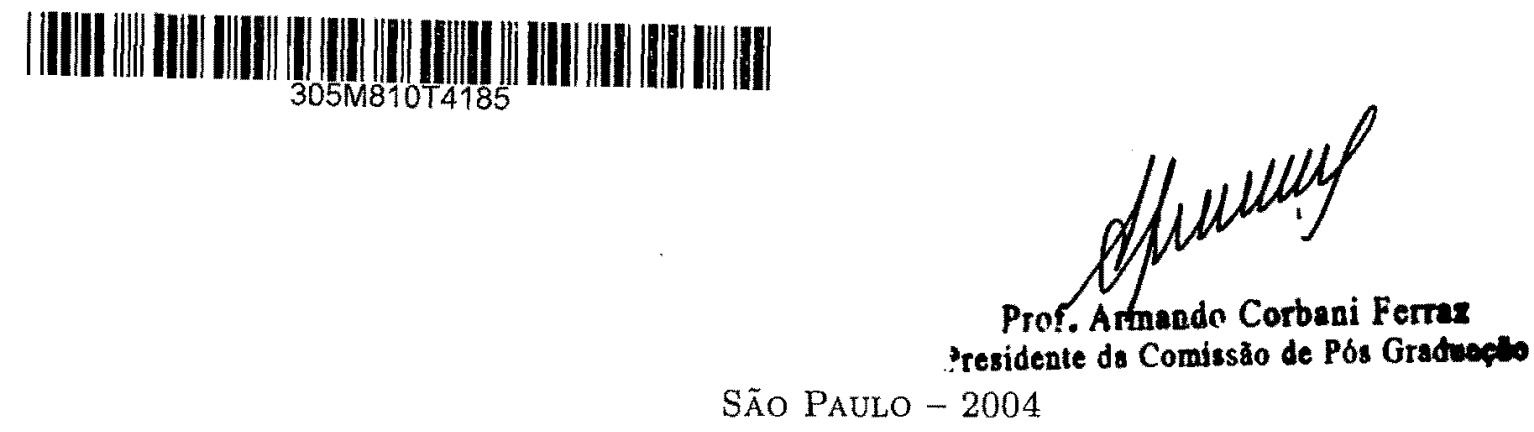

INSTITUTO DE FISICA

Serviço de Biblioteca e Informação

Tombo: 4185 


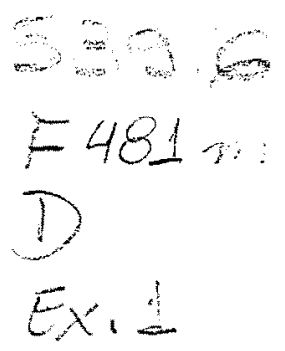

FICHA CATALOGRÁFICA

Preparada pelo Serviço de Biblioteca e Informação do Instituto de Física da Universidade de São Paulo Fileti, Eudes Eterno

Moléculas em Aglomerados e em Meio Líquido. São Paulo - 2004

Tese (Doutoramento) Universidade de São Paulo. Instituto de Física - Departamento de Física dos Materiais e Mecânica.

Orientador: Prof. Dr. Sylvio Canuto

Área de Concentração: Física

Unitermos

1. Física Molecular;

2. Física do Estado Líquido;

3. Física da Matéria Condensada;

4. Química Quântica.

USP/IF/SBI - 070/2004 


\section{Fundamental}

Agradeço ao Professor Sylvio por eu ter sido membro de seu grupo de pesquisa. Por permitir que sua experiência contribuísse para minha formação como pesquisador e como homem.

\section{Importante}

\section{Indispensável}

Agradeço também a valiosa colaboração da Professora Kaline com a qual contei desde da época em que fora minha orientadora no mestrado sendo muito útil até hoje.

Externo que a amizade de todos os colegas, professores e funcionários foi um fator muito importante para esta conquista. Sem ela o fardo teria sido pesado demais.

\section{Sinequanon}

Finalmente agradeço ao apoio financeiro do CNPq e da FAPESP, sem o qual o desenvolvimento e conclusão deste trabalho não seria possível. 


\section{Resumo}

As mudanças nas propriedades estruturais, eletrônicas, óticas e magnéticas de moléculas em aglomerados e em meio líquido são apresentadas. Para os aglomerados moleculares tais propriedades foram obtidas usando métodos $a b$ initio tradicionais de mecânica quântica em configurações otimizadas de mínima energia. A fase líquida é mais complexa e ainda hoje se mostra como um desafio teórico. Modelos convencionais para a descrição teórica dos efeitos de solvente, como o campo de reação auto-consistente e a aproximação de aglomerado rígido, apesar de largamente aplicados não satisfazem importantes características da fase líquida como por exemplo, a natureza estatística dos líquidos. Adicionalmente, interações específicas tais como, formação de ligações de hidrogênio e transferência de carga são mais difíceis de incluir. Modelos mais realísticos para tratar a estrutura eletrônica de sistemas líquidos envolvem algum tipo de simulação computacional. Entre estes, os métodos conhecidos como QM/MM são modelos híbridos aplicados com sucesso e que empregam tanto simulações clássicas como métodos de mecânica quântica. Existem hoje dois principais tipos de cálculos QM/MM. Nos cálculos convencionais, o sistema é particionado em duas regiões (clássica e quântica) e0 as interações são calculadas separada e simultaneamente. Nos cálculos seqüenciais QM/MM, as configurações do líquido são geradas via simulações clássicas e posteriomente submetidas à calculos quânticos. Neste trabalho a metodologia seqüencial (Simulaçao/MQ) foi empregada no estudo de sistemas em fase líquida, como soluções aquosas de piridina e metanol e líquidos homogêneos como benzeno e água. Empregando simulações Monte Carlo ou Dinâmica Molecular as estruturas do líquido são geradas à temperatura ambiente para subseqüentes cálculos quânticos. Os resultados para o líquido são comparados com aqueles obtidos para a molécula isolada e fornecem uma clara descrição dos efeitos de solvente. Entre as propriedades estudadas nesta tese estão energia de interação, momento de dipolo, freqüência vibracional, polarizabilidade, blindagem magnética e propriedades de espalhamento Raman e Rayleigh. 


\section{Conteúdo}

I Introdução, Metodologia e Propriedades 1

1 Introdução 3

2 Métodos $\quad 7$

2.1 Simulações . . . . . . . . . . . . . . . . . . 7

2.1.1 Monte Carlo Metropolis . . . . . . . . . . . . . 7

2.1.2 Dinâmica Molecular . . . . . . . . . . . . . . . . . 9 9

2.1.3 Condições periódicas de contorno . . . . . . . . . . . 10

2.1.4 Potencial intermolecular . . . . . . . . . . . . . . 11

2.1.5 Correlação estatística . . . . . . . . . . . . . . 12

2.1.6 Metodologia seqüencial Simulação/MQ . . . . . . . . . 13

2.1.7 Critérios para ligações de hidrogênio . . . . . . . . . . . 14

2.2 Métodos quânticos . . . . . . . . . . . . . . 15

2.2 .1 O método Hartree-Fock . . . . . . . . . . . . 15

2.2 .2 Teoria de perturbação . . . . . . . . . . . . . 17

2.2.3 Teoria funcional da densidade . . . . . . . . . . . . 19

3 Propriedades moleculares $\quad 21$

3.1 Energia . . . . . . . . . . . . . . . . . . 21

3.2 Polarizabilidades . . . . . . . . . . . . . . . 23

3.2 .1 Campo finito . . . . . . . . . . . . . 23

3.3 Taxas de despolarização e atividades de espalhamento . . . . . . 24

3.3.1 Espalhamento Rayleigh . . . . . . . . . . . . . . . 24

3.3.2 Espalhamento Raman . . . . . . . . . . . . . . 25

3.4 Blindagem magnética e deslocamento químico . . . . . . . . 27

3.4.1 Dependência orientacional da blindagem magnética . . . . 27

3.4 .2 Deslocamento químico . . . . . . . . . . . . 28 
4 Espalhamentos Raman e Rayleigh no complexo $\mathrm{CH}_{3} \mathrm{CN} \cdots \mathrm{H}_{2} \mathrm{O} 33$

4.1 Motivação . . . . . . . . . . . . . . . 33

4.2 Detalhes de cálculo . . . . . . . . . . . . 35

4.3 Resultados e discussão . . . . . . . . . . . . . . . . . 36

4.3.1 Geometrias, constantes rotacionais e momentos de dipolo 36

4.3.2 Deslocamento na freqüência vibracional . . . . . . . 38

4.3 .3 Energias de ligação . . . . . . . . . . . . . . . . 41

4.3.4 Atividades de espalhamento Rayleigh e Raman . . . . . . 43

4.4 Conclusões . . . . . . . . . . . . . . . . . . 45

5 Espalhamento Rayleigh em sistemas com ligação de hidrogênio 47

5.1 Motivação . . . . . . . . . . . . . . . . . 47

5.2 Detalhes de cálculo . . . . . . . . . . . . . . . . 49

5.3 Resultados e discussão . . . . . . . . . . . . . . . . . . 49

5.3.1 Polarizabilidades médias e anisotrópicas . . . . . . . . . 49

5.3.2 Taxas de despolarização e intensidades para o espalhamento Rayleigh . . . . . . . . . . . . . . . . . . 52

5.3.3 Espalhamento Rayleigh em isômeros . . . . . . . . . 54

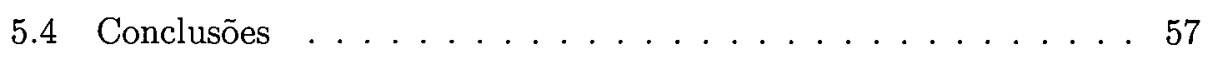

6 Propriedades RMN em complexos de metanol-água $\quad 59$

6.1 Motivação . . . . . . . . . . . . . . . . . 59

6.2 Detalhes de cálculo . . . . . . . . . . . . . . . 61 61

6.3 Resultados e discussão . . . . . . . . . . . . . . . . 61

6.3.1 As blindagens magnéticas absolutas . . . . . . . . . 61

6.3 .2 A população de Mulliken . . . . . . . . . . . 65

6.3.3 Metanol como aceitador de próton . . . . . . . . 66

6.3.4 Metanol como doador de próton . . . . . . . . 68

6.3.5 As componentes $\delta_{/ /}$e $\delta_{\perp}$ do deslocamento químico isotrópico 71

6.3.6 O efeito de relaxação do monômero . . . . . . . . . . . 73

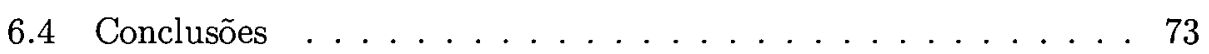

7 Estabilidades relativas de ligações de hidrogênio $\quad 77$

7.1 Motivação . . . . . . . . . . . . . . . 77

7.2 Detalhes de cálculo . . . . . . . . . . . . . 78

7.3 Resultados e discussões . . . . . . . . . . . 79 
8 Desordem térmica de ligações de hidrogênio em líquidos

8.1 Motivação . . . . . . . . . . . . . . . . . . 93

8.2 Detalhes de cálculo . . . . . . . . . . . . . . . . 94

8.2 .1 Simulação . . . . . . . . . . . . . . . . . . 94 94

8.2 .2 Identificação das ligações de hidrogênio . . . . . . . . . 94

8.2.3 Cálculos de mecânica quântica . . . . . . . . . . . 97

8.3 Resultados e discussão . . . . . . . . . . . . . . . . 97

8.4 Conclusōes . . . . . . . . . . . . . . . . . . . . . 103

9 Estabilidade dos complexos metanol-água em meio aquoso 105

9.1 Motivação . . . . . . . . . . . . . . . . . . . . . . . 105

9.2 Detalhes de cálculo . . . . . . . . . . . . . . . 106

9.2 .1 Simulação . . . . . . . . . . . . . . . 106

9.2 .2 Cálculos de mecânica quântica . . . . . . . . 107

9.3 Resultados e discussão . . . . . . . . . . . . . . . 107

9.3.1 Interação (1:1) em fase gasosa . . . . . . . . . . 110

9.3 .2 Interação $(1: 1)$ em fase líquida . . . . . . . . . 111

9.4 Conclusôes . . . . . . . . . . . . . . . . . . . 113

10 Polarizabilidade de dipolo do benzeno líquido 115

10.1 Motivação . . . . . . . . . . . . . . . . . 115

10.2 Detalhes de cálculo . . . . . . . . . . . . . . . 116

10.2 .1 Simulação . . . . . . . . . . . . . . 116

10.2.2 Cálculos de mecânica quântica . . . . . . . . . 117

10.3 Resultados e discussão . . . . . . . . . . . . . . . . 118

10.4 Conclusões . . . . . . . . . . . . . . . . 125

11 Deslocamentos químicos no líquido de água $\quad 127$

11.1 Motivação . . . . . . . . . . . . . . . . . . . . 127

11.2 Detalhes de cálculo . . . . . . . . . . . . . . 129

11.2 .1 Simulações . . . . . . . . . . . . . . . . 129

11.2.2 Cálculos de mecânica quântica . . . . . . . . . 130

11.3 Resultados e discussão . . . . . . . . . . . . . . . 131 
11.3.1 Blindagem magnética da fase gasosa . . . . . . . . . . 131

11.3.2 Blindagem magnética da fase líquida . . . . . . . . . 133

11.3.3 Bases localmente densas . . . . . . . . . . . . . 137

11.3.4 Deslocamento químico gás-líquido . . . . . . . . 138

11.4 Conclusões . . . . . . . . . . . . . . . . 146

$\begin{array}{ll}\text { IV Conclusões gerais } & 149\end{array}$

12 Conclusōes Gerais $\quad 151$

12.1 Conclusões Gerais . . . . . . . . . . . . . . . . 151

$\begin{array}{lll}V & \text { Apêndices } & 187\end{array}$

A Polarizabilidade elétrica 189

A.1 Respostas ao campo elétrico . . . . . . . . . . . . . . . . . 189

A.2 A polarizabilidade elétrica estática . . . . . . . . . . . 191

A.3 Polarizabilidades e propriedades moleculares . . . . . . . . . . 193

A.4 Polarizabilidades e espectroscopia molecular . . . . . . . . 195

A.5 Polarizabilidades e forças de dispersão . . . . . . . . . . 196

A.6 Constante dielétrica e susceptibilidade elétrica . . . . . . . . 199

B Espalhamentos Raman e Rayleigh 205

B.1 Espalhamento Raman . . . . . . . . . . . . . . . 205

B.2 Propriedades óticas das moléculas . . . . . . . . . 207

B.2.1 Propriedades direcionais da radiação emitida . . . . . . 207

B.2.2 Polarização do espalhamento Raman por uma molécula . 208

B.2.3 Transformação das componentes da polarizabilidade . . . 210

B.2.4 Média dos quadrados das componentes do tensor polarizabilidade . . . . . . . . . . . . . . . . 212

B.2.5 Taxas de despolarização do espalhamento Raman . . . . . 213

B.2.6 Taxas de despolarização do espalhamento Rayleigh . . . . 215

$\begin{array}{ll}\text { C Deslocamento químico } & 217\end{array}$

C.1 Considerações teóricas . . . . . . . . . . . . . . 217

C.1.1 A blingagem magnética . . . . . . . . . . . . 217

C.1.2 O método GIAO . . . . . . . . . . . . 224 
D Constantes, fatores de conversão e tabela periódica

D.1 Constantes fundamentais relacionadas . . . . . . . . 227

D.2 Fatores de conversão para energia . . . . . . . . . . 228

D.3 Fatores de conversão para comprimentos . . . . . . . . . 228

D.4 Tabela periódica . . . . . . . . . . . . . 228

E Artigos Publicados $\quad 229$ 


\begin{abstract}
The changes of structural, electronic, optical and magnetic properties of molecules in clusters and in liquid phase are presented. For molecular clusters such properties were obtained using traditional and well defined quantum mechanics ab initio methods in the minimum energy geometry-optimized configurations. The liquid phase is more complex and represents a current theoretical challenge. Conventional models for the theoretical description of solvent effects, such as self-consistent reaction field and rigid cluster approximation, although widely applied do not satisfy important characteristics of the liquid phase such as statistical nature of liquids. In addition, specific interactions such as the formation of hydrogen bonds and charge transfer are more difficult to include. More realistic models to treat the electronic structure of liquid systems include some sort of computer simulation. Among these the so-called $Q M / M M$ methods are successful hybrid models that uses both the classical simulation and quantum mechanics. There are now two main classes of $Q M / M M$ calculations. In the conventional $Q M / M M$ the system is partitioned into two regions (classical and quantum) and the interactions are calculated separated and simultaneously. In the sequential $Q M / M M$, the configurations of the liquid are generated via classical simulations and subsequently the quantum calculations are performed. In this work the sequential methodology (Simulation/MQ) is used to study molecular systems in the liquid phase as aqueous solutions of pyridine and methanol and homogeneous liquid as water and benzene. Using Monte Carlo or Molecular Dynamics simulations liquid structures at room temperature are generated for subsequent quantum mechanics calculations. The results for the liquid are compared with those obtained for the isolated molecule and give a clear picture of the liquid effects. Among the properties studied in this thesis are interaction energies, dipole moments, vibrational frequencies, polarizabilities, magnetic shielding, chemical shift and optical properties of the Raman and Rayleigh scattering.
\end{abstract}


Esta tese é baseada parcialmente nos seguintes trabalhos

- Rayleigh light-scattering of hydrogen-bonded clusters from ab initio calculations, E. E. Fileti, R. Rivelino, S. Canuto, J. Phys. B: At. Mol. Opt. Phys., $36,399,2003$

- Electronic changes due to thermal disorder of hydrogen bonds in liquids: Pyridine in aqueous environment, E. E. Fileti, K Coutinho, T. V. M. Malaspina, S. Canuto, Phys. Rev. E., 67, 61504, 2003

- Rayleigh and Raman light scattering in hydrogen bonded acetonitrile-water, E. E. Fileti, E. Rissi, S. Canuto, Theor. Chem. Acc., 110, 360, 2003

- Is there a favorite isomer for hydrogen-bonded methanol in water?, E. E. Fileti, Kaline Coutinho, S. Canuto, Adv. Quantum Chem., 47, 51, 2004

- A sequential Monte Carlo-quantum mechanics study of the dipole polarizability of liquid benzene, E. E. Fileti, S. Canuto, J. Comput. Meth. Science Eng., 4, em impressão, 2004. Edição Especial

- Relative Strength of Hydrogen Bond Interaction in Alcohol-Water Complexes, E. E. Fileti, P. Chaudhuri, S. Canuto, Chem. Phys. Lett., 400, 496, 2004.

- An ab initio NMR study of the hydrogen bond properties in methanol-water complexes, E. E. Fileti, S. Canuto, Int. J. Quantum Chem., 102, em impressão, 2005.

- Calculated infrared spectra of hydrogen bonded methanol-water, water-methanol and methanolmethanol complexes, E. E. Fileti, S. Canuto, Int. J. Quantum Chem., aceito para publicação, 2005.

- Isotropic and anisotropic chemical shifts in liquid water. A QM/MM study, E. E. Fileti, H. C. Georg, K. Coutinho, S. Canuto, (em preparação) 
i. 


\section{Parte I}

\section{Introdução, Metodologia e Propriedades}




\section{Capítulo 1}

\section{Introdução}

O entendimento teórico da estrutura eletrônica da fase gasosa, ou moléculas isoladas têm progredido enormemente nas últimas décadas. Desde o surgimento da equação de Schrödinger o progresso nos métodos, técnicas e algoritmos aliados ao avanço computacional permitiram que a teoria alcançasse status de complemento dos experimentos de laboratório. Contudo a maioria dos fenômenos químicos e físicos ocorrem não para moléculas isoladas mas para moléculas interagindo com o meio. Este é o caso, por exemplo da maioria dos experimentos químicos onde solventes estão sempre presentes. Isto leva à necessidade de se tratar a influência do meio sobre as propriedades moleculares. Para isto existem atualmente certos modelos teóricos com a finalidade de descrever a fase líquida. Um destes é o modelo de campo de reação auto consistente (SCRF), onde o soluto é tratado quanticamente dentro de uma cavidade enquanto que o solvente é descrito por sua constante dielétrica em torno desta cavidade [1-6]. Outro modelo é a aproximação de aglomerado rígido, onde algumas moléculas de solvente são consideradas explicitamente a fim de descrever as camadas de solvatação da molécula de soluto [7, 8]. Apesar de largamente aplicados nenhum dos métodos trata a fase líquida de forma realística; no caso do SCRF, embora tenha sido aplicado com sucesso a vários tipos de sistemas [5] não leva em conta. interações específicas como a ligação de hidrogênio, o que pode ocasionalmente conduzir a erros significativos. No caso dos aglomerados rígidos, ignora-se que um líquido possui natureza estatística $[9,10]$, evidenciada pela existência de vários arranjos geométricos possíveis de moléculas com probabilidade equiva- 
lente para uma dada temperatura diferente de zero. Assim, nota-se que um líquido não é fixo por nenhuma condição de mínima energia, de forma que a descrição da fase líquida por uma única estrutura rígida, não considera a desordem térmica que é uma característica fundamental. Uma aproximação mais consistente é a combinação de cálculos de mecânica quântica com cálculos de mecânica clássica, conhecida como QM/MM [11] e pode ser classificada como QM/MM híbrido $[12,13]$, onde a parte mais importante do sistema é tratada quanticamente e o resto classicamente, ou QM/MM seqüencial [14] onde as estruturas do líquido são geradas via simulações clássicas e em seguida submetidas a cálculos quânticos. Dessa maneira as propriedades eletrônicas de um líquido são melhor descritas por uma distribuição estatística [14-18].

Esta tese apresenta uma série de estudos envolvendo sistemas moleculares em interação com o meio. Serão tratados neste trabalho tanto complexos e aglomerados moleculares, como sistemas em fase líquida. Em ambos os casos o tratamento dado às ligações de hidrogênio é apropriado uma vez que o meio interagente é considerado explicitamente. A descrição de um aglomerado ou complexo é de grande interesse em experiências de jet-cooling e não deve ser confundida com aquela encontrada num líquido. Enquanto num aglomerado a estrutura é fixa por uma condição de energia mínima, num ambiente líquido existem várias configurações governadas pela temperatura e que são relacionadas à desordem natural de um líquido. Portanto o sítio aceitador de próton numa molécula de soluto experimenta uma grande desordem térmica local. Como mencionado acima, a descrição desta desordem é um grande desafio e é necessária para compreender a importância dos efeitos eletrônicos locais. $\mathrm{O}$ entendimento da natureza das ligações de hidrogênio formadas entre a molécula de soluto e as moléculas de água é crucial na descrição de vários processos biomoleculares e de solvatação [19].

Neste trabalho são apresentados os resultados obtidos para uma série de sistemas (complexos, aglomerados ou líquidos) e as modificações nas suas propriedades devidas ao meio são analisadas. O trabalho é dividido basicamente em cinco partes. Na primeira são apresentados, além desta introdução, os capítulos referentes à metodologia empregada e às principais propriedades 
moleculares determinadas aqui. Nas segunda e terceira partes são apresentados os resultados para os aglomerados e líquidos, respectivamente. Na quarta parte são feitas conclusōes e considerações gerais e é dado o conjunto de referências bibliográficas utilizadas nesta tese.

Este texto é escrito de forma que sua compreensão básica seja dada apenas pelas quatro primeiras partes. Contudo houve a preocupação com a descrição da teoria envolvida nos cálculos das propriedades de interesse. Assim na quinta parte são apresentados três apêndices referentes a este conteúdo. Estes apêndices, embora não sejam necessários para a compreensão do trabalho da forma que está exposto, são importantes para o leitor interessado em maiores detalhes sobre as propriedades em estudo. 


\section{Capítulo 2}

\section{Métodos}

Este capítulo descreverá os métodos teóricos empregados na caracterização dos sistemas moleculares estudados neste trabalho. Na primeira parte serāo apresentadas as técnicas de simulações clássicas, Monte Carlo e Dinâmica Molecular, bem como a metodologia seqüencial Siulação-Mecânica Quântica. Na seqüencia, também serão descritos os métodos quânticos (Hartree-Fock, Teoria de Perturbação e Teoria Funcional da Densidade) para a determinação de propriedades moleculares.

\subsection{Simulações}

\subsubsection{Monte Carlo Metropolis}

O princípio básico do método Monte Carlo Metropolis (MCM) é produzir configuraçōes com a distribuição de probabilidades

$$
P\left(\Gamma_{i}\right)=\frac{\varrho\left(\Gamma_{i}\right)}{Z}
$$

onde $\dot{z}$ representa um estado do espaço de configurações $\Gamma, Z$ é a função de partição do sistema e $\varrho\left(\Gamma_{i}\right)$ é a densidade de probabilidade dada por $e^{-\frac{U_{i}}{k T}}$, em que $U_{i}=U\left(\Gamma_{i}\right)$ é a energia do estado $i, T$ é a temperatura e $k$ a constante de Boltzmann. O método consiste em fornecer uma estimativa para a média de uma propriedade qualquer do sistema, $\langle f\rangle$, de forma simplificada. Utilizando a mecânica estatística tem-se que [20-23]:

$$
\langle f\rangle=\frac{1}{Z} \sum_{i}^{M} f\left(\Gamma_{i}\right) \exp \left(-\frac{U\left(\Gamma_{i}\right)}{k T}\right) .
$$


Entretanto utilizando o MCM um certo número $L$ de estados é produzido de acordo com a probabilidade $P\left(\Gamma_{i}\right)$, de forma que a equação anterior, escrita como a média aritmética

$$
\langle f\rangle=\frac{1}{L} \sum_{i}^{L} f\left(\Gamma_{i}\right)
$$

é uma estimativa para a propriedade $f$. O problema então se reduz à geração de estados com probabilidade $P\left(\Gamma_{i}\right)$. Isto pode ser resolvido utilizando um procedimento de amostragem ponderada, que gera uma cadeia de Markov. Uma característica importante deşe procedimento é que a função de partição, $Z$, não precisa ser determinada mas somente as probabilidades relativas dos diferentes estados $[24,25]$. Isto é muito mais fácil de ser obtido uma vez que é requerida somente a mudança na energia de um estado para outro.

O desenvolvimento da simulação se dá a partir de movimentos sucessivos de cada átomo dentro da caixa, com uma amplitude máxima determinada. Como muitos destes movimentos podem ser rejeitados por aumentar a energia do sistema, aplica-se um critério de auto-ajuste do deslocamento para que a razão entre o número de movimentos aceitos e movimentos rejeitados fique em torno de 0.5. Esta razão é comumente utilizada [10] e proporciona uma boa razão custo/benefício, onde o custo representa o tempo de processamento e o benefício corresponde à minimização do número de passos necessários para descorrelacionar as configurações.

A probabilidade de existência de uma configuração qualquer antes de um movimento atômico, na distribuição de Boltzmann é dada por:

$$
P_{a}=\exp \left(-\frac{U_{a}}{k T}\right) \text {. }
$$

Após um movimento atômico aleatório a probabilidade da nova configuração é:

$$
P_{d}=\exp \left(-\frac{U_{d}}{k T}\right)
$$

Assim, de acordo com as equaçōes 2.4 e 2.5 tem-se:

$$
\frac{P_{d}}{P_{a}}=\exp \left[-\frac{\left(U_{d}-U_{a}\right)}{k T}\right]=\exp \left(-\frac{\Delta U}{k T}\right) .
$$

Se $\Delta U \leq 0$, ou seja, se o movimento levou o sistema para um estado de energia igual ou mais baixa, permite-se o movimento e coloca-se a molécula 
nesta nova posição, mas se $\Delta U>0$ a configuração é aceita com probabilidade $\exp \left(-\frac{\Delta U}{k T}\right)$. Para aceitar a configuração neste caso, um número aleatório $\xi$ uniforme entre 0 e 1 é gerado, ou seja, $0 \leq \xi<1$. O número é comparado com a probabilidade dada pela expressão 2.6. Se este número for menor ou igual à probabilidade o movimento é aceito, senão ele é rejeitado e a molécula continua na posição anterior ao movimento. Este procedimento é repetido até que $N$ moléculas sejam visitadas, sendo que cada visita é definida como um passo MCM.

\subsubsection{Dinâmica Molecular}

A produção de configurações via Dinâmica Molecular [26-29] é obtida através da solução das equações de Newton para cada uma das moléculas da caixa, a partir de posições e velocidades iniciais e do conhecimento da força que atua em cada molécula num determinado instante. Calcula-se assim as posições e velocidades de cada molécula ao fim de intervalos de tempo sucessivos, ou seja, obtém-se a evolução temporal do sistema.

As forças que atuam na molécula $i$ pode ser obtidas através de:

$$
\mathbf{F}=-\nabla U(r)=m_{i} \frac{d^{2} \mathbf{r}_{i}(t)}{d t^{2}}
$$

onde $U(r)$ é a energia potencial total das interações entre as moléculas de massa $m_{i}$ e que depende apenas do módulo $r$ da distância entre elas.

Freqüentemente, basta escolher uma forma simples de $U(r)$. As suas características mais importantes são a forte repulsão para pequenos valores de $r$ e a fraca atração para valores grandes de $r$. Uma das formas mais comuns é o potencial de Lennard-Jones, que será comentado na próxima seção.

Existem vários métodos numéricos para resolver as equações 2.7 $[10,30]$. Neste trabalho foi empregado o algoritmo leapfrog [31]. Este algoritmo é largamente usado para se integrar as equações de movimento (é uma variação do algoritmo de Verlet [32]) e foi eleborado para melhorar a avalição das velocidades.

Em contraste ao método Monte Carlo, Dinâmica Molecular é deter- 
minística no sentido de que dado um conjunto de posições e velocidades iniciais, a evolução temporal subseqüente é em princípio completamente determinada. O computador calcula uma trajetória num espaço de fase de $6 N$ dimensões ( $3 N$ posições e $3 N$ momentos). Contudo, tal trajetória não é usualmente relevante por si só. Como Monte Carlo, Dinâmica Molecular é um método estatístico e consiste numa forma de se obter configuraçōes distribuidas de acordo com uma função de distribuição estatística ou um ensemble estatístico.

\subsubsection{Condições periódicas de contorno}

O comportamento de sistemas finitos é bastante diferente do comportamento de sistemas macroscópicos. A menos que se queira simular aglomerados de átomos ou moléculas, onde se tem um número de constituintes bem definido, o número de partículas usadas para simular as propriedades de bulk de sistemas macroscópicos tem papel fundamental. Independente de quão grande seja o sistema que possa ser tratado via simulação computacional, o número de partículas $N$ ainda seria desprezível comparado ao número de partículas contidas num sistema macroscópico (da ordem de $10^{23}$ ). Para um sistema macroscópico a razão entre o número de átomos na superfície e o número total de átomos é desprezível. Contudo, o número típico de partículas que pode ser tratado por simulações computacionais atualmente é da ordem de $10^{6}$. Neste caso a fração de átomos na superfície passa a ser significante e o comportamento do sistema passa a ser interferido por efeitos de superfície. A solução mais conveniente para minimizar tais efeitos é o uso de condições periódicas de contorno. Esta condição implica que os átomos são confinados numa caixa e esta caixa é replicada infinitamente em todas as direções Cartesianas, preenchendo completamente o espaço. Todas as partículas "imagens"movem-se solidariamente com sua "original". Quando uma particula entra ou sai da região de simulação uma imagem da particula sai ou entra nesta região, tal que o número de partículas simuladas é sempre conservado.

Este método introduz uma periodicidade indesejada no sistema. Contudo é possível eliminá-la implantando um raio de corte. Este artifício faz com que a interação entre as moléculas só se dê através de uma distância menor 
que a metade do lado da caixa impondo que uma molécula não interaja com outra molécula e a respectiva imagem simultaneamente. Outra exigência é de que a caixa tenha a mesma densidade, $N / L^{3}$, que a do sistema real.

\subsubsection{Potencial intermolecular}

Em sistemas moleculares, a interação total entre as moléculas é geralmente composta de interações de pares e de ordens superiores. Assim a energia potencial total pode ser escrita como [10]:

$$
U(r)=\sum_{i=1} \sum_{i<j} \phi(i j)+\sum_{i=1} \sum_{i<j} \sum_{j<k} \phi(i j k)+\cdots
$$

onde $\phi(i j)$ e $\phi(i j k)$ representam a energia de pares e a contribuição de três corpos respectivamente. Restrições do tipo $i<j$ são impostas para evitar que o mesmo par de átomos seja contado duas vezes. Como para fase condensada o termo de pares é dominante na expressão 2.8 , em simulações computacionais é comum considerar somente este termo para a energia potencial total. Assim, neste trabalho, o potencial de interação é assumido como sendo um potencial de pares efetivo que leva em conta implicitamente todos os termos de ordem superior.

Aqui será considerado, na maioria dos casos, o potencial intermolecular Lennard-Jones [33] adicionado ao potencial Coulombiano. Este potencial é um modelo comumente usado para representar interações moleculares e pode ser expresso na seguinte forma:

$$
U\left(r_{i j}\right)=4 \varepsilon_{i j}\left[\left(\frac{\sigma_{i j}}{r_{i j}}\right)^{12}-\left(\frac{\sigma_{i j}}{r_{i j}}\right)^{6}\right]+\frac{q_{i} q_{j}}{r_{i j}} .
$$

onde $\varepsilon_{i j}$ e $\sigma_{i j}$ são os parâmetros do potencial que podem ser obtidos usando $\varepsilon_{i j}=\left(\varepsilon_{i} \varepsilon_{j}\right)^{1 / 2}$ e $\sigma_{i j}=\left(\sigma_{i} \sigma_{j}\right)^{1 / 2}[10]$. $\varepsilon$ governa a intensidade da interação enquanto que $\sigma$ define uma escala de comprimento. Estes parâmetros são escolhidos para ajustar certas propriedades físicas do sistema. $q_{i}$ é a carga no átomo $i$ e $r_{i j}$ representa a distância entre os átomos $i$ e $j$.

O termo proporcional a $r_{i j}^{-12}$, dominante em distância curtas, modela a repulsão entre os átomos. Este termo tem a forma um tanto quanto 
arbitrária e outros expoentes ou até mesmo outras formas funcionais são preferidas.

O termo atrativo proporcional a $r_{i j}^{-6}$, dominante em distâncias maiores, modela as forças de dispersão de van der Waals devidas às interações entre dipolos. No apêndice A, são discutidas a natureza das forças de dispersão bem como a origem da dependência $r_{i j}^{-6}$.

\subsubsection{Correlação estatística}

A análise da correlação estatística permite calcular o intervalo de configurações para que o sistema evolua de uma configuração para outra de forma que esta última não tenha correlação estatística com a primeira. Em estudos anteriores $[14,18,34,35]$ verificou-se que é suficiente considerar configuraçōes com cerca de $10 \%$ de correlação estatística.

O intervalo de correlação estatística é definido como $[36,37]$ :

$$
\tau=\int_{0}^{\infty} C(i) d i
$$

onde

$$
C(i)=\frac{\left\langle E_{j} E_{j+i}\right\rangle_{l-i}-\left\langle E_{j}\right\rangle_{l-i}\left\langle E_{j+i}\right\rangle_{l-i}}{\left\langle E^{2}\right\rangle_{l}-\langle E\rangle_{l}^{2}}
$$

é função de autocorrelação da energia configuracional, $i$ representa o intervalo no número de passos da simulação e $l$ o tamanho da cadeia. Como as simulações são finitas não é possível calcular $C(i)$ para valores de $i$ muito grandes, o que torna a integração da equação 2.10 inviável. Para resolver este problema é necessário fazer um ajuste dos valores de $C(i)$ por uma função integrável neste intervalo. Um ajuste sugerido para processos Markovianos [36,37] é dado por:

$$
C(i)=c_{1} e^{-\frac{i}{\tau_{1}}}+c_{2} e^{-\frac{i}{\tau_{2}}}
$$

de forma que:

$$
\tau=c_{1} \tau_{1}+c_{2} \tau_{2}
$$

onde $c_{1}, \tau_{1}, c_{2}$ e $\tau_{2}$ são obtidos do ajuste. Assim, como se deseja realizar cálculos com configurações estatisticamente independentes, deve-se através de cálculos preliminares, determinar o intervalo de correlação. 


\subsubsection{Metodologia seqüencial Simulação/MQ}

Uma vez que a fase líquida é caracterizada pela grande quantidade de átomos ou moléculas seu tratamento através de métodos quânticos tradicionais se torna inviável. Uma aproximação recente que tem produzido bons resultados é a combinação de cálculos de mecânica quântica e métodos de mecânica molecular (QM/MM - quantum mechanics-molecular mechanics) [11]. Como mencionado na introdução, existem de fato duas vertentes para este tipo de aproximação. Numa o sistema é particionado em duas regiões nas quais as interações são calculadas separada e simultaneamente, como tradicionalmente é feito. Outra é a proposta de Canuto e Coutinho [14] onde a parte clássica é realizada antes da parte quântica. Assim, para o estudo das propriedades de moléculas em líquido as estruturas do líquido são, primeiramente, geradas usando simulação Monte Carlo Metropolis ou Dinâmica Molecular. Depois, as configurações estatisticamente relevantes são separadas e submetidas a cálculos de mecânica quântica (discutidos a seguir). Obtem-se a média estatisticamente convergida sobre os valores obtidos nos cálculos de mecânica quântica. Vários cálculos quânticos são necessários para obter um ensemble médio necessário para caracterizar a natureza estatística do líquido [34,38]. Esta é uma aproximação conceitualmente segura, uma vez que o sistema líquido é explicitamente considerado e um ensemble estatístico apropriado é usado. Determinados estudos através desta metodologia podem necessitar cuidados uma vez que certos efeitos quânticos sobre a estrutura eletrônica (tunelamento, por exemplo) não podem ser apropriadamente descritos se as interações entre as moléculas na simulação forem tratadas classicamente.

Uma vez que as simulações são regidas pela estatística de Boltzmann o valor médio de uma determinada propriedade $A$ obtida a partir das estruturas das simulações pode ser obtido através de uma média simples sobre o número de configurações utilizado, $N$, isto é:

$$
\langle A\rangle=\frac{1}{N} \sum_{i}^{N} A_{i} .
$$

É sabido que valores não correlacionados da propriedade $A_{i}$ produzem uma 
distribuição normal com desvio padrão, $s$, dado por:

$$
s=\sqrt{\frac{N}{N-1}\left[\left\langle A^{2}\right\rangle-\langle A\rangle^{2}\right]}
$$

e um erro estatístico, $\Delta$, dado simplesmente por

$$
\Delta=\frac{s}{\sqrt{N-1}}
$$

Convém notar que para $N$ grande o desvio padrão $s$ converge para um valor constante enquanto que o erro estatístico $\Delta$ tende a zero. Dessa maneira o valor final da propriedade será representado pela distribuição $\langle A\rangle \pm s$ que descreve a distribuição gaussiana e contém $68 \%$ dos valores.

\subsubsection{Critérios para ligações de hidrogênio}

Um importante ponto nesta metodologia é a identificação, em sistemas solvatados, das ligações de hidrogènio nas estruturas geradas pela simulação. Ligações de hidrogênio são normamente extraídas da simulação usando a função de distribuição radial de pares. Ela fornece a coordenação das moléculas de água em torno do soluto mas não assegura que todas as moléculas vizinhas realmente fazem ligações de hidrogênio com o soluto [38-42]. Este ponto tem sido objeto de grande interesse e a definição de ligação de hidrogênio num líquido não é livre de ambigüidades. Um procedimento eficiente pode ser obtido usando o critério energético em adição ao critério geométrico [38-41,43,44]. Aqui, são considerados tais critérios; a distância entre o átomo aceitador de próton, $A$, e o átomo doador de próton, $D$ (ligado covalentemente ao hidrogênio da ligação), $R_{A-D}$, o ângulo $\theta(A \hat{D} H)$ e a energia de ligação. As condições geométricas $(R$ e $\theta)$ são obtidas a partir das funções de distribuição radial e angular. Para o critério energético, é importante analisar a distribuição de energia de pares. Usando estes critérios nas configurações obtidas pela simulação é possível encontrar o número de ligaçōes de hidrogênio formadas no átomo de interesse. Conforme o problema que está se tratando todas as estruturas com ligações de hidrogênio podem ser levadas a cálculos quânticos. Em determinados casos as configurações que formam apenas uma ligação de hidrogênio são as configurações de interesse, assim o número de configuraçōes a ser estudado é diminuído. 


\subsection{Métodos quânticos}

A determinação de propriedades quânticas de um sistema baseia-se na solução da equação de Schrödinger [45-47]:

$$
H \psi=E \psi
$$

Na descrição de um líquido esta equação deve ser resolvida para todas as estruturas advindas da simulação e para isto vários métodos estão disponíveis na literatura científica e sāo brevemente discutidos aqui. Nesta discussão é dado maior enfoque ao aspecto qualitativo do que ao aspecto quantitativo dos métodos, dada a grande difusão de tais métodos nos meios científicos. De qualquer forma houve a preocupação de sugerir um abundante conjunto de referências onde o leitor poderá encontrar todos os elementos matemáticos de cada método e algum aspecto qualitativo, por ventura, não apresentado aqui.

\subsubsection{O método Hartree-Fock}

No cálculo da estrutura eletrônica de uma molécula o Hamiltoniano da equação 2.17 depende apenas das coordenadas dos elétrons e apenas parametricamente das coordenadas dos núcleos. Born e Oppenheimer mostraram [48-50] que em boa aproximação os movimentos dos elétrons e dos núcleos podem ser considerados separadamente. Para isto eles se basearam na grande diferença entre as massas do elétron e dos núcleos. Devido à esta grande diferença entre as massas, os elétrons podem responder quase instantaneamente aos deslocamentos dos núcleos. Assim ao invés de se tentar resolver a equação de Schrödinger para todas as partículas simultaneamente é possivel considerar os núcleos fixos em suas posições e resolver a equação para os elétrons no potencial estático criado pelos núcleos naquele arranjo particular.

Estando os núcleos fixos, assume-se agora que a interação detalhada entre os elétrons é trocada por um potencial de interação médio, no qual os elétrons interagem com uma distribuição eletrônica média devida aos outros elétrons. Esta é a aproximação de campo médio ou Hartree-Fock [51-54]. Podese escrever uma função de onda teste na qual cada elétron ocupa uma função 
denominada spin-orbital [45-47,55-58]. Desta forma a função de onda toma a forma:

$$
\psi=A\left(\psi_{1}\left(\tau_{1}\right) \ldots \psi_{N}\left(\tau_{N}\right)\right)
$$

Aqui $A$ é um operador antissimetrizante que assegura que a função de onda como um todo obedece o princípio de Pauli, isto é, é antissimétrica com respeito a permutação de qualquer elétron. As funções $\psi_{i}$ são os orbitais Hartree-Fock, $\tau_{i}$, denota as coordenadas espaciais e as coordenadas de spin.

Os orbitais Hartree-Fock são funções desconhecidas e podem ser determinadas usando o princípio variacional [55-58]. O princípio variacional diz que para uma função de onda teste $\psi(\alpha)$, a energia funcional:

$$
E(\alpha)=\frac{\langle\psi(\alpha)|H| \psi(\alpha)\rangle}{\langle\psi(\alpha) \mid \psi(\alpha)\rangle}
$$

pode ser feita estacionária com respeito aos parâmetros $\alpha$. Assim a solução resultante define um conjunto de orbitais ótimos dados por:

$$
\hat{F} \phi(i)=\varepsilon \phi(i)
$$

onde $\hat{F}(i)$ é o operador de Fock e $\varepsilon$ é a energia do orbital $\phi(i)$. Para sistemas de camada fechada $\hat{F}(i)$ é dado por

$$
\hat{F}(i)=\hat{h}(i)+\sum_{l=1}^{n} 2 \hat{J}_{l}(i)-\hat{K}_{l}(i)
$$

onde $\hat{h}$ é o operador de um elétron do Hamiltoniano, $\hat{J}$ é operador de Coulomb responsável pela repulsão Coulombiana entre os elétrons e $\hat{K}$ é o operador de troca responsável pela mudança na energia devido aos efeitos de correlação de spin $[45-47,55-58]$.

Naturalmente as funções Hartree-Fock não são uma representação completa da estrutura eletrônica, isto porque a interação verdadeira entre os elétrons não acontece via potencial médio mas sim através da repulsão Coulombiana entre os elétrons. Assim, o movimento eletrônico é mais correlacionado que no modelo Hartree-Fock devido à repulsão Coulombiana. A diferença entre a energia não-relativística exata de um sistema e a energia Hartree-Fock foi denominada por Löwdin [59] como energia de correlação. À primeira vista a 
energia de correlação parece um tanto quanto desimportante devido à pequena fração da energia total que ela representa. De fato para átomos da primeira linha e moléculas por eles formadas, a energia Hartree-Fock é tipicamente maior que $99 \%$ da energia total. Contudo as diferenças de energia que são de interessse em química, tais como energia de ligação 3.1 , são também $1 \%$ ou menos da energia total. Portanto não é surpreendente o fato de que a aproximação Hartree-Fock não seja adequada para descrever vários fenômenos de interesse. Desta forma surge a necessidade de métodos que levam em conta correlação eletrônica e que são analisados a seguir.

\subsubsection{Teoria de perturbação}

A aplicação da teoria de perturbação para um sistema composto por diversas partículas interagentes é geralmente chamado de teoria de perturabação de muitos corpos (MBPT). A teoria de perturbação para se tratar problemas de mecânica quântica foi desenvolvida por Schrödinger [60] e adaptada para o estudo de sistemas moleculares por Møller e Plesset [61]. Esta seçāo descreve o meio pelo qual a correlação eletrônica pode ser tratada, considerando-a como uma perturbação sobre o sistema. Para tal é necessário solucionar o problema do estado estacionário da equação de Schrödinger no caso em que o Hamiltoniano for escrito da seguinte forma $[59,60,62-65]$ :

$$
H=H^{(0)}+\lambda H^{(1)} .
$$

Assume-se aqui que $H^{(0)}$ é o Hamiltoniano de um problema solúvel, com autovalores e autofunções conhecidos e que o parâmetro $\lambda$ pode ser arbitrariamente pequeno. O termo $\lambda H^{(1)}$ representa uma perturbação enquanto $H^{(0)}$ é referido como Hamiltoniano não perturbado. Por exemplo, quando um campo elétrico (ou magnético) externo é aplicado a um sistema não perturbado, pode-se considerar $\lambda$ como a intensidade do campo e $H^{(1)}$ como o operador momento de dipolo elétrico (ou magnético). Neste caso $\lambda$ tem um significado físico direto e é apropriado pensar em um processo no qual $\lambda$ aumenta gradualmente seu valor a partir do zero até certa magnitude. Contudo, existem casos, em que o Hamiltoniano está dividido em duas partes artificialmente. O que importa 
em tais casos é que uma parte possa ser considerada pequena em comparação com a outra. Embora o parâmetro perturbação (colocando $\lambda=1$ ) possa ser descartado é conveniente mantê-lo para que não se perca de vista a ordem da aproximação; um termo contendo $\lambda^{n}$ é um termo de $n$-ésima ordem.

Assume-se aqui que todos os autovalores, $E_{n}^{(0)}$, e autofunções, $\psi_{n}^{(0)}$, do Hamiltoniano não perturbado são conhecidos. Eles satisfazem a

$$
H_{n}^{(0)} \psi_{n}^{(0)}=E_{n}^{(0)} \psi_{n}^{(0)}
$$

Quando uma perturbação é adicionada ao Hamiltoniano, os autovalores e as autofunçōes mudam, mas suas mudanças são contínuas em $\lambda$. Assume-se também que o estado considerado aqui é não degenerado. Finalmente assumindo que o conjunto $\left\{\psi_{n}^{(0)}\right\}$ é ortonormal e completo, expande-se ambos os autovalores e as autofunções em termos do parâmetro $\lambda[45-47,55-58]$ :

$$
\begin{aligned}
& E_{n}=E_{n}^{(0)}+\lambda E_{n}^{(1)}+\lambda^{2} E_{n}^{(2)}+\cdots \\
& \psi_{n}=\psi_{n}^{(0)}+\lambda \psi_{n}^{(1)}+\lambda^{2} \Psi_{n}^{(2)}+\cdots .
\end{aligned}
$$

Feito isto não é difícil verificar que $[45-47,55-58]$

$$
E_{n}^{(1)}=\left\langle\psi_{n}^{(0)}\left|H^{(1)}\right| \psi_{n}^{(0)}\right\rangle
$$

e

$$
E_{n}^{(2)}=-\sum_{m \neq n} \frac{\left|\left\langle\psi_{m}^{(0)}\left|H^{(1)}\right| \psi_{n}^{(0)}\right\rangle\right|^{2}}{E_{m}-E_{n}}
$$

Claro que todos os outros termos de ordens superiores são dados por expressōes similares, tornando-se, a cada ordem, mais complexos.

É interessante notar que apesar de se ter obtido expressões para a energia nada é dito a respeito da natureza dos Hamiltonianos $H^{(0)}$ e $H^{(1)}$. De fato existem várias formas pelas quais o Hamiltoniano para um sistema de partículas poderia ser particionado. Naturalmente para uma dada situação física, certas partições fornecerão resultados mais precisos que outras.

Para o estudo de estruturas atômicas e moleculares, o primeiro palpite para a função de onda exata para um sistema molecular é a função de onda Hartree-Fock. Desta maneira considerar a correlação eletrônica como uma 
perturbação sobre a energia HF torna-se um recurso intuitivo. Esta partição do Hamiltoniano forma a base da teoria de perturbação de Møller-Plesset [61].

Assim Møller-Plesset, consiste numa formulação particular da teoria de perturbação de muitos corpos formulada para o estudo de estrutura eletrônica. Esta teoria usa a soma dos operadores de Fock como o Hamiltoniano de ordem zero, $H^{(0)}$. Assim sendo:

$$
H^{(0)}=\sum_{i=1} \hat{F}(i)
$$

e trata a correlação eletrônica como uma perturbação, dada por:

$$
H^{(1)}=H-\sum_{i=1} \hat{F}(i)
$$

\subsubsection{Teoria funcional da densidade}

O conceito do funcional da densidade para energia era a base de alguns modelos anteriores, tais como o método Thomas-Fermi [66,67], que introduziu a idéia de expressar a energia total como um funcional da densidade eletrônica total. Devido ao tratamento inadequado dado ao termo de energia cinética, isto é, a ausência de orbitais moleculares, a precisão do método ficou longe de ser satisfatória. Foi somente nos anos 60 que a estrutura teórica do método foi estabelecida $[68,69]$.

Em contraste ao método Hartree-Fock, que inicia conceitualmente com a descrição de elétrons individuais interagindo com os núcleos e todos os outros elétrons no sistema, a teoria funcional da densidade (DFT) inicia com a consideração do sistema eletrônico como um todo. A idéia básica da DFT é que a energia de um sistema eletrônico possa ser escrita em termos da densidade de probabilidade eletrônica, $\rho$ [68-71]. Para um sistema com $n$ elétrons, $\rho(\mathbf{r})$ denota a densidade eletrônica total em um ponto particular do espaço. A energia $E$ é dita ser um funcional da densidade eletrônica, denotada por $E[\rho]$, no sentido de que para uma dada função $\rho(\mathbf{r})$ existe um único valor correspondente à energia.

Um esquema computacional conveniente para aplicação prática é 
obtido pela representaçāo da densidade em termos dos orbitais ocupados, $\psi_{i}$,

$$
\rho(\mathbf{r})=\sum_{i}\left|\psi_{i}(\mathbf{r})\right|^{2}
$$

e a minimização da energia em termos destes orbitais. Esta aproximação resulta nas equações de Kohn-Sham de uma partícula [69],

$$
\hat{h}_{K S} \psi_{i}=\varepsilon \psi_{i}
$$

para os orbitais, semelhantes às equações de Hartree-Fock. $\hat{h}_{K S}$ é o operador de Kohn-Sham, composto de termos para as várias interaçōes do sistema tratado e que possibilita escrever a energia como

$$
E=E[\rho(\mathbf{r})]=T[\rho(\mathbf{r})]+N[\rho(\mathbf{r})]+C[\rho(\mathbf{r})]+X C[\rho(\mathbf{r})]
$$

onde $T[\rho(\mathbf{r})]$ é a energia cinética e $N[\rho(\mathbf{r})]$ é o potencial de atração dos núcleos. A energia elétron-elétron é dividida em duas partes, a saber: a repulsão Coulombiana clássica, $C[\rho(\mathbf{r})]$, e a energia de troca e correlação $X C[\rho(\mathbf{r})]$ que leva em conta os efeitos quânticos de muitos corpos. A densidade eletrônica para o estado fundamental é obtida pela minimização da energia. A decomposição da energia feita desta forma é formalmente exata, mas na verdade, as expressões para as interações de troca e correlação de muitos corpos são desconhecidas e sua precisão depende do funcional empregado na sua determinação. Assim, deve-se fazer certas aproximações para se obter o termo $X C[\rho(\mathbf{r})]$. Naturalmente dependendo do problema que é tratado, determinada aproximação poderá surtir melhor resultado dando uma precisão melhor para o termo $X C[\rho(\mathbf{r})]$ e conseqüentemente para o cálculo da propriedade de interesse. 


\section{Capítulo 3}

\section{Propriedades moleculares}

Neste capítulo serão apresentadas as principais propriedades moleculares determinadas para os sistemas estudados neste trabalho. Além da energia de ligação e da polarizabilidade elétrica serão também descritas as propriedades ópticas dos espalhamentos Rayleigh e Raman bem como as propriedades magnéticas.

\section{$3.1 \quad$ Energia}

O comportamento da energia eletrônica (incluindo a repulsão nuclear) em função da distância internuclear $R$, pode ser analisado através de uma curva como a da Figura 3.1. $\operatorname{Em} R=0$, a repulsão internuclear faz com que a energia $U$ tenda

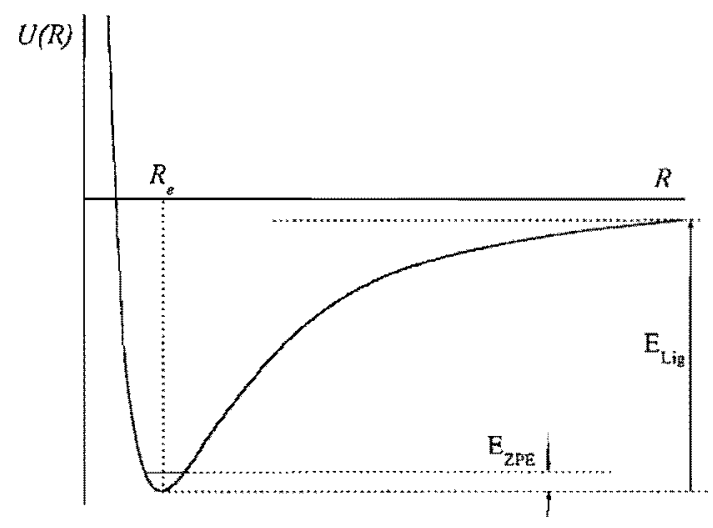

Figura 3.1: Energia eletrônica (incluindo a repulsão nuclear) em função da distância $R$ para o estado ligado de um sistema

ao infinito. A separação internuclear correspondente ao mínimo da curva é a distância de equilíbrio $R_{e}$. A diferença entre o valor da energia na posição $R_{e}$, 
$U\left(R_{e}\right)$, e seu valor límite no infinito, $U(\infty)$, é definida como sendo a energia de ligação do sistema [45-47], ou seja:

$$
E_{L i g}=U\left(R_{e}\right)-U(\infty)
$$

O estado mais baixo do movimento nuclear tem energia rotacional nula porém tem energia vibracional diferente de zero - a energia de ponto zero, $E_{Z P E}$. No caso de uma aproximação harmônica, $E_{Z P E}=\frac{h \nu}{2}$. Esta energia eleva o nível fundamental do movimento nuclear $\frac{h \nu}{2}$ acima do mínimo na curva $U(R)$.

Para o cálculo da energia de ligação entre moléculas avalia-se a energia total do complexo e compara-se com a soma das energias das espécies isoladas, ou seja,

$$
E_{L i g}=\left(E_{A}+E_{B}\right)-E_{A B}
$$

onde $A B$ representa o complexo formado pelas moléculas $A$ e $B$. Porém, devido ao uso de bases incompletas a descrição de uma molécula num complexo é melhorada pelas funçōes base sobre a outra molécula. Uma vez que a energia da molécula descrita nas bases completas do complexo é menor que a energia da molécula somente nas suas bases, existirá uma interação atrativa espúria entre as duas moléculas que se origina devido à melhoria da energia de uma molécula devido à base da outra. Isto é chamado de erro de superposição de base (BSSE). É importante perceber que o BSSE aparece em todos os cálculos realizados com conjuntos de funções base finitos e localizados. Um meio de estimar o BSSE em um cálculo é através do método sugerido por Boys e Bernardi [72]. Neste método, ao invés de se determinar a energia de ligação através de 3.2 onde a molécula $A$ é descrita no seu próprio conjunto de funções base, bem como a molécula $B$, uma melhor estimativa da energia de ligação é [72]:

$$
\Delta E=E_{A B}-E_{A}(A B)-E_{B}(A B),
$$

onde a notação implica que todos os três cálculos: complexo, molécula $A$ e molécula $B$ são realizados no conjunto completo que é usado para o complexo $A B$. É interessante notar que em uma base finita $E_{A}(A B)<E_{A}$ e $E_{B}(A B)<$ $E_{B}, \Delta E$ na equação 3.3 é menor (em módulo) que o valor obtido pela equação 3.2. O uso da equação 3.3 é chamado correção counterpoise [72] e está muito bem discutido e detalhado por van Duijneveldt na referência [73]. 


\subsection{Polarizabilidades}

\subsubsection{Campo finito}

Procedimentos que incluem o campo elétrico explicitamente no Hamiltoniano são freqüentemente chamados de métodos de campo finito [74-79]. Nestas formulações, o Hamiltoniano molecular inclui um termo $(-\mathbf{r} \cdot \mathbf{F})$ que descreve a interação entre o campo elétrico estático e a estrutura eletrônica. Para qualquer intensidade do campo aplicado, os valores esperados apropriados da energia molecular dependente do campo, $E(\mathbf{F})$, e o momento de dipolo molecular, $\mu(\mathbf{F})$ podem ser avaliados a partir da função de onda $\psi(\mathbf{F})$. Assim,

$$
\begin{gathered}
E(\mathbf{F})=\langle\psi(\mathbf{F})|H(\mathbf{F})| \psi(\mathbf{F})\rangle \\
\mu(\mathbf{F})=\left\langle\psi(\mathbf{F})\left|\sum_{i} q_{i}(\mathbf{F}) \cdot \mathbf{r}_{i}(\mathbf{F})\right| \psi(\mathbf{F})\right\rangle
\end{gathered}
$$

onde $q_{i}$ é a carga, $\mathbf{r}_{i}$ é o vetor posição da $i$-ésima partícula e $i$ corre sobre todos os núcleos e elétrons. $\mu(\mathbf{F})$ é também relacionado às (hiper)polararizabilidades por [80]:

$$
\mu(F)_{i}=\mu_{i}^{0}+\sum_{i} \alpha_{i j} F_{j}+\frac{1}{2} \sum_{j, k} \beta_{i j k} F_{i} F_{j}+\frac{1}{6} \sum_{j, k, l} \gamma_{i j k l} F_{i} F_{j} F_{k}+\cdots,
$$

onde $\mu_{i}^{0}$ é o momento de dipolo na ausência de campo e $\left(\mu_{i}-\mu_{i}^{0}\right)$ é o momento de dipolo induzido na direção $i$. Assim combinando as equações (3.4) e (3.5) é possível obter as polarizabilidades de ordem superior diferenciando $\mu(\mathbf{F})$ em relação a F, como nas expressões abaixo:

$$
\begin{gathered}
\alpha_{i j}=\left.\frac{\partial \mu_{i}}{\partial F_{j}}\right|_{F=0} \\
\beta_{i j k}=\left.\frac{\partial^{2} \mu_{i}}{\partial F_{j} \partial F_{k}}\right|_{F=0} \\
\gamma_{i j k l}=\left.\frac{\partial^{3} \mu_{i}}{\partial F_{j} \partial F_{k} \partial F_{l}}\right|_{F=0}
\end{gathered}
$$

Alternativamente, para funções de onda que satisfazem o teorema de Hellmann-Feynman [81-83], pode-se obter estas propriedades pela diferenciação da energia $E(\mathbf{F})$. 
Observa-se aqui que as relações acima são válidas somente para - limite de campo elétrico estático para o qual todas a frequências das (hiper)polarizabilidades se anulam. Maiores detalhes sobre polarizabilidades são dados no Apêndice A.

\subsection{Taxas de despolarização e atividades de espalha- mento}

O espalhamento molecular de luz fornece uma grande variedade de informações sobre os detalhes de fenômenos observados na interação da radiação eletromagnética com a matéria [84-86]. A radiação pode ser espalhada por meio de dois processos: um é o espalhamento elástico ou Rayleigh e o outro é o espalhamento inelástico ou Raman $[87,88]$, no qual o comprimento de onda da radiação é mudado no processo. Examinando o estado da polarização do feixe de luz incidente sobre o sistema em estudo, é possível encontrar a taxa de despolarização de cada desvio da freqüência no espectro de luz espalhada, que é a quantidade mais importante na interpretação de resultados experimentais. Esta quantidade é a razão para a luz espalhada, das intensidades das componentes polarizadas perpendicular e paralela, respectivamente, à direção do feixe de luz incidente. Em tal descrição o estado da polarização da luz espalhada é relacionado à anisotropia molecular (Apêndice B).

\subsubsection{Espalhamento Rayleigh}

De acordo com o formalismo de espalhamento, no caso de moléculas que não sejam esfericamente simétricas uma pequena componente da radiação espalhada é despolarizada $[84,85,89]$. As quantidades mais freqüentemente observadas em experimentos de espalhamento Rayleigh são as taxas de despolarização para luz natural e plano-polarizada, dadas respectivamente por:

$$
\begin{gathered}
\sigma_{n}=\frac{6(\Delta \alpha)^{2}}{45(\bar{\alpha})^{2}+7(\Delta \alpha)^{2}}, \\
\sigma_{p \perp}=\frac{3(\Delta \alpha)^{2}}{45(\bar{\alpha})^{2}+4(\Delta \alpha)^{2}}
\end{gathered}
$$


onde $\bar{\alpha}=\frac{1}{3}\left(\alpha_{x x}+\alpha_{y y}+\alpha_{z z}\right)$ é a polarizabilidade média, $(\Delta \alpha)=\left[\frac{1}{2}\left[\left(\alpha_{x x}-\alpha_{y y}\right)^{2}+\right.\right.$ $\left.\left.\left(\alpha_{y y}-\alpha_{z z}\right)^{2}+\left(\alpha_{z z}-\alpha_{x x}\right)^{2}\right]+3\left[\left(\alpha_{x y}\right)^{2}+\left(\alpha_{x z}\right)^{2}+\left(\alpha_{y z}\right)^{2}\right]\right]^{\frac{1}{2}}$ é a polarizabilidade anisotrópica e $\alpha_{i j}$ são as componentes do tensor polarizabilidade, $\alpha$, ao longo dos eixos Cartesianos do sistema molecular.

O maior valor da taxa de despolarização ocorre para o caso mais anisotrópico. Como $\bar{\alpha}$ é sempre diferente de zero para o espalhamento Rayleigh, o valor máximo para a taxa de despolarização da luz natural é $\sigma_{n}^{\max }$ é $\frac{1}{2}$, enquanto que o valor máximo para a taxa de despolarização da luz plano-polarizada é $\sigma_{p}^{\max }$ é $\frac{1}{3}$. Por completeza é conveniente também obter a despolarização para a luz circularmente polarizada. Assim, a luz espalhada, que é circularmente polarizada, pode conter uma componente da polarização circular dada por:

$$
\sigma_{c}=\frac{\sigma_{n}}{1-\sigma_{n}}
$$

Neste caso o valor máximo da despolarização é $\sigma_{c}^{\max }=1$. A intensidade Rayleigh espalhada (ou atividade Rayleigh) pode também ser obtida em termos da polarizabilidade para luz natural e luz plano-polarizada como se segue $[84,85,89]$ :

$$
\begin{gathered}
\Re_{n}=45(\bar{\alpha})^{2}+13(\Delta \alpha)^{2}, \\
\Re_{p \perp}=45(\bar{\alpha})^{2}+7(\Delta \alpha)^{2}, \\
\Re_{p / /}=6(\Delta \alpha)^{2} .
\end{gathered}
$$

Como usual $[84,85,89]$, a intensidade Rayleigh associada à luz plano-polarizada, $\Re_{p}$, é dividida em duas partes ortogonais: $\Re_{p \perp}$, que corresponde à luz perpendicularmente polarizada dentro no plano de espalhamento, e $\Re_{p / /}$, que corresponde à luz polarizada no mesmo plano de espalhamento.

\subsubsection{Espalhamento Raman}

No caso do espalhamento Raman as expressões para as taxas de despolarização, bem como para as atividades de espalhamento são análogas às do espalhamento 
Rayleigh, porém com a derivada da polarizabilidade média em relação à coordenada normal, $\bar{\alpha}^{\prime}$, no lugar de $\bar{\alpha}$ e a derivada da polarizabilidade anisotrópica $\Delta \alpha^{\prime}$ no lugar de $\Delta \alpha$. Assim, as expressões para as taxas de despolarização são dadas por $[84,85,89]$ :

$$
\begin{gathered}
\rho_{n}=\frac{6\left(\Delta \alpha^{\prime}\right)^{2}}{45\left(\bar{\alpha}^{\prime}\right)^{2}+7\left(\Delta \alpha^{\prime}\right)^{2}} \\
\rho_{p \perp}=\frac{3\left(\Delta \alpha^{\prime}\right)^{2}}{45\left(\bar{\alpha}^{\prime}\right)^{2}+4\left(\Delta \alpha^{\prime}\right)^{2}} \\
\rho_{p / /}=1 \\
\rho_{c}=\frac{\rho_{n}}{1-\rho_{n}}
\end{gathered}
$$

Quando $\bar{\alpha}^{\prime}$ se anular, sem que $\left(\Delta \alpha^{\prime}\right)^{2}$ se anule o valor de $\rho_{n}$ poderá chegar a $\frac{6}{7}$ e o valor de $\rho_{p \perp}$ poderá chegar a $\frac{3}{4}$. Para a luz circularmente polarizada o valor do grau de despolarização poderá chegar a 6 . Então escrevese $[84,85,89]$

$$
\begin{aligned}
& 0 \leq \rho_{n} \leq \frac{6}{7} \\
& 0 \leq \rho_{p \perp} \leq \frac{3}{4} \\
& 0 \leq \rho_{c} \leq 6
\end{aligned}
$$

A intensidade total do espalhamento Raman, isto é, a soma das intensidades das componentes plano-polarizadas, é proporcional a $[84,85,89]$ :

$$
\mathcal{A}_{n}=45\left(\bar{\alpha}^{\prime}\right)^{2}+13\left(\Delta \alpha^{\prime}\right)^{2}
$$

para a luz incidente natural.

Quando a luz é polarizada em um plano perpendicular ao plano de espalhamento a intensidade total é proporcional a:

$$
\mathcal{A}_{p \perp}=45\left(\bar{\alpha}^{\prime}\right)^{2}+7\left(\Delta \alpha^{\prime}\right)^{2}
$$

Finalmente, se a luz é polarizada no plano do espalhamento a intensidade total é proporcional a:

$$
\mathcal{A}_{p / /}=6\left(\Delta \alpha^{\prime}\right)^{2},
$$

neste caso, uma vez que o grau de despolarização é igual a unidade, a luz espalhada é não polarizada. 


\subsection{Blindagem magnética e deslocamento químico}

Quando um átomo é colocado num campo magnético, $\mathbf{B}_{0}$, seus elétrons circulam em torno da direção do campo magnético aplicado, criando uma corrente induzida $[90,91]$. Esta corrente causa um pequeno campo magnético no núcleo que se opõe ao campo externamente aplicado.

O campo magnético experimentado pelo núcleo, $\mathbf{B}$, é então, geralmente menor que o campo aplicado por uma fração $\sigma$, tal que

$$
\mathbf{B}=\mathbf{B}_{0}(\mathbf{1}-\sigma)
$$

Esta fração, que normalmente é da ordem de $10^{-6}$, é a blindagem magnética que pode ser particionada em duas componentes: a blindagem diamagnética e a blindagem paramagnética [90-93].

- A blindagem diamagnética se origina a partir da circulação dos elétrons nos orbitais tipo $s$ e núcleos envoltos por camada fechada e é dependente do estado fundamental da molécula. A contribuição diamagnética está normalmente associada com o aumento da blindagem, com o campo local no núcleo oposto ao campo magnético.

- A blindagem paramagnética, que se origina a partir de orbitais não esféricos, está associada com o momento angular orbital dos elétrons e é portanto dependente dos estados excitados da molécula. As contribuições paramagnéticas normalmente resultam na diminuição da blindagem com o campo local no mesmo sentido do campo aplicado.

\subsubsection{Dependência orientacional da blindagem magnética}

A blindagem magnética é uma propriedade dependente de orientação, isto é, a blindagem magnética no núcleo de uma molécula depende da orientação relativa da molécula em relação ao campo magnético aplicado. Assim, a blindagem magnética pode ser descrita como um tensor Cartesiano não simétrico de segunda ordem, $\sigma$, no qual nove valores independentes especificam a orientação 
da blindagem em relação ao sistema de coordenadas do laboratório. Assim tem-se [90-93]:

$$
\sigma=\left[\begin{array}{lll}
\sigma_{11} & \sigma_{12} & \sigma_{13} \\
\sigma_{21} & \sigma_{22} & \sigma_{23} \\
\sigma_{31} & \sigma_{32} & \sigma_{33}
\end{array}\right] .
$$

Em experimentos de ressonância magnética nuclear (RMN) convencionais, é muito difícil determinar todas as componentes da blindagem magnética, assim somente a parte simétrica da blindagem é determinada, logo define-se a blindagem isotrópica, $\sigma^{i s o}$, como sendo o traço do tensor $\sigma$, ou seja [90-93]:

$$
\sigma^{i s o}=\frac{1}{3}\left(\sigma_{11}+\sigma_{22}+\sigma_{33}\right) \text {. }
$$

Em muitos casos, é suficiente analisar somente esta propriedade para efeito de comparação com valores experimentais, porém importantes informações fornecidas são perdidas, assim introduz-se a blindagem anisotrópica, $\sigma^{\text {anis }}$, expressa por:

$$
\sigma^{i s o}=\sigma_{33}-\frac{\sigma_{11}+\sigma_{22}}{2}
$$

$\operatorname{com} \sigma_{11}<\sigma_{22}<\sigma_{33}$.

Uma breve discussão sobre a teoria envolvida no cálculo da blindagem magnética é dada no Apêndice $\mathrm{C}$.

\subsubsection{Deslocamento químico}

O deslocamento químico é obtido teoricamente pela diferença entre a blindagem magnética do sistema em meio e a blindagem magnética do sistema isolado. Experimentalmente sua obtenção é um pouco mais complicada. Medidas de freqüências absolutas com alto grau de precisão e reprodutibilidade são difíceis em RMN [93]. Apesar disso é possível medir diferenças de freqüências com elevada precisão. Esta é a razão pela qual um sinal de RMN é na verdade uma medida da diferença entre a freqüência de precessão da magnetização da amostra, $\nu_{i}$, e a freqüência de operação do espectrômetro, $\nu_{0}$, ou seja:

$$
\Delta \nu_{i}=\nu_{i}-\nu_{0}
$$

Levando em conta o fato de que medidas precisas de freqüências absolutas são inviáveis, enquanto que medidas precisas de diferença de freqüências são 
trivialmente obtidas, uma escala reprodutivel apropriada é desejável. Para isto em cada amostra a ser medida é dissolvida uma pequena quantidade $(<1 \%$ do volume da amostra) de um composto padrão para servir como referência interna dando origem a um sinal em algum lugar a partir dos sinais de interesse. $O$ sinal deste composto é arbitrariamente colocado no ponto de freqüência zero, e as medidas de diferenças de freqüências em hertz são feitas em relação a este sinal. Estas diferenças são dadas por [90-93]:

$$
\delta \nu_{i}=\Delta \nu_{i}-\Delta \nu_{r e f}
$$

Da forma em que está dado na equação 3.31 , a medida é dependente do campo magnético do espectrômetro. Para que esta medida não varie de instrumento para instrumento (uma vez que existe uma grande variedade de aparelhos que operam em freqüências diferentes), define-se o deslocamento químico da seguinte forma

$$
\delta_{i}=\frac{10^{6}\left(\Delta \nu_{i}-\Delta \nu_{r e f}\right)}{\nu_{0}}=10^{6} \frac{\delta \nu_{i}}{\nu_{0}}=\frac{\delta \nu_{i}}{\nu_{0}^{\prime}}
$$

onde $\nu_{0}$ e $\nu_{0}^{\prime}$ são as freqüências de operação em $\mathrm{Hz}$ e $\mathrm{MHz}$ respectivamente. A escala $\delta$ é na verdade adimensional mas possui a unidade ppm (parte por milhão) como conseqüência do fator $10^{6}$ na equação acima.

O valor do deslocamento químico pode ser calculado como sendo a diferença na blindagem magnética devido ao ambiente químico do isótopo de interesse, assim, o deslocamento gás-líquido de um isótopo $X$ é dado por:

$$
\delta(X)=\sigma(X)^{l i q}-\sigma(X)^{g a s}
$$




\section{Parte II}

\section{Estudo de aglomerados}




\section{Capítulo 4}

\section{Espalhamentos Raman e Rayleigh no complexo $\mathrm{CH}_{3} \mathrm{CN} \cdots \mathrm{H}_{2} \mathrm{O}$}

\subsection{Motivação}

$\mathrm{O}$ estudo do complexo acetonitrila-água $\left(\mathrm{CH}_{3} \mathrm{CN} \cdots \mathrm{H}_{2} \mathrm{O}\right)$ é fundamental para o entendimento de misturas binárias [94] que são importantes solventes com aplicações em físico-química [95]. Além disso complexos iônicos de acetonitrilaágua são importantes na atmosfera terrestre [96] e $\mathrm{CH}_{3} \mathrm{CN}$ é de grande interesse em astrofísica [97-100]. Para uma compreensão mais detalhada da interação entre acetonitrila e água, a ligação de hidrogênio entre as espécies deve ser levada em consideração. Com o desenvolvimento da vaporização a laser e técnicas de jet-cooling, complexos com ligações de hidrogênio têm sido produzidos [101-103] e o ramo da físico-química de complexos tem experimentado um grande avanço [104-106] e despertado o interesse desde muitos anos, como vem sendo indicado por trabalhos tanto teóricos [107] quanto experimentais [108-110]. Em um trabalho teórico e experimental, Schermann e colaboradores [108] sugeriram duas estruturas estáveis (Figura 4.1), embora eles tenham observado apenas a aparentemente mais estável (Figura 4.1a) com um momento de dipolo total de 5.5D. Eles sugeriram um isômero com um dipolo total de $2.6 \mathrm{D}$, como sendo possivelmente uma segunda geometria estável (Figura 4.1b). A identificação das estruturas do complexo é de difícil obtenção 


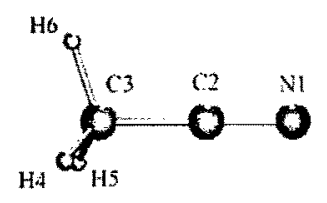

(a)

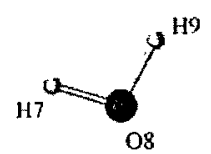

08

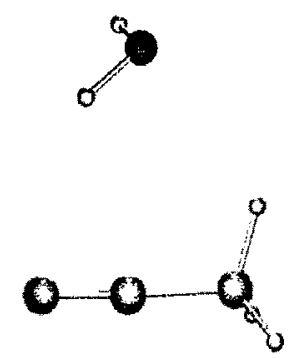

(b)

Figura 4.1: Estruturas geométricas do complexo acetonitrila-água

direta e aproximações usuais contam com a comparação entre os deslocamentos espectrais teórico e experimental. Para moléculas polares um procedimento conveniente $[108,109]$ compara os momentos de dipolo teórico e experimental. As ligações de hidrogênio podem contudo ser estudadas com uma grande variedade de técnicas, e a análise de deslocamentos espectrais na região do infra-vermelho é talvez a técnica mais empregada. Apesar de sua importância, cálculos precisos do complexo acetonitrila-água ainda não foram realizados, portanto, neste trabalho cálculos $a b$ initio são empregados na obtenção da estrutura e espectro do complexo. Para auxiliar no entendimento das mudanças espectrais, cálculos dos deslocamentos no espectro infra-vermelho devido à complexação e os momentos de dipolo do complexo e das espécies isoladas foram determinados. Outra informação importante calculada aqui é a mudança nas taxas de despolarização para os espalhamentos Raman e Rayleigh. O tensor polarizabilidade de dipolo, suas derivadas, as atividades de espalhamento e as taxas de despolarização do complexo $\mathrm{CH}_{3} \mathrm{CN} \cdots \mathrm{H}_{2} \mathrm{O}$ são calculados e os resultados comparados aos resul- 
tados obtidos para as duas espécies isoladas. Uma estimativa precisa para a energia de ligação, usando cálculos de alto nível teórico e a inclusão de correções de superposição de base e correções de vibrações de ponto zero também são apresentadas.

\subsection{Detalhes de cálculo}

As estruturas de equilibrio foram completamente otimizadas através de quatro modelos teóricos: MP2/6-311++G(d,p) ${ }^{1}, \mathrm{MP} 2 /$ aug-cc-pVDZ, B3LYP/6$311++\mathrm{G}(\mathrm{d}, \mathrm{p})$ e B3P86/6-311++G(d,p). Os cálculos DFT foram realizados com dois dos funcionais mais comuns: o funcional híbrido de Becke combinando o termo de correlação de Lee-Yang-Parr (B3LYP) $[111,112]$ e o funcional híbrido de Becke combinando o termo de correlação de Perdew (B3P86) [113]. Estes métodos foram usados com os conjuntos de funçōes base $6-311++G(d, p)$ e aug-cc-pVDZ [114]. Em todos os casos as constantes rotacionais e os momentos de dipolo foram determinados nas geometrias de equilíbrio. Estes são os parâmetros relevantes na caracterização das estruturas geométricas usando espectroscopia rotacional. Um cálculo do espectro infravermelho foi realizado para as moléculas isoladas e para o complexo. Os deslocamentos nas freqüências após a complexação também foram calculados. Uma atenção particular foi dedicada às transições mais intensas e às vibrações de estiramento das ligações $\mathrm{C}-\mathrm{N}$ e O-H. Adicionalmente, as energias de ligação para o complexo foram calculadas e a contribuição dos efeitos de correlação foi sistematicamente analisada. Nestas geometrias foram realizados cálculos pontuais em coupled-cluster [115] incluindo excitações simples (S), duplas (D) e triplas aproximadas (T) relativas ao estado de referência dos complexos. Este modelo é usualmente chamado de $\operatorname{CCSD}(\mathrm{T})$ e inclui contribuições perturbativas de muitos corpos em segunda (MP2), terceira (MP3) e excitações simples, duplas e quádruplas em quarta ordem (SDQ-MP4) $[64,116]$. O erro de superposição de base foi tratado pela correção counterpoise. As taxas de despolarização para os espalhamentos Raman e Rayleigh foram calculadas através das polarizabilidades

\footnotetext{
${ }^{1} \mathrm{O}$ significado da nomeclatura das bases empregadas aqui pode ser encontrado, dentre outras fontes, nas referências [46] e [55].
} 
média e anisótrópica e suas derivadas, em níveis correlacionados usando método MP2/aug-cc-pVDZ. Todos os cálculos foram realizados com o programa Gaus$\operatorname{sian} 98[117]$.

\subsection{Resultados e discussão}

\subsubsection{Geometrias, constantes rotacionais e momentos de dipolo}

A Figura 4.1 mostra as estruturas obtidas neste trabalho. A estrutura da Figura 4.1b foi obtida antes em nível HF [107] e empregada em considerações experimentais [109]. Contudo foi verificado aqui que tal estrutura é instável em níveis mais altos de cálculo. De fato, usando bases pequenas $(6-31 \mathrm{G}(\mathrm{d}, \mathrm{p}))$ é possível encontrar um mínimo estável em nível HF e níveis correlacionados tais como MP2, B3LYP e B3P86. Contudo, a melhoria do modelo teórico leva invariavelmente a estruturas não ligadas. Através do método $\mathrm{MP} 2 / 6-31 \mathrm{G}(\mathrm{d}, \mathrm{p})$ foi verificado que o complexo é ligado com uma distância O8-N1 de $3.065 \AA$ e uma energia de ligação de somente $2 \mathrm{kcal} / \mathrm{mol}$ (com correções de superposição de base e de vibrações de ponto zero). O momento de dipolo total calculado para este complexo foi de 2.43D. Os momentos de dipolo calculados correspondentes em nível B3LYP/6-31G(d,p) e B3P 86/6-31G(d,p) são 2.58D e 2.62D. Estes valores estão em bom acordo com o valor de $2.6 \mathrm{D}$ inferido usando desenvolvimento teórico multipolar [108]. Contudo, como esta estrutura é instável em níveis teóricos mais sofisticados não será considerada posteriormente. A estrutura da Figura 4.1a é de fato um mínimo estável em todos os métodos teóricos considerados aqui. Para uma análise mais crítica dos resultados, a Tabela 4.1 mostra os quatro diferentes cálculos para a geometria, constantes rotacionais e momentos de dipolo do complexo $\mathrm{CH}_{3} \mathrm{CN} \cdots \mathrm{H}_{2} \mathrm{O}$ (Figura 4.1a) e suas espécies isoladas. Os resultados experimentais para a geometria da molécula $\mathrm{CH}_{3} \mathrm{CN}$ atribuem à distância $\mathrm{N} 1-\mathrm{C} 1$ o valor de $1.159 \AA$ [118], os resultados DFT para a distância N1-C2 estão em bom acordo com o experimento. Estes são mais curtos que aqueles obtidos com MP2 e isto é consistente com a natureza da ligação tripla. Contudo, todos os métodos teóricos concordam que esta distância diminui por $0.002 \AA$ depois da formação da ligação de hidrogênio. Por outro lado, 


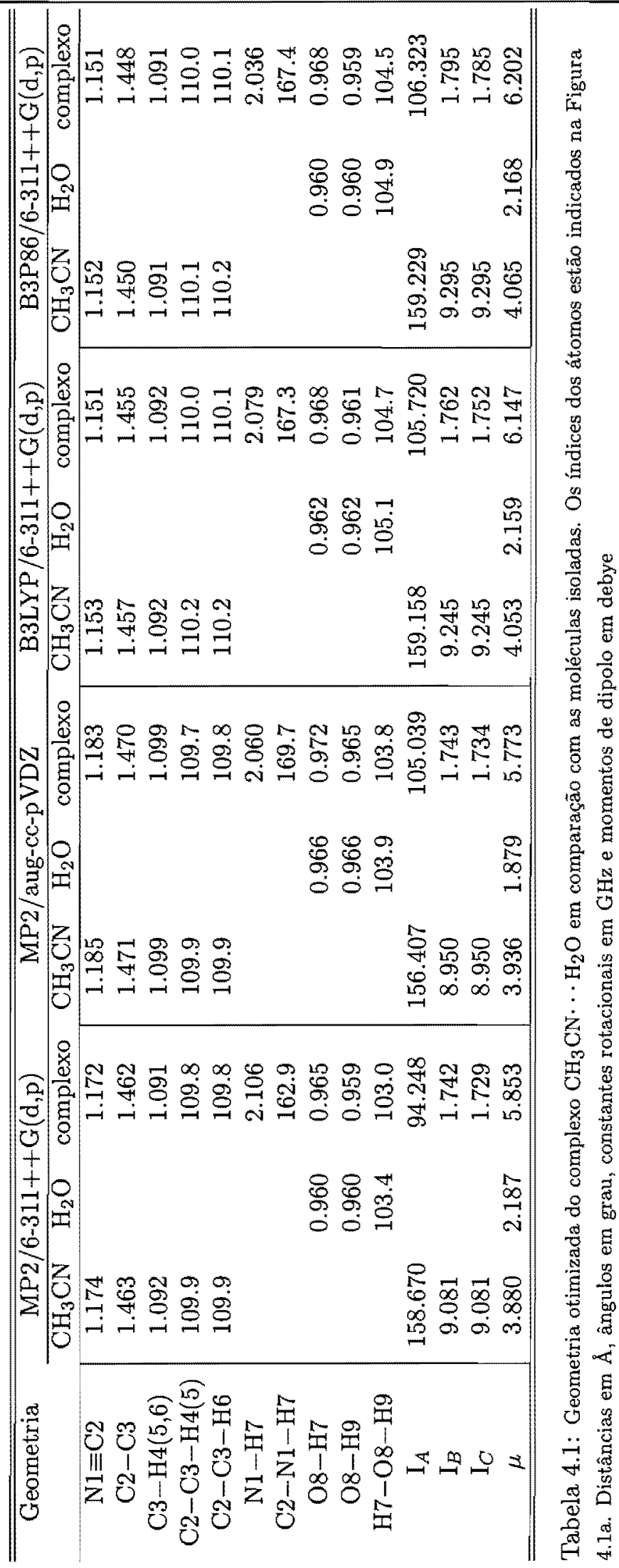


como esperado, na molécula de água a distância $\mathrm{O}-\mathrm{H}$ envolvida na ligação aumenta cerca de 0.005 a $0.008 \AA$ dependendo do modelo teórico. O menor aumento é obtido com o modelo MP2/6-311++G(d,p) e o maior aumento com o modelo B3P86/6-311++G(d,p). A diminuição da distância $\mathrm{N}-\mathrm{C}$ leva a um deslocamento para o azul na freqüência de vibração do estiramento como será mostrado adiante.

Após a complexação o complexo $\mathrm{CH}_{3} \mathrm{CN} \cdots \mathrm{H}_{2} \mathrm{O}$ ainda se comporta como um rotor aproximadamente prolato e as correspondentes constantes rotacionais são dadas também na Tabela 4.1. Em complexos polares preparados por experimentos de feixes supersônicos os momentos de dipolo são requeridos para a dedução de informações estruturais [109]. Assim a Tabela 4.1 também apresenta os momentos de dipolo. O resultado experimental [119] de 1.86D para o momento de dipolo da molécula de água em fase gasosa foi bem reproduzido somente pelo modelo MP2/aug-cc-pVDZ. Similarmente o valor experimental [120] de 3.96D para a molécula de acetonitrila em fase gasosa foi obtido como 3.94D. Todos os resultados DFT para os momentos de dipolo da água e da acetonitrila são maiores que o valor experimental. O valor do momento de dipolo calculado para o complexo, 5.77D, obtido em MP2/aug-cc-pVDZ se mostra em bom acordo com o resultado experimental de Schermann de 5.5D [108]. A presente precisão deve ser útil na possível deteç̧ão deste complexo com ligação de hidrogênio.

\subsubsection{Deslocamento na freqüência vibracional}

As Tabelas 4.2 e 4.3 mostram as freqüências vibracionais calculadas para as moléculas separadas e para o complexo ligado. A molécula de acetonitrila possui 12 modos vibracionais correspondendo a 8 modos ativos fundamentais; 4 freqüências vibracionais não degeneradas (simetria $a_{1}$ ) e 4 duplamente degeneradas (simetria $e$ ). A pós a complexação, os modos degenerados de simetria $e$ podem se desdobrar e todas as freqüências sofrerem um deslocamento. A magnitude do deslocamento pode ser usada para a caracterização da estrutura do complexo. Como as freqüências vibracionais simétricas $\left(a_{1}\right)$ e as assimétricas $\left(b_{2}\right)$ da molécula de água sofrem um deslocamento para o vermelho enquanto 


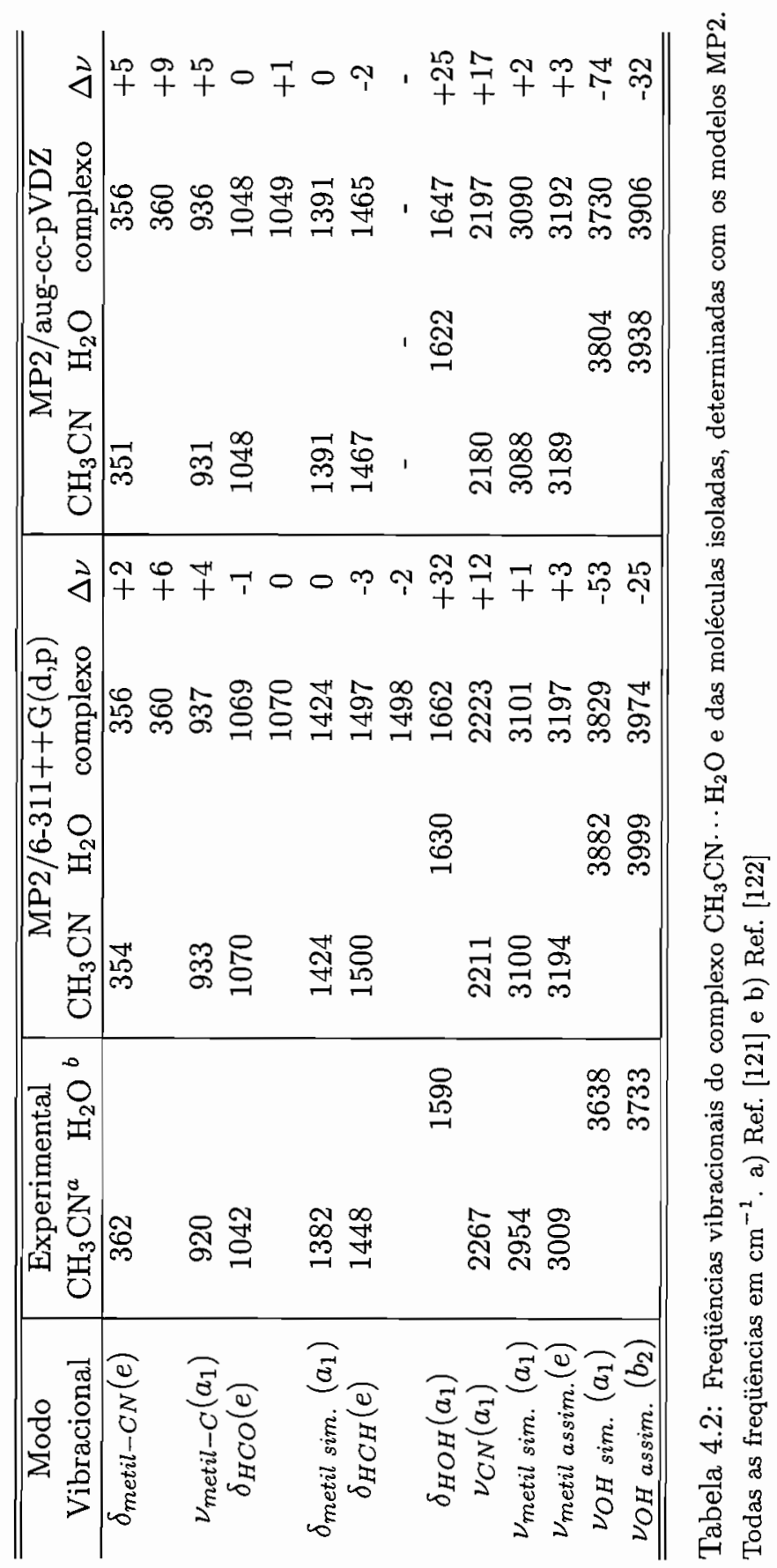




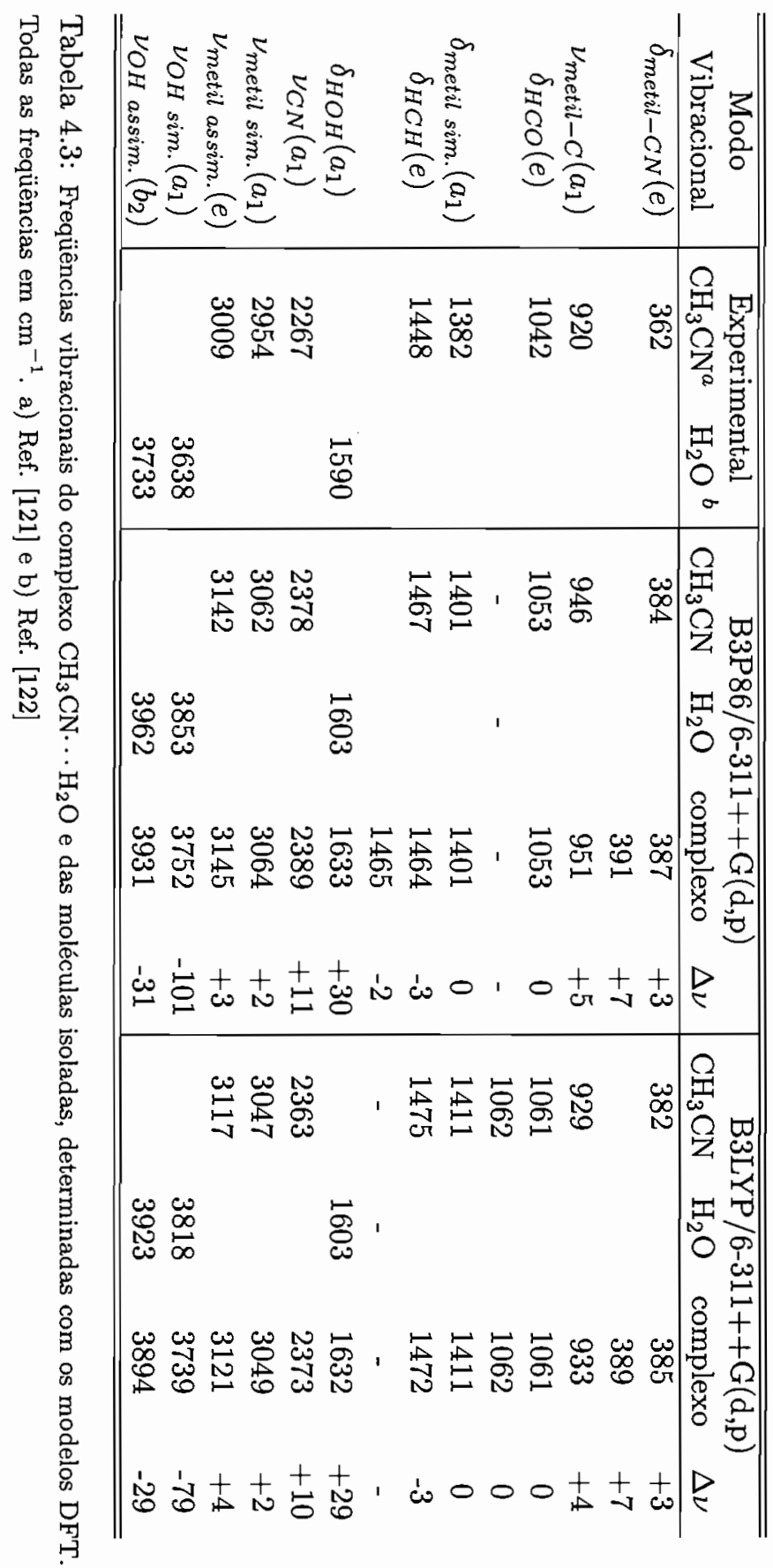


que o modo tesoura $\left(a_{1}\right)$ na região de $1600 \mathrm{~cm}^{-1}$ sofrem um deslocamento para o azul. Os resultados calculados estão devidamente em acordo com esta descrição qualitativa, como pode ser observado nas Tabelas 4.2 e 4.3. O deslocamento do estiramento vibracional simétrico $\mathrm{O}-\mathrm{H}$ para o vermelho é calculado entre $-53 \mathrm{~cm}^{-1}$ e $-101 \mathrm{~cm}^{-1}$. O deslocamento calculado em MP2/aug-cc-pVDZ é $-74 \mathrm{~cm}^{-1}$. Para a acetonitrila o maior deslocamento foi obtido para o estiramento $\mathrm{N}-\mathrm{C}$ e em todos os modelos teóricos foi encontrado que este deslocamento é para o azul e que sua magnitude varia entre $10 \mathrm{~cm}^{-1}$ e $17 \mathrm{~cm}^{-1}$. Este deslocamento calculado é condizente com a diminuição na distância $\mathrm{N}-\mathrm{C}$, após a complexação, obtida teoricamente e discutida na seção prévia. As vibrações de estiramento para os átomos envolvidos na ligação de hidrogênio são normalmente desviadas para freqüências vibracionais menores (para o vermelho). Os deslocamentos para o azul dos modos de estiramento devidos à ligação de hidrogênio estão atraindo considerável atenção após o estudo de Hobza e colaboradores [123].

\subsubsection{Energias de ligação}

Os resultados calculados para as energias de ligação são mostrados na Tabela 4.4. Todos os resultados mostrados incluem correção counterpoise contra BSSE.

\begin{tabular}{ccc}
\hline \hline Método & MP2/6-311++G(d,p) & MP2/aug-cc-pVDZ \\
\hline HF & 3.67 & 3.23 \\
MP2 & 4.33 & 4.45 \\
MP3 & 4.05 & 4.08 \\
DQ-MP4 & 3.97 & 3.99 \\
SDQ-MP4 & 4.03 & 4.08 \\
MP4 & 4.19 & 4.33 \\
CCSD & 3.99 & 4.02 \\
CCSD(T) & 4.13 & 4.23 \\
\hline \hline
\end{tabular}

Tabela 4.4: Energias de ligação calculadas (kcal/mol) e os efeitos da correlação eletrônica no complexo $\mathrm{CH}_{3} \mathrm{CN} \cdots \mathrm{H}_{2} \mathrm{O}$. Todos os resultados são obtidos usando geometrias otimizadas em nível MP2 (funçôes base indicadas na tabela) e corrigidos contra BSSE

Dois conjuntos de cálculos de energia foram realizados. Um empregando o modelo $\operatorname{CCSD}(\mathrm{T}) / 6-311++\mathrm{G}(\mathrm{d}, \mathrm{p})$ com a geometria $\mathrm{MP} 2 / 6-311++\mathrm{G}(\mathrm{d}, \mathrm{p})$ e outro empregando o modelo CCSD(T)/aug-cc-pVDZ com a geometria MP2/aug- 
cc-pVDZ. Os resultados intermediários, como os resultados em MP4 incompleto e completo, foram também obtidos e são úteis para analisar os efeitos da correlação eletrônica na energia de ligação. Pode-se notar que tais efeitos são importantes, aumentando as energias de ligação com respeito ao resultado HF. Com o modelo MP2/aug-cc-pVDZ a energia de ligação foi calculada como $4.45 \mathrm{kcal} / \mathrm{mol}$. Este valor é apenas ligeiramente diminuído com a inclusão dos efeitos de correlação de altas ordens. No nível mais alto, $\operatorname{CCSD}(\mathrm{T})$, este valor diminui para $4.23 \mathrm{kcal} / \mathrm{mol}$. Os resultados MP2 são portanto um bom modelo teórico para o cálculo de energias de ligação de sistemas com ligações de hidrogênio [124,125]. A contribuição da excitação tripla é de particular importância. Em quarta ordem a contribuição da excitação tripla, obtida a partir da diferença entre MP4 e SDQ-MP4, foi de $+0.25 \mathrm{kcal} / \mathrm{mol}$ na energia de ligação. Todas as excitações triplas obtidas a partir da diferença entre CCSD(T) e CCSD fornecem um resultado similar, $0.21 \mathrm{kcal} / \mathrm{mol}$. Assim a maior parte da contribuição da excitação tripla para a energia de ligação foi obtida já em quarta ordem e o efeito total da excitação tripla é aumentar a energia de ligação por $\sim 5 \%$. A Tabela 4.4 mostra também que as excitações simples chegam a contribuir menos para a energia de ligação. Em quarta ordem, a contribuição das excitações simples é obtida pela diferença entre os resultados SDQ-MP4 e DQ-MP4, o que dá uma contribuição de apenas $0.09 \mathrm{kcal} / \mathrm{mol}$ usando a base aug-cc-pVDZ nas geometrias otimizadas no nível MP2/aug-cc-pVDZ, por exemplo. Excitações simples em altas ordens são menores ainda, como pode ser visto usando a diferença entre os resultados CCSD e DQ-MP4. Novamente, usando a geometria MP2/aug-cc-pVDZ e a base aug-cc-pVDZ o resultado foi somente $0.03 \mathrm{kcal} / \mathrm{mol}$. Isto explica porque MP2 é um bom modelo para o cálculo de energia de ligação de sistemas com ligações de hidrogênio. Resultados similares foram obtidos com os outros modelos teóricos. Os resultados obtidos com DFT foram ligeiramente maiores que aqueles obtidos com as teorias MP ou CC. O resultado para a energia de ligação usando exclusivamente o modelo B3LYP/6-311++G(d,p) para ambas as geometrias foi $4.81 \mathrm{kcal} / \mathrm{mol}$. O resultado CCSD(T) de $4.23 \mathrm{kcal} / \mathrm{mol}$ obtido com a geometria MP2/aug-cc-pVDZ está em bom acordo com o resultado experimental de $4.18 \mathrm{kcal} / \mathrm{mol}$ obtido na referência [108]. Em todos os 
valores a correção de superposição de base se mostrou menor que $1.0 \mathrm{kcal} / \mathrm{mol}$ na energia de ligação com os modelos correlacionados, de MP2 a CCSD(T).

Ao se considerar a melhor estimativa para a energia de ligação, deve-se levar em conta a energia de vibração de ponto zero. Utilizando a aproximação harmônica as frequiências calculadas foram obtidas e dadas nas Tabelas 4.2 e 4.3. Com o uso destes valores a diferença nas energias de vibração de ponto zero foi $1.31 \mathrm{kcal} / \mathrm{mol}$. Contudo apesar das vibrações intramoleculares serem razoavelmente bem descritas pela aproximação harmônica, as vibrações intermoleculares são largamente anarmônicas. Levando isto em consideração, a diferença na energia de vibração de ponto zero foi estimada em $0.70 \mathrm{kcal} / \mathrm{mol}$. Usando este resultado a melhor estimativa para a energia de ligação do complexo é $3.53 \mathrm{kcal} / \mathrm{mol}$. Este resultado foi obtido com um cálculo de energia no modelo CCSD(T)/aug-cc-pVDZ realizado na geometria MP2/aug-cc-pVDZ e freqüências calculadas.

\subsubsection{Atividades de espalhamento Rayleigh e Raman}

A taxa de despolarização foi calculada para a molécula $\mathrm{CH}_{3} \mathrm{CN}$ tanto isolada como quando fazendo a ligação de hidrogênio com a água. A mudança na despolarização é reportada na Tabela 4.5 que mostra as polarizabilidades calculadas bem como os resultados para o espalhamento Rayleigh. As polarizabilidades

\begin{tabular}{cccccc}
\hline \hline Sistema & $\left.\alpha^{a}\right)$ & $\Delta \alpha$ & $\sigma_{n}$ & $\sigma_{p}$ & $\sigma_{c}$ \\
\hline $\mathrm{H}_{2} \mathrm{O}$ & 9.30 & 1.04 & 0.0017 & 0.0008 & 0.0017 \\
$\mathrm{CH}_{3} \mathrm{CN}$ & 29.43 & 15.65 & 0.0361 & 0.0184 & 0.0375 \\
$\mathrm{CH}_{3} \mathrm{CN} \cdots \mathrm{H}_{2} \mathrm{O}$ & 39.67 & 21.78 & 0.0384 & 0.0196 & 0.0399 \\
\hline \hline
\end{tabular}

Tabela 4.5: Polarizabilidades de dipolo média, $\alpha$, e anisotrópica, $\Delta \alpha$, calculadas (em ua) e taxa de despolarização Rayleigh $\mathrm{CH}_{3} \mathrm{CN}$ e $\mathrm{CH}_{3} \mathrm{CN} \cdots \mathrm{H}_{2} \mathrm{O}$. Todos os cálculos foram realizados no nível MP2/aug-cc-pVDZ e nas correspondentes geometrias otimizadas. a) O valor experimental para a polarizabilidade de dipolo da água é 9.80ua. No caso da acetonitrila tem-se dois valores reportados 29.72 ua e 30.27 ua, Ref. [1.18]

de dipolo de ambas as moléculas $\mathrm{CH}_{3} \mathrm{CN}$ e $\mathrm{H}_{2} \mathrm{O}$ estão em bom acordo com os resultados experimentais. A polarizabilidade de dipolo média do complexo $\mathrm{CH}_{3} \mathrm{CN} \cdots \mathrm{H}_{2} \mathrm{O}$, como esperado foi somente ligeiramente maior que a soma das polarizabilidades de dipolo das moléculas $\mathrm{CH}_{3} \mathrm{CN}$ e $\mathrm{H}_{2} \mathrm{O}$ separadas. A mudança 
nas polarizabilidades anisotrópicas da molécula de acetonitrila e do complexo juntamente com o aumento na polarizabilidade média, leva à variação nas taxas de despolarização como dadas na Tabela 4.5. Em todos os casos a taxa de despolarização aumenta após a complexação. A Tabela 4.6 mostra os valores calculados para as atividades de espalhamento Raman. Todos os oito

\begin{tabular}{ccccccc}
\hline \hline Modo vibracional & \multicolumn{2}{c}{$\mathrm{CH}_{3} \mathrm{CN}$} & \multicolumn{2}{c}{$\mathrm{H}_{2} \mathrm{O}$} & \multicolumn{3}{c}{$\mathrm{CH}_{3} \mathrm{CN} \cdots$} & $\mathrm{H}_{2} \mathrm{O}$ \\
\hline & $A_{p}$ & $\sigma_{p}$ & $A_{p}$ & $\sigma_{p}$ & $A_{p}$ & $\sigma_{p}$ \\
$\nu_{\text {metil-C}}\left(a_{1}\right)$ & 7.07 & 0.071 & - & - & 7.92 & 0.101 \\
$\delta_{H C O}(e)$ & 3.48 & 0.432 & - & - & 3.90 & 0.418 \\
$\nu_{C N}\left(a_{1}\right)$ & 49.37 & 0.169 & - & - & 64.02 & 0.202 \\
$\nu_{\text {metil sim. }}(e)$ & 188.21 & 0.002 & - & - & 196.37 & 0.005 \\
$\delta_{H O H}\left(a_{1}\right)$ & - & - & 1.95 & 0.633 & 0.58 & 0.644 \\
$\nu_{O H}$ sim. $\left(a_{1}\right)$ & - & - & 104.10 & 0.042 & 206.78 & 0.153 \\
$\nu_{O H \text { assim. }}\left(a_{1}\right)$ & - & - & 24.17 & 0.750 & 40.94 & 0.484 \\
\hline \hline
\end{tabular}

Tabela 4.6: Atividades Raman $A_{p}$ (em ua) e a taxa de despolarização para a luz planopolarizada para $\mathrm{CH}_{3} \mathrm{CN}$ e $\mathrm{CH}_{3} \mathrm{CN} \cdots \mathrm{H}_{2} \mathrm{O}$. Todos os cálculos foram realizados no nível MP2/aug-cc-pVDZ nas correspondentes geometrias otimizadas

modos fundamentais ativos da acetonitrila foram considerados mas no caso de vibrações degeneradas (não mostradas na Tabela 4.6)a taxa de despolarização assumiu seu valor máximo, $3 / 4$, uma vez que neste caso a derivada da polarizabilidade média avaliada na origem da vibração molecular é zero. A maior seção de choque para o espalhamento Raman foi obtida para o modo simétrico $\mathrm{C}-\mathrm{H}\left(\nu_{\text {metil sim. }}\right)$ na região de $3090 \mathrm{~cm}^{-1}$. Contudo para esta vibração a taxa de despolarização para a luz plano-polarizada foi essencialmente zero e não mudou após a complexação. Desta forma o modo vibracional mais importante associado a $\mathrm{CH}_{3} \mathrm{CN}$ foi o estiramento $\nu_{C N}$. Sua taxa de despolarização muda de 0.17 para 0.20 após a formação da ligação de hidrogênio. Outra mudança pronunciada na taxa de despolarização é obtida para o estiramento menos intenso $\nu_{\text {metil }-C}$ na região de $930 \mathrm{~cm}^{-1}$. Neste caso a taxa de despolarização muda por um percentual que é maior que $45 \%$, de 0.07 para 0.10 , mas a despolarização absoluta foi menor que para o estiramento $\nu_{C N}$ e a atividade $A_{p}$ também foi menor. Estes efeitos foram mais pronunciados nos modos da molécula de água. Foi observado [126] num trabalho anterior sobre o dímero de água, em nível HF que a taxa de despolarização do modo simétrico $\nu_{O H}$ sim. doador aumenta 
por um fator de aproximadamente dois. A mesma situação é vista aqui onde foi verificada uma grande intensificação da atividade de espalhamento para o estiramento simétrico da água (Tabela 4.6). Para fazer uma comparação com o caso do dímero de água foi calculada também sua atividade de espalhamento em nível MP2/aug-cc-pVDZ. Partindo da molécula água isolada, a atividade de espalhamento do estiramento vibracional $\mathrm{O}-\mathrm{H}$ (104.1ua) aumentou $55 \%$ no dímero de água (161.6ua) e aumentou $99 \%$ (206.8ua) no caso $\mathrm{CH}_{3} \mathrm{CN} \cdots \mathrm{H}_{2} \mathrm{O}$. Isto é indicativo de uma ligação forte e corrobora o resultado para o deslocamento de $-74 \mathrm{~cm}^{-1}$ do estiramento simétrico $\nu_{O H}$ sim. no espectro vibracional. Em relação à taxa de despolarização foi possível notar uma mudança de um fator próximo de quatro da água isolada (0.042) para o complexo (0.153).

\subsection{Conclusões}

A ligação de hidrogênio entre acetonitrila e água, $\mathrm{CH}_{3} \mathrm{CN} \cdots \mathrm{H}_{2} \mathrm{O}$ foi analisada através de métodos $a b$ initio. Otimização de geometria, freqüências vibracionais, atividades Raman e Rayleigh, taxas de despolarização, momento de dipolo e energias de ligação foram consideradas. As geometrias do complexo e das moléculas separadas foram calculadas usando modelos teóricos diferentes. Em todos os modelos foi encontrado um encurtamento da distância $\mathrm{N}-\mathrm{C}$, levando a um deslocamento para o azul de $15 \mathrm{~cm}^{-1}$ no espectro infravermelho. A distância da ligação de hidrogênio $\mathrm{N} \cdots \mathrm{H}$ em nível MP2/aug-cc-pVDZ foi calculada como sendo $2.06 \AA$, com pequenas variações entre os resultados obtidos com outros modelos teóricos. O momento de dipolo do complexo é 5.77D e está em bom acordo com a sugestão de Desfrançois e outros [108]. A energia de ligação foi obtida usando diferentes modelos teóricos e a relevância da correlação eletrônica foi analisada. Levando em conta o erro de superposição de base e a correção vibracional de ponto zero a melhor estimativa para a energia de ligação foi de $3.53 \mathrm{kcal} / \mathrm{mol}$, obtida com o modelo CCSD(T)/aug-cc-pVDZ na geometria otimizada em nível MP2/aug-cc-pVDZ com freqüências calculadas que garatiram uma geometria de mínima energia. De interesse particular aqui foram a atividade de espalhamento e a taxa de despolarização. Uma análise 
do espalhamento de luz foi feita tanto para o espalhamento Rayleigh quanto para o espalhamento Raman. As polarizabilidades de dipolo e suas derivadas em relação aos modos vibracionais intramoleculares foram calculadas em nível MP2/aug-cc-pVDZ. A polarizabilidade de dipolo média calculada foi de 39.67ua, e a polarizabilidade anisotrópica se mostrou razoavelmente grande, correspondendo a 21.78ua. A taxa de despolarização da luz espalhada foi então reportada para o complexo $\mathrm{CH}_{3} \mathrm{CN} \cdots \mathrm{H}_{2} \mathrm{O}$ e os resultados foram comparados com os resultados obtidos para as moléculas isoladas. Foi observado que no caso Raman a despolarização devida ao modo intenso de estiramento vibracional $\mathrm{N}-\mathrm{C}$ aumenta cerca de $20 \%$. Para o estiramento $\mathrm{O}-\mathrm{H}$ simétrico da água foi verificado um grande deslocamento para o vermelho de $75 \mathrm{~cm}^{-1}$ na freqüência vibracional e uma grande intensificação da atividade de espalhamento Raman; a seção de choque do espalhamento aumentou por um fator de dois e a despolarização por um fator de aproximadamente 4. 


\section{Capítulo 5}

\section{Espalhamento Rayleigh em sistemas com ligação de hidrogênio}

\subsection{Motivação}

Técnicas empregando espalhamento Rayleigh têm sido usadas com sucesso na obtenção de tamanhos médios de complexos moleculares formados em feixes moleculares sobre diferentes condições de expansão [127-129]. A componente despolarizada da radiação espalhada também tem sido usada para obter espécies moleculares em plasmas [130], uma vez que o sinal do espalhamento está relacionado com o número de partículas espalhadoras no meio $[127,128]$. Recentemente Park e outros [131] propuseram que mudanças na estabilidade de ligações de hidrogênio podem ser monitoradas em processos de fotoisomerização cis-trans por técnicas de espalhamento Rayleigh. Aspectos dinâmicos da formação de ligações de hidrogênio em soluções aquosas podem ser estudados por meio do espalhamento de luz Rayleigh despolarizada. Nesta linha, Micali e outros [132] investigaram o tempo de relaxação rotacional da água em soluções de metanolágua como função da concentração e da temperatura. Assim, o espectro molecular de luz espalhada pode dar informações sobre propriedades microscópicas e coletivas dos centros espalhadores. A partir do ponto de vista estrutural, é sabido que moléculas assimétricas dão uma grande contribuição à intensidade da luz Rayleigh despolarizada, de forma que o espalhamento Rayleigh pode ser 
empregado para estudar a dinâmica rotacional molecular [132] ou até mesmo a estabilidade de um complexo molecular [86]. Mais geralmente, o fenômeno de espalhamento molecular de luz pode ser estudado em gases, vapores, líquidos e cristais [87].

As taxas de despolarização e as atividades de espalhamento Rayleigh de luz são determinadas aqui em termos da polarizabilidade média dos complexos, tal como discutido na seção 3.3. A formação das ligações de hidrogênio leva a um aumento da polarizabilidade anisotrópica e portanto à mudança na taxa de despolarização Rayleigh. Os sistemas estudados aqui são diferentes tipos de complexos orgânicos formados com água. Estes sistemas são, $\mathrm{H}_{2} \mathrm{O} \cdots \mathrm{H}_{2} \mathrm{O}, \mathrm{HCHO} \cdots \mathrm{H}_{2} \mathrm{O}, \mathrm{CH}_{3} \mathrm{HO} \cdots \mathrm{H}_{2} \mathrm{O}, \mathrm{HCOOH} \cdots \mathrm{OH}_{2}, \mathrm{CH}_{3} \mathrm{CN} \cdots \mathrm{H}_{2} \mathrm{O}$ e $\left(\mathrm{CH}_{3}\right)_{2} \mathrm{CO} \cdots \mathrm{H}_{2} \mathrm{O}$. O dímero de água já foi extensivamente estudado antes $[106,133-140]$ contudo estudos sobre os outros complexos são mais escassos e em particular a caracterização de sistemas de álcool e água é de grande importância $[132,141,142]$. As mudanças eletrônicas após a formação da ligação de hidrogênio podem ser observadas por uma grande variedade de técnicas tais como espectroscopia de infravermelho, espectroscopia rotacional milimétrica, ressonância magnética nuclear, espectroscopia Raman, etc. Contudo, a técnica de espalhamento Rayleigh tem sido muito pouco empregada no estudo de sistemas com ligação de hidrogênio. Uma possível razão para isto é a pequena magnitude das mudanças esperadas. Devido à falta de resultados tanto teóricos como experimentais sobre taxas de despolarização do espalhamento Rayleigh para pequenos complexos com ligações de hidrogênio, este estudo pode ser de interesse no estabelecimento de possíveis tendências e predições para a luz espalhada elasticamente nestes sistemas. Além disso, a diferença na despolarização para a radiação espalhada também tem sido investigada aqui para dois grupos de sistemas isoméricos com ligações de hidrogênio: $\mathrm{HCN} \cdots \mathrm{H}_{2} \mathrm{O}$ e $\mathrm{H}_{2} \mathrm{O} \cdots \mathrm{HCN}$; e $\mathrm{CH}_{3} \mathrm{HO} \cdots \mathrm{H}_{2} \mathrm{O}$ e $\mathrm{CH}_{3} \mathrm{OH} \cdots \mathrm{OH}_{2}$. Para estes casos a molécula de água atua tanto como doadora como aceitadora de próton. Assim, as mudanças na despolarização da luz espalhada é usada para avaliar criticamente o espalhamento Rayleigh como um possível meio de distinção entre estes dois isômeros intermoleculares. 


\subsection{Detalhes de cálculo}

O tensor polarizabilidade de dipolo, $\alpha$, foi calculado aqui usando a aproximação de campo finito na qual a energia é calculada na ausência e na presença campos elétricos fracos. Assim, as propriedades elétricas foram determinadas como derivadas da energia com respeito ao campo elétrico. Os cálculos $a b$ initio para moléculas isoladas e complexos moleculares, foram realizados em nível MP2/aug-cc-pVDZ. Assim, as geometrias de equilíbrio dos sistemas foram encontradas e as polarizabilidades de dipolo foram calculadas. Como todos os complexos considerados envolvem a molécula de água, é importante mencionar que o modelo teórico MP2/aug-cc-pVDZ fornece um momento de dipolo de 1.88D para esta molécula, que está em muito bom acordo com o valor experimental de 1.86D [119]. Os cálculos de mecânica quântica reportados aqui foram realizados usando o programa Gaussian 98 [117].

\subsection{Resultados e discussão}

\subsubsection{Polarizabilidades médias e anisotrópicas}

As estruturas dos complexos otimizadas são apresentadas na Figura 5.1, juntamente com os comprimentos das ligações de hidrogênio. Todos estes sistemas se mostraram estáveis em diferentes níveis teóricos. Existem vários estudos teóricos sobre o dímero de água. Schütz e outros [143] e Xantheas [144] obtiveram um valor preciso de $2.925 \AA$ para a distância interatômica $\mathrm{O}$... O. Mais recentemente, Maroulis [145] obteve o valor de 2.911Å. Estes valores estão em bom acordo com a distância $\mathrm{O} \cdots \mathrm{O}$ calculada neste trabalho que é de $2.918 \AA \AA$. No caso de $\mathrm{HCHO} \cdots \mathrm{H}_{2} \mathrm{O}$, o comprimento obtido para ligação de hidrogênio $(\mathrm{O} \cdots \mathrm{H})$ de $1.986 \AA$ é mais curto por $0.075 \AA$ que o valor obtido por Tsuzuki e outros [146] obtido usando o método MP2/6-311G(d,p). Para o cluster $\mathrm{CH}_{3} \mathrm{HO} \cdots \mathrm{H}_{2} \mathrm{O}$ o comprimento da ligação de hidrogênio foi verificado ser de $1.904 \AA$ correspondendo a uma distância $\mathrm{O}$. O O de $2.844 \AA$, que se compara bem com o valor experimental de $2.997 \AA$ [147] e com o resultado teórico obtido recentemente de $2.840 \AA$ usando o método MP2/aug-cc-pVDZ [148]. Para 


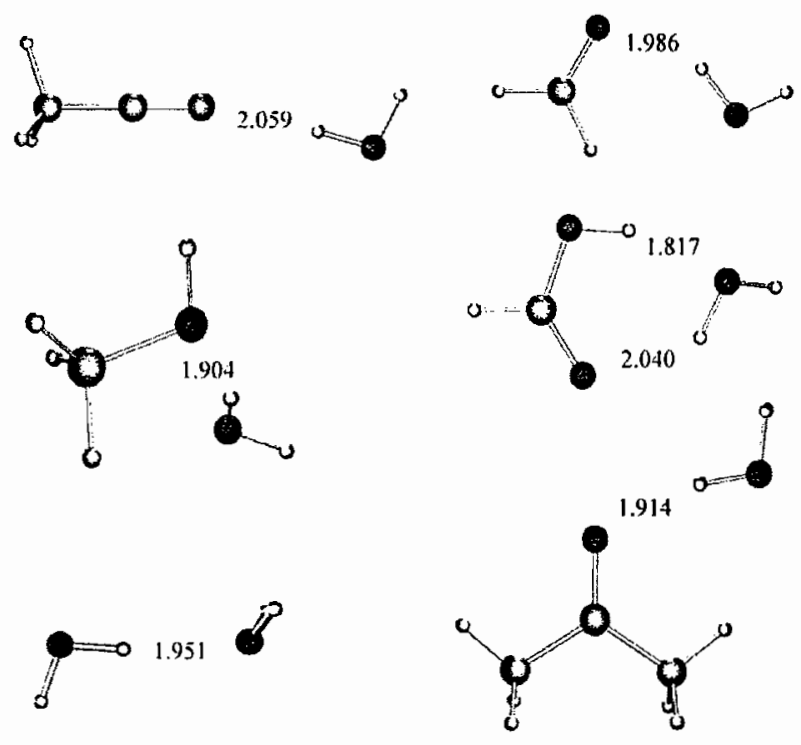

Figura 5.1: Estruturas otimizadas dos complexos: $\mathrm{CH}_{3} \mathrm{CN} \cdots \mathrm{H}_{2} \mathrm{O}, \mathrm{HCHO} \cdots \mathrm{H}_{2} \mathrm{O}$, $\mathrm{CH}_{3} \mathrm{HO} \cdots \mathrm{H}_{2} \mathrm{O}, \mathrm{HCOOH} \cdots \mathrm{OH}_{2}, \mathrm{H}_{2} \mathrm{O} \cdots \mathrm{H}_{2} \mathrm{O}(1)$ e $\left(\mathrm{CH}_{3}\right)_{2} \mathrm{CO} \cdots \mathrm{H}_{2} \mathrm{O}$. Os comprimentos das ligações de hidrogênio são dados em $\AA$, e foram obtidos em nível MP2/aug-cc-pVDZ

$\mathrm{HCOOH} \cdots \mathrm{H}_{2} \mathrm{O}$ as distâncias de ligação de hidrogênio apresentaram um valor de $2.040 \AA$ e $1.817 \AA$ que está em bom acordo com os resultados de Wei e outros [149] de $2.10 \AA$ e $1.80 \AA$ obtidos usando o modelo $M P 2 / 6-311+\mathrm{G}(2 \mathrm{~d}, 2 \mathrm{p})$. No caso do $\mathrm{CH}_{3} \mathrm{CN} \cdots \mathrm{H}_{2} \mathrm{O}$, a distância de $2.059 \AA$ pode ser comparada com um resultado prévio de $2.108 \AA$ [150] obtido com o método $M P 2 / 6-311+G(d, p)$ e para $\left(\mathrm{CH}_{3}\right)_{2} \mathrm{CO} \cdots \mathrm{H}_{2} \mathrm{O}$ a distância da ligação de hidrogênio de $1.914 \AA$ compara bem com uma estimativa prévia de $1.918 \AA$ [151] obtido usando MP2/6-311+G. Os resultados apresentados aqui foram todos obtidos usando um único modelo teórico, MP2/aug-cc-pVDZ, servindo melhor para comparação entre diferentes espécies.

A Tabela 5.1 mostra as polarizabilidades médias e as polarizabilidades anisotrópicas das moléculas isoladas e seus correspondentes complexos com a molécula de água, obtidos com o método MP2/aug-cc-pVDZ. Os resultados para as polarizabilidades das moléculas isoladas estão razoavelmente em bom acordo com os dados experimentais [118]. Para o dímero de água, Maroulis [145] calculou uma polarizabilidade média de 19.5ua, em bom acordo com o resultado de 19.10ua obtido aqui. Em alguns casos, diferentes valores experimentais são reportados. Por exemplo no caso do metanol $\left(\mathrm{CH}_{3} \mathrm{HO}\right)$ 


\begin{tabular}{cccccc}
\hline \hline Sistema & $\bar{\alpha}$ & $\bar{\alpha}_{\text {inter }}$ & $\Delta \alpha$ & $\bar{\alpha}_{\text {exp }}^{a}$ & Outros rslt. p/ $\bar{\alpha}$ \\
\hline $\mathrm{H}_{2} \mathrm{O}$ & 9.30 & - & 1.04 & 9.80 & $9.78[145]$ \\
$\mathrm{H}_{2} \mathrm{O} \cdots \mathrm{H}_{2} \mathrm{O}$ & 19.10 & 0.50 & 3.56 & & $19.5[145]$ \\
$\mathrm{HCHO}$ & 17.58 & - & 8.57 & $18.9,16.55$ & $17.83[152]$ \\
$\mathrm{HCHO} \cdots \mathrm{H}_{2} \mathrm{O}$ & 27.01 & 0.13 & 10.31 & & \\
$\mathrm{CH}_{3} \mathrm{OH}$ & 21.22 & - & 3.38 & $22.21,21.80$ & $21.6[153]$ \\
$\mathrm{CH}_{3} \mathrm{HO} \cdots \mathrm{H}_{2} \mathrm{O}$ & 31.19 & 0.67 & 5.90 & & \\
$\mathrm{HCOOH}$ & 22.53 & - & 10.64 & 22.97 & $20.29[154]$ \\
$\mathrm{HCOOH} \cdots \mathrm{H}_{2} \mathrm{O}$ & 32.15 & 0.32 & 12.93 & & \\
$\mathrm{CH} \mathrm{CN}_{3} \mathrm{CN}$ & 29.43 & - & 15.65 & $29.72,30.27$ & $28.14[154]$ \\
$\mathrm{CH}_{3} \mathrm{CN} \cdots \mathrm{H}_{2} \mathrm{O}$ & 39.67 & 0.94 & 21.78 & & \\
$\left(\mathrm{CH}_{3}\right)_{2} \mathrm{CO}$ & 42.38 & - & 12.38 & $43.17,42.77$ & $43.30[152]$ \\
$\left(\mathrm{CH}_{3}\right)_{2} \mathrm{CO} \cdots \mathrm{H}_{2} \mathrm{O}$ & 52.20 & 0.52 & 17.30 & & \\
\hline \hline
\end{tabular}

Tabela 5.1: Polarizabilidades médias, polarizabilidades de interação e polarizabilidades anisotrópicas (em ua), calculadas com o método MP2/aug-cc-pVDZ. Fator de conversão para a polarizabilidade médias: 1 ua $=0.148 \AA^{3}$. a) Polarizabilidades experimentais estão avaliadas somente para as moléculas isoladas [118]

o resultado calculado de 21.22 ua está em acordo com os três resultados reportados. Em geral, contudo, as polarizabilidades médias calculadas foram ligeiramente menores que os valores experimentais, porém, ligeiramente maiores que os outros resultados teóricos disponíveis [154], como no caso do ácido fórmico $(\mathrm{HCOOH})$ e acetonitrila $\left(\mathrm{CH}_{3} \mathrm{CN}\right)$. $\mathrm{O}$ acordo entre a polarizabilidade teórica e seu respectivo valor experimental depende fortemente do conjunto de funções base empregado no cálculo, como apontou Nakagawa para o metanol [153]. Adicionalmente, a denominada polarizabilidade de interação [145] após a complexação de cada monômero com a água foi analisada. Isto é definido por $\bar{\alpha}_{\text {inter }}=\bar{\alpha}($ complexo $)-\left[\bar{\alpha}\left(H_{2} O\right)+\bar{\alpha}\right.$ (monômero $\left.)\right]$. Como observado por Maroulis [145], o erro de superposição de base é bastante pequeno para esta quantidade neste nível de cálculo. Os valores calculados de $\bar{\alpha}_{\text {inter }}$ para todos os complexos dados na Tabela 5.1 são muito pequenos, sendo menores que 1.0ua em todos os casos. Por exemplo, no caso do dímero de água foi verificado que $\bar{\alpha}_{\text {inter }}$ é 0.5ua; o valor encontrado por Maroulis [145] é menor, em um nível de cálculo diferente. É claro que um valor pequeno para $\bar{\alpha}_{\text {inter }}$ indica que a polarizabilidade média de sistemas com ligações de hidrogênio é aproximadamente a soma de suas partes separadas. O maior valor para $\bar{\alpha}_{\text {inter }}$ calculado aqui foi 
para acetonitrila. Como as polarizabilidades anisotrópicas refletem a simetria do sistema, é interessante notar suas mudanças devido à formação da ligação de hidrogênio. Por exemplo, a polarizabilidade anisotrópica do dímero de água e do complexo $\mathrm{CH}_{3} \mathrm{HO} \cdots \mathrm{H}_{2} \mathrm{O}$ muda igualmente por 2.52ua. Este valor foi somente 1.74 ua para $\mathrm{HCHO} \cdots \mathrm{H}_{2} \mathrm{O}$ e 2.29 ua para $\mathrm{HCOOH} \cdots \mathrm{H}_{2} \mathrm{O}$, e aumenta para 4.92ua para $\left(\mathrm{CH}_{3}\right)_{2} \mathrm{CO} \cdots \mathrm{H}_{2} \mathrm{O}$ e 6.13ua para $\mathrm{CH}_{3} \mathrm{CN} \cdots \mathrm{H}_{2} \mathrm{O}$. Estas diferenças nas polarizabilidades anisotrópicas levarão a diferenças nas taxas de despolarização.

\subsubsection{Taxas de despolarização e intensidades para o espalha- mento Rayleigh}

As quantidades mais comumente observadas em experimentos com espalhamento de luz são as taxas de despolarização (veja seção 3.3.1) definidas pelas equações (3.10), (3.11) e (3.12). As mudanças nas polarizabilidades média e anisotrópica conduzem a variações nas taxas de despolarização dos complexos. Todas as componentes da despolarização devida à incidência de luz natural, plano-polarizada e circularmente polarizada foram calculadas para as moléculas isoladas e seus respectivos complexos mostrados na Figura 5.1. A Tabela 5.2 apresenta as componentes das taxas de despolarização para cada sistema obtidas em nível MP2/aug-cc-pVDZ. O aumento na polarizabilidade anisotrópica deveria levar, sistematicamente, a um aumento nas taxas de despolarização. Contudo ocorreu o oposto nos casos do formaldeído (HCHO) e do ácido fórmico (HCOOH) após a complexação com a água. No primeiro caso, a variação na despolarização da luz plano-polarizada $\left(\sigma_{p}\right)$ foi de $-38 \%$ após a ligação com a água. Similarmente, no caso do $\mathrm{HCOOH}$ esta variação foi de $-27 \%$ após a formação da ligação de hidrogênio. Por outro lado, esta variação aumentou para $18 \%$ para $\mathrm{CH}_{3} \mathrm{HO} \cdots \mathrm{H}_{2} \mathrm{O}, 22 \%$ para $\left(\mathrm{CH}_{3}\right)_{2} \mathrm{CO} \cdot \mathrm{H}_{2} \mathrm{O}$, e somente $6.4 \%$ para $\mathrm{CH}_{3} \mathrm{CN} \cdots \mathrm{H}_{2} \mathrm{O}$. Para o caso do dímero de água, $\sigma_{n}$ alcançou um valor muito superior, isto é, aumentou de $0.08 \times 10^{-2}$ para $0.23 \times 10^{-2}$. Um comportamento análogo foi observado para a luz natural e para luz circularmente polarizada, como mostrado na Tabela 5.2. É interessante observar que todas as componentes da despolarização para o dímero de água e para o complexo $\mathrm{CH}_{3} \mathrm{HO} \cdots \mathrm{H}_{2} \mathrm{O}$ 


\begin{tabular}{cccc}
\hline \hline Sistema & $\sigma_{n}\left(\times 10^{-2}\right)$ & $\sigma_{p}\left(\times 10^{-2}\right)$ & $\sigma_{c}\left(\times 10^{-2}\right)$ \\
\hline $\mathrm{H}_{2} \mathrm{O}$ & 0.17 & 0.08 & 0.17 \\
$\mathrm{H}_{2} \mathrm{O} \cdots \mathrm{H}_{2} \mathrm{O}$ & 0.46 & 0.23 & 0.46 \\
$\mathrm{HCHO}$ & 3.05 & 1.55 & 3.15 \\
$\mathrm{HCHO} \cdots \mathrm{H}_{2} \mathrm{O}$ & 1.90 & 0.96 & 1.94 \\
$\mathrm{CH}_{3} \mathrm{OH}$ & 0.34 & 0.17 & 0.34 \\
$\mathrm{CH}_{3} \mathrm{HO} \cdots \mathrm{H}_{2} \mathrm{O}$ & 0.47 & 0.24 & 0.47 \\
$\mathrm{HCOOH}$ & 2.87 & 1.46 & 2.95 \\
$\mathrm{HCOOH} \cdots \mathrm{OH}_{2}$ & 2.10 & 1.06 & 2.14 \\
$\mathrm{CH}_{3} \mathrm{CN}$ & 3.61 & 1.84 & 3.74 \\
$\mathrm{CH}_{3} \mathrm{CN}^{2} \cdots \mathrm{H}_{2} \mathrm{O}$ & 3.84 & 1.96 & 3.99 \\
$\left(\mathrm{CH}_{3}\right)_{2} \mathrm{CO}$ & 1.12 & 0.56 & 1.13 \\
$\left(\mathrm{CH}_{3}\right)_{2} \mathrm{CO} \cdots \mathrm{H}_{2} \mathrm{O}$ & 1.44 & 0.72 & 1.46 \\
\hline \hline
\end{tabular}

Tabela 5.2: Taxas de despolarizaçāo para diferentes tipos de luz incidente calculadas em termos das polarizabilidades médias e anisotrópicas. Todos valores foram obtidos em nível MP2/aug-cc-pVDZ

possuem essencialmente o mesmo valor. Por exemplo, a taxa de despolarização para a luz circularmente polarizada $\sigma_{c}$ foi calculada como sendo $0.46 \%$ para $\left(\mathrm{H}_{2} \mathrm{O}\right)_{2}$ e $0.47 \%$ para $\mathrm{CH}_{3} \mathrm{HO} \cdots \mathrm{H}_{2} \mathrm{O}$. Estes valores são muito próximos devido ao fato de que a diferença básica entre os dois complexos, $\mathrm{XOH} \cdots \mathrm{H}_{2} \mathrm{O}$ é somente o grupo substituinte $\mathrm{X}=\mathrm{H}$ ou $\mathrm{CH}_{3}$ nas estruturas geométricas. As-

\begin{tabular}{cccc}
\hline \hline Sistema & $\Re_{n}$ & $\Re_{p \perp}$ & $\Re_{p / l}$ \\
\hline $\mathrm{H}_{2} \mathrm{O} \cdots \mathrm{H}_{2} \mathrm{O}$ & $1.658(4.24)$ & $1.650(4.23)$ & $0.008(11.73)$ \\
$\mathrm{HCHO} \cdots \mathrm{H}_{2} \mathrm{O}$ & $3.420(2.30)$ & $3.357(2.33)$ & $0.064(1.45)$ \\
$\mathrm{CH}_{3} \mathrm{HO} \cdots \mathrm{H}_{2} \mathrm{O}$ & $4.424(2.17)$ & $4.403(2.16)$ & $0.021(3.03)$ \\
$\mathrm{HCOOH} \mathrm{OH}_{2}$ & $4.868(2.00)$ & $4.767(2.02)$ & $0.100(1.47)$ \\
$\mathrm{CH}_{3} \mathrm{CN} \cdots \mathrm{H}_{2} \mathrm{O}$ & $7.700(1.83)$ & $7.415(1.82)$ & $0.284(1.94)$ \\
$\left(\mathrm{CH}_{3}\right)_{2} \mathrm{CO} \cdots \mathrm{H}_{2} \mathrm{O}$ & $12.652(1.53)$ & $12.472(1.52)$ & $0.180(1.95)$ \\
\hline \hline
\end{tabular}

Tabela 5.3: Intensidades Rayleigh (em $10^{4}$ ua) calculadas em termos das polarizabilidades de dipolo e anisotrópica. Valores em parênteses correspondem ao fator de aumento da intensidade após a complexação com água. Todos os valores foram calculados em nível MP2/aug-cc-pVDZ

sim, é difícil distinguir entre os dois complexos usando somente espalhamento Rayleigh despolarizado. De acordo com a próxima seção, os dois heterodímeros de metanol e água apresentam a mesma taxa de despolarização que o dímero de água, de modo que determinações complementares de outras propriedades são necessárias para distinguir entre diferentes complexos. A Tabela 5.3 mos- 


\section{Espalhamento Rayleigh em sistemas com ligação de hidrogênio}

tra as intensidades Rayleigh para os complexos para todas as componentes da luz. Os fatores de aumento com respeito à molécula isolada também são dados. Por exemplo, a intensidade Rayleigh para a luz natural no caso do complexo formaldeído-água, $\Re_{n}\left(\mathrm{HCHO} \cdots \mathrm{H}_{2} \mathrm{O}\right)$, foi calculado como $3.420 \times 10^{4}$ ua. Isto representa um fator de 2.3 comparado à mesma intensidade para a molécula de formaldeído isolada $\left(1.487 \times 10^{4} u a\right)$. Como pode ser visto, a formação da ligação de hidrogênio levou a um considerável aumento na intensidade Rayleigh. Isto ocorreu para todas polarizações como mostra a Tabela 5.3. Tipicamente o fator de aumento é próximo de 2.0, mas no caso do dímero de água este fator é até mesmo maior. As variações de $\Re_{n}$ e $\Re_{p \perp}$ refletem a forte dependência da atividade Rayleigh com a polarizabilidade médias e a menor contribuição da polarizabilidade anisotrópica. Para molécula de água isolada a intensidade foi calculada como sendo $3.907 \times 10^{3}$ ua enquanto que para o menor complexo considerado aqui $\left(\mathrm{H}_{2} \mathrm{O}\right)_{2}$ foi $1.658 \times 10^{4} \mathrm{ua}$, correspondendo a um fator de 4.2 e um aumento absoluto de $1.267 \times 10^{4}$ ua para luz natural. Para o complexo acetona-água, o maior complexo considerado aqui, o fator de aumento foi 1.5 com um aumento absoluto de $4.372 \times 10^{4}$ ua. $\mathrm{O}$ aumento percentual apresentou comportamento oposto ao tamanho dos complexos. Enquanto as diferenças nas intensidades Rayleigh da luz espalhada após a dimerização da água correspondeu a $76 \%$ da intensidade de espalhamento total do dímero, a formação do complexo da acetona com a água deu somente $35 \%$. Além disso, para o caso da molécula de água, sua polarizabilidade assumiu valor superior ao dobro do valor original para uma molécula antes da dimerização, enquanto que para a complexação da acetona, este aumento foi de apenas $23 \%$. Como visto na seção 3.3.1, $\Re_{p / /}$ é dada inteiramente pela polarizabilidade anisotrópica, $6(\Delta \alpha)^{2}$. O dímero de água é o complexo mais anisotrópico, dando uma variação em $\Re_{p / /}$ de $92 \%$, enquanto $\mathrm{HCHO} \cdots \mathrm{H}_{2} \mathrm{O}$ e $\mathrm{HCOOH} \cdots \mathrm{OH}_{2}$ deram somente $31 \%$ e $32 \%$ respectivamente.

\subsubsection{Espalhamento Rayleigh em isômeros}

A caracterização espectroscópica de isômeros intermoleculares pode efetivamente ser realizada usando técnicas espectroscópicas ro-vibracionais. Além 
disso, após a formação da ligação de hidrogênio os modos de estiramento sofrem deslocamentos de freqüência para energias mais baixas. As propriedades do espalhamento Rayleigh foram investigadas aqui para dois grupos de isômeros com ligações de hidrogênio: $\mathrm{H}_{2} \mathrm{O} \cdots \mathrm{HCN}$ e $\mathrm{HCN} \cdots \mathrm{H}_{2} \mathrm{O}$; e $\mathrm{CH}_{3} \mathrm{HO} \cdots \mathrm{H}_{2} \mathrm{O}$ e $\mathrm{CH}_{3} \mathrm{OH} \cdots \mathrm{OH}_{2}$, onde a molécula de água atua tanto como doadora como aceitadora de próton. As geometrias otimizadas MP2/aug-cc-pVDZ dos dois possíveis heterodímeros, cianeto de hidrogênio-água e metanol-água, são dadas esquematicamente na Figura 5.2. A estabilidade dos isômeros de cianeto de
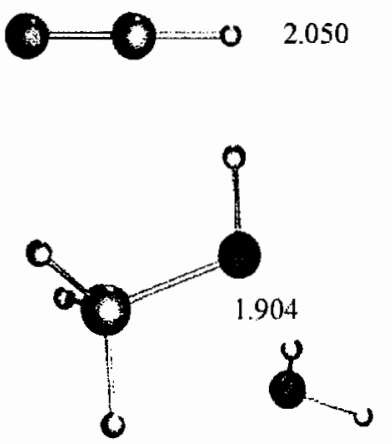
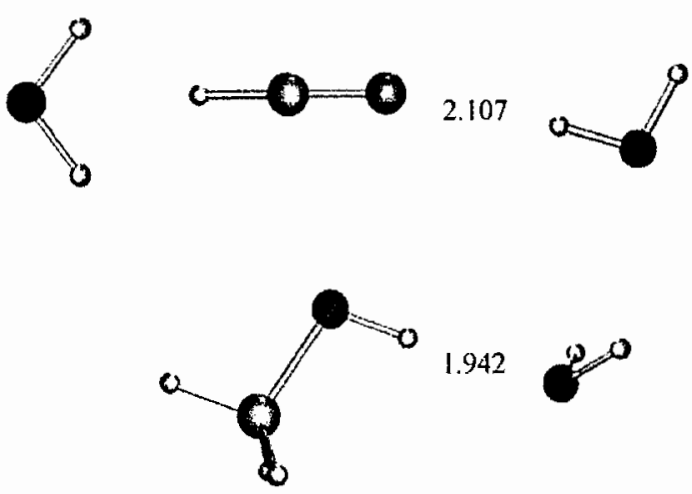

1.942

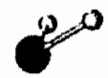

Figura 5.2: Estruturas dos complexos cianeto de hidrogênio-água e metanol-água. Os comprimentos das ligaçōes de hidrogênio são dados em $\AA$, e foram obtidos em nível MP2/augcc-pVDZ

hidrogênio-água foi determinada em um trabalho anterior usando CCSD(T)// MP2/6-311++G(d,p) [124]. Para $\mathrm{H}_{2} \mathrm{O} \cdots \mathrm{HCN}$ a energia de ligação obtida foi $5.17 \mathrm{kcal} / \mathrm{mol}$, enquanto para $\mathrm{HCN} \cdots \mathrm{H}_{2} \mathrm{O}$ a energia foi $3.38 \mathrm{kcal} / \mathrm{mol}$, que é $1.8 \mathrm{kcal} / \mathrm{mol}$ menor que a energia do primeiro isômero. A existência destes isômeros foi confirmada por fotólise de formaldóxido [155]. No caso dos isômeros de metanol-água tanto resultados experimentais [1.56-159] quanto teóricos [160] encontraram os dois heterodímeros estáveis, Figura 5.2. Neste caso, o complexo $\mathrm{CH}_{3} \mathrm{HO} \cdots \mathrm{H}_{2} \mathrm{O}$ se mostrou mais estável que o isômero $\mathrm{CH}_{3} \mathrm{OH} \cdots \mathrm{OH}_{2}$ por um valor estimado de $0.7 \mathrm{kcal} / \mathrm{mol}$ usando o modelo B3LYP $/ 6-311+\mathrm{G}(3 \mathrm{df}, 2 \mathrm{p})$ [1.60]. Para os complexos metanol-água é verificado que o isômero $\mathrm{CH}_{3} \mathrm{HO} \cdots \mathrm{H}_{2} \mathrm{O}$ é mais estável por $0.8 \mathrm{kcal} / \mathrm{mol}$. No estudo teórico destes dímeros, González e outros $[160]$ obtiveram uma distância $\mathrm{O} \cdots \mathrm{H}$ de $1.890 \AA$ no caso do complexo $\mathrm{CH}_{3} \mathrm{HO} \cdots \mathrm{H}_{2} \mathrm{O}$ e de $1.937 \AA$ no caso do complexo $\mathrm{CH}_{3} \mathrm{OH} \cdots \mathrm{OH}_{2}$. Estes resulta- 
dos são comparados favoravelmente com os resultados correspondentes apresentados aqui de 1.904 e $1.942 \AA$, apesar das distâncias $\mathrm{O} \cdots \mathrm{H}$ serem ligeiramente maiores por 0.014 e $0.005 \AA$, respectivamente. As propriedades do espalhamento Rayleigh determinadas aqui para estes dois grupos de isômeros são apresentadas nas Tabelas 5.4 e 5.5. Como pode ser visto na Tabela 5.4 apesar das polariza-

\begin{tabular}{cccccc}
\hline \hline Isômeros & $\bar{\alpha}$ & $\Delta \alpha$ & $\sigma_{n}\left(\times 10^{-2}\right)$ & $\sigma_{p}\left(\times 10^{-2}\right)$ & $\sigma_{c}\left(\times 10^{-2}\right)$ \\
\hline $\mathrm{H}_{2} \mathrm{O} \cdots \mathrm{HCN}$ & 26.74 & 13.74 & 3.38 & 1.72 & 3.49 \\
$\mathrm{HCN} \cdots \mathrm{H}_{2} \mathrm{O}$ & 22.60 & 15.37 & 5.75 & 2.96 & 6.10 \\
$\mathrm{CH}_{3} \mathrm{HO} \cdots \mathrm{H}_{2} \mathrm{O}$ & 31.19 & 5.90 & 0.47 & 0.24 & 0.47 \\
$\mathrm{CH}_{3} \mathrm{OH} \cdots \mathrm{OH}_{2}$ & 30.67 & 5.25 & 0.40 & 0.20 & 0.40 \\
\hline \hline
\end{tabular}

Tabela 5.4: Polarizabilidades média e anisotrópica (em ua) e taxas de despolarização Rayleigh. Todos os valores foram determinados em nível MP2/aug-cc-pVDZ

\begin{tabular}{ccccccc}
\hline \hline Isômeros & $\Re_{n}$ & $\Re_{p \perp}$ & $\Re_{p / /}$ & $I_{A}$ & $I_{B}$ & $I_{C}$ \\
\hline $\mathrm{H}_{2} \mathrm{O} \cdots \mathrm{HCN}$ & $3.463(2.51)$ & $3.350(2.52)$ & $0.113(2.35)$ & 430.0 & 3.0 & 3.0 \\
$\mathrm{HCN} \cdots \mathrm{H}_{2} \mathrm{O}$ & $2.606(1.89)$ & $2.464(1.85)$ & $0.142(2.95)$ & 476.6 & 3.2 & 3.2 \\
$\mathrm{CH}_{3} \mathrm{HO} \cdots \mathrm{H}_{2} \mathrm{O}$ & $4.424(2.17)$ & $4.403(2.16)$ & $0.021(3.03)$ & 24.9 & 4.6 & 4.0 \\
$\mathrm{CH}_{3} \mathrm{OH} \cdots \mathrm{OH}_{2}$ & $4.269(2.09)$ & $4.252(2.09)$ & $0.016(2.39)$ & 32.0 & 3.8 & 3.2 \\
\hline \hline
\end{tabular}

Tabela 5.5: Intensidade Rayleigh (em $10^{4} \mathrm{ua}$ ) calculadas em termos das polarizabilidades médias e anisotrópica. Valores em parênteses correspondem ao fator de aumento da intensidade após a complexação com a água. Todos os valores foram calculados em nível MP2/augcc-pVDZ. $I_{A}, I_{B}$ e $I_{C}$ são as constantes rotacionais dadas em $\mathrm{GHz}$

bilidades de médias e anisotrópicas dos isômeros de cianeto de hidrogênio-água serem similares, as componentes da despolarização de $\mathrm{HCN} \cdots \mathrm{H}_{2} \mathrm{O}$ diferem das componentes da despolarização de $\mathrm{H}_{2} \mathrm{O} \cdots \mathrm{HCN}$ por um fator de 1.7. Contudo isto não foi verificado para os isômeros metanol-água, para os quais as polarizabilidades médias, polarizabilidades anisotrópicas e todas as componentes das taxas de despolarização possuem valores similares. As variações nas atividades dos dois grupos de isômeros são dadas na Tabela 5.5. Novamente, o efeito observado para $\Re_{n}$ e $\Re_{p \perp}$ foi fortemente dominado pelo termo $(\bar{\alpha})^{2}$, com uma pequena contribuição do termo $(\Delta \alpha)^{2}$, enquanto $\Re_{p / /}$ depende somente do último termo. Depois da complexação estes sistemas são aproximadamente rotores prolatos, como indica as constantes rotacionais $\left(I_{A}, I_{B}, I_{C}\right)$ na Tabela 5.5. Estas quantidades são relevantes para uma descrição de espectroscopia de 
onda milimétrica e também foi obtida previamente tanto teórica [160] como experimentalmente [159].

\subsection{Conclusões}

Uma investigação baseada no espalhamento clássico de luz foi realizada para analisar pequenos complexos com ligações de hidrogênio. Usando cálculos $a b$ initio em nível MP2/aug-cc-pVDZ as geometrias de diferentes complexos $\left(\mathrm{H}_{2} \mathrm{O} \cdots \mathrm{H}_{2} \mathrm{O}, \mathrm{HCHO} \cdots \mathrm{H}_{2} \mathrm{O}, \mathrm{CH}_{3} \mathrm{HO} \cdots \mathrm{H}_{2} \mathrm{O}, \mathrm{H}_{2} \mathrm{COOH} \cdots \mathrm{OH}_{2}, \mathrm{CH}_{3} \mathrm{CN} \cdots \mathrm{H}_{2} \mathrm{O}\right.$, e $\left.\left(\mathrm{CH}_{3}\right)_{2} \mathrm{CO} \cdots \mathrm{H}_{2} \mathrm{O}\right)$ foram completamente otimizadas. As polarizabilidades médias e anisotrópica foram calculadas para as moléculas isoladas e para os complexos. A partir destes cálculos, propriedades de espalhamento Rayleigh foram determinadas e comparadas para analisar as mudanças após a formação da ligação de hidrogênio. A intensidade foi consideravelmente aumentada por um fator próximo de 2.0 para todos os casos, com exceção do dímero $\left(\mathrm{H}_{2} \mathrm{O}\right)_{2}$. Diferentes tipos de polarização para a luz foram considerados (ou seja, natural, plano-polarizada e circularmente polarizada) para analisar as taxas de despolarização. Para avaliar o espalhamento Rayleigh despolarizado como um possível meio de identificar isômeros intermoleculares, as interações entre cianeto de hidrogênio e água bem como metanol e água foram investigadas. Detecções viáveis destes complexos têm sido de grande interesse em físico-química. No caso do HCN os diferentes isômeros respondem diferentemente ao espalhamento de luz, mas no caso do metanol a distinção entre os isômeros é mais difícil de discernir com base na atividade de espalhamento e nas taxas de despolarização. 


\section{Capítulo 6}

\section{Propriedades RMN em complexos de metanol-água}

\subsection{Motivação}

Misturas de álcool e água exibem um comportamento anômalo comparado com seus constituientes puros. Quando álcool e água se misturam a entropia da mistura aumenta menos que o esperado. Este efeito foi primeiramente apontado por Frank e Evans [161] e explicado em termos de uma interação hidrofóbica com os grupos não polares do álcool, que induz uma estrutura como a do gelo nas moléculas de água vizinhas. Existe uma extensa literatura sobre este tópico [141,142, 162-170]. Estudos espectroscópicos [141, 142,162-167] e simulações computacionais $[141,168-170]$ foram realizados para descrever a estrutura das misturas álcool-água. Resultados de difração de nêutrons forneceram informações estruturais sobre as "gaiolas" de água em torno do grupo hidrofóbico $[162,165]$. Mais recentemente novos estudos de difração de nêutrons demonstraram que a mistura incompleta em nível molecular é essencial para explicar o pequeno aumento da entropia quando se dissolve metanol em água [141]. Um recente estudo de emissão de raios-X forneceram uma descrição dos detalhes da mistura incompleta a nível molecular [142].

Um importante aspecto que é crucial para a interpretação da estrutura álcool-água é a rede de ligações de hidrogênio que é formada. Para racionalizar a estrutura da mistura incompleta do ponto de vista microscópico é importante compreender esta interação molecular. Assim, o estudo de com- 
plexos de alcool-água são bons modelos para compreender o comportamento da ligação de hidrogênio $(\mathrm{O} \cdots \mathrm{HO})$, porque assim como a água a molécula de metanol é tanto aceitadora como doador de próton. Recentemente foi estabelecido que os dois possíveis complexos envolvendo metanol e água possuem energias equivalentes $[159,160,171]$ inclusive no estado líquido [172].

Uma importante técnica espectroscópica que tem sido empregada na investigação de ligações de hidrogênio é a ressonância magnética nuclear. Contudo existem poucos estudos de RMN em sistemas envolvendo álcool e água. Em um trabalho experimental Ludwig estudou a relaxação RMN em misturas de álcool e água [173], mostrando que o tempo de correlação reorientacional e as constantes de acoplamento de quadrupolo da água são muito sensíveis à concentração do soluto. Noutro trabalho o comportamento da ligação de hidrogênio com a temperatura foi analisado através de cálculos $a b$ initio de álcoois em fase líquida [174]. Propriedades magnéticas tais como deslocamentos químicos isotrópicos e anisotrópicos têm sido empregados na deteção e caracterização de ligações de hidrogênio. Essas aplicações começaram cerca de 50 anos atrás com experimentos sobre o efeito da temperatura e solvente no deslocamento químico isotrópico do próton da ligação O-H na molécula de etanol [175]. Muitos pesquisadores determinaram o deslocamento químico do próton em fase líquida e gasosa para vários sistemas com ligações de hidrogênio tais como hidretos [176], alcoóis [177], fenóis [178], ácidos carboxílicos [178], peptídeos [179], aminas e proteínas $[180,181]$. Em um estudo sobre a água, Ditchfield observou que o deslocamento químico anisotrópico era mais sensível à presença da ligação de hidrogênio que o deslocamento químico isotrópico [182-184]. Em outros estudos Ditchfield e colaboradores $[185,186]$ notaram que as componentes do deslocamento químico que são perpendiculares ao eixo da ligação de hidrogênio são mais sensíveis à formação da ligação de hidrogênio que a componente paralela. Muitos trabalhos teóricos foram publicados desde então e mostraram credibilidade na interpretação de dados experimentais. Hinton e Wolisnki [187] reviram as principais aplicaçōes de cálculos ab initio para sistemas que apresentam ligações de hidrogênio.

Aqui, uma completa descrição do ambiente químico de cada núcleo 
nos complexos é dada para verificar os efeitos relativos sobre os núcleos que participam da ligação de hidrogênio.

\subsection{Detalhes de cálculo}

O método MP2 tem provado ser um bom modelo teórico para o estudo de aglomerados que apresentam ligações de hidrogênio. É sabido que esta aproximação fornece geometrias moleculares com precisão e confiabilidade [55] e assim cálculos MP2/6-311++G(2d,2p) foram realizados para se obter as geometrias dos complexos $\mathrm{CH}_{3} \mathrm{HO} \cdots \mathrm{H}_{2} \mathrm{O}$ e $\mathrm{CH}_{3} \mathrm{OH} \cdots \mathrm{OH}_{2}$ bem como das espécies isoladas (monômeros). Os complexos otimizados são mostrados na figura 5.2, porém como neste trabalho é utilizado um conjunto de funções base diferente os valores mostrados são ligeiramente diferentes. As constantes RMN foram obtidas para estes complexos e para os monômeros em três diferentes níveis teóricos usando orbitais atômicos com invariança de calibre (GIAO) [182, 188]. Primeiramente o método GIAO/Hartree-Fock [188] foi empregado e os efeitos da correlação eletrônica foram obtidos em nível GIAO/MP2 [189, 190]. Para comparação, foram realizados também cálculos GIAO/DFT [191-193] com o funcional B3LYP. Em todos os casos o conjunto de funções base $6-311++\mathrm{G}(2 \mathrm{~d}, 2 \mathrm{p})$ foi empregado, uma vez que já foi demonstrado que o conjunto $6-311++\mathrm{G}(\mathrm{d}, \mathrm{p})$ é suficiente para fornecer resultados em bom acordo com o experimento $[188,191]$. O erro de superposição de base foi corrigido para os valores dos deslocamentos químicos usando a correção counterpoise. Todos os cálculos foram realizados com o programa Gaussian 98 [117].

\subsection{Resultados e discussão}

\subsubsection{As blindagens magnéticas absolutas}

Assim como na seç̧ão 5.3.3 as geometrias otimizadas para ambos os complexos estão em bom acordo com outros resultados teóricos. A distância $\mathrm{O} \cdots \mathrm{O}$ para os complexos no qual a molécula de metanol é aceitadora e doadora de próton foi calculada como $2.860 \AA$ e $2.913 \AA$, respectivamente. Num estudo teórico prévio, 
Kirschner e Woods encontraram os resultados de $2.845 \AA$ e $2.912 \AA$ respectivamente, usando o mesmo método (MP2) mas com uma base diferente (aug-ccpVDZ) [148], o que está em bom acordo com os valores apresentados aqui. O resultado experimental para o caso do metanol aceitador de próton foi inferido como sendo $2.997 \pm 0.009 \AA$ [159], porém este valor não pôde ser obtido nem mesmo em alto nível de cálculo [148].

Existe indicações de que para propriedades RMN de moléculas grandes seja suficiente realizar cálculos em nível DFT ou até mesmo em nível SCF $[182,191,194,195]$, mas em geral efeitos de correlação eletrônica são importantes. No cálculo da blindagem magnética absoluta é importante incluir os tais efeitos de uma maneira mais controlável do que são usualmente incluídos no método DFT. Logo todos os cálculos são realizados em nível MP2 mas os resultados são também dados para o caso de B3LYP e SCF para comparação. As blindagens magnéticas isotrópicas e anisotrópicas para as espécies isoladas, metanol e água, são mostradas na Tabela 6.1.

São reportados aqui os valores determinados usando os três níveis teóricos considerados, mas em todos os casos, a geometria usada é aquela obtida em nível MP2/6-311++G(2d,2p). Todos os valores para a blindagem isotrópica estão em bom acordo com o respectivo resultado experimental. Pode-se observar que os resultados MP2 estão em razoável acordo com outros valores teóricos para a blindagem anisotrópica dos átomos da molécula de metanol. Este resultado foi melhorado para os átomos da molécula de água. É interessante observar que a correlação eletrônica obtida em nível B3LYP mostrou sinal oposto àquela obtida em nível MP2. Por exemplo, a blindagem isotrópica para o átomo de oxigênio da molécula de metanol usando B3LYP foi menor que sua respectiva usando SCF, mostrando que a correlação eletrônica diminui esta blindagem. Isto foi oposto ao que foi obtido em nível MP2 onde os efeitos de correlação aumentam o valor da blindagem melhorando o resultado teórico. Comparando os resultados SCF com MP2 para a blindagem isotrópica pode-se notar que os efeitos de correlação eletrônica aumentaram os valores para blindagem isotrópica do oxigênio por cerca de $13 \mathrm{ppm}$. 


\begin{tabular}{|c|c|c|c|c|c|}
\hline \multicolumn{6}{|c|}{ Blindagem magnética isotrópica $\left(\sigma^{i s o}\right)$} \\
\hline $\mathrm{CH}_{3} \mathrm{OH}$ & SCF & B3LYP & MP2 & \multicolumn{2}{|c|}{ Exp } \\
\hline $\mathrm{O}$ & 337.77 & 321.65 & 350.47 & \multicolumn{2}{|c|}{$345.9^{a}$} \\
\hline $\mathrm{C}$ & 145.52 & 130.22 & 144.37 & \multicolumn{2}{|c|}{$136.6^{b}$} \\
\hline $\mathrm{H}$ & 28.88 & 28.21 & 28.27 & \multicolumn{2}{|c|}{$27.34^{c}$} \\
\hline $\mathrm{H}$ & 28.88 & 28.21 & 28.27 & \multicolumn{2}{|c|}{$27.34^{c}$} \\
\hline $\mathrm{H}$ & 28.90 & 28.43 & 28.42 & \multicolumn{2}{|c|}{$27.34^{c}$} \\
\hline $\mathrm{H}_{0}$ & 31.98 & 32.33 & 31.99 & \multicolumn{2}{|c|}{$30.73^{c}$} \\
\hline \multicolumn{6}{|l|}{$\mathrm{H}_{2} \mathrm{O}$} \\
\hline $\mathrm{H}$ & 30.86 & 31.45 & 30.99 & $30.09^{c}$ & $30.05^{d}$ \\
\hline $\mathrm{O}$ & 327.08 & 326.36 & 344.78 & $344.0^{e}$ & $323.6^{f}$ \\
\hline $\mathrm{H}$ & 30.86 & 31.45 & 30.99 & $30.09^{c}$ & $30.05^{d}$ \\
\hline \multicolumn{6}{|c|}{ Blindagem magnética anisotrópica $\left(\sigma^{a n i s}\right)$} \\
\hline $\mathrm{CH}_{3} \mathrm{OH}$ & SCF & B3LYP & MP2 & \multicolumn{2}{|c|}{ Outros } \\
\hline $\mathrm{O}$ & 97.57 & 95.90 & 90.96 & \multicolumn{2}{|c|}{$96.9^{9}$} \\
\hline $\mathrm{C}$ & 67.92 & 80.54 & 77.97 & \multicolumn{2}{|c|}{$63.8^{g}$} \\
\hline $\mathrm{H}$ & 8.30 & 8.26 & 8.61 & \multicolumn{2}{|c|}{$7.83^{h}$} \\
\hline $\mathrm{H}$ & 8.30 & 8.26 & 8.61 & \multicolumn{2}{|c|}{$7.83^{h}$} \\
\hline $\mathrm{H}$ & 7.76 & 7.28 & 7.68 & \multicolumn{2}{|c|}{$7.63^{h}$} \\
\hline $\mathrm{H}_{0}$ & 20.40 & 18.11 & 19.72 & & \\
\hline \multicolumn{6}{|l|}{$\mathrm{H}_{2} \mathrm{O}$} \\
\hline $\mathrm{H}$ & 20.41 & 19.18 & 20.35 & $20.39^{i}$ & $19.10^{j}$ \\
\hline $\mathrm{O}$ & 56.49 & 54.05 & 46.03 & $46.05^{i}$ & $46.97^{j}$ \\
\hline $\mathrm{H}$ & 20.41 & 19.18 & 20.35 & $20.39^{i}$ & $19.10^{j}$ \\
\hline
\end{tabular}

Tabela 6.1: Valores das blindagens magnéticas isotrópicas, $\sigma^{i s o}$, anisotrópicas, $\sigma^{\text {anis }}$ dos átomos nas moléculas de metanol e água (em ppm) determinadas em três níveis teóricos. $\mathrm{Na}$ quarta coluna são apresentados os resultados experimentais para $\sigma^{\text {iso }}$ e outros resultados teóricos para $\sigma^{a \pi i s}$. a) Resultado de fase líquida convertido para escala absoluta citado por Kitzinger [196]; b) Ref. [197]; c) Ref. [198]; d) Ref. [1.99]; e) Ref. [200]; f) Ref. [201]; g) Ref. [194]; h) Calculado para o grupo metil na molécula de metilformato Ref. [202]; i) Ref. [203]; j) Ref. [204] 
Uma comparação apropriada entre os resultados obtidos nos níveis DFT e MP2 requer valores experimentais confáveis para referência. O valor experimental da blindagem isotrópica do átomo de oxigênio da molécula de água foi obtido como sendo 344.0 ppm [200] em bom acordo com nosso resultado MP2, como visto na Tabela 6.1. Isto implicaria uma má concordância do modelo B3LYP. Contudo este valor foi recentemente revisitado [201] e o valor experimental de $323.6 \mathrm{ppm}$ foi sugerido. Agora a concordância foi invertida, mostrando um excelente desempenho do modelo B3LYP e uma superestimativa pelo método MP2. Este último valor experimental para o átomo de oxigênio da molécula de água está em acordo com a tendência observada de que o método MP2 de fato superestima o valor das blindagens isotrópicas para átomos pesados $[189,190,195,203]$. Contudo é importante ter em mente as contribuições vibracionais, que não foram consideradas nestes cálculos. Embora estas contribuições não sejam essenciais para uma boa descrição dos deslocamentos químicos, uma vez que elas tendem a se cancelar, a presente discussão diz respeito à blindagem magnética absoluta. Estas contribuições vibracionais tem sido estimadas como -12 ppm para a blindagem química do átomo de oxigênio da molécula de água [?, ?]. Se isto for levado em conta agora, MP2 é novamente mais realístico. O mesmo argumento pode ser aplicado para a blindagem anisotrópica. Valores teóricos recentes obtidos por Helgaker e colaboradores [204] usando um elaborado cálculo multiconfiguracional confirmaram que o valor para o átomo de oxigênio da molécula de água está próximo de 46.97 ppm mas sugeriram um valor de 19.10 ppm para os átomos de hidrogênio, novamente em melhor acordo com os resultados B3LYP.

Para os átomos de hidrogênio do grupo metil, bem como para o átomo de carbono, os efeitos da correlação eletrônica diminuíram o valor da blindagem isotrópica por um valor relativamente pequeno, da ordem de 0.5-1.0 ppm. Para a blindagem anisotrópica (parte de baixo da Tabela 6.1) uma descrição mais compatível surge quando se considera os efeitos de correlação. Neste caso B3LYP e MP2 apresentam a mesma tendência em relação aos resultados SCF. Novamente, esta concordância foi melhor no caso da molécula de água. Os resultados para a blindagem anisotrópica podem apenas ser comparados 
a outros resultados teóricos prévios e em geral estão em bom acordo. Como observado antes [195] os efeitos da correlação eletrônica foram mais pronunciados para os átomos pesados (oxigênio e carbono neste caso). Para a molécula de água, a diferença entre os resultados MP2 e SCF foi $17.70 \mathrm{ppm}$ no caso da blindagem isotrópica do átomo de oxigênio. Para a molécula de metanol esta diferença foi de $10.05 \mathrm{ppm}$ para a blindagem anisotrópica do átomo de carbono. Os valores prévios para a molécula de metanol $[195,202]$ mostrados na Tabela 6.1 para a blindagem anisotrópica foram obtidos em nível SCF e assim são melhor comparáveis aos resultados SCF encontrados aqui. Contudo, a correlação eletrônica mostrou grandes efeitos, por exemplo, ela diminuiu o valor da blindagem anisotrópica do átomo de oxigênio por 6.61 ppm e aumentou a do átomo de carbono por $10.05 \mathrm{ppm}$. Um resultado prévio para a água, usando o modelo MP2/6-311++G(2d,2p) com a correlação obtida usando todos os elétrons [203] está em muito bom acordo com nosso resultado apresentado na Tabela 6.1 usando a aproximação de núcleo congelado (frozen core), indicando assim que os orbitais mais internos praticamente não contribuem para o cálculo das blindagens magnéticas.

\subsubsection{A população de Mulliken}

Após a formação da ligação de hidrogênio ocorre um rearranjo de cargas com um leve aumento da densidade eletrônica no sítio aceitador de próton e uma leve diminuição no próton da ligação. Normalmente existe também um aumento da densidade eletrônica no átomo de oxigênio doador devido à transferência de carga e à diminuição desta densidade no próton da ligação. Este rearranjo de cargas está relacionado às blindagens magnéticas e ajuda a compreender os valores dos deslocamentos químicos calculados e discutidos a seguir. Claro que a carga atômica não é observável físico e a análise de população de Mulliken sofre com o efeito do conjunto de funções base e outras dependências. Assim os resultados para as densidades de cargas apresentados aqui tem interesse apenas em comparações qualitativas entre rearranjo de cargas e deslocamentos químicos. A Tabela 6.2 apresenta a densidade de cargas de Mulliken sobre os átomos dos monômeros e a variação desta densidade após a complexação. 


\begin{tabular}{cccc}
\hline \hline & Monômeros & \multicolumn{2}{c}{ Diferença na carga } \\
\hline $\mathrm{H}_{2} \mathrm{O}$ & & $\mathrm{CH}_{3} \mathrm{OH} \cdots \mathrm{OH}_{2}$ & $\mathrm{CH}_{3} \mathrm{HO} \cdots \mathrm{H}_{2} \mathrm{O}$ \\
$\mathrm{H}$ & 0.24 & 0.02 & 0.07 \\
$\mathrm{O}$ & -0.48 & -0.05 & -0.07 \\
$\mathrm{H}$ & 0.24 & 0.02 & 0.00 \\
\hline $\mathrm{CH}_{3} \mathrm{OH}$ & & & \\
$\mathrm{O}$ & -0.48 & -0.09 & -0.05 \\
$\mathrm{C}$ & 0.13 & 0.00 & -0.01 \\
$\mathrm{H}$ & 0.03 & 0.00 & 0.01 \\
$\mathrm{H}$ & 0.03 & 0.00 & 0.02 \\
$\mathrm{H}$ & 0.05 & -0.01 & 0.01 \\
$\mathrm{H}$ & 0.24 & 0.11 & 0.02 \\
\hline \hline
\end{tabular}

Tabela 6.2: Variação nas cargas atômicas de Mulliken (em unidade elementar) sobre os átomos dos complexos $\mathrm{CH}_{3} \mathrm{HO} \cdots \mathrm{H}_{2} \mathrm{O}$ e $\mathrm{CH}_{3} \mathrm{OH} \cdots \mathrm{OH}_{2}$

É possível observar que o átomo aceitador $\mathrm{O}$ acumulou uma carga de $-0.05 e$ tanto na molécula de água quanto na molécula de metanol, enquanto que no hidrogênio da ligação existiu uma perda de 0.07 e e 0.11 e nas moléculas de água e metanol respectivamente. No átomo de oxigênio da ligação $\mathrm{O}-\mathrm{H}$, a diminuição (em módulo) da densidade de carga foi $-0.09 e$ e $-0.07 e$ para as moléculas de metanol e água respectivamente.

\subsubsection{Metanol como aceitador de próton}

A Tabela 6.3 apresenta os resultados calculados para os deslocamentos ${ }^{1} \delta^{i s o} \mathrm{e}$ $\delta^{\text {anis }}$ para o complexo $\mathrm{CH}_{3} \mathrm{HO} \cdots \mathrm{H}_{2} \mathrm{O}$. Primeiro foram considerados os átomos envolvidos na ligação de hidrogênio. Na molécula de metanol os valores calculados com correção counterpoise para $\delta^{i s o}(\mathrm{O})$ foram $-3.78 ;-5.85$ e $-5.21 \mathrm{ppm}$ e na molécula de água $\delta^{i s o}(\mathrm{H})$ foram $-3.14 ;-3.18$ e -2.98 ppm nos métodos $\mathrm{SCF}$, B3LYP e MP2, respectivamente. Para os outros átomos do complexo $\delta^{\text {iso }}$ é pequeno mas para o oxigênio da molécula de água, foi encontrado $-0.84 \mathrm{ppm}$ (com MP2) devido à modificação qua a esstrutura da água sofre após a com-

\footnotetext{
${ }^{1}$ Em espectros NMR experimentais um sistema padrāo é escolhido como referência. Assim, experimentalmente, o deslocamento químico é tomado como a diferença entre a blindagem do átomo no sistema de interesse e a blindagem do sistema padrão. Teoricamente, usando um mesmo sistema padrão o deslocamento químico corresponderá à diferença entre a blindagem para o sistema de interesse isolado e o mesmo sistema no complexo molecular, já que a blindagem para o sistema padrão se cancela nesta diferença.
} 


\begin{tabular}{|c|c|c|c|c|c|c|}
\hline \multicolumn{7}{|c|}{ Deslocamento químico isotrópico $\left(\delta^{i s o}\right)$} \\
\hline \multirow{2}{*}{$\mathrm{CH}_{3} \mathrm{HO} \cdots \mathrm{H}_{2} \mathrm{O}$} & \multicolumn{2}{|c|}{ SCF } & \multicolumn{2}{|c|}{ B3LYP } & \multicolumn{2}{|c|}{ MP2 } \\
\hline & $\mathrm{sCC}$ & $\mathrm{cCC}$ & $\mathrm{sCC}$ & cCC & $\mathrm{sCC}$ & $\mathrm{cCC}$ \\
\hline $\mathrm{O}^{*}$ & -4.81 & -3.78 & -6.96 & -5.85 & -5.95 & -5.21 \\
\hline $\mathrm{C}$ & -0.58 & -0.08 & -0.42 & 0.06 & -0.50 & -0.02 \\
\hline $\mathrm{H}$ & -0.07 & -0.04 & 0.02 & 0.05 & -0.02 & 0.01 \\
\hline $\mathrm{H}$ & -0.14 & -0.13 & -0.06 & -0.06 & -0.08 & -0.07 \\
\hline $\mathrm{H}$ & -0.14 & -0.13 & -0.11 & -0.12 & -0.11 & -0.11 \\
\hline $\mathrm{H}_{o}$ & -0.52 & -0.48 & -0.62 & -0.58 & -0.56 & -0.51 \\
\hline $\mathrm{H}^{*}$ & -3.50 & -3.14 & -3.51 & -3.18 & -3.34 & -2.98 \\
\hline $\mathrm{O}$ & 0.98 & 2.97 & -1.52 & 0.23 & -1.81 & -0.84 \\
\hline $\mathrm{H}$ & 0.54 & 0.57 & 0.50 & 0.54 & 0.43 & 0.47 \\
\hline \multicolumn{7}{|c|}{ Deslocamento químico anisotrópico $\left(\delta^{a n i s}\right)$} \\
\hline \multirow[t]{2}{*}{$\mathrm{CH}_{3} \mathrm{HO} \cdots \mathrm{H}_{2} \mathrm{O}$} & \multicolumn{2}{|c|}{ SCF } & \multicolumn{2}{|c|}{ B3LYP } & \multicolumn{2}{|c|}{ MP2 } \\
\hline & sCC & $\mathrm{cCC}$ & $\mathrm{sCC}$ & $\mathrm{cCC}$ & sCC & cCC \\
\hline $\mathrm{O}^{*}$ & -7.11 & -5.69 & -9.35 & -7.51 & -6.77 & -5.35 \\
\hline C & 0.72 & 0.15 & 0.47 & -0.07 & 0.71 & 0.18 \\
\hline $\mathrm{H}$ & 0.51 & 0.53 & 0.33 & 0.33 & 0.44 & 0.45 \\
\hline $\mathrm{H}$ & -0.05 & 0.02 & -0.04 & 0.03 & -0.07 & 0.01 \\
\hline $\mathrm{H}$ & -0.22 & -0.15 & -0.11 & -0.02 & -0.18 & -0.10 \\
\hline $\mathrm{H}_{o}$ & 0.19 & 0.26 & 0.12 & 0.21 & 0.15 & 0.23 \\
\hline $\mathrm{H}^{*}$ & 11.51 & 11.90 & 11.58 & 12.00 & 11.53 & 11.95 \\
\hline $\mathrm{O}$ & 8.22 & 6.67 & 11.24 & 9.40 & 11.50 & 9.31 \\
\hline $\mathrm{H}$ & 0.41 & 0.54 & 0.25 & 0.42 & 0.26 & 0.39 \\
\hline
\end{tabular}

Tabela 6.3: Valores dos deslocamentos químicos isotrópicos, $\delta^{\text {iso }}$, e anisotrópicos, $\delta^{\text {anis }}$ para o complexo $\mathrm{CH}_{3} \mathrm{HO} \cdots \mathrm{H}_{2} \mathrm{O}$ (em ppm) determinados em três níveis teóricos. Os asteriscos indicam os átomos que estão diretamente envolvidos na ligação de hidrogênio. SCC indica resultados sem correção e cCC com correção counterpoise 
plexação. Para $\delta^{i s o}(\mathrm{O})$ a correlação em $\mathrm{MP2}$ é responsável por uma variação de $\sim 1.0$ ppm quando comparado com SCF e de $\sim-1.0$ ppm quando comparado com B3LYP para o átomo de oxigênio da molécula de metanol. A correção counterpoise contra BSSE foi relativamente pequena mas pode ser substancial para o átomo de oxigênio da água. É esperado que após a complexação exista uma redistribuição de cargas na ligação $\mathrm{O}-\mathrm{H}(0.07 e$ no átomo $\mathrm{H}$ e $-0.07 e$ no átomo O) levando a um deslocamento mais apreciável. De maneira geral os três métodos teóricos produziram resultados similares e consitentes para o deslocamento químico isotrópico.

Os valores de $\delta^{\text {anis }}$ para mesmo complexo foram mais pronunciados; $-5.69 ;-7.51$ e -5.35 ppm para o átomo de oxigênio e $11.90 ; 12.00$ e 11.95 ppm para o átomo de hidrogênio que participa diretamente da ligação de hidrogênio. Novamente, para o átomo $\mathrm{O}$ da molécula de água $\delta^{\text {anis }}(\mathrm{O})$ foi muito influencido pelos efeitos da correlação eletrônica. A diferença entre os valores corrigidos contra o BSSE nos níveis SCF e MP2 foi $2.64 \mathrm{ppm}$ (6.67 e $9.31 \mathrm{ppm}$ ). A correção do BSSE afeta os resultados por somente 1.5-2.2 ppm e em alguns casos se mostrou desprezível.

\subsubsection{Metanol como doador de próton}

Agora uma análise similar é feita na Tabela 6.4 para o complexo $\mathrm{CH}_{3} \mathrm{OH} \cdots \mathrm{OH}_{2}$. Neste caso $\delta^{i s o}(\mathrm{O})$ do átomo de oxigênio da molécula de metanol foram todos positivos, ao contrário do complexo $\mathrm{CH}_{3} \mathrm{HO} \cdots \mathrm{H}_{2} \mathrm{O}$. Para este átomo os valores de $\delta^{i s o}(\mathrm{O})$ corrigidos contra BSSE foram 7.11, 4.85 e 2.81 ppm enquanto os valores $\delta^{\text {anis }}(\mathrm{O})$ corrigidos foram $-13.24,-10.54$ e $-5.85 \mathrm{ppm}$ com os três níveis teóricos empregados. Note que neste complexo o BSSE foi maior. Por exemplo os valores $\delta^{\text {anis }}(\mathrm{O})$ das moléculas de metanol e água mudaram de $-1.40 \mathrm{ppm}$ para -5.85 ppm no caso do metanol e de -6.93 para -8.75 ppm no caso da água. Para o átomo de hidrogênio da molécula de metanol que é doadora de próton os valores de $\delta^{i s o}(\mathrm{H})$ foram $-3.05,-3.10 \mathrm{e}-2.91 \mathrm{ppm}$. Para o átomo de oxigênio da molécula de água os valores de $\delta^{i s o}(\mathrm{O})$ foram todos negativos $(-5.31,-7.57$ e $-6.32 \mathrm{ppm}$ ) ao contrário do que ocorreu para o complexo $\mathrm{CH}_{3} \mathrm{HO} \cdots \mathrm{H}_{2} \mathrm{O}$. É interessante notar aqui que $\delta^{i s o}(\mathrm{C})=0.88 \mathrm{ppm}$ em MP2 é maior que seu 


\begin{tabular}{|c|c|c|c|c|c|c|}
\hline \multicolumn{7}{|c|}{ Deslocamento químico isotrópico $\left(\delta^{i s o}\right)$} \\
\hline \multirow[t]{2}{*}{$\mathrm{CH}_{3} \mathrm{OH} \cdots \mathrm{OH}_{2}$} & \multicolumn{2}{|c|}{ SCF } & \multicolumn{2}{|c|}{ B3LYP } & \multicolumn{2}{|c|}{ MP2 } \\
\hline & sCC & $\mathrm{cCC}$ & $\mathrm{sCC}$ & $\mathrm{cCC}$ & $\mathrm{sCC}$ & $\mathrm{cCC}$ \\
\hline $\mathrm{O}$ & 5.37 & 7.11 & 3.11 & 4.85 & 1.66 & 2.81 \\
\hline $\mathrm{C}$ & 1.23 & 1.03 & 1.23 & 1.08 & 1.06 & 0.88 \\
\hline $\mathrm{H}$ & 0.10 & 0.11 & 0.08 & 0.09 & 0.06 & 0.08 \\
\hline $\mathrm{H}$ & 0.10 & 0.11 & 0.08 & 0.09 & 0.06 & 0.08 \\
\hline $\mathrm{H}$ & 0.14 & 0.14 & 0.09 & 0.10 & 0.08 & 0.09 \\
\hline $\mathrm{H}_{o}^{*}$ & -3.33 & -3.05 & -3.35 & -3.10 & -3.17 & -2.91 \\
\hline $\mathrm{H}$ & -0.55 & -0.46 & -0.60 & -0.52 & -0.57 & -0.47 \\
\hline $\mathrm{O}^{*}$ & -5.69 & -5.31 & -7.59 & -7.57 & -6.22 & -6.32 \\
\hline $\mathrm{H}$ & -0.55 & -0.46 & -0.60 & -0.52 & -0.57 & -0.47 \\
\hline \multicolumn{7}{|c|}{ Deslocamento químico anisotrópico $\left(\delta^{a n i s}\right)$} \\
\hline \multirow{2}{*}{$\mathrm{CH}_{3} \mathrm{OH} \cdots \mathrm{OH}_{2}$} & \multicolumn{2}{|c|}{ SCF } & \multicolumn{2}{|c|}{ B3LYP } & \multicolumn{2}{|c|}{ MP2 } \\
\hline & $\mathrm{sCC}$ & cCC & $\mathrm{sCC}$ & cCC & $\mathrm{sCC}$ & $c \mathrm{CC}$ \\
\hline $\mathrm{O}$ & -8.42 & -13.24 & -5.39 & -10.54 & -1.40 & -5.85 \\
\hline C & -1.61 & -1.40 & -1.75 & -1.51 & -1.28 & -1.16 \\
\hline $\mathrm{H}$ & 0.19 & 0.17 & 0.34 & 0.32 & 0.25 & 0.23 \\
\hline $\mathrm{H}$ & 0.19 & 0.17 & 0.34 & 0.32 & 0.25 & 0.23 \\
\hline $\mathrm{H}$ & 0.52 & 0.52 & 0.48 & 0.49 & 0.52 & 0.52 \\
\hline $\mathrm{H}_{o}^{*}$ & 11.14 & 11.35 & 11.38 & 11.59 & 11.26 & 11.48 \\
\hline $\mathrm{H}$ & -0.02 & 0.08 & -0.15 & -0.03 & -0.10 & 0.02 \\
\hline $\mathrm{O}^{*}$ & -9.08 & -9.85 & -8.40 & -10.19 & -6.93 & -8.75 \\
\hline $\mathrm{H}$ & -0.02 & 0.08 & -0.15 & -0.03 & -0.10 & 0.02 \\
\hline
\end{tabular}

Tabela 6.4: Valores dos deslocamentos químicos isotrópicos, $\delta^{i s o}$, e anisotrópicos, $\delta^{a n i s}$ para o complexo $\mathrm{CH}_{3} \mathrm{OH} \cdots \mathrm{OH}_{2}$ (em ppm) determinados em três níveis teóricos. Os asteriscos indicam os átomos que estão diretamente envolvidos na ligação de hidrogênio. sCC indica resultados sem correção e cCC com correção counterpoise 
correspondente no outro complexo $(-0.2 \mathrm{ppm})$. Isto está possivelmente relacionado à maior quantidade de carga acumulada no átomo de oxigênio vizinho $(-0.09 e)$ em comparação com a quantidade acumulada no correspondente do outro complexo (0.05e).

Existem poucos estudos teóricos sobre parâmetros RMN de complexos álcool-água. Mas este isômero de metanol-água, $\mathrm{CH}_{3} \mathrm{OH} \cdots \mathrm{OH}_{2}$, já foi objeto de estudo de um trabalho prévio [205] e algumas das constantes RMN foram obtidas usando o modelo MP2/aug-cc-pVTZ sem correção do BSSE. De forma geral existe um bom acordo entre os resultados. É importante notar contudo (Tabela 6.4) que em alguns casos BSSE apresentou tamanho considerável.

Os resultados teóricos para ambos os complexos podem também ser analisados pictoricamente nas Figuras 6.1 e 6.2 . A Figura 6.1 mostra $\delta^{i s o}$

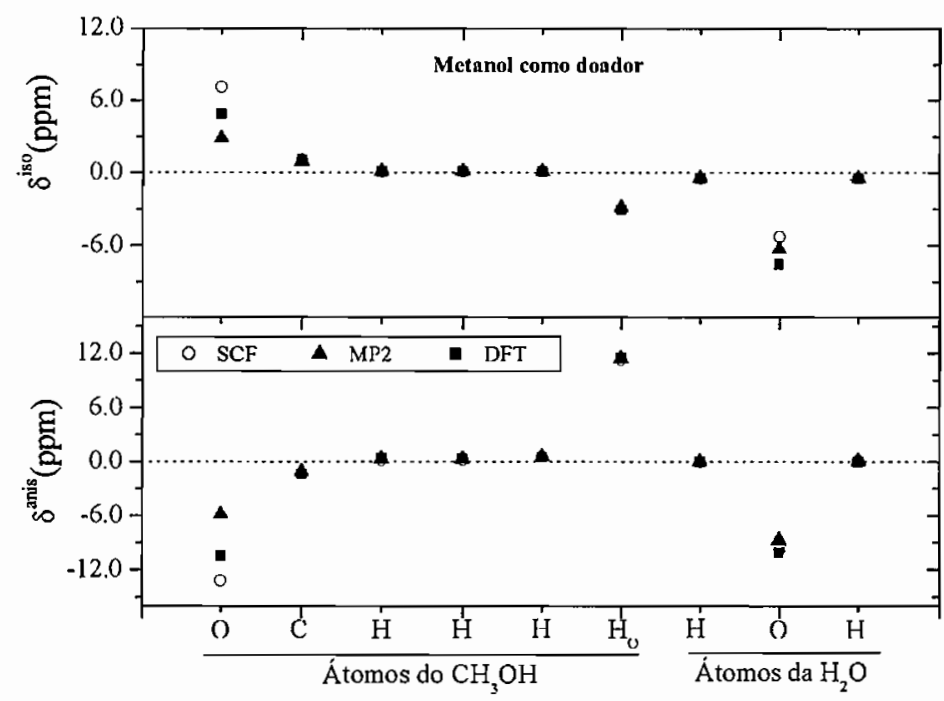

Figura 6.1: Deslocamento químico isotrópico e anisotrópico para o complexo $\mathrm{CH}_{3} \mathrm{OH} \cdots \mathrm{OH}_{2}$ em três niveis teóricos. Resultados corrigidos contra BSSE

e $\delta^{\text {anis }}$ para cada núcleo do complexo $\mathrm{CH}_{3} \mathrm{OH} \cdots \mathrm{OH}_{2}$, enquanto que a Figura 6.2 mostra os mesmos resultados para o complexo $\mathrm{CH}_{3} \mathrm{HO} \cdots \mathrm{H}_{2} \mathrm{O}$. Estas duas figuras ilustram mais claramente os deslocamentos químicos após a formação da ligação de hidrogênio. Pode-se ver que os átomos $\mathrm{C} \mathrm{e} \mathrm{H}$ do grupo metil apresentaram um pequeno deslocamento enquanto que os átomos que participam da 


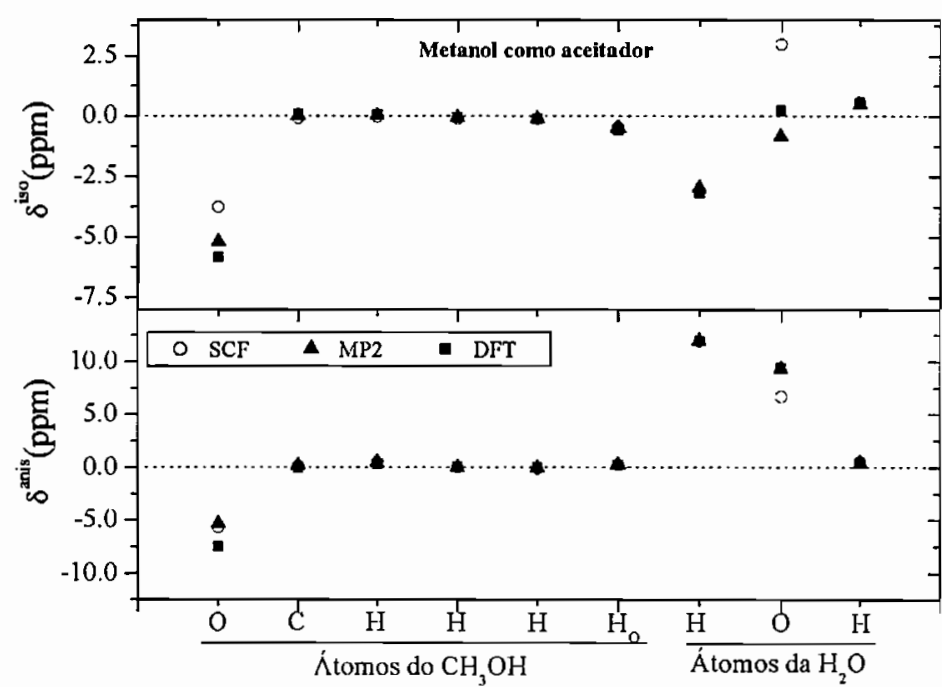

Figura 6.2: Deslocamento químico isotrópico e anisotrópico para o complexo $\mathrm{CH}_{3} \mathrm{HO} \cdots \mathrm{H}_{2} \mathrm{O}$ em três níveis teóricos. Resultados corrigidos contra BSSE

ligação de hidrogênio apresentaram deslocamentos bem maiores. A partir das Figuras 6.2 e 6.1 pode-se analisar os valores relativos obtidos em cada método teórico. Nota-se que no caso da molécula de metanol aceitadora de próton a correlação eletrônica foi mais importante para o deslocamento isotrópico do oxigênio da água. Os resultados SCF e B3LYP foram positivos enquanto que o método MP2 forneceu valores negativos. Para os átomos de hidrogênio da água os efeitos de correlação se mostraram pequenos.

\subsubsection{As componentes $\delta_{/ /}$e $\delta_{\perp}$ do deslocamento químico isotrópico}

Experimentalmente é sabido que para o tensor blindagem magnética de um próton envolvido numa ligação de hidrogênio, a direção mais blindada é aproximadamente paralela ao eixo da ligação de hidrogênio enquanto que a direção menos blindada é perpendicular a este eixo $[186,206]$. Foi observado para o dímero de água $[185,186]$ que estas componentes perpendiculares do tensor blindagem magnética do próton na ligação de hidrogênio são mais sensíveis à formação de uma ligação que a componente paralela. Apesar destas duas componentes não serem independentes é interessante analisá-las separadamente. As 
componentes paralela e perpendiculares são definidas para o átomo $X$ como:

$$
\delta(X)_{/ /}=\sigma(X)^{i s o}+\frac{2}{3} \sigma(X)^{a n i s}
$$

e

$$
\delta(X)_{\perp}=\sigma(X)^{i s o}-\frac{1}{3} \sigma(X)^{a n i s}
$$

A Tabela 6.5 apresenta os valores para $\delta_{/ /}$e $\delta_{\perp}$ para todos os átomos de ambos os complexos. Para o complexo $\mathrm{CH}_{3} \mathrm{HO} \cdots \mathrm{H}_{2} \mathrm{O} \delta_{\perp}$ é negativa e geralmente

\begin{tabular}{ccccccc}
\hline \hline & \multicolumn{3}{c}{$\delta_{/ /}$} & & $\delta_{\perp}$ \\
\hline $\mathrm{CH}_{3} \mathrm{HO} \cdots \mathrm{H}_{2} \mathrm{O}$ & SCF & B3LYP & MP2 & SCF & B3LYP & MP2 \\
$\mathrm{O}^{*}$ & -9.55 & -13.20 & -10.47 & -2.44 & -3.85 & -3.70 \\
$\mathrm{C}$ & -0.09 & -0.10 & -0.03 & -0.82 & -0.57 & -0.73 \\
$\mathrm{H}$ & 0.27 & 0.24 & 0.27 & -0.24 & -0.09 & -0.17 \\
$\mathrm{H}$ & -0.18 & -0.09 & -0.13 & -0.12 & -0.05 & -0.06 \\
$\mathrm{H}$ & -0.29 & -0.18 & -0.23 & -0.06 & -0.07 & -0.05 \\
$\mathrm{H}_{o}$ & -0.39 & -0.54 & -0.46 & -0.58 & -0.66 & -0.62 \\
$\mathrm{H}^{*}$ & 4.17 & 4.21 & 4.35 & -7.34 & -7.37 & -7.18 \\
$\mathrm{O}$ & 6.45 & 5.97 & 5.85 & -1.76 & -5.26 & -5.65 \\
$\mathrm{H}$ & 0.81 & 0.66 & 0.61 & 0.41 & 0.41 & 0.34 \\
& & $\delta / /$ & & & $\delta_{\perp}$ & \\
\hline $\mathrm{CH}_{3} \mathrm{OH} \cdots \mathrm{OH}_{2}$ & $\mathbf{S C F}$ & $\mathbf{B 3 L Y P}$ & $\mathbf{M P 2}$ & $\mathbf{S C F}$ & $\mathbf{B 3 L Y P}$ & $\mathbf{M P 2}$ \\
$\mathrm{O}$ & -0.24 & -0.49 & 0.72 & 8.17 & 4.91 & 2.12 \\
$\mathrm{C}$ & 0.16 & 0.07 & 0.21 & 1.76 & 1.82 & 1.48 \\
$\mathrm{H}$ & 0.23 & 0.30 & 0.23 & 0.04 & -0.03 & -0.02 \\
$\mathrm{H}$ & 0.23 & 0.30 & 0.23 & 0.04 & -0.03 & -0.02 \\
$\mathrm{H}$ & 0.48 & 0.41 & 0.43 & -0.04 & -0.07 & -0.10 \\
$\mathrm{H}_{o}^{*}$ & 4.09 & 4.24 & 4.33 & -7.04 & -7.14 & -6.93 \\
$\mathrm{H}$ & -0.56 & -0.70 & -0.63 & -0.54 & -0.55 & -0.53 \\
$\mathrm{O}^{*}$ & -11.74 & -13.19 & -10.84 & -2.66 & -4.79 & -3.91 \\
$\mathrm{H}$ & -0.56 & -0.70 & -0.63 & -0.54 & -0.55 & -0.53 \\
\hline \hline
\end{tabular}

Tabela 6.5: Valores das componentes paralela $\left(\delta_{/ /}\right)$e perpendiculares $\left(\delta_{\perp}\right)$ da blindagem magnética isotrópica (em ppm) em três níveis teóricos e seus respectivos valores experimentais. Asteriscos indicam os átomos que estão diretamente envolvidos na ligação de hidrogênio. Resultados sem correção counterpoise

maior (em valor absoluto) que $\delta_{/ /}$, exceto para os átomos de oxigênio, tanto da molécula de metanol quanto da molécula de água. Por exemplo, em nível MP2 $\delta_{\perp}(\mathrm{H})$ do próton da ligação foi $-7.18 \mathrm{ppm}$, comparado com valor de 4.35 para $\delta_{/ /}(\mathrm{H})$ (Tabela 6.5). Resultado similar pode ser observado para o outro 
complexo, $\mathrm{CH}_{3} \mathrm{OH} \cdots \mathrm{OH}_{2}$. Agora, novamente em nível $\mathrm{MP} 2, \delta_{\perp}(\mathrm{H})$ do hidrogênio da ligação foi $-6.93 \mathrm{ppm}$ comparado com o valor de $4.33 \mathrm{ppm}$ para $\delta_{/ /}(\mathrm{H})$. Contudo, é também de considerável interesse analisar os correspondentes deslocamentos químicos nos átomos de oxigênio aceitadores de próton. $\mathrm{O}$ inverso ocorreu e $\delta_{/ /}(\mathrm{O})$ é agora dominante. Note, por exemplo, que o valor para $\delta_{/ /}(\mathrm{O})$ na molécula de metanol foi $-10.47 \mathrm{ppm}$ e na molécula de água foi $-10.84 \mathrm{ppm}$, enquanto que $\delta_{\perp}$ foram -3.70 e $-3.91 \mathrm{ppm}$ respectivamente. Além disso, eles apresentaram o mesmo sinal (negativo) para ambos os complexos. Assim nota-se que a componente perpendicular do deslocamento isotrópico foi maior em magnitude do que a componente paralela. Contudo esta tendência é invertida para o oxigênio envolvido na ligação de hidrogênio.

\subsubsection{O efeito de relaxação do monômero}

É interessante agora considerar o efeito de relaxação do monômero. Este efeito foi obtido aqui como a diferença entre a blindagem magnética do átomo na geometria otimizada do complexo e na geometria otimizada do monômero. Esta diferença foi apreciável apenas para os átomos de oxigênio da molécula doadora de próton devido ao estiramento da ligação $\mathrm{O}-\mathrm{H}$ após a formação da ligação de hidrogênio. No caso do oxigênio na molécula de metanol o efeito de relaxação foi de $1.33 \mathrm{ppm}$ (MP2) e $1.76 \mathrm{ppm}$ (B3LYP) para a blindagem isotrópica e $-4.62 \mathrm{ppm}$ (MP2) e $-5.38 \mathrm{ppm}$ (B3LYP) para a blindagem anisotrópica. Para a molécula de água doadora de próton a contribuição da relaxação foi de 1.70 ppm (MP2) e 2.18 ppm (B3LYP) ppm para a blindagem isotrópica e -0.16 ppm (MP2) e -0.41 ppm (B3LYP) para a blindagem anisotrópica.

\subsection{Conclusões}

Os efeitos da formação da ligação de hidrogênio sobre as blindagens magnéticas dos átomos dos complexos de metanol-água foram analisados no intuito de fornecer dados RMN que possam ajudar a compreender misturas de álcool e água. A descrição completa dos deslocamentos químicos nos complexos pode ser uma ferramenta teórica útil para dar uma previsão na compreensão dos 
efeitos da ligação de hidrogênio.

As blindagens magnéticas foram calculadas para todos os átomos nos dois possíveis complexos, $\mathrm{CH}_{3} \mathrm{OH} \cdots \mathrm{OH}_{2}$ e $\mathrm{CH}_{3} \mathrm{HO} \cdots \mathrm{H}_{2} \mathrm{O}$. usando os modelos SCF, B3LYP e MP2 sobre as geometrias optmizadas em MP2. Foi observado que os átomos do grupo metil apresentam um deslocamento químico isotrópico muito pequeno, embora o átomo de carbono da molecula doadora seja mais influenciado.

Os resultados obtidos para $\delta^{i s o}$ bem como para $\delta^{a n i s}$ são mais sensíveis para os átomos que participam diretamente da ligação de hidrogênio. A componente $\delta^{a n i s}$ parece ser um bom indicador da presença de ligação de hidrogênio, uma vez que os deslocamentos químicos anisotrópicos são maiores que os seus correspondentes deslocamentos isotrópicos. Estes resultados corroboram a afirmação prévia de que $\delta^{\text {anis }}(\mathrm{H})$ do próton ligante é um indicador mais sensível da presença de uma ligação de hidrogênio que $\delta^{i s o}(\mathrm{H})$. Foi encontrado também que os átomos da molécula doadora se tornam mais blindados enquanto que na molécula aceitadora os átomos se tornam mais desblindados. Como os deslocamentos químicos são uma diferença entre duas blindagens magnéticas os efeitos da correlação eletrônica tenderam a se cancelar, sendo portanto menos drásticos. Contudo tais efeitos se mostraram muito importantes na descrição das blindagens magnéticas absolutas.

Foi verificado que enquanto para os átomos que participam diretamente da ligação de hidrogênio o BSSE é mais relevante, para os outros átomos do complexo este erro é desprezível. Observou-se que os deslocamentos químicos anisotrópicos tem variações maiores que os deslocamentos isotrópicos e mesmo assim BSSE apresentou-se relativamente pequeno, num intervalo de 1.5-2.2 ppm para os átomos de oxigênio.

Apesar das cargas atômicas não serem observáveis físicos a análise populacional de Mulliken foi empregada como indicador do rearranjo de cargas e para racionalizar os deslocamentos químicos. No caso do complexo $\mathrm{CH}_{3} \mathrm{HO} \cdots \mathrm{H}_{2} \mathrm{O}$, por exemplo, o hidrogênio da ligação perde 0.07e que é transferido para o átomo de oxigênio da molécula de água. Esta análise mostrou o caráter doador e acei- 
tador de cada molécula nos complexos.

As componentes $\delta_{\perp}$ e $\delta_{/ /}$do deslocamento químico isotrópico também foram estudadas. Foi corroborado o fato de que para o próton da ligação de hidrogênio a componente $\delta_{/ /}(\mathrm{H})$ é mais blindada que a componente $\delta_{\perp}(\mathrm{H})$. Em nível MP2, $\delta_{/ /}(\mathrm{H})$ para o próton ligante do complexo $\mathrm{CH}_{3} \mathrm{HO} \cdots \mathrm{H}_{2} \mathrm{O}$ é 4.35 ppm enquanto que $\delta_{\perp}(\mathrm{H})$ é $-7.18 \mathrm{ppm}$. Para o oxigênio aceitador de próton, o ocorre inverso, isto é, $\delta_{/ /}(\mathrm{O})$ é menos blindada que $\delta_{\perp}(\mathrm{O})$. Estas componentes possibilitam avaliar o caráter direcional de cada ligação de hidrogênio. Foi observado que a blindagem anisotrópica do átomo de oxigênio na molécula de água aceitadora de próton é menor que na molécula de metanol aceitadora de próton, mostrando uma isotropia da ligação de hidrogênio que é maior para o complexo $\mathrm{CH}_{3} \mathrm{OH} \cdots \mathrm{OH}_{2}$ que para o complexo $\mathrm{CH}_{3} \mathrm{HO} \cdots \mathrm{H}_{2} \mathrm{O}$.

Finalmente, os efeitos da relaxação do monômero nos parâmetros RMN foram considerados. Verificou-se que este efeito é apreciável apenas para o átomo de oxigênio da molécula doadora de próton, em maior parte devido à deformação da distância O-H após a formação da ligação de hidrogênio. 


\section{Capítulo 7}

\section{Estabilidades relativas de ligações de hidrogênio}

\subsection{Motivação}

Como mencionado na seção 6.1 misturas de álcool e água apresentam aspectos intrigantes que se devem possivelmente à grande habilidade de ambos, álcool e água, formarem ligações de hidrogênio sendo tanto doadores como aceitadores de próton. Assim tais sistemas podem ter duas estruturas ligadas por ligações de hidrogênio correspondendo a dois possíveis heterodímeros (ou isômeros) onde álcool é aceitador de próton, $\mathrm{RHO} \cdots \mathrm{H}_{2} \mathrm{O}$, ou um doador de próton, $\mathrm{ROH} \cdots \mathrm{OH}_{2}$. A existência destes dois isômeros é muito fácil de compreender mas a estabilidade relativa das duas possíveis conformações é mais difícil de estabelecer. A questão de qual dos dois isômeros é mais estável é controversa $[158,207,208]$. Isto foi somente esclarecido muito recentemente para complexos em fase gasosa. Espectroscopia de microoondas estabeleceu [159] que o complexo no qual a molécula de metanol é aceitadora de próton e a de água é doadora, $\mathrm{CH}_{3} \mathrm{HO} \cdots \mathrm{H}_{2} \mathrm{O}$, é o isômero mais estável em fase gasosa. Resultados teóricos $[148,160,172]$ têm de fato confirmado a maior estabilidade deste isômero mas obtido uma estabilidade relativa menor que $1 \mathrm{kcal} / \mathrm{mol}$.

Resultados experimentais recentes demonstraram que álcool-água leva à mistura incompleta [141,142] e inferiram [1.41] que a entropia negativa da mistura de álcool-água origina-se a partir da formação de ligações de hidrogênio entre álcool-álcool, álcool-água e água-água. Portanto existe con- 
siderável interesse na determinação da energia de ligação dos heterodímeros. Existe um considerável número de trabalhos dedicados ao estudo de estruturas e energia de ligação de alguns complexos de álcool e água usando vários modelos teóricos $[146,157,209-217]$. Neste contexto, sistemas álcool-água são também de interesse e heterodímeros de metanol-etanol tem sido muito pouco estudados teoricamente. Para obter a energia de ligação relativa, livre de artefatos ou diferentes aproximações, é imperativo que se aplique o mesmo nível teórico para todos os heterodímeros de interesse. Este trabalho emprega cálculos ab initio em alto nível para estudar a energia de ligação relativa dos complexos 1:1 obtidos a partir de água, metanol e etanol. Estes complexos incluem três possíveis heterodímeros obtidos a partir de água-metanol, água-etanol e metanol-etanol e dímeros de água, metanol e etanol. É sabido que a molécula de etanol existe em duas formas diferentes, trans e gauche, veja 7.2. No caso dos dímeros de água-etanol e etanol-água é considerado aqui ambas as configurações do etanol. No total, onze complexos diferentes foram obtidos e suas energias de ligação relativas foram sistematicamente comparadas e os efeitos da correlação eletrônica foram analisados.

\subsection{Detalhes de cálculo}

Inicialmente, as geometrias dos complexos envolvendo água, metanol e etanol foram otimizadas em nível MP2/aug-cc-pVDZ. Uma completa otimização foi realizada para os dímeros $\left(\mathrm{H}_{2} \mathrm{O}\right)_{2},\left(\mathrm{CH}_{3} \mathrm{OH}\right)_{2} \mathrm{e}\left(\mathrm{CH}_{3} \mathrm{CH}_{2} \mathrm{OH}\right)_{2}$, e os heterodímeros $\mathrm{CH}_{3} \mathrm{HO} \cdots \mathrm{H}_{2} \mathrm{O}$ e $\mathrm{CH}_{3} \mathrm{OH} \cdots \mathrm{OH}_{2} ; \mathrm{CH}_{3} \mathrm{CH}_{2} \mathrm{HO} \cdots \mathrm{H}_{2} \mathrm{O}$ e $\mathrm{CH}_{3} \mathrm{CH}_{2} \mathrm{OH} \cdots \mathrm{OH}_{2}$; $\mathrm{CH}_{3} \mathrm{CH}_{2} \mathrm{HO} \cdots \mathrm{HOCH}_{3}$ e $\mathrm{CH}_{3} \mathrm{CH}_{2} \mathrm{OH} \cdots \mathrm{OHCH}_{3}$. Para abreviar esta notação foi adotado o acrônimo DA para a molécula doadora e para a molécula aceitadora de próton da ligação de hidrogênio. Por exemplo, MW indica o isômero $\mathrm{CH}_{3} \mathrm{OH} \cdots \mathrm{OH}_{2}$. A forma gauche do etanol é representada por $\mathrm{E}_{g}$, caso contrário é assumida a forma gauche. As figuras 7.1, 7.2 e 7.3 mostram os resultados para as distâncias $\mathrm{R}_{O \ldots O}$ entre os átomos que participam da ligação de hidrogênio dos complexos otimizados. As energias de ligação, momentos de dipolo e constantes rotacionais foram obtidos para todos este complexos. As freqüencias de vibração 


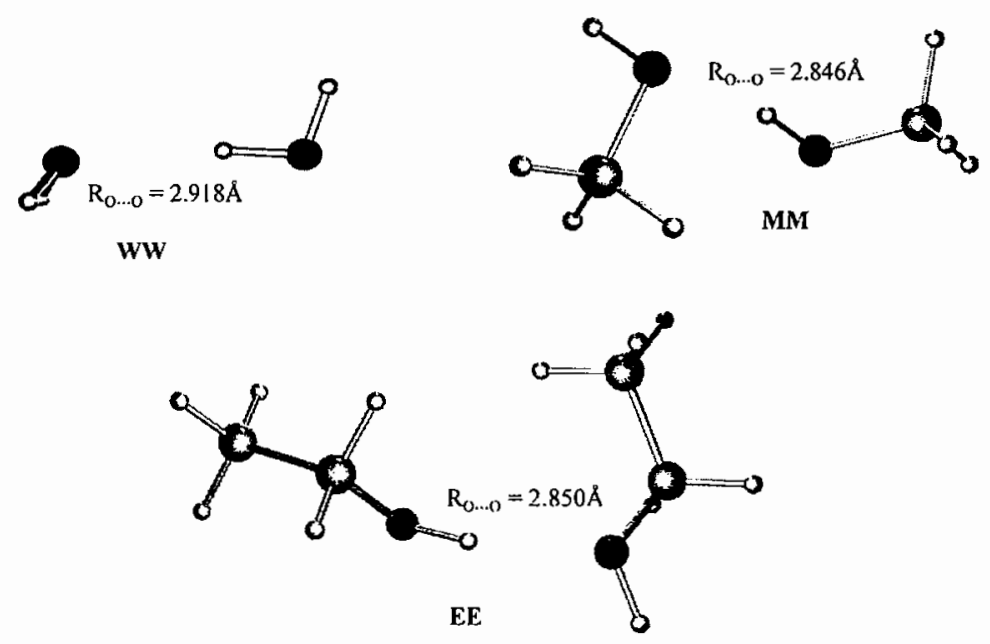

Figura 7.1: Estruturas otimizadas em nível MP2/aug-cc-pVDZ para os dímeros de água (WW), metanol (MM) e etanol (EE). As distâncias $\mathrm{R}_{O} \ldots$..o são mostradas

foram analisadas para assegurar que as estruturas obtidas são de fato mínimos das superfícies de energia potencial e para avaliar as energias de vibração de ponto zero. Para analisar a importância dos efeitos de correlação eletrônica sobre a estabilidade relativa de diferentes heterodímeros foram realizados cálculos pontuais da energia com teoria de perturbação de segunda, terceira e quarta ordem, com a teoria de coupled-cluster com excitações simples e duplas (CCSD) e com excitações simples, duplas e triplas parciais $(\operatorname{CCSD}(\mathrm{T}))$ [1.15]. Isto permite uma análise sistemática da importância das diferentes contribuições dos efeitos de correlação eletrônica nas energias de ligação. O erro de superposição de base foi levado em conta usando a correção counterpoise [72]. Todos os cálculos foram realizados com o programa Gaussian 98 [117].

\subsection{Resultados e discussões}

As Figuras 7.1, 7.2 e 7.3 mostram todos os sistemas considerados aqui e fornece as distâncias $\mathrm{R}_{O} \ldots$ o otimizadas. Estas são resumidas na Tabela 7.1 que mostra também os momentos de dipolo e as constantes rotacionais. O dímero de água tem sido objeto de inúmeros trabalhos teóricos e os resultados apre- 

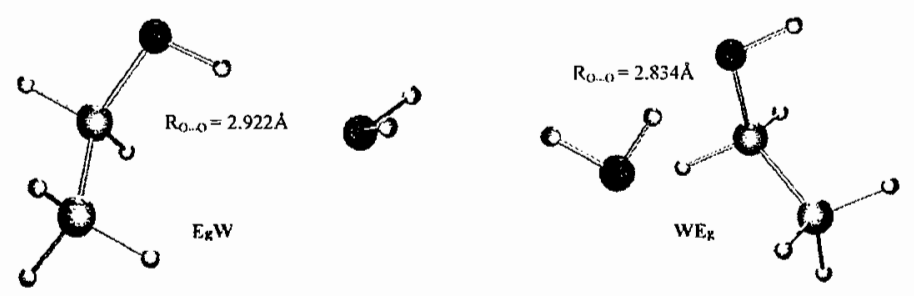

Figura 7.2: Estruturas otimizadas em nível MP2/aug-cc-pVDZ para os heterodímeros envolvendo etanol gauche e água $\left(\mathbf{E}_{g} \mathbf{W}\right.$ e $\left.\mathbf{W E} \mathbf{E}_{g}\right)$. A convenção usada indica moléculas doadora e aceitadora de próton respectivamente (DA). As distâncias $\mathrm{R}_{O} \ldots O$ são mostradas<smiles>[R]OC(=O)C=O</smiles><smiles>COC(=O)C(=O)O</smiles>

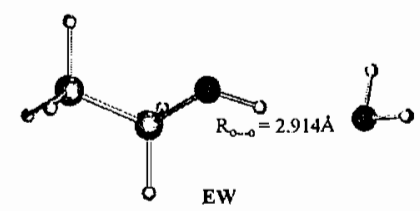

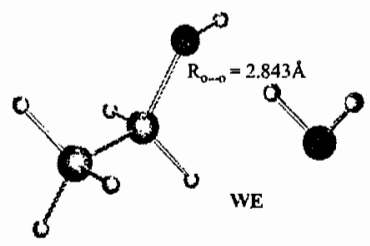<smiles>O=C(O)COC1CO1</smiles>

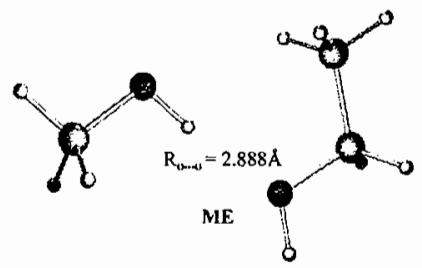

Figura 7.3: Estruturas otimizadas em nível MP2/aug-cc-pVDZ para os heterodímeros envolvendo metanol e água (MW e WM); etanol e água (EW e WE); e metanol e etanol (ME e EM). A convenção usada indica moléculas doadora e aceitadora de próton respectivamente (DA). As distâncias Ro...o são mostradas 


\begin{tabular}{ccccccc}
\hline \hline & $\mathrm{R}_{O} \ldots O$ & $\mathrm{R}_{O \ldots H}$ & $\mu$ & $\mathrm{I}_{A}$ & $\mathrm{I}_{B}$ & $\mathrm{I}_{C}$ \\
\hline Monômero & & & & & & \\
$\mathrm{H}_{2} \mathrm{O}(\mathrm{W})$ & - & - & 1.879 & 796.37 & 433.47 & 280.69 \\
Metanol (M) & - & - & 1.714 & 126.02 & 24.36 & 23.51 \\
Etanol (E) & - & - & 1.624 & 34.42 & 9.33 & 8.10 \\
Etanol (E $\left.\mathrm{E}_{g}\right)$ & & & 1.756 & 33.93 & 9.09 & 8.03 \\
& & & & & & \\
Dímero & & & & & & \\
WW & 2.918 & 1.951 & 2.640 & 213.86 & 6.38 & 6.38 \\
$\mathrm{MM}$ & 2.846 & 1.887 & 2.499 & 16.05 & 2.39 & 2.31 \\
$\mathrm{EE}$ & 2.850 & 1.885 & 2.593 & 6.13 & 1.21 & 1.10 \\
& & & & & & \\
Heterodímero & & & & & & \\
$\mathrm{WM}$ & 2.844 & 1.904 & 2.040 & 24.92 & 4.62 & 4.05 \\
$\mathrm{MW}$ & 2.912 & 1.942 & 2.734 & 31.96 & 3.80 & 3.53 \\
& & & & & & \\
$\mathrm{EW}$ & 2.914 & 1.951 & 2.494 & 26.56 & 2.05 & 1.97 \\
$\mathrm{WE}$ & 2.843 & 1.900 & 1.944 & 8.97 & 3.55 & 2.85 \\
$\mathrm{E}_{g} \mathrm{~W}$ & 2.922 & 1.949 & 2.839 & 9.61 & 3.05 & 2.51 \\
$\mathrm{WE} \mathrm{E}_{g}$ & 2.834 & 1.890 & 2.044 & 8.69 & 3.69 & 2.88 \\
& & & & & & \\
$\mathrm{ME}$ & 2.888 & 1.919 & 3.323 & 8.50 & 1.75 & 1.50 \\
$\mathrm{EM}$ & 2.853 & 1.986 & 2.664 & 12.10 & 1.46 & 1.43 \\
\hline \hline
\end{tabular}

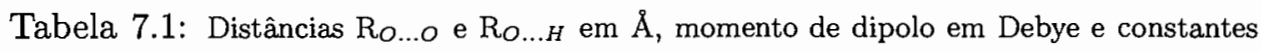
rotacionais em $\mathrm{GHz}$ para os monômeros, dímeros e heterodímeros. Todos os resultados foram obtidos usando as geometrias otimizadas em nível MP2/aug-cc-pVDZ 
sentados aqui são somente para referência. De maneira geral, as distâncias das ligações de hidrogênio estão em bom acordo com os resultados previamente avaliados. A distância $\mathrm{R}_{O . . .}$ na água é calculada aqui como $2.918 \AA$ em bom acordo com os resultados teóricos de $2.911 \AA$ [211] e $2.913 \AA$ [144] obtidos previamente. O sistema metanol-água tem sido o sistema mais abordado tanto por trabalhos teóricos como experimentais sobre misturas de álcool e água.

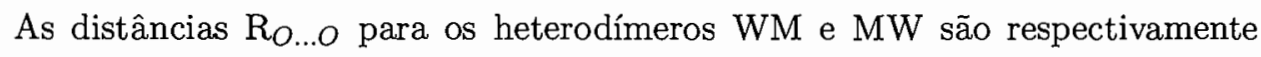
$2.844 \AA$ e $2.912 \AA$ e estão em bom acordo com resultados teóricos prévios recentes $[146,148,160,210,211]$. Para o dímero de etanol foi obtido um valor de $2.879 \AA$ em nível DFT [209] que é ligeiramente maior que o resultado de $2.850 \AA$ encontrado aqui, e similarmente para o dímero de metanol o resultado MP2 de $2.846 \AA$ calculado neste trabalho é menor que o valor B3LYP de 2.875 $[215]$. Todos estes cálculos fornecem resultados consistentes e similares. Cálculos recentes em nível Hartree-Fock produziram distancias $\mathrm{R}_{O \ldots O}$ que são muito grandes mas que confirmaram a tendência de que as ligações de hidrogênio nos dímeros de etanol e metanol são muito similares [216]. Os momentos de dipolo calculados estão em muito bom acordo com os resultados conhecidos experimentalmente para as moléculas isoladas. Para a molécula de água, o resultado de $1.88 \mathrm{D}$ compara bem com o resultado de 1.86D [218]. Analogamente os momentos de dipolo calculados aqui para o metanol (1.71D) e etanol (1.62D) estão em bom acordo com os resultados experimentais [118] (1.70 e $1.69 \mathrm{D}$, respectivamente). Após a formação da ligação de hidrogênio o momento de dipolo combinado do heterodímero ME tem o maior valor enquanto que o heterodímero WE apresenta o menor valor. No primeiro caso existe uma grande componente paralela e no último existe uma grande componente anti-paralela dos momentos de dipolo das moléculas em separado como pode ser visto na Figura 7.3. Antes de proceder é conveniente considerar as formas trans e gauche da molécula de etanol. A Tabela 7.2 apresenta as energias totais da molécula de etanol nas duas conformações. Em todos modelos teóricos considerados aqui pode se notar que a forma trans é mais estável que forma gauche embora a energia relativa seja muito pequena, de acordo com estudos anteriores [209,219]. No mais alto nível de correlação, $\operatorname{CCSD}(\mathrm{T})$, a diferença é somente $0.16 \mathrm{kcal} / \mathrm{mol}$, em 
muito bom acordo com o resultado de $0.14 \mathrm{kcal} / \mathrm{mol}$ obtido usando DFT [209]. Quando o etanol faz a ligação de hidrogênio com a água a diferença na energia relativa para os heterodímeros trans e gauche é consideravelmente menor. Considerando a energia de ponto zero a diferença é essencialmente nula. A energia total do sistema etanol-água é a mesma se a molécula de etanol está em sua forma trans ou gauche. Uma questão mais delicada quando se considera o dímero de etanol é a grande variedade de complexos que podem ser formados $[209,220]$. Investigações recentes mostram que estas várias possibilidades têm energia de ligação equivalentes. Por exemplo, a forma trans-gauche difere da forma trans-trans por menos que $0.06 \mathrm{kcal} / \mathrm{mol}$ [209]. A forma gauchegauche tem uma diferença maior mas ainda assim é menor que $0.3 \mathrm{kcal} / \mathrm{mol}$. A consideração explícita de todas as formas possíveis está fora do objetivo deste trabalho, assim nas análises seguintes o dímero de etanol será considerado somente na forma trans-trans. A Tabela 7.3 apresenta as energias de ligação de todos os onze sistemas considerados aqui e permite uma análise sistemática da estabilidade relativa dos diferentes isômeros. Note que para o caso do complexo etanol-água, onde a molécula de água é doadora de próton, é mais estável pela mesma quantidade, não dependendo da forma (trans ou gauche) da molécula de etanol. Por exemplo, em nível MP2, considerando a correção de vibração de ponto zero, a estabilidade relativa é de $0.71 \mathrm{kcal} / \mathrm{mol}$ para ambas as comformações do etanol. CCSD(T) e os intermediários MP3 e MP4 fornecem uma clara descrição do papel dos efeitos da correlação eletrônica sobre as energias de ligação. A energia de ligação para o dímero de água estimada em nível MP2 no limite de base completa $[143,144]$ é $4.9 \mathrm{kcal} / \mathrm{mol}$. Aqui foi encontrado em nível MP2/aug-cc-pVDZ um valor menor por cerca de $0.4 \mathrm{kcal} / \mathrm{mol}$. O valor da energia de ligação no limite de base completa, estimado para o metanol em nível MP2 é $5.58 \mathrm{kcal} / \mathrm{mol}$ [212]. Novamente, o resultado MP2 encontrado aqui para o dímero de metanol é menor que o valor estimado no limite de base completa por cerca de $0.4 \mathrm{kcal} / \mathrm{mol}$. Para o caso do dímero de etanol o valor no limite de base completa parece não ter sido estimado. Contudo, um resultado B3LYP/6-311+G(3df,2p) [209] da energia de ligação para o dímero de etanol foi encontrado como $3.6 \mathrm{kcal} / \mathrm{mol}$ após a correção de ZPE. O resultado equivalente 


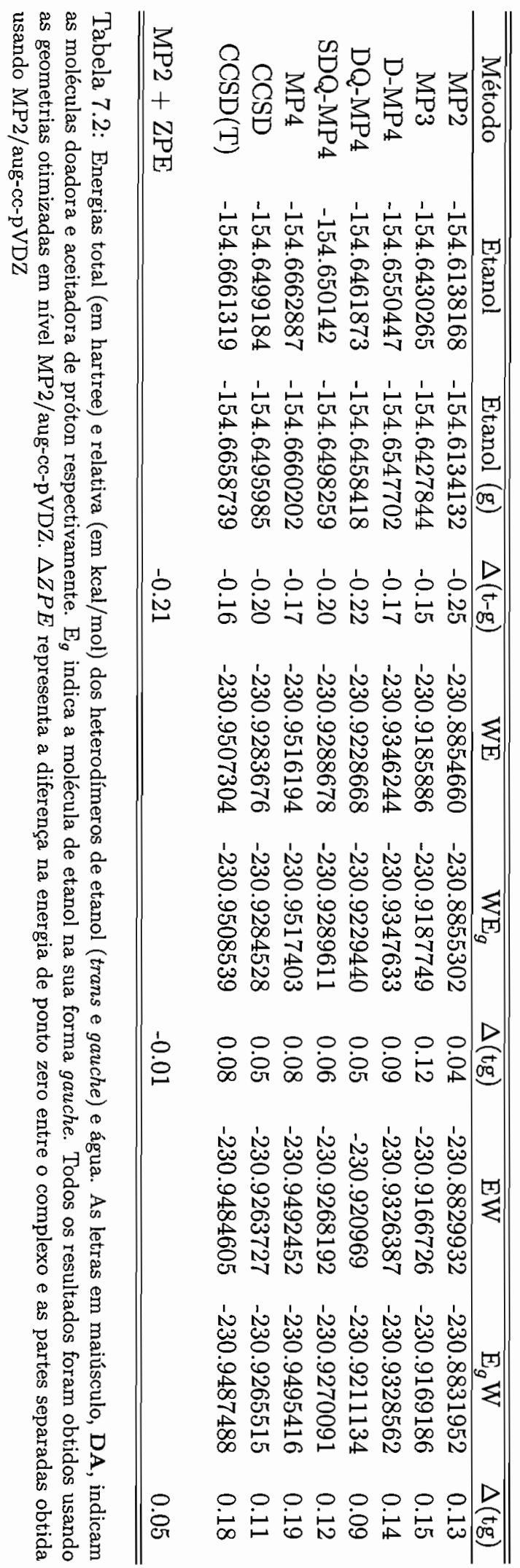




\begin{tabular}{cccccccccc}
\hline \hline Método & WW & MM & EE & WM & MW & WE & EW & ME & EM \\
\hline MP2 & 4.46 & 5.22 & 5.69 & 5.15 & 4.48 & 5.49 & 4.27 & 5.15 & 5.08 \\
MP3 & 4.39 & 4.96 & 5.34 & 4.90 & 4.40 & 5.18 & 4.21 & 4.91 & 4.83 \\
D-MP4 & 4.31 & 4.88 & 5.25 & 4.82 & 4.32 & 5.10 & 4.13 & 4.83 & 4.75 \\
DQ-MP4 & 4.20 & 4.69 & 4.96 & 4.67 & 4.17 & 4.92 & 3.96 & 4.63 & 4.53 \\
SDQ-MP4 & 4.23 & 4.80 & 5.14 & 4.76 & 4.22 & 5.03 & 4.03 & 4.74 & 4.66 \\
MP4 & 4.39 & 5.14 & 5.68 & 5.04 & 4.44 & 5.38 & 4.27 & 5.11 & 5.06 \\
CCSD & 4.23 & 4.77 & 5.09 & 4.74 & 4.22 & 5.01 & 4.02 & 4.70 & 4.63 \\
CCSD(T) & 4.41 & 5.11 & 5.62 & 5.02 & 4.45 & 5.35 & 4.28 & 5.06 & 5.02 \\
$\Delta$ ZPE & 2.11 & 1.29 & 1.24 & 1.94 & 1.58 & 1.96 & 1.45 & 1.18 & 0.93 \\
MP2- $\triangle$ ZPE & 2.35 & 3.93 & 4.45 & 3.21 & 2.90 & 3.53 & 2.82 & 3.97 & 4.15 \\
\hline \hline
\end{tabular}

Tabela 7.3: Energias de ligação corrigidas contra BSSE em $\mathrm{kcal} / \mathrm{mol}$ dos complexos. As letras em maiúsculo, DA, indicam as moléculas doadora e aceitadora de próton respectivamente. Todos os resultados foram obtidos usando as geometrias otimizadas em nível MP2/aug-ccpVDZ. $\triangle Z P E$ representa a diferença na energia de ponto zero entre o complexo e as partes separadas obtida usando MP2/aug-cc-pVDZ

obtido aqui é de $4.45 \mathrm{kcal} / \mathrm{mol}$. O dímero de etanol também foi estudado por Masella e Flament [217] que obtiveram o valor de $6.4 \mathrm{kcal} / \mathrm{mol}$. Este valor parece ser alto se comparado ao seu valor correspondente de $6.3 \mathrm{kcal} / \mathrm{mol}$ para o dímero de metanol. Uma estimativa da entalpia de dimerização para o dímero de etanol sugere um valor próximo a $4.0 \mathrm{kcal} / \mathrm{mol}$ [221]. Em todos os níveis de cálculo considerados neste trabalho o dímero de etanol é o sistema mais fortemente ligado. Um estudo combinado HF//MP2 [216] considerou ambos dímeros de metanol e de água. Usando cálculos MP2 em geometrias otimizadas em nível HF [216] foi encontrado que a energia de ligação no dímero de etanol é mais forte que no dímero de metanol por $0.5-0.8 \mathrm{kcal} / \mathrm{mol}$. Os resultados apresentados aqui para a forma trans-trans consistentes com esta descrição indicando uma maior estabilidade para o dímero de etanol por um valor de $0.5 \mathrm{kcal} / \mathrm{mol}$ em nível MP2//CCSD(T).

Os resultados para os heterodímeros MW e WM são similares aqueles obtidos antes e são consistentes com o fato de que o isômero WM é mais fortemente ligado que o isômero MW por menos que $1 \mathrm{kcal} / \mathrm{mol}[148,159,160]$. Em nível MP2 foi encontrado que o isômero WM é mais estável que o isômero MW por $0.7 \mathrm{kcal} / \mathrm{mol}$. Esta é a mesma diferença de energia obtida usando o modelo B3LYP [160], apesar de que individualmente as energias DFT são mais altas. $\mathrm{O}$ valor para energia relativa diminui somente $0.3 \mathrm{kcal} / \mathrm{mol}$ se a correção 
da ZPE for considerada. No caso do sistema etanol-água foi encontrado sistematicamente que o heterodímero WE é mais estável que o heterodímero EW por cerca de $1.2 \mathrm{kcal} / \mathrm{mol}$. Esta diferença (WE - EW) é a maior encontrada entre os possíveis considerados aqui. Nos casos das misturas de alcool e água, metanol-água e etanol-água, foi encontrado que o heterodímero mais estável tem o álcool como aceitador de próton e a água como doador. Todavia no caso do etanol a diferença na energia entre os dois heterodímeros é mais significativa. O sistema metanol-etanol tem sido menos estudado. Foi obtido aqui que estes isômeros tem energia de ligação de $5.15 \mathrm{kcal} / \mathrm{mol}(\mathrm{ME})$ e $5.08 \mathrm{kcal} / \mathrm{mol}(\mathrm{EM})$ em nível MP2. Nenhuma estimativa teórica foi encontrada para estas energias de ligação. Aqui, o isômero ME foi encontrado ser mais estável que o isômero EM por uma quantidade desprezível de aproximadamente $0.1 \mathrm{kcal} / \mathrm{mol}$ em todos os modelos teóricos considerados, desde MP2 até $\operatorname{CCSD}(\mathrm{T})$. A inclusão da diferença na energia de vibrações de ponto zero na estabilidade relativa, por sua vez, favorece o heterodímero EM por $0.2 \mathrm{kcal} / \mathrm{mol}$. Assim os heterodímeros de metanol-etanol têm essencialmente a mesma energia de ligação sem indicação de um isômero mais estável. É possível observar que a estabilidade relativa dos diferentes isômeros reflete a tendência das distâncias das ligações de hidrogênio mostradas na Figura 7.2 e 7.3 .

Em todos os resultados foi verificado que o papel dos efeitos da correlação eletrônica além de MP2 não é muito importante na definição dos valores das estabilidades relativas dos diferentes heterodímeros. Como observado antes para as energias de ligação absolutas [124,222], estender os resultados de MP2 para MP4 não introduz nenhuma correção relevante. Isto não quer dizer que os efeitos de correlação eletrônica nas energias de ligações não são importantes, mas sim que os resultados em nível MP2 são balanceados. Nos sistemas em estudo aqui a influência dos efeitos de correlação em altas ordens é sistemática porém pequena. Por exemplo, excitações triplas em alta ordem, como obtida a partir da diferença entre os resultados em níveis CCSD e CCSD(T) sempre aumentam a energia de ligação. No caso do dímero de etanol esta quantidade aumenta para $0.5 \mathrm{kcal} / \mathrm{mol}$. Nos outros casos o aumento é da ordem de $0.3 \mathrm{kcal} / \mathrm{mol}$. O mesmo padrão pode ser obtido comparando as excitações tri- 
plas em quarta ordem, como obtida pela diferença entre os resultados em níveis MP4 completo e SDQ-MP(4). Isto indica que a contribuição das excitações triplas à energia relativa é muito pequena e a maior parte já pode ser alcançada em quarta ordem. Efeitos de correlação em altas ordens, isto é, além de MP2, no caso considerado aqui fornece um padrão diferente das energias de ligação relativas dos dois possíveis heterodímeros.

Uma importante informação teórica para entender misturas líquidas é a energética envolvida na formação e na quebra das ligações de hidrogênio. Foi discutido que metanol-água leva a misturas incompletas em nível macroscópico e isto está relacionada a um valor negativo da entropia associada às misturas álcool-água [141,142]. Usando os resultados MP2 com correções de vibrações de ponto zero extraídas da Tabela 7.3 pode-se observar que a quebra da ligação do dímero de metanol para formar o isômero MW (ou WM) diminui a energia por cerca de $1.0 \mathrm{kcal} / \mathrm{mol}$. A quebra de duas ligações de hidrogênio tais como nos dímeros de metanol ou de água para formar $\mathrm{MW}$ e $\mathrm{WM}(\mathrm{MM}+\mathrm{WW} \rightarrow$ $\mathrm{MW}+\mathrm{WM}$ ) é calculada aqui como desfavorável por cerca de $0.2 \mathrm{kcal} / \mathrm{mol}$, utilizando os resultados MP2 corrigidos para energia de vibrações de ponto zero. Este custo energético é pequeno. Para o caso dos sistemas envolvendo água e etanol, a quebra da ligação de hidrogênio no complexo EE para formar os heterodímeros $\mathrm{EW}$ ou WE diminui a energia por $0.95 \mathrm{kcal} / \mathrm{mol}$ (WE) e $1.65 \mathrm{kcal} / \mathrm{mol}$ (EW). Mas, quebrando duas ligações de hidrogênio em EE + WW para formar $\mathrm{EW}+\mathrm{WE}$ é desfavorável por $0.45 \mathrm{kcal} / \mathrm{mol}$. Uma análise similar mostra que $\mathrm{EE}+\mathrm{MM} \rightarrow \mathrm{EM}+\mathrm{ME}$ diminui a energia de ligação por $0.26 \mathrm{kcal} / \mathrm{mol}$, novamente com correção de ZPE em nível MP2. O diagrama da Figura 7.4 resume a relação entre as estabilidades relativas da ligações de hidrogênio. Estas pequenas diferenças de energias podem explicar em parte a mistura incompleta em termos de estabilidades relativas similares. É claro que a situação encontrada num líquido não é a mesma que em complexo otimizado. Neste sentido, ela foi calculada usando a metodologia seqüencial e será apresentada no Capítulo 9. 


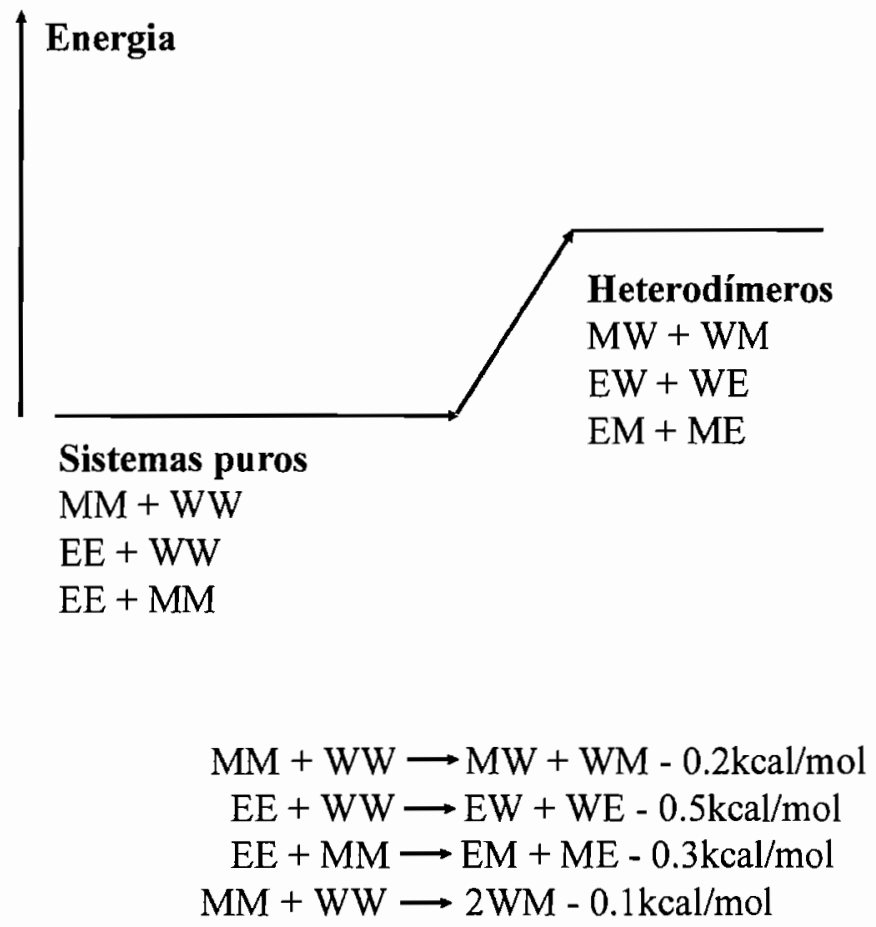

Figura 7.4: Estabilidades relativas dos sistemas homogêneos e misturados 


\subsection{Conclusões}

Energias de ligação foram calculadas para duas misturas comuns de álcool e água usando métodos altamente correlacionados variando do nível MP2 ao nível $\operatorname{CCSD}(\mathrm{T})$. Foi encontrado que no caso dos heterodímeros de metanol-água e etanol-água, o heterodímero mais estável é aquele onde a água atua como doadora de próton. Para os heterodímeros de metanol-água a estabilidade relativa é encontrada ser menor que $1.0 \mathrm{kcal} / \mathrm{mol}$ em acordo com cálculos prévios. No caso dos heterodímeros de etanol-água a diferença é maior que $1.0 \mathrm{kcal} / \mathrm{mol}$. Levando-se em conta correções de vibrações de ponto zero estes valores diminuem. Os efeitos de correlação eletrônica além de MP2 não tem influência na estabilidade relativa dos heterodímeros. No caso da mistura metanol-etanol as energias de ligação corrigidas contra o erro de superposição de base em MP2 são $5.15 \mathrm{kcal} / \mathrm{mol}$ e $5.08 \mathrm{kcal} / \mathrm{mol}$, para o caso onde metanol é o doador e aceitador de próton respectivamente. Foi verificado que estes dois isômeros têm essencialmente, em todos os níveis teóricos considerados, a mesma energia e nenhum isômero preferível poderia ser discernido. Estas diferenças relativas são brevemente discutidas em possível conjunção com a mistura incompleta de sistemas álcool-água. 
Parte III

\section{Estudo de líquidos}




\section{Capítulo 8}

\section{Desordem térmica de ligações de hidrogênio em líquidos}

\subsection{Motivação}

Devido ao grande interesse pelos anéis aromáticos nitrogenados, como blocos construtores de proteínas e nucleotídeos [223], o sistema considerado aqui para o estudo de ligações de hidrogênio é o complexo piridina-água $\left(\mathrm{C}_{5} \mathrm{H}_{5} \mathrm{~N} \cdots \mathrm{H}_{2} \mathrm{O}\right)$. Neste sistema o átomo de nitrogênio da piridina é o aceitador de próton que faz a ligação de hidrogênio com o átomo de hidrogênio doador da água. As mudanças locais nas cargas atômicas, momento de dipolo e polarizabilidades de dipolo do complexo são estudadas usando métodos $a b$ initio de mecânica quântica em ambos os casos, isto é, no complexo otimizado e no líquido desordenado. Os resultados são usados para a comparação entre a ligação de hidrogênio no complexo e no líquido, de forma a dar uma informação teórica quantitativa sobre a influência da desordem local.

Como mencionado anteriormente, as maiores dificuldades no estudo de ligações de hidrogênio em líquidos estão relacionadas ao grande número de possíveis estruturas em uma dada temperatura, a identificação não trivial destas ligações em fase líquida e a dificuldade de se obter resultados estatisticamente convergidos. Estes pontos estão de fato relacionados à representação correta e realística do espaço de configurações ocupados pelas estruturas que apresentam ligações de hidrogênio e são considerados e tratados com sucesso aqui. 


\subsection{Detalhes de cálculo}

\subsubsection{Simulação}

A estrutura do líquido foi gerada através de simulação Monte Carlo, usando o programa Dice [224]. As simulações foram realizadas no ensemble canônico (NVT) com uma molécula de piridina e 400 moléculas de água usando a densidade experimental da água, que em $T=298.15 \mathrm{~K}$ é $0.9966 \mathrm{~g} / \mathrm{cm}^{3}$. As interações intermoleculares foram descritas pelo potencial de Lennard-Jones com o termo eletrostático Coulombiano. Para a molécula de água foi adotado o potencial SPC [225] e para a molécula de piridina o potencial de 11 sítios OPLS [226]. Nos cálculos das energias de pares cada molécula interagiu com todas as outras moléculas dentro da separação de centro de massa que é menor que o raio de corte que neste caso foi de $11.9 \AA$. Para separações maiores que o raio de corte foi empregada a correção de longo alcance para a energia potencial [10]. As simulações consistiram de um estágio de termalização de $2.0 \times 10^{6}$ passos MCM, seguido por um longo estágio de $80.0 \times 10^{6}$ passos MCM, onde as configurações foram geradas. Configurações sucessivas geradas na simulação, por serem altamente correlacionadas não fornecem importantes informações adicionais. Portanto o intervalo de correlação estatística foi calculado usando a função de autocorrelação da energia $[14,35,43]$. Para as simulações apresentadas aqui, depois do cálculo da autocorrelação da energia foram obtidas configurações separadas por $320 \times 10^{3}$ passos MCM estatisticamente relevantes (menos de $10 \%$ de correlação estatística). Assim o número de configurações foi reduzido para 250 estruturas descorrelacionadas sem perda de informação estatística [38, 44,227].

\subsubsection{Identificação das ligações de hidrogênio}

Aqui, foi considerada estrutura ligada a estrutura que apresenta a distância $\mathrm{R}_{N-O} \leq 3.50 \AA$, o ângulo 1 (NÔH) $\leq 30^{\circ}$ e a energia de interação menor que $-2.0 \mathrm{kcal} / \mathrm{mol}$. Estas condições geométricas foram obtidas a partir da função de distribuição radial. Para o critério energético a distribuição de energia de

\footnotetext{
${ }^{1}$ Este ângulo é formado pela ligação covalente $\mathrm{OH}$ e a linha que une os átomos $\mathrm{N}$ e $\mathrm{O}$.
} 
pares foi analisada. Primeiro a Figura 8.1 mostra a função de distribuição radial de pares entre os átomos $\mathrm{N}$ da piridina e $\mathrm{O}$ da água. $\mathrm{O}$ primeiro pico na

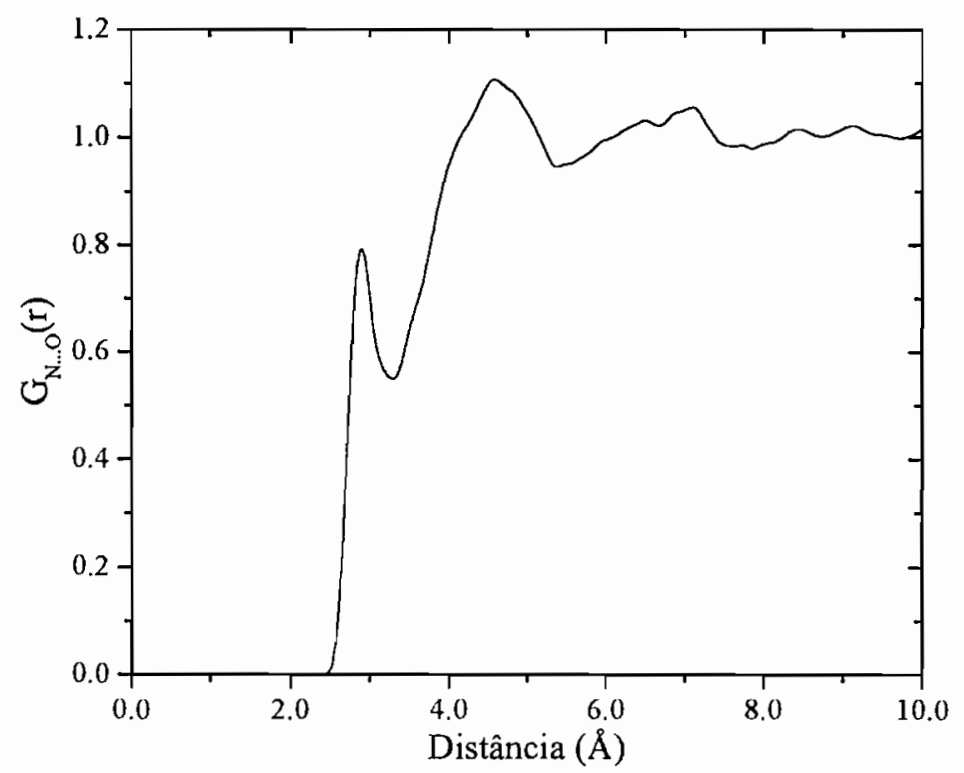

Figura 8.1: Função de distribuição radial entre o átomo de nitrogênio da molécula de piridina e o átomo de hidrogênio das moléculas de água

$\mathrm{G}_{N-O}(\mathrm{r})$ começa em $2.45 \AA$ e termina em $3.50 \AA$, com um máximo em $2.94 \AA$. As ligações de hidrogênio podem se localizar a partir da distância de $\mathrm{R}_{N-O} \leq$ $3.50 \AA$. Uma análise similar fornece um critério para o ângulo $\theta(\mathrm{NO} H) \leq 30^{\circ}$. A Figura 8.2 identifica as ligações de hidrogênio para a energia de interação de pares piridina-água menor que $-2.0 \mathrm{kcal} / \mathrm{mol}$. Usando estes critérios, nas 250 MCM configurações foram encontradas 269 ligações de hidrogênio formadas com o átomo de nitrogênio da piridina. Mais especificamente foi verificado que em $17 \%$ das configurações não existe ligação de hidrogênio, em $62 \%$ existe apenas uma ligação, em $20 \%$ existem duas, e somente em $1 \%$ existem três ligações de hidrogênio. Isto forneceu uma média de 1.1 ligações de hidrogênio. Foram encontradas no total 155 configurações fazendo uma ligação de hidrogênio. Todas estas 155 estruturas, consistindo de uma molécula de piridina e uma molécula de água, foram submetidas a cálculos quânticos. A Figura 8.3 mostra a superposição de todas estas 155 estruturas com uma molécula de piridina e uma molécula de água (1:1) no líquido. Pode-se observar claramente a eficiência do procedimento para se obter as ligações de hidrogênio formadas entre a piridina 


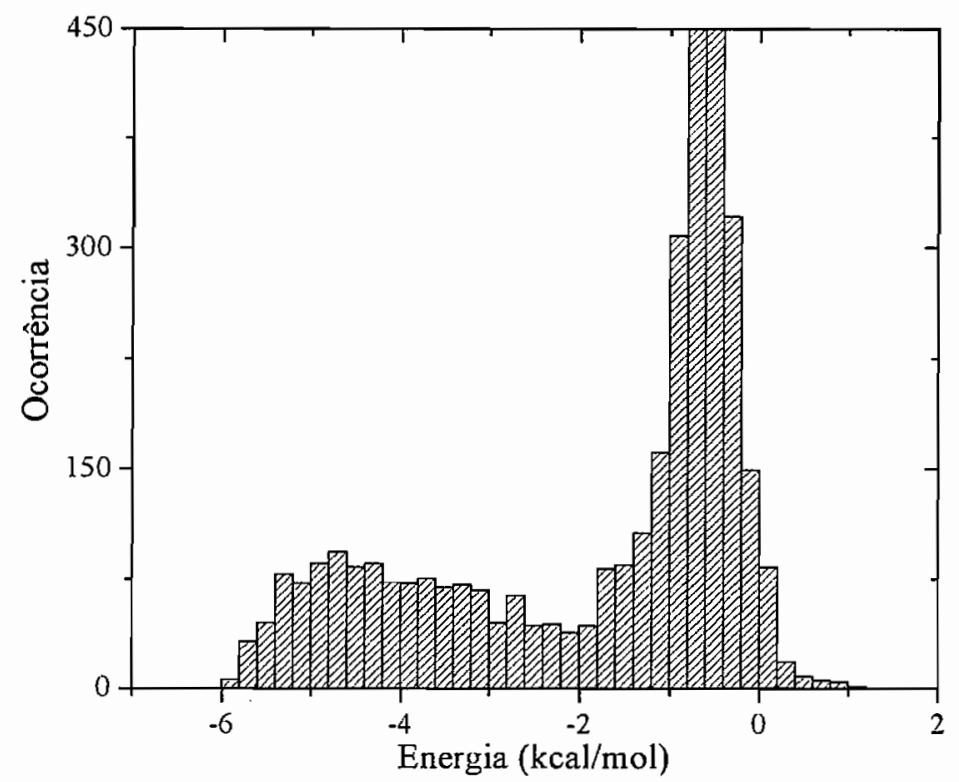

Figura 8.2: Histograma de energias de interação de pares entre as moléculas de piridina e água

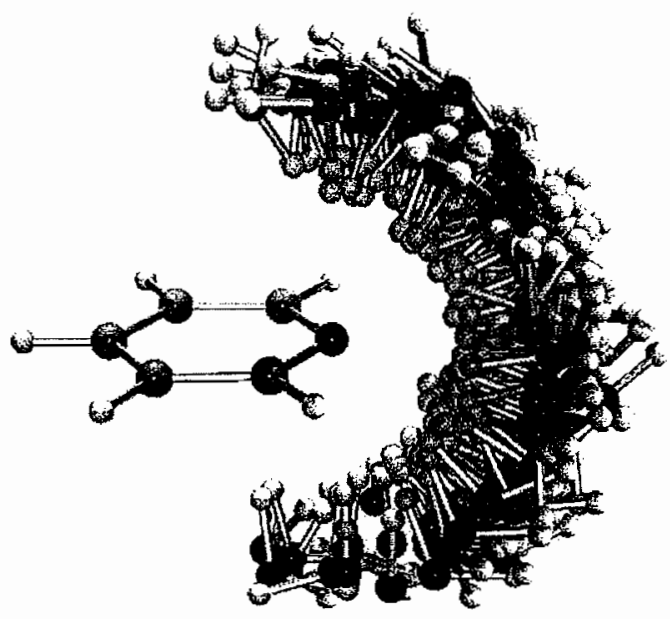

Figura 8.3: Superposição de configurações das ligações de hidrogênio formadas pela piridina em solução aquosa

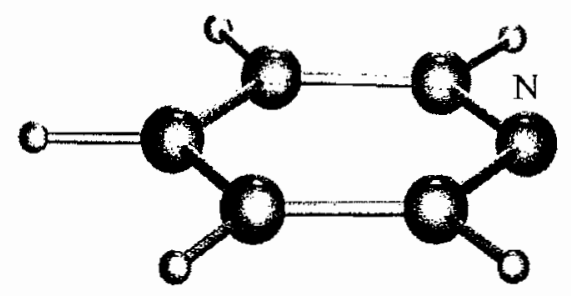

1.964

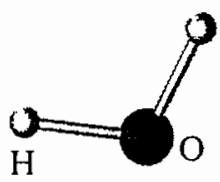

Figura 8.4: A estrutura do complexo otimizado de piridina-água 
e a água. É interessante notar como o espaço de configurações é bem preenchido com todas as moléculas de água se ligando ao nitrogênio da piridina. A Figura 8.4 mostra a estrutura de um único (1:1) complexo piridina-água completamente otimizado. O comprimento da ligação de hidrogênio $\mathrm{N} \cdots \mathrm{H}$ no complexo foi calculado como sendo $1.964 \AA$, correspondendo à distância $N$... O de $2.947 \AA$. No caso líquido esta última distância apresentou o valor de $2.94 \pm 0.16 \AA$.

\subsubsection{Cálculos de mecânica quântica}

O momento de dipolo e as polarizabilidades de dipolo foram calculadas individualmente para cada uma das 155 (1:1) estruturas separadas da simulação MCM do líquido e para o complexo otimizado (1:1). As taxas de despolarização e as intensidades de espalhamento Rayleigh foram obtidas a partir das polarizabilidades de dipolo média e anisotrópica. Foi empregado nestes cálculos o modelo teórico MP2/6-31+G(d) através do programa Gaussian 98 [117].

\subsection{Resultados e discussão}

Primeiramente é conveniente discutir as cargas atômicas uma vez que elas desempenha um papel central no modelo físico da ligação de hidrogênio [101, 106,228]. O ponto de vista dominante defende a idéia de que a interação eletrostática é a maior contribuinte para o modelo realístico das ligações de hidrogênio [1.06, 229-232]. Tem existido também um debate sobre a transferência de carga [232-235] e efeitos covalentes [236-238]. Estudos recentes argumentam que transferência de carga não pode ser ignorada e pode dar uma contribuição significante para a estabilização da ligação de hidrogênio [234, 235, 239-241]. A crítica sobre o artefato computacional relacionada à transferência de carga foi detalhada em um recente trabalho teórico [242]. Vaart e Merz [242] afirmam que transferência de carga ocorre até mesmo na ausência total de erro de superposição de base. Eles averiguaram que a carga é transferida do aceitador para o doador próton numa ligação de hidrogênio por uma quantidade entre $0.01 \mathrm{e}$ 0.05 elétron por ligação. Este é um ponto de grande importância e foi usado aqui para fornecer uma possível distinção entre a ligação de hidrogênio entre a 
piridina e a água na estrutura de mínima energia e nas estruturas termicamente desordenadas. Aqui é usada a análise de população de Mulliken e a correção counterpoise contra BSSE [72]. Assim todos os cálculos foram realizados com os conjuntos de base completos para ambas as moléculas, piridina e água. Foi verificado que na configuração de mínima energia, existiu uma transferência de carga da molécula de piridina para a molécula de água de $-0.039 e$, isto é, a molécula de água se tornou mais negativa depois da formação da ligação de hidrogênio. Este resultado, com correção para BSSE, está condizente com os resultados de Vaart e Merz [242]. Eles apontaram também que este resultado não depende muito da qualidade do conjunto base após a correção de BSSE. Contudo, os resultados para a população de Mulliken obtidos aqui são mais sistemáticos. A Figura 8.5 mostra o resultado da transferência de carga do líquido. Neste caso, foi determinada a distribuição estatística de valores. Como pode

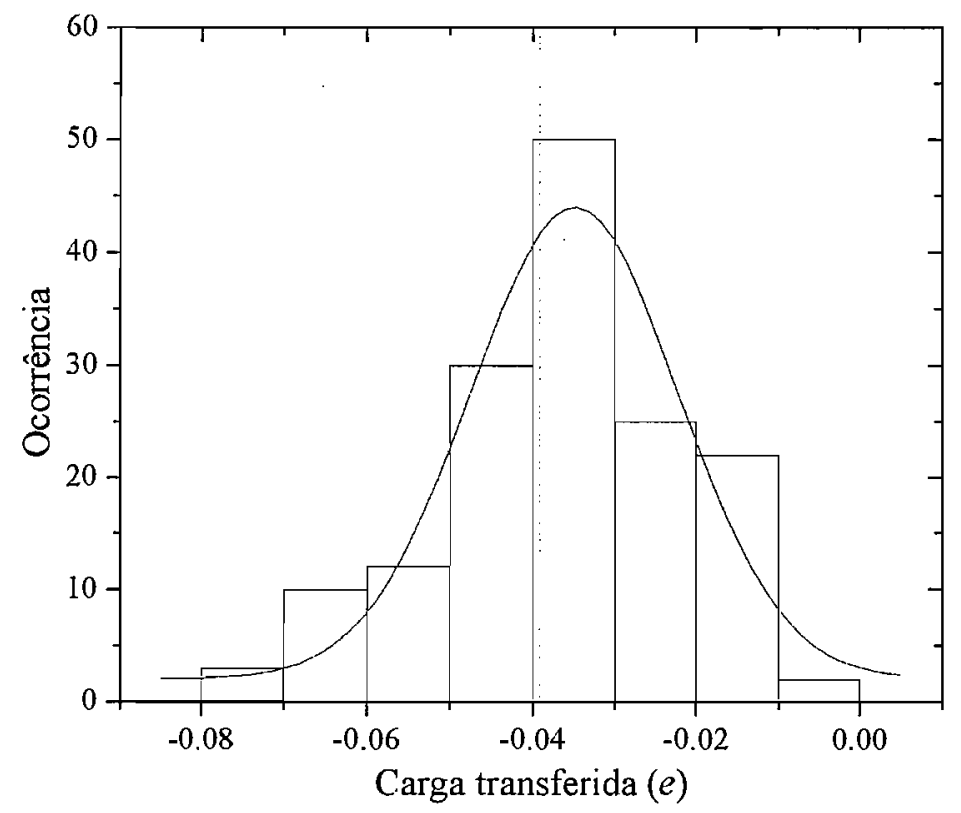

Figura 8.5: Transferência de carga (em unidade elementar) da molécula de piridina para a molécula de água em comparação com o valor para o complexo otimizado (linha pontilhada)

ser visto, todas as configurações apresentaram uma transferência de carga dominante (resultados negativos) para a água. Na média, a molécula de piridina transferiu para a molécula de água $-0.036 \pm 0.015$ carga elementar. É discutível se esta transferência de carga é importante na estabilidade da ligação. Contudo 
foi observada uma transferência sistemática em ambos os casos, com magnitude comparável à obtida por Vaartz e Merz [242]. Pode ser visto também que a molécula doadora na configuração de energia mínima do complexo foi apenas ligeiramente mais negativa. Logo, a relevância da transferência de carga é essencialmente a mesma tanto no complexo otimizado quanto nas estruturas termicamente desordenadas. Os momentos de dipolo do complexo otimizado e a

\begin{tabular}{cccc}
\hline \hline & Piridina & Complx (1:1) & Líq (1:1) \\
\hline Momento de dipolo (D) & 2.51 & 5.07 & $4.71 \pm 0.68$ \\
Modelo vetorial & & 4.73 & $4.54 \pm 0.68$ \\
Polarizabilidade de dipolo (ua) & & & \\
Média & 60.00 & 68.16 & $68.37 \pm 0.24$ \\
Polarizabilidade anisotrópica (ua) & 35.11 & 39.29 & $37.36 \pm 2.07$ \\
\hline \hline
\end{tabular}

Tabela 8.1: Momento de dipolo e polarizabilidades do sistema piridina-água. Os resultados mostrados para o líquido são os valores médios com os respectivos desvios padrão. Modelo vetorial assume uma soma vetorial simples dos momentos de dipolo das moléculas separadas.

média desta propriedade para as estruturas desordenadas do líquido são dados na Tabela 8.1. Todos estes resultados foram corrigidos contra BSSE. O momento de dipolo calculado para o complexo otimizado foi 5.07D, razoavelmente maior que a média do dipolo calculada para o momento de dipolo do líquido 4.71 $\pm 0.68 \mathrm{D}$. A conclusão é que a desordem leva a uma diminuição do dipolo combinado. No modelo vetorial, o momento de dipolo do complexo foi obtido por uma simples adição vetorial dos momento de dipolo das partes separadas e isto deu um valor de 4.73D (complexo) e $4.54 \pm 0.68 \mathrm{D}$ (líquido). As estruturas desordenadas levaram a um momento de dipolo menor, reduzindo seu valor de 5 a 10\%. Naturalmente a diminuição no momento de dipolo levou a uma diminuição na interação de dipolo e conseqüentemente a uma menor energia de ligação no líquido comparado à energia ligação no complexo otimizado. Considerando-se agora a diferença entre a aproximação de soma vetorial e o resultado calculado explicitamente como um efeito de indução [101,106,243], é possível ver que esta indução contribui menos que $10 \%$ tanto no complexo quanto nas estruturas termicamente desordenadas. A Figura 8.6 mostra a distribuição dos valores do momento de dipolo calculado usando valores das estruturas do líquido e a distribuição normal com $\langle\mu\rangle=4.71 \mathrm{D}$ e $\delta=0.68 \mathrm{D}$. 


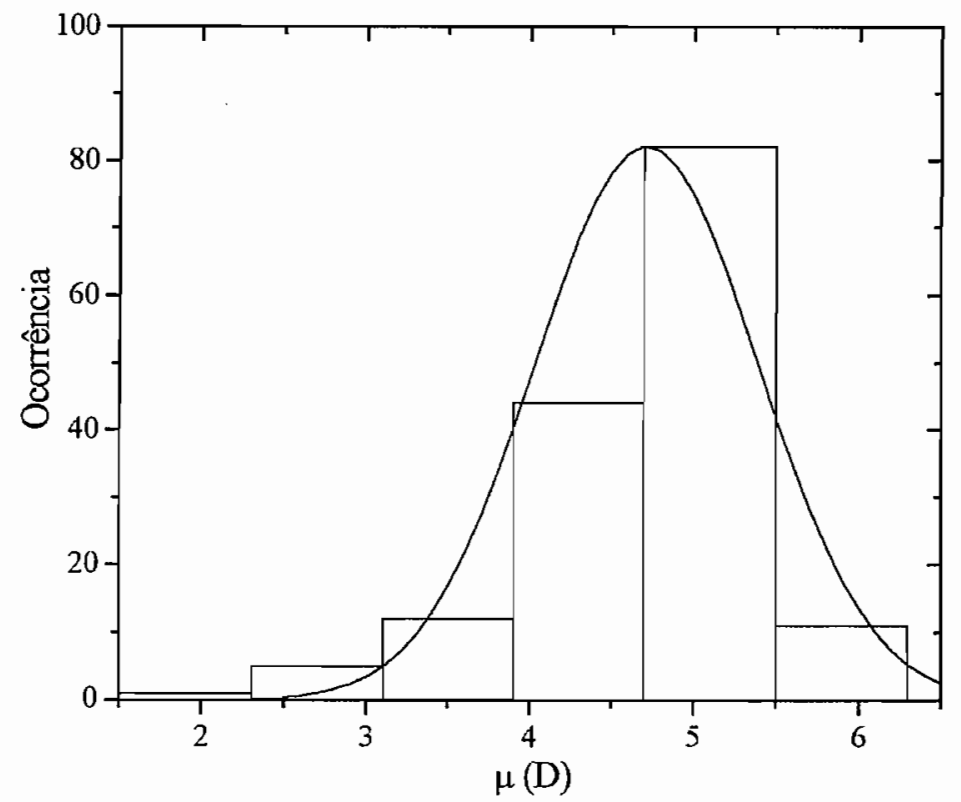

Figura 8.6: Distribuição dos valores dos momentos de dipolo calculados e a distribuição normal $\operatorname{com}\langle\mu\rangle=4.71 \mathrm{D}$ e $\delta=0.68 \mathrm{D}$

A polarizabilidade de dipolo tem sido muito usada na caracterização de complexos [244-246], incluindo sistemas com ligação de hidrogênio [145,171]. O interesse aqui é analisar as mudanças nas polarizabilidades de dipolo devidas à desordem térmica do sistema soluto-água e a conseqüência desta mudança nas propriedades Rayleigh. As polarizabilidades calculadas para o complexo otimizado e para as estruturas do líquidos estão resumidas na Tabela 8.1. A

\begin{tabular}{cccc}
\hline \hline despolarização & Piridina & complexo (1:1) & Líquido (1:1) \\
\hline$\sigma_{p}$ & 2.21 & 2.15 & $1.94 \pm 0.20$ \\
$\sigma_{n}$ & 4.33 & 4.21 & $3.81 \pm 0.38$ \\
$\sigma_{c}$ & 4.53 & 4.40 & $3.96 \pm 0.41$ \\
\hline \hline
\end{tabular}

Tabela 8.2: Taxa de despolarização Rayleigh $\left(10^{-2}\right)$ do complexo de piridina-água. Os resultados mostrados para o líquido são os valores médios com os respectivos desvios padrão.

polarizabilidade média do sistema piridina-água é essencialmente aditiva, mas a polarizabilidade anisotrópica é mais sensível à ligação. Esta aditividade não é surpreendente e já foi notada antes para complexos otimizados [145,171,247]. No líquido esta aditividade é mais peculiar uma vez que a polarizabilidade de dipolo é uma distribuição estatística. A polarizabilidade de dipolo média é li- 


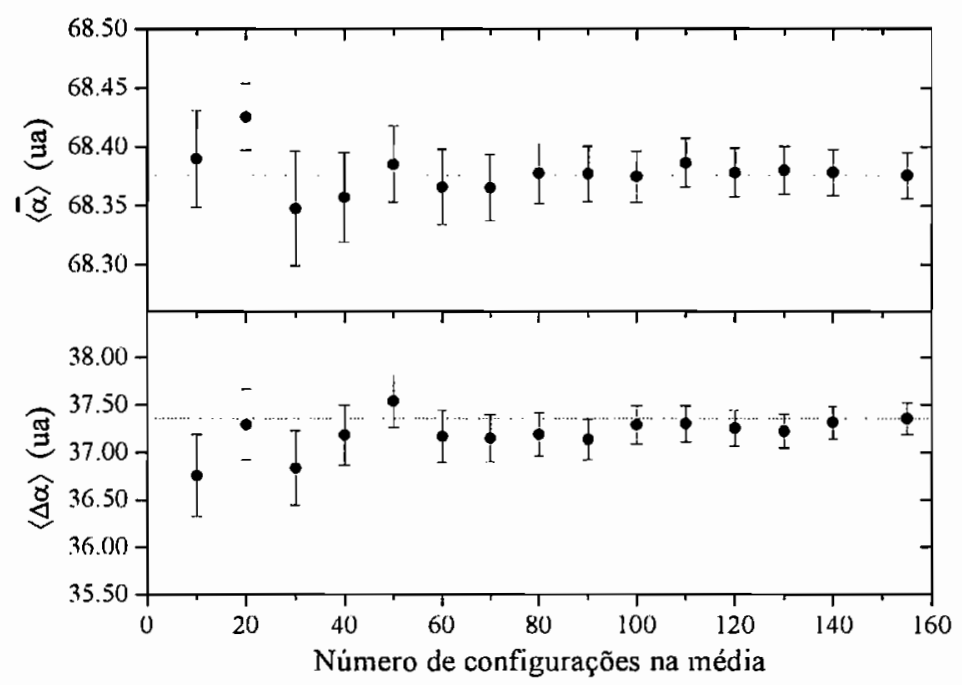

Figura 8.7: Convergência da média calculada da polarizabilidade de dipolo média

geiramente maior devido à distribuição da desordem térmica. $O$ desvio padrão $\delta$ para o líquido reflete a grande variação vista no caso líquido. Assim o valor final representado por $\langle\alpha\rangle \pm \delta$ mostra as informações que descrevem uma distribuição normal e que abrange $68 \%$ dos dados. A Figura 8.7 mostra a convergência dos valores calculados para a polarizabilidade média e anisotrópica quando o número de configurações, $L$, cresce até o máximo, $L=155$, usado aqui. Os resultados claramente demonstraram que o valor convergiu após 100 cálculos. As ligações de hidrogênio escolhidas a partir da simulação MCM e mostradas anteriormente na Figura 8.3 foram realmente capazes de representar o espaço configuracional necessário para dar resultados estatisticamente convergidos. A inomogeneidade da distribuição eletrônica leva à despolarização da luz elasticamente espalhada e esta despolarização é obtida a partir das polarizabilidades de dipolo (veja seção 3.3.1). Após a formação da ligação de hidrogênio em ambiente aquoso, as taxas de despolarização tornaram-se distribuições com os valores médios diminuídos em relação ao valor obtido para o complexo otimizado. No caso do líquido, estes valores foram sempre menores que no complexo otimizado. Uma clara distinção entre os dois casos pode ser feita e é bastante interessante; para todos os tipo de polarizações a redução nas 
taxas de despolarização, do complexo para o líquido, foi a mesma. Em termos gerais, o resultado médio das taxas diferem somente $10 \%$ quando comparados com o complexo. O movimento térmico contudo implica num alargamento dos resultados. A Figura 8.8 mostra a comparação entre a distribuição das taxas de despolarização para as estruturas desordenadas do líquido e a mesma despolarização para o complexo otimizado. Os valores calculados para o complexo,

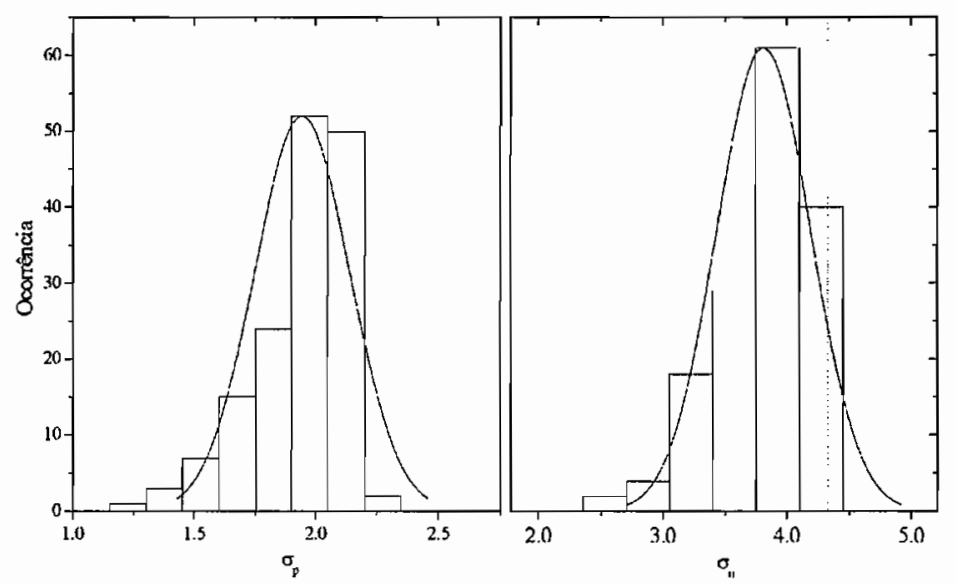

Figura 8.8: Histograma mostrando a distribuição da taxa de despolarização no líquido em comparação com o valor para o complexo otimizado (linha pontilhada)

ficaram fora da semi-largura da distribuição para o líquido, isto é, eles foram superiores a $85 \%$ dos pontos dados da distribuição estatística normal. Embora este seja um estudo de um único caso, deve ser mencionado que resultados similares têm sido obtidos para outros sistemas, com a despolarização calculada para complexos otimizados com ligação de hidrogênio, dando valores maiores que os valores obtidos levando em consideração a distribuição térmica das estruturas. Naturalmente, isto pode também ser extendido além dos cálculos de polarizabilidades. Uma vez que as polarizabilidades de dipolo estão relacionadas às forças intermoleculares, os resultados apresentados aqui podem também ser usados para racionalizar a interação dos sistemas ligados com o amb̆iente externo. Neste caso o efeito do solvente deve ser adequadamente tratado $[248,249]$. Uma análise similar pode ser feita para deslocamentos químicos em ressonância magnética nuclear [250] e constantes de acoplamento quadrupolar [251], e realmente estas propriedades podem ser obtidas pelo uso de uma aproximação 
teórica análoga à empregada aqui.

\subsection{Conclusões}

A influência da desordem térmica sobre as estruturas com ligações de hidrogênio obtidas para a molécula de piridina em ambiente aquoso foi analisada. Para isto o momento de dipolo e a polarizabilidade de dipolo foram escolhidos como propriedades eletrônicas de prova, incluindo a componente anisotrópica da polarizabilidade que é responsável pela despolarização da luz. Cálculos ab initio foram realizados somente sobre o complexo piridina-água e a influência das outras moléculas de solvente não foi considerada. Alguns testes indicaram que isto têm somente uma pequena influência que é estimada ser menos que $10 \%$. Foi verificado que os resultados para o momento de dipolo, polarizabilidades de dipolo e taxas de despolarização calculados para o complexo de piridina e água são estatisticamente convergidos e incorporam a natureza desordenada do líquido. Já que as polarizabilidades de dipolo estão relacionadas a forças intermoleculares, os resultados apresentados aqui podem ser úteis também para racionalizar a interação de sistemas com ligação de hidrogênio com o ambiente externo. Analogamente os resultados para o momento de dipolo mostraram que a desordem afeta o momento de dipolo local. No meio líquido, a desordem levou a um momento de dipolo médio para o complexo inferior aquele para o complexo otimizado. Contudo, no caso estudado aqui, as diferenças foram importantes porém não mensuráveis. A transferência de cargas da molécula aceitadora (piridina) para a molécula doadora (água) também foi calculada. Em média $0.036 e$ foi transferido para a água. Este resultado foi apenas ligeiramente menor que o obtido para o complexo otimizado (0.039e). Isto indica até que ponto a transferência de carga pode ser importante numa ligação de hidrogênio, neste caso particular esta importância foi essencialmente a mesma e não foi muito afetado pela desordem térmica. Uma conseqüência espectroscópica direta das polarizabilidades de dipolo e anisotrópica foi o efeito da despolarização Rayleigh. Novamente, os resultados para as taxas de despolarização foram dados por uma distribuição e no caso piridina-água considerado aqui o desvio padrão 
foi em torno de $10 \%$ do valor médio. Tais resultados indicam que as taxas de despolarização foram sistematicamente diminuídas no líquido em relação ao complexo otimizado para todos os três tipos de polarização considerados aqui. As intensidades Rayleigh foram essencialmente as mesmas. As taxas de despolarização, foram contudo, diferentes para a luz natural, planar e circularmente polarizada, mas nos três casos esta diferença foi uma redução de $10 \%$ em relação ao complexo otimizado. Reduções de $20 \%$ foram obtidas em outros sistemas em estudo no grupo de pesquisa. O desvio padrão no presente caso foi de $\sim 10 \%$ do valor médio. Isto significa que no caso considerado aqui o valor calculado para o complexo otimizado ficou dentro do intervalo $\langle\sigma\rangle+\delta$. Os valores abaixo da distribuição das estruturas termicamente desordenadas compreende $85 \%$ dos dados calculados para o líquido e foram menores que o valor calculado para o complexo otimizado. 


\section{Capítulo 9}

\section{Estabilidade dos complexos metanol-água em meio aquoso}

\subsection{Motivação}

Misturas de álcool-água exibem propriedades que são de grande interesse em física, química e biologia $[162,252,253]$. Em grande parte isto se deve à grande habilidade de ambos, água e álcool, formarem ligações de hidrogênio. Estas moléculas podem ser tanto doadoras como aceitadoras de próton em ligações de hidrogênio. O sistema metanol-água pode ter duas estruturas correspondendo a dois heterodímeros possíveis (ou isômeros) onde o metanol é aceitador de próton $\mathrm{CH}_{3} \mathrm{HO} \cdots \mathrm{H}_{2} \mathrm{O}$, ou doador de próton, $\mathrm{CH}_{3} \mathrm{OH} \cdots \mathrm{OH}_{2}$, da ligação de hidrogênio (veja Figura 5.2). A existência destes dois isômeros é fácil de perceber e as estabilidades das duas possíveis interações são de grande interesse. De fato elas estão relacionadas a várias propriedades termodinâmicas e físico-químicas. Por exemplo, como já mencionado na seção 6.1, a mistura de metanol e água exibe uma entropia que é consideravelmente menor do que o esperado $[141,142,252]$. Também existem enormes conseqüências na segregação e no papel hidrofóbico do grupo $\mathrm{CH}_{3}$ levando a questōes fundamentais considerando a ordem local orientacional [141,142]. Metanol e água é um dos mais simples exemplos de relações anfotéricas devido ao fato de as moléculas atuarem tanto como doadoras como aceitadoras de próton nas ligações de hidrogênio, logo a questão sobre qual dos dois isômeros é mais estável é importante. Estudos teóricos anteriores apresentaram resultados controversos $[157,207,208,254,255]$ 
considerando a estabilidade relativa dos dois isômeros. Nem mesmo resultados experimentais existem para o isômero $\mathrm{CH}_{3} \mathrm{OH} \cdots \mathrm{OH}_{2}$, existindo somente para o isômero $\mathrm{CH}_{3} \mathrm{HO} \cdots \mathrm{H}_{2} \mathrm{O}$ [156]. Como visto na seção 6.1, até pouco tempo a questão sobre a estabilidade ainda não estava seguramente respondida para a fase gasosa dos complexos. Espectroscopia rotacional de microondas estabeleceu que o complexo no qual o metanol é aceitador de próton, $\mathrm{CH}_{3} \mathrm{HO} \cdots \mathrm{H}_{2} \mathrm{O}$, é o isômero mais estável em fase gasosa [159]. Resultados teóricos mais recentes confirmaram a maior estabilidade deste isômero mas obtiveram uma estabilidade relativa que é menor que $1 \mathrm{kcal} / \mathrm{mol}[160,171]$. Apesar dos resultados em fase gasosa serem interessantes por natureza, resultados sobre a fase líquida podem mostrar uma grande variedade de interesses para misturas de álcoolágua $[169,170,256,257]$. Infelizmente os resultados obtidos em fase gasosa não podem ser diretamente extrapolados para a situação em um líquido sem um grande risco uma vez que a contribuição térmica leva a uma diminuição da estabilidade da ligação de hidrogênio [38,258]. Desta forma, a estabilidade da ligação de hidrogênio formada entre metanol e água em fase gasosa não é a mesma em fase líquida. Para tornar claro este aspecto é determinada aqui a estabilidade relativa da ligação dos dois isômeros formados entre metanol e água em meio líquido à temperatura ambiente. Estes resultados além de estabelecerem a estabilidade relativa em ambiente líquido fornecem também uma estimativa teórica do decréscimo da interação da ligação de hidrogênio quando comparada à situação em fase gasosa.

\subsection{Detalhes de cálculo}

\subsubsection{Simulação}

A estrutura do líquido foi gerada por simulação Monte Carlo, usando o programa Dice [224]. As simulaçōes foram realizadas no ensemble NVT com uma molécula de metanol e 400 moléculas de água usando a densidade experimental da água, que à temperatura $T=298.15 K$ é $0.9966 \mathrm{~g} / \mathrm{cm}^{3}$. As interações intermoleculares foram descritas pela soma dos potenciais Lennard-Jones e Coulomb. Para as moléculas de água foi usado potencial SPC [225] e para a molécula de 
metanol o potencial OPLS-AA [259]. A simulação consistiu de um estágio de termalização de $2.0 \times 10^{6}$ passos $\mathrm{MCM}$, seguido por um longo estágio de equilibrio de $80.0 \times 10^{6}$ passos $\mathrm{MCM}$, onde as configuraçōes foram geradas. Para as simulações apresentadas aqui, após o cálculo da autocorrelação da energia foi observado que configurações separadas por $4.0 \times 10^{5}$ passos MCM foram estatisticamente relevantes ( $\sim 20 \%$ de correlação estatística). Assim, depois da simulação inteira, 200 configuraçōes separadas por $4.0 \times 10^{5}$ passos MCM foram selecionadas.

\subsubsection{Cálculos de mecânica quântica}

A energia de ligação foi calculada individualmente para cada uma das estruturas (1:1) extraídas da simulação do líquido e para os complexos otimizados (1:1). Todos os valores foram corrigidos contra BSSE. Estes cálculos foram realizados com o modelo teórico MP2/aug-cc-pVDZ, implementado no programa Gaussian $98[117]$.

\subsection{Resultados e discussão}

De acordo com a discussão da seção 8.2 a caracterização de uma ligação de hidrogênio se deu, neste caso, quando a distância $R_{O} \ldots . .0 \leq 3.35 \AA$ o ângulo $\theta(O O H) \leq 40^{\circ}$ e a energia de ligação maior que $2.5 \mathrm{kcal} / \mathrm{mol}$. Estas condições geométricas foram obtidas a partir das funções de distribuição radial e angular. Para o critério energético a distribuição de energias de pares foi analisada. A Figura 9.1 mostra a função de distribuição radial de pares entre o átomo de oxigênio do metanol e o átomo de oxigênio da água. O primeiro pico nesta função de distribuição $G_{O} . ., o(r)$ começa em $2.45 \AA$ e termina em $3.35 \AA$, com um máximo em $2.75 \AA$. Portanto, ligações de hidrogênio foram localizadas para distância $R_{O} \ldots O \leq 3.35 \AA$. Uma análise similar fornece o critério para o ângulo $\theta(O \cdots O H) \leq 40^{\circ}$. A Figura 9.2, por sua vez, identifica as ligações de hidrogênio para energias de interação de pares entre metanol e água menor que $-2.5 \mathrm{kcal} / \mathrm{mol}$. Usando estes três critérios, nas 200 configuraçōes MCM, foi verificado que 287 ligações de hidrogênio são formadas no isômero $\mathrm{CH}_{3} \mathrm{HO} \cdots \mathrm{H}_{2} \mathrm{O}$ 


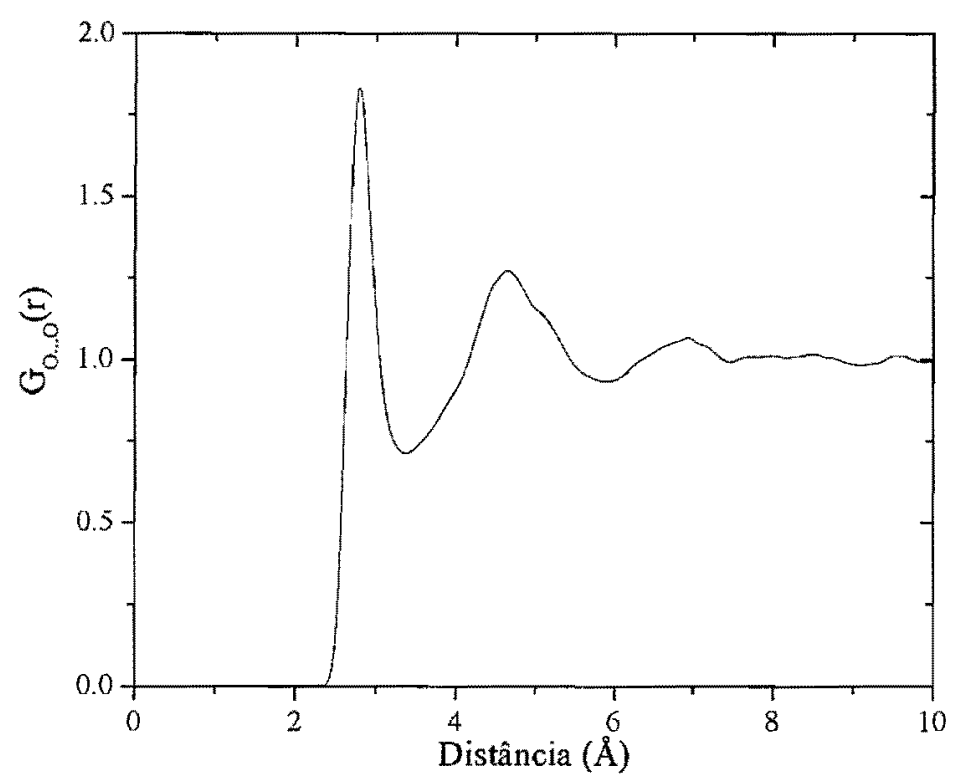

Figura 9.1: Função de distribuição radial de pares entre os átomos de oxigênio do metanol e da água

e 160 são formadas no isômero $\mathrm{CH}_{3} \mathrm{OH} \cdots \mathrm{OH}_{2}$. A Tabela 9.1 mostra a estatística das ligações de hidrogênio de maneira detalhada. Para o isômero $\mathrm{CH}_{3} \mathrm{HO} \cdots \mathrm{H}_{2} \mathrm{O}$ foi encontrado que $7(3.5 \%)$ das configurações não formaram ligações, em 103 (51.5\%) formaram apenas uma, e em 86 (43\%) formaram 2 e somente $4(2 \%)$ formaram três ligações. Isto deu uma média de 1.43 ligações de hidrogênio entre metanol e água no isômero $\mathrm{CH}_{3} \mathrm{HO} \cdots \mathrm{H}_{2} \mathrm{O}$. Para o isômero $\mathrm{CH}_{3} \mathrm{OH} \cdots \mathrm{OH}_{2}$ o panorama foi diferente e $40(20 \%)$ configurações não formaram ligação de hidrogênio enquanto que o resto, $160(80 \%)$, formaram uma ligação de hidrogênio, o que levou a uma média de 0.80 ligações de hidrogênio.

\begin{tabular}{ccc}
\hline \hline Número de ligações de hidrogênio & $\mathrm{CH}_{3} \mathrm{HO} \cdots \mathrm{H}_{2} \mathrm{O}$ & $\mathrm{CH}_{3} \mathrm{OH} \cdots \mathrm{OH}_{2}$ \\
\hline 0 & $7(3.5 \%)$ & $40(20.0 \%)$ \\
1 & $103(51.5 \%)$ & $160(80.0 \%)$ \\
2 & $86(43.0 \%)$ & - \\
3 & $4(2.0 \%)$ & - \\
Média & 1.43 & 0.80 \\
\hline \hline
\end{tabular}

Tabela 9.1: Estatística das ligaçöes de hidrogênio formadas entre metanol e água

Devido à grande diversidade de estruturas da mistura de metanol-água [170] uma explanação é necessária. A situação física considerada aqui é metanol 


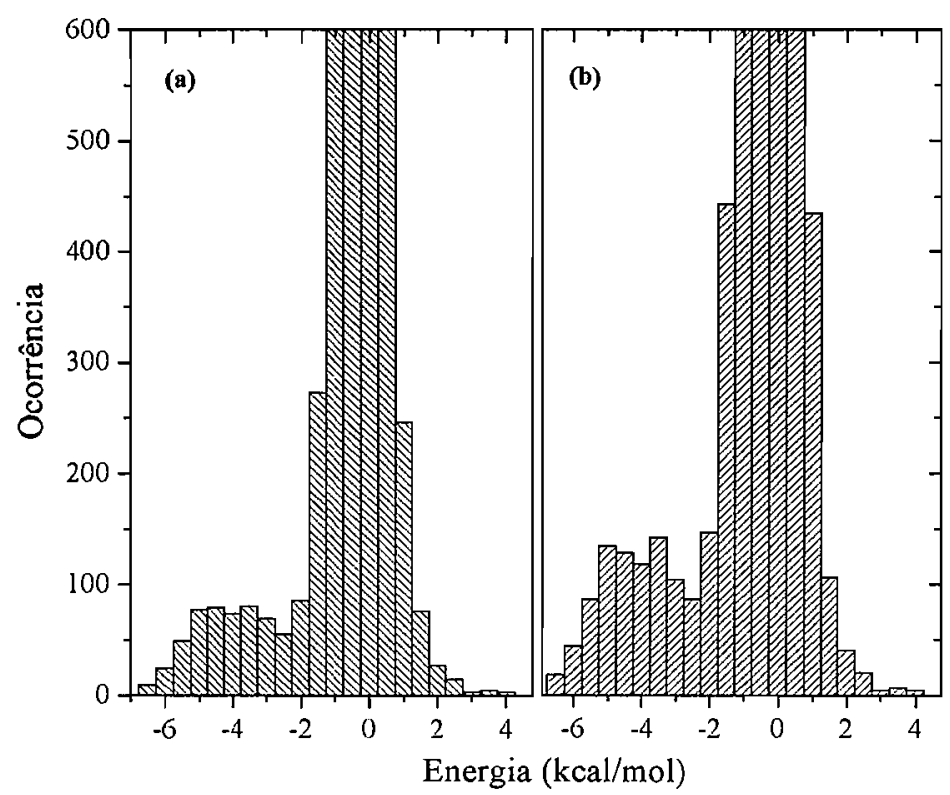

Figura 9.2: Histograma das energias de interação de pares entre metanol e água. (a) se refere ao isômero $\mathrm{CH}_{3} \mathrm{OH} \cdots \mathrm{OH}_{2}$ e (b) ao isômero $\mathrm{CH}_{3} \mathrm{HO} \cdots \mathrm{H}_{2} \mathrm{O}$

extremamente diluído em água. Assim, somente uma molécula de metanol foi considerada. Em uma mistura líquida com proporções adequadas existirão também configurações onde duas moléculas de metanol atuam como doadoras de próton para uma única molécula de água. Isto contudo não foi representado aqui e portanto tem-se uma descrição mais simplificada e uma comparação mais direta com o resultado de fase gasosa (1:1). Assim somente as 103 configurações fazendo uma ligação de hidrogênio no isômero $\mathrm{CH}_{3} \mathrm{HO} \cdots \mathrm{H}_{2} \mathrm{O}$ e as 160 configurações no isômero $\mathrm{CH}_{3} \mathrm{OH} \cdots \mathrm{OH}_{2}$ foram consideradas. Todas estas configurações (1:1) compostas de uma molécula de metanol e uma molécula de água foram submetidas a cálculos de mecânica quântica, porém a convergência estatística foi alcançada antes do uso de todas estas configurações. A Figura 9.3 mostra, em uma única representação a superposição de todas estruturas (1:1) no líquido para ambos os isômeros. Ela mostra claramente a eficiência da identificação das ligações de hidrogênio bem como do procedimento de seleção de tais ligações formadas entre metanol e água. De fato, pode ser visto como o espaço de configuração é preenchido e como as moléculas de água se ligam à molécula de metanol. A distância entre os átomos de oxigênio das duas moléculas, $\mathrm{O}-\mathrm{O}$, na ligação de hidrogênio, calculada no complexo foi $2.844 \AA$, 


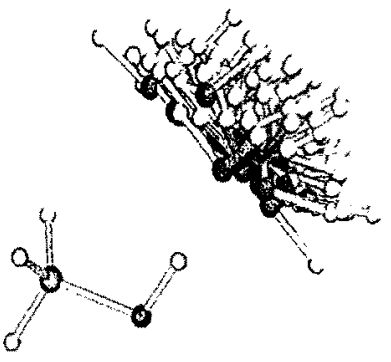

(a)

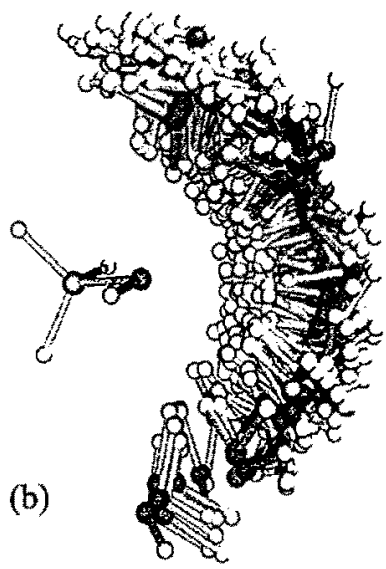

Figura 9.3: Superposição das configuraçōes das ligações de hidrogênio formadas pelo metanol em solução aquosa

para o isômero $\mathrm{CH}_{3} \mathrm{HO} \cdots \mathrm{H}_{2} \mathrm{O}$ e $2.912 \AA$ para o isômero $\mathrm{CH}_{3} \mathrm{OH} \cdots \mathrm{OH}_{2}$. Por comparação, no caso líquido (1:1), as médias destas distâncias foram calculadas como $2.84 \pm 0.16 \AA$ e $2.84 \pm 0.15 \AA$, respectivamente,

\subsubsection{Interação (1:1) em fase gasosa}

O sistema metanol-água isolado foi considerado como correspondente à fase gasosa. Uma otimização completa foi realizada para ambos os isômeros usando o modelo MP2/aug-cc-pVDZ. A distância $\mathrm{O}-\mathrm{O}$ para o isômero $\mathrm{CH}_{3} \mathrm{HO} \cdots \mathrm{H}_{2} \mathrm{O}$ foi encontrada ser de $2.844 \AA$ enquanto que no caso do isômero $\mathrm{CH}_{3} \mathrm{OH} \cdots \mathrm{OH}_{2}$ esta distância foi de $2.912 \AA ̊$ Ėstas distâncias estão em bom acordo com os resultados prévios de $2.851 \AA$ e $2.901 \AA$ [160]. A Tabela 9.2 mostra os resultados calculados para a energia de ligação de ambos os isômeros após levar em conta a correção para BSSE. Para analisar a importância dos efeitos da correlação eletrônica em maiores detalhes, níveis de cálculo até coupled-cluster $\operatorname{CCSD}(\mathrm{T})$ foram empregados na determinação das energias das estruturas otimizadas com o modelo MP2/aug-cc-pVDZ. Em nível MP2, o isômero $\mathrm{CH}_{3} \mathrm{HO} \cdots \mathrm{H}_{2} \mathrm{O}$ é mais estável por $0.7 \mathrm{kcal} / \mathrm{mol}$. Este está em bom acordo com cálculos DFT prévios de González et al [160] que obtiveram o mesmo valor para a estabilidade relativa deste isômero. Com todos resultados teóricos mostrados na Tabela 9.2 verifica-se que o isômero $\mathrm{CH}_{3} \mathrm{HO} \cdots \mathrm{H}_{2} \mathrm{O}$ é mais estável mas a estabilidade relativa é menor que $1 \mathrm{kcal} / \mathrm{mol}$. De fato no nível mais alto usado 


\begin{tabular}{|c|c|c|c|}
\hline Método & $\mathrm{CH}_{3} \mathrm{HO} \cdots \mathrm{H}_{2} \mathrm{O}$ & $\mathrm{CH}_{3} \mathrm{OH} \cdots \mathrm{OH}_{2}$ & $\begin{array}{c}\text { Estabilidade } \\
\text { Relativa }\end{array}$ \\
\hline MP2 & 5.2 & 4.5 & 0.7 \\
\hline MP3 & 4.9 & 4.4 & 0.5 \\
\hline D-MP4 & 4.8 & 4.3 & 0.5 \\
\hline DQ-MP4 & 4.7 & 4.2 & 0.5 \\
\hline SDQ-MP4 & 4.8 & 4.2 & 0.6 \\
\hline MP4 & 5.0 & 4.4 & 0.6 \\
\hline CCSD & 4.7 & 4.2 & 0.5 \\
\hline $\operatorname{CCSD}(\mathrm{T})$ & 5.0 & 4.5 & 0.5 \\
\hline B3LYP & 5.9 & 5.2 & 0.7 \\
\hline $\mathrm{ZPE}$ & 1.9 & 1.6 & - \\
\hline
\end{tabular}

Tabela 9.2: Energias de ligação ( $\mathrm{kcal} / \mathrm{mol}$ ) dos dois isômeros de metanol-água calculada em fase gasosa. Todos os cálculos apresentados foram realizados com a base aug-cc-pVDZ usando a geometria otimizada com MP2/aug-cc-pVDZ. B3LYP se refere a cálculos DFT de González et. al. [160] usando uma geometria otimizada com B3LYP/6-311+G(d,p) . ZPE se refere à diferença da energia de ponto zero entre o complexo e as partes separadas usando MP2/aug-cc-pVDZ

aqui, $\operatorname{CCSD}(\mathrm{T}) /$ aug-cc-pVDZ//MP2/aug-cc-pVDZ, foi obtida uma estabilidade relativa de $0.5 \mathrm{kcal} / \mathrm{mol}$. Este acordo entre $\mathrm{MP} 2$ e $\operatorname{CCSD}(\mathrm{T})$ corrobora que MP2/aug-cc-pVDZ é um bom modelo teórico para se obter a interação da ligação de hidrogênio. Levando-se em conta a correção de energia de ponto zero, que é importante para os resultados de fase gasosa, a estabilidade relativa diminui para $0.5 \mathrm{kcal} / \mathrm{mol}(\mathrm{MP} 2)$ e $0.2 \mathrm{kcal} / \mathrm{mol}(\mathrm{CCSD}(\mathrm{T}))$. É claro a partir destes resultados que cálculos $a b$ initio em altas ordens sistematicamente predizem a existência de ambos isômeros com o isômero $\mathrm{CH}_{3} \mathrm{HO} \cdots \mathrm{H}_{2} \mathrm{O}$ sendo mais estável. A estabilidade relativa foi, contudo, muito pequena, menor que $1 \mathrm{kcal} / \mathrm{mol}$ e com o melhor resultado indicando uma estabilidade relativa do isômero $\mathrm{CH}_{3} \mathrm{HO} \cdots \mathrm{H}_{2} \mathrm{O}$ por somente $0.5 \mathrm{kcal} / \mathrm{mol}$.

\subsubsection{Interação (1:1) em fase líquida}

Os resultados obtidos usando as estruturas geradas pela simulação MCM em temperatura ambiente são discutidos a seguir. As energias médias obtidas usando as estruturas (1:1) da simulação MCM, selecionadas de acordo com a correlação estatística, como discutido na seção 2.1.5, são mostradas na Tabela 9.3. Estes resultados incluem correção counterpoise para o erro de superposição 


\begin{tabular}{ccccc}
\hline & \multicolumn{2}{c}{$\mathrm{CH}_{3} \mathrm{HO} \cdots \mathrm{H}_{2} \mathrm{O}$} & \multicolumn{2}{c}{$\mathrm{CH}_{3} \mathrm{OH} \cdots \mathrm{OH}_{2}$} \\
& liquido & gás & liquido & gás \\
\hline$\Delta \mathrm{E}$ & $3.05 \pm 1.09$ & 5.15 & $3.04 \pm 0.64$ & 4.48 \\
$\mu$ & $3.68 \pm 0.34$ & 2.04 & $3.42 \pm 0.29$ & 2.73 \\
$\alpha$ & $31.45 \pm 0.09$ & 31.19 & $31.27 \pm 0.18$ & 30.67 \\
$\Delta \alpha$ & $5.72 \pm 0.74$ & 5.90 & $5.69 \pm 1.1$ & 5.25 \\
$\sigma_{N}\left(10^{-3}\right)$ & $4.5 \pm 1.1$ & 4.7 & $4.5 \pm 1.8$ & 4.0 \\
$\sigma_{P}\left(10^{-3}\right)$ & $2.2 \pm 0.6$ & 2.4 & $2.3 \pm 0.9$ & 2.0 \\
$\sigma_{C}\left(10^{-3}\right)$ & $4.5 \pm 1.1$ & 4.7 & $4.6 \pm 1.8$ & 4.0 \\
\hline \hline
\end{tabular}

Tabela 9.3: Valores médios da energia de ligação (kcal/mol) em fase líquida dos dois isômeros de metanol-água obtidos com MP2/aug-cc-pVDZ incluindo correção para BSSE. Os momentos de dipolo estão em Debye e as polarizabilidades (média e anisotrópica) estão em ua. Despolarizações Rayleigh ( $\sigma$ para polarização natural, planar e circular) são adimensionais. Os desvios padrão também são mostrados

de base. Os resultados mostram que as energias de ligação são iguais dentro de $0.01 \mathrm{kcal} / \mathrm{mol}$ que é muito menor que o desvio padrão dos cálculos. O isômero $\mathrm{CH}_{3} \mathrm{HO} \cdots \mathrm{H}_{2} \mathrm{O}$ apresentou energia de ligação média de $3.05 \pm 1.09 \mathrm{kcal} / \mathrm{mol}$ comparada com $3.04 \pm 0.64 \mathrm{kcal} / \mathrm{mol}$ para o isômero $\mathrm{CH}_{3} \mathrm{OH} \cdots \mathrm{OH}_{2}$. É claro que para a situação no líquido a temperatura ambiente estes resultados são similares e favorecem a conclusão de que os dois isômeros são, do ponto de vista energético, igualmente prováveis. O maior desvio padrão obtido para o isômero $\mathrm{CH}_{3} \mathrm{HO} \cdots \mathrm{H}_{2} \mathrm{O}$ é uma conseqüência da maior desordem estrutural como pode ser visto na Figura 9.3. As duas distribuições dos valores calculados säo mostradas na Figura 9.4 enquanto que a Figura 9.5 mostra a energia de ligação média para as estruturas $(1: 1)$ do caso líquido. Os resultados são claramente convergidos demonstrando a eficiência do procedimento amostral e a credibilidade dos resultados apresentados aqui. Outro aspecto importante de se observar é a diminuição da energia de ligação no caso do líquido. Como um resultado da flutuação térmica e da seleção de possíveis configurações no líquido pode-se notar que a energia de ligação foi reduzida para 60-70\% do valor correspondente para a configuração de energia mínima da fase gasosa. A Tabela 9.3 também apresenta os momentos de dipolo calculados. Observa-se que a média do momento de dipolo para o caso (1:1) no líquido foi consideravelmente maior que no caso (1:1) para o complexo otimizado. Por completeza, a Tabela 9.3 também mostra as polarizabilidades médias e anisotrópicas das estruturas 


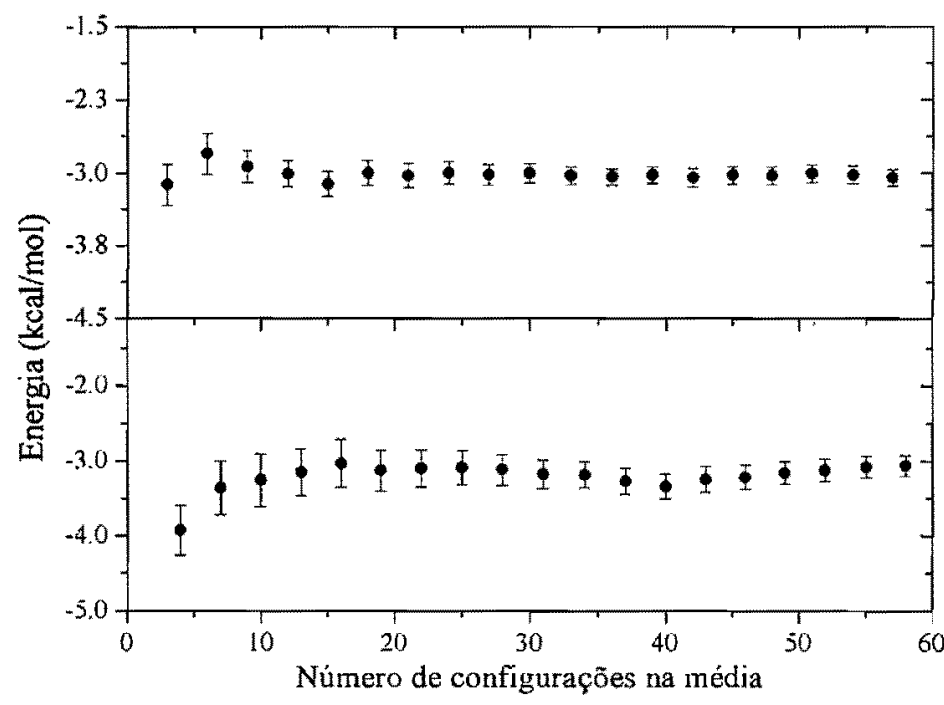

Figura 9.4: Convergência das energias de ligação para o complexo metanol-água. (a) se refere ao isômero $\mathrm{CH}_{3} \mathrm{OH} \cdots \mathrm{OH}_{2}$ e (b) ao isômero $\mathrm{CH}_{3} \mathrm{HO} \cdots \mathrm{H}_{2} \mathrm{O}$. Os erros estatísticos são mostrados

(1:1) do líquido comparadas a suas correspondentes da fase gasosa. Nenhuma mudança significativa foi observada quando se compara a fase gasosa com a fase líquida para estas propriedades. A inomogeneidade na distribuição eletrônica leva à despolarização da luz elasticamente espalhada e esta despolarização Rayleigh é obtida a partir das polarizabilidades de dipolo (1:1). Após a formação da ligação de hidrogênio em meio aquoso a taxa de despolarização torna-se uma distribuição com o valor médio sendo apenas levemente diminuído com respeito ao valor obtido para o complexo otimizado. As taxas de despolarização foram essencialmente as mesmas para ambos isômeros.

\subsection{Conclusões}

Neste estudo foi considerada a situação do metanol em condições de extrema diluição: uma molécula de metanol envolvida por um volume de água. Esta condição simplificada não considerou a existência de formação mais diversificada de complexos e torna mais fácil a comparação com o resultado para a fase gasosa (1:1). A partir das estruturas do líquido geradas por simulaçōes MCM realísticas, a energia de interação média entre metanol e água foi determinada 


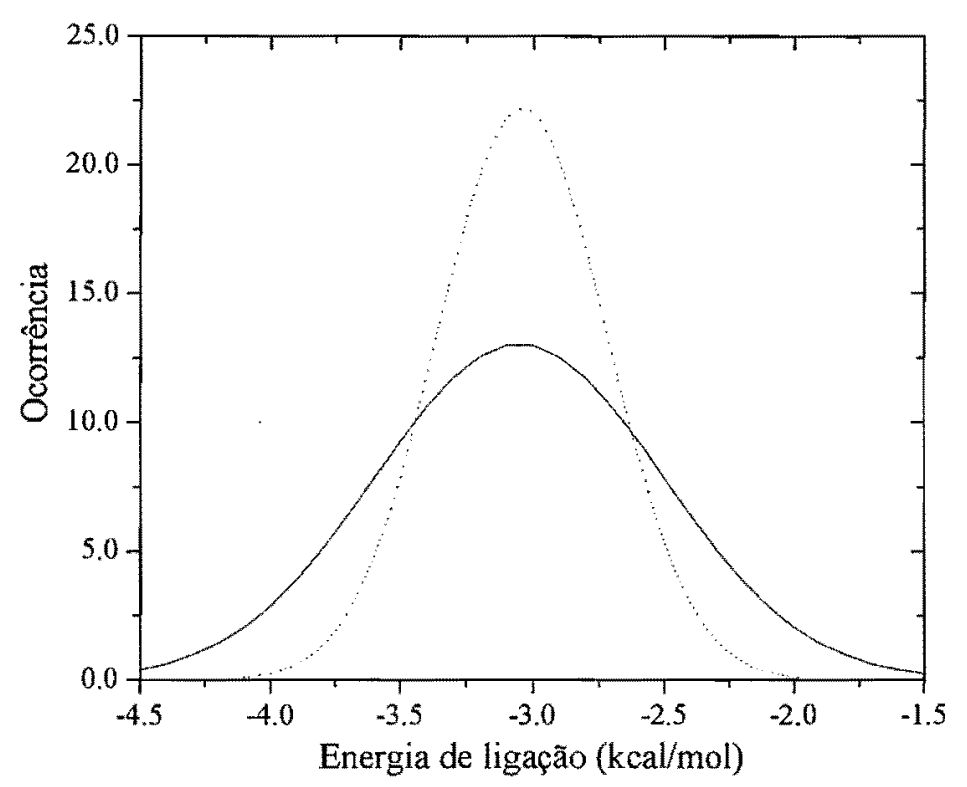

Figura 9.5: Histograma mostrando a distribuição das energias de ligaçäo entre metanol e água. A linha cheia se refere ao isômero $\mathrm{CH}_{3} \mathrm{HO} \cdots \mathrm{H}_{2} \mathrm{O}$ e a linha pontilhada ao isômero $\mathrm{CH}_{3} \mathrm{OH} \cdots \mathrm{OH}_{2}$

usando cálculos de primeiros princípios no nível teórico MP2/aug-cc-pVDZ com correção para o erro de superposição de base. Foi verificado que energias de ligação (1:1) em fase líquida, convergidas estatisticamente, diminui para cerca de $2 / 3$ comparada à energia das estruturas otimizadas e que em meio líquido os dois isômeros têm a mesma energia de ligação média. 


\section{Capítulo 10}

\section{Polarizabilidade de dipolo do benzeno líquido}

\subsection{Motivação}

Polarizabilidades de dipolo são muito importantes para a compreensão da polarização de um meio eletrônico $[260,261]$ e naturalmente se relacionam a várias propriedades moleculares, incluindo contribuição de dispersão da interação de van der Waals [262] (veja Apêndice A). Desta forma o estudo sobre a polarizabilidade de um sistema líquido é muito importante. Este capítulo é dedicado ao estudo da polarizabilidade de dipolo do líquido de benzeno. A escolha do benzeno é natural uma vez que todos seus momentos permanentes de ordem ímpar se anulam por simetria. O momento de dipolo e a primeira hiperpolarizabilidade, por exemplo, são zero. Assim a contribuição mais importante para a polarização é a polarizabilidade de dipolo. De interesse particular é a comparação entre as médias da polarizabilidade de dipolo do líquido e da fase gasosa. Enquanto a maioria das teorias de meios contínuos têm obtido que a polarizabilidade de dipolo aumenta na fase líquida, recentemente estudos teóricos têm desafiado esta idéia, ou afirmado que nenhuma mudança apreciável deve ser observada no líquido ou que a polarizabilidade de dipolo pode até mesmo sofrer uma diminuição [248, 249,263]. Como visto a descrição apropriada do estado líquido requer um procedimento estatístico e a garantia de que as propriedades estejam convergidas é necessária para a credibilidade dos resultados teóricos. Para isto foi empregada a metodologia seqüencial tal como discutida na seção 
2.1.6. Aqui a polarizabilidade de dipolo do líquido de benzeno é obtida usando teoria do funcional da densidade (DFT) e o modelo semi-empírico INDO [264]. Contudo, a precisão absoluta não é o ponto de maior interesse aqui. Ao invés disso, o mais importante é a comparação da polarizabilidade de dipolo em fase líquida com seu valor para fase gasosa. Resultados teóricos recentes apontaram uma leve diminuição da polarizabilidade na fase líquida $[248,249,265]$.

\subsection{Detalhes de cálculo}

\subsubsection{Simulação}

O líquido de benzeno foi gerado por simulações MCM através do programa Dice [224]. A simulação foi realizada no ensemble NVT. O sistema total consistiu de 343 moléculas de benzeno à temperatura ambiente (298K) e densidade de $0.8990 \mathrm{~g} / \mathrm{cm}^{3}$. As interações intermoleculares foram descritas pelo potencial de Lennard-Jones. Os parâmetros de seis sítios OPLS [266] e geometria experimental foram usados para o potencial. Estes valores são mostrados na Tabela 10.1. A simulação consistiu de um estágio de termalização de $1.7 \times 10^{6}$ passos

\begin{tabular}{cccccc}
\hline \hline Sítio & $x$ & $y$ & $z$ & $\varepsilon(\mathrm{kcal} / \mathrm{mol})$ & $\sigma(\AA)$ \\
\hline $\mathrm{C}$ & 0.0000 & 1.4000 & 0.0000 & 0.110 & 3.750 \\
$\mathrm{C}$ & 1.2124 & 0.7000 & 0.0000 & 0.110 & 3.750 \\
$\mathrm{C}$ & 1.2124 & -0.7000 & 0.0000 & 0.110 & 3.750 \\
$\mathrm{C}$ & 0.0000 & -1.4000 & 0.0000 & 0.110 & 3.750 \\
$\mathrm{C}$ & -1.2124 & -0.7000 & 0.0000 & 0.110 & 3.750 \\
$\mathrm{C}$ & -1.2124 & 0.7000 & 0.0000 & 0.110 & 3.750 \\
$\mathrm{H}$ & 0.0000 & 2.4881 & 0.0000 & 0.000 & 0.000 \\
$\mathrm{H}$ & 2.1547 & 1.2440 & 0.0000 & 0.000 & 0.000 \\
$\mathrm{H}$ & 2.1547 & -1.2440 & 0.0000 & 0.000 & 0.000 \\
$\mathrm{H}$ & 0.0000 & -2.4881 & 0.0000 & 0.000 & 0.000 \\
$\mathrm{H}$ & -2.1547 & -1.2440 & 0.0000 & 0.000 & 0.000 \\
$\mathrm{H}$ & -2.1547 & 1.2440 & 0.0000 & 0.000 & 0.000 \\
\hline \hline
\end{tabular}

Tabela 10.1: Geometria (em $\AA$ ) e parâmetros do potencial do benzeno.

MCM, seguido por um estágio de equilíbrio de $17.15 \times 10^{6}$ passos MCM. A metodologia seqüencial foi novamente empregada devido à grande vantagem de que toda a informação estatística importante é disponível antes de processar os cálculos quânticos $[34,35,43]$. Além disso tal metodologia reduz conside- 
ravelmente o número de estruturas supermoleculares que são submetidas aos cálculos de mecânica quântica, uma vez que as estruturas foram selecionadas de acordo com a sua correlação estatística, obtida a partir da função de autocorrelação estatística da energia $[14,18,34,35]$. Usando um passo de correlação de $2.7 \times 10^{5} \mathrm{MCM}$, um total de 62 configurações com menos de $5 \%$ de correlação estatística foi selecionado. Estas 62 configuraçōes foram submetidas a cálculos de mecânica quântica. As camadas de solvatação foram definidas a partir da análise da função de distribuição radial. A primeira camada de solvatação contém 14 moléculas de benzeno. A segunda camada um total de 63 moléculas de benzeno. Este sistema, naturalmente é muito grande para a maioria das metodologias $a b$ initio de forma que certos limites não puderam ser ultrapassados.

\subsubsection{Cálculos de mecânica quântica}

Os cálculos semi-empíricos INDO foram realizados usando o programa de Zerner na parametrização original [264,267]. Já foi mostrado que o modelo INDO fornece resultados razoavelmente bons para hiperpolarizabilidades dentro da metodologia de soma-sobre-estados [268]. Contudo para a polarizabilidade de dipolo de estados fundamentais todos os termos da soma são positivos e leva a uma convergência lenta. Os cálculos quânticos das polarizabilidades de dipolo foram então realizados na aproximação de campo finito $[74,79,269]$ no nível INDO. Cinco campos elétricos foram aplicados em cada uma das três orientações Cartesianas. As intensidades dos campos foram $\pm 0.002, \pm 0: 001 \mathrm{e}$ 0.0 ua. As polarizabilidades de dipolo reportadas são o resultado de uma média simples sobre os resultados dos cálculos INDO para as 62 configurações estatisticamente descorrelacionadas. Cinco campos elétricos foram usados para os sistemas supermoleculares pequenos (14 moléculas) e grandes (28 moléculas) nas três componentes Cartesianas. Um total de 1612 cálculos quânticos foram realizados. Para verificar a maioria das afirmações deste estudo também foi empregada a teoria funcional da densidade com o funcional B3LYP [111,112] associado com o conjunto de funções 6-31G. Para o aglomerado menor (14 moléculas) isto levou a um total de 924 funçōes contraídas do tipo gaussianas. 
É importante enfatizar que os cálculos para as estruturas supermoleculares geradas no líquido foram feitos usando a antissimetrização do sistema inteiro. Por exemplo, no caso do aglomerado menor isto corresponde a um total de 420 elétrons de valência no modelo INDO e 596 elétrons no caso B3LYP/6-31G. Os cálculos DFT foram realizados no programa Gaussian [117].

\subsection{Resultados e discussão}

A Figura 10.1 mostra a função distribuição radial de centro de massa do benzeno. Uma clara primeira camada de solvatação terminando em $7.5 \AA$ pode ser vista. A segunda camada termina em $12.9 \AA$. A integração esférica até es-

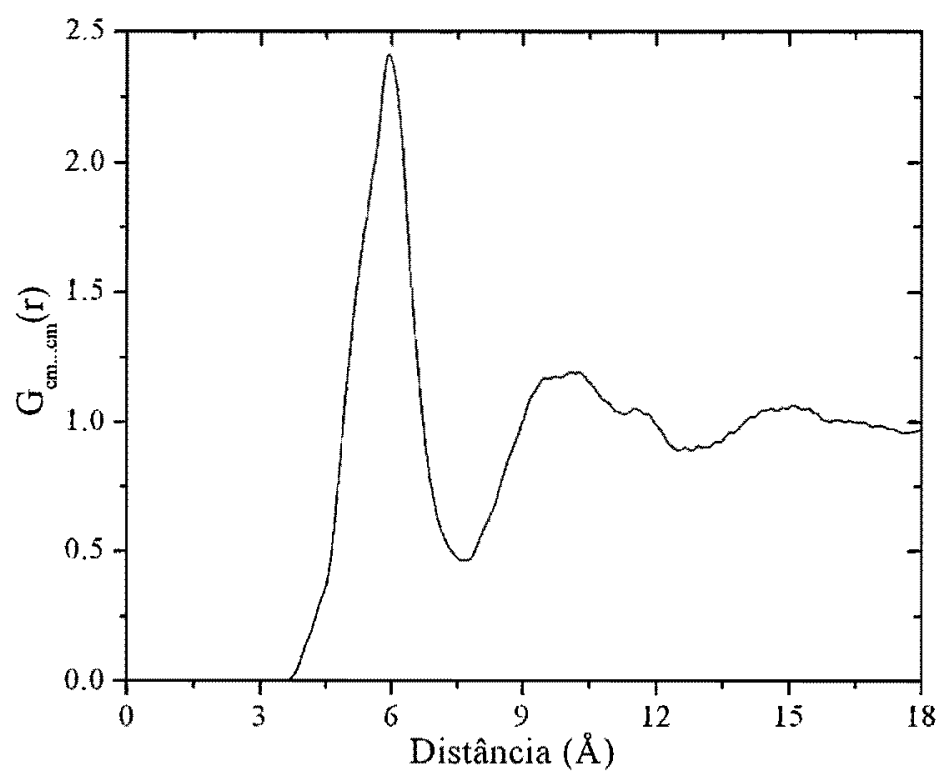

Figura 10.1: Função de distribuição radial de pares entre os centros de massa das moléculas de benzeno

tas distâncias corresponde a 14 e 63 moléculas de benzeno respectivamente. Entre estes dois mínimos existe um máximo em $10.0 \AA$ e a integração esférica até este ponto corresponde a 28 moléculas de benzeno. Até mesmo em nível semi-empírico INDO um cálculo na aproximação de campo finito para a 63 moléculas de benzeno é inviável. Assim os cálculos aqui foram limitados à primeira camada de solvatação (14 moléculas) e à camada intermediária entre a primeira e segunda camadas (28 moléculas). A Figura 10.2 ilustra uma das 
62 estruturas supermoleculares compostas de 14 e 28 moléculas de benzeno usadas nos cálculos quânticos. Uma vez definido o tamanho das estruturas

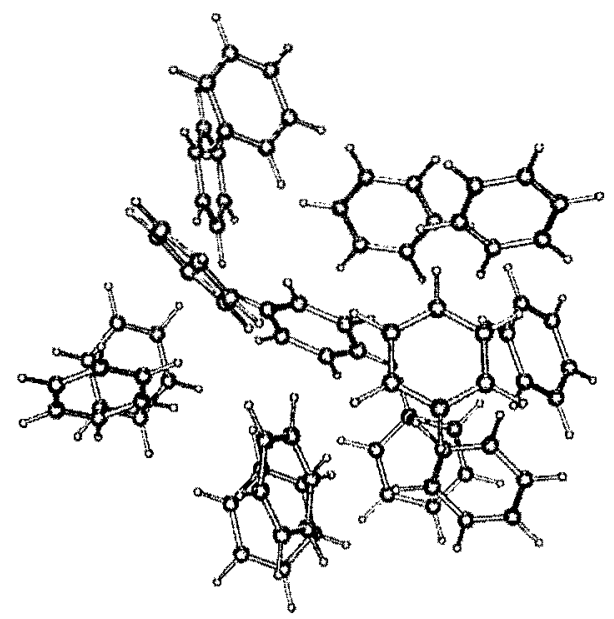

14 moléculas

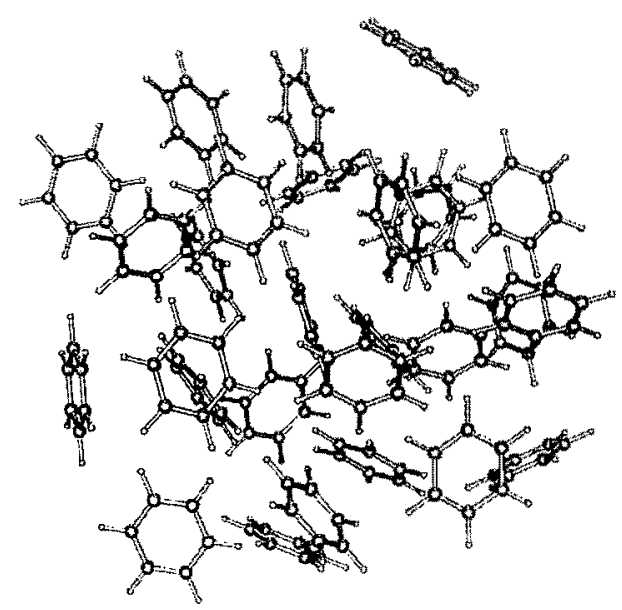

28 moléculas

Figura 10.2: Ilustração das duas configuraçōes supermoleculares, em cima com 14 moléculas e em baixo com 28 moléculas

supermoleculares é importante estabelecer o número de cálculos necessários para obter a convergência estatística. A Figura 10.3 mostra a função de autocorrelação da energia calculada para o líquido de benzeno, através da qual foi obtido um passo de correlação normalizado de $\sim 40$. O passo normalizado 


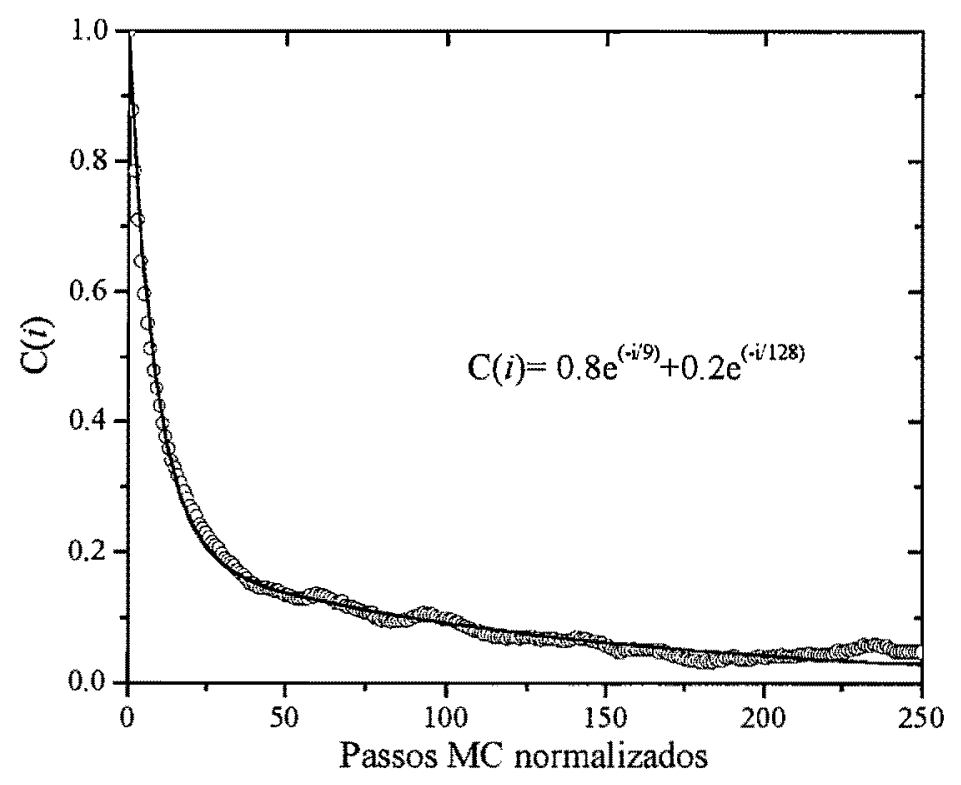

Figura 10.3: Função de autocorrelação da energia. O passo MCM é normalizado ao número total de moléculas

corresponde aqui a 343 (número de moléculas de benzeno) passos MCM. Nos cálculos das médias foram selecionadas estruturas com um intervalo de 800 passos normalizados correspondendo a $2.744 \times 10^{5}$ passos $\mathrm{MCM}$. Como o número total de configurações geradas foi $17.150 \times 10^{6}$ (ou 50000 passos normalizados), as médias foram tomadas sobre 62 configurações, com correlação menor que $5 \%$. Estas 62 configurações foram submetidas a cálculos quânticos. Estes cálculos foram realizados nos níveis INDO e B3LYP/6-31G usando o modelo de campo finito. A função de onda foi antissimétrica sobre o sistema como um todo e o campo finito foi aplicado sobre todas as moléculas do sistema supermolecular. A polarização de dipolo foi calculada de forma que a polarizabilidade de dipolo foi obtida como o termo linear da polarização através de interpolação numérica. A partir da polarizabilidade do sistema inteiro com $N$ moléculas o resultado para a polarizabilidade por molécula foi obtido dividindo o resultado por $N$, fornecendo a polarizabilidade por molécula. Um importante ponto é que não foram realizados cálculos separados para o solvente; os resultados para as supermoléculas foram comparados com os cálculos para a molécula de benzeno isolada. Assim, a diferença entre estes dois resultados é a influência da condensação. O uso de uma função de onda antissimétrica é importante para 
incluir a interação de troca entre as diferentes moléculas de benzeno no líquido e também para obter as interações intermoleculares. É sabido que para a inclusão da contribuição de dispersão na interação de van der Waals necessita-se dos efeitos de correlação que por sua vez são excluídos nos cálculos INDO. Como o método DFT é correlacionado, é idealmente esperado que ele inclua a parte de correlação do efeito de dispersão. Isto contudo não é garantido e a inclusão explícita e apropriada da contribuição de van der Waals é um tópico central nas metodologias teóricas DFT. Vale enfatizar que o uso da aproximação supermolecular com uma função de onda antissimétrica adequada pode incluir interação de dispersão em níveis mais baixos [270]. De fato, para a molécula de benzeno o deslocamento solvatocrômico devido a condensação, que é devido à interação de dispersão, é bem descrito usando a metodologia teórica INDO empregada aqui $[18,35]$. Nos cálculos INDO ambas as supermoléculas com 14 e com 28 moléculas de benzeno foram utilizadas. A Figura 10.4 mostra a convergência do momento de dipolo calculado das 14 moléculas de benzeno no campo externo finito de 0.002 ua na direção $x$. Como pode ser visto o momento

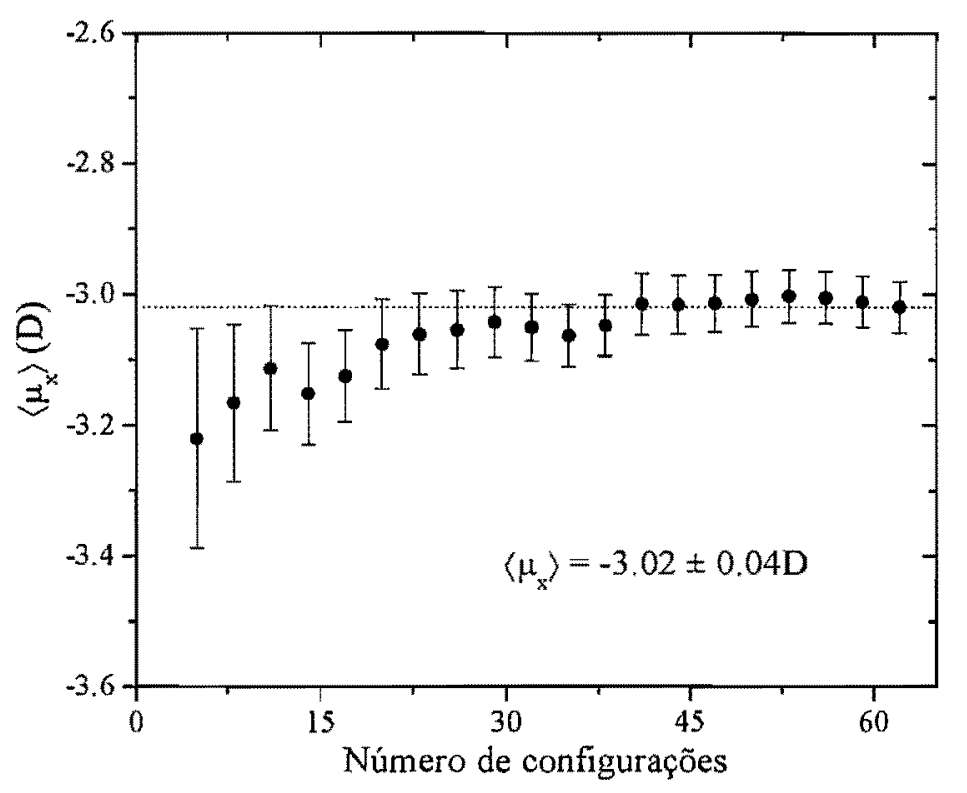

Figura 10.4: Convergência estatística da polarização de dipolo. As barras representam o erro estatístico. $O$ exemplo corresponde ao campo finito de intensidade 0.002 ua aplicado na menor supermolécula ao longo da direção $x$

de dipolo calculado é estatisticamente convergido após 40 cálculos quânticos. 
O mesmo procedimento foi repetido para todos os outros campos elétricos, para as direções $y$ e $z$ e também para a configuração supermolecular com 28 moléculas de benzeno. A convergência estatística foi alcançada em todos os casos. Usando estes resultados para campos finitos, as componentes da polarizabilidade de dipolo foram obtidas como mostrado na Figura 10.5 usando intepolação numérica através da expressão A.8 do apêndice A. Aqui são re-

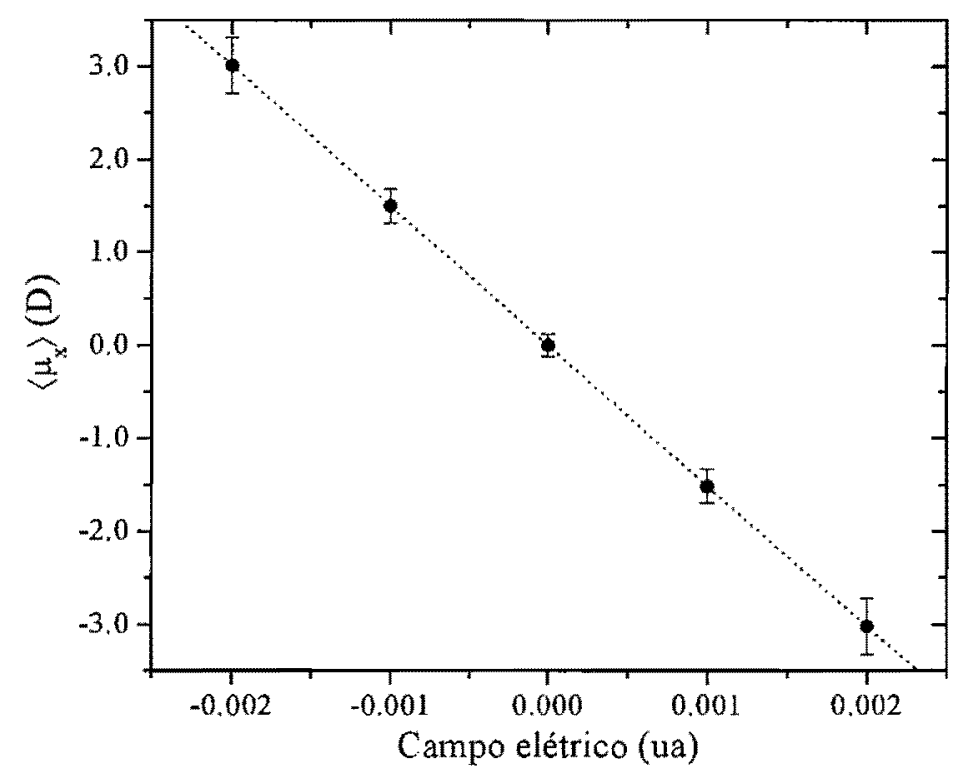

Figura 10.5: Momento de dipolo induzido como função do campo elétrico aplicado. Cada ponto mostrado é o resultado convergido de uma média estatística de 62 cálculos de mecânica quântica (veja Figura 10.4)

portados ambos os invariantes da polarizabilidade de dipolo, a polarizabilidade média, $\bar{\alpha}$, e a polarizabilidade anisotrópica, $\Delta \alpha$. Os valores destas propriedades para a fase líquida são as médias estatísticas, $\langle\bar{\alpha}\rangle$ e $\langle\overline{\Delta \alpha}\rangle$ obtidas usando as polarizabilidades de dipolo calculadas das supermoléculas a partir da simulação MCM. Os resultados numéricos são finalmente resumidos na Tabela 10.2. Como esperado a polarizabilidade de dipolo calculada em nível semi-empírico INDO não é competitiva com outros resultados numéricos. Parkinson e Zerner consideraram a possibilidade de estender estes cálculos para a aproximação de fase aleatória (RPA) [271]. O resultado teórico para a fase gasosa é 43.0ua, que é equivalente ao resultado RPA mas ainda é muito pequeno comparado ao resultado experimental de 69.7ua [118]. Provavelmente a ausência de mais funções 


\begin{tabular}{ccc}
\hline \hline Modelo & $\Delta \alpha$ & $\langle\bar{\alpha}\rangle$ \\
\hline INDO & & \\
14 moléculas & 2.1 & 42.7 \\
28 moléculas & 0.9 & 43.7 \\
& & \\
B3LYP/6-31G & & \\
14 moléculas & 12.5 & 55.6 \\
Ref. [249] & 36.5 & 63.7 \\
\hline \hline
\end{tabular}

Tabela 10.2: Polarizabilidade de dipolo calculada para o líquido de benzeno (em ua) usando a aproximação de campo finito com os métodos INDO e DFT. $\langle\bar{\alpha}\rangle$ é a média estatística da polarizabilidade de dipolo média e $\Delta \alpha$ é a a média estatística da polarizabilidade anisotrópica. $O$ valor de $\bar{\alpha}$ calculado para a fase gasosa é $43.0 u a$ (INDO) e 53,4 ua (DFT)

difusas foi responsável por esta diminuição no valor. Em fase condensada esta falta foi menos importante. Contudo, em comparação com o resultado para fase condensada pode-se notar que a polarizabilidade de dipolo tende a assumir, essencialmente, o mesmo valor. É importante notar dois aspectos. Primeiro, a ênfase neste presente estudo está na representação realística do líquido. Desta forma é importante também notar que a polarizabilidade de dipolo obtida aqui para o líquido de benzeno é aproximadamente isotrópica. Para o sistema supermolecular maior a componente anisotrópica é somente $0.9 \mathrm{ua}$. Isto indica que uma razoável representação da polarizabilidade do volume foi obtida aqui. Segundo, a polarizabilidade é representada por uma distribuição estatística. A Figura 10.6 ilustra a distribuição do momento de dipolo induzido na direção $x$ para o campo de 0.002 ua. Portanto o valor médio é uma distribuição de valores do momento de dipolo induzido, neste caso $\left\langle\mu_{x}\right\rangle=-3.08 \mathrm{D}$.

Os cálculos B3LYP/6-31G para a fase condensada foram realizados somente para a menor supermolécula ( 14 moléculas de benzeno). Os resultados para a polarizabilidade de dipolo média são mostrados na Figura 10.7 e tendem a convergir para a média de $55.6 \pm 0.5$ ua. Por comparação o resultado de fase gasosa obtido para a molécula de benzeno isolada foi 53.4 ua. É bem conhecido que funções difusas são fundamentais nos cálculos de polarizabilidades de dipolo. Neste trabalho, contudo, foi possível usar apenas bases relativamente pequenas, sem uma descrição apropriada da parte difusa do conjunto de funções base. $\mathrm{Na}$ verdade, neste estudo o conjunto de funções base para a 


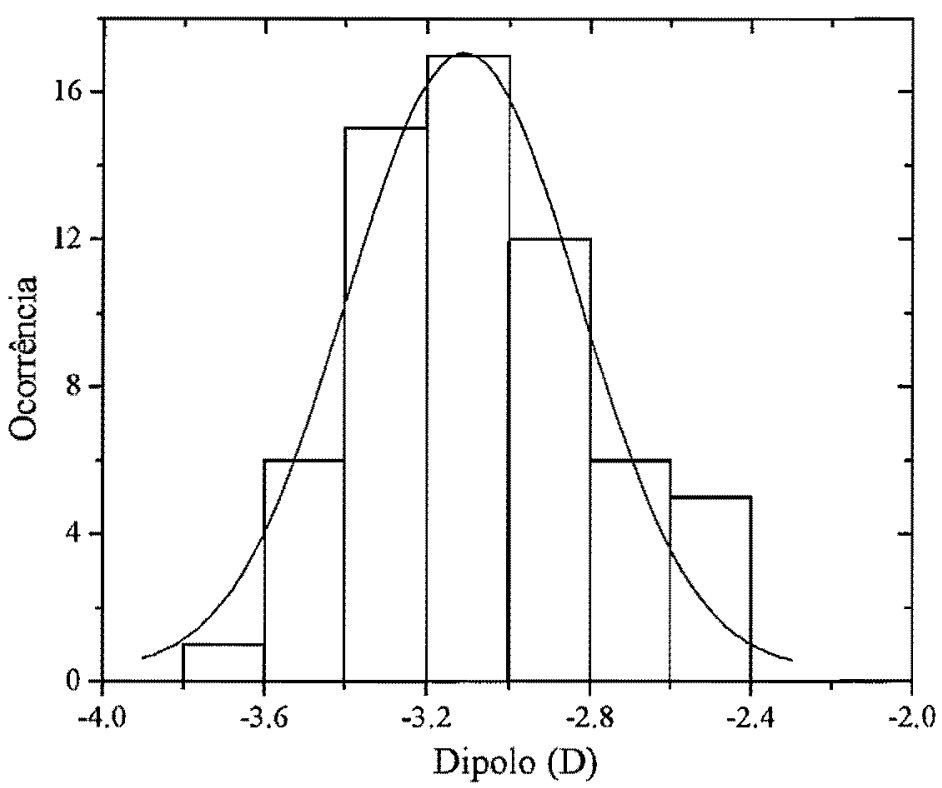

Figura 10.6: Distribuição estatística do momento de dipolo calculado com o campo de intensidade 0.002 ua ao longo da direção $x$

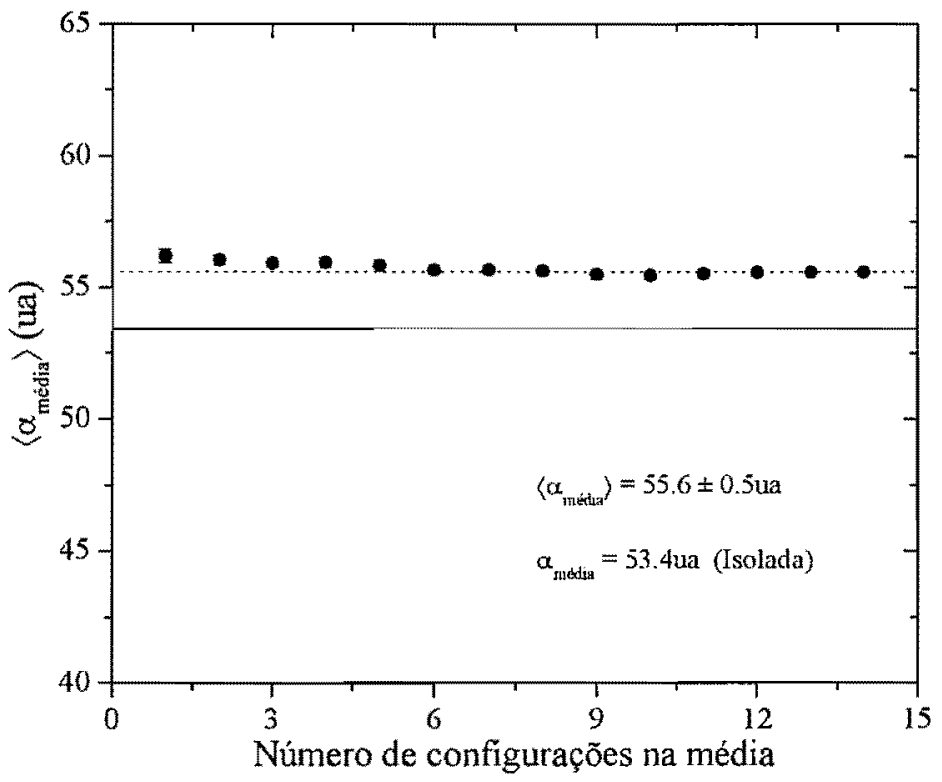

Figura 10.7: Resultados calculados para a polarizabilidade de dipolo média por molécula de benzeno para a menor supermolécula usando o modelo B3LYP/6-31G 
menor supermolécula incluiu aproximadamente mil funções base e não poderia mais ser extendido. Note que o resultado para a polarizabilidade de dipolo de uma única supermolécula requer, de fato, vários cálculos pontuais para diferentes intensidades de campo elétrico. Uma vez que as supermoléculas incluem várias moléculas de benzeno, é esperado que a falta de funções difusas seja mais prejudicial aos resultados de fase gasosa que para os resultados em fase líquida. Por isto, a diferença de $2.2 \pm 0.5$ ua entre os resultados da fase líquida e da fase gasosa deve ser ligeiramente superestimada. Novamente, os resultados dos cálculos DFT, e similarmente os semi-empíricos INDO, apresentaram um valor médio para a polarizabilidade média que foi essencialmente o mesmo resultado de fase gasosa.

Como discutido por Jensen e outros [249] usando DFT dependente do tempo, o resultado para a fase líquida é diminuído de $8 \%$ comparado com os resultados da fase gasosa. Morita e Kato [248] consideraram anteriormente a perturbação do meio (água) sobre a polarizabilidade de dipolo de pequenos sistemas como $\mathrm{Ne}, \mathrm{Ar}, \mathrm{CH}_{4}$ e ânions como $\mathrm{Cl}^{-}$. Analogamente, eles concluíram que para o caso de sistemas neutros na água existe uma diminuição na polarizabilidades de dipolo entre 13 e $18 \%$. Para o ânion $\mathrm{Cl}^{-}$em água a diminuição está em torno de 37\%. van Duijnen e outros [265] argumentaram que a polarizabilidade de dipolo do formaldeído em água não mostra mudança apreciável e caso mostrasse a polarizabilidade deveria diminuir devido ao efeito do meio. De acordo com este resultado a polarizabilidade de dipolo do líquido de benzeno não mostrou mudança apreciável $\mathrm{e}$, de fato, usando valores estatisticamente convergidos foi verificado que os resultados são equivalentes.

\subsection{Conclusões}

A metodologia seqüencial foi empregada aqui na determinação das polarizabilidades do líquido de benzeno. Cálculos na aproximação de campo finito com a metodologia INDO foram realizados nas estruturas supermoleculares incluindo todas as moléculas de benzeno dentro de $10 \AA$. Para cada intensidade de campo finito o momento de dipolo induzido foi estatisticamente convergido. Como um 
complemento, cálculos de mecânica quântica também foram realizados com o método DFT com o modelo B3LYP/6-31G. Os resultados finais indicam que a polarizabilidade de dipolo do líquido é equivalente à de fase gasosa. 


\section{Capítulo 11}

\section{Deslocamentos químicos no líquido de água}

\subsection{Motivação}

Uma importante classe de sistemas cuja estrutura eletrônica pode ser sondada através de cálculos RMN se refere aos sistemas solvatados. Uma molécula solvatada sofre o efeito das interações devido sua vizinhança, como por exemplo, ligações de hidrogênio $[101,228]$. Vários modelos teóricos foram propostos para descrever o efeito de solvente sobre a blindagem magnética [7,272-277]. Duas grandes vertentes são os métodos de campo de reação autoconsistente (SCRF) $[1,2]$ onde o soluto é tratado dentro de uma cavidade esférica em um solvente polarizável representado por sua constante dielétrica; e a aproximação de aglomerado rígido, onde algumas moléculas de solvente são consideradas explicitamente a fim de descrever as camadas de solvatação da molécula de soluto $[7,8]$. Foi mostrado que o primeiro método não funciona para a determinação do deslocamento gás-líquido e o segundo apesar de servir como uma aproximação grosseira não serve como um modelo para líquido [278] uma vez que o sistema é fixo por uma condição de equilíbrio, conseqüentemente não descrevendo a desordem térmica que caracteriza a fase líquida. Contudo, Chesnut e Rusiloski [278], propuseram um modelo mais realista para descrever o efeito de solvente sobre a blindagem magnética dos átomos de uma molécula no líquido de água. Seu modelo consistia basicamente na simulação computacional do líquido de água, na subseqüente seleção de alguns aglomerados da simulação e 
na realização de posteriores cálculos quânticos sobre estas estruturas. Devido à má descrição das camadas de solvatação e às limitações computacionais os resultados obtidos apresentaram deslocamentos significativos comparados ao valor esperado, apesar disso mostraram um acordo qualitativo bem superior aos resultados obtidos com SCRF e aglomerado rígido. Dois anos após a publicação deste trabalho, Malkin e colaboradores [276] mostraram num estudo sobre o deslocamento químico isotrópico, que melhorando a descrição das camadas de solvatação e a amostragem levada a cálculos quânticos poderiam encontrar melhores valores para o deslocamento químico gás-líquido. De fato tais resultados estão em melhor acordo com o experimento do que os resultados de Chesnut e Rusiloski. Os métodos SCRF, aglomerados rígidos e o amostral de Malkin, anteriormente mencionados foram comparados por Cheeseman e colaboradores [191]. Neste trabalho os autores verificaram que o método de solvente contínuo falha na reprodução até mesmo do sinal do deslocamento químico isotrópico e que a aproximação discreta é a mais razoável. Verificaram também que o modelo de aglomerado rígido, no caso do aglomerado $\left(\mathrm{H}_{2} \mathrm{O}\right)_{5}$ fornece resultados próximos aos obtidos pela média sobre as estruturas da simulação. $O$ acordo entre o melhor resultado obtido com SCRF e o valor experimental contudo ficou aquém dos resultados de Malkin e outros. No trabalho de Malkin, o deslocamento químico isotrópico foi representado por uma distribuição de valores em torno de um valor médio obtido a partir dos cálculos quânticos e não mais um valor absoluto obtido a partir de um único cálculo quântico. Contudo em nenhum dos trabalhos um rigoroso tratamento estatístico foi dado para a obtenção de médias estatisticamente convergidas. Resultados recentes $[35,38,44,258,279]$ mostram que um número mínimo de configurações deve ser submetido aos cálculos de mecânica quântica a fim de se obter uma média estatisticamente convergida.

A proposta deste capítulo é revisitar o estudo do deslocamento químico isotrópico no líquido de água através da metodologia seqüencial simulação/DFT, e analisar como diferentes funcionais descrevem o valor da blindagem magnética tanto na fase gasosa como na fase líquida. Outros aspectos do método são abordados, como a dependência com o potencial empregado nas 
simulações, o efeito das vibraçōes das moléculas, a dependência com tamanho dos aglomerados selecionados. Adicionalmente à análise dos resultados para o deslocamento químico isotrópico, são analisados também os resultados obtidos para a blindagem química anisotrópica em fase líquida, para a qual resultados teóricos são escassos. Pretende-se também formalizar os cálculos das média, em bases estatísticas. Além disso, os resultados obtidos aqui podem ser diretamente comparados com a nova escala de blindagem absoluta recentemente proposta para o átomo de oxigênio [201] bem como com os novos valores experimentais determinados para o átomo de hidrogênio [280].

\subsection{Detalhes de cálculo}

\subsubsection{Simulações}

As configurações do líquido foram geradas através de simulações Monte Carlo e Dinâmica molecular. Potenciais de moléculas rígidas e flexíveis foram usados para descrever as interações inter e intramoleculares. Usou-se dois potenciais rígidos; SPC [225] e TIPS [281] e dois potenciais flexíveis; o potencial de Ferguson [282] onde os parâmetros intramoleculares foram obtidos tendo como referência a geometria do potencial SPC (FERG) e o potencial de Dang e Pettit [283] onde os parâmetros intramoleculares foram obtidos tendo como referência a geometria do potencial TIPS (DP). A forma geral do potencial é dada pelo potencial intermolecular de Lennard-Jones-Coulomb (equação 2.9) acrescido do potencial intramolecular na forma:

$$
U^{i n t r a}=\sum_{l i g} K_{q}\left(l-l_{0}\right)^{2}+K_{q} K_{c}\left(l-l_{0}\right)^{3}+\sum_{a n g} K_{\theta}\left(\theta-\theta_{0}\right)^{2}
$$

onde o primeiro somatório é o termo do potencial intramolecular que descreve os estiramentos da ligação $\mathrm{O}-\mathrm{H}$ representados por $l$ e o segundo somatório o

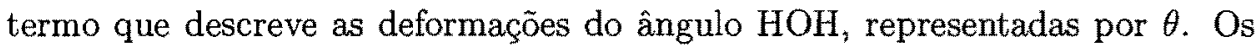
parâmetros destes potenciais são dados na Tabela 11.1.

Para as simulações com moléculas rígidas foi empregado o método Monte Carlo Metropolis tal como implementado no programa Dice [224]. O líquido foi simulado por $10^{5}$ passos Monte Carlo a uma temperatura de $298 \mathrm{~K}$, 


\begin{tabular}{cccccc}
\hline \hline Constantes & SPC & TIPS & FERG & DP & Unidade \\
\hline$l_{0}$ & 1.00 & 0.96 & 1.00 & 0.96 & $\AA$ \\
$\theta_{0}$ & 109.5 & 104.5 & 109.5 & 104.5 & $\mathrm{grau}$ \\
$A$ & - & - & 650 & 580 & $\mathrm{Mcal} \AA^{6} / \mathrm{mol}$ \\
$C$ & - & - & -625.47 & -525.00 & $\mathrm{kcal} \AA^{12} / \mathrm{mol}$ \\
$q(H)$ & - & - & 0.413 & 0.400 & $e$ \\
$K_{q}$ & - & - & 547.5 & 529.6 & $\mathrm{kcal} / \mathrm{mol} / \AA^{2}$ \\
$K_{c}$ & - & - & -1.65 & 0.00 & $\mathrm{kcal} / \mathrm{mol} / \AA^{3}$ \\
$K_{\theta}$ & - & - & 49.9 & 34.1 & $\mathrm{kcal} / \mathrm{mol} / \mathrm{rad}^{2}$ \\
\hline \hline
\end{tabular}

Tabela 11.1: Parâmetros dos potenciais utilizados

no ensemble NVT com 500 moléculas de água. No caso de moléculas flexíveis utilizou-se o método Dinâmica Molecular empregando o programa GROMACS $[284,285]$. Tanto para a fase gasosa quanto para a fase líquida foram realizadas simulações de $1000 \mathrm{ps}$ com intervalos temporais de $0.25 \mathrm{fs}$ a uma temperatura de 298K. No caso do potencial FERG foi usado o ensemble NPT e no caso do potencial DP com o ensemble NVT.

As estruturas foram selecionadas de 1000 em 1000 passos para simulações com Monte Carlo e de $10 \mathrm{em} 10$ ps para as simulações com Dinâmica Molecular, o que para ambas as técnicas de simulação são suficientemente descorrelacionadas.

\subsubsection{Cálculos de mecânica quântica}

Uma vez que a teoria funcional da densidade vem sendo aplicada a vários problemas de química quântica com sucesso, particularmente na determinação de deslocamentos químicos $[276,277,286-289]$, ela foi empregada neste estudo na descrição dos deslocamentos químicos isotrópicos e anisotópicos no líquido de água. Em uma primeira abordagem o funcional B3LYP [111,112] foi empregado a fim de estudar a convergência em relação ao tamanho do aglomerado. $\mathrm{O}$ conjunto de funçôes base $6-311++\mathrm{G}(2 \mathrm{~d}, 2 \mathrm{p})$ foi empregado para o cálculo da blindagem da molécula de referência. Para a avaliação do efeito do tamanho dos aglomerados sobre o deslocamento químico, foi utilizado para as moléculas além das quatro primeiras vizinhas a base $3-21 G$, enquanto que para a primeira ca- 
mada de solvatação ( $1+4$ moléculas) foi tratada com a base $6-311++G(2 d, 2 p)$. A fim de se observar a dependência dos deslocamentos com o funcional empregado vários outros funcionais foram empregados para estruturas de tamanho apropriado. O método GIAO $[182,183,188]$ foi escolhido para tratar do problema da invariância de calibre. Todos os cálculos quânticos foram realizados através do programa Gaussian nas edições G98 [117] e G03 [290].

\subsection{Resultados e discussão}

\subsubsection{Blindagem magnética da fase gasosa}

Antes de discutir os resultados obtidos para o deslocamento químico para a molécula no líquido é necessário discutir as blindagens magnéticas absolutas obtidas para a molécula de água isolada e para as configurações advindas das simulações com potenciais de geometria flexível. A Tabela 11.2 mostra os valores das blindagens magnéticas isotrópicas, $\sigma^{i s o}$, e anisotrópicas, $\sigma^{a n i s}$, para os átomos da molécula de água isolada, em geometria rígida, e para 100 geometrias geradas com os potenciais de geometria flexíveis em fase gasosa, estas obtidas via simulações DM. Foram realizados cálculos também sobre uma geometria B3LYP $/ 6-311++\mathrm{G}(2 \mathrm{~d}, 2 \mathrm{p})$ (designada na Tabela 11.2 por OPT) para servir de referência para as geometrias dos potenciais.

Pode-se ver que todos os valores para a geometria rígida SPC, bem como para as configurações produzidas pelo potencial FERG (baseado na geometria SPC) não apresentaram bom acordo com o valor experimental. O átomo de oxigênio, por exemplo, apresentou uma diferença na blindagem isotrópica de $\sim 22$ ppm a partir do valor experimental de 323.6 ppm [201]. No caso da blindagem anisotrópica a maior sensibilidade ocorreu para os átomos de hidrogênio para os quais os potenciais tipo SPC forneceram uma diferença de $\sim 2 \mathrm{ppm}$. Estas diferenças se devem ao fato de que a geometria SPC é bastante diferente daquela encontrada experimentalmente (veja Tabela 11.1). Por outro lado os valores para o potencial TIPS (baseado nos parâmetros geométricos experimentais), bem como o potencial DP (baseado por sua vez na geometria TIPS) apresentaram valores satisfatórios para a blindagem dos átomos das moléculas tanto 
em geometria fixa quanto nas configuraçōes de fase gasosa, onde as vibrações foram levadas em consideração. Em particular para o átomo de oxigênio na geometria TIPS o desvio percentual comparado com o experimental foi da ordem de $0.5 \%$. Para os átomos de hidrogênio a obtenção de valores precisos para a blindagem magnética isotrópica é bastante cara. Um valor de $30.9 \mathrm{ppm}$ [291] foi obtido em nível $\mathrm{CCSD}(\mathrm{T})$, contudo a melhor estimativa teórica para este valor, $30.2 \mathrm{ppm}$, foi alcançada com o modelo RASSCF com um grande espaço ativo associado a um grande conjunto de funções base [204]. Os resultados apresentados aqui naturalmente não se mostraram tão precisos e apresentaram um desvio $\sim 4 \%$ em relação ao valor experimental, apesar disso estão em muito bom acordo com outros valores da literatura recente que em nível MP2/6-311++G(2d,2p) foi de $31.02 \mathrm{ppm}[203]$.

\begin{tabular}{|c|c|c|c|c|}
\hline & \multicolumn{2}{|c|}{ Rígida } & \multicolumn{2}{|c|}{$\overline{\text { Flexível }}$} \\
\hline Ríg / Flex & $\sigma^{i s o}\left({ }^{17} O\right)$ & $\sigma^{i s o}\left({ }^{1} H\right)$ & $\sigma^{i S O}\left({ }^{17} O\right)$ & $\sigma^{i s o}\left({ }^{1} H\right)$ \\
\hline SPC/FERG & 301.61 & 29.52 & $299.94 \pm 10.59$ & $29.46 \pm 0.67$ \\
\hline TIPS/DP & 325.30 & 31.36 & $324.92 \pm 9.23$ & $31.37 \pm 0.70$ \\
\hline Opt & 324.69 & 31.27 & & \\
\hline \multirow[t]{3}{*}{$\operatorname{Exp}$} & $323.6^{a}$ & $30.05^{b}$ & $323.6^{a}$ & $30.05^{b}$ \\
\hline & \multicolumn{2}{|c|}{ Rígida } & \multicolumn{2}{|c|}{ Flexível } \\
\hline & $\sigma^{\text {anis }}\left({ }^{17} \mathrm{O}\right.$ & $\sigma^{a n i s}\left({ }^{1} H\right)$ & $\sigma^{\text {anis }}\left({ }^{17} O\right)$ & $\overline{\sigma^{a n i s}}\left({ }^{1} H\right)$ \\
\hline SPC/FERG & 55.20 & 16.96 & $58.74 \pm 3.72$ & $16.87 \pm 0.87$ \\
\hline TIPS/DP & 54.14 & 19.07 & $55.88 \pm 2.53$ & $19.08 \pm 0.95$ \\
\hline Opt & 54.31 & 19.02 & & \\
\hline Vaara et al ${ }^{c}$ & 46.97 & 19.1 & 46.97 & 19.1 \\
\hline
\end{tabular}

Tabela 11.2: Blindagem isotrópica, $\sigma^{\text {iso }}$, e anisotrópica, $\sigma^{\text {anis }}$, para os átomos da molécula de âgua em geometria rígida e em geometria flexível. Valores em ppm obtidos em nível $\mathrm{B} 3 \mathrm{LYP} / 6-311++\mathrm{G}(2 \mathrm{~d}, 2 \mathrm{p})$. OPT designa os valores para a geometria otimizada em nível B3LYP $/ 6-311++G(2 d, 2 p)$. As incertezas são os desvios padrão da média obtida sobre 100 configuraçōes a) Ref. [201]; b) Ref. [199]; c) Ref. [204]

Não existe resultado experimental para a blindagem anisotrópica em fase gasosa, assim a Tabela 11.2 apresenta o resultado teórico mais aceito. Tomando este valor como referência observa-se que os valores calculados para as estruturas SPC e FERG não apresentaram boa concordância. Para o potencial FERG foi obtido o valor de $16.87 \pm 0.87$ ppm para $\sigma^{\text {anis }}\left({ }^{1} \mathrm{H}\right)$ enquanto que o valor teoricamente mais aceito é $19.1 \pm 0.1 \mathrm{ppm}$ [204]. Os potenciais 
baseados na geometria experimental por sua vez mostraram melhor acordo; $19.07 \mathrm{ppm}$ (TIPS) e $19.08 \pm 0.95 \mathrm{ppm}$ (DP). No caso do oxigênio, $\sigma^{\text {anis }}\left({ }^{17} \mathrm{O}\right)$ foi calculado em alto nível RASSCF como sendo 46.97 ppm [204] e em nível MP2/6-311++G(2d,2p) como sendo $46.05 \mathrm{ppm}$ [203], contudo o valor obtido neste trabalho foi de $55.88 \pm 2.53 \mathrm{ppm}$, o que sugere que a correlação eletrônica deva ser importante para a caracterização desta propriedade.

A diferença entre os valores para as moléculas rígidas e para a média das geometrias flexíveis revela a importância de se considerar as vibrações intramoleculares. Tais vibrações inserem uma flutuação nos valores e a propriedade passa a ser descrita não mais por um valor absoluto, mas sim por uma distribuição de valores. Finalmente é possível observar que os valores apresentados na Tabela 11.2 para a geometria TIPS são bastante similares aos valores obtidos para a molécula otimizada o que indica a similaridade entre as duas geometrias.

\subsubsection{Blindagem magnética da fase líquida}

Para uma descrição realista de um sistema em fase líquida muitos aspectos importantes devem ser considerados. Primeiramente o modelo empregado para descrever o líquido não deve ser otimizado, uma vez que no líquido as moléculas sofrem deformações devido às constantes interações com suas vizinhas, de forma que não existe nenhuma condição de mínima energia. Em segundo lugar, tornase cada vez mais importante considerar as moléculas de solvente explicitamente, uma vez que interações fundamentais, como ligações de hidrogênio, precisam ser bem descritas. Em último lugar, deve ser levado em conta um número mínimo de moléculas para descrever o ambiente líquido em volta da molécula de soluto. Para a água líquida é sabido que cinco moléculas ( 1 soluto +4 solventes) determinam a primeira camada de solvatação do líquido [292]. Aqui a metodologia seqüencial será empregada para satisfazer três aspectos. As blindagens magnéticas para os átomos da molécula de água central (molécula de referência), calculadas em nível B3LYP/6-311++G(2d,2p) estão mostradas na Tabela 11.3. Como os átomos de hidrogênio desfrutam do mesmo ambiente químico, suas blindagens tendem ao mesmo valor, assim o valor reportado na Tabela 11.3 se refere à média das blindagens dos dois átomos da molécula de água (veja Figura. 


\begin{tabular}{ccc}
\hline \hline & $\sigma^{i s o}\left({ }^{17} \mathrm{O}\right)$ & $\sigma^{i s o}\left({ }^{1} H\right)$ \\
\hline SPC & $275.09 \pm 7.11$ & $26.45 \pm 1.01$ \\
TIPS & $297.36 \pm 7.75$ & $29.01 \pm 0.96$ \\
FERG & $261.46 \pm 10.95$ & $25.59 \pm 1.23$ \\
DP & $288.66 \pm 10.98$ & $28.26 \pm 1.33$ \\
Exp & $287.5^{a}$ & $25.71^{b}$ \\
& & \\
& $\sigma^{\text {anis }}\left({ }^{17} \mathrm{O}\right)$ & $\sigma^{\text {anis }}\left({ }^{1} H\right)$ \\
\hline SPC & $51.24 \pm 10.79$ & $25.78 \pm 3.60$ \\
TIPS & $49.09 \pm 10.01$ & $25.19 \pm 3.71$ \\
FERG & $46.55 \pm 12.97$ & $25.11 \pm 3.77$ \\
DP & $48.15 \pm 12.49$ & $25.35 \pm 3.49$ \\
Exp & - & $27.4^{b}$ \\
\hline \hline
\end{tabular}

Tabela 11.3: Blindagem isotrópica, $\sigma^{i s o}$, e anisotrópica, $\sigma^{\text {anis }}$, para os átomos da molécula de água de referência da primeira camada de solvataçäo. Valores em ppm obtidos em nivel B3LYP $/ 6-311++\mathrm{G}(2 \mathrm{~d}, 2 \mathrm{p})$. OPT designa os valores para a geometria otimizada em nível B3LYP $/ 6-311++G(2 d, 2 p)$. As incertezas são os desvios padrão da média obtida sobre 100 configurações. a) Ref. [201]; b) Ref. [280]

11.1). Os valores apresentados na Tabela 11.3 não são diretamente comparáveis aos valores experimentais uma vez que possuem erro de superposição de base, contudo nos servem para outras análises. Foi observado, por exemplo, que para os potenciais flexíveis os valores para o desvio padrão foram maiores que para os potenciais rígidos devido à inclusão da contribuição vibracional ao valor da blindagem. Os potenciais rígidos apresentaram valores sistematicamente maiores do que os valores apresentados pelos seus respectivos potenciais flexíveis, por exemplo a blindagem magnética para o átomo de oxigênio TIPS é $297.36 \pm 7.75$ ppm enquanto que para o oxigênio DP é $288.66 \pm 10.98$ ppm. A diferença entre estas médias pode ser atribuída aos efeitos vibracionais, que neste exemplo é $\sim 9$ ppm. Os gráficos da Figura 11.2 mostram a convergência estatística para as blindagens calculadas para configurações obtidas com o potencial FERG (bolas vazias) e com o potencial DP (bolas cheias). Estes gráficos mostram que os valores médios das blindagens isotrópicas e anisotrópicas dados na Tabela 11.3 alcançaram a convergência estatística com cerca de 50 configurações. É importante notar também na Tabela 11.3 que a blindagem isotrópica sofreu um efeito maior devido à escolha do potencial do que a blindagem anisotrópica. A sensibilidade das blindagens com o potencial utilizado é mais evidente nos 


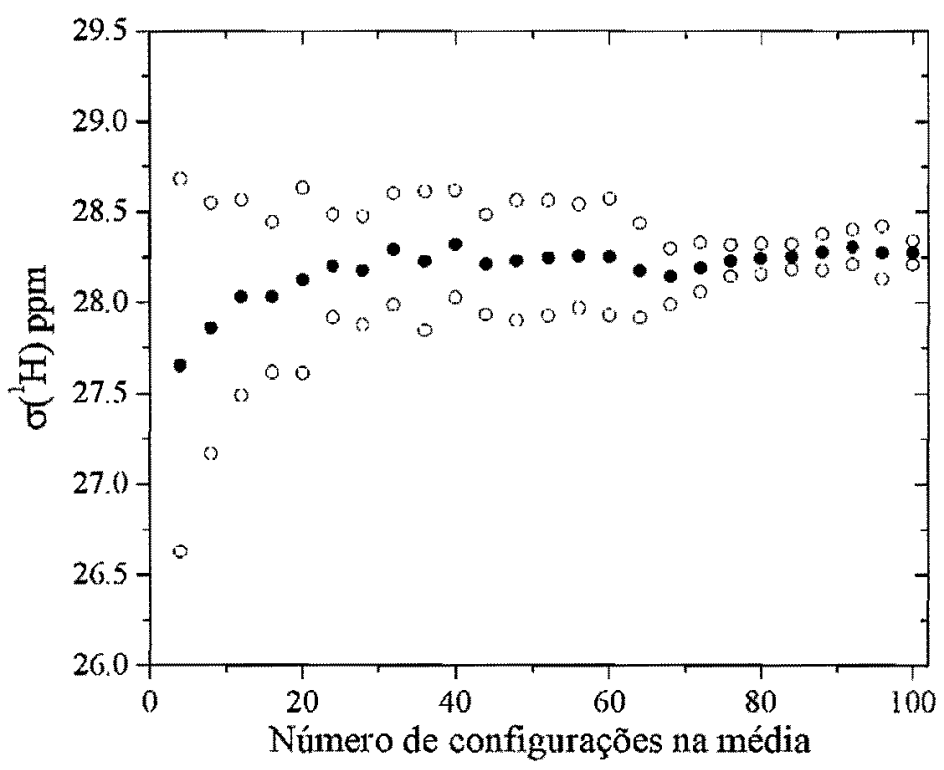

Figura 11.1: Conyergência da média da blindagem isotrópica, $\sigma^{i s o}$, para os dois átomos de hidrogênio da molécula de referência da primeira camada de solvatação do líquido de água (potencial DP). A curva de bolas cheias representa a convergência para a média da blindagem dos dois hidrogênios

gráficos da Figura 11.2. Uma vez analisada a blindagem química para a fase líquida, pode-se agora discutir o deslocamento químico gás-liquido. Dois aspectos fundamentais até agora não discutidos serão levados em conta nas próximas seções. O primeiro é a convergência do valor da blindagem com relação ao tamanho do aglomerado. É sabido que apenas a primeira camada de solvatação não é suficiente para reproduzir os resultados experimentais para deslocamentos químicos [278] e que para uma boa descrição da blindagem magnética no líquido é necessário considerar mais do que quatro moléculas para a descrição do meio [276]. O segundo aspecto a ser considerado é o erro de superposição de base. Dado que nosso estudo se trata de cálculos supermoleculares a correção do BSSE é indispensável para a confiabilidade dos resultados. Assim, a correção counterpoise foi empregada, determinando o deslocamento químico com o uso da blindagem da molécula de referência calculada na presença das bases das moléculas de solvente.

Nas próximas análises apenas as estruturas geradas com o potencial DP, foram consideradas uma vez que este potencial foi o que melhor descreveu a blindagem magnética, tanto na fase líquida como na gasosa. Uma característica 


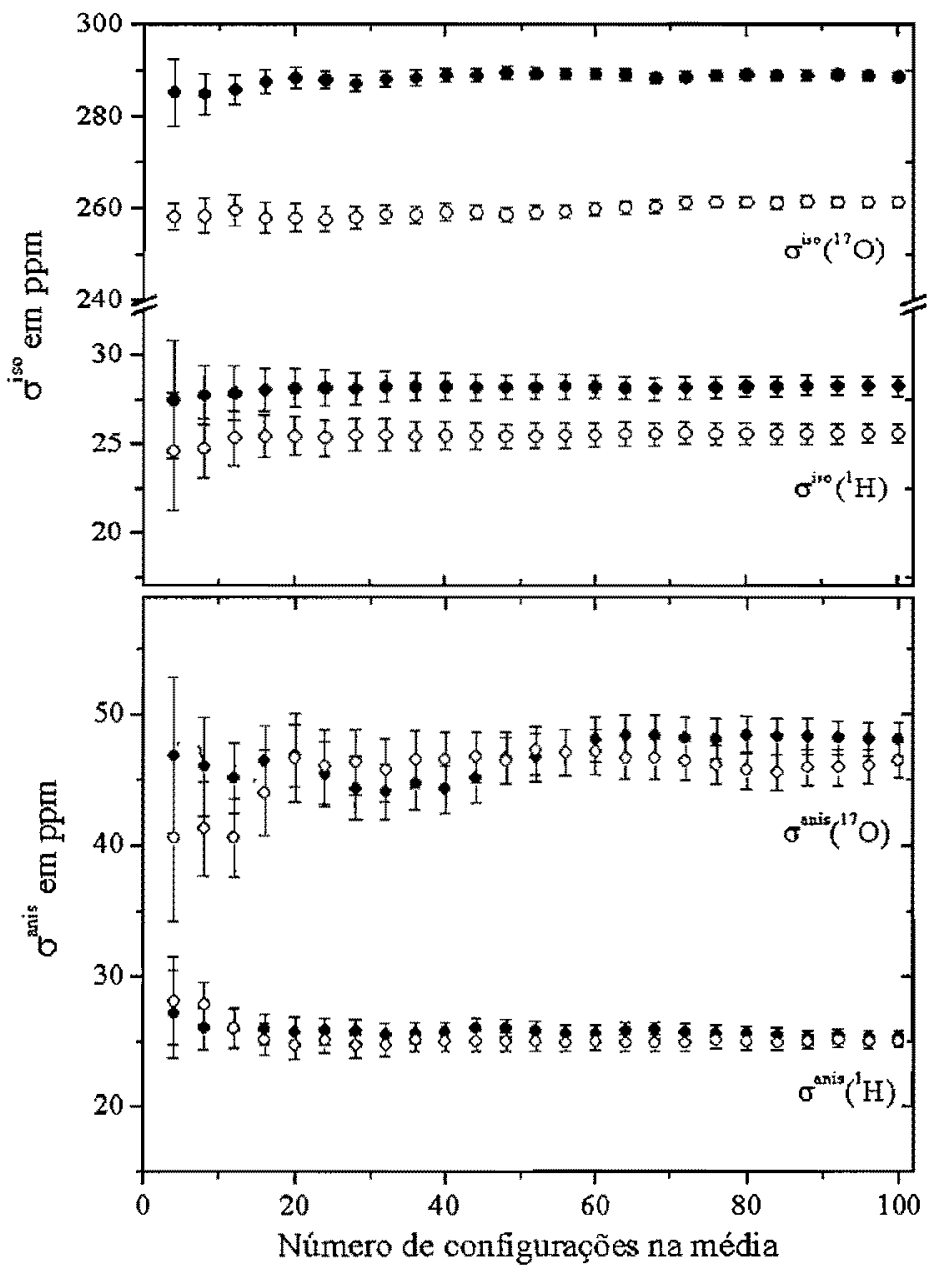

Figura 11.2: Convergência da média da blindagem isotrópica, $\sigma^{i s o}$, e anisotrópica, $\sigma^{a n i s}$, para os átomos da molécula da primeira camada de solvatação do líquido de água. As bolas cheias representam a convergência dos resultados obtidos com o potencial DP e as vazias para o potencial FERG. As barras verticais se referem ao erro estatístico 
importante de se notar nestes resultados é o fato de que apesar do potencial DP ser um potencial empírico ele foi capaz de reproduzir bem tais propriedades, contrariando o estudo de Malkin [276] que sugere que a descrição apropriada de deslocamentos químicos só é possível com potenciais ab initio.

\subsubsection{Bases localmente densas}

Como o custo computacional cresce bastante com o aumento do número de moléculas no aglomerado é importante tentar descrever o sistema da maneira mais econômica possível. Assim, para a descrição das moléculas de solvente foi empregado aqui o expediente comumente empregado por Chesnut e colaboradores [293-296], no qual a molécula de referência é tratada por um conjunto de funções base relativamente grande sobre os átomos de interesse e bases consideravelmente menores nos outros átomos do sistema. Este procedimento que reduz drasticamente o tempo computacional, fornece bons resultados quando comparados com a aproximação convencional de bases balanceadas. Num estudo sobre a primeira camada de coordenação da estrutura geométrica cristalina do gelo, $\left(\mathrm{H}_{2} \mathrm{O}\right)_{17}$ [296], foram empregadas duas bases; a base $6-311 \mathrm{G}(\mathrm{d}, \mathrm{p})$ para o aglomerado inteiro e uma base localmente densa com 6-311G(d,p) descrevendo a molécula central e 4-31G as suas vizinhas. Os resultados encontrados foram praticamente idênticos mostrando a validade de tal aproximação. Neste trabalho foi realizado um teste para se ter idéia da magnitude dos efeitos desta aproximação sobre as estruturas da simulação. A Tabela 11.4 apresenta os valores obtidos para as blindagens magnéticas isotrópica, $\sigma^{i s o}$, e anisotrópica, $\sigma^{\text {anis }}$, para dois tamanhos diferentes de aglomerados retirados da simulação, com 5 e 9 moléculas de água. Para o pentâmero foi utilizada a base $6-311++\mathrm{G}(2 \mathrm{~d}, 2 \mathrm{p})$ para a descrição do sistema inteiro (Balanceada) e em seguida a base $6-311++\mathrm{G}(2 \mathrm{~d}, 2 \mathrm{p})$ para descrever a molécula central e 3-21G para descrever suas vizinhas (Densa). Observou-se que a diferença entre os dois tratamentos foi substancial apenas para o átomo de oxigênio. Tanto para $\sigma^{\text {iso }}$ quanto para $\sigma^{\text {anis }}$ esta diferença é significativa, $\sim 2 \mathrm{ppm}$, sugerindo que descrever o pentâmero somente com a molécula central tendo a base maior não é suficiente. Assim um aglomerado maior, com 9 moléculas, foi considerado agora, por um lado, a base balanceada 


\begin{tabular}{ccccc}
\hline \hline & \multicolumn{2}{c}{$\sigma^{i s o}\left({ }^{17} \mathrm{O}\right)$} & \multicolumn{2}{c}{$\sigma^{i s o}\left({ }^{1} \mathrm{H}\right)$} \\
\hline Balanceada & $288.66 \pm 10.98$ & $282.29 \pm 10.20$ & $28.26 \pm 1.33$ & $28.04 \pm 1.32$ \\
Densa & $290.77 \pm 10.48$ & $281.61 \pm 11.31$ & $28.22 \pm 1.49$ & $28.23 \pm 1.26$ \\
\hline \multicolumn{3}{c}{$\sigma^{\text {anis }}\left({ }^{17} \mathrm{O}\right)$} & \multicolumn{3}{c}{$\sigma^{\text {anis }}\left({ }^{1} \mathrm{H}\right)$} \\
\hline Balanceada & $48.15 \pm 12.49$ & $42.60 \pm 13.09$ & $25.35 \pm 3.49$ & $25.05 \pm 2.96$ \\
Densa & $46.82 \pm 12.37$ & $44.50 \pm 11.88$ & $25.93 \pm 3.64$ & $24.71 \pm 3.13$ \\
\hline \hline
\end{tabular}

Tabela 11.4: Dependência da blindagem magnética isotrópica e anisotrópica com o uso de bases localmente densas. Balanceada se refere a base $6-311++\mathrm{G}(2 \mathrm{~d}, 2 \mathrm{p})$ e densa se refere à combinação 6-311++G(2d,2p) e 3-21G (veja texto). Valores em ppm obtidos em nível B3LYP para estruturas geradas com o potencial DP. As incertezas são os desvios padrão da média obtida sobre 100 configuraçōes.

em todas as moléculas do aglomerado e por outro as moléculas da primeira camada descritas pela base $6-311++\mathrm{G}(2 \mathrm{~d}, 2 \mathrm{p})$ e as moléculas restantes com base 3-21G. A diferença agora para $\sigma^{i s o}$ do átomo de oxigênio é menor que $0.7 \mathrm{ppm}$ enquanto que a diferença para $\sigma^{\text {anis }}$ é de $\sim 1 \mathrm{ppm}$. Estas diferenças foram consideradas aceitáveis tendo em vista a grande redução do custo computacional que possibilitou o estudo detalhado de aglomerados maiores.

Baseado nesta análise, nosso estudo sobre os efeitos das camadas de solvatação da molécula de referência foi realizado com a base $6-311++\mathrm{G}(2 \mathrm{~d}, 2 \mathrm{p})$ tendo em vista a descrição dos átomos do pentâmero e 3-21G para as demais moléculas.

\subsubsection{Deslocamento químico gás-líquido}

\section{Dependência com o tamanho do aglomerado e BSSE}

Para determinadas propriedades a primeira camada de solvatação do líquido de água já basta para se obter uma boa descrição dos efeitos de solvente [292]. Para a blindagem magnética contudo é preciso ir mais longe para se obter um valor convergido em relação ao número de moléculas de solvente. Este efeito foi examinado aqui variando o tamanho dos aglomerados e observando o valor da blindagem magnética da molécula de referência. A Figura 11.3 apresenta uma configuração do líquido para cada tamanho considerado. Em cada foto a primeira camada de solvatação está em destaque, indicando que todas as 5 
moléculas foram descritas com a base $6-311++\mathrm{G}(2 \mathrm{~d}, 2 \mathrm{p})$. Os outros aglomerados, de $9,13,17$ e 24 moléculas, tiveram as moléculas além da primeira camada de solvatação descritas pela base 3-21G. Como visto na Figura 11.2 os valores para a blindagem magnética tanto isotrópica quanto anisotrópica alcançaram seu valor médio estatisticamente convergido a partir de aproximadamente 40 configurações. Assim para os aglomerados de 13, 17 e 24 moléculas foram tomadas médias sobre 50 configurações.

A Tabela 11.5, apresenta os valores não corrigidos (sCC) e corrigidos (cCC) contra BSSE para os deslocamentos químicos isotrópico, $\delta^{i s o}$, e anisotrópico, $\delta^{\text {anis }}$, da molécula de água de referência. Pode-se observar que

\begin{tabular}{|c|c|c|c|c|}
\hline & \multicolumn{2}{|c|}{$\mathrm{sCC}$} & \multicolumn{2}{|c|}{ cCC } \\
\hline & $\delta^{i s o}\left({ }^{17} O\right)$ & $\delta^{i s o}\left({ }^{1} H\right)$ & $\delta^{2 s o}\left({ }^{17} O\right)$ & $\delta^{i s o}\left({ }^{1} H\right)$ \\
\hline 1 & 0.0 & 0.0 & 0.0 & 0.0 \\
\hline 5 & $-36.25 \pm 13.15$ & $-3.11 \pm 1.36$ & $-29.49 \pm 8.33$ & $-2.77 \pm 1.02$ \\
\hline 9 & $-43.31 \pm 13.52$ & $-3.14 \pm 1.28$ & $-36.61 \pm 7.67$ & $-2.88 \pm 0.92$ \\
\hline 13 & $-44.32 \pm 15.59$ & $-3.22 \pm 1.40$ & $-38.10 \pm 7.37$ & $-2.91 \pm 0.98$ \\
\hline 17 & $-44.54 \pm 11.77$ & $-3.29 \pm 1.39$ & $-38.12 \pm 7.95$ & $-2.99 \pm 1.01$ \\
\hline 24 & $-44.32 \pm 11.79$ & $-3.47 \pm 1.42$ & $-38.11 \pm 7.92$ & $-3.12 \pm 0.99$ \\
\hline \multirow[t]{3}{*}{$\operatorname{Exp}$} & -36.1 & -4.26 & -36.1 & -4.26 \\
\hline & \multicolumn{2}{|c|}{$\mathrm{sCC}$} & \multicolumn{2}{|c|}{$\mathrm{cCC}$} \\
\hline & $\delta^{a n i s}\left({ }^{17} O\right)$ & $\delta^{\text {anis }}\left({ }^{1} H\right)$ & $\delta^{a n i s}\left({ }^{17} O\right)$ & $\delta^{a n i s}\left({ }^{1} H\right)$ \\
\hline 1 & 0.0 & 0.0 & 0.0 & 0.0 \\
\hline 5 & $-7.74 \pm 12.74$ & $6.27 \pm 3.85$ & $-5.96 \pm 10.73$ & $7.08 \pm 3.78$ \\
\hline 9 & $-11.28 \pm 12.12$ & $5.82 \pm 3.72$ & $-10.99 \pm 11.01$ & $6.93 \pm 3.28$ \\
\hline 13 & $-13.78 \pm 13.02$ & $5.83 \pm 3.20$ & $-11.94 \pm 10.54$ & $6.59 \pm 3.35$ \\
\hline 17 & $-14.27 \pm 13.01$ & $5.75 \pm 3.31$ & $-12.57 \pm 10.13$ & $6.62 \pm 3.22$ \\
\hline 24 & $-14.55 \pm 13.22$ & $6.03 \pm 3.22$ & $-12.69 \pm 10.78$ & $6.78 \pm 3.40$ \\
\hline
\end{tabular}

Tabela 11.5: Dependência dos deslocamentos químicos isotrópico, $\delta^{i s o}$, e anisotrópico, $\delta^{a n i s}$ com o tamanho do aglomerado. Valores em ppm não corrigidos (sCC) e corrigidos (cCC) contra BSSE. As estruturas usadas nas médias foram geradas com o potencial DP e os cálculos quânticos foram realizados em nível B3LYP/6-311++G(2d,2p)

o erro de superposição de base é fundamental para a boa descrição da blindagem magnética do átomo de oxigênio e conseqüentemente do seu deslocamento químico isotrópico. Para as configuraçōes com 9 moléculas de água por exemplo, o BSSE foi de $\sim 6 \mathrm{ppm}$. Para os átomos de hidrogênio contudo este erro foi apenas $\sim 0.3 \mathrm{ppm}$. Para o deslocamento químico anisotrópico o valor do BSSE 

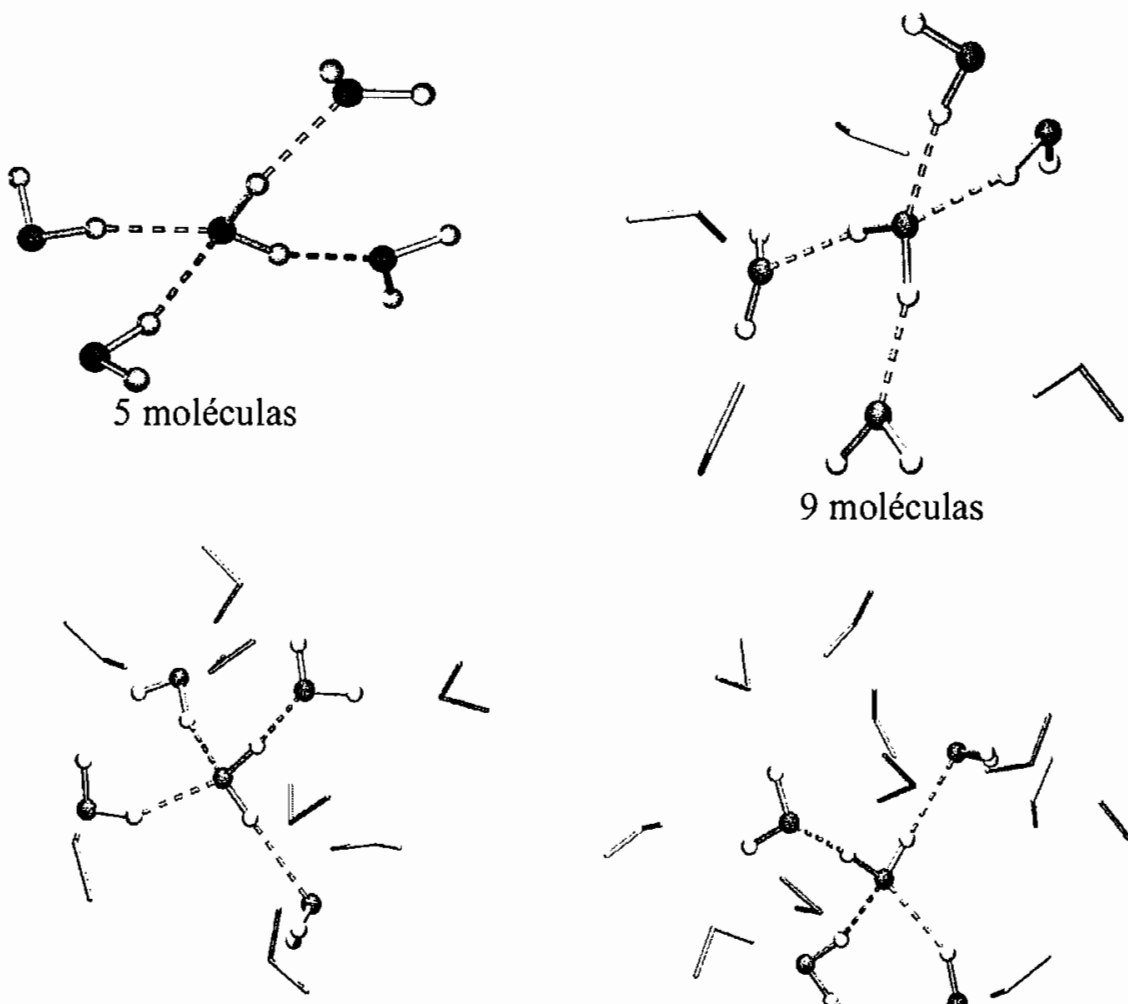

13 moléculas

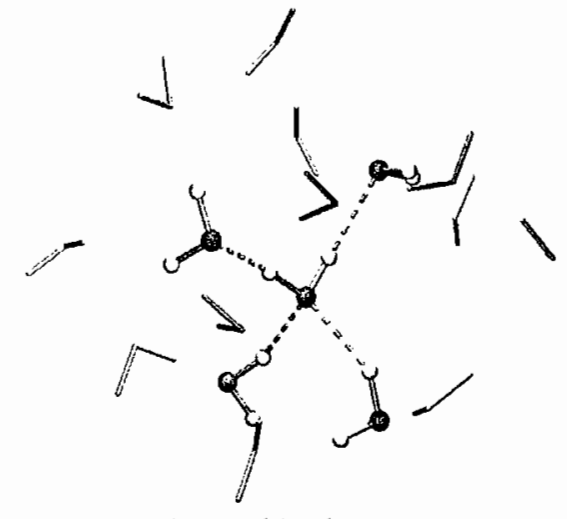

17 moléculas

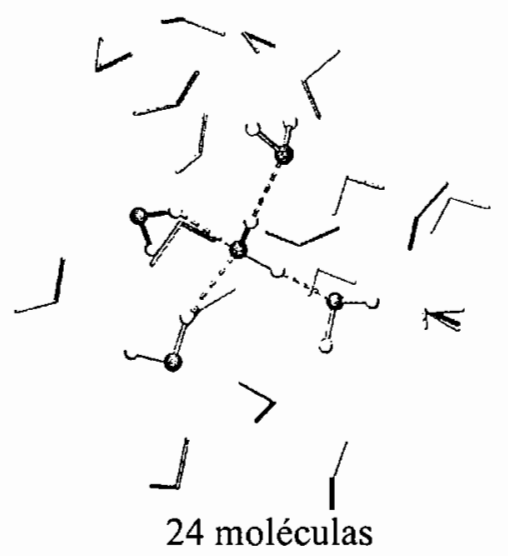

Figura 11.3: Tamanhos de aglomerados usados 
foi menor, não alcançando 2 ppm para o átomo de oxigênio e 1 ppm para os átomos de hidrogênio.

É possível ver também, a partir da Tabela 11.5, que o valor do deslocamento químico teve seu valor convergido apenas para aglomerados que continham mais que 13 moléculas de água (veja Figura 11.4). Para estes aglo-

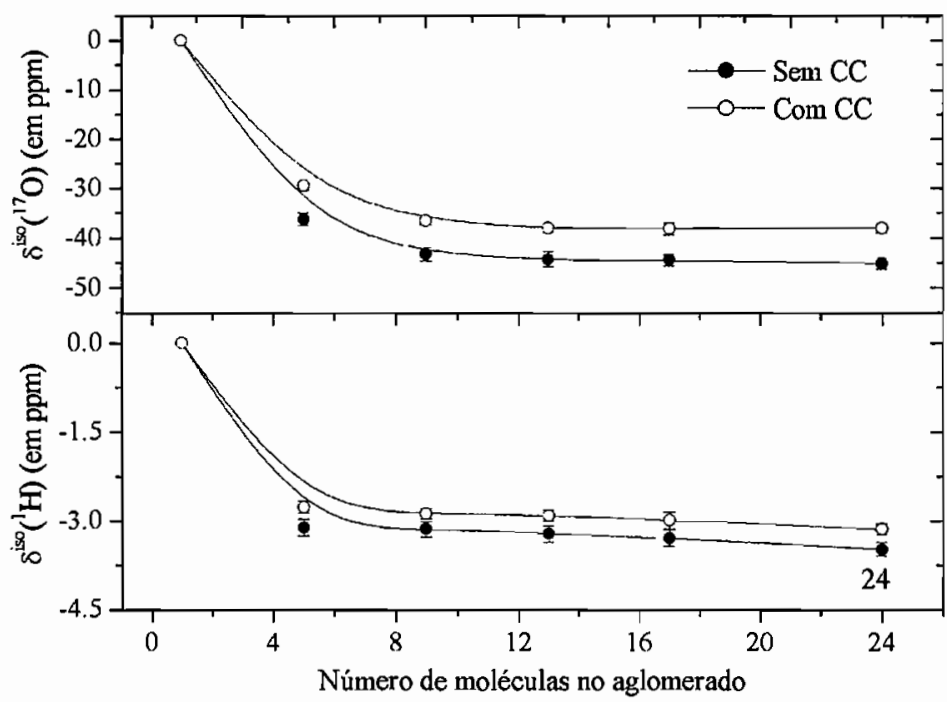

Figura 11.4: Convergência do deslocamento químico isotrópico, $\delta^{i s o}$, com o número de moléculas nos aglomerados usados no cálculo da média. Cada ponto no gráfico se refere a uma média sobre 50 cálculos B3LYP com base localmente densas, exceto para os aglomerados com 5 e 9 moléculas para os quais foram realizados 100 cálculos quânticos

merados foi encontrado um deslocamento químico isotrópico de $38.10 \pm 7.37 \mathrm{ppm}$ que compara relativamente bem com o valor experimental de $36.1 \mathrm{ppm}$. Para os átomos de hidrogênio foi obtido um valor de $2.91 \pm 0.98 \mathrm{ppm}$, que possivelmente seria melhor se fosse possível ter empregado aqui um método quântico mais sofisticado que descrevesse melhor tanto a blindagem em fase gasosa quanto em fase líquida. Estes valores corrigidos contra BSSE e calculados com o potencial DP, podem ser diretamente comparados com o valor obtido por Malkin [276] que obteve $\delta^{i s o}\left({ }^{17} \mathrm{O}\right)=-44.8 \pm 2.3 \mathrm{ppm}$ e $\delta^{i s o}\left({ }^{1} \mathrm{H}\right)=-2.8 \pm 0.3 \mathrm{ppm}$. Observa-se que em relação ao deslocamento para o átomo de oxigênio foi encontrada uma diferença de $\sim 7$ ppm enquanto que para os átomos de hidrogênio esta diferença foi de $\sim 0.1 \mathrm{ppm}$. Outra diferença notável é referente aos desvios padrão, que no caso de Malkin foi encontrado ser menor por um fator de aproximadamente 3. Estas diferenças provavelmente se devem ao pequeno número de configurações 
(apenas 10) utilizado por Malkin no cálculo da média. A Tabela 11.5 apresenta também valores para o deslocamento químico anisotrópico, para o qual existe apenas um estudo teórico via aproximação de aglomerado rígido [296], que como visto anteriormente falha na descrição do deslocamento isotrópico. Pode-se observar que este deslocamento para o átomo de oxigênio diminuiu (em módulo)com o aumento do número de moléculas vizinhas enquanto que para o átomo de hidrogênio ocorreu uma tendência oposta (veja Figura 11.5). Este efeito já foi observado antes para o dímero de água [182] e discutido à luz

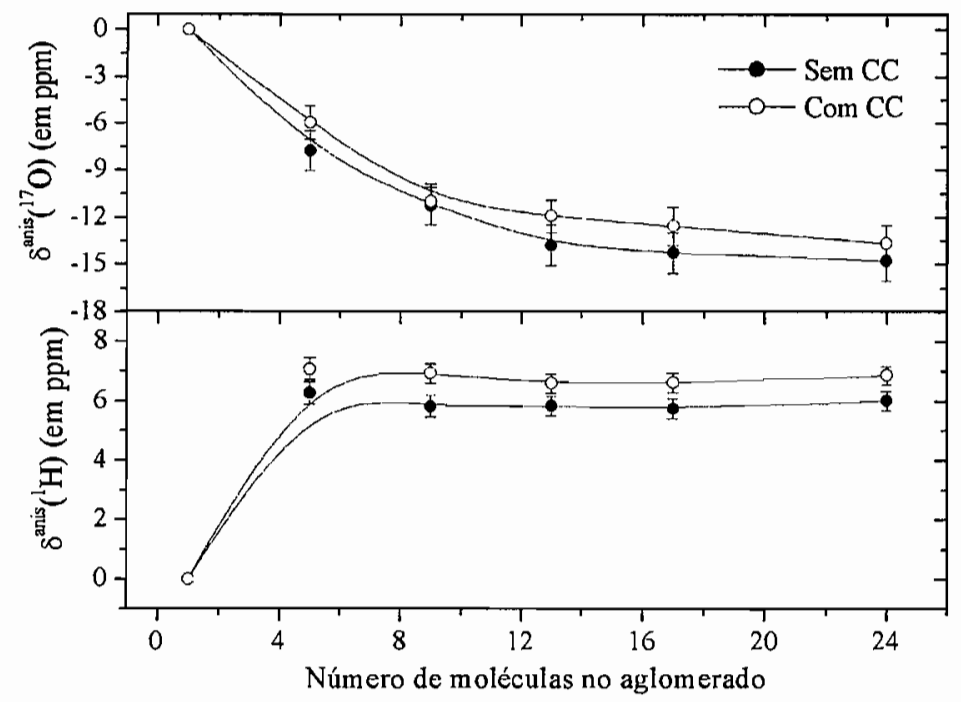

Figura 11.5: Convergência do deslocamento químico anisotrópico, $\delta^{a n i s}$, com o número de moléculas nos aglomerados usados no cálculo da média. Cada ponto no gráfico se refere a uma média sobre 50 cálculos B3LYP com base localmente densa, exceto para os aglomerados com 5 e 9 moléculas para os quais foram realizados 100 cálculos quânticos.

de resultados experimentais [280] e sua principal causa é atribuída às correntes induzidas no átomo de oxigênio aceitador de próton [183].

A Tabela 11.6 apresenta os deslocamentos das componentes do tensor deslocamento químico que são paralela, $\delta_{/ /}$, e perpendiculares, $\delta_{\perp}$, ao eixo de simetria do tensor que por sua vez é aproximadamente paralelo ao eixo da ligação de hidrogênio. Estas componentes podem ser obtidas a partir das combinações lineares de $\sigma^{i s o}$ e $\sigma^{a n i s}$, dadas pelas equações 6.1 e 6.2. Pode-se ver que os valores para o átomo de oxigênio obedeceram à mesma tendência, isto é, tanto a componente paralela quanto a componente perpendicular sempre diminuíram (em módulo) de intensidade à medida que o número de moléculas 


\begin{tabular}{|c|c|c|c|c|}
\hline & $\delta_{/ /}\left({ }^{17} \mathrm{O}\right)$ & $\delta_{/ /}\left({ }^{1} H\right)$ & $\delta_{/ /}\left({ }^{17} \mathrm{O}\right)$ & $\delta_{/ /}\left({ }^{1} H\right)$ \\
\hline 1 & 0.0 & 0.0 & 0.0 & 0.0 \\
\hline 5 & $-41.41 \pm 16.69$ & $1.07 \pm 2.25$ & $-33.46 \pm 13.04$ & $1.95 \pm 1.73$ \\
\hline 9 & $-50.90 \pm 16.68$ & $0.74 \pm 2.26$ & $-43.94 \pm 12.94$ & $1.75 \pm 1.63$ \\
\hline 13 & $-53.50 \pm 14.37$ & $0.66 \pm 1.81$ & $-46.06 \pm 12.32$ & $1.48 \pm 1.57$ \\
\hline 17 & $-54.05 \pm 14.47$ & $0.54 \pm 1.88$ & $-46.50 \pm 12.63$ & $1.42 \pm 1.71$ \\
\hline \multirow[t]{2}{*}{24} & $-54.02 \pm 14.67$ & $0.55 \pm 1.79$ & $-46.57 \pm 15.90$ & $1.35 \pm 1.57$ \\
\hline & $\delta_{\perp}\left({ }^{17} \mathrm{O}\right)$ & $\delta_{\perp}\left({ }^{1} H\right)$ & $\overline{\delta_{\perp}\left({ }^{17} O\right)}$ & $\overline{\delta_{\perp}}\left({ }^{1} H\right)$ \\
\hline 1 & 0.0 & 0.0 & 0.0 & 0.0 \\
\hline 5 & $-33.67 \pm 13.20$ & $-5.20 \pm 2.28$ & $-27.50 \pm 7.58$ & $-5.13 \pm 2.20$ \\
\hline 9 & $-39.52 \pm 13.56$ & $-5.08 \pm 2.07$ & $-32.95 \pm 6.69$ & $-5.19 \pm 1.87$ \\
\hline 13 & $-39.72 \pm 12.44$ & $-5.17 \pm 2.17$ & $-34.12 \pm 6.52$ & $-5.11 \pm 1.99$ \\
\hline 17 & $-39.78 \pm 12.63$ & $-5.21 \pm 2.19$ & $-33.93 \pm 6.54$ & $-5.20 \pm 2.26$ \\
\hline 24 & $-39.48 \pm 12.61$ & $-5.48 \pm 2.21$ & $-33.88 \pm 7.03$ & $-5.42 \pm 2.02$ \\
\hline
\end{tabular}

Tabela 11.6: Dependência das componentes paralela, $\delta / /$, perpendicular $\delta_{\perp}$ do tensor deslocamento químico isotrópico com o tamanho do aglomerado. Valores em ppm não corrigidos (sCC) e corrigidos (cCC) contra BSSE através da correção. As estruturas usadas nas médias foram geradas com o potencial DP e os cálculos quânticos foram realizados em nível B3LYP. As incertezas são os desvios padrão da média

nos aglomerados foi aumentado. Estes valores também convergiram para aglomerados com 13 moléculas, sendo $\delta_{/ /}\left({ }^{17} \mathrm{O}\right)=-46.06 \pm 12.32 \mathrm{ppm}$ e $\delta_{\perp}\left({ }^{17} \mathrm{O}\right)$ $=-34.12 \pm 6.52 \mathrm{ppm}$ os valores corrigidos contra BSSE. Quanto aos valores para os átomos de hidrogênio, foi observado que os deslocamentos $\delta / /\left({ }^{1} \mathrm{H}\right) \mathrm{e}$ $\delta_{\perp}\left({ }^{1} \mathrm{H}\right)$ têm sentidos opostos, sendo o valor convergido do primeiro $1.48 \pm 1.57$ ppm e do segundo $-5.11 \pm 1.99 \mathrm{ppm}$, ambos corrigidos contra BSSE. A Figura 11.6 mostra como os dois deslocamentos se comportam quando se aumenta o número de moléculas das camadas de solvatação.

\section{Dependência com o funcional}

Um importante fator para a descrição da blindagem magnética, e conseqüentemente para a descrição dos deslocamentos químicos através do método DFT é sem dúvida a escolha do funcional. Vários trabalhos têm explorado o uso de funcionais bem como sugerido melhorias para a aplicação da DFT em cálculos de blindagens magnéticas [297-299]. Nesta seção o comportamento dos deslocamentos químicos em relação ao uso dos funcionais foi analisado para uma 


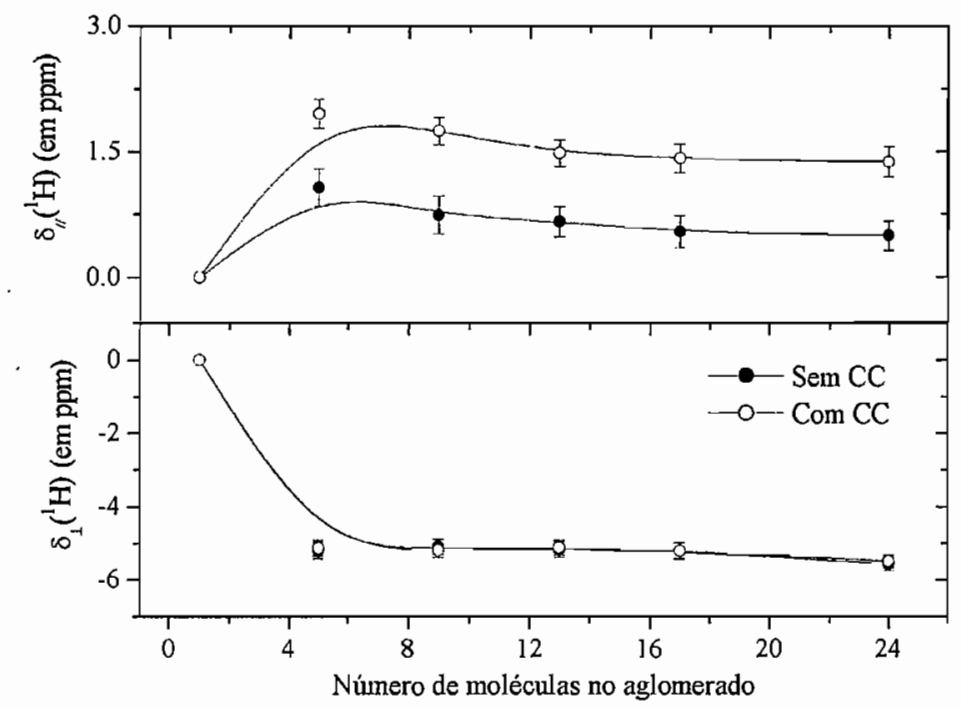

Figura 11.6: Convergência das componentes paralela, $\delta_{/ /}$, e perpendiculares, $\delta_{\perp}$, do deslocamento químico isotrópico do átomo de hidrogênio. Cada ponto no gráfico se refere a uma média sobre 50 cálculos B3LYP com base localmente densa, exceto para os aglomerados com 5 e 9 moléculas para os quais foram realizados 100 cálculos quânticos

vasta série de funcionais. Os funcionais de troca B [112], B3 [112] e G96 [300] foram empregados em combinação com os funcionais de correlação eletrônica P86 [113], LYP [111], PW91 [301]. Foi considerado interessante incluir também nesta análise os funcionais híbridos PBE1PBE [302], MPW1PW91 [303] e B971 [304]. Tendo em vista os resultados apresentados nas seções anteriores, foram usadas para esta análise médias sobre estruturas com 13 moléculas. Estas médias são apresentadas na Tabela 11.7 para o deslocamento químico isotrópico.

A dependência com o funcional ofereceu valores num intervalo de 7.24 ppm para o átomo de oxigênio, sendo o maior valor (em módulo) obtido com o funcional BLYP, $-43.10 \mathrm{ppm}$ e o menor obtido com o funcional B3PW91, $-35.86 \mathrm{ppm}$. Para os átomos de hidrogênio observou-se um intervalo de 0.18 ppm sendo o menor obtido com os funcionais MPW1PW91 e PBE1PBE e o maior obtido com o funcional G96P86. Nota-se que a escolha do funcional de troca é fundamental para a boa descrição do deslocamento isotrópico. Isto pode ser observado comparando os valores obtidos com os funcionais que usam B, B3 e G96 como funcionais de troca, por exemplo, para os quais a diferença chegou a $5 \mathrm{ppm}$ para o deslocamento isotrópico do átomo de oxigênio (é o caso dos funcionais BLYP e B3LYP), mostrando uma melhor qualidade do funcional de 


\begin{tabular}{ccccc}
\hline \hline & $\delta^{i s o}\left({ }^{17} \mathrm{O}\right)$ & $\delta^{\text {iso }}\left({ }^{1} \mathrm{H}\right)$ & $\delta^{\text {anis }}\left({ }^{17} \mathrm{O}\right)$ & $\delta^{\text {anis }}\left({ }^{1} \mathrm{H}\right)$ \\
\hline$B L Y P$ & $-43.10 \pm 7.93$ & $-2.98 \pm 1.04$ & $-11.50 \pm 10.28$ & $6.44 \pm 3.16$ \\
$B 3 L Y P$ & $-38.10 \pm 7.37$ & $-2.91 \pm 0.98$ & $-11.94 \pm 10.54$ & $6.59 \pm 3.35$ \\
$G 96 L Y P$ & & & & \\
& & & & \\
$B P 86$ & $-42.68 \pm 7.91$ & $-3.04 \pm 1.00$ & $-11.85 \pm 10.88$ & $6.44 \pm 3.33$ \\
$B 3 P 86$ & $-36.96 \pm 7.30$ & $-2.94 \pm 0.98$ & $-12.19 \pm 10.41$ & $6.41 \pm 3.33$ \\
$G 96 P 86$ & $-39.87 \pm 7.78$ & $-3.08 \pm 0.99$ & $-12.25 \pm 10.66$ & $6.64 \pm 3.34$ \\
& & & & \\
$B P W 91$ & $-40.35 \pm 7.70$ & $-3.03 \pm 1.00$ & $-11.58 \pm 10.74$ & $6.48 \pm 3.32$ \\
$B 3 P W 91$ & $-35.86 \pm 7.23$ & $-2.93 \pm 0.99$ & $-11.90 \pm 10.45$ & $6.55 \pm 3.32$ \\
$G 96 P W 91$ & $-37.53 \pm 7.64$ & $-3.06 \pm 1.00$ & $-11.96 \pm 10.62$ & $6.59 \pm 3.31$ \\
& & & & \\
$M P W 1 P W 91$ & $-35.86 \pm 7.15$ & $-2.90 \pm 0.98$ & $-11.66 \pm 10.36$ & $6.53 \pm 3.31$ \\
$P B E 1 P B E$ & $-36.14 \pm 7.13$ & $-2.90 \pm 0.97$ & $-11.76 \pm 10.29$ & $6.60 \pm 3.34$ \\
$B 971$ & $-36.29 \pm 7.14$ & $-2.92 \pm 0.98$ & $-11.91 \pm 10.28$ & $6.61 \pm 3.34$ \\
& & & & \\
$E x p$ & -36.1 & -4.26 & & \\
\hline \hline
\end{tabular}

Tabela 11.7: Valores médios em ppm para os deslocamento químicos obtidos para aglomerados com 13 moléculas de água com vários funcionais diferentes. As incertezas são os desvios padrão da média. Ref. [201]; b) Ref. [280]

troca B3. Em todos os casos os valores obtidos com o funcional de troca G96 foram intermediários aos valores obtidos com os funcionais B e B3.

Pode-se também comparar a qualidade dos funcionais de correlação. Nota-se que para o mesmo funcional de troca (B, B3 ou G96) o funcional PW91 foi o que apresentou os melhores valores para $\delta^{i s o}\left({ }^{17} \mathrm{O}\right)$, enquanto que os valores com o funcional P86 foram ligeiramente superiores ao PW91 para $\delta^{\text {iso }}\left({ }^{1} \mathrm{H}\right)$. Com o uso do funcional de correlação LYP foram obtidos os maiores valores para $\delta^{i s o}\left({ }^{17} \mathrm{O}\right)$ e os menores valores para $\delta^{\text {iso }}\left({ }^{1} \mathrm{H}\right)$. Em um trabalho recente sobre determinação de deslocamentos químicos para prótons de 105 moléculas em fase gasosa foi observado que os funcionais B3LYP, B3P86 e B3PW91 apresentavam essencialmente o mesmo desempenho. Contudo aqui observou-se que o funcional B3PW91 apresenta um desvio percentual em relação ao valor experimental bem menor $(0.7 \%)$ que os funcionais B3LYP $(5.5 \%)$ e B3P86 (2.4\%).

Os funcionais MPW1PW91 e PBE1PBE já foram empregados anteriormente com sucesso na determinação de deslocamentos químicos $[277,305]$. 
Aqui também se mostraram como bons modelos para o cálculo do deslocamentos químico gás-líquido, apresentando para $\delta^{i s o}\left({ }^{17} \mathrm{O}\right)$ um desvio menor que $0.7 \%$ em relação ao valor experimental.

Finalmente os valores obtidos para o deslocamento químico anisotrópico, tanto para os átomos de oxigênio quanto para os átomos de hidrogênio, se mostraram menos sensíveis ao funcional empregado, estando compreendidos num intervalo de apenas $0.75 \mathrm{ppm}$ para $\delta^{\text {anis }}\left({ }^{17} \mathrm{O}\right)$ e $0.23 \mathrm{ppm}$ para $\delta^{\text {anis }}\left({ }^{1} \mathrm{H}\right)$.

\subsection{Conclusões}

A dependência das blindagens absolutas com o potencial empregado na produção das estruturas do líquido foi analisada numa primeira abordagem. Através deste estudo inicial, que foi realizado em nível B3LYP/6-311++G(2d,2p), foi verificado que os potenciais de molécula rígida não são apropriados para a descrição do deslocamento químico, mostrando a necessidade de se considerar efeitos vibracionais no estudo da fase líquida. Foi verificado também que o potencial FERG, apesar de reproduzir relativamente bem o deslocamento químico, não proporcionou uma boa descrição para a blindagem magnética absoluta. Assim, foi considerado nas análises seguintes apenas o potencial DP que reproduziu de maneira satisfatória tanto as blindagens absolutas quanto os deslocamentos químicos.

Para o estudo da convergência em relação ao tamanho dos aglomerados a serem considerados nas médias foram analisados aglomerados contendo $5,9,13,17$ e 24 moléculas. O expediente de base localmente densa foi empregado para a realização dos cálculos onde a primeira camada de solvatação (a molécula de referência e suas primeiras quatro vizinhas) foram tratadas com a base $6-311++G(2 d, 2 p)$ enquanto que as demais moléculas do aglomerado foram descritas pela base 3-21G. Foi observado que a diferença entre os resultados obtidos com o método convencional, onde todas as moléculas são descritas com a base melhor e pelo método de base localmente densa, foi pequena, não chegando a 1 ppm para o deslocamento químico isotrópico do átomo de oxigênio 
no aglomerado com 9 moléculas. Isto permitiu que a demanda computacional fosse drasticamente reduzida.

Para cada tamanho de aglomerado foram obtidos os deslocamentos químicos isotrópicos e anisotrópicos com e sem correção de superposição de base, representados por médias sobre 50 configurações, exceto para os aglomerados com 5 e 9 moléculas onde foram usadas 100 configurações na obtenção da média. Verificou-se que o deslocamento químico isotrópico para o átomo de oxigênio só alcançou concordância aceitável com o valor experimental quando o tamanho do aglomerado atingiu 13 moléculas e quando o BSSE foi corrigido. Para o deslocamento químico anisotrópico o erro foi menor, não alcançando 2 ppm para o átomo de oxigênio e $1 \mathrm{ppm}$ para os átomos de hidrogênio. Assim, com o funcional B3LYP, foi obtido o valor de $-38.10 \pm 7.37 \mathrm{ppm}$ e $-2.91 \pm 0.98$ ppm como sendo a melhor descrição para os deslocamentos químicos isotrópicos para os átomos de oxigênio e hidrogênio respectivamente. Este valor apesar de razoável, apresentou um desvio percentual de $5 \%$ em relação ao valor experimental fornecendo um motivo para analisar a dependência do deslocamento químico com o funcional utilizado.

Para esta análise foram considerados 12 funcionais diferentes, e verificou-se um intervalo de de $7.24 \mathrm{ppm}$ para o átomo de oxigênio, sendo o maior valor obtido com o funcional BLYP, $-43.10 \mathrm{ppm}$ e o menor obtido com o funcional B3PW91, $-35.86 \mathrm{ppm}$ (ambos em módulo). Notou-se que a escolha do funcional de troca é fundamental para a descrição do deslocamento químico, podendo variar até $5 \mathrm{ppm}$ em os funcionais B e B3. Notou-se também que os valores obtidos com funcionais que empregam os funcionais de troca G96 produzem resultados intermediários aqueles obtidos com funcionais de troca $\mathrm{B}$ e B3, sendo B3 o funcional que produz os melhores resultados. Os funcionais MPW1PW91, PBE1PBE e B971 apresentaram resultados para $\delta \delta^{i s o}\left({ }^{17} \mathrm{O}\right)$ em excelente acordo com o valor experimental, todos com desvio percentual menor que $0.7 \%$. Foi verificado que o deslocamentos químicos anisotrópicos, se mostraram menos sensíveis ao funcional empregado, estando compreendidos num intervalo de apenas $0.75 \mathrm{ppm}$ para $\delta^{\text {anis }}\left({ }^{17} \mathrm{O}\right)$. 


\section{Parte IV}

\section{Conclusões gerais}




\section{Capítulo 12}

\section{Conclusões Gerais}

\subsection{Conclusões Gerais}

Neste trabalho foi apresentada uma série de estudos que detalhou a influência do meio sobre as propriedades moleculares. Tais estudos são importantes para a compreensão de muitos fenômenos físicos, químicos e biológicos uma vez que a maior parte de tais fenômenos ocorrem em fase condensada. Os trabalhos sobre aglomerados, mostrados nos capítulos 4, 5, 6 e 7, analisaram as modificações de várias propriedades moleculares devido à complexação em fase gasosa. No caso do estudo dos aglomerados todos os cálculos foram realizados nas geometrias de equilíbrio. Para o complexo $\mathrm{CH}_{3} \mathrm{CN} \cdots \mathrm{H}_{2} \mathrm{O}$ (capítulo 4) foram analisadas as freqüências vibracionais, atividades Raman e Rayleigh, taxas de despolarização, momento de dipolo e energias de ligação. Quatro modelos envolvendo os métodos MP2 e DFT foram empregados nas análises e se mostraram bastante eficazes para o entendimento da estrutura eletrônica do sistema tratado.

No capítulo 5 foi feita uma investigação baseada no espalhamento Rayleigh para analisar pequenos complexos com ligações de hidrogênio. O modelo MP2/aug-cc-pVDZ foi empregado para otimizar as geometrias dos complexos em estudo. A partir do tensor polarizabilidade de dipolo foram obtidas, para diferentes tipos de polarização da luz (natural, plano-polarizada e circularmente polarizada), as taxas de despolarização e as atividades de espalhamento Rayleigh. A técnica de espalhamento Rayleigh foi avaliada como um possível meio de identificar complexos moleculares, através do estudo das interações 
entre cianeto de hidrogênio e água bem como metanol e água uma vez que detecções viáveis destes complexos têm sido de grande interesse em físico-química.

O estudo sobre o deslocamento químico da blindagem magnética em complexos de metanol-água, apresentado no capítulo 6 analisou resultados para as duas possibilidades isoméricas $\mathrm{CH}_{3} \mathrm{HO} \cdots \mathrm{H}_{2} \mathrm{O}$ (metanol aceitador de próton) e $\mathrm{CH}_{3} \mathrm{OH} \cdots \mathrm{OH}_{2}$ (metanol doado de próton). Para tal estudo foram empregados cálculos SCF, MP2 e DFT associados com o conjunto de funções base $6-311++G(2 d, 2 p)$ para a determinação da blindagem magnética isotrópica e anisotrópica dos complexos e das espécies isoladas. Foi observado que o deslocamento isotrópico bem como o deslocamento anisotrópico são mais sensíveis para os átomos que participam diretamente da ligação de hidrogênio e foi observado também que, geralmente, o deslocamento anisotrópico é mais sensível à formação da ligação do que o deslocamento isotrópico. Os resultados em geral mostraram que os átomos das moléculas doadoras tornam-se mais blindados enquanto que os átomos da moléculas aceitadoras tornam-se mais "desblindados". Os valores para as componentes perpendiculares do deslocamento químico foram mais sensíveis à formação da ligação de hidrogênio que a componente paralela no caso do próton que participa da ligação.

O último estudo sobre aglomerados moleculares é apresentado no capítulo 7 onde a intensidade relativa das ligações de hidrogênio em complexos envolvendo álcool e água foi estabelecida. Foi verificado que que no caso dos heterodímeros de metanol-água e etanol-água, o heterodímero mais estável é aquele onde a água atua como doadora de próton e que no caso dos heterodímeros de metanol e etanol estes dois isômeros têm essencialmente, em todos os níveis teóricos considerados, a mesma energia.

Nos capítulos de 8 a 11 foram apresentados resultados referentes à modificação de propriedades quando comparadas à fase líquida. Um dos mais importantes aspectos teóricos do líquido provém da desordem térmica que apresenta sua essência estatística. Esta desordem térmica é contemplada pela metodologia seqüencial, simulação/MQ, onde as análises da simulação são completamente disponíveis antes da realização dos cálculos de mecânica quântica. 
Esta metodologia é conceitualmente segura e versátil pois pode ser aplicada na determinação de várias propriedades moleculares levando-se em conta o caráter aléatorio das configurações moleculares da fase líquida fornecendo resultados estatisticamente convergidos.

A influência da desordem térmica sobre as estruturas com ligações de hidrogênio foi analisada para dois sistemas: piridina em água e metanol em água (capítulos 8 e 9). Para a molécula de piridina em ambiente aquoso foram determinados o momento de dipolo e a polarizabilidade de dipolo como propriedades eletrônicas de prova. Foi verificado que os resultados para o momento de dipolo, polarizabilidades de dipolo e taxas de despolarização calculadas para o complexo de piridina e água são estatisticamente convergidos e incorporam a natureza desordenada do líquido. Os resultados para o momento de dipolo mostraram que a desordem afeta o momento de dipolo local. No meio líquido, a desordem levou a um momento de dipolo médio para o complexo inferior aquele para o complexo otimizado. Contudo, neste caso, as diferenças foram importantes porém não mensuráveis. O efeito da despolarização Rayleigh foi também considerado para este sistema. Os resultados indicam que as taxas de despolarização foram sistematicamente diminuídas no líquido em relação ao complexo otimizado para todos os três tipos de polarização considerados aqui. As intensidades Rayleigh foram essencialmente as mesmas. As taxas de despolarização, foram contudo, diferentes para a luz natural, planar e circularmente polarizada, mas nos três casos esta diferença foi uma redução de $10 \%$ em relação ao complexo otimizado. Para a solução líquida de metanol e água foram considerados os dois possíveis isômeros. A partir das estruturas do líquido geradas por simulações Monte Carlo, a energia de interação média entre metanol e água foi determinada em nível MP2/aug-cc-pVDZ. Foi verificado que energias de ligação (1:1) em fase líquida, convergidas estatisticamente, diminui para cerca de $2 / 3$ comparada à energia das estruturas otimizadas enquanto que em meio aquoso os dois isômeros têm a mesma energia de ligação média.

No capítulo 10 a metodologia seqüencial Simulação/MQ foi usada para estudar o líquido de benzeno em temperatura ambiente. Cálculos na aproximação de campo finito com a metodologia INDO foram realizados nas estru- 
turas supermoleculares incluindo todas as moléculas de benzeno dentro de $10 \AA$. Os resultados para este sistema indicaram que a polarizabilidade de dipolo do líquido é equivalente à de fase gasosa, o que corrobora a recente contenda de que a polarizabilidade de dipolo da molécula de benzeno sofre somente uma pequena mudança em fase líquida quando comparada à fase gasosa.

Finalmente no capítulo 11 o estudo de blindagens magnéticas e deslocamentos químicos foi apresentado para o líquido de água. Para isto o líquido foi simulado com quatro potenciais empíricos simples; dois sem termos intramoleculares e dois com termos intramoleculares. Vários aspectos foram considerados, como por exemplo a dependência do deslocamento com o potencial usado na simulação do líquido, com o tamanho dos aglomerados sobre os quais as médias foram tomadas e com o funcional utilizado. Foi verificado que o deslocamento químico experimental foi muito bem descrito com o uso do funcional B3PW91 e que a metodologia seqüencial é uma poderosa ferramenta para o estudo de deslocamento químicos gás-liquido.

Para o estudo das propriedades de moléculas em líquido as estruturas do líquido foram, primeiramente, geradas usando simulação clássica. $\mathrm{Na}$ seqüencia, as configurações estatisticamente relevantes são separadas e submetidas a cálculos de mecânica quântica. Desta forma todas as propriedades obtidas para os sistemas em fase líquida foram representadas por médias estatisticamente convergidas sobre os valores obtidos nos cálculos de mecânica quântica. 


\section{Bibliografia}

[1] J. G. Kirkwood, Theory of solutions of molecules containing widely separated charges with special applications to zwitterions, J. Chem. Phys. 2, 351 (1934).

[2] L. Onsager, Electric moments of molecules in liquids, J. Am. Chem. Soc. 58, $1486(1936)$.

[3] O. Tapia e O. Goscinski, Self-consistent reaction field-theory of solvent effects, Mol. Phys. 29, 1653 (1975).

[4] J. L. Rivail e D. Rinaldi, Quantum chemical approach to dielectric solvent effects in molecular liquids, Chem. Phys. 18, 233 (1976).

[5] J. Tomasi e M. Persico, Molecular interactions in solution - An overview of methods based on continuous distributions of the solvent, Chem. Rev. 94, 2027 (1994).

[6] M. M. Karelson e M. C. Zerner, Theoretical treatment of solvent effects on electronic spectroscopy, J. Phys. Chem. 96, 6949 (1992).

[7] K. Jackowski e A. Barszczewicz, Additivity of intermolecular effects calculated by the CHF-GIAO method fot the nitrogen and proton shielding constants in solid ammonia, J. Mol. Struct. 431, 47 (1998).

[8] K. Jackowski, Effects of molecular association on the NMR shielding constants in acetonitrile, Chem. Phys. Lett. 194, 167 (1992).

[9] D. M. Heyes, The liquid state. Applications of molecular simulations, John Wiley, New York, 1998. 
[10] M. P. Allen e D. J. Tildesley, Computer simulation of liquids, Clarendon Press, Oxford, 1987.

[11] J. Gao e M. A. Thompson, Combined Quantum Mechanical and Molecular Mechanical Models , ACS Symposium Series, Washington DC, 1998.

[12] A. Warshel e M. Levitt, Theoretical studies of enzymic reactions - Dielectric, electrostatic and steric stabilization of carbonium-ion in reaction of lysozyme, J. Mol. Biol. 103, 227 (1976).

[13] A. Warshel, Calculations of chemical processes in solutions, J. Phys. Chem. 83, 1640 (1979).

[14] S. Canuto e K. Coutinho, Solvent effects from a sequential Monte Carloquantum mechanical approach, Adv. Quantum Chem. 28, 89 (1997).

[15] J. T. Blair, K. Krogh-Jespersen e R. M. Levy, Solvent effects on opticalabsorption spectra - The ${ }^{1} A_{1} \rightarrow^{1} A_{2}$ transition of formaldehyde in water, J. Am. Chem. Soc. 111, 6948 (1989).

[16] J. Gao, Monte-Carlo quantum mechanical-configuration interaction and molecular mechanics simulation of solvent effects on the $n-\pi^{*}$ blue-shift of acetone, J. Am. Chem. Soc. 116, 9324 (1994).

[17] J. Zeng, N. S. Hush e J. R. Reimers, Solvent effects on molecular spectra. 2. Simulations of hydrated clusters and dilute-solutions of pyrimidine in its lowest $\left(n, \pi^{*}\right)$ singlet excited-state, J. Chem. Phys. 99, 1496 (1993).

[18] K. Coutinho, S. Canuto e M. C. Zerner, Calculation of the absorption spectrum of benzene in condensed phase. A study of the solvent effects, Int. J. Quantum Chem. 65, 885 (1997)

[19] C. L. Perrin e J. B. Nielson, Strong hydrogen bonds in chemistry and biology, Ann. Rev. Phys. Chem. 48, 511 (1997).

[20] R. K. Pathria, Statistical mechanics, Pergamon Press, Oxford, 1977.

[21] R. Kubo, Statistical mechanics, North-Holland, Amsterdam, 1965. 
[22] D. Chandler, Introduction to Modern Statistical Mechanics, Oxford University Press, New York, 1987.

[23] D. McQuarrie, Statistical Mechanics, Harper and Row, New York, 1976.

[24] N. Metropolis e S. Ulam, The Monte Carlo method, J. Am. Stat. Ass. 44, 335 (1949).

[25] N. Metropolis, A. W. Rosenbluth, M. N. Rosenbluth, A. H. Teller e E. Teller, Equation of state calculations by fast computing machines, J. Chem. Phys. 21, 1087 (1953).

[26] B. J. Alder e T. E. Wainwright, Phase transition for a hard sphere system, J. Chem. Phys. 27, 1208 (1957).

[27] B. J. Alder e T. E. Wainwright, Studies in molecular dynamics. I General methods, J. Chem. Phys. 31, 459 (1959).

[28] A. Rahman, Correlations in motion of atoms in liquid argon, Phys. Rev. A 136, 405 (1964).

[29] F. H. Stillinger e A. Rahman, Improved simulation of liquid water by molecular dynamics, J. Chem. Phys. 60, 1545 (1974).

[30] D. C. Rapaport, The art of Molecular Dynamics, Cambridge University Press, Cambridge, 1995.

[31] R. W. Hockney, S. P. Goel e J. W. Eastwood, Quiet high-resolution computer models of a plasma, J. Comp. Phys. 14, 148 (1974).

[32] L. Verlet, Computer experiments on classical fluids. I Thermodynamical properties of Lennard-Jones molecules, Phys. Rev. 159, 98 (1967).

[33] J. E. Lennard-Jones, The determination of molecular fields. II. From the equation of state of a gas, Proc. R. Soc. Lon. 106, 463 (1924).

[34] K. Coutinho, M. J. Oliveira e S. Canuto, Sampling configurations in the Monte Carlo simulation of solvent effects, Int. J. Quantum Chem. 66, 249 (1998). 
[35] K. Coutinho, S. Canuto e M. C. Zerner, A Monte Carlo-quantum mechanics study of the solvatochromic shift of the lowest excited state of benzene, J. Chem. Phys. 112, 9874 (2000).

[36] R. Krätschmer, K. Binder e D. Stauffer, Linear and nonlinear relaxation and cluster dynamics near critical-points, J. Stat. Phys. 15, 267 (1976).

[37] S. Tang e D. P. Landau, Monte Carlo study of dynamic universality in two-dimensional Potts models, Phys. Rev. B 36, 567 (1987).

[38] T. Malaspina, K. Coutinho e S. Canuto, Ab initio calculation of hydrogen bonds in liquids: A sequential Monte Carlo quantum mechanics study of pyridine in water, J. Chem. Phys. 117, 1692 (2002).

[39] F. H. Stillinger, Theory and molecular models for water, Adv. Chem. Phys. 31, 1 (1975).

[40] M. Mezei e D. L. Beveridge, Monte-Carlo studies of the structure of dilute aqueous-solutions of $\mathrm{Li}^{+}, \mathrm{Na}^{+}, \mathrm{K}^{+}, \mathrm{F}^{-}$, and $\mathrm{Cl}^{-}, J$. Chem. Phys. 74, $6902(1981)$.

[41] W. L. Jorgensen, J. M. Briggs e M. L. Contreras, Relative partitioncoefficients for organic solutes from fluid simulations, J. Phys. Chem. 94, $1683(1990)$.

[42] H. Sato e F. Hirata, Ab initio study of water. II. Liquid structure, electronic and thermodynamic properties over a wide range of temperature and density, J. Chem. Phys. 111, 8545 (1999).

[43] S. Canuto e K. Coutinho, From hydrogen bond to bulk: Solvation analysis of the $n-\pi^{*}$ transition of formaldehyde in water, Int. J. Quantum Chem. 77, $192(2000)$.

[44] K. Coutinho e S. Canuto, Solvent effects in emission spectroscopy. A Sequential Monte Carlo-quantum mechanics study of the $n-\pi^{*}$ shift of formaldehyde in water, J. Chem. Phys. 113, 9132 (2000). 
[45] P. W. Atkins e R. S. Friedman, Molecular quantum mechanics, Oxford University Press, Oxford, 1997.

[46] F. Jensen, Introduction to computational chemistry, John Wyley, New York, 1999.

[47] I. N. Levine, Quantum Chemistry, Prentice Hall, New Jersey, 2000.

[48] M. Born e J. R. Oppenheimer, Zur Quantentheorie der Molekeln, Annln. Phys. 84, 457 (1927).

[49] M. Born e K. Huang, Dynamical theory of cristal lattices, Oxford University Press, London, 1954.

[50] B. T. Sutcliffe, in Computational techniques in quantum chemistry; Fundamentals of computational quantum chemistry, Oxford University Press, New York, 1989.

[51] D. R. Hartree, The wave mechanics of an atom with a non-Coulomb central field. Part I - Theory and methods, Proc. Camb. Phil. Soc. 24, 111 (1928).

[52] V. A. Fock, Näherungsmethode zur lösung des quantenmechanischen mehrkörperproblems, Z. Phys. 61, 126 (1930).

[53] J. C. Slater, Note on Hartree's Method, Phys. Rev. 35, 210 (1930).

[54] C. C. J. Roothaan, New developments in molecular orbital theory, Mod. Phys. 23, 69 (1951).

[55] W. J. Hehre, L. Radom, P. V. R. Schleyer e J. A. Pople, Ab initio molecular orbital theory, John Wiley, New York, 1986.

[56] R. McWeeny, Methods of molecular quantum mechanics, Academic Press, London, 1989.

[57] J. D. Vianna, A. Fazzio e S. Canuto, Teoria quântica de moléculas e sólidos, Livraria da Física, São Paulo, 2004. 
[58] A. Szabo e N. S. Ostlund, Modern quantum chemistry. Introduction to advanced electronic structure theory, Dover, New York, 1982.

[59] P.-O. Löwdin, A note on the quantum-mechanical perturbation theory, J. Chem. Phys. 19, 1396 (1951).

[60] E. Schrödinger, Quantisation as a problem of characteristic values, the perturbation theory and its application to the Stark-effect of the $\mathrm{H}$ Balmer lines, Ann. Phys. 80, 437 (1926).

[61] C. Møller e M. S. Plesset, Note on an approximation treatment for manyelectron systems, Phys. Rev. 46, 618 (1934).

[62] S. Wilson, Electron correlation in molecules, Clarendon Press, Oxford, 1984.

[63] P.-O. Löwdin, Correlation problem in many-electron quantum mechanics.

1. Review of different approaches and discussion of some current ideas, Adv. Chem. Phys. 2, 207 (1959).

[64] R. J. Bartlett, Many-body perturbation theory and coupled cluster theory for electon correlation in molecules, Ann. Rev. Phys. Chem. 32, 359 (1981).

[65] J. Paldus e J. Cizek, Time-independent diagrammatic approach to perturbation theory of fermion systems, Adv. Quantum Chem. 9, 105 (1975).

[66] L. H. Thomas, The calculation of atomic fields, Proc. Camb. Phil. Soc. 23, 542 (1927).

[67] E. Fermi, Eine statistische methode zur bestimmung einiger eigenschaften des atoms und ihre anwendung auf die theorie des periodischen systems der elemente, Z. Phys. 48, 73 (1928).

[68] P. Hohenberg e W. Kohn, Inhomogeneous electron gas, Phys. Rev. 136, 864 (1964).

[69] W. Kohn e L. J. Sham, Self-consistent equations including exchange and correlation effects, Phys. Rev. 140, 1133 (1965). 
[70] R. G. Parr e W. Yang, Density functional theory of atoms and molecules, Oxford University Press, New York, 1989.

[71] T. Ziegler, Approximate density functional theory as a practical tool in molecular energetics and dynamics, Chem. Rev. 91, 651 (1991).

[72] S. F. Boys e F. Bernardi, Calculation of small molecular interactions by differences of separate total energies - Some procedures with reduced errors, Mol. Phys. 19, 553 (1970).

[73] F. B. van Duijneveldt, in Molecular interactions; From van der Waals to strongly bond complexes; Basis set superposition error, John Wiley, New York, 1997.

[74] H. D. Cohen e C. C. Roothaan, Electric dipole polarizability of atoms by Hartree-Fock method. I. Theory for closed-shell systems, J. Chem. Phys. 43, 034 (1965).

[75] J. E. Gready, G. B. Bacskay e N. S. Hush, Finite-field method calculations. 4. Higher-order moments, dipole-moment gradients, polarizability gradients and field-induced shifts in molecular-properties - Application to $\mathrm{N}_{2}, \mathrm{CO}, \mathrm{CN}^{-}, \mathrm{HCN}$ and HNC, Chem. Phys. 31, 467 (1978).

[76] G. H. F. Diercksen e A. J. Sadlej, Finite-field many-body perturbationtheory - quadrupole polarizability of Be, Chem. Phys. Lett. 89, 423 (1982).

[77] S. Wilson e A. J. Sadlej, Finite-field many-body perturbation-theory Calculations of the dipole polarizability of the fluoride-ion using electricfield-variant gaussian-type orbitals, Theor. Chim. Acta 60, 19 (1981).

[78] G. H. F. Diercksen e A. J. Sadlej, Electric properties of ionic diatoms LiF, Chem. Phys. Lett. 153, 93 (1988).

[79] G. Maroulis, Static electric polarizability and hyperpolarizability of $\operatorname{BCl}\left(\mathrm{X}^{1} \Sigma^{+}\right)$, J. Phys. B: At. Mol. Opt. Phys. 34, 3727 (2001). 
[80] D. R. Kanis, M. A. Ratner e T. J. Marks, Design and construction of molecular assemblies with large $2^{\text {nd }}$-order optical nonlinearities - Quantumchemical aspects, Chem. Rev. 94, 195 (1994).

[81] P. Ehrenfest, Bemerkung über die angenäherte Gültigkeit der klassischen Mechanik innerhalb der Quantenmechanik, Z. Phys. 45, 455 (1927).

[82] H. Hellman, Einführung in die Quantumchemie, Leipzig, Deuticke, 1937.

[83] R. P. Feynman, Forces in Molecules, Phys. Rev. 56, 340 (1939).

[84] G. Herzberg, Infrared and Raman spectra of polyatomic molecules, Van Nostrand, Princeton, 1945.

[85] L. A. Woodward, Introduction to the theory of molecular vibrations and vibrational spectrospy, Clarendon Press, Clarendon, 1972.

[86] I. L. Fabellinskii, Molecular scattering of light, Plenum Press, New York, 1968.

[87] C. V. Raman, A new radiation, Indian. J. Phys. 2, 387 (1928).

[88] C. V. Raman e K. S. Krishnan, A new type of secondary radiation, Nature 121, 501 (1928).

[89] E. B. W. Jr., J. C. Decius e P. C. Cross, Molecular vibrations: The theory of infrared and Raman vibrational spectra, Dover, New York, 1980.

[90] J. A. Pople, W. G. Schneider e H. J. Bernstein, High-resolution nuclear magnetic resonance, McGraw-Hill, New York, 1959.

[91] E. D. Becker, High-resolution NMR. Theory and chemical applications, Academic Press, New York, 1969.

[92] A. Carrington e A. D. McLachlan, Introduction to magnetic resonance. With applications to chemistry and chemical physics, Harper and Row, London, 1967.

[93] C. P. Slichter, Principles of magnetic resonance, Harper and Row, New York, 1963. 
[94] D. N. Shin, J. W. Wijnen, J. B. F. N. Engberts e A. Wakisaka, On the origin of microheterogeneity: Mass spectrometric studies of acetonitrile-water and dimethyl sulfoxide-water binary mixtures (part 2), J. Phys. Chem. B 106, 6014 (2002).

[95] J. B. F. N. Engberts e M. J. Blandamer, Understanding organic reactions in water: from hydrophobic encounters to surfactant aggregates, Chem. Comm. 18, 1701 (2001).

[96] R. Plasil, J. Glosik e P. Zakouoil, Formation and recombination of protonated acetonitrile clusters, J. Phys. B: At. Mol. Opt. Phys. 32, 3575 (1999).

[97] P. Pratap, S. T. Megeath e E. A. Bergin, High-angular resolution millimeter-wave and near-infrared imaging of the ultracompact HII region G29.96-0.02, Astrophysical Journal 517, 799 (1999).

[98] S. V. Kalenskii, V. G. Promislov, A. V. Alakoz, A. Winnberg e L. E. B. Johansson, Probing the properties of methyl cyanide sources, Astronomy and Astrophysics 354, 1036 (2000).

[99] S. V. Kalenskii, V. G. Promislov, A. V. Alakoz, A. Winnberg e L. E. B. Johansson, Determination of molecular gas properties using methyl cyanide lines, Astronomy Reports 44, 725 (2000).

[100] H. D. Kim, S. H. Cho, H. S. Chung, H. R. Kim, D. G. Roh, H. G. Kim, Y. C. Minh, e Y. K. Minn, A spectral line survey of G34.3+0.15 at 3 millimeters (84.7-115.6 GHz) and 2 millimeters (123.5-155.3 GHz), Astrophysical Journal Supplement Series 131, 483 (2000).

[101] S. Scheiner, Hydrogen bonding: A theoretical perspective, Oxford University Press, Oxford, 1997.

[102] T. S. Zwier, The spectroscopy of solvation in hydrogen-bonded aromatic clusters, Ann. Rev. Phys. Chem. 47, 205 (1996). 
[103] W. Caminati, P. Moreschini e P. G. Favero, The hydrogen bond between water and aromatic bases of biological interest: Rotational spectrum of pyridazine-water, J. Phys. Chem. A 102, 8097 (1998).

[104] G. Scoles, editor, The chemical physics of atomic and molecular clusters, North-Holland, Amsterdam, 1990.

[105] E. R. Bernstein, editor, Atomic and molecular clusters, Elsevier, Amsterdam, 1990.

[106] A. D. Buckingham, P. W. Fowler e J. M. Hutson, Theoretical studies of van der Waals and intermolecular forces, Chem. Rev. 88, 963 (1988).

[107] J. R. Damewood e R. A. Kumpf, Hidratation of polar organic-molecules. The interaction of acetonitrile with water, J. Phys. Chem. 91, 3449 (1987).

[108] C. Desfrançois, H. Abdoul-Carime, N. Khelifa, J. P. Schermann, V. Brenner, e P. Millie, Dipole binding - An experimental test for small cluster structure calculations, J. Chem. Phys. 102, 4952 (1995).

[109] C. Desfrançois, H. Abdoul-Carime, C. P. Schulz e J. P. Schermann, Laser separation of geometrical-isomers of weakly-bound molecular-complexes, Science 269, 1707 (1995).

[110] A. Burneau, L. Schriver, L. Manceron e J. P. Perchard, Matrix-isolation study of water interacting with organic-bases. 1 . Water-dimethyl ethers system - An approach to the structural-properties of the water trimer, J. Chim. Phys. Phys. Chim. Biol. 82, 19 (1985).

[111] C. T. Lee, W. T. Yang e R. G. Parr, Development of the ColleSalvetti correlation-energy formula into a functional of the electrondensity, Phys. Rev. B 37, 785 (1988).

[112] A. D. Becke, Density-functional exchange-energy approximation with correct asymptotic-behavior, Phys. Rev. A 38, 3098 (1988). 
[113] J. P. Perdew, Density-functional approximation for the correlation-energy of the inhomogeneous electron-gas, Phys. Rev. B 33, 8822 (1986).

[114] A. Wilson, T. van Mourik e T. H. Dunning, Gaussian basis sets for use in correlated molecular calculations. 6. Sextuple zeta correlation consistent basis sets for boron through neon, J. Mol. Struct. (THEOCHEM) 388, 339 (1996).

[115] K. Raghavachari, Electron correlation techniques in quantum-chemistry - Recents advances, Ann. Rev. Phys. Chem. 42, 615 (1991).

[116] R. J. Bartlett, Coupled-cluster approach to molecular-structure e spectra - A step toward predictive quantum-chemistry, J. Phys. Chem. 93, 1697 (1989).

[117] M. J. Frisch, G. W. Trucks, H. B. Schlegel, G. E. Scuseria, M. A. Robb, J. R. Cheeseman, V. G. Zakrzewski, J. A. Montgomery, Jr., R. E. Stratmann, J. C. Burant, S. Dapprich, J. M. Millam, A. D. Daniels, K. N. Kudin, M. C. Strain, O. Farkas, J. Tomasi, V. Barone, M. Cossi, R. Cammi, B. Mennucci, C. Pomelli, C. Adamo, S. Clifford, J. Ochterski, G. A. Petersson, P. Y. Ayala, Q. Cui, K. Morokuma, D. K. Malick, A. D. Rabuck, K. Raghavachari, J. B. Foresman, J. Cioslowski, J. V. Ortiz, A. G. Baboul, B. B. Stefanov, G. Liu, A. Liashenko, P. Piskorz, I. Komaromi, R. Gomperts, R. L. Martin, D. J. Fox, T. Keith, M. A. Al-Laham, C. Y. Peng, A. Nanayakkara, C. Gonzalez, M. Challacombe, P. M. W. Gill, B. Johnson, W. Chen, M. W. Wong, J. L. Andres, C. Gonzalez, M. HeadGordon, E. S. Replogle e J. A. Pople, Gaussian 98: Revision A.7, 1998.

[118] D. R. Lide, editor, Handbook of chemistry and physics, $73^{\text {rd }}$ edition, 1992-1993, CRC-Pres, Boca Raton, 1992.

[119] W. J. Lafferty e F. J. Lovas, Microwave-spectra of molecules of astrophysical interest. 13. Cyanoacetylene, J. Phys. Chem. Ref. Data 7, 441 (1978).

[120] L. G. Christophorou e A. A. Christodoulides, Scattering of thermal electrons by polar molecules, J. Phys. B: At. Mol. Opt. Phys. 2, 71 (1969). 
[121] Y. Koga, S. Kondo, S. Saeki e W. B. Person, Infrared intensities of acetonitrile, J. Phys. Chem. 88, 3152 (1984).

[122] R. M. Bentwood, A. J. Barnes e W. J. OrvilleThomas, Studies of intermolecular interactions by matrix-isolation vibrational spectoscopy Self-association of water, J. Mol. Struct. 84, 391 (1980).

[123] P. Hobza e Z. Havlas, Blue-shifting hydrogen bonds, Chem. Rev. 100, 4253 (2000).

[124] R. Rivelino e S. Canuto, An ab initio study of the hydrogen bonded $\mathrm{HCN} \cdots \mathrm{H}_{2} \mathrm{O}$ and $\mathrm{H}_{2} \mathrm{O} \cdots \mathrm{HCN}$ isomers, Chem. Phys. Lett. 322, 207 (2000).

[125] S. Scheiner, T. Kar e Y. Gu, Strength of the (CH)-H-alpha ... O hydrogen bond of amino acid residues, J. Biol. Chem. 276, 9832 (2001).

[126] D. J. Swanton, G. B. Bacskay e N. S. Hush, An ab initio SCF calculation of the polarizability tensor, polarizability derivatives and Ramanscattering activities of the water-dimer molecule, Chem. Phys. 83, 69 (1984).

[127] A. M. Bush, A. J. Bell e J. G. Frey, Rayleigh scattering of laser and synchrotron radiation from pulsed free jets of $\operatorname{Ar}-\mathrm{N}$ and $\left(\mathrm{N}_{2} \mathrm{O}\right)_{n}$ clusters, J. Phys. Chem. A 102, 6457 (1998).

[128] A. J. Bell, J. M. M. A. J., J. Berlande, X. Biquard, J. Cuvellier, A. Lallement, P. Meynadier, O. Sublemontier, and J.-P. Visticot, Mean clusters size by Rayleigh-scattering, J. Phys. D: Appl. Phys. 26, 994 (1993).

[129] Y. Teragishi e K. Aoki, Formation of conducting clusters of polyaniline films detected by light scattering, J. Electroanal. Chem. 473, 132 (1999).

[130] R. F. G. Meulenbroeks, D. C. Schram, L. J. M. Jaegers e M. C. M. van de Sanden, Depolarization Rayleigh-scattering as a means of molecular concentration determination in plasmas, Phys. Rev. Lett. 69, 1379 (1992). 
[131] H. S. Park, K. S. Oh, K. S. Kim, T. Chang e D. R. Spiegel, Change of internal hydrogen bonding of methyl red upon photoisomerization monitored by forced Rayleigh scattering, J. Phys. Chem. B 103, 2355 (1999).

[132] N. Micali, S. Trusso, C. Vasi, D. Blaudez e F. Mallamace, Dynamical properties of water-methanol solutions studied by depolarized Rayleigh scattering, Phys. Rev. E 54, 1720 (1996).

[133] L. A. Curtiss e J. A. Pople, Ab initio calculation of vibrational force-field of water dimer, J. Mol. Struct. 55, 1 (1975).

[134] G. H. F. Diercksen, W. P. Kraemer e B. O. Roos, SCF-CI studies of correlation effects on hydrogen-bonding and ion hydration systems $\mathrm{H}_{2} \mathrm{O} ; \mathrm{H}^{+} \cdots \mathrm{H}_{2} \mathrm{O}, \mathrm{Li}^{+} \cdots \mathrm{H}_{2} \mathrm{O}, \mathrm{F}^{-} \cdots \mathrm{H}_{2} \mathrm{O}$, and $\mathrm{H}_{2} \mathrm{O} \cdots \mathrm{H}_{2} \mathrm{O}$, Theor. Chim. Acta 36, 249 (1975).

[135] M. J. Frisch, J. A. Pople e J. E. del Bene, Molecular-orbital study of the dimers $(\mathrm{AHN})_{2}$ formed from $\mathrm{NH}_{3}, \mathrm{OH}_{2}, \mathrm{FH}, \mathrm{PH}_{3}, \mathrm{SH}_{2}$, and $\mathrm{ClH}$, J. Phys. Chem. 89, 3664 (1985).

[136] C. E. Dykstra, Structures and vibrational frequencies of small water complexes from electrical molecular mechanics, J. Chem. Phys. 91, 6472 (1989).

[137] S. S. Xantheas e T. H. Dunning, Ab initio studies of cyclic water clusters $\left(\mathrm{H}_{2} \mathrm{O}\right)_{n}, n=1-6.1$. Optimal structures and vibrational-spectra, J. Chem. Phys. 99, 8774 (1993).

[138] M. W. Feyereisen, D. Feller e D. A. Dixon, Hydrogen bond energy of the water dimer, J. Phys. Chem. 100, 2993 (1996).

[139] A. Engdahl e B. Nelander, On the structure of the water trimer - A matrix-isolation study, J. Chem. Phys. 86, 4831 (1987).

[140] K. Liu, J. D. Cruzan e R. J. Saykally, Water clusters, Science 271, 929 (1996). 
[141] S. Dixit, J. Crain, W. C. K. Poon, J. L. Finney e A. K. Soper, Molecular segregation observed in a concentrated alcohol-water solution, Nature 416, 829 (2002).

[142] J.-H. Guo, Y. Luo, A. Augustsson, S. Kashtanov, J.-E. Rubensson, D. K. Shuh, H. Ågren e J. Nordgren, Molecular structure of alcohol-water mixtures, Phys. Rev. Lett. 91, 157401 (2003).

[143] M. Schütz, S. Brdarski, P. O. Widmark, R. Lindh e G. Karlstrom, The water dimer interaction energy: Convergence to the basis set limit at the correlated level, J. Chem. Phys. 107, 4597 (1997).

[144] S. S. Xantheas, On the importance of the fragment relaxation energy terms in the estimation of the basis set superposition error correction to the intermolecular interaction energy, J. Chem. Phys. 104, 8821 (1996).

[145] G. Maroulis, Static hyperpolarizability of the water dimer and the interaction hyperpolarizability of two water molecules, J. Chem. Phys. 113 , $1813(2000)$.

[146] S. Tsuzuki, T. Uchimaru, K. Matsumura, M. Mikami e K. Tanabe, Effects of basis set and electron correlation on the calculated interaction energies of hydrogen bonding complexes: MP2/cc-pV5Z calculations of $\mathrm{H}_{2} \mathrm{O} \cdots \mathrm{MeOH}, \mathrm{H}_{2} \mathrm{O} \cdots \mathrm{Me} 2 \mathrm{O}, \mathrm{H}_{2} \mathrm{O} \cdots \mathrm{H}_{2} \mathrm{CO}, \mathrm{MeOH} \cdots \mathrm{MeOH}$, and $\mathrm{HCOOH} \cdots \mathrm{HCOOH}$ complexes, J. Chem. Phys. 110, 11906 (1999).

[147] J. A. Odutola e T. R. Dyke, Partially deuterated water dimers Microwave-spectra and structure, J. Chem. Phys. 72, 5062 (1980).

[148] K. N. Kirschner e R. J. Woods, Quantum mechanical study of the nonbonded forces in water-methanol complexes, J. Phys. Chem. A 105, 4150 (2001).

[149] D. Wei, J.-F. Truchon, S. Sirois e D. Salahub, Solvation of formic acid and proton transfer in hydrated clusters, J. Chem. Phys. 116, 6028 (2002). 
[150] R. Rivelino, V. Ludwig, E. Rissi e S. Canuto, Theoretical studies of hydrogen bonding in water-cyanides and in the base pair Gu-Cy, J. Mol. Struct. 615,259 (2002).

[151] K. Coutinho, N. Saavedra e S. Canuto, Theoretical description of the hydrogen bond interaction between acetone and water, J. Mol. Struct. (THEOCHEM) 466, 69 (1999).

[152] V. W. Couling, B. W. Halliburton, R. I. Keir e G. L. D. Ritchie, Anisotropic molecular polarizabilities of $\mathrm{HCHO}, \mathrm{CH}_{3} \mathrm{CHO}$, and $\mathrm{CH}_{3} \mathrm{COCH}_{3}$. Rayleigh depolarization ratios of $\mathrm{HCHO}$ and $\mathrm{CH}_{3} \mathrm{CHO}$ and first and second Kerr virial coefficients of $\mathrm{CH}_{3} \mathrm{COCH}_{3}$, J. Phys. Chem. A 105, 4365 (2001).

[153] S. Nakagawa, Transferability in multicenter polarizabilities of alkanes and alcohols derived from ab initio polarized one-electron potentials, Chem. Phys. Lett. 278, 272 (1997).

[154] T. Zhou e C. E. Dykstra, Additivity and transferability of atomic contributions to molecular second dipole hyperpolarizabilities, J. Phys. Chem. A 104, 2204 (2000).

[155] A. Heikkilä, M. Pettersson, J. Lundell, L. Khriachtchev, and M. Räsänen, Matrix isolation and ab initio studies of 1:1 hydrogen-bonded complexes $\mathrm{HCN} \cdots \mathrm{H}_{2} \mathrm{O}$ and $\mathrm{HNC} \cdots \mathrm{H}_{2} \mathrm{O}$ produced by photolysis of formaldoxime, J. Phys. Chem. A 103, 2945 (1999).

[156] F. Huisken e M. Stemmler, On the structure of the methanol-water dimer, Chem. Phys. Lett. 180, 332 (1991).

[157] N. Bakkas, Y. Bouteiller, A. Louteiller, J. P. Perchard e S. Racine, The water-methanol complexes. 1. A matrix-isolation study and an ab initio calculation on the 1:1 species, J. Chem. Phys. 99, 3335 (1993).

[158] N. Bakkas, Y. Bouteiller, A. Louteiller, J. P. Perchard e S. Racine, The water-methanol complexes - Matrix induced structural conversion of the 1:1 species, Chem. Phys. Lett. 232, 90 (1995). 
[159] P. A. Stockman, G. A. Blake, F. J. Lovas e R. D. Suenran, Microwave rotation-tunneling spectroscopy of the water-methanol dimer: Direct structural proof for the strongest bound conformation, J. Chem. Phys. 107, 3782 (1997).

[160] L. González, O. Mó e M. Yánez, High level ab initio and density functional theory studies on methanol-water dimers and cyclic methanol(water) $)_{2}$ trimer, J. Chem. Phys. 109, 139 (1998).

[161] H. S. Frank e M. W. Evans, Free volume and entropy in condensed systems, J. Chem. Phys. 13, 507 (1945).

[162] A. K. Soper e J. L. Finney, Hydration of methanol in aqueous-solution, Phys. Rev. Lett. 71, 4346 (1993).

[163] M. D'Angelo, G. Onori e A. Santucci, Self-association of monohydric alcohols in water: Compressibility and infrared absorption measurements, J. Chem. Phys. 100, 3107 (1994).

[164] K. Egashira e N. Nishi, Low-frequency Raman spectroscopy of ethanolwater binary solution: Evidence for self-association of solute and solvent molecules, J. Phys. Chem. B 102, 4054 (1998).

[165] S. S. N. Murthy, Detailed study of ice clathrate relaxation: Evidence for the existence of clathrate structures in some water-alcohol mixtures, J. Phys. Chem. A 103, 7927 (1999).

[166] S. Dixit, W. C. K. Poon e J. Crain, Hydration of methanol in aqueous solutions: A Raman spectroscopic study, J. Phys. Condens. Matter 12, $323(2000)$.

[167] D. T. Bowron, A. K. Soper e J. L. Finney, Temperature dependence of the structure of a 0.06 mole fraction tertiary butanol-water solution, J. Chem. Phys. 114, 6203 (2001).

[168] M. Ferrario, M. Haughney e I. R. McDonald, Molecular-dynamics simulation of aqueous mixtures: Methanol, acetone, and ammonia, J. Chem. Phys. 93, 5156 (1990). 
[169] H. Tanaka e K. Gubbins, Structure and thermodynamic properties of water-methanol mixtures - Role of the water water interaction, J. Chem. Phys. 97, 2626 (1992).

[170] A. Laaksonen, P. G. Kusalik e I. M. Svishchev, Three-dimensional structure in water-methanol mixtures, J. Phys. Chem. A 101, 5910 (1997).

[171] E. E. Fileti, R. Rivelino e S. Canuto, Rayleigh light scattering of hydrogen bonded clusters, J. Phys. B: At. Mol. Opt. Phys. 36, 399 (2003).

[172] E. E. Fileti, K. Coutinho e S. Canuto, Is there a favorite isomer for hydrogen-bonded methanol in water?, Adv. Quantum Chem. 47, 51 (2004).

[173] R. Ludwig, NMR relaxation studies in water-alcohol mixtures - The water-rich region, Chem. Phys. 195, 329 (1995).

[174] M. Huelsekopf e R. Ludwig, Temperature dependence of hydrogen bonding in alcohols, J. Mol. Liq. 85, 105 (2000).

[175] J. T. Arnold e M. E. Packard, Variations in absolute chemical shift of nuclear induction signals of hydroxyl groups of methyl and ethyl alcohol, J. Chem. Phys. 19, 1608 (1951).

[176] W. G. Schneider, W. G. Bernstein e J. A. Pople, Proton magnetic resonance chemical shift of free (gaseous) and associated (liquid) hydride molecules, J. Chem. Phys. 28, 601 (1958).

[177] E. D. Becker, U. Liddel e J. N. Shoolery, Nuclear magnetic resonance studies of hydrogen bonding in ethanol, J. Mol. Struct. 2, 1 (1958).

[178] C. M. Huggins, G. C. Pimentel e J. N. Shoolery, Proton magnetic resonance studies of the hydrogen bonding of phenol, substituted phenols and acetic acid, J. Phys. Chem. 60, 1311 (1956).

[179] N. Asakawa, S. Kuroki, H. Kurosu, I. Ando, A. Shoji e T. Ozaki, Hydrogen-bonding effect on ${ }^{13} \mathrm{C}$ NMR chemical-shifts of L-alanine re- 
sidue carbonyl carbons of peptide in the solid-state, J. Am. Chem. Soc. 114, 3261 (1992).

[180] C. L. Perrin, T. J. Dwyer, J. Rebek e R. J. Duff, Exchange of amide protons - Effect of intramolecular hydrogen-bonding, J. Am. Chem. Soc. 112, $3122(1990)$.

[181] N. E. Zhou, B. Y. Zhu, B. D. Sykes e R. S. Hodges, Relationship between amide proton chemical-shifts and hydrogen-bonding in amphipathic alpha-helical peptides, J. Am. Chem. Soc. 114, 4320 (1992).

[182] R. Ditchfield, Self-consistent perturbation theory of diamagnetism. 1. Gauge-invariant LCAO method for NMR chemical-shifts, Mol. Phys. 27, 789 (1974).

[183] R. Ditchfield, Theoretical studies of magnetic shielding in $\mathrm{H}_{2} \mathrm{O}$ and $\left(\mathrm{H}_{2} \mathrm{O}\right)_{2}$, J. Chem. Phys. 65, 3133 (1976).

[184] R. Ditchfield, Giao studies of magnetic shielding in $\mathrm{FHF}^{-}$and $\mathrm{HF}$, Chem. Phys. Lett. 40, 53 (1976).

[185] C. M. Rohlfing, L. C. Allen e R. Ditchfield, Proton chemical-shift tensors in hydrogen-bonded dimers of $\mathrm{RCOOH}$ and $\mathrm{ROH}, J$. Chem. Phys. 79, 4958 (1983).

[186] C. M. Rohlfing, L. C. Allen e R. Ditchfield, Proton chemical-shift tensors in neutral and ionic $\mathrm{O}-\mathrm{H} \cdots \mathrm{O}$ hydrogen-bonds, Chem. Phys. Lett. 86, 380 (1982).

[187] J. F. Hinton e K. Wolinski, in Theoretical treatments of hydrogen bonding; Ab initio GIAO Magnetic Shielding Tensor for Hydrogen Bonded Systems, John Wiley, New York, 1997.

[188] K. Wolinski, J. F. Hinton e P. Pulay, Efficient implementation of the gauge-independent atomic orbital method for NMR chemical-shift calculations, J. Am. Chem. Soc. 112, 8251 (1990). 
[189] J. Gauss, Calculation of NMR chemical shifts at second-order many-body perturbation theory using gauge including atomic orbitals, Chem. Phys. Lett. 191, 614 (1992).

[190] J. Gauss, Effects of electron correlation in the calculation of nuclear magnetic resonance chemical shifts, J. Chem. Phys. 99, 3629 (1993).

[191] J. R. Cheeseman, G. W. Trucks, T. A. Keith e M. J. Frisch, A comparison of models for calculating nuclear magnetic resonance shielding tensors, J. Chem. Phys. 104, 5497 (1996).

[192] G. Rauhut, S. Puyear, K. Wolinski e P. Pulay, Comparison of NMR chemical shieldings calculated from Hartree-Fock and density functional wavefunctions using gauge-including atomic orbitals, J. Phys. Chem. 100, 6310 (1996).

[193] G. Schreckenbach e T. Ziegler, The calculation of NMR shielding tensors using GIAO's and modern density functional theory, J. Phys. Chem. 99, 606 (1995).

[194] D. B. Chesnut e C. G. Phung, Functional counterpoise correction for the NMR chemical shift in a model dimeric water-system, Chem. Phys. 147, 91 (1990).

[195] D. B. Chesnut, Some recent ab initio calculations of the NMR chemical shift, Ann. Rep. NMR Spec. 29, 71 (1994).

[196] J. P. Kitzinger, Oxigen NMR. Characteristic parameters and aplications, NMR Basic Princ. Prog. 17, 1 (1982).

[197] C. J. Jameson, A. K. Jameson, D. Oppusunggu, S. Wille, P. M. Burrell, and J. Mason, ${ }^{15} \mathrm{~N}$ nuclear magnetic shielding scale from gas-phase studies, J. Chem. Phys. 74, 81 (1981).

[198] J. P. Chauvel e N. S. True, Gas-phase NMR-studies of alcohols - Intrinsic acidities, Chem. Phys. 95, 435 (1985). 
[199] J. C. Hindman, Proton resonance shift of water in the gas and liquid states, J. Chem. Phys. 44, 4582 (1966).

[200] R. E. Wasylishen, S. Mooibroek e J. B. Macdonald, A more reliable ${ }^{17} \mathrm{O}$ absolute chemical shielding scale, J. Chem. Phys. 81, 1057 (1984).

[201] R. E. Wasylishen e D. L. Bryce, A revised experimental absolute magnetic shielding scale for oxygen, J. Chem. Phys. 117, 10061 (2002).

[202] B. Tesche e U. Haeberlen, Proton chemical-shift tensors of methyl groups; A multiple-pulse NMR and LORG/IGLO ab initio study, J. Mag. Reson. A 117, 186 (1995).

[203] P. B. Karadakov, Electron correlation and basis set effects on the ${ }^{17} \mathrm{O}$ and ${ }^{1} \mathrm{H}$ nuclear magnetic shieldings in water clusters $\left(\mathrm{H}_{2} \mathrm{O}\right)_{n}(n=2-5)$, J. Mol. Struct. 602, 293 (2002).

[204] J. Vaara, J. Lounilla, K. Ruud e T. Helgaker, Rovibrational effects, temperature dependence, and isotope effects on the nuclear shielding tensors of water: A new ${ }^{17} \mathrm{O}$ absolute scale, J. Chem. Phys. 109, 8388 (1998).

[205] M. Pecul, J. Leszczynski e J. Sadlej, Comprehensive ab initio studies of nuclear magnetic resonance shielding and coupling constants in $\mathrm{XH} \ldots \mathrm{O}$ hydrogen-bonded complexes of simple organic molecules, J. Chem. Phys. 112, $7930(2000)$.

[206] U. Haeberlen, editor, High resolution NMR in solids, Academic Press, New York, 1976.

[207] J. E. D. Bene, Theoretical study of open chain dimers ans trimers containing $\mathrm{CH}_{3} \mathrm{OH}$ and $\mathrm{H}_{2} \mathrm{O}$, J. Chem. Phys. 55, 4633 (1971).

[208] S. Kim, M. S. Jhon e H. A. Scheraga, Analytic intermolecular potential functions from ab initio SCF calculations of interaction energies between $\mathrm{CH}_{4}, \mathrm{CH}_{3} \mathrm{OH}, \mathrm{CH}_{3} \mathrm{COOH}$, and $\mathrm{CH}_{3} \mathrm{COO}$ and water, J. Phys. Chem. 92, $7216(1988)$. 
[209] L. González, O. Mó e M. Yáñez, Density functional theory study on ethanol dimers and cyclic ethanol trimers, J. Chem. Phys. 111, 3855 (1999).

[210] T. S. van Erp e E. J. Meijer, Hydration of methanol in water. A DFTbased molecular dynamics study, Chem. Phys. Lett. 333, 290 (2001).

[211] M. Masella e J. P. Flament, Relation between cooperative effects in cyclic water, methanol/water, and methanol trimers and hydrogen bonds in methanol/water, ethanol/water, and dimethylether/water heterodimers, J. Chem. Phys. 108, 7141 (1998).

[212] S. Tsuzuki e H. P. Lüthi, Interaction energies of van der Waals and hydrogen bonded systems calculated using density functional theory: Assessing the PW91 model, J. Chem. Phys. 114, 3949 (2001).

[213] R. A. Provencal, R. N. Casaes, K. Roth, J. B. Paul, C. N. Chapo, R. J. Saykally, G. S. Tschumper e S. III, Hydrogen bonding in alcohol clusters: A comparative study by infrared cavity ringdown laser absorption spectroscopy, J. Phys. Chem. A 104, 1423 (2000).

[214] M. Mandado, A. N. Graña e R. A. Mosquera, On the structures of the methanol trimer and their cooperative effects, Chem. Phys. Lett. 381, 22 (2003).

[215] O. Mó, M. Yánez e J. Elguero, Study of the methanol trimer potential energy surface, J. Chem. Phys. 107, 3592 (1997).

[216] A. K. Sum e S. I. Sandler, Ab initio calculations of cooperativity effects on clusters of methanol, ethanol, 1-propanol, and methanethiol, J. Phys. Chem. A 104, 1121 (2000).

[217] M. Masella e J. P. Flament, A many-body model for alcohols: applications to the cyclic methanol/water hetero trimers, and to the (methanol)(n), (ethanol)(n) and (t-butanol)(n) cyclic clusters $(\mathrm{n}=2-6)$, Mol. Phys. 95, 97 (1998). 
[218] S. A. Clough, Y. Beers, G. P. Klein e L. S. Rothman, Dipole-moment of water from Stark measurements of $\mathrm{H}_{2} \mathrm{O}, \mathrm{HDO}$, and $\mathrm{D}_{2} \mathrm{O}$, J. Chem. Phys. 59, 2254 (1973).

[219] R. A. Shaw, H. Wieser, R. Dutler e A. Rauk, IR and VCD of (S)-a-dethanol, J. Am. Chem. Soc. 112, 5401 (1990).

[220] M. Ehbrecht e F. Huisken, Vibrational spectroscopy of ethanol molecules and complexes selectively prepared in the gas phase and adsorbed on large argon clusters, J. Phys. Chem. A 101, 7768 (1997).

[221] L. A. Curtiss e M. Blander, Thermodynamic properties of gas-phase hydrogen-bonded complexes, Chem. Rev. 88, 827 (1988).

[222] B. J. Smith, D. J. Swanton, J. A. Pople, H. F. Schaefer e L. Radom, Transition structures for the interchange of hydrogen-atoms within the water dimer, J. Chem. Phys. 92, 1240 (1990).

[223] T. W. Bell, A. B. Khasanov e M. G. B. Drew, Role of pyridine hydrogen-bonding sites in recognition of basic amino acid side chains, J. Am. Chem. Soc. 124, 14092 (2002).

[224] K. Coutinho e S. Canuto, Dice (version 2.8): A general Monte Carlo program for liquid simulation, 2000.

[225] H. J. C. Berendsen, J. P. M. Postma e W. F. van Gunsteren, Intermolecular forces, Reidel, Dordrecht, 1981.

[226] W. L. Jorgensen e N. A. McDonald, Development of an all-atom force field for heterocycles. Properties of liquid pyridine and diazenes, J. Mol. Struct. (THEOCHEM) 424, 145 (1998).

[227] W. R. Rocha, K. Coutinho, W. B. de Almeida e S. Canuto, An efficient quantum mechanical/molecular mechanics Monte Carlo simulation of liquid water, Chem. Phys. Lett. 335, 127 (2001).

[228] G. A. Jeffrey, An introduction to hydrogen bond, Oxford University Press, Oxford, 1997. 
[229] K. Morokuma, Why do molecules interact? - Origin of electron donoracceptor complexes, hydrogen-bonding e affinity, Acc. Chem. Res. 10, 294 (1977).

[230] C. E. Dykstra, Electrostatic interaction potentials in molecular-force fields, Chem. Rev. 93, 2339 (1993).

[231] A. D. Buckingham e P. W. Fowler, Do electrostatic interactions predict structures of van der Waals molecules?, J. Chem. Phys. 79, 6426 (1983).

[232] A. J. Stone, A. D. Buckingham e P. W. Fowler, Structure and spectroscopy of $(\mathrm{HCN})_{n}$ clusters: Cooperative and electronic delocalization effects in $\mathrm{C}-\mathrm{H} \cdots \mathrm{N}$ hydrogen bonding - Comment, J. Chem. Phys. 107, 1030 (1997).

[233] P. W. Fowler e A. D. Buckingham, The long-range model of intermolecular forces - An SCF study of Ne-HF, Mol. Phys. 50, 1349 (1983).

[234] B. F. King e F. Weinhold, Structure and spectroscopy of (HCN $)_{n}$ clusters - Cooperative and electronic delocalization effects in $\mathrm{C}-\mathrm{H} \cdots \mathrm{N}$ hydrogen bonding, J. Chem. Phys. 103, 333 (1995).

[235] B. F. King, T. C. Farrar e F. Weinhold, Quadrupole coupling-constants in linear $(\mathrm{HCN})_{n}$ clusters. Theoretical and experimental evidence for coorperative effects in $\mathrm{C}-\mathrm{H} \cdots \mathrm{N}$ hydrogen bonding, J. Chem. Phys. 103, 348 (1995).

[236] E. D. Isaacs, A. Shukla, P. M. Platzman, D. R. Hamann, B. Barbiellini, and C. A. Tulk, Covalency of the hydrogen bond in ice: A direct x-ray measurement, Phys. Rev. Lett. 82, 600 (1999).

[237] T. K. Ghanty, V. N. Staroverov, P. R. Koren e E. R. Davidson, Is the hydrogen bond in water dimer and ice covalent?, J. Am. Chem. Soc. 122, $1210(2000)$.

[238] J. H. Guo, Y. Luo, A. Augustsson, J. E. Rubensson, C. Sathe, H. Ågren, H. Siegbahn e J. Nordgren, X-ray emission spectroscopy of hydrogen 
bonding and electronic structure of liquid water, Phys. Rev. Lett. 89, $137402(2002)$.

[239] G. Cornilescu, J. S. Hu e A. Bax, Identification of the hydrogen bonding network in a protein by scalar couplings, J. Am. Chem. Soc. 121, 2949 (1999).

[240] A. J. Dingley e S. Grzesiek, Direct observation of hydrogen bonds in nucleic acid base pairs by internucleotide ${ }^{2} \mathrm{~J}_{N N}$ couplings, J. Am. Chem. Soc. 120, 8293 (1998).

[241] A. E. Reeds, L. A. Curtiss e F. Weinhold, Intermolecular interactions from a natural bond orbital, donor-acceptor viewpoint, Chem. Rev. 88, 899 (1988).

[242] A. van der Vaart e K. M. Merz, Charge transfer in small hydrogen bonded clusters, J. Chem. Phys. 166, 7380 (2002).

[243] A. D. Buckingham, P. W. Fowler e A. J. Stone, Electrostatic predictions of shapes and properties of van der Waals molecules, Int. Rev. Phys. Chem. 5, 107 (1986).

[244] K. D. Bonin e V. V. Kresin, Electric-dipole polarizabilities of atoms, molecules and clusters, World Scientific, London, 1997.

[245] V. E. Bazterra, M. C. Caputo, M. B. Ferraro e P. Fuentealba, On the theoretical determination of the static dipole polarizability of intermediate size silicon clusters, J. Chem. Phys. 117, 11158 (2002).

[246] A. Abdurahman, A. Shukla e G. Seifert, Ab initio many-body calculations of static dipole polarizabilities of linear carbon chains and chainlike boron clusters, Phys. Rev. B 66, 155423 (2002).

[247] C. E. Dykstra, S. Y. Liu e D. J. Malik, The hydrogen-bonding influence on polarizability and hyperpolarizability - A derivative Hartree-Fock study of the electrical-properties of hydrogen-fluoride and the hydrogen-fluorine dimer, J. Mol. Struct. (THEOCHEM) 28, 357 (1986). 
[248] A. Morita e S. Kato, An ab initio analysis of medium perturbation on molecular polarizabilities, J. Phys. Chem. 110, 11987 (1999).

[249] L. Jensen, M. Swart, T. P. V. Duijnen e J. G. Snijders, Medium perturbations on the molecular polarizability calculated within a localized dipole interaction model, J. Phys. Chem. 117, 3316 (2002).

[250] R. Ludwig, J. A. Bohmann e T. C. Farrar, Natural chemical shielding analysis of nuclear magnetic resonance shielding tensors from gaugeincluding atomic orbital calculations, J. Chem. Phys. 99, 6981 (1995).

[251] R. Ludwig, F. Weinhold e T. C. Farrar, Theoretical study of hydrogen bonding in liquid and gaseous N-methylformamide, J. Chem. Phys. 107, 499 (1997).

[252] F. Franks e J. E. Desnoyers, Water science reviews, Cambridge University Press, Cambridge, 1985.

[253] F. Franks e D. J. G. Ives, Structural properties of alcohol-water mixtures, Q. Rev. Chem. Soc. 20, 1 (1966).

[254] Y. C. Tse, M. D. Newton e L. C. Allen, Theoretical-study of the $\mathrm{O}-$ methyl substituent effect in $\mathrm{O}-\mathrm{H} \cdots \mathrm{O}$ hydrogen-bonds, Chem. Phys. Lett. 75, 350 (1980).

[255] G. Bolis, E. Clementi, D. H. Wertz, H. A. Scheraga e C. Tosi, Interaction of methane and methanol with water, J. Am. Chem. Soc. 105, 355 (1983).

[256] J. L. Finney, D. T. Bowron e A. K. Soper, The structure of aqueous solutions of tertiary butanol, J. Phys. Condens. Matter 12, 123 (2000).

[257] G. Palinkas, E. Hawlicka e K. Heinzinger, Molecular dynamics simulations of water-methanol mixtures, Chem. Phys. 158, 65 (1991).

[258] E. E. Fileti, K. Coutinho, T. Malaspina e S. Canuto, Electronic changes due to thermal disorder of hydrogen bonds in liquids. Pyridine in aqueous environment, Phys. Rev. E 67, 61504 (2003). 
[259] W. L. Jorgensen, D. S. Maxwell e J. T. Rives, Development and testing of the OPLS all-atom force field on conformational energetics and properties of organic liquids, J. Am. Chem. Soc. 118, 11225 (1996).

[260] A. D. Buckingham, Permanent and induced molecular moments and longrange intermolecular forces, Adv. Chem. Phys. 12, 107 (1967).

[261] D. M. Bishop, Aspects of non-linear-optical calculations, Adv. Quantum Chem. 25, 1 (1994).

[262] A. J. Stone, The theory of intermolecular forces, Clarendon Press, Oxford, 1996.

[263] P. T. van Duijnen, A. H. D. Vries, M. Swart e F. Grozema, Polarizabilities in the condensed phase and the local fields problem: A direct reaction field formulation, J. Chem. Phys. 117, 8442 (2002).

[264] J. Ridley e M. C. Zerner, Intermediate neglect of differential overlap technique for spectroscopy - Pyrrole and azines, Theor. Chim. Acta 32, 111 (1973).

[265] P. T. van Duijnen, M. Swart e F. C. Grozema, QM/MM calculations of (hyper-)polarizabilities with the direct reaction field approach, ACS Publication, Washington, D.C., 1998.

[266] W. L. Jorgensen, J. D. Madura e C. J. Swenson, Optimized intermolecular potential functions for liquids hydrocarbons, J. Am. Chem. Soc. 106, $6638(1984)$.

[267] M. C. Zerner, INDO-UF: A semi-empirical program package, 2000.

[268] S. di Bella, T. J. Marks e M. A. Ratner, Environmental-effects on nonlinear-optical chromophore performance - Calculation of molecular quadratic hyperpolarizabilities in solvating media, J. Am. Chem. Soc. 116, 4440 (1994). 
[269] I. Cernusak, G. H. F. Diercksen e A. J. Sadlej, $4^{\text {th }}$-order many-body perturbation-theory study of the electron-correlation contribution to polarizabilities of Ne, Phys. Rev. A 33, 814 (1986).

[270] S. Canuto, K. Coutinho e M. C. Zerner, Including dispersion in configuration interaction-singles calculations for the spectroscopy of chromophores in solution, J. Chem. Phys. 112, 7293 (2000).

[271] W. A. Parkinson e M. C. Zerner, Calculation of molecular polarizabilities for large systems within the random phase approximation, Chem. Phys. Lett. 139, 563 (1987).

[272] T. Yamazaki, H. Sato e F. Hirata, Solvent effect on the nuclear magnetic shielding: ab initio study by the combined reference interaction site model and electronic structure theories, J. Chem. Phys. 115, 8949 (2001).

[273] D. Sebastiani e U. Rothlisberger, Nuclear magnetic resonance chemical shifts from hybrid DFT QM/MM calculations, J. Phys. Chem. B 108, 2807 (2004).

[274] T. Nymand, P. O. Astrand e K. V. Mikkelsen, Chemical shifts in liquid water calculated by molecular dynamics simulations and shielding polarizabilities, J. Phys. Chem. B 101, 4105 (1997).

[275] Q. Cui e M. Karplus, Molecular properties from combined QM/MM methods. 2. Chemical shifts in large molecules, J. Phys. Chem. B 104, $3721(2000)$.

[276] V. G. Malkin, O. L. Malkina, G. Steinebrunner e H. Huber, Solvent effects on the NMR chemical shieldings in water calculated by a combination of molecular dynamics and density functional theory, Chem. Eur. J. 2, 452 (1996).

[277] B. Mennucci, J. M. Martinez e J. Tomasi, Solvent effects on nuclear shieldings: Continuum or discrete solvation model to treat hydrogen bond and polarity effects?, J. Phys. Chem. A 105, 7287 (2001). 
[278] D. B. Chesnut e B. E. Rusiloski, A study of NMR chemical shielding in water clusters derived from molecular dynamics simulations, J. Mol. Struct. 314, 19 (1994).

[279] S. Canuto, K. Coutinho e D. Trzresniak, New developments in Monte Carlo/quantum mechanics methodology. The solvatochromism of betacarotene in different solvents, Adv. Quantum Chem. 41, 161 (2002).

[280] K. Modig e B. Halle, Proton magnetic shielding tensor in liquid water, J. Am. Chem. Soc. 124, 12031 (2002).

[281] W. L. Jorgensen, Quantum and statistical mechanical studies of liquids. 10. Transferable intermolecular potential functions for water, alcohols, and ethers. Application to liquid water, J. Am. Chem. Soc. 103, 335 (1981).

[282] D. M. Ferguson, Parametrization and evaluation of a flexible water model, J. Comp. Chem. 16, 501 (1995).

[283] L. X. Dang e M. Pettitt, Simple intramolecular model potentials for water, J. Phys. Chem. 91, 3349 (1987).

[284] H. J. C. Berendsen, D. van der Spoel e R. van Drunen, GROMACS - A message-passing parallel molecular dynamics implementation, Comp. Phys. Comm. 91, 3349 (1987).

[285] E. Lindahl, B. Hess e D. van der Spoel, GROMACS 3.0: A package for molecular simulation and trajectory analysis, J. Mol. Mod. 7, 306 (2001).

[286] K. Krishnamurty, T. Heine e A. Goursort, Influence of dynamics on the structure and NMR chemical shift of a zeolite precursor, J. Phys. Chem. B $107,5728(2003)$.

[287] P. Zhou, G. Li, Z. Shao, X. Pan e T. Yu, Strucutre of Bombix mori silk fibroin based on the DFT chemical shift calculation, J. Phys. Chem. B 105, 12469 (2001). 
[288] U. Consentino, A. Villa, D. Pitea, G. Moro, V. Barone e A. Maiocchi, Conformational characterization of lanthanide(III)-DOTA complexes by $a b$ initio investigation in vacuo and in aqueous solution, J. Am. Chem. Soc. 124, 4901 (2002).

[289] S. Dong, R. Ida e G. Wu, A combined experimental and theoretical ${ }^{17} \mathrm{O}$ NMR study of crystalline urea: An example of large hydrogen-bonding effects, J. Phys. Chem. A 104, 11194 (2000).

[290] M. J. Frisch, G. W. Trucks, H. B. Schlegel, G. E. Scuseria, M. A. Robb, J. R. Cheeseman, J. A. Montgomery, Jr., T. Vreven, K. N. Kudin, J. C. Burant, J. M. Millam, S. S. Iyengar, J. Tomasi, V. Barone, B. Mennucci, M. Cossi, G. Scalmani, N. Rega, G. A. Petersson, H. Nakatsuji, M. Hada, M. Ehara, K. Toyota, R. Fukuda, J. Hasegawa, M. Ishida, T. Nakajima, Y. Honda, O. Kitao, H. Nakai, M. Klene, X. Li, J. E. Knox, H. P. Hratchian, J. B. Cross, C. Adamo, J. Jaramillo, R. Gomperts, R. E. Stratmann, O. Yazyev, A. J. Austin, R. Cammi, C. Pomelli, J. W. Ochterski, P. Y. Ayala, K. Morokuma, G. A. Voth, P. Salvador, J. J. Dannenberg, V. G. Zakrzewski, S. Dapprich, A. D. Daniels, M. C. Strain, O. Farkas, D. K. Malick, A. D. Rabuck, K. Raghavachari, J. B. Foresman, J. V. Ortiz, Q. Cui, A. G. Baboul, S. Clifford, J. Cioslowski, B. B. Stefanov, G. Liu, A. Liashenko, P. Piskorz, I. Komaromi, R. L. Martin, D. J. Fox, T. Keith, M. A. Al-Laham, C. Y. Peng, A. Nanayakkara, M. Challacombe, P. M. W. Gill, B. Johnson, W. Chen, M. W. Wong, C. Gonzalez e J. A. Pople, Gaussian 03: Revision B.04, 2003.

[291] J. Gauss e J. F. Stanton, Perturbative treatment of triple excitations in coupled-cluster calculations of nuclear magnetic shielding constants, J. Chem. Phys. 104, 2574 (1996).

[292] D. Eisenberg e W. Kauzmann, The structure and properties of water, Oxford University Press, London, 1969.

[293] D. B. Chesnut e K. D. Moore, Locally dense basis-sets for chemical-shift calculations, J. Comp. Chem. 10, 648 (1989). 
[294] D. B. Chesnut e C. G. Phung, Ab initio determination of chemical shielding in a model dipeptide, Chem. Phys. Lett. 183, 505 (1991).

[295] D. B. Chesnut e B. E. Rusiloski, Partial energy and chemical shielding surfaces in the $\left(\mathrm{H}_{2} \mathrm{O}\right)_{2}$ and $(\mathrm{HF})_{2}$ van der Waals complexes, J. Phys. Chem. 97, 2939 (1993).

[296] J. F. Hinton, P. Guthrie, P. Pulay e K. Wolinski, Ab initio quantum mechanical calculation of the chemical shift anisotropy of the hydrogen atom in the $\left(\mathrm{H}_{2} \mathrm{O}\right)_{17}$ cluster, J. Am. Chem. Soc. 114, 1604 (1992).

[297] M. J. Allen, T. W. Keal e D. J. Tozer, Improved NMR chemical shifts in density functional theory, Chem. Phys. Lett. 380, 70 (2003).

[298] P. J. Wilson e D. J. Tozer, NMR shielding constants from ab initio and Kohn-Sham electron densities, Chem. Phys. Lett. 337, 341 (2001).

[299] P. J. Wilson, R. D. Amos e N. C. Handy, Toward coupled-cluster accuracy in the prediction of nuclear shielding constants: A simple and efficient DFT approach, Chem. Phys. Lett. 312, 475 (1999).

[300] W. P. M. Gill, A new gradient-corrected exchange functional, Mol. Phys. 89, 433 (1996).

[301] J. P. Perdew, J. A. Chevary, S. H. Vosko, K. A. Jackson, M. R. Pederson, D. J. Singh e C. Fiolhais, Atoms, molecules, solids, and surfaces applications of the generalized gradient approximation for exchange and correlation, Phys. Rev. B 46, 6671 (1992).

[302] J. P. Perdew, K. Burke e M. Ernzerhof, Generalized gradient approximation made simple, Phys. Rev. Lett. 78, 1396 (1997).

[303] C. Adamo e V. Barone, Exchange functionals with improved long-range behavior and adiabatic connection methods without adjustable parameters: The mPW and mPW1PW models, J. Chem. Phys. 108, 664 (1998). 
[304] F. A. Hamprecht, A. J. Cohen, D. J. Tozer e N. C. Handy, Development and assessment of new exchange-correlation functionals, J. Chem. Phys. 109, 6264 (1998).

[305] V. Barone, O. Crescenzi e R. Improta, A density functional theory study of the dimers of $\mathrm{HX}(\mathrm{X}=\mathrm{F}, \mathrm{Cl}$, and $\mathrm{Br})$, Quant. Struct. Activ. Relat. 21, 105 (2002).

[306] J. D. Jackson, Classical eletrodynamics, $3^{\text {rd }}$ edition, John Wiley, New York, 1998.

[307] H. A. Lorentz, Theory of Electrons, Teubner, Leipzig, 1916.

[308] H. F. Hameka, in Advanced Quantum Chemistry; Theory of interactions between molecules and electromagnetic fields, Addison-Wesley, Massachusetts, 1965.

[309] D. B. Chesnut, Ab initio calculations of NMR chemical shieldings, Ann. Rep. NMR Spec. 21, 51 (1989).

[310] S. T. Epstein, Gauge invariance of Hartree-Fock approximation, J. Chem. Phys. 42, 2897 (1965).

[311] F. London, Quantum theory of interatomic currents in aromatic compounds, J. Phys. Radium 8, 397 (1937).

[312] T. Helgaker, M. Jaszuński e K. Ruud, Ab initio methods for the calculation of NMR shielding and indirect spin-spin coupling constants, Chem. Rev. 99, 293 (1999). 


\section{Parte V}

\section{Apêndices}




\section{Apêndice A}

\section{Polarizabilidade elétrica}

\section{A.1 Respostas ao campo elétrico}

A polarizabilidade elétrica, $\boldsymbol{\alpha}$, de uma molécula é a medida de sua habilidade para responder a um campo elétrico e adquirir um momento de dipolo elétrico, $\mu$. A perturbação causada por um campo elétrico $\mathbf{F}$ é:

$$
H^{(1)}=-\boldsymbol{\mu} \cdot \boldsymbol{F} \quad \boldsymbol{\mu}=\sum_{i} q_{i} \mathbf{r}_{i}
$$

onde $q_{i}$ é a carga da partícula $i$ na posição $\mathbf{r}_{i}$. O campo será considerado uniforme sobre toda a molécula de maneira a se evitar lidar com interações com multipolos de ordem superior. Será considerado também, para facilitar a notação, que o campo elétrico atua na direção $z$, dado assim por $\mathbf{F}=F \hat{\mathbf{k}}$, onde $\hat{\mathbf{k}}$ é um vetor unitário na direção $z$. Então

$$
H^{(1)}=-\mu_{z} F
$$

Tal como visto na seç̧ão 2.2 .2 a teoria de perturbação independente do tempo foi eleborada para fornecer expressões para a energia em potências da perturbação. É interessante aqui adaptar aquelas expressões para fornecer outras propriedades além da energia. Existem duas formas para se fazer isto. Uma é montar um operador para a propriedade de interesse e avaliar seu valor esperado usando as funções de onda perturbadas. Outra forma é deduzir uma expressão para a energia em termos da propriedade de interesse e então comparar esta expressão com aquela obtida para energia pelo uso de teoria de perturbação. Este apêndice pretende ilustrar ambas as técnicas. 
A chave para se extrair a polarizabilidade a partir da expressão de perturbação para energia é o teorema de Hellmann-Feynman [81-83], que permite afirmar que

$$
\frac{d E}{d F}=\left\langle\frac{d H}{d F}\right\rangle
$$

uma vez que o Hamiltoniano considerado aqui é função de $F$. A derivada parcial do Hamiltoniano é simplesmente

$$
\frac{\partial H}{\partial F}=\frac{\partial H^{(1)}}{\partial F}=-\mu_{z}
$$

Assim a variação da energia em relação à intensidade do campo elétrico é dada por:

$$
\frac{d E}{d F}=-\left\langle\mu_{z}\right\rangle
$$

A energia $E$ da molécula na presença de um campo elétrico pode ser expandida em série de Taylor em relação à energia $E_{0}$ na ausência de campo da seguinte forma:

$$
E=E_{0}+\left(\frac{d E}{d F}\right)_{0} F+\frac{1}{2}\left(\frac{d^{2} E}{d F^{2}}\right)_{0} F^{2}+\frac{1}{3 !}\left(\frac{d^{3} E}{d F^{3}}\right)_{0} F^{3}+\frac{1}{4 !}\left(\frac{d^{4} E}{d F^{4}}\right)_{0} F^{4}+\cdots
$$

onde o subscrito 0 indica que a derivada é avaliada em $F=0$. Segue então da equação A.5 que:

$$
\left\langle\mu_{z}\right\rangle=-\left(\frac{d E}{d F}\right)_{0}-\left(\frac{d^{2} E}{d F^{2}}\right)_{0} F-\frac{1}{2}\left(\frac{d^{3} E}{d F^{3}}\right)_{0} F^{2}-\frac{1}{6}\left(\frac{d^{4} E}{d F^{4}}\right)_{0} F^{3}-\cdots
$$

Esta expressão afirma que o valor esperado do momento de dipolo elétrico na presença de um campo elétrico é a soma de um momento de dipolo permanente e a contribuição induzida pelo campo. Assim pode-se escrever:

$$
\left\langle\mu_{z}\right\rangle=\mu_{0 z}+\alpha_{z z} F+\frac{1}{2} \beta_{z z z} F^{2}+\frac{1}{6} \gamma_{z z z z} F^{3}+\cdots
$$

Nesta expressão, $\alpha_{z z}$ é a polarizabilidade, $\beta_{z z z}$ é a primeira hiperpolarizabilidade e $\gamma_{z z z z}$ é a segunda hiperpolarizabilidade, na direção $z$. Naturalmente existem hiperpolarizabilidades de ordens superiores porém não são consideradas neste trabalho. Aqui é importante notar que tanto a polarizabilidade $\alpha$ 
quanto as hiperpolarizabilidades $\beta, \gamma$ (bem como as de ordens superiores) tensores e os subíndices indicam isto. No caso da polarizabilidade $\alpha$, por exemplo, o subíndice $z z$ indica que ela é um tensor de segunda ordem e que quando um campo elétrico é aplicado ao longo do eixo $z$, um dipolo pode ser induzido com componentes $\mu_{x}, \mu_{y}$ e $\mu_{z}$ de forma que

$$
\mu_{q}=\alpha_{q z} F_{z}
$$

$\operatorname{com} q=x, y$ e $z$. Portanto estas três componentes do tensor, $\alpha_{q z}$, relacionam a magnitude de cada componente do momento de dipolo induzido à intensidade do campo elétrico na direção $z$. Normalmente, a componente diagonal $\alpha_{z z}$ domina as outras duas devido a fato do momento de dipolo induzido ser quase paralelo ao campo elétrico aplicado. Existem em geral três direções relativas à molecula para as quais o momento de dipolo induzido é estritamente paralelo ao campo aplicado ao longo delas. Estas direções formam o chamado sistema de eixos principais da polarizabilidade.

Comparando as equações A.7 e A.8 obtem-se:

$$
\begin{array}{ll}
\mu_{0 z}=-\left(\frac{d E}{d F}\right)_{0} & \alpha_{z z}=-\left(\frac{d^{2} E}{d F^{2}}\right)_{0} \\
\beta_{z z z}=-\left(\frac{d^{3} E}{d F^{3}}\right)_{0} & \gamma_{z z z z}=-\left(\frac{d^{4} E}{d F^{4}}\right)_{0}
\end{array}
$$

e assim por diante. Estas expressões são os elos necessários entre as propriedades elétricas de interesse aqui e a energia do sistema, que por sua vez pode ser calculada pelo uso de teoria de perturbação. Através das relações A.10 é possível escrever a equação A.6 em termos das propriedades moleculares:

$$
E=E_{0}-\mu_{0 z} F-\frac{1}{2} \alpha_{z z} F^{2}-\frac{1}{3 !} \beta_{z z z} F^{3}-\frac{1}{4 !} \gamma_{z z z z} F^{4}+\cdots
$$

\section{A.2 A polarizabilidade elétrica estática}

Neste apêndice a discussão sobre o cálculo destas propriedades elétricas será restrita ao cálculo da polarizabilidade. Para a implementação da equação A.10 é necessário lançar mão da expressão de perturbação para a energia, que como 
visto na seção 2.2 .2 foi dada para o estado fundamental não perturbado $\psi_{0}^{(0)}$ por:

$$
\begin{aligned}
E_{0}= & E_{0}^{(0)}+\left\langle\psi_{0}^{(0)}\left|H^{(1)}\right| \psi_{0}^{(0)}\right\rangle \\
& +\sum_{n}^{\prime} \frac{\left\langle\psi_{0}^{(0)}\left|H^{(1)}\right| \psi_{n}^{(0)}\right\rangle\left\langle\psi_{n}^{(0)}\left|H^{(1)}\right| \psi_{0}^{(0)}\right\rangle}{E_{n}-E_{0}}+\cdots
\end{aligned}
$$

onde os índices superiores indicam a ordem da perturbação e os inferiores o estado quântico. A linha no somatório indica que a soma exclui o valor de $n=0$. Agora, substituindo $H^{(1)}=-\mu_{z} F$ tem-se:

$$
\begin{aligned}
E_{0}= & E_{0}^{(0)}-\left\langle\psi_{0}^{(0)}\left|\mu_{z}\right| \psi_{0}^{(0)}\right\rangle F \\
& +\sum_{n}^{\prime} \frac{\left\langle\psi_{0}^{(0)}\left|\mu_{z}\right| \psi_{n}^{(0)}\right\rangle\left\langle\psi_{n}^{(0)}\left|\mu_{z}\right| \psi_{0}^{(0)}\right\rangle}{E_{0}-E_{n}} F^{2}+\cdots
\end{aligned}
$$

Neste ponto já é possível empregar a primeira das relações A.10 para escrever

$$
\mu_{0 z}=-\left(\frac{d E}{d F}\right)_{0}=\left\langle\psi_{0}^{(0)}\left|\mu_{z}\right| \psi_{0}^{(0)}\right\rangle
$$

pois somente o segundo termo do lado direito da equação A.15 sobrevive depois de se tomar a primeira derivada em relação ao campo $F$ e em seguida fazêlo igual a zero. A equação A.16 não informa nada novo. Diz apenas que que o momento de dipolo elétrico permanente é o valor esperado do operador momento de dipolo no estado não perturbado do sistema. Mais interessante é a segunda derivada, que após fazer $F=0$ fornece:

$$
\alpha_{z z}=-2 \sum_{n}^{\prime} \frac{\left\langle\psi_{0}^{(0)}\left|\mu_{z}\right| \psi_{n}^{(0)}\right\rangle\left\langle\psi_{n}^{(0)}\left|\mu_{z}\right| \psi_{0}^{(0)}\right\rangle}{E_{0}-E_{n}}
$$

A equação A.17 é uma expressão explícita para a polarizabilidade da molécula em termos de integrais sobre suas funções de onda.

Prosseguindo, é possível escrever $\Delta E_{n 0}=E_{n}-E_{0}$, que é uma quantidade positiva se 0 denotar o estado fundamental da molécula. Escrevendo os elementos de matriz $\left\langle\psi_{m}^{(0)}\left|\mu_{z}\right| \psi_{n}^{(0)}\right\rangle$ como $\mu_{z, m n}$, então a equação A.17 se torna

$$
\alpha_{z z}=2 \sum_{n}^{\prime} \frac{\mu_{z, 0 n} \mu_{z, n 0}}{\Delta E_{n 0}}
$$


Expressões similares para a polarizabilidade quando o campo é aplicado ao longo dos eixos $x$ e $y$ podem ser escritas em analogia à equação A.18. Para uma molécula que gira num fluido e apresenta todas as orientações em relação ao campo aplicado só é possível medir a polarizabilidade média $\bar{\alpha}$, que é dada pelo traço do tensor polarizabilidade, de forma que:

$$
\bar{\alpha}=\frac{1}{3}\left(\alpha_{x x}+\alpha_{y y}+\alpha_{z z}\right)=\frac{2}{3} \sum_{n}^{\prime} \frac{\mu_{x, 0 n} \mu_{x, n 0}+\mu_{y, 0 n} \mu_{y, n 0}+\mu_{z, 0 n} \mu_{z, n 0}}{\Delta E_{n 0}} .
$$

A aparência desta espressão pode ser simplificada escrevendo o numerador como produto escalar de dois vetores:

$$
\boldsymbol{\mu}_{0 n} \cdot \boldsymbol{\mu}_{n 0}=\mu_{x, 0 n} \mu_{x, n 0}+\mu_{y, 0 n} \mu_{y, n 0}+\mu_{z, 0 n} \mu_{z, n 0}
$$

Contudo, como $\boldsymbol{\mu}$ é um operador Hermiteano, $\boldsymbol{\mu}_{0 n}=\boldsymbol{\mu}_{0 n}^{*}$, é melhor escrever o lado direito da expressão A.20 como $\left|\mu_{n 0}\right|^{2}$, de forma a obter:

$$
\bar{\alpha}=\frac{2}{3} \sum_{n}^{\prime} \frac{\left|\mu_{n 0}\right|^{2}}{\Delta E_{n 0}}
$$

Para usar esta expressão deve-se atentar para o fato de que o numerador representa a soma dos três termos na expressão A.20. Um último ponto interessante diz respeito à unidade de medida da polarizabilidade. Como o momento de dipolo é expresso em $\mathrm{Cm}$ e a diferença de energia em $J$, a polarizabilidade é expressa em $C^{2} m^{2} J^{-1}$. Como esta unidade é incômoda para se lidar é comum introduzir a polarizabilidade de volume (polarizability volume) $\alpha^{\prime}$ que é definida por:

$$
\alpha^{\prime}=\frac{\alpha}{4 \pi \varepsilon_{0}}
$$

onde $\varepsilon_{0}$ é a permissividade no vácuo. A polarizabilidade de volume é mais conveniente por simplificar algumas expressões e é comumente expressa em $\AA^{3}$.

\section{A.3 Polarizabilidades e propriedades moleculares}

Para se usar as expressões derivadas acima, em princípio é necessário que se conheça as funções de onda e energias de todos os estados excitados da molécula, para somente então poder avaliar a soma da expressão A.21. Usualmente esta tarefa é impossível e se torna necessário recorrer a um procedimento 
aproximado. Tais aproximações adicionais podem fornecer importantes indicadores sobre a variação das propriedades moleculares com uma variedade de parâmetros, tais como tamanho molecular, além de fornecer relações entre observáveis. Os valores numéricos sugeridos por tais aproximações contudo devem ser encarados com suspeita.

Um aproximação usual é evocar a aproximação de fechamento [45], que é freqüentemente usada quando se quer apenas ter uma idéia da magnitude de uma propriedade sem ter que avaliar a soma perturbativa em detalhes. Assim se as energias de excitação, $E_{n}-E_{0}$, são trocadas por seu valor médio, $\Delta E$, obtem-se:

$$
\begin{aligned}
\alpha & \approx \frac{2}{3 \Delta E} \sum_{n}^{\prime} \mu_{0 n} \cdot \mu_{n 0} \approx \frac{2}{3 \Delta E} \sum_{n} \mu_{0 n} \cdot \mu_{n 0}-\mu_{00} \cdot \mu_{00} \\
& \approx \frac{2}{3 \Delta E}\left\{\left\langle\mu^{2}\right\rangle-\langle\mu\rangle^{2}\right\} \approx \frac{2(\Delta \mu)^{2}}{3 \Delta E}
\end{aligned}
$$

onde $\Delta \mu$ é referido como flutuação no momento de dipolo médio, sendo de fato o desvio médio quadrático do momento de dipolo a partir de seu valor médio. Até mesmo moléculas não polares $(\langle\mu\rangle=0)$ possuem flutuação de dipolo não nula. Até certo ponto pode-se, cautelosamente, pensar na flutuação de dipolo originando-se através da flutuação clássica da densidade eletrônica da molécula sobre sua média. Como visto na expressão A.23 a polarizabilidade de uma molécula é proporcional ao quadrado da magnitude desta flutuação. Este resultado é consistente com o fato de que uma molécula pode facilmente ser distorcida por um campo elétrico se seus elétrons não estiverem fortemente ligados ao núcleo.

Seguindo esta linha de raciocínio pode-se esperar um aumento da polarizabilidade com o raio da molécula e com o número de elétrons que ela contém, pois em cada caso o núcleo téra menos controle sobre seus elétrons. Para ilustrar esta conclusão, considere um átomo de um único elétron. Como seu operador momento de dipolo é $\boldsymbol{\mu}=-e \mathbf{r}$ e a espécie não perturbada é não-polar, conclui-se da expressão A.23 que:

$$
\alpha \approx \frac{2 e^{2}\left\langle r^{2}\right\rangle}{3 \Delta E}
$$

onde $\left\langle r^{2}\right\rangle$ é o raio médio quadrático do orbital do elétron. Esta expressão 
confirma o aumento da polarizabilidade com o aumento do raio e é consistente com a perda de controle do núcleo sobre seus elétrons quando o orbital se expande. Num átomo de muitos elétrons pode-se esperar que cada elétron contribua com um termo similar, o que resulta numa polarizabilidade que é proporcional a $N_{e}\left\langle r^{2}\right\rangle$ onde $N_{e}$ é o número de elétrons e $\left\langle r^{2}\right\rangle$ é agora o raio médio quadrático de todos os orbitais ocupados. Como $\left\langle r^{2}\right\rangle \approx R_{a}^{2}$ onde $R_{a}^{2}$ é o raio do átomo, segue-se que:

$$
\alpha \approx \frac{2 e^{2} N_{e} R_{a}^{2}}{3 \Delta E} \approx \frac{e^{2} N_{e} R_{a}^{2}}{I}
$$

Nesta última passagem foi empregada outra aproximação: a energia de excitação, $\Delta E$, é aproximadamente a mesma energia de ionização, $I$. Esta aproximação é tão questionável que o fator $\frac{2}{3}$ foi descartado. Segue portanto que como o tamanho do átomo aumenta (com o aumento do número de elétrons ou com a expansão de seus orbitais) a polarizabilidade aumenta. Como a energia de ionização segue tendência oposta, a presença de $I$ no denominador reforça esta conclusão.

\section{A.4 Polarizabilidades e espectroscopia molecular}

É possível desenvolver outra linha de argumento de maneira similar. Primeiramente, note que a polarizabilidade depende do quadrado da transição de momentos de dipolo. Por outro lado uma medida útil de intensidade de absorção é a força de oscilador, que para a transição $n \leftarrow 0$ é

$$
f_{n 0}=\frac{4 \pi m_{e}}{3 e^{2} \hbar} \nu_{n 0}\left|\mu_{n 0}\right|^{2}
$$

assim segue-se que:

$$
\alpha=\frac{\hbar^{2} e^{2}}{m_{e}} \sum_{n}^{\prime} \frac{f_{n 0}}{\Delta E_{n 0}^{2}}
$$

Esta expressão é a ligação entre espectroscopia e a predição de polarizabilidades devido ao fato de as forças de oscilador de uma molécula serem determinadas a partir das intensidades das bandas e suas energias serem determinadas a partir de suas posições na escala de freqüências. A expressão A.27 indica que a maior contribuição é devida às baixas energias e às transições de altas intensidades; 
energias altas e intensidades de transição baixas contribuem pouco para a polarizabilidade. Uma implicação é que se a molécula possui uma transição intensa no seu espectro, é esperada ser altamente polarizável. A expressão exata na equação A.27 pode ser desenvolvida usando a aproximação de que todas as energias de excitação são iguais, ou seja, $\Delta E_{n 0}^{2}=\Delta E^{2}$. Logo

$$
\alpha=\frac{\hbar^{2} e^{2}}{m_{e} \Delta E^{2}} \sum_{n}^{\prime} f_{n 0}
$$

A soma sobre as forças de oscilador é um resultado padrão conhecido como regra da soma de Kuhn-Thomas.

$$
\sum_{n}^{\prime} f_{n 0}=N_{e}
$$

É provado que interpretando $N_{e}$ como o número de elétrons de valência $N_{v}$ obtem-se melhores resultados para a soma das forças de oscilador e conseqüentemente para $\alpha$. Portanto

$$
\alpha \approx \frac{\hbar^{2} e^{2} N_{v}}{m_{e} \Delta E^{2}}
$$

Esta expressão mostra que a polarizabilidade aumenta com o número de elétrons (de valência) e com a diminuição da energia de excitação. Os dois efeitos geralmente se reforçam mutuamente, tal que é possível esperar que moléculas compostas por átomos pesados sejam fortemente polarizáveis.

\section{A.5 Polarizabilidades e forças de dispersão}

Existem muitas contribuições para as forças entre moléculas. Aqui será considerada a força de dispersão, que na ausência de ligação de hidrogênio é a interação atrativa dominante entre espécies não carregadas. A intensidade da força de dispersão é intimamente ligada à polarizabilidade das moléculas e baseado no que já foi visto neste apêndice será estabelecida a sua relação com vários parâmetros moleculares. As forças de dispersão, também chamadas forças de London, se originam a partir do acoplamento de flutuações instantâneas na distribuição de cargas sobre as suas moléculas vizinhas. Já foi visto que a polarizabilidade está relacionada à flutuação de carga na molécula e então pode-se esperar que a interação de dispersão seja relacionada às polarizabilidades das duas moléculas. Esta relação será estabelecida aqui. 
A teoria de perturbação será empregada para calcular a energia mínima quando dois átomos de camada fechada são trazidos à uma distância $R$. O Hamiltoniano de perturbação é a interação dos dois operadores de momentos de dipolo sobre os dois átomos. De acordo com a eletrostática clássica, tal interação é dada por [306]:

$$
H^{(1)}=\frac{1}{4 \pi \varepsilon_{0} R^{3}}\left\{\boldsymbol{\mu}_{A} \cdot \boldsymbol{\mu}_{B}-\frac{3\left(\boldsymbol{\mu}_{A} \cdot \mathbf{R}\right)\left(\mathbf{R} \cdot \mu_{B}\right)}{R^{2}}\right\}
$$

Por simplicidade, o eixo $z$ será escolhido como sendo aquele que une os centros dos dois átomos, assim tem-se:

$$
H^{(1)}=\frac{1}{4 \pi \varepsilon_{0} R^{3}}\left\{\mu_{A x} \mu_{B x}+\mu_{A y} \mu_{B y}-2 \mu_{A z} \mu_{B z}\right\} .
$$

O Hamiltoniano total do sistema é

$$
H=H^{(0)}+H^{(1)}, \quad H^{(0)}=H_{A}+H_{B} \quad \text {; }
$$

e os estados não perturbados do par de átomos são $\left|\psi_{n A}^{(0)} \psi_{n B}^{(0)}\right\rangle$, com

$$
H^{(0)}\left|\psi_{n A}^{(0)} \psi_{n B}^{(0)}\right\rangle=\left(E_{n A}+E_{n B}\right)\left|\psi_{n A}^{(0)} \psi_{n B}^{(0)}\right\rangle
$$

Como todos os estados considerados aqui são não perturbados o índice superior será omitido daqui para frente. Escrevendo, $E_{n A n B}=E_{n A}+E_{n B}$ e cosiderando apenas interações entre os átomos nos seus estados fundamentais, $\left|\psi_{0 A} \psi_{0 B}\right\rangle$, é fácil mostrar que a correção em primeira ordem para energia é nula, ou seja:

$$
\begin{aligned}
E^{(1)} & =\left\langle\psi_{0 A} \psi_{0 B}\left|H^{(1)}\right| \psi_{0 A} \psi_{0 B}\right\rangle \propto\left\langle\psi_{0 A} \psi_{0 B}\left|\mu_{A x} \mu_{B x}+\cdots\right| \psi_{0 A} \psi_{0 B}\right\rangle \\
& =\left\langle\psi_{0 A} \psi_{0 B}\left|\mu_{A x}\right| \psi_{0 A} \psi_{0 B}\right\rangle\left\langle\psi_{0 A} \psi_{0 B}\left|\mu_{B x}\right| \psi_{0 A} \psi_{0 B}\right\rangle+\cdots=0
\end{aligned}
$$

uma vez que todos os elementos de matriz são o valor esperado do operador momento de dipolo elétrico no estado fundamental, que é zero para espécies não polares.

Como os termos em primeira ordem são nulos, as contribuições de segunda ordem devem ser consideradas. Fisicamente isto significa que a distorção da função de onda de cada átomo devido à presença do segundo átomo deve ser permitida. A energia de segunda ordem é dada por:

$$
E^{(2)}=\sum_{n A, n B}^{\prime} \frac{\left\langle\psi_{0 A} \psi_{0 B}\left|H^{(1)}\right| \psi_{n A} \psi_{n B}\right\rangle\left\langle\psi_{n A} \psi_{n B}\left|H^{(1)}\right| \psi_{0 A} \psi_{0 B}\right\rangle}{E_{0 A 0 B}-E_{n A n B}}
$$


Como antes o denominador foi expresso em termos das energias de excitação desta vez escritas como $\Delta E_{n A 0 B}+\Delta E_{0 A n B}=E_{n A n B}-E_{0 A 0 B}$. O Hamiltoniano de perturbação tem três termos, tal que a energia de segunda ordem tem nove termos, felizmente, a maioria nulos. Considere por exemplo o termo cruzado

$$
\left\langle\psi_{0 A} \psi_{0 B}\left|\mu_{A x} \mu_{B x}\right| \psi_{n A} \psi_{n B}\right\rangle\left\langle\psi_{n A} \psi_{n B}\left|\mu_{A y} \mu_{B y}\right| \psi_{0 A} \psi_{0 B}\right\rangle
$$

Este termo inclui o fator

$$
\left\langle\psi_{0 A}^{(0)}\left|\mu_{A x}\right| \psi_{n A}^{(0)}\right\rangle\left\langle\psi_{n A}^{(0)}\left|\mu_{A y}\right| \psi_{0 A}^{(0)}\right\rangle
$$

Para certificar que este termo é nulo, usa-se o fato de que é possível escolher um sistema de coordenadas alternativo sobre $A$, com o eixo $y$ apontando numa direção oposta e o eixo $x$ inalterado. O produto dos elementos de matriz muda de sinal. Contudo, uma contribuição para a energia não pode depender do sistema de coordenadas, e então a contribuição deve ser zero. O mesmo argumento se aplica a todos os termos cruzados na equação A.36 e somente restarão os três termos da forma

$$
\left\langle\psi_{0 A} \psi_{0 B}\left|\mu_{A q} \mu_{B q}\right| \psi_{n A} \psi_{n B}\right\rangle\left\langle\psi_{n A} \psi_{n B}\left|\mu_{A q} \mu_{B q}\right| \psi_{0 A} \psi_{0 B}\right\rangle
$$

onde $q=x, y$ ou $z$. Para átomos, estes termos são iguais (devido à simetria esférica de cada átomo). Além disso, pela simetria esférica

$$
\begin{aligned}
\left\langle\psi_{0 A}\left|\mu_{A x}\right| \psi_{n A}\right\rangle\left\langle\psi_{n A}\left|\mu_{A x}\right| \psi_{0 A}\right\rangle & =\left\langle\psi_{0 A}\left|\mu_{A y}\right| \psi_{n A}\right\rangle\left\langle\psi_{n A}\left|\mu_{A y}\right| \psi_{0 A}\right\rangle \\
& =\left\langle\psi_{0 A}\left|\mu_{A z}\right| \psi_{n A}\right\rangle\left\langle\psi_{n A}\left|\mu_{A z}\right| \psi_{0 A}\right\rangle \text { A.40) }
\end{aligned}
$$

o que acarreta

$$
\left\langle\psi_{0 A}\left|\mu_{A q}\right| \psi_{n A}\right\rangle\left\langle\psi_{n A}\left|\mu_{A q}\right| \psi_{0 A}\right\rangle=\frac{1}{3} \mu_{A, 0 n_{A}} \cdot \mu_{A, n_{A} 0}
$$

e o mesmo para as três componentes do átomo $B$. Portanto a expressão completa se reduz a

$$
E^{(2)}=-\frac{2}{3}\left(\frac{1}{4 \pi \varepsilon_{0} R^{3}}\right)^{2} \sum_{n A, n B}^{\prime} \frac{\left(\mu_{A, 0 n_{A}} \cdot \mu_{A, n_{A} 0}\right)\left(\mu_{B, 0 n_{B}} \cdot \mu_{B, n_{B} 0}\right)}{\Delta E_{n A 0 B}+\Delta E_{0 A n B}} .
$$

Esta expressão confirma que existe uma energia de interação que é atrativa $\left(E^{(2)}<0\right)$ e inversamente proporcional à sexta potência da separação entre os átomos $\left(E^{(2)} \propto \frac{1}{R^{6}}\right)$. 
Uma aproximação revela uma forma útil da equação A.42. Usando a relação de fechamento e fazendo $\Delta E_{n A 0 B} \approx \Delta E_{A}$ e $\Delta E_{0 A n B} \approx \Delta E_{B}$ pode-se escrever

$$
\begin{aligned}
E^{(2)} & =-\frac{1}{24 \pi^{2} \varepsilon_{0}^{2} R^{6}} \frac{1}{\Delta E_{A}+\Delta E_{B}} \sum_{n A, n B}^{\prime}\left(\mu_{A, 0 n_{A}} \cdot \mu_{A, n_{A} 0}\right)\left(\mu_{B, 0 n_{B}} \cdot \mu_{B, n_{B} 0}\right) \\
& =-\frac{1}{24 \pi^{2} \varepsilon_{0}^{2} R^{6}} \frac{\left\langle\mu_{A}^{2}\right\rangle\left\langle\mu_{B}^{2}\right\rangle}{\Delta E_{A}+\Delta E_{B}}
\end{aligned}
$$

onde $\left\langle\mu_{A}^{2}\right\rangle=\left\langle\psi_{0 A}^{(0)}\left|\mu_{A}^{2}\right| \psi_{0 A}^{(0)}\right\rangle$ e $\left\langle\mu_{B}^{2}\right\rangle=\left\langle\psi_{0 B}^{(0)}\left|\mu_{B}^{2}\right| \psi_{0 B}^{(0)}\right\rangle$. Os termos $\left\langle\mu_{A}\right\rangle^{2} \mathrm{e}$ $\left\langle\mu_{B}\right\rangle^{2}$ são ambos nulos para espécies não polares. Esta expressão pode ser melhor escrita tendo em vista a relação entre o momento de dipolo médio quadrático e a polarizabilidade, equação A.23, que para espécies não polares se simplifica para $\left\langle\mu_{A}^{2}\right\rangle \approx \frac{3}{2} \alpha_{A} \Delta E_{A}$, e analogamente para $B$. Substituindo estas relações na expressão A.43 obtem-se:

$$
E^{(2)}=-\frac{3}{32 \pi^{2} \varepsilon_{0}^{2}} \frac{\Delta E_{A} \Delta E_{B}}{\Delta E_{A}+\Delta E_{B}} \frac{\alpha_{A} \alpha_{B}}{R^{6}}=-\frac{3}{2} \frac{\Delta E_{A} \Delta E_{B}}{\Delta E_{A}+\Delta E_{B}} \frac{\alpha_{A^{\prime} \alpha_{B}}}{R^{6}}
$$

Uma indicação geral das magnitudes da energia de excitação média é a energia de ionização de cada átomo, e escrevendo $\Delta E_{A} \approx I_{A}$ e $\Delta E_{B} \approx I_{B}$ obtem-se a fórmula de London:

$$
E^{(2)} \approx-\frac{3}{2} \frac{I_{A} I_{B}}{I_{A}+I_{B}} \frac{\alpha_{A}{ }^{\prime} \alpha_{B}{ }^{\prime}}{R^{6}}
$$

A fórmula de London apesar de aproximada revela o caráter essencial da energia. de dispersão e pode ser empregada em estimativas de sua magnitude. Por exemplo, pode-se concluir que a interação de dispersão é maior entre átomos que possuam altas polarizabilidades. Já foi visto como a polarizabilidade se relaciona à estrutura dos átomos, e as observações feitas nas seções A.3 e A.4 podem ser estendidas às interações entre átomos e moléculas.

\section{A.6 Constante dielétrica e susceptibilidade elétrica}

Agora que foi obtida a expressão para a polarizabilidade de uma molécula individual é possível tecer uma discussão a respeito da polarizabilidade macroscópica e sua correspondente constante dilétrica. 
No vácuo, o potencial de Coulomb de uma carga $q$ a uma distância $r$ é

$$
\phi=\frac{q}{4 \pi \varepsilon_{0} r}
$$

onde $\varepsilon_{0}$ é a permissividade do vácuo. Num meio dielétrico a mesma carga dá origem a um potencial

$$
\phi=\frac{q}{4 \pi \varepsilon r}
$$

onde $\varepsilon$ é a permissividade do meio. A razão

$$
\varepsilon_{r}=\frac{\varepsilon}{\varepsilon_{0}}
$$

é chamada permissividade relativa, mais conhecida como constante dielétrica. Na prática a constante dielétrica é medida como a razão das capacitâncias de um capacitor com e sem dielétrico entre suas placas paralelas.

Considere agora o campo elétrico entre duas placas, cada uma de área $A$, e com densidade superficial de carga $\sigma$, de maneira que a carga total numa placa seja $A \sigma$ e na outra $-A \sigma$. Um resultado da eletrostática é que a intensidade do campo elétrico entre as placas é $\frac{\sigma}{\varepsilon_{0}}$ se o meio entre as placas for o vácuo [306], mas

$$
F=\frac{\sigma}{\varepsilon}
$$

se o meio for um dielétrico. Ao invés de imaginar a redução do campo elétrico devido ao meio dielétrico é melhor pensar nesta redução em termos da polarização $^{1}, P$, do meio devido a superfície carregada e na conseqüente indução de uma densidade de carga na superfície. A partir deste ponto de vista, o campo elétrico passa a ser escrito como:

$$
F=\frac{\sigma-P}{\varepsilon_{0}}
$$

Como as expressões A.49 e A.50 são formas diferentes para expressar o mesmo campo elétrico, é possível equacioná-las para se obter o valor de $P$. Assim:

$$
P=\frac{\varepsilon-\varepsilon_{0}}{\varepsilon} \sigma=\left(\varepsilon_{r}-1\right) \varepsilon_{0} F
$$

\footnotetext{
${ }^{1}$ Neste ponto, polarização que dizer momento de dipolo por unidade de volume e nao momento de dipolo induzido.
} 
A susceptibilidade elétrica, $\chi_{e}$, de um meio é definida por:

$$
P=\chi_{e} \varepsilon_{0} F
$$

de modo que comparando as equações A.51 e A.52 é possível relacionar a susceptibilidade elétrica com a constante dielétrica por:

$$
\chi_{e}=\varepsilon_{r}-1
$$

O próximo passo no argumento envolve a relação entre a polarização do meio e a polarizabilidade de suas moléculas. Para isto é necessário ter em mente que sendo a polarização uma densidade de carga induzida ela é também uma densidade de momento de dipolo no meio; o dipolo dividido pelo volume da amostra. Dessa forma é possível relacionar a polarização $P$ de um meio as suas propriedades moleculares uma vez que a densidade de momento de dipolo é o momento de dipolo médio de uma molécula no meio, $\langle\mu\rangle$, multiplicada pela densidade em número de moléculas, $\mathcal{N}$. Se por vez for considerado que as moléculas não possuem momento de dipolo, $\langle\mu\rangle$ é então o momento de dipolo induzido. Aqui no entanto não se pode escrever simplesmente $\langle\mu\rangle=\alpha F$ pois a molécula experimenta o campo elétrico local, $F^{*}$ e não o campo aplicado, $F$. O campo elétrico local é o campo total originado a partir do campo elétrico aplicado e dos momentos de dipolo elétrico que estimulam o campo no meio. Segue que:

$$
P=\alpha \mathcal{N} F^{*}
$$

O cálculo de campo local, até mesmo para um meio dielétrico linear é, contudo, um problema que é resolvido de forma satisfatória somente para poucos casos. A aproximação clássica para este problema foi estabelecida por Lorentz em 1916 [307]. Lorentz mostrou que para átomos ou moléculas não polares com elétrons de valência bem localizados e distribuídos aleatoriamente numa rede cúbica ou no espaço o campo local (dielétrico contínuo) pode ser dado através da bem conhecida fórmula de Lorentz:

$$
F^{*}=F+\frac{P}{3 \varepsilon_{0}}
$$


Esta expressão pode ser usada na equação A.54 para fornecer

$$
P=\left(\frac{3 \alpha \mathcal{N}}{3 \varepsilon_{0}-\alpha \mathcal{N}}\right) \varepsilon_{0} F .
$$

A comparação das equações A.52 e A.56 permite escrever a susceptibilidade elétrica como:

$$
\chi=\frac{\frac{\alpha \mathcal{N}}{\varepsilon_{0}}}{1-\frac{\alpha \mathcal{N}}{3 \varepsilon_{0}}} .
$$

Segue imediatamente da equação A.53 que a constante dielétrica é relacionada à polarizabilidade das moléculas por:

$$
\varepsilon_{r}=\frac{1+\frac{2 \alpha \mathcal{N}}{3 \varepsilon_{0}}}{1-\frac{\alpha \mathcal{N}}{3 \varepsilon_{0}}} .
$$

As últimas expressōes são aplicáveis para dielétrico composto por moléculas sem momento de dipolo permanente. No caso de dielétrico composto por moléculas que possuam momento de dipolo permanente pode-se mostrar que a polarização é dada por:

$$
P=\left(\alpha+\frac{\mu_{0}^{2}}{3 k T}\right) \mathcal{N} F^{*}
$$

e a constante dielétrica por sua vez é dada por

$$
\varepsilon_{r}=\frac{1+2 \beta}{1-\beta}
$$

onde $k$ é a constante de Boltzmann, $T$ é a temperatura e $\mu_{0}$ é o momento de dipolo permanente. $\beta$ entra na expressão A.60 para simplificá-la e é dado por:

$$
\beta=\frac{4 \pi N_{A} \rho}{3 M}\left(\alpha^{\prime}+\frac{\mu_{0}^{2}}{12 \pi \varepsilon_{0} k T}\right) .
$$

Nesta última expressão a densidade de número, $\mathcal{N}$, foi substituída pela densidade de massa, $\rho$, através de

$$
\mathcal{N}=\frac{N}{V}=\frac{N_{A} \frac{m}{M}}{V}=\frac{N_{A} \rho}{M}
$$

onde $m$ é a massa da amostra, $M$ é a massa molar das moléculas e $N_{A}$ é o número de Avogadro.

A dependência da permissividade de um meio com as características das moléculas das quais este meio é composto pode agora ser discutida da 
mesma forma que antes, pois foi visto como elas determinam a polarizabilidade. Assim é esperado que um meio tenha uma constante dielétrica alta se sua polaizabilidade for alta, se as moléculas forem polares, se seus momentos de dipolo forem grandes. 


\section{Apêndice B}

\section{Espalhamentos Raman e Rayleigh}

Quando a luz passa através de um meio ela é espalhada. Nos casos em que a luz espalhada tem a mesma freqüência da luz incidente diz-se que o espalhamento é clássico, por outro lado quando a luz espalhada possui freqüencia diferente da luz incidente diz-se que o espalhamento é quântico. Estes fenômenos são as bases das espectroscopias Raman e Rayleigh, detalhes sobre tais fenômenos são dados neste apêndice.

\section{B.1 Espalhamento Raman}

Quando um feixe de luz incide sobre uma molécula, esta o espalha em uma direção diferente da direção de incidência. Observa-se que a freqüência da luz incidente pode ser alterada durante o espalhamento. Este fenômeno, que envolve espalhamento de luz e mudança de freqüência, é denominado espalhamento Raman e foi descoberto por C. V. Raman em 1928 [87, 88].

No espalhamento Raman o principal fator a ser considerado é o momento de dipolo induzido na molécula pelo campo elétrico da luz incidente. As componentes do momento de dipolo induzido são dadas por:

$$
\pi_{i}=\sum_{j} \alpha_{i j} F_{j}
$$

onde $\alpha_{i j}$ é a componente $i j$ do tensor polarizabilidade.

Geralmente a magnitude da polarizabilidade molecular pode ser 
dada em termos das coordenadas vibracionais $q_{k}$. Então é possível expandí-la em série de Taylor como:

$$
\alpha=\alpha_{0}+\sum_{k}\left\{\left(\frac{\partial \alpha}{\partial q_{k}}\right)_{0}\right\} q_{k}+\text { termos de ordem superior. }
$$

O subscrito zero indica valores na configuração de equilíbrio. Desde que as amplitudes normais sejam muito pequenas, uma aproximação conveniente é desprezar termos de ordem superior. Daqui pra frente, a derivada da polarizabilidade em relação à coordenada normal será denotada por $\boldsymbol{\alpha}^{\prime}$.

Em termos das componentes do tensor a expressão é:

$$
\alpha_{i j}=\left(\alpha_{i j}\right)_{0}+\sum_{k}\left(\alpha_{i j}^{\prime}\right)_{0} q_{k}
$$

de maneira a se escrever a equação B.1 como

$$
\pi_{i}=\sum_{j}\left(\alpha_{i j}\right)_{0} F_{j}+\sum_{j k}\left[\left(\alpha_{i j}^{\prime}\right)_{0} q_{k}\right] F_{j}
$$

Considerando, a princípio, o segundo termo da equação B.4, maior atenção deve ser dada à contribuição vibracional do modo de coordenada normal $q_{k}$, que oscila com freqüência normal $\nu_{k}$, com dependência temporal na forma

$$
q_{k}=q_{k 0} \cos \left(2 \pi \nu_{k} t\right)
$$

e à componente do campo elétrico $E_{j}$ da luz incidente que oscila com frequência $\nu_{0}$, com dependência temporal na forma

$$
F_{j}=F_{j 0} \cos \left(2 \pi \nu_{0} t\right)
$$

O tensor $\left(\alpha_{i j}\right)_{0}$ é uma constante. Substituindo as equações B.5 e B.6 na equação B.4 obtem-se:

$$
\pi_{i}=\sum_{j}\left(\alpha_{i j}\right)_{0} F_{j 0} \cos \left(2 \pi \nu_{0} t\right)+\sum_{j k}\left[\left(\alpha_{i j}^{\prime}\right)_{0} q_{k 0}\right] F_{j 0} \times \cos \left(2 \pi \nu_{0} t\right) \cos \left(2 \pi \nu_{k} t\right)
$$

Tendo em vista a identidade $\cos \theta \cos \phi=\frac{1}{2}\{\cos (\theta+\phi)+\cos (\theta-\phi)\}$, observa-se que as contribuições para o momento de dipolo induzido, $\pi_{i}$ são caracterizadas por duas novas freqüências $\nu_{0}+\nu_{k}$ e $\nu_{0}-\nu_{k}$, conhecidas como freqüências 
Raman. Luz com uma destas freqüêcias pode ser emitida pela molécula e é observável em direções diferentes da direção da luz incidente. Elas constituem a contribuição do k-ésimo modo normal ao espectro Raman da molécula que espalha.

A probabilidade de ocorrer uma transição entre dois estados caracterizados pelas funções de onda $\psi_{n}$ e $\psi_{n^{\prime}}$ é proporcional ao quadrado de $\left\langle\psi_{n}\left|\pi_{i}\right| \psi_{n^{\prime}}\right\rangle$ que pode ser escrito como:

$$
\left\langle\psi_{n}\left|\pi_{i}\right| \psi_{n^{\prime}}\right\rangle=\sum_{j}\left(\alpha_{i j}\right)_{0} F_{j}\left\langle\psi_{n} \mid \psi_{n^{\prime}}\right\rangle+\sum_{j}\left(\alpha_{i j}^{\prime}\right)_{0} F_{j} \sum_{k}\left\langle\psi_{n}\left|q_{k}\right| \psi_{n^{\prime}}\right\rangle
$$

A primeria integral só não se anulará se $\psi_{n}$ e $\psi_{n^{\prime}}$ caracterizarem o mesmo estado quântico. Uma vez que $\left(\alpha_{i j}\right)_{0}$ é uma simples constante e $F_{j}$ oscila com a freqüência da luz incidente, $\nu_{0}$, segue-se que a parte correspondente do momento de dipolo induzido deve oscilar com a mesma freqüência. Assim a luz de freqüência $\nu_{0}$ é emitida e observada em direções que diferem da direção de incidência. Este fenômeno é chamado de espalhamento clássico ou Rayleigh. Pelo fato da polarizabilidade ser diferente de zero para todas as moléculas, o espalhamento Rayleigh nunca é proibido.

A segunda integral é nula exceto quando $n-n^{\prime}= \pm 1$, para um dos modos normais e zero para os outros. Deste modo a luz incidente de freqüência $\nu_{0}$ é espalhada com freqüência $\nu_{0} \pm \nu_{k}$, o que caracteriza o espalhamento Raman. Para que um modo normal seja ativo no espalhamento Raman deve-se ter

$$
\left(\alpha_{i j}^{\prime}\right)_{0} \neq 0
$$

para pelo menos uma das componentes.

\section{B.2 Propriedades óticas das moléculas}

\section{B.2.1 Propriedades direcionais da radiação emitida}

De acordo com a eletrodinâmica clássica, a intensidade de emissão de radiação a partir de uma pequena oscilação do momento de dipolo elétrico não é a mesma em todas as direções. Esta intensidade é dada por [306]:

$$
I_{\theta}=K \mu^{2} \cos ^{2} \theta
$$


onde $\mu$, é a magnitude do momento de dipolo oscilante e $K$ é uma constante de proporcionalidade. A figura B.1 mostra sua distribuição em um plano que contém o vetor momento de dipolo. As setas indicam a direção de propagação. Note que o momento de dipolo não irradia na direção de seu eixo e que a intensidade máxima ocorre para uma direção perpendicular a este eixo. Uma outra

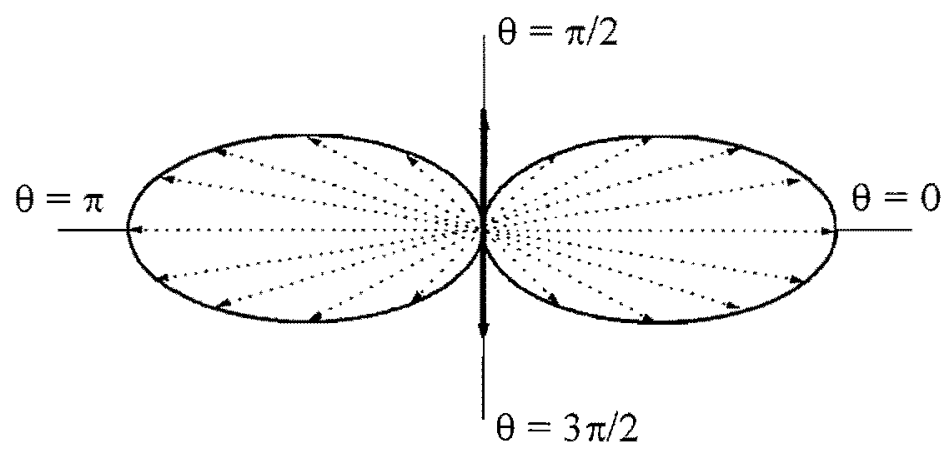

Figura B.1: Representação em coordenadas polares da intensidade de emissão de radiação por um momento de dipolo oscilante

propriedade importante é a polarização. Como é sabido, a radiação eletromagnética está associada a um campo elétrico transversalmente oscilante. $\mathrm{Na}$ luz natural (não polarizada) todas as direções transversais para este campo são igualmente representadas, mas na luz plano-polarizada somente uma direção particular está presente. Aqui, define-se plano de polarização como o plano no qual o vetor campo elétrico está confinado.

\section{B.2.2 Polarização do espalhamento Raman por uma molécula}

No efeito Raman trabalha-se com a parte da luz que sofre mudança de frequência no ato do espalhamento. Considere uma molécula, situada na origem de um sistema de coordenadas fixo em relação à direção de incidência e à direção da luz espalhada. A molécula é irradiada ao longo da direção positiva do eixo y por luz natural de freqüência $\nu_{0}$. Luz polarizada deste tipo pode ser considerada como composta de duas partes com intensidades iguais: uma polarizada no plano $x y$ e outra polarizada no plano $y z$ (figura B.2). Foi visto que o espalhamento Raman é descrito pelo segundo termo da equação B.4, isto é, a parte do momento de dipolo induzido que é determinado somente pela derivada do 


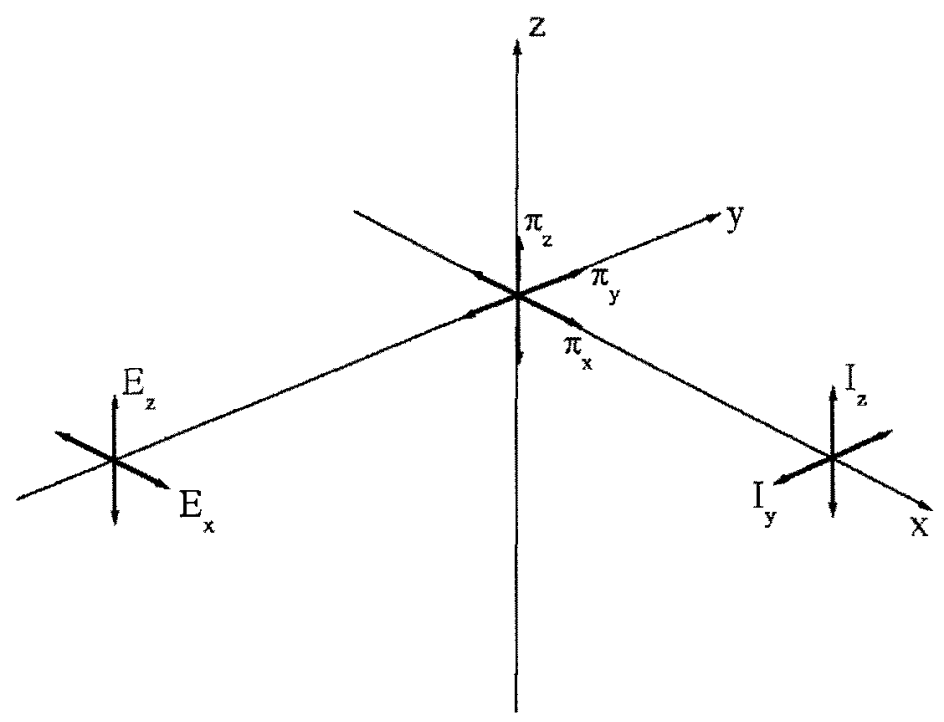

Figura B.2: Espalhamento Raman a ângulos retos a partir da direção do feixe incidente, mostrando as componentes polarizadas

tensor polarizabilidade em sua configuração de equilíbrio, $\left(\alpha_{i j}^{\prime}\right)_{0}$. Considere o espalhamento Raman na direção positiva do eixo $x$, ou seja perpendicularmente à direção do feixe de luz incidente. Para isto considera-se o momento de dipolo induzido com componentes $y$ e $z$, pois a componente $x$ não contribui para emissão na direção $x$.

Uma vez que $F_{y}=0$ pode-se escrever:

$$
\begin{aligned}
& \pi_{y}=\alpha_{y x}^{\prime} q_{k} F_{x}+\alpha_{y z}^{\prime} q_{k} F_{z} \\
& \pi_{z}=\alpha_{z x}^{\prime} q_{k} F_{x}+\alpha_{z z}^{\prime} q_{k} F_{z}
\end{aligned}
$$

Em geral, $\pi_{y} \neq \pi_{z}$, e conseqüentemente as intensidades das duas componentes plano-polarizadas da luz espalhada ao longo do eixo $x$ são diferentes. A razão entre as intensidades é chamada taxa de despolarização do espalhamento Raman e é escrita como:

$$
\rho_{n}=\frac{I_{y}}{I_{z}},
$$

onde o índice $n$ indica que a luz incidente é natural.

Devido ao fato da luz ser natural, $F_{x}=F_{z}$, é possível escrever a expressão para as intensidades devidas às componentes plano-polarizadas da 
luz espalhada da seguinte forma

$$
\begin{aligned}
& I_{y}=K F^{2} q_{k}\left[\left(\alpha_{y x}^{\prime}\right)^{2}+\left(\alpha_{y z}^{\prime}\right)^{2}\right] \\
& I_{z}=K F^{2} q_{k}\left[\left(\alpha_{z x}^{\prime}\right)^{2}+\left(\alpha_{z z}^{\prime}\right)^{2}\right] .
\end{aligned}
$$

Ao invés de usar luz incidente natural, é possível experimentalmente usar luz incidente plano-polarizada. Além disso existe uma escolha de planos de polarização que inclui dois casos muito importantes. No primeiro, a luz incidente é polarizada no plano $y z$, isto é, somente $F_{z}$ está presente enquanto $F_{x}$ e $F_{y}$ são zero, de modo que o vetor campo elétrico é perpendicular ao plano de espalhamento, portanto:

$$
\rho_{p \perp}=\left(\frac{\alpha_{y z}^{\prime}}{\alpha_{z z}^{\prime}}\right)^{2}
$$

No segundo caso a luz é polarizada no plano $x y$, de forma que somente a componente $F_{x}$ permanece e o vetor campo elétrico é paralelo ao plano de espalhamento. Assim

$$
\rho_{p / /}=\left(\frac{\alpha_{y x}^{\prime}}{\alpha_{z x}^{\prime}}\right)^{2}
$$

O índice $p$ indica luz plano-polarizada.

\section{B.2.3 Transformação das componentes da polarizabilidade}

Num sistema eletricamente polarizável, tal como uma molécula, existem três direções mutuamente perpendiculares (eixos principais), em que a aplicação de um campo elétrico em uma delas resulta na indução de um momento de dipolo na mesma direção. A relação entre as componentes do campo elétrico, relativa a estes eixos mutuamente perpendiculares é

$$
\begin{aligned}
\pi_{X} & =\alpha_{X} F_{X} \\
\pi_{Y} & =\alpha_{Y} F_{Y} \\
\pi_{Z} & =\alpha_{Z} F_{Z}
\end{aligned}
$$

onde $\alpha_{X}, \alpha_{Y}$ e $\alpha_{Z}$ são os valores principais da polarizabilidade.

A forma simples das equações B.16 obtida quando o tensor é referido aos eixos principais, está em desacordo com a equação B.1 na qual o tensor 
é referido ao sistema de eixos Cartesianos gerais. Pode-se então escrever as equações mencionadas como:

$$
\left[\begin{array}{c}
\pi_{X} \\
\pi_{Y} \\
\pi_{Z}
\end{array}\right]=\left[\begin{array}{ccc}
\alpha_{X} & 0 & 0 \\
0 & \alpha_{Y} & 0 \\
0 & 0 & \alpha_{Z}
\end{array}\right]\left[\begin{array}{c}
F_{X} \\
F_{Y} \\
F_{Z}
\end{array}\right]
$$

Assim nestas bases, cujos eixos coordenados são os eixos principais da polarizabilidade, a matriz correspondente $\alpha^{\prime}$ é uma matriz diagonal. É fácil mostrar [85] que a relação entre as componentes do tensor polarizabilidade no sistema Cartesiano geral, $x, y$ e $z$ e no sistema Cartesiano especial $X, Y$ e $Z$ é

$$
\alpha_{i j}^{\prime}=\sum_{p} \alpha_{p}^{\prime} \cos (i, p) \cos (j, p)
$$

onde $i$ ou $j=x, y$ ou $z, p=X, Y$ ou $Z$ e $(i, p)$ é o ângulo formado entre o eixo $i$ do sistema Cartesiano geral e o eixo $p$ do sistema Cartesiano especial.

Esta equação mostra que a troca de $i$ por $j$ deixa o lado direito inalterado, e portanto $\alpha_{i j}^{\prime}=\alpha_{j i}^{\prime}$, isto é a polarizabilidade é um tensor simétrico.

No caso particular em que $i=j$ tem-se:

$$
\alpha_{i i}^{\prime}=\sum_{p} \alpha_{p}^{\prime} \cos ^{2}(i, p)
$$

Os nove $\cos (i, p)$ não são independentes. De fato eles constituem os elementos de uma matriz quadrada de transformação

$$
\left[\begin{array}{l}
x \\
y \\
z
\end{array}\right]=\left[\begin{array}{ccc}
\cos (x, X) & \cos (x, Y) & \cos (x, Z) \\
\cos (y, X) & \cos (y, Y) & \cos (y, Z) \\
\cos (z, X) & \cos (z, Y) & \cos (z, Z)
\end{array}\right]\left[\begin{array}{c}
X \\
Y \\
Z
\end{array}\right]
$$

Uma vez que esta é uma transformação ortogonal, os elementos devem satỉsfazer às relações:

$$
\begin{gathered}
\sum_{i} \cos ^{2}(i, p)=1 \\
\sum_{i} \sum_{p \neq q} \cos (i, p) \cos (i, q)=0
\end{gathered}
$$

Em conseqüência destas relaçōes, certas combinações das componentes do tensor $\alpha^{\prime}$ permanecem inalteradas quando a orientação dos eixos principais relativa aos Cartesianos gerais varia, isto é, quando a molécula em questão gira. Estas 
combinações são os invariantes do tensor. Eles são em número de dois, chamados de valor médio $\bar{\alpha}^{\prime}$ e anisotropia $\Delta \alpha^{\prime}$. Suas definições são as seguintes:

$$
\bar{\alpha}^{\prime}=\frac{1}{3}\left(\alpha_{x x}^{\prime}+\alpha_{y y}^{\prime}+\alpha_{z z}^{\prime}\right)
$$

$\mathrm{e}$

$$
\begin{aligned}
\left(\Delta \alpha^{\prime}\right)^{2}= & \frac{1}{2}\left[\left(\alpha_{x x}^{\prime}-\alpha_{y y}^{\prime}\right)^{2}+\left(\alpha_{y y}^{\prime}-\alpha_{z z}^{\prime}\right)^{2}+\left(\alpha_{z z}^{\prime}-\alpha_{x x}^{\prime}\right)^{2}\right] \\
& +3\left[\left(\alpha_{x y}^{\prime}\right)^{2}+\left(\alpha_{x z}^{\prime}\right)^{2}+\left(\alpha_{y z}^{\prime}\right)^{2}\right]
\end{aligned}
$$

Eles são realmente invariantes e por isto é possivel escrevê-los em função das coordenadas dos eixos principais. Assim mostra-se que [85]:

$$
\bar{\alpha}^{\prime}=\frac{1}{3}\left(\alpha_{X}^{\prime}+\alpha_{Y}^{\prime}+\alpha_{Z}^{\prime}\right)
$$

e

$$
\left(\Delta \alpha^{\prime}\right)^{2}=\frac{1}{2}\left[\left(\alpha_{X}^{\prime}-\alpha_{Y}^{\prime}\right)^{2}+\left(\alpha_{Y}^{\prime}-\alpha_{Z}^{\prime}\right)^{2}+\left(\alpha_{Z}^{\prime}-\alpha_{X}^{\prime}\right)^{2}\right]
$$

\section{B.2.4 Média dos quadrados das componentes do tensor polari- zabilidade}

As equações B.12, B.14 e B.15 dão os valores de $\rho_{n}, \rho_{p \perp}$ e $\rho_{p / /}$ para a luz espalhada por uma única molécula com orientação fixa no espaço. Para adaptálas a um caso prático (uma amostra gasosa por exemplo) deve-se encontrar as médias dos quadrados dos componentes do tensor sobre todas as orientações dos eixos principais relativamente aos eixos Cartesianos gerais. As quantidades médias são distinguidas por barras sobre seus símbolos. Usando a equação B.18 obtem-se:

$$
\begin{aligned}
\left(\alpha_{i j}^{\prime}\right)^{2}= & \sum_{p}\left(\alpha_{p}^{\prime}\right)^{2} \overline{\cos ^{2}(i, p) \cos ^{2}(j, p)} \\
& \sum_{p} \sum_{p \neq q} \alpha_{p}^{\prime} \alpha_{q}^{\prime} \overline{\cos (i, p) \cos (j, p) \cos (i, q) \cos (j, q)} .
\end{aligned}
$$

Como antes, $i$ ou $j=x, y$ ou $z$ e $p=X, Y$ ou $Z$. Os valores principais de $\alpha_{p}$ (ou $\alpha_{q}$ ) são constantes, e $p \neq q$.

Então para se obter o valor de $\left(\bar{\alpha}_{i j}^{\prime}\right)^{2}$ é preciso conhecer os valores médios nos somatórios. Estes podem ser determinados [85] através de cálculos 
que envolvem as equações B.21 e B.22 e são dados por:

$$
\begin{gathered}
\overline{\cos ^{2}(i, p) \cos ^{2}(j, p)}=\frac{1}{15} \\
\overline{\cos (i, p) \cos (j, p) \cos (i, q) \cos (j, q)}=-\frac{1}{30} .
\end{gathered}
$$

Com estes valores é possível agora avaliar as médias desejadas. Tomando primeiro o caso de uma componente da diagonal, $\vec{\alpha}_{i i}^{\prime}$, usando a equação B.19 e $j=i$, obtem-se:

$$
\left(\alpha_{i i}^{\prime}\right)^{2}=\sum_{p}\left(\alpha_{p}^{\prime}\right)^{2} \overline{\cos ^{4}(i, p)}++\sum_{p q} \alpha_{p}^{\prime} \alpha_{q}^{\prime} \overline{\cos ^{2}(i, p) \cos ^{2}(i, q)}
$$

Inserindo os valores das respectivas médias, (equações B.28 e B.29) tem-se:

$$
\left(\alpha_{i i}^{\prime}\right)^{2}=\frac{1}{5}\left[\left(\alpha_{X}^{\prime}\right)^{2}+\left(\alpha_{Y}^{\prime}\right)^{2}+\left(\alpha_{Z}^{\prime}\right)^{2}\right]+\frac{1}{15}\left(2 \alpha_{X}^{\prime} \alpha_{Y}^{\prime}+2 \alpha_{Y}^{\prime} \alpha_{Z}^{\prime}+2 \alpha_{Z}^{\prime} \alpha_{X}^{\prime}\right)
$$

É usual expressar esta média em termos dos dois invariantes do tensor, $\bar{\alpha}^{\prime} \mathrm{e}$ $\Delta \alpha^{\prime}$. Pode-se confirmar facilmente que:

$$
\left(\alpha_{i i}^{\prime}\right)^{2}=\frac{1}{45}\left\{45\left(\bar{\alpha}^{\prime}\right)^{2}+4\left(\Delta \alpha^{\prime}\right)^{2}\right\} .
$$

Agora ainda resta avaliar as médias dos quadrados das componentes fora da diagonal. Usando a equação B.18 e inserindo os valores das médias dadas pelas expressōes B.28 e B.29 tem-se:

$$
\left(\alpha_{i j}^{\prime}\right)^{2}=\frac{1}{15}\left[\left(\alpha_{X}^{\prime}\right)^{2}+\left(\alpha_{Y}^{\prime}\right)^{2}+\left(\alpha_{Z}^{\prime}\right)^{2}\right]-\frac{1}{30}\left(2 \alpha_{X}^{\prime} \alpha_{Y}^{\prime}+2 \alpha_{Y}^{\prime} \alpha_{Z}^{\prime}+2 \alpha_{Z}^{\prime} \alpha_{X}^{\prime}\right)
$$

Pela equação B.26 nota-se que o lado direito da expressão B.33 é:

$$
\left(\alpha_{i j}^{\prime}\right)^{2}=\frac{1}{15}\left(\Delta \alpha^{\prime}\right)^{2}
$$

É claro que todos os elementos da diagonal assim como os elementos fora da diagonal tềm a mesma média.

\section{B.2.5 Taxas de despolarização do espalhamento Raman}

As expressões para as taxas de despolarização para a luz incidente no espalhamento Raman podem ser dadas em função de $\bar{\alpha}^{\prime}$ e $\Delta \alpha^{\prime}$. Assim a partir das 
expressões (B.12), (B.13), (B.14) e (B.15), tem-se:

$$
\begin{gathered}
\rho_{n}=\frac{6\left(\Delta \alpha^{\prime}\right)^{2}}{45\left(\bar{\alpha}^{\prime}\right)^{2}+7\left(\Delta \alpha^{\prime}\right)^{2}} \\
\rho_{p \perp}=\frac{3\left(\Delta \alpha^{\prime}\right)^{2}}{45\left(\bar{\alpha}^{\prime}\right)^{2}+4\left(\Delta \alpha^{\prime}\right)^{2}} \\
\rho_{p / /}=1 .
\end{gathered}
$$

O valor de $\Delta \alpha^{\prime}$ evidentemente é nulo para o caso de moléculas isotrópicas e o valor de $\bar{\alpha}^{\prime}$ por sua vez pode ser positivo, negativo ou nulo por ser uma derivada tomada em torno da posição de equilíbrio. Isto significa que em certas circunstâncias $\bar{\alpha}^{\prime}$ e $\Delta \alpha^{\prime}$ poderão se anular simultaneamente, proibindo o espalhamento Raman.

A expressão, $\rho_{p / /}=1$, não é aplicável a espécies isotrópicas; o valor da unidade é a razão das duas intensidades, cada uma das quais é proporcional a $\left(\Delta \alpha^{\prime}\right)^{2}$ e portanto $\rho_{p / /}$ é zero quando $\left(\Delta \alpha^{\prime}\right)^{2}$ for zero.

É interessante obter também a taxa de despolarização para a luz circularmente polarizada [84]. Esta taxa é definida pela expressão:

$$
\rho_{c}=\frac{\rho_{n}}{1-\rho_{n}}
$$

Quando $\bar{\alpha}^{\prime}$ se anular sem que $\left(\Delta \alpha^{\prime}\right)^{2}$ se anule o valor de $\rho_{n}$ poderá chegar a $\frac{6}{7}$ e o valor de $\rho_{p \perp}$ poderá chegar a $\frac{3}{4}$. Então pode-se escrever:

$$
\begin{aligned}
& 0 \leq \rho_{n} \leq \frac{6}{7} \\
& 0 \leq \rho_{p \perp} \leq \frac{3}{4}
\end{aligned}
$$

Quando $\rho_{n}=\frac{6}{7}$, a linha Raman é descrita como despolarizada. Uma linha para a qual $\rho_{n}<\frac{6}{7}$ é dita polarizada.

A intensidade total do espalhamento Raman, isto é, a soma das intensidades das componentes plano-polarizadas, é proporcional a

$$
\mathcal{A}_{n}=45\left(\bar{\alpha}^{\prime}\right)^{2}+13\left(\Delta \alpha^{\prime}\right)^{2}
$$

para a luz incidente natural. 
Quando a luz é polarizada em um plano perpendicular ao plano de espalhamento a intensidade total é proporcional a

$$
\mathcal{A}_{p \perp}=45\left(\bar{\alpha}^{\prime}\right)^{2}+7\left(\Delta \alpha^{\prime}\right)^{2}
$$

Finalmente, se a luz é polarizada no plano do espalhamento a intensidade total é proporcional a

$$
\mathcal{A}_{p / /}=6\left(\Delta \alpha^{\prime}\right)^{2}
$$

neste caso, uma vez que a taxa de despolarização é igual a unidade, a luz espalhada é não polarizada.

\section{B.2.6 Taxas de despolarização do espalhamento Rayleigh}

Foi mostrado que exceto por um fator de proporcionalidade o espalhamento Rayleigh para um molécula é determinado pelo tensor $\alpha_{0}$ da mesma forma que se determina o espalhamento Raman pelo tensor $\alpha^{\prime}$. Assim como $\alpha^{\prime}$, a própria polarizabilidade $\alpha_{0}$, é um tensor simétrico e tem um valor médio, $\bar{\alpha}_{0}$, e uma anisotropia, $\Delta \alpha_{0}$, invariantes. Suas definições sāo análogas às definições de $\bar{\alpha}^{\prime}$ e $\Delta \alpha^{\prime}$. Além disso, as médias dos quadrados das componentes $\left(\alpha_{i j}\right)_{0}$ são precisamente as mesmas que suas equivalentes para o caso Raman. Existe, contudo, uma diferença muito importante entre $\bar{\alpha}^{\prime}$ e $\bar{\alpha}_{0}$ : em certos casos, $\bar{\alpha}^{\prime}$ pode se anular, enquanto que $\bar{\alpha}_{0}$ nunca é nulo de forma que o espalhamento Rayleigh é sempre permitido.

Para o espalhamento Rayleigh, as expressões para as taxas de despolarização são similares às equações para o espalhamento Raman, porém com $\bar{\alpha}_{0}$ e $\Delta \alpha_{0}$ no lugar de $\bar{\alpha}^{\prime}$ e $\Delta \alpha^{\prime}$ respectivamente. Assim pode-se escrever:

$$
\begin{gathered}
\sigma_{n}=\frac{6(\Delta \alpha)^{2}}{45\left(\bar{\alpha}_{0}\right)^{2}+7(\Delta \alpha)^{2}} \\
\sigma_{p \perp}=\frac{3(\Delta \alpha)^{2}}{45\left(\bar{\alpha}_{0}\right)^{2}+4(\Delta \alpha)^{2}} \\
\sigma_{p / /}=1 \\
\sigma_{c}=\frac{\sigma_{n}}{1-\sigma_{n}}
\end{gathered}
$$


As correspondentes intensidades totais para o espalhamento Rayleigh são proporcionais a

$$
\mathcal{R}_{n}=45\left(\bar{\alpha}_{0}\right)^{2}+13(\Delta \alpha)^{2}
$$

para a luz natural e

$$
\mathcal{R}_{p \perp}=45\left(\bar{\alpha}_{0}\right)^{2}+7(\Delta \alpha)^{2}
$$

e

$$
\mathcal{R}_{p / /}=6(\Delta \alpha)^{2}
$$

para a luz plano-polarizada.

Devido ao fato de $\bar{\alpha}_{0}$ nunca se anular, o valor de $\sigma_{n}$ nunca chegará a $\frac{6}{7}$, e o valor de $\sigma_{p \perp}$ nunca chegará a $\frac{3}{4}$, de maneira que

$$
0 \leq \sigma_{n}<\frac{6}{7}
$$

e

$$
0 \leq \sigma_{p \perp}<\frac{3}{4}
$$

Contudo é possível imaginar um caso particular para a despolarização Rayleigh quando todas as componentes $\alpha_{i i}$ são nulas exceto uma (maior anisotropia possível) [84]. Assim $\Delta \alpha=3 \bar{\alpha}_{0}$, resultando $\sigma_{n}=\frac{1}{2}, \sigma_{p \perp}=\frac{1}{3}$ e $\sigma_{c}=$ 1 . 


\section{Apêndice C}

\section{Deslocamento químico}

\section{C.1 Considerações teóricas}

Se a interação Zeemam fosse a única interação presente nos experimentos RMN, este seria muito pouco utilizado pelos químicos, pois somente os núcleos com razões giromagnéticas muito grandes seriam diferenciados. Contudo, um campo magnético externo, $\mathbf{B}$, gera corrente elétrica na nuvem eletrônica que envolve os núcleos, que por sua vez produz um campo magnético secundário que é proporcional a $\mathbf{B}$. Para uma distribuição de carga esfericamente simétrica em torno do núcleo, o campo induzido no núcleo, $\mathbf{B}^{(i n d)}$, é oposto ao campo magnético aplicado. A diferença entre o campo local no núcleo e o campo magnético aplicado é proporcional ao campo magnético aplicado e pode ser escrito como:

$$
\mathbf{B}^{(n u c)}=B(\mathbf{1}-\sigma)
$$

onde $\sigma$ é a constante de blindagem magnética (ou química). A constante de blingagem magnética é expressa em unidades adimensionais, ppm. Estas unidades são independentes do campo magnético aplicado, e são portanto características moleculares. Nesta seção são fornecidos alguns detalhes sobre a metodologia empregada no cálculo de tal propriedade.

\section{C.1.1 A blingagem magnética}

A física por trás da blingagem química tem base clássica e é relativamente simples. Uma partícula de massa $m$ e carga $q$ movendo-se com vetor velocidade 
$\mathbf{v}$ a uma distância $\mathbf{r}$ da origem induz um campo magnético na origem, e segundo a lei de Biot-Savart [306], tal campo induzido é dado por:

$$
\mathbf{B}^{(i n d)}=\frac{\mu_{o}}{4 \pi} \frac{q}{m} \frac{\mathbf{r} \times m \mathbf{v}}{r^{3}}=\frac{\mu_{o}}{4 \pi} \frac{q}{m} \frac{\mathbf{r} \times[\mathbf{p}-q \mathbf{A}]}{r^{3}}=\frac{\mu_{o}}{4 \pi} \frac{q}{m} \frac{\mathbf{r} \times \pi}{r^{3}},
$$

onde $m \mathbf{v}$ é expresso em termos de seu momento linear, $\mathbf{p}$, e o potencial vetor, $\mathbf{A}$, devido ao campo magnético externo, $\mathbf{B}=\nabla \times \mathbf{A}$, redefinindo na última passagem o momento cinético $\pi$. Quando se usa o sistema internacional (SI), $\frac{\mu_{o}}{4 \pi}$ é um termo requerido contudo pode ser trocado por $c^{-1}$ no sistema $\mathrm{cgs}$.

Considere uma molécula com um único momento nuclear magnético, $\mu$, na presença de um campo magnético externo, B. Os níveis de energia do momento nuclear são caracterizados pelo Hamiltoniano de spin dado por

$$
H_{\mu}^{s p i n}=\sum_{i, j}-\mu_{i} \cdot\left(1-\sigma_{i j}\right) \cdot B_{j}=-\mu \cdot \mathbf{B}+\mu \cdot \sigma \cdot \mathbf{B}
$$

onde o termo $-\mu \cdot \mathbf{B}$ é a interação clássica entre o momento e o campo magnéticos, o termo $\mu \cdot \sigma \cdot \mathbf{B}$ caracteriza as interações dominantes do momento magnético com o campo induzido, ou seja, $\mathbf{B}^{(i n d)}=\sigma \cdot \mathbf{B}$. Nestas expressões $\sigma$ é o tensor blingagem química, um tensor assimétrico de segunda ordem.

Freqüentemente o tensor blingagem química é dado por

$$
\sigma_{i j}=\frac{\partial^{2} E}{\partial \mu_{i} \partial B_{j}}
$$

onde $E$ é a energia eletrônica do sistema. Esta definição pode gerar alguma confusão já que, enquanto o campo externo, B, é de fato um parâmetro no qual a energia eletrônica pode ser expandida, o momento nuclear, $\boldsymbol{\mu}$, deve ser tratado como um operador e não é imediatamente claro como é possível tomar a derivada com respeito a ele. A relação entre as duas últimas definições fica clara somente após uma dedução mais formal que é resumida a seguir.

É necessário considerar o tratamento de perturbação de dois subsistemas interagentes, no presente caso o momento nuclear por um lado e os elétrons e núcleos fixos da molécula por outro. Enquanto tal tratamento é focalizado sobre um sistema de spin nuclear e um sistema eletrônico, a aproximação é geral. Considerando que o Hamiltoniano do sistema combinado seja dado por

$$
H=H_{\mu}+H_{e}+H_{\mu e}
$$


onde os primeiros dois termos são os Hamiltonianos para os sistemas nuclear e eletrônico não interagentes, respectivamente, e o último termo representa o acoplamento entre os dois. Presume-se aqui que as funções de onda de ordem zero dos sistemas não interagentes sejam conhecidas, e além do mais é usado o fato de que os espaçamentos entre os níveis de energia eletrônicos são muito maiores comparados aqueles dos níveis nucleares [90,93]. Considera-se também o nivel fundamental como não degenerado. Assim, o termo de acoplamento $H_{\mu e}$, pode ser tratado como uma perturbação sobre os estados mais baixos do sistema, que na ausência do termo de acoplamento são dados pelo produto da função de onda eletrônica fundamental, $\psi_{e, g}$, e os $2 I+1$ estados de spin associados com o momento nuclear, $\mu$, de spin $I$. Assim, enquanto existem $2 I+1$ estados de spin nuclear associados com estes níveis mais baixos, a parte eletrônica é caracterizada por uma única função de onda.

Apesar do campo magnético externo, B, remover a degenerescência dos níves de spin nuclear, eles ainda ficam muito próximos comparados com o desdobramento dos níveis eletrônicos. No caso da degenerescência ou quasedegenerescência, o procedimento mais apropriado é encontrar os elementos de matriz do Hamiltoniano nestes múltiplos estados e diagonalizar esta matriz neste subconjunto finito de estados. Denotando as várias funções de spin por $s_{j}$, então é necessário avaliar integrais do tipo:

$$
\left\langle s_{j}, \psi_{e, g}\left|H_{\mu e}\right| s_{i}, \psi_{e, g}\right\rangle=\left\langle s_{j}\left|\left\langle\psi_{e, g}\left|H_{\mu e}\right| \psi_{e, g}\right\rangle\right| s_{i}\right\rangle
$$

onde é possível isolar a integração sobre as coordenadas por causa da natureza única de $\psi_{e, g}$. Desta maneira o sistema de spin 'sente' um Hamiltoniano efetivo da forma

$$
H_{\mu}^{s p i n}=-\mu \cdot \mathbf{B}+\left\langle\psi_{e, g}\left|H_{\mu e}\right| \psi_{e, g}\right\rangle
$$

onde o primeiro termo na equação C.6 é $H_{\mu}$ e a integral é somente sobre as coordenadas eletrônicas.

O problema agora é determinar $H_{\mu e}$. Para isto escreve-se o Hamiltoniano completo dos sistemas acoplados como:

$$
H=-\boldsymbol{\mu} \cdot \mathbf{B}+\frac{1}{2 m} \sum_{k}\left[\mathbf{p}_{k}+e \mathbf{A}_{k}\right]^{2}+V\left(\ldots, \mathbf{r}_{k}, \ldots\right),
$$


onde $V$ representa a energia potencial e a soma corre sobre todos os elétrons. Para um sistema contendo núcleo com momento magnético diferente de zero o potencial vetor na posição, $\mathbf{r}_{k}$, do elétron pode ser escrito como:

$$
\mathbf{A}_{k}=\mathbf{A}_{k}^{B}+\mathbf{A}_{k}^{\mu}+\nabla f
$$

O primeiro termo da equação C.8 descreve o campo magnético externo. Para um campo homogêneo este termo é dado por [306]:

$$
\mathbf{A}_{k}^{B}=\frac{1}{2} \mathbf{B} \times \mathbf{r}_{k}
$$

O segundo termo está relacionado ao campo originado a partir do momento magnético, $\boldsymbol{\mu}$, dos núcleos na molécula e expresso por [306]:

$$
\mathbf{A}_{k}^{\mu}=\frac{\mu_{0}}{4 \pi} \frac{\boldsymbol{\mu} \times \mathbf{r}_{k \mu}}{r_{k \mu}^{3}}
$$

onde $\mathbf{r}_{k \mu}=\mathbf{r}_{k}-\mathbf{R}_{\mu}$, é a coordenada eletrônica medida a partir da coordenada nuclear, $\mathbf{R}_{\mu}$. Finalmente, o último termo da equação C.8 contém uma função arbitrária escalar e diferenciável das coordenadas $f$. Aqui é suficiente restringir a classe das funções de calibre a:

$$
f=-\frac{1}{2}(\mathbf{B} \times \mathbf{G}) \cdot \mathbf{r}_{k}
$$

com o ponto arbitrário $\mathbf{G}$ sendo a origem do calibre. Substituindo as equações C.9, C.10 e C.11 em C.8 tem-se finalmente a forma do potencial vetor:

$$
\mathbf{A}_{k}=\frac{1}{2} \mathbf{B} \times(\mathbf{r}-\mathbf{G})+\frac{\mu_{0}}{4 \pi} \frac{\mu \times \mathbf{r}_{k \mu}}{r_{k_{\mu}}^{3}}
$$

Cabe aqui uma breve digressão. A intensidade do campo magnético é dada por [306]

$$
\mathbf{B}=\nabla \times \mathbf{A}
$$

e permanece inalterada quando o potencial vetor sofre uma transformação como:

$$
\mathbf{A} \Longrightarrow \mathbf{A}+\nabla f
$$

onde $f$ é uma função arbitrária escalar e diferenciável das coordenadas. Esta é a conhecida transformação de calibre $[306,308]$. A energia de um sistema 
molecular na presença de um campo magnético depende da intensidade de $\mathbf{B}$, assim ele deve ser o mesmo, independente da forma da função $f$. Como será visto na seção C.1.2 isto só é verdade no caso de soluções exatas da equação de Schrödinger com o Hamiltoniano na forma da equação C.7. A invariança de calibre da energia e das propriedades magnéticas de uma molécula é agora equivalente a sua independência da origem arbitrária do calibre, G. Termos dependentes de $\mathbf{G}$ aparecerão nas expressões para as propriedades magnéticas bem como para a energia de um sistema na presença de um campo magnético externo. Para funçōes de onda do tipo SCF, estes termos se cancelarão somente no limite de base completa. Para bases finitas, contudo, somente uma parte se cancelará, permanecendo assim a dependência de $\mathbf{G}$ nos resultados finais. Vários métodos foram propostos para assegurar a invariança de calibre para o cálculo de propriedades magnéticas, contudo o método GIAO (gauge including atomic orbitals) é provavelmente o mais bem sucedido [182-184]. Na equação C.7 o termo $e \mathbf{A}$ pode ser trocado por $\frac{e}{c} \mathbf{A}$ no sistema cgs. Definindo o momento cinético por

$$
\pi_{k}=\mathbf{p}_{k}+e \mathbf{A}_{k}^{B}
$$

pode-se reescrever o Hamiltoniano como:

$H=-\mu \cdot \mathbf{B}+\frac{1}{2 m} \sum_{k} \pi_{k}^{2}+V\left(\ldots, \mathbf{r}_{k}, \ldots\right)+\frac{e}{2 m} \sum_{k}\left(\pi_{k} \cdot \mathbf{A}_{k}^{\mu}+\mathbf{A}_{k}^{\mu} \cdot \pi_{k}\right)+\frac{e^{2}}{2 m} \sum_{k} \mathbf{A}_{k}^{\mu} \cdot \mathbf{A}_{k}^{\mu}$

Os dois últimos termos da equação C.16, envolvendo o potencial vetor, $\mathbf{A}_{k}^{\mu}$, podem ser vistos como os termos de primeira e segunda ordem no momento nuclear, $\boldsymbol{\mu}$. Usando o calibre de Coulomb, para o qual $\nabla \cdot \mathbf{A}=0$, pode-se escrever o Hamiltoniano da seguinte forma $[187,195,309]$ :

$$
H=-\boldsymbol{\mu} \cdot \mathbf{B}+H_{e}+\boldsymbol{\mu} H_{\mu e}^{\mu(1)}+\boldsymbol{\mu} \cdot \boldsymbol{\mu} H_{\mu e}^{\mu(2)}
$$

onde

$$
H_{\mu e}^{(\mu 1)}=\frac{e}{m} \frac{\mu_{o}}{4 \pi} \sum_{k} \frac{\mu \times \mathbf{r}_{k \mu}}{r_{k \mu}^{3}} \cdot \pi_{k}=\frac{e}{m} \frac{\mu_{o}}{4 \pi} \mu \cdot \sum_{k} \frac{\mathbf{r}_{k \mu} \times \pi_{k}}{r_{k \mu}^{3}}
$$

O termo $H_{\mu e}^{(\mu 2)}$ de segunda ordem é importante nos cálculos de susceptibilidade magnética, contudo não é importante para a blingagem química, assim este 
termo pode ser desprezado aqui. Para determinar o Hamiltoniano de spin fazse necessário integrar

$$
\mathbf{H}_{\mu}^{\text {spin }}=\left\langle\psi_{e, g}|H| \psi_{e, g}\right\rangle=-\mu \cdot \mathbf{B}+H_{e}+\left\langle\psi_{e, g}\left|H_{\mu e}^{\mu(1)}+H_{\mu e}^{\mu(2)}\right| \psi_{e, g}\right\rangle .
$$

sobre todas as coordenadas eletrônicas. Os primeiros dois termos da equação acima correspondem à integração sobre $H_{\mu}$ e $H_{e}$, sendo que este último termo é constante para o sistema de spin, desviando todos os níveis por uma mesma quantidade, podendo então ser desconsiderado. Como deseja-se apenas termos de primeira ordem em $\boldsymbol{\mu}$, a última integral pode ser dezprezada, assim basta avaliar:

$$
\begin{array}{r}
\left\langle\psi_{e, g}\left|H_{\mu e}^{\mu(1)}\right| \psi_{e, g}\right\rangle=\frac{e}{m} \frac{\mu_{o}}{4 \pi} \mu \cdot \sum_{k} \int \psi_{e, g}^{*} \frac{\mathbf{r}_{k \mu} \times \pi_{k}}{r_{k \mu}^{3}} \psi_{e, g} d \tau_{3} \\
=-\frac{\mu_{o}}{4 \pi} \mu \cdot \sum_{k} \int \frac{\mathbf{r}_{k \mu} \times\left[-\frac{e}{2 m}\left(\psi_{e, g}^{*} \pi_{k} \psi_{e, g}+\psi_{e, g} \pi_{k}^{*} \psi_{e, g}^{*}\right)\right]}{r_{k \mu}^{3}} d \tau_{3} \\
=-\frac{\mu_{o}}{4 \pi} \mu \cdot \sum_{k} \int \frac{\mathbf{r}_{k \mu} \times \mathbf{J}_{k}(\mathbf{r})}{r_{k \mu}^{3}} d \tau_{3} \\
=-\mu \cdot \mathbf{B}^{(i n d)}
\end{array}
$$

onde as manipulações na equação C.17 são permitidas pelo caráter Hermiteano de $\pi_{k}$ e permite exibir a densidade de corrente devida ao elétron $k, \mathbf{J}_{k}(\mathbf{r})$ [91-93]. A relação entre o campo induzido e a lei de Biot-Savart é agora completamente transparente. É a partir da equação C.17 que deve-se derivar o termo $\boldsymbol{\mu} \cdot \boldsymbol{\sigma} \cdot \mathbf{B}$. Precisa-se encontrar através dela os termos lineares no campo externo, B. É importante observar que $\psi_{e, g}$ é a solução do problema eletrônico desacoplado na presença do campo externo, B. Isto é,

$$
\begin{aligned}
\psi_{e, g} & =\psi_{e, g}(\mathbf{B}) \\
& =\psi_{e, g}^{(0)}+\sum_{j=x, y, z} B_{j} \psi_{e, g ; j}^{(1)}+\frac{1}{2} \sum_{i, j} B_{i} B_{j} \psi_{e, g ; i, j}^{(2)}+\cdots,
\end{aligned}
$$

a função de onda eletrônica, é uma função de $\mathbf{B}$ e assumindo que o efeito de $\mathbf{B}$ sobre os elétrons possa ser tratado como uma perturbação (a segunda perturbação), esta função pode ser expandida em série de potências nas várias componentes de $\mathbf{B}$. O termo de acoplamento perturbativo no sistema eletrônico está entre os elétrons e o campo externamente aplicado dado pela expressão 
usual

$$
H_{e}^{p e r t}=\frac{e}{2 m} \sum_{k} \mathbf{B} \cdot\left(\mathbf{r}_{\mathbf{k}}-\mathbf{G}_{\mathbf{k}}\right) \times \mathbf{p}_{k}
$$

Assim sendo, deseja-se encontrar termos lineares em B na expansão da função de onda, equação C.18 ou nos operadores $\pi_{k}$ na equação C.17; este último vindo da parte $\mathbf{A}_{k}^{(B)}$ da expressão C.12. Usando a notação $D$ e $P$ para definir as contribuições diamagnética e paramagnética, respectivamente, para o campo induzido, pode-se mostrar que estes dois termos são dados por:

$$
\begin{aligned}
\boldsymbol{\mu} \cdot \boldsymbol{B}_{D}^{(i n d)} & =\frac{e}{m} \frac{\mu_{o}}{4 \pi} \boldsymbol{\mu} \cdot\left\langle\psi_{e, g}^{0}\left|\frac{\mathbf{r}_{k \mu} \times \mathbf{A}_{k}^{(B)}}{r_{k \mu}^{3}}\right| \psi_{e, g}^{0}\right\rangle \\
& =\frac{e}{2 m} \frac{\mu_{o}}{4 \pi} \boldsymbol{\mu} \cdot\left\langle\psi_{e, g}^{0}\left|\frac{\mathbf{r}_{k \mu} \times \mathbf{B} \times\left(\mathbf{r}_{\mathbf{k}}-\mathbf{G}_{\mathbf{k}}\right)}{r_{k \mu}^{3}}\right| \psi_{e, g}^{0}\right\rangle
\end{aligned}
$$

$\mathrm{e}$

$$
\begin{aligned}
\boldsymbol{\mu} \cdot \boldsymbol{B}_{P}^{(i n d)}= & \frac{e}{m} \frac{\mu_{o}}{4 \pi} \boldsymbol{\mu} \cdot \sum_{j=x, y, z} B_{j}\left\langle\psi_{e, g ; j}^{(1)}\left|\frac{\mathbf{r}_{k \mu} \times \mathbf{p}_{k}}{r_{k \mu}^{3}}\right| \psi_{e, g}^{0}\right\rangle \\
& + \text { complexo conjugado }
\end{aligned}
$$

Finalmente tem-se que

$$
H_{\mu}^{s p i n}=-\mu \cdot B+\mu \cdot\left(\mathbf{B}_{D}^{(i n d)}+\mathbf{B}_{P}^{(i n d)}\right) .
$$

O campo diamagnético, $\mathbf{B}_{D}^{(i n d)}$, é associado com a função de onda do estado eletrônico fundamental na ausência de um campo externo, é geralmente alinhado em uma direção aproximadamente oposta que o campo magnético externo e tende a causar um deslocamento para freqüências de ressonância menores; o campo paramagnético, $\mathbf{B}_{P}^{(i n d)}$, está associado com as funções de onda dos estados eletrônicos perturbados, está geralmente alinhado numa direção aproximadamente paralela com o campo externo, e tende a causar um deslocamento para freqüências de ressonância maiores.

\section{Dependência orientacional da blindagem magnética}

A blindagem química é uma propriedade dependente de orientação, isto é, a blindagem magnética no núcleo de uma molécula depende da orientação relativa da molécula em relação ao campo magnético aplicado. Como visto anteriormente, a blindagem magnética pode ser descrita como um tensor Cartesiano 
não simétrico de segunda ordem, $\boldsymbol{\sigma}$, no qual nove valores independentes especificam sua orientação em relação ao sistema de coordenadas do laboratório. Assim tem-se:

$$
\boldsymbol{\sigma}=\left[\begin{array}{lll}
\sigma_{11} & \sigma_{12} & \sigma_{13} \\
\sigma_{21} & \sigma_{22} & \sigma_{23} \\
\sigma_{31} & \sigma_{32} & \sigma_{33}
\end{array}\right] .
$$

Em experimentos de RMN convencionais, é muito difícil determinar todas as componentes da blindagem magnética, assim somente a parte simétrica da blindagem é determinada, logo define-se [90-93] a blindagem isotrópica, $\sigma^{\text {iso }}$, como sendo o traço do tensor $\sigma$, ou seja:

$$
\sigma^{i s o}=\frac{1}{3}\left(\sigma_{11}+\sigma_{22}+\sigma_{33}\right)
$$

Em muitos casos, é suficiente analisar somente esta propriedade para efeito de comparação com valores experimentais, porém importantes informações fornecidas são perdidas, assim introduz-se a blindagem anisotrópica [90-93], $\sigma^{\text {anis }}$, expressa por:

$$
\sigma^{i s o}=\frac{2 \varepsilon_{3}-\varepsilon_{1}-\varepsilon_{2}}{2}
$$

onde os $\varepsilon_{i}$ são os autovalores do tensor simetrizado

$$
\sigma^{\prime}=\frac{\sigma+\sigma^{T}}{2}
$$

em que $\sigma^{T}$ é o tensor transposto de $\sigma$. Outra definição equivalente para a blindagem anisotrópica é dada por:

$$
\Delta \sigma=\frac{2 \sigma_{33}^{S}-\sigma_{11}^{S}-\sigma_{22}^{S}}{2}
$$

onde o índice $S$ indica o sistema de coordenadas onde o tensor blindagem magnética é diagonal.

\section{C.1.2 O método GIAO}

Como foi visto, o campo magnético externo aparece no Hamiltoniano molecular através do potencial vetor definido em relação a um calibre de origem arbitrária. Porém todos os observáveis devem ser independentes da escolha particular da origem do calibre. Em outras palavras, todas as propriedades magnéticas calculadas devem ser invariantes ante uma transformação de calibre [308] realizada 
sobre o potencial vetor. Infelizmente, isto só é satisfeito para soluções exatas da equação de Schrödinger. Em nível SCF isto pode ser alcançado somente no limite de base completa [308]. Para conjuntos de bases finitos padrões utilizados nos cálculos $a b$ initio a invariança de calibre é violada.

Uma vez que a equação de Schrödinger para um sistema molecular não pode ser resolvida exatamente soluções aproximadas são definidas num espaço de um dado conjunto de funções base e encontradas usualmente por procedimentos autoconsistentes. A energia aproximada de um sistema molecular influenciada por um campo magnético externo não é mais invariante por calibre, a menos que um conjunto de funções base completo seja empregado [310]. Assim, nos cálculos de propriedades magnéticas, a invariança de calibre é muito importante e deve ser levada em conta.

Existem duas aproximações gerais para resolver o problema do calibre. Um conjunto de funções base muito grande leva a uma invariança aproximada uma vez que no limite de de base completa os resultados devem ser independentes da escolha da origem do calibre [310]. Assim esta técnica é viável apenas para sistemas pequenos. A segunda aproximação introduz origens de calibres locais para definir o vetor potencial do campo magnético externo. Esta idéia foi sugerida e utilizada em primeira mão por London no seu estudo sobre diamagnetismo molecular [311]. Para cálculos de blindagem magnética, ela foi implementado primeiramente por Ditchfield [182] no método de orbitais atômicos independentes do calibre (GIAO) onde cada orbital atômico possui sua própria origem do calibre colocado no seu centro.

A constante de blindagem química nuclear $\sigma$, como foi visto, é definida como sendo a segunda derivada da energia molecular com relação ao campo magnético externo, $\mathbf{B}$, e ao momento magnético do núcleo, $\mu_{N}$. Esta é uma quantidade adimensional de segunda ordem e é representada por um tensor não simétrico com nove componentes independentes,

$$
\sigma_{i j}=\frac{\partial^{2} E}{\partial B_{i} \partial \mu_{j}}
$$

onde $i, j=x, y, z$ denota as componentes do campo magnético e do momento magnético nuclear. Num conjunto de funções base finito o tensor blindagem 
magnética de um núcleo pode ser escrito de forma geral como [188]:

$$
\sigma^{i j}=\operatorname{Tr}\left[\mathbf{D}^{(00)} \times \mathbf{H}^{(i j)}\right]+\operatorname{Tr}\left[\mathbf{D}^{(i 0)} \times \mathbf{H}^{(0 j)}\right]
$$

onde os superíndices representam a diferenciação com em relação ao campo magnético e ao momento magnético nuclear, nesta ordem. O primeiro termo na equação acima é a componente diamagnética da blindagem e o segundo termo representa a parte paramagnética. Percebe-se assim que para a determinação de $\sigma$ é necessário que a matriz densidade não perturbada, $\mathbf{D}^{(00)}$, e a matriz densidade perturbada em primeira ordem, $\mathbf{D}^{(i 0)}$ sejam conhecidas, bem como as derivadas das integrais de um elétron $\mathbf{H}^{(i j)}$ e $\mathbf{H}^{(0 j)}$.

A equação C.29 é válida em vários níveis de teoria (HF, MPn, CC, DFT) com a única diferença estando na definição da matrizes $\mathbf{D}^{(00)}$ e $\mathbf{D}^{(i 0)}$. Bons textos tratam bem todos estes níveis individualmente e um bom artigo de revisão sobre todos eles é dado na referência [312]. 


\section{Apêndice D}

\section{Constantes, fatores de conversão e tabela periódica}

\section{D.1 Constantes fundamentais relacionadas}

\begin{tabular}{ccc}
\hline \hline Quantidade & Símbolo & Valor \\
\hline Velocidade da luz no vácuo & $c$ & $2.99792458 \times 10^{8} \mathrm{~m} / \mathrm{s}$ (exato) \\
Permeabilidade do vácuo & $\mu_{0}$ & $4 \pi \times 10^{-7} \mathrm{H} / \mathrm{m}(\mathrm{exato})$ \\
Permissividade do vácuo & $\varepsilon_{0}=1 /\left(\mu_{0} c^{2}\right)$ & $8.854 \times 10^{-12} \mathrm{~F} / \mathrm{m}$ \\
Constante de Planck & $h$ & $6.6260755 \times 10^{-34} \mathrm{Js}$ \\
& $\hbar=h / 2 \pi$ & $1.05457266 \times 10^{-34} \mathrm{Js}$ \\
Carga elementar & $\mathrm{e}$ & \\
Magneton de Bohr & $\mu_{B}=e \hbar / 2 m_{e}$ & $9.60217733 \times 10^{-19} \mathrm{C}$ \\
Magneton nuclear & $\mu_{N}=e \hbar / 2 m_{p}$ & $5.0507866 \times 10^{-27} \mathrm{~J} / \mathrm{T}$ \\
& & \\
Constante de estrutura fina & $\alpha$ & $7.29735308 \times 10^{-3}$ \\
Constante de Rydberg & $R=m_{e} c \alpha^{2} / 2 h$ & $1.0973731534 \times 10^{7} \mathrm{~m}-1$ \\
Raio de Bohr & $a_{0}$ & $0.529177249 \times 10^{-10} \mathrm{~m}$ \\
Energia de Hartree & $E_{h}$ & $27.2113961 \mathrm{eV}$ \\
Massa do elétron & $m_{e}$ & $9.1093897 \times 10^{-31} \mathrm{~kg}$ \\
Massa do próton & $m_{p}$ & $1.6726231 \times 10^{-27} \mathrm{~kg}$ \\
Massa do nêutron & $m_{n}$ & $1.6749286 \times 10^{-27} \mathrm{~kg}$ \\
Constante de Avogadro & $N_{A}$ & $6.0221367 \times 10^{23} \mathrm{~mol}-1$ \\
Unidade de Massa atômica & $a m_{u}$ & $1.6605402 \times 10^{-27} \mathrm{~kg}$ \\
Constante de Faraday & $F=N_{A} e$ & $9.6485309 \times 10^{4} \mathrm{C} / \mathrm{mol}$ \\
Constante molar do gás ideal & $R$ & $8.314510 \mathrm{~J} /(\mathrm{Kmol})$ \\
Constante de Boltzmann & $k$ & $1.380658 \times 10^{-23} \mathrm{~J} / \mathrm{K}$ \\
Atmosfera padrão & $a t m$ & $101325 \mathrm{~Pa} \mathrm{(exato)}$ \\
\hline \hline
\end{tabular}




\section{D.2 Fatores de conversão para energia}

\begin{tabular}{||c|c|c|c|c|c||}
\hline \hline 1 unidade & hartree & $\mathrm{kJ} \mathrm{mol}^{-1}$ & $\mathrm{kcal} \mathrm{mol}^{-1}$ & $\mathrm{eV}$ & $\mathrm{cm}^{-1}$ \\
\hline hartree & 1 & 2625.50 & 627.51 & 27.212 & $2.1947 \mathrm{E}^{5}$ \\
\hline$k J \mathrm{~mol}^{-1}$ & $3.8088 E^{-4}$ & 1 & 0.23901 & $1.0364 E^{-2}$ & 83.593 \\
\hline$k c a l ~ \mathrm{~mol}^{-1}$ & $1.5936 E^{-3}$ & 4.1840 & 1 & $4.3363 E^{-2}$ & 349.75 \\
\hline $\mathrm{eV}$ & $3.6749 E^{-2}$ & 96.485 & 23.061 & 1 & 8065.5 \\
\hline $\mathrm{cm}^{-1}$ & $4.5563 E^{-6}$ & $1.1963 E^{-2}$ & $2.8591 E^{-3}$ & $1.2398 E^{-4}$ & 1 \\
\hline \hline
\end{tabular}

$E^{x}=10^{x}$

\section{D.3 Fatores de conversão para comprimentos}

$$
1 b o h r=0.529177 \AA=5.29177 \times 10^{-11} \mathrm{~m}
$$

\section{D.4 Tabela periódica}

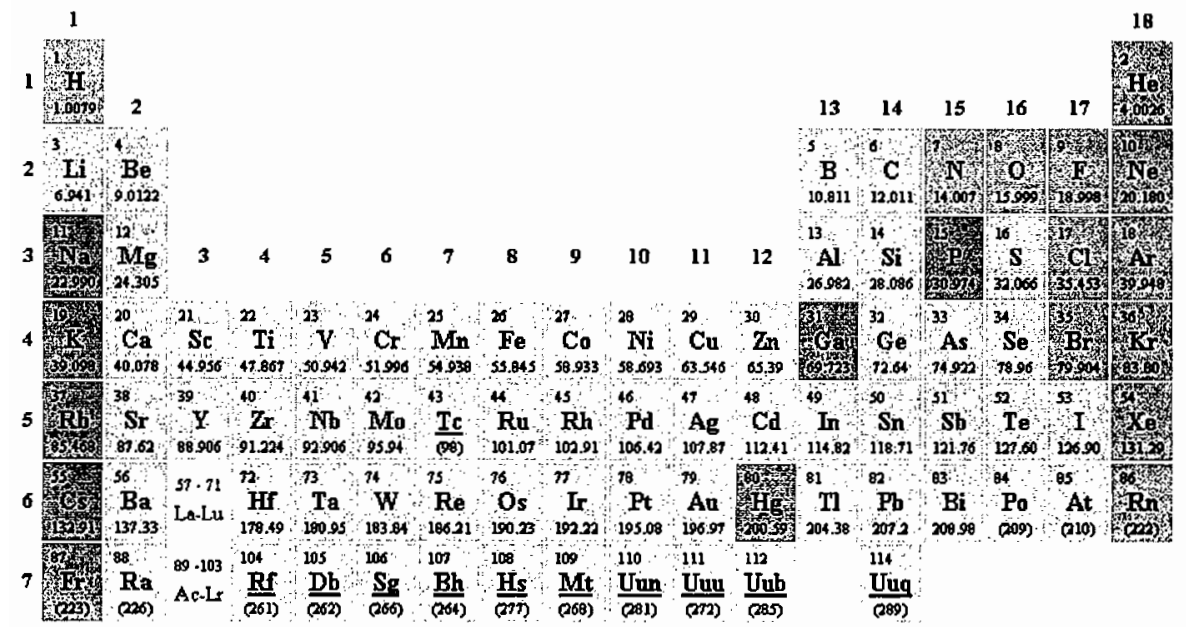

$\begin{array}{llllllllllllllll} & 57 & 58 & 50 & 60 & 61 & 62 & 63 & 64 & 65 & 66 & 67 & 68 & 69 & 70 & 71 \\ \text { Lemerideos } & \text { La } & \text { Ce } & \text { Pr } & \text { Nd } & \text { Pm } & \text { Sm } & \text { Eu } & \text { Gd } & \text { Tb } & \text { Dy } & \text { Ho } & \text { Er } & \text { Tm } & \text { Yb } & \text { Lu }\end{array}$ $\begin{array}{lllllllllllllll}138.91 & 140.12 & 140.91 & 14424 & \underline{(145)} & 150.36 & 151.96 & 157.25 & 158.93 & 162.50 & 164.93 & 167.26 & 16893 & 133.04 & 174.97\end{array}$

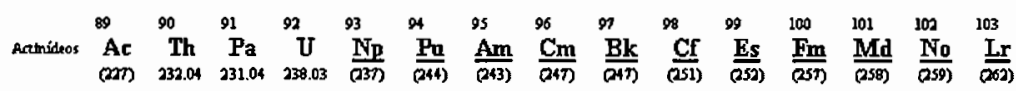

sö́mo : 
Apêndice E

Artigos Publicados 


\title{
Regular article \\ Rayleigh and Raman light scattering in hydrogen-bonded acetonitrile-water
}

\author{
Eduardo Rissi, Eudes E. Fileti, Sylvio Canuto \\ Instituto de Física, Universidade de São Paulo, CP 66318, 05315-970 São Paulo, SP, Brazil
}

Received: 3 September 2002/ Accepted: 30 April 2003 / Published online: 1 December 2003

(C) Springer-Verlag 2003

\begin{abstract}
The structure, vibrational frequencies, light scattering activities and binding energies of $\mathrm{CH}_{3} \mathrm{CN} \cdots \mathrm{H}_{2} \mathrm{O}$ are obtained from ab initio methods. The hydrogen $\mathrm{N} \cdots \mathrm{H}$ bond distance is calculated as $2.06 \AA$, the dipole moment as $5.77 \mathrm{D}$ and our best estimate for the binding energy is $3.5 \mathrm{kcal} \mathrm{mol}^{-1}(14.7 \mathrm{~kJ}$ $\mathrm{mol}^{-1}$ ), after correcting for zero-point vibrations. The calculated average dipole polarizability is 39.67 au and the anisotropy is fairly large, corresponding to $21.78 \mathrm{au}$. The changes in intramolecular vibrational frequencies are analyzed. The scattering activities and depolarization of the Rayleigh and Raman light scattered are calculated. In the Raman case the depolarization due to the intense NC stretching vibration is increased by $20 \%$ after the hydrogen bond. For the $\mathrm{OH}$ symmetric stretch of water there is a large redshift of $75 \mathrm{~cm}^{-1}$ and a great intensification of the Raman scattering activity by a factor of 2 and a considerable increase of the depolarization by a factor of nearly 4 .
\end{abstract}

Keywords: Hydrogen bond - Acetonitrile - Infrared shift - Dipole polarizabilities - Light scattering

\section{Introduction}

The study of the acetonitrile-water $\left(\mathrm{CH}_{3} \mathrm{CN}-\mathrm{H}_{2} \mathrm{O}\right)$ system is very important for understanding binary mixtures [1] leading to powerful solvents with applications in chemistry and environment studies [2]. Acetonitrile-water ionic clusters play an important role in the terrestrial atmosphere [3] and $\mathrm{CH}_{3} \mathrm{CN}$ is of great interest

From the Proceedings of the 28th Congreso de Quimicos Teóricos de Expresión Latina (QUITEL 2002)

Correspondence to: $\mathrm{S}$. Canuto

e-mail: canuto@if.usp.br in astrophysics $[4,5,6,7]$. A more detailed understanding of the acetonitrile-water interaction should consider the important hydrogen-bond interaction. With the development of laser vaporization and jet cooling techniques the field of cluster physical chemistry has seen great advances $[8,9,10]$ and hydrogen-bonded clusters have been produced [11, 12, 13]. Indeed, hydrogen-bonded $\mathrm{CH}_{3} \mathrm{CN} \cdots \mathrm{H}_{2} \mathrm{O}$ clusters have been produced in supersonic beam experiments $[14,15]$. In addition, the hydrogen bond is a topic of continuing interest in physics, chemistry and biology $[11,16,17]$. The hydrogen-bonded system $\mathrm{CH}_{3} \mathrm{CN} \cdots \mathrm{H}_{2} \mathrm{O}$ has been of interest for many years and has been studied theoretically (at the Hartree-Fock, HF, level) [18], experimentally $[14,15]$ and its vibrational spectrum has been studied in inert matrices [19]. In a theoretical and experimental work, Desfrançois et al. [14] suggested two stable structures (Fig. 1), although they just observed the apparently stablest one (Fig. 1a), with a calculated total dipole moment of $5.5 \mathrm{D}$. They suggested $[14,15]$ an isomer with a total dipole moment of $2.6 \mathrm{D}$, possibly being a second stable geometry. The identification of cluster structures is difficult to achieve directly and usually approaches rely on the comparison between theoretical and experimental spectral shifts. For closedshell polar molecules a suitable procedure $[14,15]$ compares theoretical and experimental dipole moments. Hydrogen bonds can, however, be studied with a great variety of techniques and spectral shifts in the IR region is perhaps the most widely used technique. Despite its importance, accurate theoretical calculations of the acetonitrile-water system are still missing. In this work we use $a b$ initio calculations to obtain the structure and spectrum of the $\mathrm{CH}_{3} \mathrm{CN} \cdots \mathrm{H}_{2} \mathrm{O}$ complex. To contribute to the understanding of the experimental spectral changes we calculate the IR shifts upon complexation and the dipole moments of the complex and the separate moieties. The change in the depolarization ratio for both elastic (Rayleigh) and inelastic (Raman) light scattering is also of great interest. Hence, we calculate the dipole 
(a)
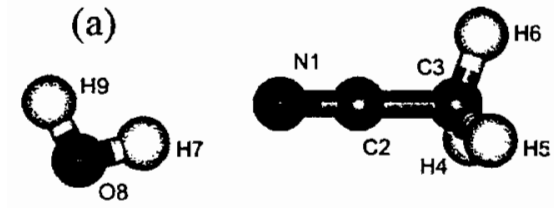

(b)
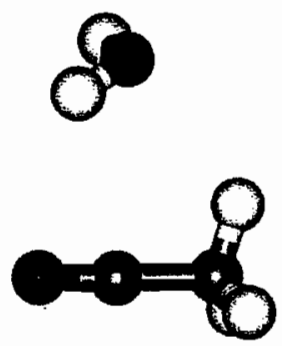

Fig. 1. Geometrical structures of the acetonitrile-water hydrogenbonded complex

polarizability tensor, the polarizability derivatives with respect to the vibrational modes and the Rayleigh and Raman scattering activities and depolarizations of $\mathrm{CH}_{3} \mathrm{CN} \cdots \mathrm{H}_{2} \mathrm{O}$ and compare the results with those obtained for the two isolated species. We also present an accurate estimate for the binding energy, using highlevel ab initio calculations obtained at the coupled-cluster level with large basis sets and including corrections for basis set superposition and zero-point energy vibrations.

\section{Methods}

Full geometry optimization was performed using four theoretical models: MP2/6-311++G(d,p), MP2/aug-cc-pVDZ, B3LYP/ $6-311++\mathrm{G}(\mathrm{d}, \mathrm{p})$ and $\mathrm{B} 3 \mathrm{P} 86 / 6-311++\mathrm{G}(\mathrm{d}, \mathrm{p})$. As usual, MP2 stands for second-order perturbation in the Møller-Plesset partitioning. The density functional theory (DFT) calculations use two of the most common gradient-corrected functionals: Becke's threeparameter hybrid functional combining the Lee-Yang-Parr correlation term [20, 21], namely B3LYP, and Becke's three-parameter hybrid functional with the Perdew correlation term [22], B3P86. These methods were used with the $6-311++G(d, p)$ and the augcc-pVDZ basis sets [23]. In all cases the rotational constants and dipole moments were calculated in the equilibrium geometries. These are the relevant parameters for characterization of geometrical structures using rotational spectroscopy. The calculation of theIR spectrum was performed for isolated water, $\mathrm{CH}_{3} \mathrm{CN}$ and $\mathrm{CH}_{3} \mathrm{CN} \cdots \mathrm{H}_{2} \mathrm{O}$. Shifts in the vibrational frequencies upon complexation resulting in the formation of $\mathrm{CH}_{3} \mathrm{CN} \cdots \mathrm{H}_{2} \mathrm{O}$ were also calculated. Particular attention is devoted to the most intense transitions and the $\mathrm{CN}$ and $\mathrm{OH}$ stretching vibrations. Additionally, the hydrogen binding energies for the complex were calculated and the contribution of the electron correlation effect was systematically analyzed. In these geometries we performed single-point calculations with many-body perturbation theory of second, third and fourth order and with quantum-chemical coupled-cluster theory with single and double excitations (CCSD) and single, double and partial triple excitations, $\operatorname{CCSD}(\mathrm{T})$ [24]. This allows a systematic analysis of the electron correlation contribution to the binding energy. Full counterpoise correction for the basis set superposition error (BSSE), as proposed by Boys and Bernardi [25], was taken into account for all the calculated binding energies. The depolarization ratios for Rayleigh and Raman scattering were calculated after obtaining the dipole polarizabilities (average and anisotropic) and their derivatives at the correlated level using the consistent MP2/aug-cc-pVDZ level. All the calculations were performed with the Gaussian 98 program [26].

\section{Results}

\section{Geometries, rotational constants and dipole moments}

The structures obtained in this work are shown in Fig. 1. The structure in Fig. $1 \mathrm{~b}$ has been obtained before at the HF level [18] and has been considered in experimental situations [15]. However the structures were found here to be unstable at higher levels of calculation. Indeed, using small basis sets [6-31G(d,p)] it was possible to get a stable minimum at the uncorrelated $\mathrm{HF}$ level and correlated levels such as MP2, B3LYP and B3P86. However, improvement of the theoretical model led invariably to an unbound structure. Using the MP2/6-31G(d,p) model we find that the complex is bound with an $\mathrm{O}-\mathrm{C}(\mathrm{N})$ distance of $3.056 \AA$ and a binding energy of only $2 \mathrm{kcal}$ $\mathrm{mol}^{-1}$ (after correcting for basis set superposition error and zero-point vibration corrections). The calculated total dipole moment for this complex is $2.43 \mathrm{D}$. The corresponding dipole moments calculated at the B3LYP/ 6-31G(d,p) and B3P86/6-31G(d,p) levels are 2.58 and $2.62 \mathrm{D}$. These are in good agreement with the value of $2.6 \mathrm{D}$ inferred using theoretical multipolar development [14]. However, as this structure is found to be unstable after improvement of the theoretical model, we give it no further consideration. The structure in Fig. la is found to be a true stable minimum using all the theoretical levels considered here. To assess the results more critically the four different calculations for the geometry, rotational constants and dipole moments of the acetonitrile-water complex (Fig. 1a) and its moieties are shown in Table 1. Experimental values for the geometry of gaseous $\mathrm{CH}_{3} \mathrm{CN}$ give the NC distance as $1.59 \AA$ [27]. The DFT results give NC distances in good agreement with experiment. These are shorter than those obtained with MP2 and this is consistent with its triple-bond nature. However, all the theoretical methods agree that this NC distance decreases by $0.002 \AA$ after hydrogen binding with water. In contrast, in water, as expected, the $\mathrm{OH}$ distance involved in the binding increases by 0.005 $0.008 \AA$, depending on the theoretical model. The least increase is obtained with MP2/6-311++G(d,p) and the largest increase with B3P86/6-311+ $+\mathrm{G}(\mathrm{d}, \mathrm{p})$. A consequence of the decrease in the NC distance will be a blueshift in the NC stretching vibration frequency as shown later.

After complexation the $\mathrm{CH}_{3} \mathrm{CN} \cdots \mathrm{H}_{2} \mathrm{O}$ system still behaves as a nearly prolate rotor and the corresponding rotational constants are also given in Table 1 . In polar clusters prepared by supersonic beam experiments, dipole moments are required to deduce structural information [15]; so the calculated dipole moments are also given in Table 1. The experimental result [28] of $1.86 \mathrm{D}$ for the dipole moment of gas-phase water is well reproduced only in the MP2/aug-cc-pVDZ model. 
Table 1. Optimized geometry of the $\mathrm{CH}_{3} \mathrm{CN} \cdots \mathrm{H}_{2} \mathrm{O}$ complex in comparison with the isolated moieties. Refer to Fig. 1 for a definition of the atomic indices. Dimer stands for the complex $\mathrm{CH}_{3} \mathrm{CN} \cdots \mathrm{H}_{2} \mathrm{O}$. Distances in angstroms, angles in degrees, rotational constants in gigahertz and dipole moments in debyes

\begin{tabular}{|c|c|c|c|c|c|c|c|c|c|c|c|c|}
\hline & \multicolumn{3}{|c|}{$\mathrm{MP} 2 / 6-311++\mathrm{G}(\mathrm{d}, \mathrm{p})$} & \multicolumn{3}{|c|}{ MP2/aug-cc-pVDZ } & \multicolumn{3}{|c|}{ B3LYP/6-311 + + G(d,p) } & \multicolumn{3}{|c|}{ B3P86/6-311 + + G(d,p) } \\
\hline & $\mathrm{CH}_{3} \mathrm{CN}$ & $\mathrm{H}_{2} \mathrm{O}$ & Dimer & $\mathrm{CH}_{3} \mathrm{CN}$ & $\mathrm{H}_{2} \mathrm{O}$ & Dimer & $\mathrm{CH}_{3} \mathrm{CN}$ & $\mathrm{H}_{2} \mathrm{O}$ & Dimer & $\mathrm{CH}_{3} \mathrm{CN}$ & $\mathrm{H}_{2} \mathrm{O}$ & Dimer \\
\hline $\mathrm{N} 1 \equiv \mathrm{C} 2$ & 1.174 & & 1.172 & 1.185 & & 1.183 & 1.153 & & 1.151 & 1.152 & & 1.151 \\
\hline $\mathrm{C} 2-\mathrm{C} 3$ & 1.463 & & 1.462 & 1.471 & & 1.470 & 1.457 & & 1.455 & 1.450 & & 1.448 \\
\hline $\mathrm{C} 3-\mathrm{H} 4(5,6)$ & 1.092 & & 1.091 & 1.099 & & 1.099 & 1.092 & & 1.092 & 1.091 & & 1.091 \\
\hline $\mathrm{C} 2-\mathrm{C} 3-\mathrm{H} 4(5)$ & 109.9 & & 109.8 & 109.9 & & 109.7 & 110.2 & & 110.0 & 110.1 & & 110.0 \\
\hline $\mathrm{C} 2-\mathrm{C} 3-\mathrm{H}_{6}$ & 109.9 & & 109.8 & 109.9 & & 109.8 & 110.2 & & 110.1 & 110.2 & & 110.1 \\
\hline $\mathrm{N} 1-\mathrm{H} 7$ & & & 2.106 & & & 2.060 & & & 2.079 & & & 2.036 \\
\hline $\mathrm{C} 2-\mathrm{N} 1-\mathrm{H} 7$ & & & 162.9 & & & 169.7 & & & 167.3 & & & 167.4 \\
\hline $\mathrm{O} 8-\mathrm{H} 7$ & & 0.960 & 0.965 & & 0.966 & 0.972 & & 0.962 & 0.968 & & 0.960 & 0.968 \\
\hline O8-H9 & & 0.960 & 0.959 & & 0.966 & 0.965 & & 0.962 & 0.961 & & 0.960 & 0.959 \\
\hline H7-O8-H9 & & 103.4 & 103.0 & & 103.9 & 103.8 & & 105.1 & 104.7 & & 104.9 & 104.5 \\
\hline$I_{\mathrm{A}}$ & 158.670 & & 94.248 & 156.407 & & 105.039 & 159.158 & & 105.720 & 159.229 & & 106.323 \\
\hline$I_{\mathrm{B}}$ & 9.081 & & 1.742 & 8.950 & & 1.743 & 9.245 & & 1.762 & 9.295 & & 1.795 \\
\hline$I_{\mathrm{C}}$ & 9.081 & & 1.729 & 8.950 & & 1.734 & 9.245 & & 1.752 & 9.295 & & 1.785 \\
\hline$\mu$ & 3.880 & 2.187 & 5.853 & 3.936 & 1.879 & 5.773 & 4.053 & 2.159 & 6.147 & 4.065 & 2.168 & 6.202 \\
\hline
\end{tabular}

Similarly, the experimental value [29] of $3.96 \mathrm{D}$ for gaseous $\mathrm{CH}_{3} \mathrm{CN}$ is obtained as $3.94 \mathrm{D}$, in fairly good agreement. All DFT results for the dipole moments of water and $\mathrm{CH}_{3} \mathrm{CN}$ are too large. The calculated dipole moment value of $5.77 \mathrm{D}$ for the complex obtained at the MP2/aug-cc-pVDZ level is in good agreement with a previously inferred value of $5.5 \mathrm{D}$ [14]. The present accuracy should be useful in the possible detection of this hydrogen-bonded complex.

\section{Vibrational frequency shifts}

The calculated vibrational frequencies for the separate molecules and the hydrogen-bonded complex are shown in Table 2. Acetonitrile has 12 vibrational modes corresponding in fact to eight active fundamentals: four nondegenerate ( $a_{1}$ symmetry) and four doubly degenerate (e symmetry) vibrational frequencies. After complexation the $e$-degenerate modes may split and all vibrational frequencies may shift. The magnitude of the shift may be used for characterization of the structure of the complex. As is well known, after hydrogen binding the symmetric $\left(a_{1}\right)$ and asymmetric $\left(b_{2}\right)$ vibrational frequencies of the water shift to the red, whereas the scissor $\left(a_{1}\right)$ mode in the region of $1,600 \mathrm{~cm}^{-1}$ shifts towards the blue. The calculated results are in agreement with this qualitative picture, as seen in Table 2 . The redshift of the $\mathrm{OH}$ stretching vibration is calculated to vary between -53 and $-101 \mathrm{~cm}^{-1}$. The calculated shift at the MP2/aug-cc-pVDZ level is $-74 \mathrm{~cm}^{-1}$. For acetonitrile the largest shift is obtained for the intense NC stretching mode. All the theoretical models predict that this shift is toward the blue and that the magnitude varies between 10 and $17 \mathrm{~cm}^{-1}$. This calculated blueshift is in agreement with the decrease in the NC distance, after complexation, obtained theoretically and discussed in the previous section. Stretching vibrations of atoms involved in hydrogen bonds are normally shifted towards smaller vibrational frequencies (redshift). IR blueshifts of stretching modes due to hydrogen bonds are attracting considerable attention after the studies of Hobza and Havlas [32].

\section{Binding energies}

The calculated results for the binding energies are shown in Table 3. All the results shown include counterpoise correction to BSSE. Two sets of single-point energy calculations were performed. One is $\operatorname{CCSD}(\mathrm{T}) /$ $6-311++G(d, p)$ using the geometry obtained previously with the MP2/6-311+ $+\mathrm{G}(\mathrm{d}, \mathrm{p})$ method and the other is CCSD(T)/aug-cc-pVDZ using the geometry obtained with the MP2/aug-cc-pVDZ method. Intermediate results, like the incomplete and complete MP4 results, are useful to analyze the electron correlation effects in the binding energy. It can be noted that electron correlation effects are important; they increase the calculated binding energies with respect to the HF result. With the MP2/augcc-pVDZ model the binding energy is calculated as $4.45 \mathrm{kcal} \mathrm{mol} \mathrm{m}^{-1}$. This value is only slightly decreased after including higher-order electron correlation effects. At the highest level, $\operatorname{CCSD}(T)$, this value is decreased to $4.23 \mathrm{kcal} \mathrm{mol}^{-1}$. The MP2 results confirm that this is a good theoretical model for calculating binding energies of hydrogen-bonded systems [33, 34]. Of particular importance is the contribution of high-order triple excitation. At the fourth-order the triple excitation contribution, as derived from the difference between MP4 and SDQ-MP4, amounts to $+0.25 \mathrm{kcal} \mathrm{mol}^{-1}$ in the binding energy. Including all triple excitations derived from the difference between $\operatorname{CCSD}(\mathrm{T})$ and $\mathrm{CCSD}$ gives a similar result of $0.21 \mathrm{kcal} \mathrm{mol}^{-1}$. Thus, most of the triple excitation contribution to the binding energy is obtained already in fourth order and the total effect of triple excitation is to increase the binding energy by around $5 \%$. Table 3 also shows that single excitations contribute even less to the binding energy. In fourth order, single excitation is 


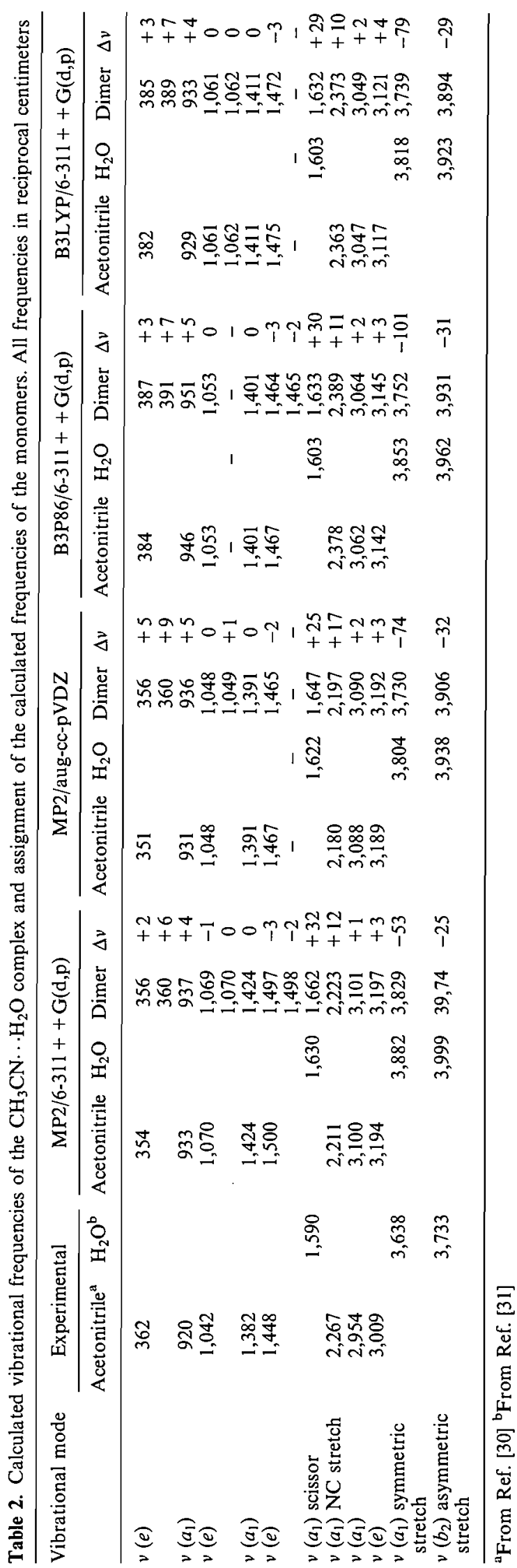

Table 3. Calculated binding energies $(\mathrm{kcal} / \mathrm{mol})$ and electron correlation effects in the hydrogen-bonded complex $\mathrm{CH}_{3} \mathrm{CN} \ldots \mathrm{H}_{2} \mathrm{O}$ All results were obtained at the optimized MP2 geometries indicated and include counterpoise correction to the basis set superposition error

\begin{tabular}{lcc}
\hline Method & MP2/6-311+ $+\mathrm{G}(\mathrm{d}, \mathrm{p})$ & MP2/aug-cc-pVDZ \\
\hline HF & 3.67 & 3.23 \\
MP2 & 4.33 & 4.45 \\
MP3 & 4.05 & 4.08 \\
DQ-MP4 & 3.97 & 3.99 \\
SDQ-MP4 & 4.03 & 4.08 \\
MP4 & 4.19 & 4.33 \\
CCSD & 3.99 & 4.02 \\
CCSD(T) & 4.13 & 4.23 \\
\hline
\end{tabular}

obtained as the difference between the SDQ-MP4 and DQ-MP4 results and contributes only $0.09 \mathrm{kcal}^{\mathrm{mol}} \mathrm{m}^{-1}$ using the aug-cc-pVDZ basis in the MP2/aug-cc-pVDZ optimized geometries, for instance. High-order single excitations are even smaller, as seen using the difference between CCSD and DQ-MP4 results. Again, using the MP2/aug-cc-pVDZ geometry and the aug-cc-pVDZ basis set this is only $0.03 \mathrm{kcal} \mathrm{mol}^{-1}$. This explains why MP2 is a good model for calculating binding energies of hydrogen-bonded systems. Similar results are obtained with the other theoretical models. The results obtained with DFT are slightly larger than those obtained with Møller-Plesset or coupled-cluster theories. The result for the binding energy using exclusively the B3LYP/6-311++G(d,p) method, for both geometry and energies, is $4.81 \mathrm{kcal}$ $\mathrm{mol}^{-1}$. The result of $4.23 \mathrm{kcal} \mathrm{mol}^{-1}$ obtained with MP2/ aug-cc-pVDZ is in good agreement with the result of $4.18 \mathrm{kcal} \mathrm{mol}^{-1}$ obtained in Ref. [14]. Overall, the BSSE amounts to a correction of less than $1.0 \mathrm{kcal} \mathrm{mol}^{-1}$ in the binding energy with the correlated models, from MP2 to $\operatorname{CCSD}(\mathrm{T})$.

Before giving our best estimate for the binding energy, we should take into account the difference in zero-point vibrational energies. Using the harmonic approximation the calculated frequencies were obtained and are given in Table 2. Using these values we obtained a difference in zero-point vibrational energies of $1.31 \mathrm{kcal} \mathrm{mol} \mathrm{mol}^{-1}$. However, although the intramolecular vibrations may be reasonably well described by the harmonic approximation, the intermolecular vibrations are largely anharmonic. Taking this into consideration, we estimate the difference in zero-point vibrational energies as $0.70 \mathrm{kcal}$ $\mathrm{mol}^{-1}$. Using this result we give our best estimate of the binding energy of the hydrogen-bonded complex as $3.53 \mathrm{kcal} \mathrm{mol} \mathrm{m}^{-1}$. This result is obtained with the $\operatorname{CCSD}(\mathrm{T}) /$ aug-cc-pVDZ single-point calculation performed in the MP2/aug-cc-pVDZ geometry and calculated frequencies.

\section{Rayleigh and Raman scattering activities}

Light scattering cross-section and depolarization are related to the anisotropy of the electronic polarization of 
a molecular system. As the hydrogen-bond formation leads to a change in the anisotropy, it should lead to a corresponding change in the light depolarization. In the case of elastic Rayleigh scattering the degrees of depolarization of the light scattered at right angles to the direction of incidence for natural and plane-polarized light are given by $[35,36,37,38]$

$$
\sigma_{\mathrm{n}}=6(\Delta \alpha)^{2} /\left[45 \alpha^{2}+7(\Delta \alpha)^{2}\right]
$$

and

$\sigma_{\mathrm{p}}=3(\Delta \alpha)^{2} /\left[45 \alpha^{2}+4(\Delta \alpha)^{2}\right]$.

The average, $\alpha$, and anisotropic, $\Delta \alpha$, dipole polarizabilities are the invariants of the polarizability tensor and are obtained from

$\alpha=\left(\alpha_{x x}+\alpha_{y y}+\alpha_{z z}\right) / 3$

and

$$
\begin{aligned}
(\Delta \alpha)^{2}= & 1 / 2\left[\left(\alpha_{x x}-\alpha_{y y}\right)^{2}+\left(\alpha_{y y}-\alpha_{z z}\right)^{2}+\left(\alpha_{z z}-\alpha_{x x}\right)^{2}\right] \\
& +3\left(\alpha_{x y}^{2}+\alpha_{x z}^{2}+\alpha_{y z}^{2}\right) .
\end{aligned}
$$

The maximum value [35] of $\sigma$ in the Rayleigh scattering corresponds to the most anisotropic case, corresponding to the extreme where $\Delta \alpha=3 \alpha$. In this case, $\sigma_{\mathrm{n}}^{\max }$ $=1 / 2$ and $=1 / 3$. It is also of interest to obtain the depolarization for circularly polarized light. The light circularly polarized scattered backwards may have a component of circular polarization. The degree of reversal is given by [35]

$\sigma_{\mathrm{c}}=\sigma_{\mathrm{n}} /\left(1-\sigma_{\mathrm{n}}\right)$.

It is easy to see that in this Rayleigh case $\sigma_{c}^{\max }$ is 1. In the inelastic case of the Raman scattering in the same experimental setup the degree of depolarization is given by the same expressions but the derivative with respect to the vibrational mode should be taken. Hence, for the plane-polarized case one has

$$
\sigma_{\mathrm{p}}^{(v)}=3\left(\Delta \alpha^{\prime}\right)^{2} /\left[45\left(\alpha^{\prime}\right)^{2}+4\left(\Delta \alpha^{\prime}\right)^{2}\right]
$$

where the prime indicates a derivative with respect to the $v$ vibrational mode. We calculate the depolarization for all the fundamentals of $\mathrm{CH}_{3} \mathrm{CN}$ both isolated and after hydrogen binding with water. In this case the value of $\sigma_{\mathrm{p}}^{\max }$ is $3 / 4$. The cross-section for Raman scattering is completely determined by the scattering activity given by [35]

$A_{\mathrm{p}}=45\left(\alpha^{\prime}\right)^{2}+7\left(\Delta \alpha^{\prime}\right)^{2}$.
The change in depolarization is now reported for $\mathrm{CH}_{3} \mathrm{CN}$ both isolated and after hydrogen binding with water. The result for the Rayleigh case and also the calculated polarizabilities are given in Table 4 . The dipole polarizabilities of both $\mathrm{CH}_{3} \mathrm{CN}$ and $\mathrm{H}_{2} \mathrm{O}$ are found to be in good agreement with the experimental results. The average dipole polarizability of $\mathrm{CH}_{3} \mathrm{CN} \cdots \mathrm{H}_{2} \mathrm{O}$, as expected, is only slightly larger than the sum of the dipole polarizabilities of separated $\mathrm{CH}_{3} \mathrm{CN}$ and $\mathrm{H}_{2} \mathrm{O}$. The change in the anisotropic polarizabilities of $\mathrm{CH}_{3} \mathrm{CN}$ and $\mathrm{CH}_{3} \mathrm{CN} \cdots \mathrm{H}_{2} \mathrm{O}$ and the increase in the average polarizabilities lead to the variation in the depolarization ratios as given in Table 4. In all cases the depolarization increases upon complexation. The calculated activities for the Raman scattering are given in Table 5. All eight active fundamentals of $\mathrm{CH}_{3} \mathrm{CN}$ are considered, but in the case of the degenerate vibrations the depolarization has its maximum value of $3 / 4$ as in this case the derivative of the dipole polarizability evaluated at the origin of the molecular vibration is zero. The largest cross-section for the inelastic scattered light transition is obtained for the $\mathrm{CH}$ symmetric mode in the region of $3,090 \mathrm{~cm}^{-1}$, however, for this vibration the depolarization for planepolarized light is essentially zero and does not change after complexation. In this direction the most important vibrational mode associated with $\mathrm{CH}_{3} \mathrm{CN}$ is the $\mathrm{NC}$ stretching mode. Its depolarization ratio changes from 0.17 to 0.20 after the hydrogen-bond formation. Another pronounced change in depolarization is obtained for the less intense $\mathrm{CC}$ stretching at the calculated frequency of $930 \mathrm{~cm}^{-1}$. In this case the depolarization changes by a percentually large amount of $45 \%$, from 0.07 to 0.10 , but the absolute depolarization is smaller than that for the NC stretching and $A_{\mathrm{p}}$ is also smaller. These effects are more pronounced in the $\mathrm{H}_{2} \mathrm{O}$ modes. It has been noted before [39] in the water dimer, at the HF level, that the symmetric $\mathrm{OH}$ donor vibration increases by nearly 2 . The same situation is seen here, where we find a great intensification of the scattering activity for the symmetric stretch vibration of $\mathrm{H}_{2} \mathrm{O}$ (Table 5). To make a comparison with the case of the hydrogen-bonded water dimer $(\mathrm{H} 2 \mathrm{O})_{2}$ we also calculated its scattering activity at the present MP2/aug-cc-pVDZ level. Starting from pure $\mathrm{H}_{2} \mathrm{O}$, the scattering activity of the $\mathrm{OH}$ stretching vibration $\left(104.1 a_{0}^{4} / \mathrm{amu}\right)$ increases by $55 \%$ in the water dimer

Table 4. Calculated dipole polarizabilities, both average, $\alpha$, and anisotropic, $\Delta \alpha$, in atomic units, depolarization ratio for $\mathrm{CH}_{3} \mathrm{CN}$ and $\mathrm{CH}_{3} \mathrm{CN} \ldots \mathrm{H}_{2} \mathrm{O}$. All calculations were made at the MP2/augcc-pVDZ level and the corresponding optimized geometries

\begin{tabular}{lccccc}
\hline Molecule & $\alpha^{a}$ & $\Delta \alpha$ & $\sigma_{\mathbf{n}}$ & $\sigma_{\mathbf{p}}$ & $\sigma_{\mathrm{c}}$ \\
\hline $\mathrm{H}_{2} \mathrm{O}$ & 9.30 & 1.04 & 0.0017 & 0.0008 & 0.0017 \\
$\mathrm{CH}_{3} \mathrm{CN}$ & 29.43 & 15.65 & 0.0361 & 0.0184 & 0.0375 \\
$\mathrm{CH}_{3} \mathrm{CN} \ldots \mathrm{H}_{2} \mathrm{O}$ & 39.67 & 21.78 & 0.0384 & 0.0196 & 0.0399 \\
\hline
\end{tabular}

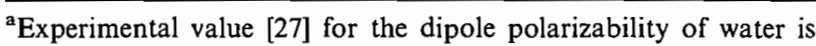
$9.80 \mathrm{au}$ and for acetonitrile two values are reported, 29.72 and 30.27 au 
Table 5. Calculated Raman activities $A_{\mathrm{p}}\left(a_{0}{ }^{4} / \mathrm{amu}\right)$ and depolarization of planepolarized light for $\mathrm{CH}_{3} \mathrm{CN}$ and $\mathrm{CH}_{3} \mathrm{CN} \cdots \mathrm{H}_{2} \mathrm{O}$. All calculations were made at the MP2/aug-cc-pVDZ level and the corresponding optimized geometries

\begin{tabular}{|c|c|c|c|c|c|c|}
\hline \multirow[t]{2}{*}{ Vibrational mode } & \multicolumn{2}{|c|}{$\mathrm{CH}_{3} \mathrm{CN}$} & \multicolumn{2}{|c|}{$\mathrm{H}_{2} \mathrm{O}$} & \multicolumn{2}{|c|}{$\mathrm{CH}_{3} \mathrm{CN} \cdots \mathrm{H}_{2} \mathrm{O}$} \\
\hline & $A_{\mathrm{p}}$ & $\sigma_{\mathrm{p}}$ & $A_{\mathrm{p}}$ & $\sigma_{\mathrm{p}}$ & $A_{\mathrm{p}}$ & $\sigma_{\mathrm{p}}$ \\
\hline$v\left(1 a_{1}\right)$ & 7.07 & 0.071 & - & - & 7.92 & 0.101 \\
\hline$v\left(2 a_{1}\right)$ & 3.48 & 0.432 & - & - & 3.90 & 0.418 \\
\hline$v\left(3 a_{1}\right)$ NC stretch & 49.37 & 0.169 & - & - & 64.02 & 0.202 \\
\hline$v\left(4 a_{1}\right)$ & 188.21 & 0.002 & - & - & 196.37 & 0.005 \\
\hline$v\left(1 a_{1}\right)$ scissor & - & - & 1.95 & 0.633 & 0.58 & 0.644 \\
\hline$v\left(2 a_{1}\right)$ symmetric stretch & - & - & 104.10 & 0.042 & 206.78 & 0.153 \\
\hline$v\left(1 b_{2}\right)$ asymmetric stretch & - & - & 24.17 & 0.750 & 40.94 & 0.484 \\
\hline
\end{tabular}

$\mathrm{H}_{2} \mathrm{O} \cdots \mathrm{H}_{2} \mathrm{O}\left(161.6 a_{0}{ }^{4} / \mathrm{amu}\right)$ and increases by $99 \%$ $\left(206.8 a_{0}^{4} / \mathrm{amu}\right)$ in the case of $\mathrm{CH}_{3} \mathrm{CN} \cdots \mathrm{H}_{2} \mathrm{O}$. This is indicative of a stronger bond and corroborates the result for the frequency shift of $-74 \mathrm{~cm}^{-1}$ calculated for the symmetric $\mathrm{OH}$ stretch in the vibrational spectrum. As to the depolarization ratio, we may note that it changes from a factor of nearly 4 from the free water $(0.042)$ to the $\mathrm{CH}_{3} \mathrm{CN} \cdots \mathrm{H}_{2} \mathrm{O}$ complex $(0.153)$.

\section{Summary and conclusions}

The hydrogen-bond interaction between acetonitrile and water, $\mathrm{CH} 3 \mathrm{CN} \cdots \mathrm{H}_{2} \mathrm{O}$, has been analyzed by ab initio methods. Geometry optimization, vibrational frequencies, Rayleigh and Raman activities including light scattering depolarization and binding energies were considered. The geometries of the complex and of the separate moieties were calculated using different theoretical models. In all the models we found a shortening of the NC distance, leading to a blueshift of around $15 \mathrm{~cm}^{-1}$ in the IR spectrum. The calculated hydrogenbond $\mathrm{N}-\mathrm{H}$ distance at the MP2/aug-cc-pVDZ level is $2.06 \AA$, with small variations between the results obtained using the different theoretical methods. The dipole moment of the complex $\mathrm{CH}_{3} \mathrm{CN} \cdots \mathrm{H}_{2} \mathrm{O}$ is $5.77 \mathrm{D}$ in good agreement with the suggestion of Desfrançois et al. [14]. The binding energy was obtained using different theoretical models and the role of electron correlation effects was analyzed. Taking into account the BSSE and the difference in zero-point anharmonic vibrational energies our best estimate for the binding energy is $3.53 \mathrm{kcal} \mathrm{mol}^{-1}$, obtained with the CCSD(T)/ aug-cc-pVDZ single-point calculation performed in the MP2/aug-cc-pVDZ geometry and calculated frequencies. Of particular interest here are the Rayleigh and Raman cross-section depolarization ratios. A light scattering analysis was made both for the elastic Rayleigh and for the inelastic Raman cases after calculation of the dipole polarizabilities and their corresponding derivatives with respect to the intramolecular vibrational modes, at the MP2/aug-cc-pVDZ level. The calculated average dipole polarizability is 39.67 au and the anisotropy is fairly large, corresponding to $21.78 \mathrm{au}$. The depolarization of the light scattered was then reported for the $\mathrm{CH}_{3} \mathrm{CN} \cdots \mathrm{H}_{2} \mathrm{O}$ complex and the results were compared with the results obtained for the two separated moieties. It is noted that in the Raman case the depo- larization due to the intense $\mathrm{NC}$ stretching vibration is increased by $20 \%$. For the $\mathrm{OH}$ symmetric stretch of water there is a large redshift of $75 \mathrm{~cm}^{-1}$ in the vibrational frequency and a great intensification of the Raman scattering activity: the cross-section increases by a factor of 2 and the depolarization by a factor of nearly 4 .

Acknowledgements. This work was partially supported by CNPq and FAPESP (Brazil).

\section{References}

1. Shin DN, Wijnen JW, Engberts JBFN, Wakisaka A (2002) J Phys Chem B 106:6014

2. Engberts JBFN, Blandamer MJ (2002) J Chem Commun 18:1701

3. Plašil R, Glosik J, Zakouřil P (1999) J Phys B At Mol Opt Phys 32:3575

4. Pratap P, Megeath ST, Bergin EA (1999) Astrophys J 517:799

5. Kalenskii SV, Promislov VG, Alakoz AV, Winnberg A, Johansson LEB (2000) Astron Astrophys 354:1036

6. Kalenskii SV, Promislov VG, Alakoz AV, Winnberg A, Johansson LEB (2000) Astron Rep 44:725

7. Kim HD, Cho SH, Chung HS, Kim HR, Roh DG, Kim HG, Minh YC, Minn YK (2000) Astrophys J Suppl Ser 131:483

8. Scoles G (ed) (1990) The chemical physics of atomic and molecular clusters. North-Holland, Amsterdam

9. Bernstein ER (ed) (1990) Atomic and molecular clusters. Elsevier, Amsterdam

10. Buckingham AD, Fowler PW, Hutson JM (1988) Chem Rev 88:963

11. Scheiner S (1997) Hydrogen bonding: a theoretical perspective. Oxford University Press, Oxford

12. Zwier TS (1996) Annu Rev Phys Chem 47:205

13. Caminati W, Moreschini P, Favero PG (1998) J Phys Chem A 102:8097

14. Desfrançois C, Abdoul-Carime H, Khelifa N, Schermann JP, Brenner V, Millie P (1995) J Chem Phys 102:4952

15. Desfrançois C, Abdoul-Carime H, Schulz CP, Schermann JP (1995) Science 269:1707

16. Smith DA (ed) (1994) Modeling the hydrogen bond. ACS symposium series 569 . American Chemical Society, Washington, DC

17. Malaspina T, Coutinho K, Canuto S (2002) J Chem Phys 117:1692

18. Damewood JR, Kumpf RA (1987) J Phys Chem 91:3449

19. Burneau A, Schriver L, Manceron L, Perchard JP (1985) J Chim Phys PCB 82:19

20. Lee C, Yang W, Parr RG (1988) Phys Rev B 37:785

21. Becke AD (1988) Phys Rev A 38:3098

22. Perdew JP (1986) Phys Rev B 33:8822

23. Wilson A, van Mourik T, Dunning TH Jr (1996) J Mol Struct (THEOCHEM) 388:339

24. Raghavachari K (1991) Annu Rev Phys Chem 42:615

25. Boys SF, Bernardi F (1970) Mol Phys 19:553 
26. Frisch MJ, Trucks GW, Schlegel HB, Scuseria GE, Robb MA, Cheeseman JR, Zakrzewski VG, Montgomery JA Jr, Stratmann RE, Burant JC, Dapprich S, Millam JM, Daniels AD, Kudin KN, Strain MC, Farkas O, Tomasi J, Barone V, Cossi M, Cammi R, Mennucci B, Pomelli C, Adamo C, Clifford S, Ochterski J, Petersson GA, Ayala PY, Cui Q, Morokuma K, Malick DK, Rabuck AD, Raghavachari K, Foresman JB, Cioslowski J, Ortiz JV, Baboul AG, Stefanov BB, Liu G, Liashenko A, Piskorz P, Komaromi I, Gomperts R, Martin RL, Fox DJ, Keith T, Al-Laham MA, Peng CY, Nanayakkara A, Gonzalez C, Challacombe M, Gill PMW, Johnson B, Chen W, Wong MW, Andres JL, Gonzalez C, Head-Gordon M, Replogle ES, Pople IA (1998) Gaussian 98, revision A.7. Gaussian, Pittsburgh, PA

27. Lide DR (ed) (1992) Handbook of chemistry and physics, 73rd edn, CRC, Boca Raton, FL

28. Lovas FJ (1978) J Phys Chem Ref Data 7:1445
29. Christophorou LG, Christodoulides AA (1969) J Phys B At Mol Opt Phys 2:71

30. Koga Y, Kondo S, Saeki S, Person WB (1984) J Phys Chem $88: 3152$

31. Bentwood RM, Barnes A, Orville-Thomas W (1980) J Mol Spectrose 84:391

32. Hobza P, Havlas Z (2000) Chem Rev 100:4253

33. Rivelino R, Canuto S (2000) Chem Phys Lett 322:207

34. Scheiner S, Kar T, Gu Y (2001) J Biol Chem 276:9832

35. Herzberg $G$ (1945) Infrared and Raman spectra of polyatomic molecules. Van Nostrand, Princeton, NJ

36. Suzuki H (1979) Prog Theor Phys 62:936

37. Castro MA, Canuto S (1993) J Phys B 26:4301

38. Serrano A, Canuto S, Castro M (1999) J Mol Struct (THEOCHEM) 489:29

39. Swanton DJ, Bacskay GB, Hush NS (1984) Chem Phys 83:69 


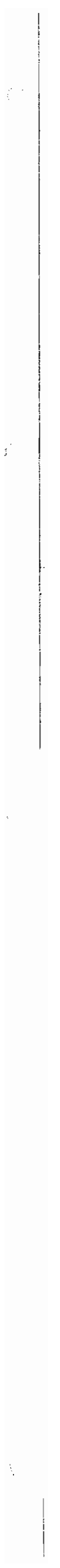




\title{
Rayleigh light scattering of hydrogen bonded clusters investigated by means of $a b$ initio calculations
}

\author{
Eudes E Fileti, Roberto Rivelino and Sylvio Canuto ${ }^{1}$ \\ Institulo de Física, Universidade de São Paulo, CP 663I8, 05315-970 São Paulo, SP, Brazil \\ E-mail: canuto@if.usp.br
}

Received 21 September 2002, in final form 9 December 2002

Published 13 January 2003

Online at stacks.iop.org/JPhysB/36/399

\begin{abstract}
$A b$ initio calculations of depolarization ratios and intensities of classically scattered light, in terms of dipole polarizabilities and polarizability anisotropies, are reported for different hydrogen bonded molecular clusters. Five different groups of organic heterodimers formed with water are considered: $\mathrm{HCHO} \cdots \mathrm{H}_{2} \mathrm{O}, \mathrm{CH}_{3} \mathrm{HO} \cdots \mathrm{H}_{2} \mathrm{O}, \mathrm{HCOOH} \cdots \mathrm{H}_{2} \mathrm{O}, \mathrm{CH}_{3} \mathrm{CN} \cdots \mathrm{H}_{2} \mathrm{O}$, and $\left(\mathrm{CH}_{3}\right)_{2} \mathrm{CO} \cdots \mathrm{H}_{2} \mathrm{O}$, together with the water dimer $\mathrm{H}_{2} \mathrm{O} \cdots \mathrm{H}_{2} \mathrm{O}$. The geometries of all complexes have been optimized by means of the second-order Møller-Plesset many-body perturbation theory (MP2), using the augmented correlation-consistent basis set with polarized valence of double-zeta quality (aug-cc-pVDZ). The calculated average dipole polarizabilities of the isolated molecules are in good agreement with available experimental results. The calculations are then extended to the complexes and, from these, the Rayleigh scattering activities and depolarization ratio changes, upon hydrogen bond formation, are obtained and analysed. The differences in activity and depolarization for Rayleigh scattered radiation between two groups of isomers, (i) $\mathrm{HCN} \cdots \mathrm{H}_{2} \mathrm{O}$ and $\mathrm{H}_{2} \mathrm{O} \cdots \mathrm{HCN}$ and (ii) $\mathrm{CH}_{3} \mathrm{HO} \cdots \mathrm{H}_{2} \mathrm{O}$ and $\mathrm{CH}_{3} \mathrm{OH} \cdots \mathrm{OH}_{2}$, have also been investigated.
\end{abstract}

\section{Introduction}

The molecular scattering of light provides a great spread of information about the finest details of phenomena observed in the interaction of radiation with matter [1,2]. The basic descriptor of the interaction of the molecular charge distribution with an electric field is the dipole polarizability [3], which is also connected with the partial orientation of anisotropic pairs [4]. Electromagnetic radiation can scatter off molecules in two well-understood processes: one is elastic or Rayleigh scattering and the other is inelastic scattering, better known as Raman scattering, in which the wavelength of the radiation is degraded in the process. The elastic

\footnotetext{
: Author to whom any correspondence should be addressed.
} 
scattering of light is primarily a classical effect caused by optical inhomogeneities in the medium or time fluctuations in its optical density. In this sense, by examining the state of polarization of the incident light beam of the system under study, it is possible to find the degree of depolarization of each frequency shift in the light scattering spectrum, a quantity that is important in the interpretation of the experimental results. This quantity is the ratio, for the scattered light, of the intensities of the components polarized perpendicular and parallel, respectively, to the direction of polarization of the incident beam. In such a description, the state of polarization of the scattered light is related to the molecular anisotropy [2]. Hence, for molecules, the Rayleigh scattering properties are connected with both the dipole polarizability and the polarizability anisotropy [5].

Rayleigh scattering investigation has been used as a successful technique for obtaining the average size of clusters formed in molecular beams under different expansion conditions [6-8]. The depolarized component of the Rayleigh scattered radiation has also been used to obtain molecular species concentrations in plasmas [9], because the scattering signal is related to the number of scattering particles in the medium [6,7]. Recently, Park et al [10] have proposed that the internal hydrogen bonding strength changes in cis-trans photoisomerization processes can be monitored by forced Rayleigh scattering. Also, dynamical aspects of hydrogen bond formation in aqueous solutions can be studied by means of depolarized Rayleigh light scattering (DRLS). Along this lines, Micali et al [1 1 ] have investigated the water rotational relaxation time in water-methanol solutions as a function of concentration and temperature. Thus, molecular light scattering spectra can give information on both microscopic and collective properties of the scatterer centres. From the structural point of view, asymmetrical molecules are well known to give a strong contribution to the depolarized Rayleigh intensity, so DRLS can be used to study molecular rotational dynamics [11] or even the strength of the bond energy for assembled molecules [1]. More generally, the phenomenon of molecular scattering of light can be studied in gases or vapours, liquids, and crystals [2].

In this work we determine depolarization ratios and activities for Rayleigh light scattering in terms of $a b$ initio polarizabilities of hydrogen bonded molecular clusters. The formation of hydrogen bonds is expected to lead to an increase in the polarizability anisotropy and therefore a change in the Rayleigh depolarization ratio. The systems studied here are different types of hydrogen bonded complexes formed with water, for instance $\mathrm{H}_{2} \mathrm{O} \cdots \mathrm{H}_{2} \mathrm{O}, \mathrm{HCHO} \cdots \mathrm{H}_{2} \mathrm{O}$, $\mathrm{CH}_{3} \mathrm{HO} \cdots \mathrm{H}_{2} \mathrm{O}, \mathrm{HCOOH} \cdots \mathrm{H}_{2} \mathrm{O}, \mathrm{CH}_{3} \mathrm{CN} \cdots \mathrm{H}_{2} \mathrm{O}$, and $\left(\mathrm{CH}_{3}\right)_{2} \mathrm{CO} \cdots \mathrm{H}_{2} \mathrm{O}$. The water dimer has been extensively [12-21] studied before, but studies of other hydrogen bonded systems are more scarce and, in particular, the characterization of alcohol-water systems is of great importance [11]. The electronic changes upon hydrogen bond formation can be probed by a great variety of techniques such as infrared spectroscopy, rotational millimetre spectroscopy, nuclear magnetic resonance, Raman spectroscopy, and depolarization studies. However, very little time has been dedicated to the Rayleigh scattering techniques used in hydrogen bonded systems. One possible reason for this is the small magnitude of the changes expected. Another is that Rayleigh light scattering is related to dipole polarizability which is, in fact, the basic property that describes the interaction of a molecule with an electric field [22]. Because of the lack of both theoretical and experimental results on depolarization ratios of Rayleigh scattering for small hydrogen bonded clusters, this study might be of interest in establishing possible trends and predictions for classically scattered light in these systems. In addition, the difference in depolarization for Rayleigh scattered radiation between two groups of hydrogen bonded isomers, (i) $\mathrm{HCN} \cdots \mathrm{H}_{2} \mathrm{O}$ and $\mathrm{H}_{2} \mathrm{O} \cdots \mathrm{HCN}$ and (ii) $\mathrm{CH}_{3} \mathrm{HO} \cdots \mathrm{H}_{2} \mathrm{O}$ and $\mathrm{CH}_{3} \mathrm{OH} \ldots \mathrm{OH}_{2}$, has also been investigated here. For these cases the water molecule acts as both proton donor and proton acceptor. Hence, the changes in the molecular depolarization light scattering spectra of the clusters are used to critically assess the depolarized Rayleigh 
scattering as an additional possible mean of distinguishing among these intermolecular isomers. Furthermore, a study of the Rayleigh light scattering, such as that carried out here, could be a viable alternative method for possible identification and characterization of molecular segregation in alcohol-water mixtures [23].

\section{Theory and methods}

According to the formalism of classical scattering, in the case of non-spherically symmetric molecules a small component of the scattered radiation is depolarized at right angles to the direction of incidence $[24,25]$. In depolarized Rayleigh scattering the scattered light is detected with a polarization perpendicular to that of the incident radiation, whereas the polarized Rayleigh spectrum detects light scattered with the same polarization direction as the incident light [5]. The quantities most frequently observed experimentally are the depolarization ratios (or degree of depolarization) for both natural and plane-polarized light, given, respectively, by

$$
\begin{aligned}
\sigma_{n} & =\frac{6(\Delta \alpha)^{2}}{45(\bar{\alpha})^{2}+7(\Delta \alpha)^{2}}, \\
\sigma_{p} & =\frac{3(\Delta \alpha)^{2}}{45(\bar{\alpha})^{2}+4(\Delta \alpha)^{2}} .
\end{aligned}
$$

In equations (1) and (2), $\bar{\alpha}=\frac{1}{3}\left(\alpha_{x x}+\alpha_{y y}+\alpha_{z z}\right)$ is the average dipole polarizability and $(\Delta \alpha)^{2}=\frac{1}{2}\left[\left(\alpha_{x x}-\alpha_{y y}\right)^{2}+\left(\alpha_{y y}-\alpha_{z z}\right)^{2}+\left(\alpha_{z z}-\alpha_{x x}\right)^{2}\right]+3\left[\left(\alpha_{x y}\right)^{2}+\left(\alpha_{x z}\right)^{2}+\left(\alpha_{y z}\right)^{2}\right]$ is the polarizability anisotropy, where $\alpha_{i j}$ are the components of the polarizability tensor, $\alpha$, along the molecular axis of the system.

The largest value of the degree of depolarization occurs for the most anisotropic case. Because $\bar{\alpha}$ always has a non-zero value for Rayleigh scattering, the maximum value of $\sigma_{n}^{\max }$ is $\frac{1}{2}$, while the maximum value of $\sigma_{p}^{\max }$ is $\frac{1}{3}$. For the sake of completeness, it is also of interest to obtain the depolarization for circularly polarized light. The scattered light, which is circularly polarized, may contain a component of circular polarization given by

$$
\sigma_{c}=\frac{\sigma_{n}}{1-\sigma_{n}} .
$$

In this case the maximum value of the depolarization is $\sigma_{c}^{\max }=1$. The Rayleigh scattered light intensity (or Rayleigh activity) can also be obtained in terms of polarizability for natural and plane-polarized light as follows:

$$
\begin{aligned}
& \mathfrak{R}_{n}=45(\bar{\alpha})^{2}+13(\Delta \alpha)^{2}, \\
& \mathfrak{R}_{p \perp}=45(\bar{\alpha})^{2}+7(\Delta \alpha)^{2}, \\
& \mathfrak{R}_{p \|}=6(\Delta \alpha)^{2} .
\end{aligned}
$$

As usual [5, 24], the Rayleigh intensity associated with the plane-polarized light, $\Re_{p}$, has been split into two orthogonal parts: $\mathfrak{R}_{p \perp}$, which corresponds to light perpendicularly polarized into the scattering plane; and $\mathfrak{R}_{p \|}$, which corresponds to light polarized in the same plane of scattering.

The static polarizability tensor, $\alpha$, is calculated here using the finite-field approx-imation [21, 26, 27], in which the total energy of the system is calculated both in the absence and in the presence of a weak electric field [28]. Thus, the electric properties are determined as derivatives of the energy with respect to the electric field. The components of the field strengths used here are 0.001 au. The $a b$ initio calculations for the isolated molecules and their water complexes are performed by using the Møller-Plesset perturbation theory up to second order (MP2) [29]. This is carried out utilizing the augmented correlation-consistent 
basis set with polarized valence of double-zeta quality (aug-cc-pVDZ) [30]. Thus, the full equilibrium geometries of the systems are found and the dipole polarizabilities are calculated with the MP2/aug-cc-pVDZ method. At this level of theory, the size extensivity is guaranteed. As all hydrogen bonded systems considered here involve the water molecule, it is important to mention that the MP2/aug-cc-pVDZ theoretical model gives a dipole moment of $1.88 \mathrm{D}$ for this molecule, which is in very good agreement with the experimental value of $1.86 \mathrm{D}$ [31]. Finally, the quantum mechanical calculations reported in this work were performed using the GAUSSIAN98 program [32].

\section{Results and discussion}

\subsection{Dipole polarizabilities and polarizability anisotropies}

The fully optimized structures of the clusters considered in this work are presented in figure 1 , where the hydrogen bond lengths are shown. All these hydrogen bonded systems have been found to be stable complexes at different levels of theory. There have been several theoretical studies of the water dimer. Schütz et al [33] and Xantheas [34] have obtained an accurate value of $2.925 \AA$ for the $\mathrm{O}-\mathrm{O}$ interatomic distance. More recently, Maroulis [35] has obtained the value of $2.911 \AA$. These values are in good agreement with our calculated O-O distance of $2.918 \AA$. In the case of $\mathrm{HCHO} \cdots \mathrm{H}_{2} \mathrm{O}$, our calculated hydrogen bond distance of $1.986 \AA$ is shorter by $0.075 \AA$ than the result of Tsuzuki et al [36] obtained using MP2/6-311G(d,p). For $\mathrm{CH}_{3} \mathrm{HO} \cdots \mathrm{H}_{2} \mathrm{O}$ our calculated hydrogen bond distance $(\mathrm{O} \cdots \mathrm{H})$ of $1.904 \AA$ corresponds to an O-O distance of $2.844 \AA$, which compares well with the experimental result of $2.997 \AA$ [37] and the recent theoretical result of $2.840 \AA$ obtained using the MP2/aug-cc-pVDZ model [38]. For $\mathrm{HCOOH} \cdots \mathrm{H}_{2} \mathrm{O}$ our calculated hydrogen bond distances of 2.040 and $1.817 \AA$ compare well with the results of Wei et al [39] of 2.10 and $1.80 \AA$ obtained using MP2/6-311 ++ G(2d, 2p). In the case of $\mathrm{CH}_{3} \mathrm{CN} \cdots \mathrm{H}_{2} \mathrm{O}$, the distance of $2.059 \AA$ can be compared with a previous result of $2.108 \AA$ [40] obtained with another basis set using MP2/6-311++ G(d, p), and for $\left(\mathrm{CH}_{3}\right)_{2} \mathrm{CO} \cdots \mathrm{H}_{2} \mathrm{O}$ the distance of $1.914 \AA$ compares well with our previous estimate [41] of $1.918 \AA$ obtained using MP2/6-311 $\mathrm{G}$. The results presented here are all obtained using a single theoretical model, MP2/aug-cc-pVDZ, and serve better for comparison purposes among the different species.

In table 1 we report the calculated dipole polarizabilities and anisotropies of the isolated molecules, and their corresponding water clusters, obtained with the MP2/aug-cc-pVDZ method. Our results for the average polarizabilities of the isolated molecules are in fairly good agreement with the available experimental data [42]. For the water dimer, Maroulis [35] has calculated an average dipole polarizability of $19.5 \mathrm{au}$, in good agreement with our present result of 19.10 au. In some cases different experimental values have been reported. For instance, in the case of methanol $\left(\mathrm{CH}_{3} \mathrm{OH}\right)$ our calculated result of 21.22 au is in good agreement with three reported values. In general, however, our calculated mean polarizabilities are slightly smaller than the experimental values but slightly larger than other reported theoretical results [43], as in the case of formic acid $(\mathrm{HCOOH})$ and acetonitrile $\left(\mathrm{CH}_{3} \mathrm{CN}\right)$. The agreement of the theoretical polarizability with the corresponding experimental values depends strongly on the quality of the basis set, as pointed out by Nakagawa [44] for methanol $\left(\mathrm{CH}_{3} \mathrm{OH}\right)$. Additionally, we have evaluated the so-called interaction polarizability [35] upon complexation of each monomer with water. This is defined by $\bar{\alpha}_{\text {inter }}=\bar{\alpha}$ (complex) $-\left[\bar{\alpha}\left(\mathrm{H}_{2} \mathrm{O}\right)+\bar{\alpha}\right.$ (monomer) $]$. As observed by Maroulis [35], the basis set superposition error (BSSE) is quite small for this quantity at correlated levels. The calculated values of $\bar{\alpha}_{\text {inter }}$ for all complexes given in table 1 are very small, being less than 1.0 au in all cases. For instance, in the case of the water dimer we have 

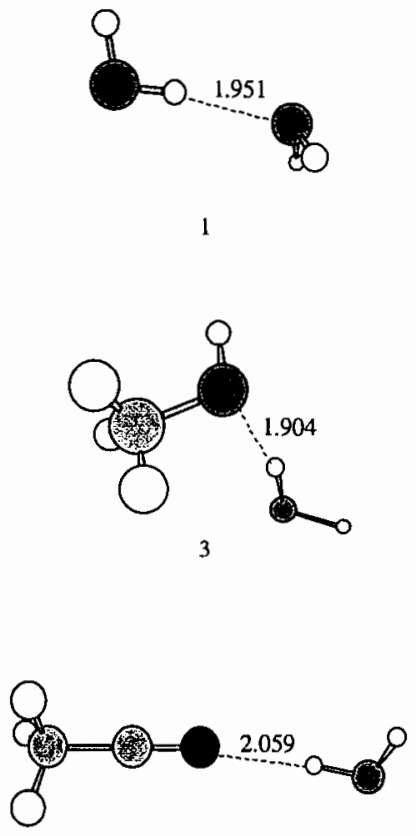

5

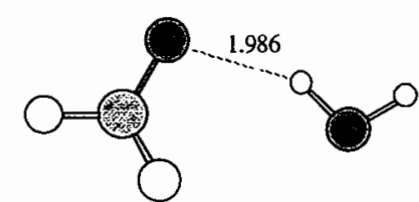

2

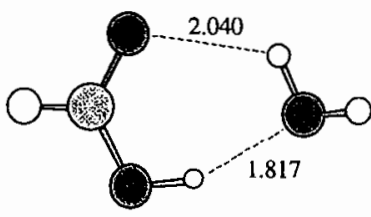

4

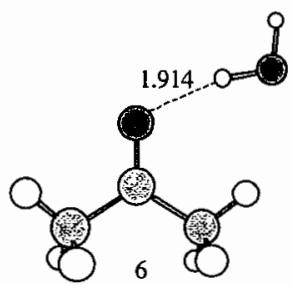

Figure 1. Structures of the hydrogen bonded water complexes: $\mathrm{H}_{2} \mathrm{O} \cdots \mathrm{H}_{2} \mathrm{O}$ (1) $\mathrm{HCHO} \cdots \mathrm{H}_{2} \mathrm{O}(2), \mathrm{CH}_{3} \mathrm{HO} \cdots \mathrm{H}_{2} \mathrm{O}$ (3), $\mathrm{HCOOH} \cdots \mathrm{H}_{2} \mathrm{O}$ (4), $\mathrm{CH}_{3} \mathrm{CN} \cdots \mathrm{H}_{2} \mathrm{O}$ (5), and $\left(\mathrm{CH}_{3}\right)_{2} \mathrm{CO} \cdots \mathrm{H}_{2} \mathrm{O}(6)$. The lengths of the $\mathrm{H}$ bonds are given in $\AA$, as obtained at the MP2/augcc-pVDZ level.

calculated such an interaction as having the value 0.5 au; the value found by Maroulis [35] was even smaller, at a very different level of calculation. Of course, a small value for $\bar{\alpha}_{\text {inter }}$ indicates that the dipole polarizability of the hydrogen bonded systems is approximately the sum of the separate parts. The largest deviation of $\bar{\alpha}_{\text {inter }}$ calculated here is for acetonitrile. As the polarizability anisotropies reflect the symmetry of the system, it is interesting to note their changes due to hydrogen bond formation. For instance, the anisotropies of the water dimer and $\mathrm{CH}_{3} \mathrm{HO} \cdots \mathrm{H}_{2} \mathrm{O}$ change equally, by $2.52 \mathrm{au}$. This value is only 1.74 au for $\mathrm{HCHO} \cdots \mathrm{H}_{2} \mathrm{O}$ and $2.29 \mathrm{au}$ for $\mathrm{HCOOH} \cdots \mathrm{H}_{2} \mathrm{O}$, and increases to about 4.92 au for $\left(\mathrm{CH}_{3}\right)_{2} \mathrm{CO} \cdots \mathrm{H}_{2} \mathrm{O}$ and 6.13 au for $\mathrm{CH}_{3} \mathrm{CN} \cdots \mathrm{H}_{2} \mathrm{O}$. These different anisotropies will lead to different changes in the depolarization ratios.

\subsection{Depolarization ratios and intensities for Rayleigh scattering}

The quantities most commonly observed in light scattering experiments are the depolarization ratios [5], defined previously in equations (1), (2), and (3). The changes in the polarizability and anisotropy lead to variations in the depolarization ratios of the hydrogen bonded clusters. We have computed all the components of the depolarization due to natural, plane-polarized, and circularly polarized light incident on the isolated molecules and their corresponding water clusters, which are shown in figure 1 . In table 2 we give the components of the depolarization ratios for each system as obtained at the MP2/aug-cc-pVDZ level. As normally expected, the increase in anisotropy should lead to an increase in the depolarization ratios. The opposite 
Table 1. Calculated mean polarizabilities, interaction polarizabilities, and polarizability anisotropies (in au), at the MP2/aug-cc-pVDZ level. Conversion unit for dipole polarizability: $\mathrm{l}$ au $=0.148 \AA^{3}$.

\begin{tabular}{|c|c|c|c|c|c|}
\hline System & $\bar{\alpha}$ & $\bar{\alpha}_{\text {inter }}$ & $\Delta \alpha$ & $\alpha_{\exp }$ & Other results for $\bar{\alpha}$ \\
\hline $\mathrm{H}_{2} \mathrm{O}$ & 9.30 & - & 1.04 & 9.80 & $9.78[35]$ \\
\hline $\mathrm{H}_{2} \mathrm{O} \cdots \mathrm{H}_{2} \mathrm{O}$ & 19.10 & 0.50 & 3.56 & & 19.5 [35] \\
\hline $\mathrm{HCHO}$ & 17.58 & - & 8.57 & $18.9,16.55$ & $17.83[4]$ \\
\hline $\mathrm{HCHO} \cdots \mathrm{H}_{2} \mathrm{O}$ & 27.01 & 0.13 & 10.31 & & \\
\hline $\mathrm{CH}_{3} \mathrm{OH}$ & 21.22 & - & 3.38 & $22.21,21.80,22.41$ & $21.6[44]$ \\
\hline $\mathrm{CH}_{3} \mathrm{HO} \cdots \mathrm{H}_{2} \mathrm{O}$ & 31.19 & 0.67 & 5.90 & & \\
\hline $\mathrm{HCOOH}$ & 22.53 & - & 10.64 & 22.97 & $20.29[43]$ \\
\hline $\mathrm{HCOOH} \cdots \mathrm{H}_{2} \mathrm{O}$ & 32.15 & 0.32 & 12.93 & & \\
\hline $\mathrm{CH}_{3} \mathrm{CN}$ & 29.43 & - & 15.65 & $29.72,30.27$ & $28.14[43]$ \\
\hline $\mathrm{CH}_{3} \mathrm{CN} \cdots \mathrm{H}_{2} \mathrm{O}$ & 39.67 & 0.94 & 21.78 & & \\
\hline$\left(\mathrm{CH}_{3}\right)_{2} \mathrm{CO}$ & 42.38 & - & 12.38 & $43.24,43.17,42.77$ & $43.30[4]$ \\
\hline$\left(\mathrm{CH}_{3}\right)_{2} \mathrm{CO} \cdots \mathrm{H}_{2} \mathrm{O}$ & 52.20 & 0.52 & 17.30 & & \\
\hline
\end{tabular}

a Experimental polarizabilities are available only for the isolated molecules [42].

occurs, however, in the cases of formaldehyde ( $\mathrm{HCHO}$ ) and formic acid ( $\mathrm{HCOOH})$ upon complexation with water. In the first case, the variation in the depolarization of plane-polarized light $\left(\sigma_{p}\right)$ is $-38 \%$ upon binding the water molecule. Similarly, in the case of $\mathrm{HCOOH}$ this variation is $-27 \%$ upon hydrogen bond formation. On the other hand, this variation increases to $18 \%$ for $\mathrm{CH}_{3} \mathrm{HO} \cdots \mathrm{H}_{2} \mathrm{O}, 22 \%$ for $\left(\mathrm{CH}_{3}\right)_{2} \mathrm{CO} \cdots \mathrm{H}_{2} \mathrm{O}$, and only $6.4 \%$ for $\mathrm{CH}_{3} \mathrm{CN} \cdots \mathrm{H}_{2} \mathrm{O}$. For the case of the water dimer, $\sigma_{p}$ more than doubles, that is, increases from $0.17 \times 10^{-2}$ to $0.46 \times 10^{-2}$. A similar behaviour is also observed for the natural and circularly polarized light, as shown in table 2. It is interesting to observe that all components of depolarization for the water dimer and $\mathrm{CH}_{3} \mathrm{HO} \cdots \mathrm{H}_{2} \mathrm{O}$ complex give essentially the same values. For instance, the depolarization ratio for circularly polarized light $\left(\sigma_{c}\right)$ is computed as $0.46 \times 10^{-2}$ for $\left(\mathrm{H}_{2} \mathrm{O}\right)_{2}$ and only $0.47 \times 10^{-2}$ for $\mathrm{CH}_{3} \mathrm{HO} \cdots \mathrm{H}_{2} \mathrm{O}$. These values are very close, because the basic difference between the two hydrogen bonded clusters, $\mathrm{XOH} \cdots \mathrm{H}_{2} \mathrm{O}$, is just the substituent group $\mathrm{X}=\mathrm{H}$ or $\mathrm{CH}_{3}$ in the geometric structure. Thus, it is difficult to distinguish between the two complexes just by using depolarized Rayleigh scattering. As we will discuss later, the two heterodimers of methanol and water give the same degree of depolarization as the water dimer. Complementary determinations of other properties are necessary to distinguish between the different complexes.

In table 3 we give the calculated Rayleigh intensities for the hydrogen bonded complexes for all of the components of light. The increase factors with respect to the isolated molecules are also given. For instance, the Rayleigh intensity for natural light in the case of the formaldehydewater complex, $\mathfrak{A}_{n}\left(\mathrm{HCHO} \cdots \mathrm{H}_{2} \mathrm{O}\right)$, is calculated as $3.420 \times 10^{4}$ au. This represents a factor of 2.3 compared to the same intensity for the isolated HCHO formaldehyde molecule (calculated as $1.487 \times 10^{4} \mathrm{au}$ ). As can be seen, the formation of the hydrogen bond leads to a considerable increase in the Rayleigh intensity. As table 3 shows, this increase occurs for all polarizations. Typically the increase factor is close to 2.0 , but in the case of the water dimer it is even larger. The variations of $\Re_{n}$ and $\Re_{p \perp}$ reflect the strong dependence of the Rayleigh activity on the polarizability and the smaller contribution from the anisotropy. For isolated $\mathrm{H}_{2} \mathrm{O}$ the intensity is calculated as $3.907 \times 10^{4}$ au, whereas for the smallest complex considered here, the dimer $\left(\mathrm{H}_{2} \mathrm{O}\right)_{2}$, it is $1.658 \times 10^{4} \mathrm{au}$, corresponding to an increase factor of 4.2 and an absolute increase of $1.267 \times 10^{4}$ au for natural light. For acetone-water, the largest complex considered here, the corresponding increase factor is 1.5 with an absolute increase 
Table 2. Depolarization ratios for different types of incident light, calculated in terms of the polarizabilities and polarizability anisotropies. All values are obtained at the MP2/aug-cc-pVDZ level.

\begin{tabular}{llll}
\hline System & $\sigma_{n}\left(\times 10^{-2}\right)$ & $\sigma_{p}\left(\times 10^{-2}\right)$ & $\sigma_{c}\left(\times 10^{-2}\right)$ \\
\hline $\mathrm{H}_{2} \mathrm{O}$ & 0.17 & 0.08 & 0.17 \\
$\mathrm{H}_{2} \mathrm{O} \cdots \mathrm{H}_{2} \mathrm{O}$ & 0.46 & 0.23 & 0.46 \\
$\mathrm{HCHO}$ & 3.05 & 1.55 & 3.15 \\
$\mathrm{HCHO} \cdots \mathrm{H}_{2} \mathrm{O}$ & 1.90 & 0.96 & 1.94 \\
$\mathrm{CH}_{3} \mathrm{OH}$ & 0.34 & 0.17 & 0.34 \\
$\mathrm{CH}_{3} \mathrm{HO} \cdots \mathrm{H}_{2} \mathrm{O}$ & 0.47 & 0.24 & 0.47 \\
$\mathrm{HCOOH}$ & 2.87 & 1.46 & 2.95 \\
$\mathrm{HCOOH} \cdots \mathrm{H}_{2} \mathrm{O}$ & 2.10 & 1.06 & 2.14 \\
$\mathrm{CH}_{3} \mathrm{CN}$ & 3.61 & 1.84 & 3.74 \\
$\mathrm{CH}_{3} \mathrm{CN} \cdots \mathrm{H}_{2} \mathrm{O}$ & 3.84 & 1.96 & 3.99 \\
$\left(\mathrm{CH}_{3}\right)_{2} \mathrm{CO}$ & 1.12 & 0.56 & 1.13 \\
$\left(\mathrm{CH}_{3}\right)_{2} \mathrm{CO} \cdots \mathrm{H}_{2} \mathrm{O}$ & 1.44 & 0.72 & 1.46 \\
\hline
\end{tabular}

Table 3. Rayleigh intensities (in $10^{4}$ au) calculated in terms of the polarizabilities and polarizability anisotropies. Values in parentheses correspond to the increase factor of the intensity upon complexation with water. All values are computed at the MP2/aug-cc-pVDZ level.

\begin{tabular}{lrrl}
\hline System & \multicolumn{1}{l}{$\Re_{n}$} & $\Re_{p \perp}$ & $\Re_{p \|}$ \\
\hline $\mathrm{H}_{2} \mathrm{O} \cdots \mathrm{H}_{2} \mathrm{O}$ & $1.658(4.24)$ & $1.650(4.23)$ & $0.008(11.73)$ \\
$\mathrm{HCHO} \cdots \mathrm{H}_{2} \mathrm{O}$ & $3.420(2.30)$ & $3.357(2.33)$ & $0.064(1.45)$ \\
$\mathrm{CH}_{3} \mathrm{HO} \cdots \mathrm{H}_{2} \mathrm{O}$ & $4.424(2.17)$ & $4.403(2.16)$ & $0.021(3.03)$ \\
$\mathrm{HCOOH} \cdots \mathrm{H}_{2} \mathrm{O}$ & $4.868(2.00)$ & $4.767(2.02)$ & $0.100(1.47)$ \\
$\mathrm{CH}_{3} \mathrm{CN} \cdots \mathrm{H}_{2} \mathrm{O}$ & $7.700(1.83)$ & $7.415(1.82)$ & $0.284(1.94)$ \\
$\left(\mathrm{CH}_{3}\right)_{2} \mathrm{CO} \cdots \mathrm{H}_{2} \mathrm{O}$ & $12.652(1.53)$ & $12.472(1.52)$ & $0.180(1.95)$ \\
\hline
\end{tabular}

of $4.372 \times 10^{4}$ au. The percentage increase presents an opposite behaviour to the size of the hydrogen bonded clusters. While the differences in Rayleigh light scattered intensities upon dimerization of water correspond to $76 \%$ of the total intensity of the dimer, the complex formation of acetone $\left(\left(\mathrm{CH}_{3}\right)_{2} \mathrm{CO}\right)$ with water gives only $35 \%$. Indeed, for the case of the water molecule, its polarizability becomes more than twice the original value for one molecule because of dimerization, whereas for acetone-water complexation, this increase amounts to only $23 \%$. As regards $9 \hat{l}_{p \|}$, this is given entirely by the anisotropic polarizability, $6(\Delta \alpha)^{2}$. The water dimer is the most anisotropic complex, thus giving a relative variation in $\Re_{p \|}$ of $92 \%$, while $\mathrm{HCHO} \cdots \mathrm{H}_{2} \mathrm{O}$-and $\mathrm{HCOOH} \cdots \mathrm{H}_{2} \mathrm{O}$-give only $31 \%(32 \%)$.

\subsection{Rayleigh light scattering of isomers}

The spectroscopic characterization of intermolecular isomers can effectively be carried out using ro-vibrational spectroscopy techniques. Indeed, upon hydrogen bond complex formation, the stretching modes shift their vibrational frequencies towards the low-energy band. In this section we investigate the Rayleigh light scattering properties for two groups of hydrogen bonded isomers: (i) $\mathrm{HCN} \cdots \mathrm{H}_{2} \mathrm{O}$ and $\mathrm{H}_{2} \mathrm{O} \cdots \mathrm{HCN}$ and (ii) $\mathrm{CH}_{3} \mathrm{HO} \cdots \mathrm{H}_{2} \mathrm{O}$ and $\mathrm{CH}_{3} \mathrm{OH} \cdots \mathrm{OH}_{2}$, where the water molecule acts as both proton donor and proton acceptor.

The MP2/aug-cc-pVDZ optimized geometries of the two possible heterodimers, hydrogen cyanide-water and methanol-water, are given schematically in figure 2 . In a previous work, we calculated the stability of the hydrogen cyanide-water isomers using CCSD(T)//MP2/6- 
Table 4. Calculated mean polarizabilities and polarizability anisotropies (in au), and Rayleigh depolarization ratios. All values are computed at the MP2/aug-cc-pVDZ level.

\begin{tabular}{llrlll}
\hline Isomers & $\bar{\alpha}$ & $\Delta \alpha$ & $\sigma_{n}\left(\times 10^{-2}\right)$ & $\sigma_{p}\left(\times 10^{-2}\right)$ & $\sigma_{c}\left(\times 10^{-2}\right)$ \\
\hline $\mathrm{H}_{2} \mathrm{O} \cdots \mathrm{HCN}$ & 26.74 & 13.74 & 3.38 & 1.72 & 3.49 \\
$\mathrm{HCN} \cdots \mathrm{H}_{2} \mathrm{O}$ & 22.60 & 15.37 & 5.75 & 2.96 & 6.10 \\
$\mathrm{CH}_{3} \mathrm{HO} \cdots \mathrm{H}_{2} \mathrm{O}$ & 31.19 & 5.90 & 0.47 & 0.24 & 0.47 \\
$\mathrm{CH}_{3} \mathrm{OH} \cdots \mathrm{OH}_{2}$ & 30.67 & 5.25 & 0.40 & 0.20 & 0.40 \\
\hline
\end{tabular}

Table 5. Rayleigh intensities (in $10^{4}$ au) calculated in terms of the polarizabilities and polarizability anisotropies. Values in parentheses correspond to the increase factor of the intensity upon complexation with water. All values are computed at the MP2/aug-cc-pVDZ level. $I_{A}, I_{B}$, and $I_{C}$ are the calculated rotational constants given in $\mathrm{GHz}$.

\begin{tabular}{lllllll}
\hline Isomer & $\mathfrak{M}_{n}$ & $\mathfrak{N}_{p \perp}$ & $\mathfrak{S}_{\rho \|}$ & \multicolumn{1}{l}{$I_{A}$} & \multicolumn{1}{l}{$I_{B}$} & \multicolumn{1}{l}{$I_{C}$} \\
\hline $\mathrm{H}_{2} \mathrm{O} \cdots \mathrm{HCN}$ & $3.463(2.51)$ & $3.350(2.52)$ & $0.113(2.35)$ & 429.98 & 3.04 & 3.01 \\
$\mathrm{HCN} \cdots \mathrm{H}_{2} \mathrm{O}$ & $2.606(1.89)$ & $2.464(1.85)$ & $0.142(2.95)$ & 476.62 & 3.25 & 3.23 \\
$\mathrm{CH}_{3} \mathrm{HO} \cdots \mathrm{H}_{2} \mathrm{O}$ & $4.424(2.17)$ & $4.403(2.16)$ & $0.021(3.03)$ & 24.92 & 4.62 & 4.05 \\
$\mathrm{CH}_{3} \mathrm{OH} \cdots \mathrm{OH}_{2}$ & $4.269(2.09)$ & $4.252(2.09)$ & $0.016(2.39)$ & 31.96 & 3.80 & 3.23 \\
\hline
\end{tabular}

$311++\mathrm{G}(\mathrm{d}, \mathrm{p})$ [45]. For $\mathrm{H}_{2} \mathrm{O} \cdots \mathrm{HCN}$ the binding energy has been obtained as $5.17 \mathrm{kcal} \mathrm{mol}^{-1}$, whereas for $\mathrm{HCN} \cdots \mathrm{H}_{2} \mathrm{O}$ the binding energy is found to be $3.38 \mathrm{kcal} \mathrm{mol}^{-1}$, that is, $1.8 \mathrm{kcal} \mathrm{mol}^{-1}$ smaller than for the first isomer. The existence of these isomers has also been detected by photolysis of formaldoxime [46]. In the case of the methanol-water isomers, both experimental techniques [47-49] and theoretical calculations [50] have predicted the existence of two stable heterodimers (figure 2). In this case, the $\mathrm{CH}_{3} \mathrm{HO} \cdots \mathrm{H}_{2} \mathrm{O}$ complex is found to be more stable than the $\mathrm{CH}_{3} \mathrm{OH} \ldots \mathrm{OH}_{2}$ isomer by an estimated amount less than $1 \mathrm{kcal} \mathrm{mol}^{-1}$, or $0.7 \mathrm{kcal} \mathrm{mol}^{-1}$ using the hybrid density-functional theory B3LYP/6-311+G(3df, 2p) [50]. Here we find that $\mathrm{CH}_{3} \mathrm{HO} \cdots \mathrm{H}_{2} \mathrm{O}$ is more stable by $0.8 \mathrm{kcal} \mathrm{mol}^{-1}$. In the theoretical study of these heterodimers by González et al [50], they obtained a hydrogen bond distance $(\mathrm{O} \cdots \mathrm{H})$ in the case of $\mathrm{CH}_{3} \mathrm{HO} \cdots \mathrm{H}_{2} \mathrm{O}$ of $1.890 \AA$, and in the case of $\mathrm{CH}_{3} \mathrm{OH} \cdots \mathrm{OH}_{2}$ their value is $1.937 \AA$. These results compare favourably with our corresponding results of 1.904 and $1.942 \AA$, although our distances are slightly longer-by 0.014 and $0.005 \AA$, respectively. Our calculated Rayleigh scattering properties corresponding to these two groups of hydrogen bonded isomers are presented in tables 4 and 5 .

As can be seen in table 4 , although the polarizabilities and polarizability anisotropies of the hydrogen cyanide-water isomers are rather similar, the depolarization components of $\mathrm{HCN} \cdots \mathrm{H}_{2} \mathrm{O}$ differ from those of $\mathrm{H}_{2} \mathrm{O} \cdots \mathrm{HCN}$ by a factor of 1.7 . However, this finding is not verified for the methanol-water isomers, for which the polarizabilities, anisotropies, and all components of the depolarization ratios have similar values. The variations in Rayleigh activities of the two groups of isomers are given in table 5. Again, the observed effect for $\Re_{n}$ and $\Re_{p \perp \perp}$ is strongly dominated by the $(\bar{\alpha})^{2}$ term, with a smaller contribution from the $(\Delta \alpha)^{2}$ term, whereas $\mathfrak{R}_{p \|}$ depends solely on the latter term. After complexation, these systems are of nearly-prolate rotor type, as indicated by the rotational constants $\left(I_{A}, I_{B}, I_{C}\right)$ in table 5 . These quantities are relevant for a millimetre wave description and have also been obtained previously, both theoretically [50] and experimentally [49]. In addition, the present accuracy might be useful in aiding possible detection of hydrogen bonded complexes [45]. 


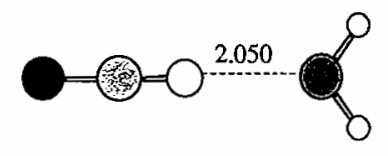

$\mathrm{H}_{2} \mathrm{O} \cdots \mathrm{HCN}$

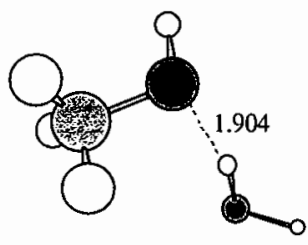

$\mathrm{CH}_{3} \mathrm{HO} \cdot \cdot \mathrm{H}_{2} \mathrm{O}$

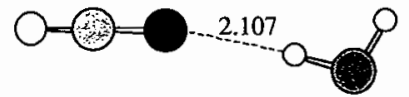

$\mathrm{HCN} \cdot \cdot \mathrm{H}_{2} \mathrm{O}$

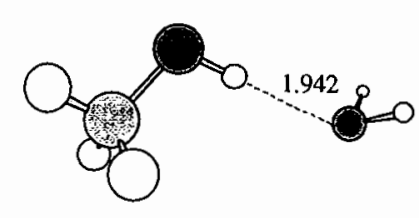

$\mathrm{CH}_{3} \mathrm{OH} \cdot \cdot \mathrm{OH}_{2}$

Figure 2. Structures of the $\mathrm{HCN}$-water and methanol-water complexes. The lengths of the $\mathrm{H}$ bonds are given in $\AA$, and were obtained at the MP2/aug-cc-pVDZ level.

\section{Summary}

A classical light scattering investigation has been made to analyse small hydrogen bonded clusters. Using $a b$ initio calculations at the MP2/aug-cc-pVDZ level, full-geometry optimizations for different water complexes $\left(\mathrm{H}_{2} \mathrm{O} \cdots \mathrm{H}_{2} \mathrm{O}, \mathrm{HCHO} \cdots \mathrm{H}_{2} \mathrm{O}, \mathrm{CH}_{3} \mathrm{HO} \cdots \mathrm{H}_{2} \mathrm{O}\right.$, $\mathrm{HCOOH} \cdots \mathrm{H}_{2} \mathrm{O}, \mathrm{CH}_{3} \mathrm{CN} \cdots \mathrm{H}_{2} \mathrm{O}$, and $\left.\left(\mathrm{CH}_{3}\right)_{2} \mathrm{CO} \cdots \mathrm{H}_{2} \mathrm{O}\right)$ have been performed. The dipole polarizabilities and polarizability anisotropies have been calculated for the separate molecules and the complexes. From these calculations, Rayleigh light scattering properties have been determined and compared, to analyse the changes upon hydrogen bond formation. The Rayleigh intensity is considerably increased by a factor of nearly two in most cases, with the exception of those of $\left(\mathrm{CH}_{3}\right)_{2} \mathrm{CO} \cdots \mathrm{H}_{2} \mathrm{O}$ and $\left(\mathrm{H}_{2} \mathrm{O}\right)_{2}$. Different degrees of polarization have been considered (i.e., natural, plane-polarized, and circularly polarized light) to analyse the depolarization ratios. To assess depolarized Rayleigh scattering as a possible means of identifying intermolecular isomers, we have investigated the interaction between hydrogen cyanide $(\mathrm{HCN})$ and water as well as methanol $\left(\mathrm{CH}_{3} \mathrm{OH}\right)$ and water. Possible detections of these clusters have recently been of great interest in physical chemistry [46-49]. In the case of $\mathrm{HCN}$ the different isomers respond differently to light scattering, but in the case of methanol the distinction between the isomers is more difficult to discern in the scattering activity and in the depolarization.

\section{References}

[1] Fabellinskii I L 1968 Molecular Scattering of Light (New York: Plenum)

[2] Raman C V 1930 The Molecular Scattering of Light (Nobel Lectures) (Amsterdam: Elsevier) p 267

[3] Buckingham A D 1967 Adv. Chem. Phys. 12107

[4] Couling V W, Halliburton B W, Keir R I and Ritchie G L D 2001 J. Phys. Chem. A 1054365

[5] Wilson E B Jr, Decius J C and Cross P C 1980 Molecular Vibrations: the Theory of Infrared and Raman Vibrational Spectra (New York: Dover)

[6] Bush A M, Bell A J and Frey J G 1998 J. Phys. Chem. 1026457 
[7] Bell A J, Mestdagh J M, Berlande J, Biquard X, Cuvellier J, Lallement A, Meynadier P, Sublemontier O and Visticot J-P 1993 J. Phys. D: Appl. Phys. 26994

[8] Teragishi Y and Aoki K 1999 J. Electroanal. Chem. 473132

[9] Meulenbroeks R F G, Schram D C, Jaegers L J M and van de Sanden M C M 1992 Phys. Rev. Letu. 691379

[10] Park H S, Oh K S, Kim K S, Chang T and Spiegel D R 1999 J. Phys. Chem. B 1032355

[11] Micali N, Trusso S and Vasi C 1996 Phys. Rev. E 541720

[12] Buckingham A D, Fowler P W and Hutson J M 1988 Chem. Rev. 88827

[13] Curtiss L A and Pople J A 1975 J. Mol. Spectrosc. 551

[14] Diercksen G H F, Kraemer W P and Roos B O 1975 Theor. Chim. Acta 21249

[15] Frisch M J, Pople J A and del Bene JE 1985 J. Phys. Chem. 893664

[16] Dykstra C E 1989 J. Chem. Phys. 916472

[17] Xantheas S S and Dunning T H Jr 1993 J. Chem. Phys. 988774

[18] Feyereisen M W, Feller D and Dixon D A 1996 J. Phys. Chem. 1002993

[19] Engdahl A and Nelander B 1987 J. Chem. Phys. 864831

[20] Liu K, Cruzan J D and Saykaily R 1996 Science 271929

[21] Maroulis G 2001 J. Phys. B: At. Mol. Opt. Phys. 343727

[22] Bonin K D and Kresin V V 1997 Electric-Dipole Polarisabilities of Atoms, Molecules and Clusters (London: World Scientific)

[23] Dixit S, Crain J, Poon W C K, Finney J L and Soper A K 2002 Nature 416829

[24] Herzberg G 1945 Infrared and Raman Spectra of Polyatomic Molecules (Princeton, NJ: Van Nostrand-Reinhold)

[25] Castro M A and Canuto S 1993 J. Phys. B: At. Mol. Opt. Phys. 264301

[26] Cernusak 1, Diercksen G H F and Sadlej A J 1986 Phys. Rev. A 33814

[27] Cohen H D and Roothaan C C J 1965 J. Chem. Phys. 43S 34

[28] Diercksen G HF and Sadlej A J 1988 Chem. Phys. Lett. 15393

[29] Bartlett R J 1989 J. Phys. Chem. 931697

[30] Dunning T H Jr 1989 J. Chem. Phys. 901007

[31] Lovas F J 1978 J. Chem. Ref. Data 71445

[32] Frisch M J et al 1998 GAUSSIAN 98 (Revision A7) (Pittsburgh, PA: Gaussian Inc.)

[33] Schütz M, Brdarski S, Widmark P O, Lindh R and Karlström G 1997 J. Chem. Phys. 1074597

[34] Xantheas S S 1996 J. Chem. Phys. 1048821

[35] Maroulis G $2000 \mathrm{~J}$. Chem. Phys. 1131813

[36] Tsuzuki S, Uchimaru T, Matsumura K, Mikami M and Tanabe K 1999 J. Chem. Phys. 11011906

[37] Odutola J A and Dyke T R 1980 J. Chem. Phys. 725062

[38] Kirschner K N and Woods R J 2001 J. Phys. Chem. A 1054150

[39] Wei D, Truchon J-F, Sirois S and Salahub D 2002 J. Chem. Phys. 1166028

[40] Rivelino R, Ludwig V, Rissi E and Canuto S 2002 J. Mol. Struct. 615259

[41] Coutinho K, Saavedra N and Canuto S 1999 J. Mol. Struct. 46669

[42] Lide R (ed) 1992 Handbook of Chemistry and Physics 73rd edn (Boca Raton, FL: Chemical Rubber Company Press)

[43] Zhou T and Dykstra C E 2001 J. Physique A 1042204

[44] Nakagawa S 1997 Chem. Phys. Lett. 278272

[45] Rivelino R and Canuto S 2000 Chem. Phys. Lett. 322207

[46] Heikkilä A, Pettersson M, Lundell J, Khriachtchev L and Räsänen M 1999 J. Phys. Chem. A 1032945

[47] Huisken F and StemmIer M 1991 Chem. Phys. Lett. 180355

[48] Bakkas N, Bouteiller Y, Louteiller A, Perchard J P and Racine S 1993 J. Chem. Phys. 993335

Bakkas N, Bouteiller Y, Louteiller A, Perchard J P and Racine S 1995 Chem. Phys. Lett. 23290

[49] Stockman P A, Blake G A, Lovas F J and Suenran R D 1997 J. Chem. Phys. 1073782

[50] González L, Mó O and Yáñez M 1998 J. Chem. Phys. 109139 


\title{
An $a b$ Initio NMR Study of the Isomeric Hydrogen Bonded Methanol-Water Complexes
}

\author{
Eudes E. Fileti and Sylvio Canuto") \\ Instituto de Física, Universidade de São Paulo, CP 66318, 05315-970, São Paulo, SP, Brazil.
}

\begin{abstract}
:
Isotropic and anisotropic chemical shifts for all atoms of the complexes $\mathrm{CH}_{3} \mathrm{HO} \cdots \cdot \mathrm{H}_{2} \mathrm{O}$ and $\mathrm{CH}_{3} \mathrm{OH} \cdots \mathrm{OH}_{2}$ have been calculated at the Hartree-Fock, second-order Møller-Plesset (MP2) and density-functional (B3LYP) theoretical levels using the $6-311++\mathrm{G}(2 \mathrm{~d}, 2 \mathrm{p})$ basis set. The influence of the hydrogen bond formation on the nuclear-magnetic-resonance chemical shifts in all atoms is analyzed. The basis set superposition error was taken into account and its effects were more significant for the anisotropic shieldings on the oxygen atoms of the proton donor $\mathrm{CH}_{3} \mathrm{OH} \cdots \mathrm{OH}_{2}$ and proton acceptor methanol $\mathrm{CH}_{3} \mathrm{HO} \cdot \bullet \mathrm{H}_{2} \mathrm{O}$. Using counterpoise correction to the MP2 results our best estimate for the calculated isotropic and anisotropic shifts of the $\mathrm{H}$ atom involved in the hydrogen bond are -2.98 and $11.95 \mathrm{ppm}$ for $\mathrm{CH}_{3} \mathrm{HO} \cdot \cdot \cdot \mathrm{H}_{2} \mathrm{O}$ and -2.91 and $11.48 \mathrm{ppm}$ for the $\mathrm{CH}_{3} \mathrm{OH} \cdots \mathrm{OH}_{2}$ isomer, respectively. For the $\mathrm{O}$ atom of the $\mathrm{OH}$ hydrogen bonded these calculated shifts are -5.21 and -5.35 ppm for $\mathrm{CH}_{3} \mathrm{HO} \cdot \bullet \mathrm{H}_{2} \mathrm{O}$ and -6.32 and $-8.75 \mathrm{ppm}$ for $\mathrm{CH}_{3} \mathrm{OH} \cdots \mathrm{OH}_{2}$. The effect of monomer relaxation was also considered and found to be appreciable only for the oxygen atom of the proton donor $\mathrm{OH}$ due to the distance increase after complex formation.
\end{abstract}

\section{Introduction}

Water-alcohol mixtures exhibit anomalous behavior compared with the properties of the pure components. When alcohol and water are mixed the entropy of the mixture increases less than expected. This effect was first pointed out by Frank and Evans [1] and explained in terms of a hydrophobic interaction with the nonpolar alcohol headgroups, which induces an ice-like structure in the surrounding water. There is an extensive literature on this topic [2-12]. Spectroscopic studies [2-9] and computer simulations [8,10-12] have been performed to study the structure of water-alcohol mixtures. Early neutron diffraction studies provided structural information about water cages around hydrophobic headgroups in solution [2,5]. More recently a neutron diffraction study demonstrated

*) Corresponding author. E-mail: canuto@if.usp.br, Fax:+55.11.3091-6831. 
that incomplete mixing at the molecular level is essential to explain the "smaller than expected" entropy increase observed when methanol dissolves in water [8]. A recent study of $\mathrm{x}$-ray emission spectroscopy provided a description of the details of the incomplete mixture at the molecular level [9].

An important aspect that is crucial to the interpretation of the alcohol-water structure is the network of hydrogen bonds that is formed. To rationalize the local structure of the incomplete mixture at the molecular level it is important to understand this molecular interaction. Thus, the study of the hydrogen-bonded complexes of alcohol-water mixtures can be important to characterize this local structure even in the cluster situation. Beyond this specific aspect, methanol-water complexes are good models to understand the behavior of the hydrogen bond $(\mathrm{O}-\mathrm{H} \cdots \mathrm{O})$, because like water, methanol is both proton acceptor $\left(\mathrm{CH}_{3} \mathrm{HO} \cdots \mathrm{H}_{2} \mathrm{O}\right)$ and proton donor $\left(\mathrm{CH}_{3} \mathrm{OH} \cdots \mathrm{OH}_{2}\right)$. It has recently been established that these two methanol-water complexes have equivalent binding energies [13-15] even in the liquid case [16].

An important spectroscopic technique that has been employed in hydrogen bond investigation is the nuclear magnetic resonance (NMR). However, there are only few NMR studies of alcohol-water. In an experimental work Ludwig has studied the NMR relaxation in alcohol-water mixtures [17], showing that the reorientational correlation time and the quadrupole coupling constants of water are very sensitive on the concentration of solute. In another work, the behavior of hydrogen bond with temperature has been analyzed by $a b$ initio calculations of liquid alcohols [18]. The magnetic properties such as the isotropic and anisotropic chemical shifts have been used to detect and characterize hydrogen bonds. These applications began about fifty years ago with experiments on the effects of temperature and solvent on the $\mathrm{OH}$ proton chemical shift of ethanol [19]. Many researchers have determined the proton chemical shift in liquid and gas phases for several hydrogenbonded systems such as hydrides [20], alcohols [21], phenols [22], carboxylic acids [22], peptides [23], amides and proteins $[24,25]$. In a study on water, Ditchfield observed that the proton anisotropic chemical shielding was more sensitive to the presence of hydrogen bond than the isotropic chemical shielding value [26-28]. In other studies Ditchfield et al $[29,30]$, pointed out that the components of the chemical shielding tensor, in the proton donor that are perpendicular to the hydrogen bond axis, are more sensitive to the formation of a hydrogen bond than the parallel component. Many theoretical studies have been published from then on and showed their reliability in understanding experimental data. Hinton and Wolinski [31] reviewed the main applications of $a b$ initio calculations on systems that present hydrogen bonds.

Hydrogen bond of methanol-water complexes are studied in this paper using ab initio calculated NMR parameters. A description of the chemical environment of each nucleus of the complexes is given to verify the relative effects on the nucleus that participates in the hydrogen bond. For this, the isotropic $\left(\delta^{\text {iso }}\right)$ and anisotropic $\left(\delta^{a n i s}\right)$ chemical shifts are analyzed as well as the parallel $\left(\delta_{/ \prime}\right)$ and perpendicular $\left(\delta_{\perp}\right)$ components of the chemical shift tensor in relation to the hydrogen bond axis. 


\section{Calculation Details}

The second-order Møller-Plesset (MP2) has proven to be a good theoretical model to study hydrogen-bonded clusters. The MP2 approach is known to provide molecular geometries with accuracy and reliability [32] and thus MP2/6-311+ $\mathrm{G}(2 \mathrm{~d}, 2 \mathrm{p})$ calculations were performed to obtain the geometries of the complexes $\mathrm{CH}_{3} \mathrm{HO} \cdots \mathrm{H}_{2} \mathrm{O}$ and $\mathrm{CH}_{3} \mathrm{OH} \cdots \mathrm{OH}_{2}$ as well as the isolated species (monomers) $\mathrm{CH}_{3} \mathrm{OH}$ and $\mathrm{H}_{2} \mathrm{O}$.

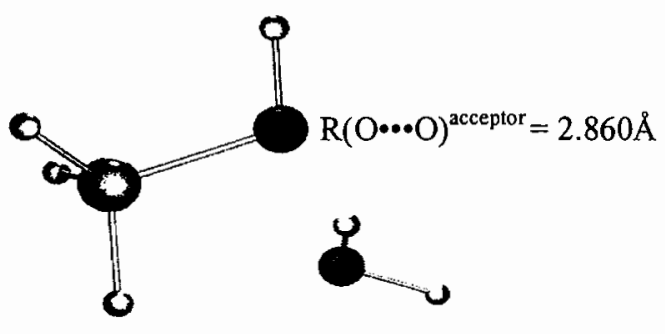

a) $\mathrm{CH}_{3} \mathrm{HO} \cdots \mathrm{H}_{2} \mathrm{O}$

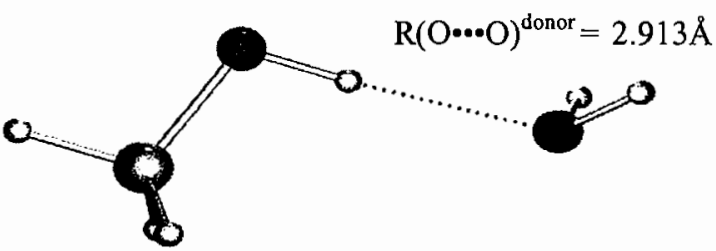

b) $\mathrm{CH}_{3} \mathrm{OH} \cdots \mathrm{OH}_{2}$

FIGURE 1: The MP2/6-311++G(2d,2p) optimized methanol-water complexes used in the NMR calculations and the $R_{O O}$ distance. In a) we have methanol as the proton acceptor and in $\mathrm{b}$ ) the methanol as proton donor.

Figures $1 \mathrm{a}$ and $1 \mathrm{~b}$ show the optimized complexes where the methanol molecule is the proton acceptor and the proton donor, respectively. NMR constants were calculated for these complexes and the monomers from three different theoretical models using the gauge-including atomic orbital method (GIAO) [26-28]. First, we use the GIAO/Hartree-Fock self-consistent-field (SCF) [33] method and electron correlation effects are obtained next using the second-order GIAO/MP2 level [34,35]. For comparison, density-functional-theory (GIAO/DFT) [3638] was also used in the three-parameter exchange correlation functional of Becke-Lee-Yang and Parr (B3LYP). The use of these three theoretical levels aim at establishing the relative importance of electron correlation effects on the calculated NMR shieldings. In all cases the extended $6-311++\mathrm{G}(2 \mathrm{~d}, 2 \mathrm{p})$ basis set was used since it has been demonstrated that basis sets at least as large as the $6-311++G(d, p)$ is needed to provide agreement with experiment $[39,40]$. The basis set superposition error (BSSE) was corrected, using the counterpoise correction [41]. This was carried out for each complex by calculating the chemical shielding of the monomer in the presence of the basis functions of the complex. The effect of monomer relaxation was also considered. It was obtained as the difference between the shielding in the geometry of the complex and the shielding in the geometry of the monomer. All calculations were carried out with the Gaussian 98 package [42].

\section{Results and Discussion}

\subsection{The absolute chemical shieldings}


The optimized geometries calculated for both complexes are in good agreement with other previous theoretical and experimental results. The $\mathrm{O} \cdots \mathrm{O}$ distances for the complexes where the methanol molecule is the proton acceptor and proton acceptor are calculated as $2.860 \AA$ and $2.913 \AA$, respectively. An early theoretical study by Kirschner and Woods found the results of $2.845 \AA$ and $2.912 \AA$, respectively, in good agreement with our results [43].

TABLE I: Values of the isotropic and anisotropic chemical shieldings of methanol and water (in ppm) using three theoretical levels. In the fourth column we present the experimental results for the isotropic shielding and other theoretical results for the anisotropic shielding.

\begin{tabular}{|c|c|c|c|c|}
\hline \multicolumn{5}{|c|}{ Isotropic Chemical Shielding $\left(\sigma^{\text {iso }}\right)$} \\
\hline $\mathrm{CH}_{3} \mathrm{OH}$ & SCF & B3LYP & MP2 & Exp \\
\hline $\mathrm{o}$ & 337.77 & 321.65 & 350.47 & $345.9^{\mathrm{a}}$ \\
\hline $\mathrm{C}$ & 145.52 & 130.22 & 144.37 & $136.6^{\mathrm{b}}$ \\
\hline $\mathrm{H}$ & 28.88 & 28.21 & 28.27 & $27.34^{c}$ \\
\hline $\mathrm{H}$ & 28.88 & 28.21 & 28.27 & $27.34^{\mathrm{c}}$ \\
\hline $\mathrm{H}$ & 28.90 & 28.43 & 28.42 & $27.34^{\mathrm{c}}$ \\
\hline $\mathrm{H}_{\circ}$ & 31.98 & 32.33 & 31.99 & $30.73^{\mathrm{c}}$ \\
\hline \multicolumn{5}{|l|}{$\mathrm{H}_{2} \mathrm{O}$} \\
\hline $\mathrm{H}$ & 30.86 & 31.45 & 30.99 & $30.09^{c}, 30.05^{i}$ \\
\hline $\mathrm{O}$ & 327.08 & 326.36 & 344.78 & $344.0^{\mathrm{d}}, 323.6^{\mathrm{h}}$ \\
\hline $\mathrm{H}$ & 30.86 & 31.45 & 30.99 & $30.09^{c}, 30.05^{i}$ \\
\hline \multicolumn{5}{|c|}{ Anisotropic Chemical Shielding $\left(\sigma^{\text {anis }}\right)$} \\
\hline & SCF & B3LYP & MP2 & Others \\
\hline $\mathrm{O}$ & 97.57 & 95.90 & 90.96 & $96.9^{\mathrm{e}}$ \\
\hline $\mathrm{C}$ & 67.92 & 80.54 & 77.97 & $63.8^{\mathrm{e}}$ \\
\hline H & 8.30 & 8.26 & 8.61 & $7.83^{f}$ \\
\hline $\mathrm{H}$ & 8.30 & 8.26 & 8.61 & $7.83^{\mathrm{f}}$ \\
\hline $\mathrm{H}$ & 7.76 & 7.28 & 7.68 & $7.63^{f}$ \\
\hline $\mathrm{H}_{\mathrm{o}}$ & 20.40 & 18.11 & 19.72 & - \\
\hline \multicolumn{5}{|l|}{$\mathrm{H}_{2} \mathrm{O}$} \\
\hline $\mathrm{H}$ & 20.41 & 19.18 & 20.35 & $20.39^{\mathrm{g}}, 19.10^{\mathrm{j}}$ \\
\hline $\mathrm{O}$ & 56.49 & 54.05 & 46.03 & $46.05^{\mathrm{g}}, 46.97^{\mathrm{j}}$ \\
\hline $\mathrm{H}$ & 20.41 & 19.18 & 20.35 & $20.39^{\mathrm{g}}, 19.10^{\mathrm{j}}$ \\
\hline
\end{tabular}

a) Liquid phase data cited by Kitzinger converted to an absolute [55]; b) Ref. [56]; c) Ref. [57]; d) Ref. [58]; e) Ref. [44]; f) Calculated for methyl group in methylformate Ref. [48]; g) Ref. [51], h) Ref. [59], i) Ref. [60], j) Ref. [61]. 
The experimental result for the proton acceptor case has been inferred as $2.997 \pm 0.009 \AA$ [15] but this experimental value could not reproduced even at a very high level of calculation [43]. In Figure 1 we also show these distances for both complexes.

There are indications that for NMR properties of larger molecules it may be sufficient to carry out calculations at the DFT or even the SCF level $[26,39,44,45]$, but in general correlation effects are important [46]. In the calculations of the absolute chemical shielding it is important to include electron correlation effects in a more controllable manner than it is usually the case in molecular DFT calculations. Therefore all calculations are made at the MP2 level but the results are also given for the case of B3LYP and SCF, for comparison. The calculated absolute isotropic and chemical anisotropic shieldings for the isolated species, methanol and water, are shown in Table I. We report the values determined using the three theoretical methods considered here but in every case, the geometry used is that obtained at the MP2/6-311++G(2d,2p) level. All values for the isotropic shieldings are in relatively good agreement with the respective experimental result. We can observe that the MP2 results are in reasonable agreement with experiment for the isotropic shielding of all atoms in the methanol molecule. This result is improved in the case of water. Interesting, the electron correlation obtained at the B3LYP level has an opposite sign with respect to the MP2 results. For instance, the isotropic shielding for the $\mathrm{O}$ atom of methanol using B3LYP is smaller than the SCF value showing that electron correlation decreases this shielding. This is opposite to what has been obtained at the MP2 level where the electron correlation effects at the secondorder increase the shielding improving the theoretical result. Comparing the SCF and MP2 results for the isotropic shielding we can note that electron correlation effects increase the values of the isotropic shielding of the oxygen atom by ca. $13 \mathrm{ppm}$.

A proper comparison between MP2 and DFT requires reliable experimental results for reference. The experimental values of the isotropic chemical shielding of the oxygen atom of water has been established earlier [58] to be $344.0 \mathrm{ppm}$ in very good agreement with our MP2 result of $344.8 \mathrm{ppm}$, as seen in Table I. This would imply a poor performance of the B3LYP model. However, this value has been recently revisited [59] and the value of $323.6 \mathrm{ppm}$ has been suggested. This now reverses the agreement showing an excellent performance of the B3LYP model and an overestimation by the MP2. This final value for the oxygen atom of the water molecule is in line with current view that MP2 tends to overestimate isotropic shieldings [49-51]. However, attention is now paid to the vibration contribution, not accounted for in our calculations. Although this is not very important in the chemical shifts, because they tend to cancel, the present discussion refers to the absolute shielding. This vibration contribution has been estimated as $-12 \mathrm{ppm}$ for the oxygen chemical shielding of water $[52,53]$. If that is considered now, the MP2 result is again more realistic. The same reasoning seems to apply to the anisotropic shieldings. Recent theoretical values for water obtained by Helgaker and co-workers [61] using elaborated multiconfigurational calculations confirmed the value for the oxygen atom of the water molecule close to $46.97 \mathrm{ppm}$, in good agreement with our MP2 results, but suggested a value of $19.10 \mathrm{ppm}$ for the hydrogen atoms, now in better comparison with our B3LYP results.

For the methyl hydrogen atoms, as well as the carbon atom of the methanol molecule, the electron correlation effects decrease the isotropic shielding by a relatively mild value, ca. 0.5-1.0 ppm. For the anisotropic 
shielding (bottom of Table I) a more compatible picture emerges regarding the effects of electron correlation. In this case B3LYP and MP2 have the same trend with respect to the results at the SCF level. Again, this agreement is improved in the case of the water molecule. The theoretical results for the anisotropic shielding can only be compared to other previous theoretical results and overall there is good agreement. As noted before [44] the effects of electron correlation are more pronounced for the heavy atoms (oxygen and carbon, in this case). For water, the difference between the MP2 and the SCF results is $17.70 \mathrm{ppm}$ in the case of the isotropic shielding of the oxygen atom and $10.05 \mathrm{ppm}$ for the anisotropic shielding of the carbon atom. The previous methanol values $[44,48]$ shown in Table I for the anisotropic case were obtained at the SCF level and as it can be seen they are in better agreement with our SCF results. Electron correlation however makes a difference, for instance, decreasing the $O$ value (by $6.61 \mathrm{ppm}$ ) and increasing the $C$ value (by $10.05 \mathrm{ppm}$ ). A previous theoretical result for water using the MP2 method with all-electron correlation obtained [51] results in very good agreement with our present results (Table I) using the frozen core approximation, thus indicating that inner orbitals do not make a difference in these calculated NMR shieldings.

\subsection{The Mulliken charges and the charges rearrangement}

Upon formation of a hydrogen bond there is a charge rearrangement with a slight increase of the electron density in the proton acceptor site and a slight decrease in the hydrogen bonded proton. Normally there is also an increase of the electron density in the donor $O$ atom due to charge transfer and a loss of electron density in the hydrogen bonded proton. These charge rearrangements affect the chemical shifts and help understanding the calculated shifts that are discussed next. Of course charge densities are not true physical observables and the Mulliken population analysis suffer from basis set and other dependences. Thus, presenting these charge density results has the only interest in qualitatively compare charge rearrangements and chemical shifts.

TABLE II: Variation in the Mulliken atomic charge (in elementary units) on the atoms of $\mathrm{CH}_{3} \mathrm{HO} \cdots{ }^{\circ} \mathrm{H}_{2} \mathrm{O}$ and $\mathrm{CH}_{3} \mathrm{OH} \cdots \mathrm{OH}_{2}$ complexes.

\begin{tabular}{cccc}
\hline \hline & Monomers & \multicolumn{2}{c}{ Difference in the charge } \\
\hline $\mathrm{H}_{2} \mathrm{O}$ & & $\mathrm{CH}_{3} \mathrm{OH} \cdots \mathrm{OH}_{2}$ & $\mathrm{CH}_{3} \mathrm{HO} \cdots \mathrm{H}_{2} \mathrm{O}$ \\
$\mathrm{H}$ & 0.24 & 0.02 & 0.07 \\
$\mathrm{O}$ & -0.48 & -0.05 & -0.07 \\
$\mathrm{H}$ & 0.24 & 0.02 & 0.00 \\
$\mathrm{CH}_{3} \mathrm{OH}$ & & & \\
$\mathrm{O}$ & -0.48 & -0.09 & -0.05 \\
$\mathrm{C}$ & 0.13 & 0.00 & -0.01 \\
$\mathrm{H}$ & 0.03 & 0.00 & 0.01 \\
$\mathrm{H}$ & 0.03 & 0.00 & 0.02 \\
$\mathrm{H}$ & 0.05 & -0.01 & 0.01 \\
$\mathrm{H}$ & 0.24 & 0.11 & 0.02 \\
\hline \hline
\end{tabular}


Table II thus presents the Mulliken charge density on the atoms of the monomers and the variation of these charges upon complexation. We can observe that the $\mathrm{O}$ atom as a bond acceptor accumulates a charge of the $0.05 e$ in both water and methanol molecules, whereas in the hydrogen bonded proton there is a decrease of charge of $0.07 e$ and an increase of $0.11 e$ in the water and methanol molecules respectively. At the $\mathrm{O}$ atom of the $\mathrm{OH}$ proton donor, the increase of electron density is $-0.09 e$ and $-0.07 e$, for the methanol and water molecules, respectively.

\subsection{The chemical shifts}

The isotropic and anisotropic chemical shifts for atom $X$ are calculated as

$$
\delta(X)^{i s o}=\sigma(X)_{\text {cluster }}^{i s o}-\sigma(\mathrm{X})_{\text {monomer }}^{\text {iso }}
$$

and

$$
\delta(X)^{\text {anis }}=\sigma(X)_{\text {cluster }}^{\text {anis }}-\sigma(X)_{\text {monomer }}^{\text {anis }}
$$

where the isotropic shielding is obtained as

$$
\sigma^{i s o}=\frac{1}{3}\left(\sigma_{11}+\sigma_{22}+\sigma_{33}\right)
$$

and the isotropic shielding as

$$
\sigma^{\text {anis }}=\sigma_{33}-\frac{1}{2}\left(\sigma_{11}+\sigma_{22}\right) \text { with } \sigma_{11}<\sigma_{22}<\sigma_{33} \text {. }
$$

$\sigma_{11}, \sigma_{22}$ and $\sigma_{33}$, are the principal values of the $\sigma$ tensor. In experimental NMR spectra a standard system is chosen as reference. Thus, the chemical shift is taken as the difference between the shielding of the atom in the system and in the reference. Using a same reference system the calculated chemical shift for the isolated and the complex systems corresponds to the difference in the two situations as the shielding for the reference system cancels out. Hence, the chemical shifts reported here refer to the difference between the shielding of the atom in the complex and the shielding of this same atom in the monomer.

All results for the isotropic and anisotropic chemical shifts were corrected for BSSE using the counterpoise correction [41] where for each complex we also calculated the shielding of the monomer using the entire basis functions of the hydrogen-bonded complex. The uncorrected (without $\mathrm{CC}$ ) and corrected (with $\mathrm{CC}$ ) results for basis set superposition error are shown at Tables III and IV and are discussed below.

\subsubsection{Methanol as proton acceptor $-\mathrm{CH}_{3} \mathrm{HO} \cdot \cdots \mathrm{H}_{2} \mathrm{O}$ complex}

Table III shows the results for the $\delta^{\text {iso }}$ and $\delta^{\text {anis }}$ for the $\mathrm{CH}_{3} \mathrm{HO} \cdots \mathrm{H}_{2} \mathrm{O}$ complex. We first consider the atoms involved in the hydrogen bond. In the methanol molecule the calculated $\delta^{\text {iso }}(\mathrm{O})$ are $-3.78 ;-5.85$ and $-5.21 \mathrm{ppm}$ and in the water molecule, $\delta^{\text {iso }}(\mathrm{H})$ are $-3.14 ;-3.18$ and $-2.98 \mathrm{ppm}$ in SCF, B3LYP and MP2 methods, respectively. For the other atoms of the complex the $\delta^{\text {iso }}$ is small but for the oxygen atom of the water molecule, that is $-0.84 \mathrm{ppm}$ (using MP2) due the modification that the structure of water undergoes upon complexation. The counterpoise correction to BSSE is relatively mild but can be more pronounced for the $\mathrm{O}$ atom of water with 
TABLE III: Values of the isotropic and anisotropic chemical shifts for the $\mathrm{CH}_{3} \mathrm{HO} \cdots{ }^{\mathrm{H}_{2}} \mathrm{O}$ complex (in ppm) using three theoretical models.

\begin{tabular}{ccccccc}
\hline \hline & \multicolumn{7}{c}{ Isotropic Chemical Shift $\left(\delta^{\text {iso }}\right)$} \\
\hline $\mathrm{CH}_{3} \mathrm{HO} \cdots \mathrm{H}_{2} \mathrm{O}$ & \multicolumn{2}{c}{ SCF } & \multicolumn{2}{c}{ B3LYP } & \multicolumn{2}{c}{ MP2 } \\
& without CC & with CC & without CC & with CC & without CC & with CC \\
$\mathrm{O}$ & -4.81 & -3.78 & -6.96 & -5.85 & -5.95 & -5.21 \\
$\mathrm{H}$ & -0.58 & -0.08 & -0.42 & 0.06 & -0.50 & -0.02 \\
$\mathrm{H}$ & -0.07 & -0.04 & 0.02 & 0.05 & -0.02 & 0.01 \\
$\mathrm{H}$ & -0.14 & -0.13 & -0.06 & -0.06 & -0.08 & -0.07 \\
$\mathrm{H}_{\mathrm{o}}$ & -0.14 & -0.13 & -0.11 & -0.12 & -0.11 & -0.11 \\
$\mathrm{H}^{*}$ & -0.52 & -0.48 & -0.62 & -0.58 & -0.56 & -0.51 \\
$\mathrm{O}$ & -3.50 & -3.14 & -3.51 & -3.18 & -3.34 & -2.98 \\
$\mathrm{H}$ & 0.98 & 2.97 & -1.52 & 0.23 & -1.81 & -0.84 \\
& 0.54 & 0.57 & 0.50 & 0.54 & 0.43 & 0.47 \\
& \multicolumn{7}{c}{ SCF } & Anisotropic Chemical Shift & $\left(\delta^{\text {anis }}\right)$ & & \\
\hline $\mathrm{CH}_{3} \mathrm{HO} \cdots \cdot \mathrm{H}_{2} \mathrm{O}$ & & \multicolumn{7}{c}{ B3LYP } & & MP2 \\
& without CC & with CC & without CC & with CC & without CC & with CC \\
$\mathrm{O}^{*}$ & -7.11 & -5.69 & -9.35 & -7.51 & -6.77 & -5.35 \\
$\mathrm{C}$ & 0.72 & 0.15 & 0.47 & -0.07 & 0.71 & 0.18 \\
$\mathrm{H}$ & 0.51 & 0.53 & 0.33 & 0.33 & 0.44 & 0.45 \\
$\mathrm{H}$ & -0.05 & 0.02 & -0.04 & 0.03 & -0.07 & 0.01 \\
$\mathrm{H}$ & -0.22 & -0.15 & -0.11 & -0.02 & -0.18 & -0.10 \\
$\mathrm{H}_{\mathrm{o}}$ & 0.19 & 0.26 & 0.12 & 0.21 & 0.15 & 0.23 \\
$\mathrm{H}^{*}$ & 11.51 & 11.90 & 11.58 & 12.00 & 11.53 & 11.95 \\
$\mathrm{O}$ & 8.22 & 6.67 & 11.24 & 9.40 & 11.50 & 9.31 \\
$\mathrm{H}$ & 0.41 & 0.54 & 0.25 & 0.42 & 0.26 & 0.39 \\
\hline \hline
\end{tabular}

Asterisk indicates the atoms that are directly involved in the hydrogen bond

a relative importance of the electron correlation effects. It is expected that upon complexation there is a charge redistribution in the $\mathrm{O}-\mathrm{H}$ bond $(0.07 e$ at $\mathrm{H}$ and $-0.07 e$ at $\mathrm{O})$ leading to a more appreciable shift. Overall the three theoretical methods give similar and consistent results for the isotropic shift. The $\delta^{\text {anis }}$ for the same complex are more pronounced, being, $-5.69 ;-7.51$ and $-5.35 \mathrm{ppm}$ for the oxygen atom and $11.90 ; 12.00$ and $11.95 \mathrm{ppm}$ for the hydrogen atom in the hydrogen bond. Again, for the $\mathrm{O}$ atom of the water molecule the $\delta^{\text {anis }}(\mathrm{O})$ is very influenced by electron correlation effects. The difference between the SCF and MP2 counterpoise corrected values is $2.64 \mathrm{ppm}$ (6.67 and $9.31 \mathrm{ppm}$ ). Counterpoise correction affects the results by only 1.5-2.2 ppm and in some cases it is negligible. 
TABLE IV: Values of the isotropic and anisotropic chemical shifts for $\mathrm{CH}_{3} \mathrm{OH} \cdots \mathrm{OH}_{2}$ complex (in ppm) using three theoretical models.

\begin{tabular}{|c|c|c|c|c|c|c|}
\hline \multicolumn{7}{|c|}{ Isotropic Chemical Shift $\left(\delta^{\text {iso }}\right)$} \\
\hline $\mathrm{CH}_{3} \mathrm{OH} \cdots \mathrm{OH}_{2}$ & \multicolumn{2}{|c|}{ SCF } & \multicolumn{2}{|c|}{ B3LYP } & \multicolumn{2}{|c|}{ MP2 } \\
\hline 0 & without $\mathrm{CC}$ & with CC & without CC & with CC & without CC & with CC \\
\hline 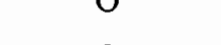 & & & & & & \\
\hline $\mathrm{C}$ & 1.23 & 1.03 & 1.23 & 1.08 & 1.06 & 0.88 \\
\hline $\mathrm{H}$ & 0.10 & 0.11 & 0.08 & 0.09 & 0.06 & 0.08 \\
\hline $\mathrm{H}$ & 0.10 & 0.11 & 0.08 & 0.09 & 0.06 & 0.08 \\
\hline $\mathrm{H}$ & 0.14 & 0.14 & 0.09 & 0.10 & 0.08 & 0.09 \\
\hline $\mathrm{H}_{\mathrm{o}}^{*}$ & -3.33 & -3.05 & -3.35 & -3.10 & -3.17 & -2.91 \\
\hline $\mathrm{H}$ & -0.55 & -0.46 & -0.60 & -0.52 & -0.57 & -0.47 \\
\hline $\mathrm{O}^{*}$ & -5.69 & -5.31 & -7.59 & -7.57 & -6.22 & -6.32 \\
\hline $\mathrm{H}$ & -0.55 & -0.46 & -0.60 & -0.52 & -0.57 & -0.47 \\
\hline \multicolumn{7}{|c|}{ Anisotropic Chemical Shift $\left(\delta^{\text {anis }}\right)$} \\
\hline $\mathrm{CH}_{3} \mathrm{OH} \cdots \mathrm{OH}_{2}$ & \multicolumn{2}{|c|}{ SCF } & \multicolumn{2}{|c|}{ B3LYP } & \multicolumn{2}{|c|}{ MP2 } \\
\hline 0 & $\begin{array}{c}\text { without CC } \\
-8.42\end{array}$ & $\begin{array}{c}\text { with CC } \\
-13.24\end{array}$ & $\begin{array}{c}\text { without CC } \\
-5.39\end{array}$ & $\begin{array}{c}\text { with CC } \\
-10.54\end{array}$ & $\begin{array}{c}\text { without CC } \\
-1.40\end{array}$ & $\begin{array}{c}\text { with CC } \\
-5.85\end{array}$ \\
\hline C & -1.61 & -1.40 & -1.75 & -1.51 & -1.28 & -1.16 \\
\hline $\mathrm{H}$ & 0.19 & 0.17 & 0.34 & 0.32 & 0.25 & 0.23 \\
\hline $\mathrm{H}$ & 0.19 & 0.17 & 0.34 & 0.32 & 0.25 & 0.23 \\
\hline $\mathrm{H}$ & 0.52 & 0.52 & 0.48 & 0.49 & 0.52 & 0.52 \\
\hline $\mathrm{H}_{\mathrm{o}}^{*}$ & 11.14 & 11.35 & 11.38 & 11.59 & 11.26 & 11.48 \\
\hline $\mathrm{H}$ & -0.02 & 0.08 & -0.15 & -0.03 & -0.10 & 0.02 \\
\hline $\mathrm{O}^{*}$ & -9.08 & -9.85 & -8.40 & -10.19 & -6.93 & -8.75 \\
\hline $\mathrm{H}$ & -0.02 & 0.08 & -0.15 & -0.03 & -0.10 & 0.02 \\
\hline
\end{tabular}

Asterisk indicates the atoms that are directly involved in the hydrogen bond

\subsubsection{Methanol as proton donor $-\mathrm{CH}_{3} \mathrm{OH} \cdots \mathrm{OH}_{2}$ complex}

A similar analysis is made in Table IV for the $\mathrm{CH}_{3} \mathrm{OH} \cdots \mathrm{OH}_{2}$ complex. In this case the $\delta^{\text {iso }}(\mathrm{O})$ of the oxygen atom of methanol are all positive, in opposition to the $\mathrm{CH}_{3} \mathrm{HO} \cdot \cdots_{2} \mathrm{O}$ O complex. For this $\mathrm{O}$ atom the counterpoise corrected $\delta^{\text {iso }}(\mathrm{O})$ are $7.11,4.85$ and $2.81 \mathrm{ppm}$ whereas the counterpoise corrected $\delta^{\text {anis }}(\mathrm{O})$ are $-13.24,-10.54$ and $-5.85 \mathrm{ppm}$ with the three theoretical models. Note that in this complex the BSSE is larger. For instance the calculated $\delta^{\text {anis }}(\mathrm{O})$ of the methanol and water molecules change from -1.40 to $-5.85 \mathrm{ppm}$ (methanol) and from 6.93 to $-8.75 \mathrm{ppm}$ (water). For the hydrogen atom of methanol that is the proton donor the calculated $\delta^{\text {iso }}(\mathrm{H})$ are respectively $-3.05,-3.10$ and $-2.91 \mathrm{ppm}$. For the oxygen atom of water the values of $\delta^{\text {iso }}(\mathrm{O})$ are all negative (- 
$5.31,-7.57$ and $-6.32 \mathrm{ppm}$ ) in opposition to the complex $\mathrm{CH}_{3} \mathrm{HO} \cdots \mathrm{H}_{2} \mathrm{O}$. It is interesting to note here, that $\delta^{\text {iso }}(\mathrm{C})$ $=0.88 \mathrm{ppm}$ in MP2 is larger than the counterpart in the other complex $(-0.02 \mathrm{ppm})$. This is possibly related to the larger amount of charge accumulated in the neighboring $\mathrm{O}$ atom $(-0.09 \mathrm{e})$ in comparison with the amount accumulated in the $\mathrm{C}$ atom in the other complex $(0.05 e)$.
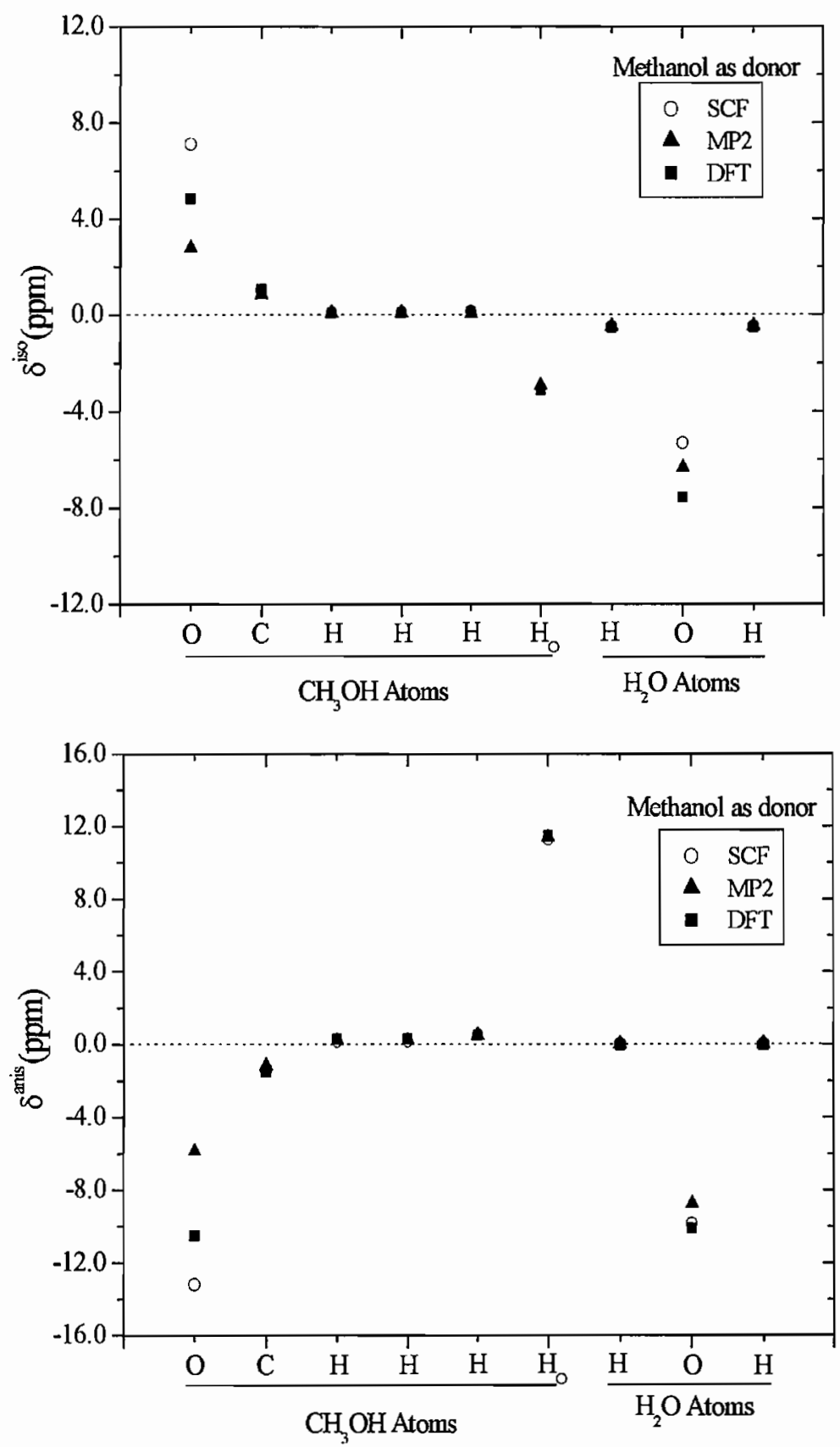

FIGURE 2: The isotropic and anisotropic chemical shifts for the $\mathrm{CH}_{3} \mathrm{OH} \cdot \cdots \mathrm{OH}_{2}$ complex using three theoretical levels. Results corrected for BSSE. 

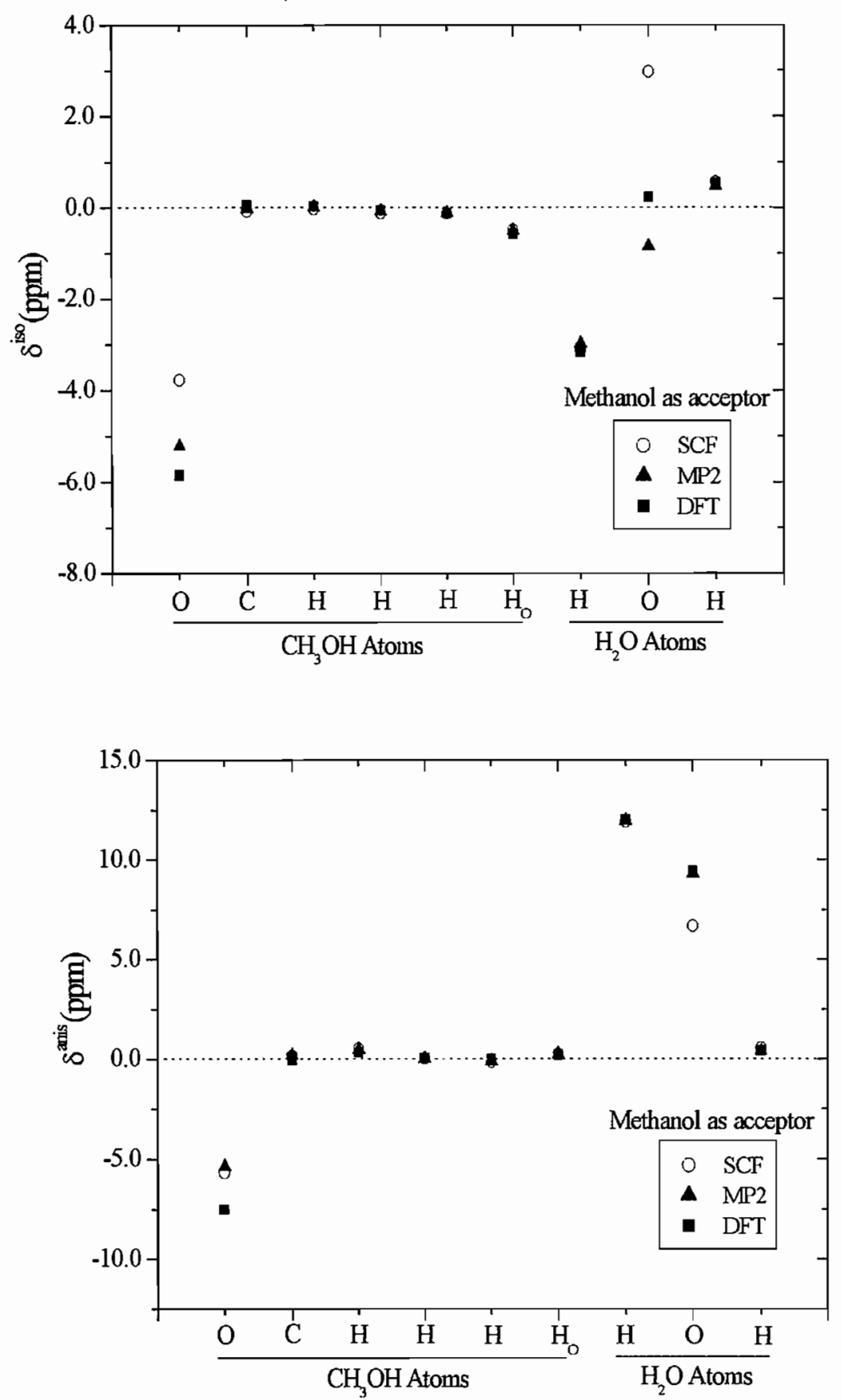

FIGURE 3: The isotropic and anisotropic chemical shifts for the $\mathrm{CH}_{3} \mathrm{HO} \cdots \mathrm{H}_{2} \mathrm{O}$ complex using three theoretical levels. Results corrected for BSSE.

There have been very few theoretical studies of NMR parameters of hydrogen-bonded water-methanol complexes. But this isomer, the $\mathrm{CH}_{3} \mathrm{OH} \cdots \mathrm{OH}_{2}$ complex, has been the subject of a previous study [54] where 
some of the shielding constants were obtained using the MP2/aug-cc-pVTZ model without counterpoise correction. Overall there is a good agreement between the results. It should be noted however (Table IV) that in some cases the counterpoise correction is sizable (for instance, the $\delta^{\text {anis }}$ of the oxygen atom of the $\mathrm{CH}_{3} \mathrm{OH} \cdots \mathrm{OH}_{2}$ complex).

The theoretical results for both complexes can be summarized pictorially in Figures 2 and 3. In Figure 2 we show the $\delta^{\text {iso }}$ and $\delta^{\text {anis }}$ for each nucleus of the $\mathrm{CH}_{3} \mathrm{OH} \cdots \mathrm{OH}_{2}$ complex, while in Figure 3 we show the same results for the complex $\mathrm{CH}_{3} \mathrm{HO} \cdot \mathrm{H}_{2} \mathrm{O}$. These two figures illustrate more clearly the chemical shifts after the hydrogen bond formation. We see that the $\mathrm{C}$ and $\mathrm{H}$ atoms of the methyl group present a small shift while the atoms that participate in the hydrogen bond present a larger shift. From Figures 2 e 3 we can analyze the relative values of each theoretical method. We note that in the case of proton acceptor methanol electron correlation is important for the isotropic shift of the oxygen atom of water. The SCF and B3LYP results are positive whereas the MP2 method gives negative value. For the hydrogen atoms of water, the electron correlation effects are small.

\subsection{The $\delta_{/ /}$and $\delta_{\perp}$ components of isotropic chemical shift tensor}

Experimentally it is known that for the shielding tensor of the hydrogen-bonded proton, the most shielded direction is nearly parallel to the axis of hydrogen bond whereas the least shielded is nearly perpendicular to this axis $[30,47]$. It has been noted before for the water dimer $[29,30]$ that these perpendicular components of the hydrogen bonded proton chemical shielding tensor, are more sensitive to the formation of a hydrogen bond than a parallel component. Although these parallel and perpendicular components are not independent from the previous results it is of interest to analyze them separately. The parallel and perpendicular components for the atom $X$ are defined as:

$$
\delta(X)_{/ /}=\sigma(X)^{i s o}+\frac{2}{3} \sigma(X)^{a n i s}
$$

and

$$
\delta(X)_{\perp}=\sigma(X)^{i s o}-\frac{1}{3} \sigma(X)^{a n i s} .
$$

Table V presents the values for the $\delta_{/ /}$and $\delta_{\perp}$ for all atoms of both complexes $\mathrm{CH}_{3} \mathrm{HO} \cdots \cdot \mathrm{H}_{2} \mathrm{O}$ and $\mathrm{CH}_{3} \mathrm{OH} \cdots \mathrm{OH}_{2}$. For the complex $\mathrm{CH}_{3} \mathrm{HO} \cdots \mathrm{H}_{2} \mathrm{O}, \delta_{\perp}$ is negative and generally larger (in absolute value) than the parallel component, except for the $\mathrm{O}$ atom of methanol and water. For instance, at the MP2 level the calculated $\delta_{\perp}(\mathrm{H})$ for the proton donor atom is $-7.18 \mathrm{ppm}$, compared to the $\delta_{/ /}(\mathrm{H})$ value of $4.35 \mathrm{ppm}$ (Table V). Similar result can be seen for the other complex $\mathrm{CH}_{3} \mathrm{OH} \cdots \mathrm{OH}_{2}$. Now, again at the MP2 level the $\delta_{\perp}(\mathrm{H})$ of the proton donor atom is $-6.93 \mathrm{ppm}$, compared to the $\delta /(\mathrm{H})$ value of $4.33 \mathrm{ppm}$. However, it is also of interest to note the corresponding shifts in the proton acceptor oxygen atoms. The reverse occurs and the $\delta_{/ /}(0)$ is now dominant. Note, for instance, the $\delta_{/}(\mathrm{O})$ of the $\mathrm{O}$ atom of methanol is $-10.47 \mathrm{ppm}$ and the $\mathrm{O}$ atom of water is $-10.84 \mathrm{ppm}$, whereas the $\delta_{\perp}(\mathrm{O})$ are -3.70 and $-3.91 \mathrm{ppm}$ respectively. Also, they show the same sign (negative) for both 
complexes. Thus we see that the perpendicular component of the isotropic shift tensor in the proton donor atom is larger in magnitude than the parallel component. However, this tendency is inverted for the oxygen atom of the hydrogen bond.

TABLE V: Values of the parallel and perpendicular components of the isotropic shielding of $\mathrm{CH}_{3} \mathrm{HO} \cdots \cdot \mathrm{H}_{2} \mathrm{O}$ and $\mathrm{CH}_{3} \mathrm{OH} \cdots \mathrm{OH}_{2}$ complexes (in ppm) using three theoretical models.

\begin{tabular}{ccccccc}
\hline \hline & & $\delta_{\| \prime}$ & & & \\
\hline $\mathrm{CH}_{3} \mathrm{HO} \cdots \mathrm{H}_{2} \mathrm{O}$ & $\mathbf{S C F}$ & $\mathbf{B 3 L Y P}$ & $\mathbf{M P 2}$ & SCF & B3LYP & MP2 \\
$\mathrm{O}^{*}$ & -9.55 & -13.20 & -10.47 & -2.44 & -3.85 & -3.70 \\
$\mathrm{C}$ & -0.09 & -0.10 & -0.03 & -0.82 & -0.57 & -0.73 \\
$\mathrm{H}$ & 0.27 & 0.24 & 0.27 & -0.24 & -0.09 & -0.17 \\
$\mathrm{H}$ & -0.18 & -0.09 & -0.13 & -0.12 & -0.05 & -0.06 \\
$\mathrm{H}$ & -0.29 & -0.18 & -0.23 & -0.06 & -0.07 & -0.05 \\
$\mathrm{H}_{\mathrm{O}}$ & -0.39 & -0.54 & -0.46 & -0.58 & -0.66 & -0.62 \\
$\mathrm{H}^{*}$ & 4.17 & 4.21 & 4.35 & -7.34 & -7.37 & -7.18 \\
$\mathrm{O}$ & $\mathbf{6 . 4 5}$ & 5.97 & 5.85 & -1.76 & -5.26 & -5.65 \\
$\mathrm{H}$ & 0.81 & 0.66 & 0.61 & 0.41 & 0.41 & 0.34 \\
& & & & & & \\
\hline $\mathrm{CH}_{3} \mathrm{OH} \cdots \mathrm{OH}_{2}$ & $\mathbf{S C F}$ & $\mathbf{B 3 L Y P}$ & $\mathbf{M P 2}$ & $\mathbf{S C F}$ & $\mathbf{B 3 L Y P}$ & $\mathbf{M P 2}$ \\
$\mathrm{O}$ & -0.24 & -0.49 & 0.72 & 8.17 & 4.91 & 2.12 \\
$\mathrm{C}$ & 0.16 & 0.07 & 0.21 & 1.76 & 1.82 & 1.48 \\
$\mathrm{H}$ & 0.23 & 0.30 & 0.23 & 0.04 & -0.03 & -0.02 \\
$\mathrm{H}$ & 0.23 & 0.30 & 0.23 & 0.04 & -0.03 & -0.02 \\
$\mathrm{H}$ & 0.48 & 0.41 & 0.43 & -0.04 & -0.07 & -0.10 \\
$\mathrm{H}_{\mathrm{o}}^{*}$ & 4.09 & 4.24 & 4.33 & -7.04 & -7.14 & -6.93 \\
$\mathrm{H}$ & -0.56 & -0.70 & -0.63 & -0.54 & -0.55 & -0.53 \\
$\mathrm{O}^{*}$ & -11.74 & -13.19 & -10.84 & -2.66 & -4.79 & -3.91 \\
$\mathrm{H}$ & -0.56 & -0.70 & -0.63 & -0.54 & -0.55 & -0.53 \\
\hline \hline
\end{tabular}

Asterisk indicates the atoms that are directly involved in the hydrogen bond

\subsection{The monomer relaxation effect}

It is now appropriate to comment on the separate effect of monomer geometry relaxation. This has been obtained here as the difference between the shielding of the atom in the optimized geometry of the complex and the shielding of the same atom in the optimized geometry of the monomer. This difference was appreciable only for the oxygen atom of the proton donor molecule because of the $\mathrm{O}-\mathrm{H}$ stretching upon hydrogen bond formation. In the case of the oxygen atom of proton donor methanol it was $1.33 \mathrm{ppm}$ (MP2) and $1.76 \mathrm{ppm}$ (B3LYP) for the isotropic shielding and $-4.62 \mathrm{ppm}$ (MP2) and $-5.38 \mathrm{ppm}$ (B3LYP) for the anisotropic shielding. For the proton 
donor water molecule the relaxation contributions are $1.70 \mathrm{ppm}$ (MP2) and $2.18 \mathrm{ppm}$ (B3LYP) ppm for the isotropic shielding and $-0.16 \mathrm{ppm}$ (MP2) and $-0.41 \mathrm{ppm}$ (B3LYP) for the anisotropic shielding.

\section{Summary and Conclusions}

In this work we have analyzed the effects of hydrogen bond formation on NMR chemical shieldings for methanol-water complexes. Our purpose is providing NMR data that could help understanding water-alcohol mixtures. This all-atom description of the chemical shift tensor in hydrogen-bonded complexes might be of value in the understanding of hydrogen bonds.

We have calculated NMR shieldings for all atoms in the two possible hydrogen bonded complexes, $\mathrm{CH}_{3} \mathrm{HO} \cdots \mathrm{H}_{2} \mathrm{O}$ and $\mathrm{CH}_{3} \mathrm{OH} \cdots \mathrm{OH}_{2}$, using SCF, B3LYP and MP2 models in the MP2 optimized geometries. We obtained that the atoms of the methyl group present only very small isotropic chemical shifts, but the carbon atom of the donor methanol is more influenced. The results obtained for the isotropic $\left(\delta^{\text {iso }}\right)$ and anisotropic $\left(\delta^{\text {anis }}\right)$ chemical shifts are more sensitive for the atoms that participate directly in the hydrogen bond. The $\delta^{\text {anis }}$ seems to be a good indicator of the hydrogen binding since the anisotropic chemical shifts are larger than the corresponding isotropic one. These results corroborate previous assumptions that the $\delta^{\text {anis }}(\mathrm{H})$ are more sensitive than the isotropic shift $[27,28]$. We also find that the atoms of the donor molecule become more shielded while in the acceptor molecule the atoms become more deshielded. Similar tendency [44] have been observed in a study of the water dimer. Electron correlation effects were found to be important in the absolute chemical shielding but not the chemical shifts. Whereas for the atoms that participate directly in the hydrogen bond the basis-setsuperposition error is numerically relevant, for the other atoms it is essentially negligible. Although atomic charges are not true physical observables we utilized the Mulliken population analysis as indicator of charge rearrangement and for rationalizing the calculated chemical shifts.

The $\delta_{\perp}$ and $\delta_{/ /}$components of the isotropic chemical shift were also studied. We corroborate that for the proton hydrogen bonded the $\delta_{/ /}(\mathrm{H})$ component is more shielded than the $\delta_{\perp}(\mathrm{H})$. For the proton acceptor $\mathrm{O}$ atom, the reverse occurs. The $\delta_{/ /}(\mathrm{O})$ is less shielded than the $\delta_{\perp}(\mathrm{O})$. These components allow us to evaluate the directional character of each hydrogen bond. We observed that the anisotropic shielding of the $\mathrm{O}$ atom in proton acceptor water is lower than in the proton acceptor methanol, showing an isotropy of the hydrogen bond that is larger for the $\mathrm{CH}_{3} \mathrm{OH} \cdots \mathrm{OH}_{2}$ than $\mathrm{CH}_{3} \mathrm{HO} \cdots \mathrm{H}_{2} \mathrm{O}$.

Finally, we considered the effects of monomer relaxation in the calculated NMR parameters. We verified that this effect was appreciable only for the $\mathrm{O}$ atom of the $\mathrm{OH}$ part of the donor molecule, because of the deformation of the $\mathrm{O}-\mathrm{H}$ distance upon the binding formation.

\section{Acknowledgments:}

It is a great privilege to contribute to this issue in memory of Prof. J. A. Pople. This work has been partially supported by CNPq and FAPESP (Brazil). 


\section{References}

[1] Frank, H. S.; Evans, M. W. J Chem Phys 1945, 13, 507.

[2] Soper, A. K.; Finney, J. L. Phys Rev Lett 1993, 71, 4346.

[3] D'Angelo, M.; Onori, G.; Santucci, A. J Chem Phys 1994, 100, 3107.

[4] Egashira, K.; Nishi, N. J Phys Chem B 1998, 102, 4054.

[5] Murthy, S. S. N. J Phys Chem A 1999, 103, 7927.

[6] Dixit, S.; Poon, W. C. K.; Crain, J. J Phys Condens Matter 2000, 102, L323.

[7] Bowron, D. T.; Soper, A. K.; Finney, J. L. J Chem Phys 2001, 114, 6203.

[8] Dixit. S.; Crain, J.; Poon, W. C. K.; Finney, J. L.; Soper, A. K. Nature 2002, 416, 829.

[9] Guo, J-H.; Luo, Y.; Augustsson, A.; Kashtanov, S.; Rubensson, J-E.; Shuh, D. K.; Ågren, H.; Nordgren, J. Phys Rev Lett 2003, 91, 157401.

[10] Ferrario, M.; Haughney, M.; McDonald, I. R.; Klein, M. L. J Chem Phys 1990, 93, 5156.

[11] Tanaka, H.; Gubbins, K. E. J Chem Phys 1992, 97, 2626.

[12] Laaksonen, A.; Kusalik, P. G.; Svishchev, I. M. J Phys Chem A 1997, 101, 5910.

[13] Fileti, E. E.; Rivelino, R.; Canuto, S. J Phys B 2003, 36, 399.

[14] González, L.; Mó, O.; Yanes, M. J Chem Phys 1998, 109, 139.

[15] Stockman, P. A.; Blake, G. A.; Lovas, F. J.; Suenran, R. D. J Chem Phys 1997, 107, 3782.

[16] Fileti, E. E.; Canuto, S. Adv Quantum Chem 2004, 47, 51.

[17] Ludwig, R. Chem Phys Lett 1995, 195, 329.

[18] Huelsekopf, M.; Ludwig, R. J Mol Liq 2000, 85, 105.

[19] Arnold, J. T.; Packard, M. E. J Chem Phys 1951, 19, 1608.

[20] Schneider, W. G.; Bernstein, W. G.; Pople, J. A. J Chem Phys 1958, 28, 601.

[21] Becker, E. D.; Liddel, U.; Schoolery, J. N. J Mol Spectroscopy 1959, 2 , 1.

[22] Huggins, C. M.; Pimentel, G. C.; Schoolery, J. N. J Phys Chem 1956, 60, 1311.

[23] Asakawa, N.; Kuroki, S.; Kurosu, H.; Ando, I.; Shoji, A.; Ozaki, T. J Am Chem Soc 1992, 114, 3261.

[24] Perrin, C. L; Dwyer, T. J.; Rebek, J.; Duff, R. J. J Am Chem Soc 1990, 112, 3122.

[25] Zhou, N. E.; Zhu, B. Y.; Sykes, B. D.; Hodges, R. S. J Am Chem Soc 1992, 114, 4320.

[26] Ditchfield, R. Mol Phys 1974, 27, 789.

[27] Ditchfield, R. J Chem Phys 1976, 65, 3123.

[28] Ditchfield, R. Chem Phys Lett 1976, 40, 53.

[29] Rohlfing, C. M.; Allen, L. C.; Ditchfield, R. J Chem Phys 1983, 79, 4958.

[30] Rohlfing, C. M.; Allen, L. C.; Ditchfield, R. Chem Phys Lett 1982, 86, 380.

[31] Hinton, J. F.; Wolinski, K. Ab initio GIAO Magnetic Shielding Tensor for Hydrogen Bonded Systems. Hadži, D., Ed. Theoretical Treatments of Hydrogen Bonding; J. Wiley \& Sons Ltd., 1997.

[32] Hehre, W. J.; Radom, L.; Schleyer, P. v. R.; Pople, J. A. Ab Initio Molecular Orbital Theory; J. Wiley \& Sons Ltd., 1986. 
[33] Wolinski, K.; Hinton, J.; F.; Pulay, P. J Am Chem Soc 1990, 112, 8251

[34] Gauss, J. Chem Phys Lett 1992, 191, 614

[35] Gauss, J. J Chem Phys 1993, 99, 3629

[36] Cheeseman, J. R.; Trucks, G. W.; Keith, T. A.; Frisch, M. J. J Chem Phys 1996, 104, 5497

[37] Rauhut, G.; Puyear, S.; Wolinski, J.; F.; Pulay, P. J Phys Chem 1996, 100, 6310

[38] Schreckenbach, G.; Ziegler, T. J Phys Chem 1995, 99, 606

[39] Cheeseman, J. R.; Trucks, G. W., Keith, T. A.; Frisch, M. J. J Chem Phys 1996, 1045497.

[40] Wolinski, K.; Hinton, J. F.; Pulay, P. J Am Chem Soc 1990, 112, 8251.

[41] Boys, S. F.; Bernardi, F. Mol Phys 1970, 19, 553.

[42] Frisch, M. J.; Trucks, G. W.; Schlegel, H. B.; Scuseria, G. E.; Robb, M. A.; Cheeseman, J. R.; Zakrzewski, V. G.; Montgomery, J. A., Jr.; Stratmann, R. E.; Burant, J. C.; Dapprich, S.; Millam, J. M.; Daniels, A. D.; Kudin, K. N.; Strain, M. C.; Farkas, O.; Tomasi, J.; Barone, V.; Cossi, M.; Cammi, R.; Mennucci, B.; Pomelli, C.; Adamo, C.; Clifford, S.; Ochterski, J.; Petersson, G. A.; Ayala, P. Y.; Cui, Q.; Morokuma, K.; Malick, D. K.; Rabuck, A. D.; Raghavachari, K.; Foresman, J. B.; Cioslowski, J.; Ortiz, J. V.; Stefanov, B. B.; Liu, G.; Liashenko, A.; Piskorz, P.; Komaromi, I.; Gomperts, R.; Martin, R. L.; Fox, D. J.; Keith, T.; Al-Laham, M. A.; Peng, C. Y.; Nanayakkara, A.; Gonzalez, C.; Challacombe, M.; Gill, P. M. W.; Johnson, B. G.; Chen, W.; Wong, M. W.; Andres, J. L.; Head-Gordon, M.; Replogle, E. S.; Pople, J. A. Gaussian 98W, Revision A.7; Gaussian: Pittsburgh, PA; 1998.

[43] Kirschner, K. N.; Woods, R. J.; J Phys Chem A 2001, 105, 4150.

[44] Chesnut, D. B.; Phung, C. G. Chem Phys 1990, 147, 91.

[45] Chesnut, D. B. Ann Rep NMR Spec 1994, $29,71$.

[46] Gauss, J.; Stanton, J. F. Adv Chem Phys 2002, 123, 355

[47] Haeberlen, U. High Resolution NMR in Solids, Academic Press, 1976.

[48] Tesche, B.; Haeberlen, U. J Mag Reson A 1995, 117, 186.

[49] Gauss, J. Chem Phys Lett 1994, 229, 175

[50] Gauss, J.; Stanton, J. F. J Chem Phys 1995, 103, 3561

[51] Karadakov, P. B. J Mol Struct 2002, 602, 293.

[52] Fowler, P. W.; Raynes, W. T. Mol Phys 1981, 43, 65

[53] Fukui, H.; Baba, T.; Narumi, J.; Inomata, H.; Miura, K.; Matsuda, H. J Chem Phys 1996, 105, 4692

[54] Pecul, M.; Leszczynski, J.; Sadlej, J. J Chem Phys 2000, 112, 7930.

[55] Kitzinger, J. P. NMR Basic Principles and Progress 1982, 17, 1.

[56] Jameson, C. J.; Jameson, A. K.; Oppusunggu, D.; Wille, S.; Burrell, P. M.; Mason, J. J Chem Phys 1981, 74, 81.

[57] Chauvel, J. P., True, N. S. Chem Phys 1985, 95, 435.

[58] Wasylishen, R. E.; Mooibroek, S.; Macdonald, J. B. J Chem Phys 1971, 75932.

[59] Wasylishen, R. E.; Bryce, D. L. J Chem Phys 2002, 117, 10061.

[60] Hindman, J. C. J Chem Phys 1966, 44, 4582.

[61] Vaara, J.; Lounilla, J.; Ruud, K.; Helgaker, T. J Chem Phys 1998, 109, 8388. 


\title{
Relative strength of hydrogen bond interaction in alcohol-water complexes
}

\author{
Eudes E. Fileti ${ }^{\text {a }}$, Puspitapallab Chaudhuri ${ }^{\text {a,b }}{ }^{\text {, Sylvio Canuto }}{ }^{\text {a,* }}$ \\ a Instituto de Física, Universidade de São Paulo, Caixa Postal 66318, 05315-970 São Paulo, SP, Brazil \\ b Department of Theoretical Physics, Indian Association for the Cultivation of Science, Jadavpur, Kolkata 700 032, India
}

Received 2 September 2004; in final form 25 October 2004

Available online 21 November 2004

\begin{abstract}
Hydrogen binding energies are calculated for the different isomers of 1:1 complexes of methanol, ethanol and water using ab initio methods from MP2 to $\operatorname{CCSD}(\mathrm{T})$. Zero-point energy vibration and counterpoise corrections are considered and electron correlation effects are analyzed. In methanol-water and ethanol-water the most stable heterodimer is the one where the water plays the role of proton donor. In methanol-ethanol the two isomers have essentially the same energy and no favorite heterodimer could be discerned. The interplay between the relative binding energy is briefly discussed in conjunction with the incomplete mixing of alcohol-water systems.
\end{abstract}

(C) 2004 Elsevier B.V. All rights reserved.

\section{Introduction}

Alcohol-water mixtures are very important systems exhibiting properties that are of great interest in physics, chemistry and biology. These include several thermodynamic and physico-chemical properties [1-3]. For instance, the mixture of alcohol and water exhibits an entropy value that is smaller than expected [1]. This leads to the concept of negative excess entropy $[1,4,5]$. Most of these intriguing aspects are consequence of the great ability of both water and alcohol to make hydrogen bonds. Alcohol-water systems can have two hydrogen-bonded structures corresponding to the two possible heterodimers (or isomers) where alcohol is a proton acceptor, $\mathrm{RHO} \cdots \mathrm{H}_{2} \mathrm{O}$, or a proton donor, $\mathrm{ROH} . . \mathrm{OH}_{2}$. The existence of these two isomers is very easy to understand but the relative strength of the two possible conformations is more difficult to ascertain.

\footnotetext{
* Corresponding author. Fax: +5511 30916831

E-mail address: canuto@if.usp.br (S. Canuto).
}

Methanol-water, for instance, is one of the examples of this amphoteric relation where both methanol and water can act as proton donor and proton acceptor of hydrogen bonds. The question of which of the two isomers is more stable has been controversial [6-8]. It was not until very recently that the question has been confidently answered for the gas phase complexes. Detailed microwave rotation tunneling spectroscopy has established [9] that the complex where methanol is the proton acceptor and water is the proton donor, $\mathrm{CH}_{3} \mathrm{HO} \cdots \mathrm{H}_{2} \mathrm{O}$, is the more stable isomer in gas phase. Theoretical calculations [10-12] have indeed confirmed the greater stability of this isomer but obtained a relative stability that is less than $1 \mathrm{kcal} / \mathrm{mol}$.

Recent experimental studies have demonstrated that alcohol-water leads to incomplete mixing [4,5] and inferred [4] that the negative entropy mixing of alcohol-water mixtures arises from the interplay between the relative strengths of the alcohol-alcohol, alcoholwater and water-water hydrogen bonds. Therefore, there is considerable interest in the theoretical determi- 
nation of the relative binding energies of heterodimers. Of course, there are a considerable number of works dedicated to the study of the structure and binding energy of some alcohol-water complexes using several theoretical models [13-23]. To obtain the relative binding energies, free from the artifact of different approximations, it is imperative to have the same high-level theoretical model for all heterodimers of interest. In this work we address to this issue and use high-level ab initio calculations to study the relative binding energy of the 1:1 complexes obtained from water, methanol and ethanol. These include the heterodimers obtained from water-methanol, waterethanol and methanol-ethanol and the dimers of water, methanol and ethanol. Ethanol is known to exist in two forms, the trans and gauche. In the case of water-ethanol and ethanol-water we have considered both the trans and gauche configurations of ethanol. In total, eleven different complexes are obtained and their relative binding energies are systematically compared and the role of electron correlation effects analyzed.

\section{Calculation details}

Second-order Møller-Plesset MP2/aug-cc-pVDZ [24] calculations were performed to obtain the geometries of the complexes involving water, methanol and ethanol. Full geometry optimization is performed for the dimers $\left(\mathrm{H}_{2} \mathrm{O}\right)_{2}, \quad\left(\mathrm{CH}_{3} \mathrm{OH}\right)_{2}$ and $\left(\mathrm{CH}_{3} \mathrm{CH}_{2} \mathrm{OH}\right)_{2}$, and the heterodimers $\mathrm{CH}_{3} \mathrm{HO} \cdots \mathrm{H}_{2} \mathrm{O}$ and $\mathrm{CH}_{3} \mathrm{OH} \cdots \mathrm{OH}_{2}$; $\mathrm{CH}_{3} \mathrm{CH}_{2} \mathrm{HO} \cdots \mathrm{H}_{2} \mathrm{O}$ and $\mathrm{CH}_{3} \mathrm{CH}_{2} \mathrm{OH} \cdots \mathrm{OH}_{2} ; \mathrm{CH}_{3} \mathrm{CH}_{2}$ $\mathrm{HO} \cdots \mathrm{HOCH}_{3}$ and $\mathrm{CH}_{3} \mathrm{CH}_{2} \mathrm{OH} \cdots \mathrm{OHCH}_{3}$. To abbreviate these different isomers we adopt the notation that the DA acronym stands for the proton donor and proton acceptor of the hydrogen bond. For instance, MW stands for the $\mathrm{CH}_{3} \mathrm{OH} \cdots \mathrm{OH}_{2}$ isomer. The gauche form of ethanol is represented by $\mathrm{E}_{g}$, otherwise the trans form is assumed. Figs. 1-3 show the results for the hydrogen bond distances of these optimized clusters. Using these optimized structures, binding energies, dipole moment and rotational constants were obtained for all these complexes. Analysis of the vibration frequencies was made to ensure that the calculated structures are true minima of the energy surfaces and to obtain the

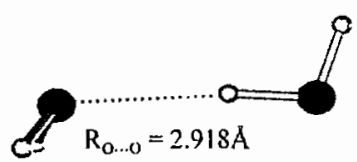

WW

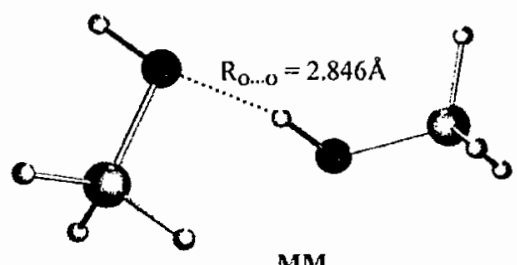

MM

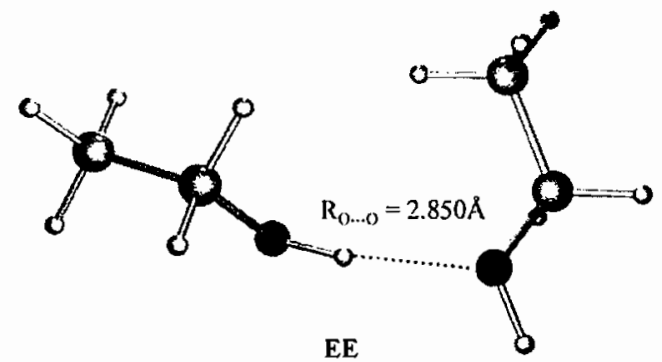

Fig. 1. The MP2/aug-cc-pVDZ optimized structures for the hydrogen bond dimers: water (WW), methanol (MM) and ethanol (EE). The calculated hydrogen bond distances $R_{\mathrm{O}} \ldots \mathrm{O}$ are shown.
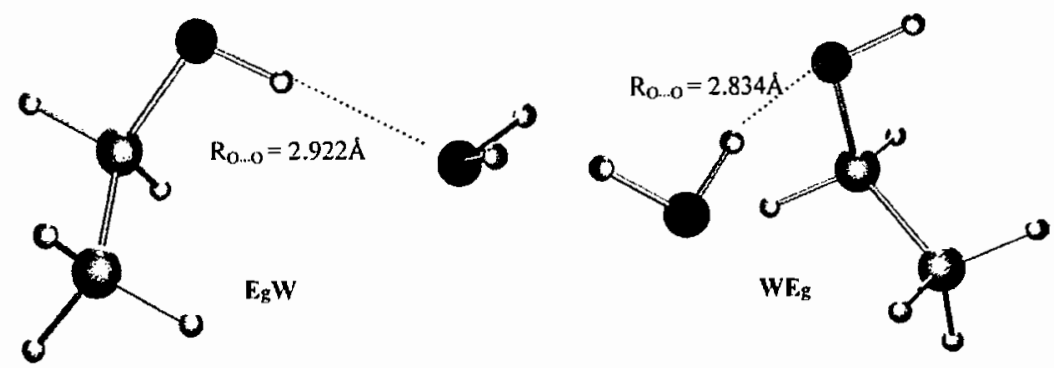

Fig. 2. The MP2/aug-cc-pVDZ optimized structures of the heterodimer complexes involving gauche ethanol and water $\left(\mathrm{E}_{g} \mathrm{~W}\right.$ and $\left.\mathrm{WE} \mathrm{E}_{\mathrm{g}}\right)$. The acronym DA stands for proton donor and acceptor, respectively. The calculated distances $R_{\mathrm{O}} \ldots \mathrm{O}$ are shown. 

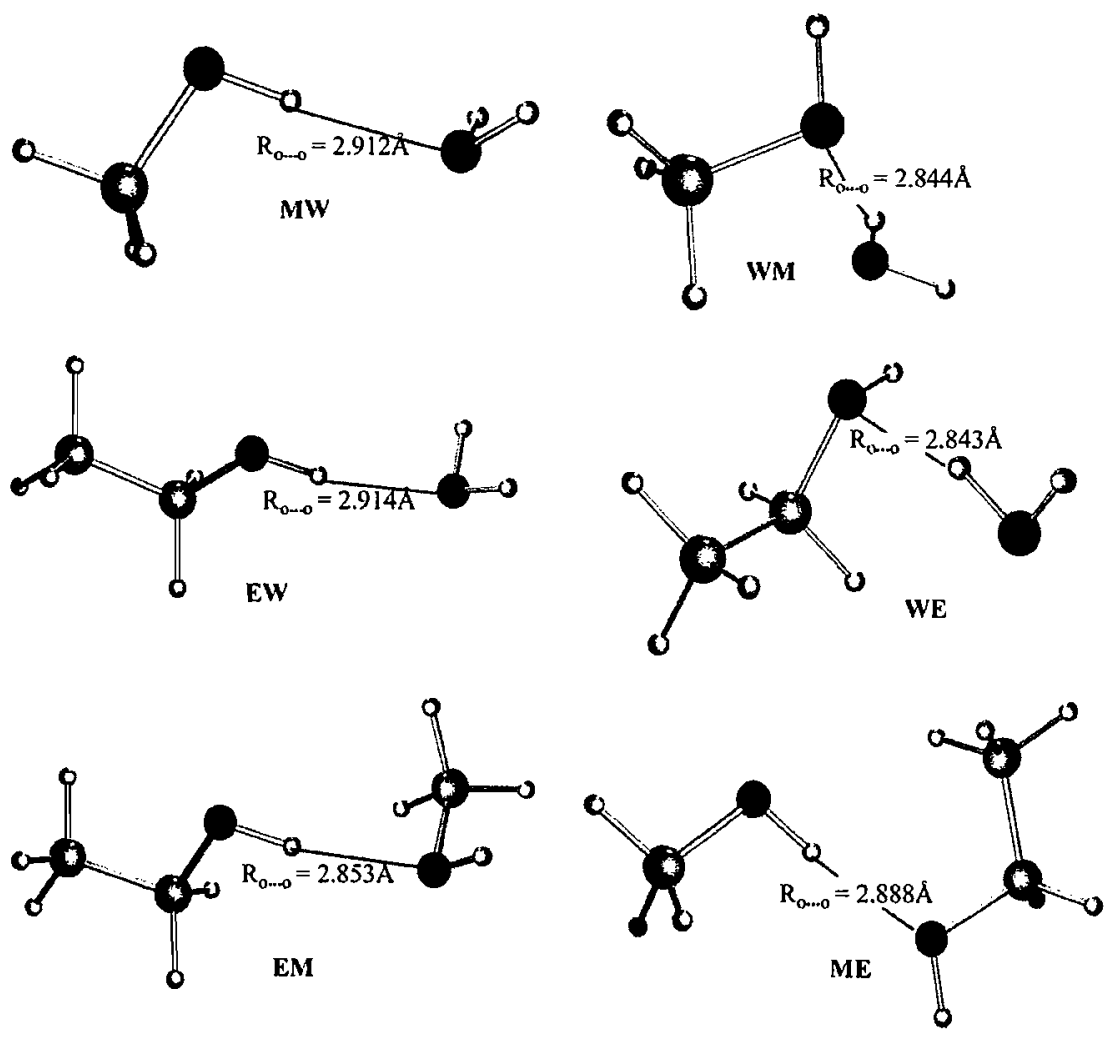

Fig. 3. The MP2/aug-cc-pVDZ optimized structures of the heterodimer complexes involving methanol and water (MW and WM); ethanol and water (EW and WE); and methanol and ethanol (ME and EM). We use the acronym DA for proton donor and acceptor, respectively. The calculated distances $R_{\mathrm{O}} \ldots \mathrm{O}$ are shown.

zero-point vibration energies. To analyze the role of the electron correlation effects on the relative stabilities of the different heterodimers single-point Coupled-Cluster [25] calculations were performed at the $\operatorname{CCSD}(\mathrm{T})$ and full-fourth-order MP4 [26] levels. As it is conventional, correction to the basis set superposition error (BSSE) is obtained for the binding energies using the counterpoise correction [27]. There has been, however, suggestions [28] that in some cases counterpoise correction may not be advised. All calculations were carried out with the Gaussian 98 ab initio package [29].

\section{Results and discussion}

Figs. 1-3 show all the systems considered here and give the optimized hydrogen bond distances. These are summarized in Table 1 that also shows the calculated dipole moments and rotational constants.

Overall the calculated hydrogen bond distances are in good agreement with previous available theoretical results, when available $[10,11,15,16,18,21,30]$. The calculated dipole moments are in very good agreement with experimentally known results for the isolated molecules. For water and methanol, the results of 1.88 and $1.71 \mathrm{D}$
Table 1

Calculated hydrogen bond distances $R_{\mathrm{O}} \ldots \mathrm{O}$ and $R_{\mathrm{O}} \cdots \mathrm{H}(\AA)$, dipole moment (Debye) and rotational constants $(\mathrm{GHz})$ for the monomers and heterodimers

\begin{tabular}{llllrrr}
\hline & $R_{\mathrm{O} \cdots \mathrm{O}}$ & $R_{\mathrm{O} \cdots \mathrm{H}}$ & $\mu$ & \multicolumn{1}{l}{$I_{\mathrm{A}}$} & \multicolumn{1}{c}{$I_{\mathrm{B}}$} & \multicolumn{1}{c}{$I_{\mathrm{C}}$} \\
\hline Monomer & & & & & & \\
$\mathrm{H}_{2} \mathrm{O}(\mathrm{W})$ & - & - & 1.879 & 796.37 & 433.47 & 280.69 \\
Methanol (M) & - & - & 1.714 & 126.02 & 24.36 & 23.51 \\
Ethanol (E) & - & - & 1.624 & 34.42 & 9.33 & 8.10 \\
Ethanol (E ${ }_{g}$ ) & & & 1.756 & 33.93 & 9.09 & 8.03 \\
Dimer & & & & & & \\
WW & 2.918 & 1.951 & 2.640 & 213.86 & 6.38 & 6.38 \\
MM & 2.846 & 1.887 & 2.499 & 16.05 & 2.39 & 2.31 \\
EE & 2.850 & 1.885 & 2.593 & 6.13 & 1.21 & 1.10 \\
Heterodimer & & & & & & \\
WM & 2.844 & 1.904 & 2.040 & 24.92 & 4.62 & 4.05 \\
MW & 2.912 & 1.942 & 2.734 & 31.96 & 3.80 & 3.53 \\
EW & 2.914 & 1.951 & 2.494 & 26.56 & 2.05 & 1.97 \\
WE & 2.843 & 1.900 & 1.944 & 8.97 & 3.55 & 2.85 \\
E $_{g} W$ & 2.922 & 1.949 & 2.839 & 9.61 & 3.05 & 2.51 \\
WE & 2.834 & 1.890 & 2.044 & 8.69 & 3.69 & 2.88 \\
ME & 2.888 & 1.919 & 3.323 & 8.50 & 1.75 & 1.50 \\
EM & 2.853 & 1.986 & 2.664 & 12.10 & 1.46 & 1.43 \\
\hline All & & & & & &
\end{tabular}

All results are obtained using the MP2/aug-cc-pVDZ optimized geometries. 
are in good agreement with the experimental results of 1.86 and $1.70 \mathrm{D}$, respectively. For ethanol, the average experimental result is $1.69 \mathrm{D}$ [31]. Upon hydrogen bond formation the combined dipole moment of $\mathrm{ME}$ has the largest value whereas the combined WE has the smallest. In the first case there is a large parallel component whereas in the latter there is a large anti-parallel component of the separate dipole moments as it can be seen in Fig. 3.

Before proceeding it is convenient to consider the trans and gauche forms of ethanol. Table 2 presents the total energies of ethanol in the trans and gauche forms. Using all theoretical models considered here the trans form is more stable than the gauche form, but the relative energy is very small in agreement with previous studies [14,32]. At the highest correlation level, $\operatorname{CCSD}(\mathrm{T})$, the difference is only $0.16 \mathrm{kcal} / \mathrm{mol}$, in very good agreement with the result of $0.14 \mathrm{kcal} / \mathrm{mol} \mathrm{ob-}$ tained in [14] using density functional theory. When ethanol is hydrogen bonded to water the difference in relative energy for the trans and gauche heterodimers is considerably smaller. Taking the MP2 level and considering the vibration zero point energy the difference is essentially null. The total energy of the water-ethanol system is the same whether the ethanol is in the trans or gauche form. A more delicate situation is involved when considering the ethanol dimer because of the large variety of conformers [14,33]. Recent investigations have shown that these conformers have equivalent binding energies. For instance, the trans-gauche differs from the trans-trans by less than $0.06 \mathrm{kcal} / \mathrm{mol}$ [14]. The gauche-gauche has a larger difference but still less than $0.3 \mathrm{kcal} / \mathrm{mol}$. Explicit consideration of all possible conformers of the ethanol dimer would depart us from the present focus of interest. In the following we consider the ethanol dimer only in the trans-trans form.

Table 3 gives the calculated binding energies of all eleven hydrogen-bonded systems considered here and it allows a systematic analysis of the relative strengths of the different isomers. Note that for the ethanol-water case we find that the water donor heterodimer is more stable by the same amount regardless whether one is considering the gauche or the trans form. For instance, at the MP2 level, considering zero point vibration correction, the relative stability is $0.71 \mathrm{kcal} / \mathrm{mol}$ for both the trans and gauche forms. The $\operatorname{CCSD}(\mathrm{T})$ and the

Table 2

Total (in hartree) and relative (in $\mathrm{kcal} / \mathrm{mol}$ ) energies of the heterodimers of ethanol (trans and gauche) and water

\begin{tabular}{|c|c|c|c|c|c|c|c|c|c|}
\hline Method & Ethanol $(t)$ & Ethanol $(g)$ & $\Delta(t-g)$ & $\mathrm{WE}_{t}$ & WE & $\Delta(t g)$ & $\mathrm{E}_{t} \mathrm{~W}$ & $\mathrm{E}_{\mathrm{s}} \mathrm{W}$ & $\Delta(t g)$ \\
\hline MP2 & -154.6138168 & -154.6134132 & -0.25 & -230.8854660 & -230.8855302 & 0.04 & -230.8829932 & -230.8831952 & 0.13 \\
\hline MP3 & -154.6430265 & -154.6427844 & -0.15 & -230.9185886 & -230.9187749 & 0.12 & -230.9166726 & -230.9169186 & 0.15 \\
\hline D-MP4 & -154.6550447 & -154.6547702 & -0.17 & -230.9346244 & -230.9347633 & 0.09 & -230.9326387 & -230.9328562 & 0.14 \\
\hline DQ-MP4 & -154.6461873 & -154.6458418 & -0.22 & -230.9228668 & -230.9229440 & 0.05 & -230.920969 & -230.9211134 & 0.09 \\
\hline SDQ-MP4 & -154.650142 & -154.6498259 & -0.20 & -230.9288678 & -230.9289611 & 0.06 & -230.9268192 & -230.9270091 & 0.12 \\
\hline MP4 & -154.6662887 & -154.6660202 & -0.17 & -230.9516194 & -230.9517403 & 0.08 & -230.9492452 & -230.9495416 & 0.19 \\
\hline CCSD & -154.6499184 & -154.6495985 & -0.20 & -230.9283676 & -230.9284528 & 0.05 & -230.9263727 & -230.9265515 & 0.11 \\
\hline $\operatorname{CcSD}(\mathrm{T})$ & -154.6661319 & -154.6658739 & -0.16 & -230.9507304 & -230.9508539 & 0.08 & -230.9484605 & -230.9487488 & 0.18 \\
\hline $\mathrm{MP} 2+\mathrm{ZPE}$ & & & -0.21 & & & -0.01 & & & 0.05 \\
\hline
\end{tabular}

The acronym DA stands for proton acceptor and donor, respectively. $\mathrm{E}_{g}$ stands for the gauche form of ethanol. All calculations are made using the MP2/aug-cc-pVDZ optimized geometry. $\triangle$ ZPE stands for zero point energy difference obtained using MP2/aug-cc-pVDZ.

Table 3

Calculated counterpoise corrected binding energies $(\mathrm{kcal} / \mathrm{mol})$ of the heterodimer complexes

\begin{tabular}{|c|c|c|c|c|c|c|c|c|c|c|c|}
\hline Method & WW & MM & $\mathrm{EE}$ & WM & MW & WE & EW & $\mathrm{WE}_{\boldsymbol{g}}$ & $\mathrm{E}_{g} \mathrm{~W}$ & $\mathrm{ME}$ & EM \\
\hline MP2 & 4.46 & 5.22 & 5.69 & 5.15 & 4.48 & 5.49 & 4.27 & 5.78 & 4.53 & 5.15 & 5.08 \\
\hline MP3 & 4.39 & 4.96 & 5.34 & 4.90 & 4.40 & 5.18 & 4.21 & 5.46 & 4.40 & 4.91 & 4.83 \\
\hline D-MP4 & 4.31 & 4.88 & 5.25 & 4.82 & 4.32 & 5.10 & 4.13 & 5.37 & 4.33 & 4.83 & 4.75 \\
\hline DQ-MP4 & 4.20 & 4.69 & 4.96 & 4.67 & 4.17 & 4.92 & 3.96 & 5.19 & 4.17 & 4.63 & 4.53 \\
\hline SDQ-MP4 & 4.23 & 4.80 & 5.14 & 4.76 & 4.22 & 5.03 & 4.03 & 5.30 & 4.24 & 4.74 & 4.66 \\
\hline MP4 & 4.39 & 5.14 & 5.68 & 5.04 & 4.44 & 5.38 & 4.27 & 5.65 & 4.50 & 5.11 & 5.06 \\
\hline CCSD & 4.23 & 4.77 & 5.09 & 4.74 & 4.22 & 5.01 & 4.02 & 5.27 & 4.23 & 4.70 & 4.63 \\
\hline $\operatorname{CCSD}(\mathrm{T})$ & 4.41 & 5.11 & 5.62 & 5.02 & 4.45 & 5.35 & 4.28 & 5.62 & 4.50 & 5.06 & 5.02 \\
\hline$\triangle \mathrm{ZPE}$ & 2.11 & 1.29 & 1.24 & 1.94 & 1.58 & 1.96 & 1.45 & 2.01 & 1.53 & 1.18 & 0.93 \\
\hline $\mathrm{MP} 2+\triangle \mathrm{ZPE}$ & 2.35 & 3.93 & 4.45 & 3.21 & 2.90 & 3.53 & 2.82 & 3.77 & 3.04 & 3.97 & 4.15 \\
\hline
\end{tabular}

The acronym DA stands for proton acceptor and donor, respectively. $\mathrm{E}_{\mathrm{g}}$ stands for the gauche form of ethanol. All calculations are made using the MP2/aug-cc-pVDZ optimized geometry. $\triangle$ ZPE stands for zero point energy difference between the complex and the separate parts obtained using MP2/aug-cc-pVDZ. 
intermediate MP3 and MP4 results give a clear picture of the role of electron correlation effects on the relative binding energies. The basis set limit estimated for the methanol dimer at the MP2 level [18] is $5.58 \mathrm{kcal} / \mathrm{mol}$. Our MP2 result for the methanol dimer is lower than this basis set limit by ca. $0.4 \mathrm{kcal} / \mathrm{mol}$. At all levels of calculations considered in this work the ethanol dimer is the strongest bond system. MP2 calculations at the HF optimized geometry [22] has found that the binding energy in the ethanol dimer is stronger than the methanol dimer by $0.5-0.8 \mathrm{kcal} / \mathrm{mol}$. Our results for the transtrans form are consistent with this picture giving more stability to the ethanol dimer by a value of $0.5 \mathrm{kcal} /$ mol using MP2 and CCSD(T).

We now consider the alcohol-water heterodimers. The results for the MW and WM isomers are similar to the ones obtained before and are consistent in that the WM isomer is more strongly bound than MW by less that $1 \mathrm{kcal} / \mathrm{mol}$ [9-11]. At the MP2 level we find that WM is more stable than MW by $0.7 \mathrm{kcal} / \mathrm{mol}$. This is the same energy difference obtained using the B3LYP model [10], in spite of the fact that the individual binding energies using DFT are slightly higher. This relative energy value decreases to only $0.3 \mathrm{kcal} / \mathrm{mol}$ if the difference in zero point energy vibrations is taken into account. Now we analyze the results for the ethanol-water system. The WE-EW (or $W E_{g}-E_{g} W$ ) heterodimer difference is the largest difference found among the possible heterodimers considered here. In the cases of alcoholwater mixtures, methanol-water and ethanol-water, it is found that the most stable heterodimer has the alcohol as the proton acceptor and water as the proton donor. But in the case of ethanol the energy difference between the two stable heterodimers is more sizable. The methanol-ethanol system has been more scarcely studied. It is obtained here that these isomers have binding energies of $5.15 \mathrm{kcal} / \mathrm{mol}(\mathrm{ME})$ and $5.08 \mathrm{kcal} / \mathrm{mol}$ (EM) at the second-order MP2 level. We are not aware of any recent theoretical estimate of these binding energies. Here, the $\mathrm{ME}$ is found to be more stable than EM by a negligible amount of less than $0.1 \mathrm{kcal} / \mathrm{mol}$ in all theoretical models considered here, from MP2 to $\operatorname{CCSD}(\mathrm{T})$. Including the difference in zero-point energy vibrations the relative stability, in turn, favors the EM heterodimer by $0.2 \mathrm{kcal} / \mathrm{mol}$. Hence the methanol-ethanol heterodimers have essentially the same binding energy with no indication of a preferred isomer. It can be noted that the relative stability of the different isomers reflects closely the trend of the calculated hydrogen bond distances, as seen in Figs. 2 and 3.

In all the results it is verified that the role of electron correlation effects beyond MP2 are not very important in defining the relative strengths of the different heterodimers. This is not the same as stating that electron correlation effects in hydrogen binding energies are not important but rather that MP2 gives balanced results

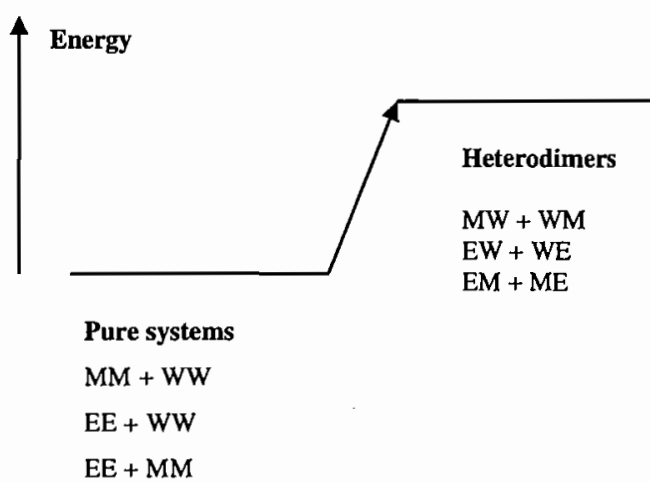

$$
\begin{aligned}
& \mathrm{MM}+\mathrm{WW} \rightarrow \mathrm{MW}+\mathrm{WM}-0.2 \mathrm{kcal} / \mathrm{mol} \\
& \mathrm{EE}+\mathrm{WW} \rightarrow \mathrm{EW}+\mathrm{WE}-0.5 \mathrm{kcal} / \mathrm{mol} \\
& \mathrm{EE}+\mathrm{MM} \rightarrow \mathrm{EM}+\mathrm{ME}-0.3 \mathrm{kcal} / \mathrm{mol} \\
& \mathrm{MM}+\mathrm{WW} \rightarrow 2 \mathrm{WM}-0.1 \mathrm{kcal} / \mathrm{mol}
\end{aligned}
$$

Fig. 4. Relative strengths of homogeneous and mixed systems.

$[34,35]$. In the present systems high-order electron correlation effect is systematic but small. High-level electron correlation, i.e. beyond MP2, in no case considered here gives a different pattern of the relative binding energies of the two possible heterodimers.

An important theoretical information to rationalize liquid mixtures is the energetic involved in making and breaking hydrogen bonds. It has been discussed that methanol-water leads to incomplete mixtures at the microscopic level and this relates to the negative entropy value associated to alcohol-water mixtures [4,5]. Using the MP2 results with zero-point energy corrections extracted from Table 3 it is seen that breaking the methanol-methanol hydrogen bond to form either $\mathrm{MW}$ or WM decreases the stability by ca. $1.0 \mathrm{kcal} / \mathrm{mol}$. The breaking of two hydrogen bonds such as in MM and WW to form MW and WM (MM + WW $\rightarrow$ $\mathrm{MW}+\mathrm{WM}$ ) is calculated to be unfavorable by less than $0.2 \mathrm{kcal} / \mathrm{mol}$, with the MP2 results corrected for zeropoint energy differences. This energetic cost is of course very small. Fig. 4 illustrates some of the relative strengths of the hydrogen bonds obtained here. The small energy differences may explain in part the incomplete mixing in terms of similar relative stabilities. The situation found in a liquid is not the same as that in geometry-optimized complexes but the energies of the methanol-water heterodimers are equivalent also in the liquid case [12].

\section{Summary and conclusions}

Hydrogen binding energies are calculated for two common alcohol and water mixtures using highly correlated methods varying from second-order MP2 to 
$\operatorname{CCSD}(\mathrm{T})$ levels. We find that in the case of methanolwater and ethanol-water the most stable heterodimer is the one where the water plays the role of proton donor. For methanol the relative stability is found to be less than $1.0 \mathrm{kcal} / \mathrm{mol}$ in agreement with previous calculations. In the case of ethanol, either the trans or gauche forms, the difference is larger than 1.0 $\mathrm{kcal} / \mathrm{mol}$. The role played by electron correlation effects beyond second-order MP2 has no influence in the relative stability of the heterodimers. In the case of the methanol-ethanol mixture the counterpoise corrected hydrogen binding energies at the second-order MP2 are 5.15 and $5.08 \mathrm{kcal} / \mathrm{mol}$, for the case where methanol is the proton donor and proton acceptor, respectively. These two isomers are found to have essentially the same energy in all theoretical models considered and no favorite isomer could be discerned. The interplay between these relative energy differences is briefly discussed in possible conjunction with the incomplete mixture of alcohol-water systems.

\section{Acknowledgements}

This work has been partially supported by $\mathrm{CNPq}$ and FAPESP (Brazil).

\section{References}

[1] F. Franks, J.E. Desnoyers, in: F. Franks (Ed.), Water Science Reviews, vol. 1, Cambridge University Press, Cambridge, 1985, p. 171.

[2] F. Franks, D.J.G. Ives, Q. Rev. 20 (1966) 1.

[3] L.A. Curtiss, M. Blander, Chem. Rev. 88 (1988) 827.

[4] S. Dixit, J. Crain, W.C.K. Poon, J.L. Finney, A.K. Soper, Nature 416 (2002) 829.

[5] J.-H. Guo, Y. Luo, A. Augustsson, S. Kashtanov, J.-E. Rubensson, D.K. Shuh, H. Ågren, J. Nordgren, Phys. Rev. Lett. 91 (2003) 157401.
[6] J.E. Del Bene, J. Chem. Phys. 55 (1971) 4633.

[7] S. Kim, M.S. Jho, H.A. Scheraga, J. Phys. Chem. 92 (1988) 7216

[8] N. Bakkas, Y. Bouteiller, A. Loutellier, J.P. Perchard, S. Racine, Chem. Phys. Lett. 232 (1995) 90.

[9] P.A. Stockman, G.A. Blake, F.J. Lovas, R.D. Suenran, J. Chem. Phys. 107 (1997) 3782.

[10] L. González, O. Mó, M. Yáñes, J. Chem. Phys. 109 (1998) 139.

[11] K.N. Kirschner, R.J. Woods, J. Phys. Chem. A 105 (2001) 4150.

[12] E.E. Fileti, K. Coutinho, S. Canuto, Adv. Quantum Chem. 47 (2004) 51.

[13] N. Bakkas, Y. Bouteiller, A. Loutellier, J.P. Perchard, S. Racine, J. Chem. Phys. 99 (1993) 3335.

[14] L. González, O. Mó, M. Yáñes, J. Chem. Phys. 111 (1999) 3855 .

[15] T.S. van Erp, E.J. Meijer, Chem. Phys. Lett. 333 (2001) 290.

[16] M. Masella, J.P. Flament, J. Chem. Phys. 108 (1998) 7141.

[17] S. Tsuzuki, H.P. Lüthi, J. Chem. Phys. 114 (2001) 3949.

[18] S. Tsuzuki, T. Uchimaru, K. Matsumura, M. Mikami, K. Tanabe, J. Chem. Phys. 110 (1999) 11906.

[19] R.A. Provençal, R.N. Casaes, K. Roth, J.B. Paul, C.N. Chapo, R.J. Saykally, G.S. Tschumper, H.F. Scheffer III, J. Phys. Chem. A 104 (2000) 1423.

[20] M. Mandado, A.N. Graña, R.A. Mosquera, Chem. Phys. Lett. 381 (2003) 22.

[21] O. Mó, M. Yáñes, J. Elguero, J. Chem. Phys. 107 (1997) 3592.

[22] A.K. Sum, S.I. Sandler, J. Phys. Chem. A 104 (2000) 1121.

[23] M. Masella, J.P. Flament, Mol. Phys. 95 (1998) 97.

[24] T.H. Dunning Jr., J.Chem. Phys. 90 (1989) 1007.

[25] K. Raghavachari, Ann. Rev. Phys. Chem. 42 (1991) 615.

[26] R.J. Bartlett, J. Phys. Chem. 93 (1989) 1697.

[27] S.F. Boys, F. Bernardi, Mol. Phys. 19 (1970) 553.

[28] J.E. del Bene, I. Shavitt, in: S. Scheiner (Ed.), Molecular Interactions from van der Waals to Strongly Bound Complexes, Wiley, New York, 1997, p. 157.

[29] M.J. Frisch et al., Gaussian 98, Revision A7, Gaussian, Pittsburgh, 1998.

[30] S.A. Clough, Y. Beers, G.P. Klein, L.S. Rothman, J. Chem. Phys. 59 (1973).

[31] D.R. Lide (Ed.), Handbook of Chemistry and Physics, 73rd edn., 1992-1993, CRC-Press, Boca Raton, 1992.

[32] R.A. Shaw, H. Wieser, R. Dutler, A. Rauk, J. Am. Chem. Soc. 112 (1990) 5401.

[33] M. Ehbrecht, F. Huisken, J. Phys. Chem. A 101 (1997) 7768.

[34] B.J. Smith, D.J. Swanton, J.A. Pople, H.F. Schaefer III, L. Radom, J. Chem. Phys. 92 (1990) 1240.

[35] R. Rivelino, S. Canuto, Chem. Phys. Lett. 322 (2000) 207. 


\title{
Electronic changes due to thermal disorder of hydrogen bonds in liquids: Pyridine in an aqueous environment
}

\author{
Eudes E. Fileti \\ Instituto de Fisica, Universidade de São Paulo, CP 66318, 05315-970 São Paulo, SP, Brazil \\ Kaline Coutinho \\ Universidade de Mogi das Cruzes, CP 411, 08701-970 Mogi das Cruzes, SP, Brazil \\ Thaciana Malaspina and Sylvio Canuto* \\ Instituto de Física, Universidade de São Paulo, CP 66318, 05315-970 São Paulo, SP, Brazil
}

(Received 21 January 2003; published 18 June 2003)

\begin{abstract}
Combined Metropolis Monte Carlo computer simulation and first-principles quantum mechanical calculations of pyridine in water are performed to analyze the role of thermal disorder in the electronic properties of hydrogen bonds in an aqueous environment. The simulation uses the $N V T$ ensemble and includes one pyridine and 400 water molecules. Using a very efficient geometric-energetic criterion, the hydrogen bonds between pyridine and water $\mathrm{C}_{5} \mathrm{H}_{5} \mathrm{~N}---\mathrm{H}_{2} \mathrm{O}$ are identified and separated for subsequent quantum mechanical calculations of the electronic and spectroscopic properties. Statistically uncorrelated configurations composed of one pyridine and one water molecule are used to represent the configuration space of the hydrogen bonds in the liquid. The quantum mechanical calculations on these structures are performed at the correlated second-order perturbation theory level and all results are corrected for basis-set superposition error. The results are compared with the equivalent electronic properties of the hydrogen bond in the minimum-energy configuration. Charge transfer, dipole moment, and dipole polarizabilities are calculated for the thermally disordered and minimum-energy structures. In addition, using the mean and anisotropic polarizabilities, the Rayleigh depolarizations are obtained. All properties obtained for the thermally disordered structures are represented by a statistical distribution and a convergence of the average values is obtained. The results indicate that the charge transfer, dipole moment, and average depolarization ratios are systematically decreased in the liquid compared to the optimized cluster. This study quantifies, using ab initio quantum mechanics and statistical analysis, the important aspect of the thermal disorder of the hydrogen bond in a liquid system.
\end{abstract}

DOl: 10.1103/PhysRevE.67.061504

\section{INTRODUCTION}

Water is the most important liquid and the natural biological solvent [1]. Most of the several anomalous behaviors of water are derived from its great ability to form hydrogen bonds and this is fundamental for the existence of life $[2,3]$. The study of hydrogen bonds has been a central topic in chemistry and biology [4-6] for quite some time and it is now attracting considerable interest also in physics [7-9]. Hydrogen bond is indeed a fundamental interaction to understand the thermodynamics of protic liquids and a series of biological phenomena that can only occur in water, including proteins, DNA, and enzymatic reactions. Hydrogen bonds between biomolecules are perhaps the most significant process regulating functions in living systems. Most of our understanding of the electronic structure of hydrogen bonds, and the associated properties and spectra, has been derived from studies in clusters where laser vaporization and jetcooling techniques have produced a large variety of hydrogen-bonded complexes [10-13]. However, the situation found in a cluster is not the same as that in a liquid. Understanding the nature of hydrogen bonds formed between a solute organic molecule and water is crucial for describing

\footnotetext{
${ }^{*}$ Corresponding author. FAX: +55.11.3091-6831; email address: canuto@if.usp.br
}

PACS number(s): $61.25 . \mathrm{Hq}, 31.70 .-\mathrm{f}, 36.40 .-\mathrm{c}, 78.35 .+\mathrm{c}$ several solvation and biomolecular processes [14]. Whereas in a cluster the hydrogen-bond structure is fixed by a minimum-energy condition, in the aqueous environment there are several configurations governed by the temperature and the related natural disorder of the liquid. Therefore, the proton-acceptor site of a solute molecule in an aqueous environment experiences a great local thermal disorder. The theoretical description of this disorder is a great challenge and it is necessary for the understanding of the important local electronic effects. The hydrogen bonds lead to a local change in the electronic environment and thus also in the atomic charges, dipole moment, and dipole polarizability. Instead of a single value the electronic properties, such as dipole moment and polarizabilities, are more properly described by a statistical distribution of possible values within a certain width. The fluctuation in the electronic anisotropy of a single molecule leads to gas phase depolarization of the light scattered [15]. The dipole anisotropy in the liquid is also responsible for the depolarization of the elastic light scattered [15-17], but the depolarization ratio is now likewise given by a distribution of values. This distribution is a measure of the manifestation of the local electronic change due to the hydrogen bonds formed in the liquid situation, compared to the cluster optimized. The Rayleigh depolarization is one of the important properties that are derived from the polarizabilities, and can serve as an additional useful spectroscopic distinction of hydrogen bonds in clusters and 
in liquids. In this paper, we thus analyze in great detail the local change of the electronic structure calculating charges, dipole moment, and polarizabilities, and from these the Rayleigh light scattering [15-18] in a hydrogen-bonded cluster and in the liquid case. This is used as a quantitative characterization of the influence of the thermal disorder.

Motivated by the strong interest involved in six-member nitrogenated aromatic rings, as the building block of proteins and nucleotides [14], the system considered here is the pyridine-water $\mathrm{C}_{5} \mathrm{H}_{5} \mathrm{~N}---\mathrm{H}_{2} \mathrm{O}$ system. In this case, the nitrogen atom of the pyridine molecule is the proton acceptor that makes a hydrogen bond with the hydrogen proton donor of water. We study the local changes in the atomic charges, dipole moment, and dipole polarizabilities of hydrogenbonded pyridine-water using first-principles quantum mechanical methods in both situations, i.e., the cluster optimized and the disordered liquid. The different results are used for a comparison between the hydrogen bond in the cluster and in the liquid, hence giving a theoretical quantitative information about the influence of the local disorder.

The major difficulties in studying hydrogen bonds in liquids are related to a very large number of possible structures at a given temperature, the nontrivial identification of these bonds in a liquid, and the difficulty in obtaining statistically converged results. All these points are, in fact, related to a correct and realistic representation of the configuration space occupied by the hydrogen-bonded structures. These points are considered and successfully handled here, and we are then able to give an $a b$ initio quantitative study of the influence of the local thermally driven disorder in the spectroscopic changes that arise because of hydrogen-bond formation between a molecule and its aqueous environment.

\section{THEORETICAL METHODOLOGY}

The structure of the liquid is first generated by Metropolis Monte Carlo (MC) computer simulation, using the DICE Monte Carlo statistical mechanics program [19]. The simulations are performed in the canonical $(N V T)$ ensemble with one pyridine molecule plus 400 water molecules using the experimental density of water, which at $T=298.15 \mathrm{~K}$ is $0.9966 \mathrm{~g} / \mathrm{cm}^{3}$. The intermolecular interactions are described by the standard Lennard-Jones plus Coulomb potential. For the water molecules we use the SPC potential [20] and for pyridine we use the 11-site OPLS potential [21]. In the calculation of the pairwise energy, each molecule interacts with all other molecules within a center of mass separation that is smaller than the cutoff radius $r_{c}=11.9 \AA$. For separations larger than $r_{c}$, we use the long range correction of the potential energy [22]. The simulations consisted of a thermalization stage of $2.0 \times 10^{6} \mathrm{MC}$ steps followed by a long averaging stage of $80.0 \times 10^{6} \mathrm{MC}$ steps, where the configurations are generated. Successive configurations generated in the MC simulation, which are statistically highly correlated, will not give important additional information. Therefore, we calculate the interval of statistical correlation using the autocorrelation function of the energy [23-25]. For the simulations presented here, after the calculation of the autocorrelation of the energy, we obtain that configurations separated by 320

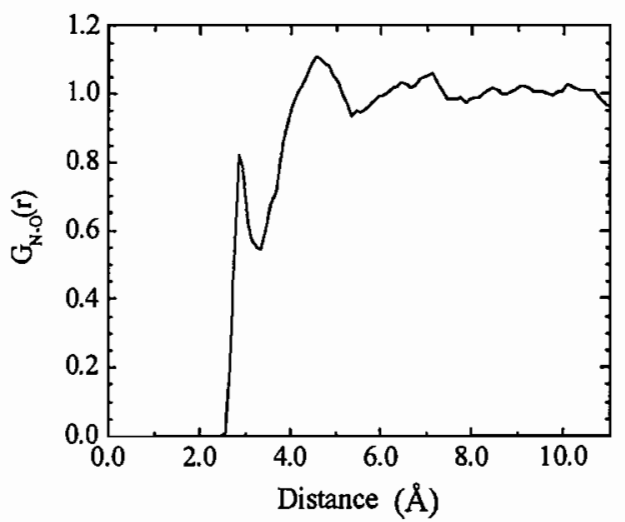

FIG. 1. The radial distribution function between the nitrogen atom of the pyridine and oxygen atom of the water molecules.

$\times 10^{3}$ MC steps are statistically relevant (less than $10 \%$ statistically correlated). Then, the number of configurations is reduced to 250 uncorrelated configurations without loss of statistical information [26-28]. Thus, after the entire simulation, 250 uncorrelated configurations separated by 320 $\times 10^{3} \mathrm{MC}$ steps were sampled. An important point now is the identification of the hydrogen bonds in the structures generated in the Monte Carlo simulation. Hydrogen bonds are normally extracted from computer simulation using the pairwise radial distribution function. This gives the coordination of water molecules around the solute, but it cannot be assured that all near-neighbor water molecules are indeed hydrogen bonded [28-32]. This point has been the subject of great concern and the definition of a hydrogen bond in a liquid is not unanimously free from ambiguity. Furthermore, lying close to the solute molecule is not a sufficient condition for a hydrogen-bonded structure as this can be a mere consequence of packing. A very efficient procedure can be obtained using in addition to a geometric, also an energetic criterion [24,26,28-31]. We consider here a hydrogenbonded structure when the distance $R_{\mathrm{N}-\mathrm{O}} \leqslant 3.5 \AA$, the angle $\theta(\mathrm{NÔH}) \leqslant 30^{\circ}$, and the binding energy is larger than 2.0 $\mathrm{kcal} / \mathrm{mol}$. These geometric conditions are obtained from the radial and the angular distribution function. For the energetic criterion, it is important to look at the pairwise energy distribution. First, Fig. 1 shows the pairwise radial distribution function between the $\mathrm{N}$ atom of pyridine and $\mathrm{O}$ atom of water. The first peak in the $G_{\mathrm{N}-\mathrm{o}}(r)$ distribution function starts at $2.45 \AA$ and ends at $3.5 \AA$, with a maximum at 2.94 $\AA$. Hydrogen bonds can be located then for the distance $R_{\mathrm{N}-\mathrm{O}} \leqslant 3.5 \AA$. A similar analysis gives the criterion for the angle $\theta(\mathrm{NO} H) \leqslant 30^{\circ}$. Figure 2 identifies the hydrogen bonds for pairwise pyridine-water interaction energy less than -2.0 $\mathrm{kcal} / \mathrm{mol}$. Using these criteria, in the $250 \mathrm{MC}$ configurations we find 269 hydrogen bonds formed in the nitrogen atom of pyridine. More specifically, we find that in $17 \%$ of the configurations the pyridine does not form any hydrogen bonds, in $62 \%$ it forms one, in $20 \%$ it forms two, and in only $1 \%$ it forms three hydrogen bonds. This gives an average of 1.1 hydrogen bonds. There is a total of 155 configurations making one hydrogen bond. All these 155 structures composed of 


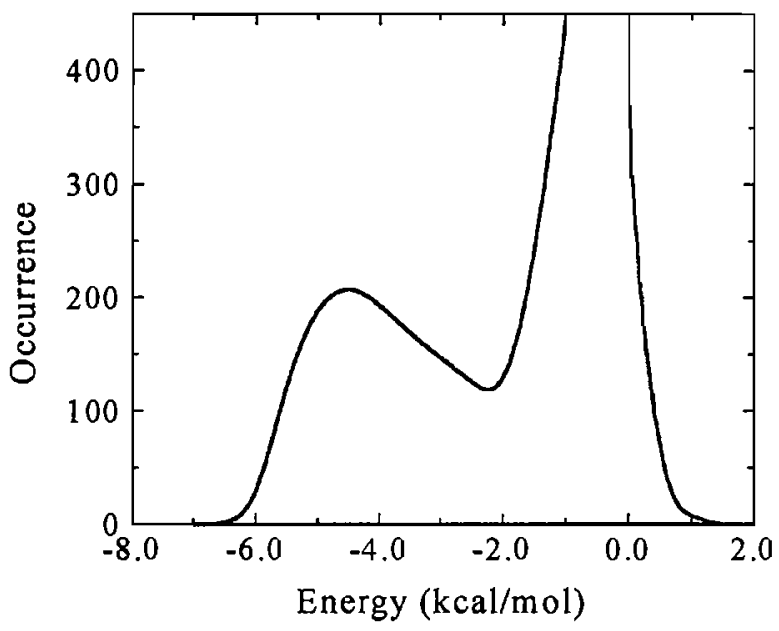

FIG. 2. Histogram of the pairwise energy interaction between pyridine and water.

one pyridine and one water will be submitted to the quantum mechanical calculations. Figure 3 shows, in a single picture, the superposition of all these (1:1) 155 hydrogen-bond structures in the liquid. It clearly shows the efficiency of the identification and the sampling procedure for obtaining hydrogen bonds formed between pyridine and water. Indeed, it can be seen how well the configuration space is filled with all water molecules being indeed hydrogen bonded to the nitrogen site of pyridine. Figure 4 gives the calculated fully optimized structure for the single $(1: 1)$ cluster. The calculated hydrogen-bond distance $\mathrm{N}--\mathrm{H}$ in the cluster is $1.964 \AA$, corresponding to a distance N-O of $2.947 \AA$. For comparison, in the liquid case, this average distance is calculated as 2.94 $\pm 0.16 \AA$.

Light scattering cross section and depolarization are related to the anisotropy of the electronic polarization of a molecular system. As the hydrogen-bond formation leads to

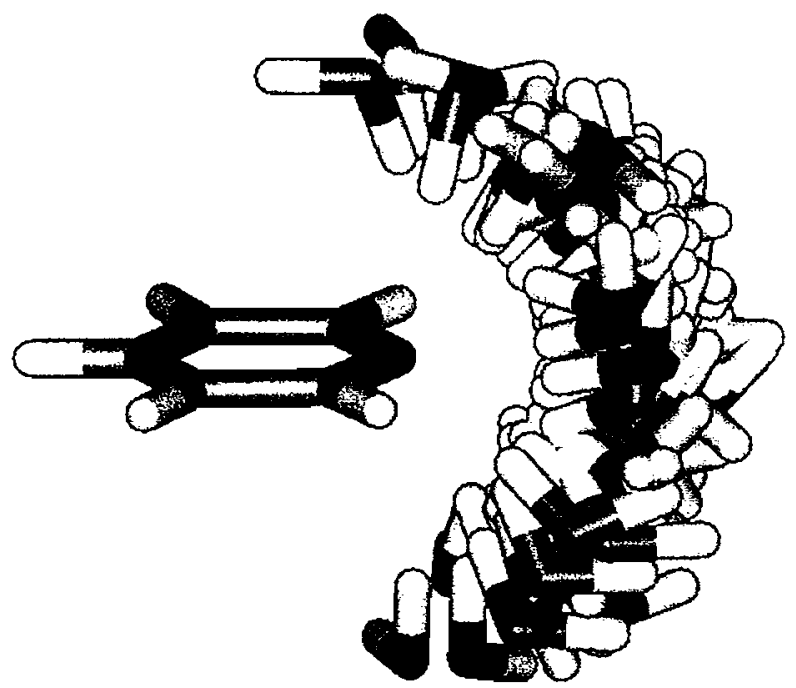

FIG. 3. (Color online) Superposition of configurations of the hydrogen bond formed by pyridine in an aqueous solution.

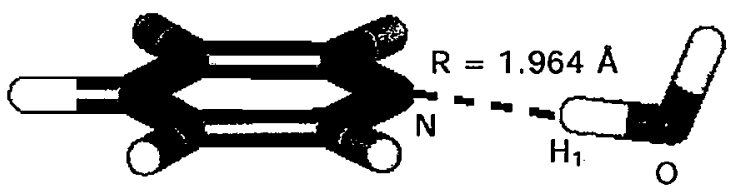

FIG. 4. The structure of the optimized pyridine-water cluster

a change in the anisotropy, it should lead to a corresponding change in the light depolarization. In the case of the elastic Rayleigh scattering, the degree of depolarization $(\sigma)$ and intensity of the light scattered $(\mathfrak{R})$ at right angles to the direction of incidence for natural and plane-polarized light are given by $[15,18]$

$$
\begin{array}{cc}
\sigma_{n}=\frac{6(\Delta \alpha)^{2}}{45(\bar{\alpha})^{2}+7(\Delta \alpha)^{2}}, & \Re_{n}=45(\bar{\alpha})^{2}+13(\Delta \alpha)^{2}, \\
\sigma_{p}=\frac{3(\Delta \alpha)^{2}}{45(\bar{\alpha})^{2}+4(\Delta \alpha)^{2}}, & \Re_{p}=45(\bar{\alpha})^{2}+7(\Delta \alpha)^{2} .
\end{array}
$$

The mean $(\alpha)$ and anisotropic $(\Delta \alpha)$ dipole polarizabilities are the invariants of the polarizability tensor and are given by

$$
\bar{\alpha}=\frac{1}{3}\left(\alpha_{x x}+\alpha_{y y}+\alpha_{z z}\right)
$$

and

$$
\begin{aligned}
(\Delta \alpha)^{2}= & \frac{1}{2}\left[\left(\alpha_{x x}-\alpha_{y y}\right)^{2}+\left(\alpha_{y y}-\alpha_{z z}\right)^{2}+\left(\alpha_{z z}-\alpha_{x x}\right)^{2}\right] \\
& +3\left[\left(\alpha_{x y}\right)^{2}+\left(\alpha_{x z}\right)^{2}+\left(\alpha_{y z}\right)^{2}\right] .
\end{aligned}
$$

The maximum values of $\sigma$ in the Rayleigh scattering corresponds to the most anisotropic case, corresponding to the extreme where $\Delta \alpha=3 \alpha$. In this case, $\sigma_{n}^{\max }=1 / 2$ and $\sigma_{p}^{\max }$ $=1 / 3$. It is also of interest to obtain the depolarization for circularly polarized light. The light circularly polarized scattered backwards may have a component of circular polarization. The degree of reversal is given by [15]

$$
\sigma_{c}=\sigma_{n} /\left(1-\sigma_{n}\right)
$$

It is easy to see that in this case $\sigma_{c}^{\max }$ is 1 .

The dipole moment and dipole polarizabilities are calculated individually for each of the 155 (1:1) structures separated from the MC simulation of the liquid and for the optimized (1:1) cluster using the second-order many-body perturbation theory [33] with the Møller-Plesset partitioning [34], using the MP2/6-31+G(d) theoretical model, using GAUSSIAN98 [35].

\section{RESULTS AND DISCUSSIONS}

We first discuss the local atomic charges as they play a central role in the physical model of the hydrogen bond $[4,5,13]$. The dominant view adopts the idea that electrostatic interaction is the major contributor toward a realistic model of hydrogen bonds [13,36-39]. There has also been some debate on the charge transfer [39-42] and covalent effects [43-45]. Some recent studies argue that charge transfer cannot be ignored and may give a significant contribution to 


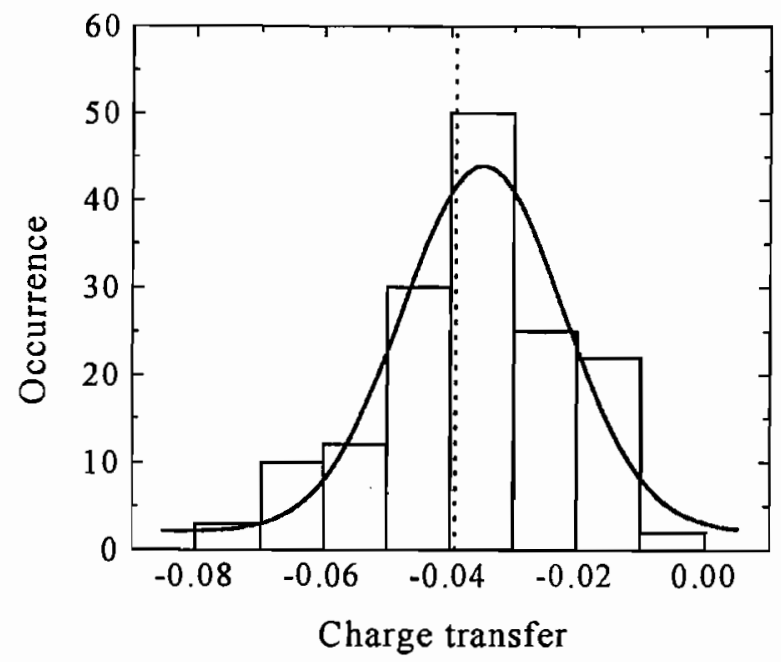

FIG. 5. Charge transfer (in elementary charge unit) from pyridine to water and comparison with the cluster value (vertical dotted line).

stabilize hydrogen bonds [41,42,46-48]. The criticism of computational artifact related to charge transfer has been considered in a recent and detailed theoretical study [49]. Vaart and Merz [49] contend that charge transfer occurs even in the total absence of basis-set superposition error (BSSE). They find that charge is transferred from the hydrogen-bond acceptor to the hydrogen-bond donor by an amount between 0.01 and 0.05 electrons per hydrogen bond. This is a point of great importance, which will be used here to give a possible distinction between the hydrogen-bond interaction between pyridine and water in the minimum-energy and thermally disordered structures. Although atomic charges are not true physical observables and theoretical values are not unique, the calculated trend can still be useful. Here, we use the Mulliken population analysis and the counterpoise correction [50] to BSSE. So all calculations are made with the full basis set of both pyridine and water. We find here that in the minimum-energy configuration, there is a charge transfer from the pyridine to the water molecule of $-0.039 e$; i.e., the water is more negative upon hydrogen bonding. This result, corrected for BSSE, is in line with the findings of Vaart and Merz [49]. They also made the observation that this result is not very dependent on the quality of the basis set after correcting for BSSE. However, the Mulliken population results that we obtained here are more systematic. Figure 5 shows the result of the charge transfer for the configurations of the liquid. In this case, we obtain a statistical distribution of values. As it can be seen, all configurations present a dominant charge transfer (negative results) to the water. In the average, the pyridine transfers to the water molecule $-0.036 \pm 0.015$ elementary charge. Whether this charge transfer plays a significant role in the strength of the hydrogen bond is a subject of debate. However, we find a systematic transfer in both cases, with magnitude comparable to that obtained by Vaart and Merz [49]. Also, as it can be seen, the hydrogen-bond donor (the water molecule) in the minimum-energy configuration of the complex is only slightly more negative. Hence, the role played by charge transfer will be essentially the same in the cluster-optimized and the thermally disordered structures.

The dipole moments of the cluster-optimized structure and the average value for the disordered pyridine-water liquid structure are given in Table 1 . All these results are again corrected against basis-set superposition error, using the counterpoise correction [50]. The calculated dipole moment for the optimized pyridine-water cluster is $5.07 \mathrm{D}$, reasonably larger than the calculated average dipole moment for the liquid, $4.71 \pm 0.68 \mathrm{D}$. The conclusion is that the disorder leads to a decrease of the combined dipole moment. In a vector model, the dipole moment of the complex is obtained by a simple vector addition of the dipole moment of the separate parts and this gives the value of $4.73 \mathrm{D}$ (cluster) and $4.54 \pm 0.68 \mathrm{D}$. The disordered structures lead to a smaller dipole moment, reducing its value by $5-10 \%$. Of course, the decrease in the dipole moment leads to a decreased dipole interaction and hence a smaller binding of the hydrogen bond in the liquid compared to the hydrogen bond in the minimum-energy pyridine-water configuration. If now we consider the difference between the vector sum approximation and the explicitly calculated result as an induction effect $[5,13,51]$, we can see that induction contributes to less than $10 \%$ both in the cluster and in the thermally disordered structures. Figure 6 shows the distribution of the calculated dipole moment values using the disordered pyridine-water structures and the normal distribution with $\langle\mu\rangle=4.54 \mathrm{D}$ and $s$ $=0.10 \mathrm{D}$.

Dipole polarizability is an important electronic property that has been very much used in cluster characterization [52$54]$, including hydrogen-bonded system $[18,55]$. The interest here is to analyze the changes in dipole polarizabilities coming from thermal disorder of the solute-water system and the

TABLE I. Calculated dipole moment and polarizabilities of hydrogen-bonded pyridine and water. Results shown for the liquid are average values and the standard deviations are also shown. Vector model assumes a simple vector addition of the dipole moments of the separate molecules.

\begin{tabular}{cccc}
\hline \hline & Pyridine & Cluster (1:1) & Liquid (1:1) \\
\hline Dipole moment (D) & 2.51 & 5.07 & $4.71 \pm 0.68$ \\
Vector model & & 4.73 & $4.54 \pm 0.10$ \\
Dipole polarizability (a.u.) & & & \\
Mean & 60.00 & 68.16 & $68.37 \pm 0.24$ \\
Anisotropy & 35.11 & 39.29 & $37.36 \pm 2.07$ \\
\hline
\end{tabular}




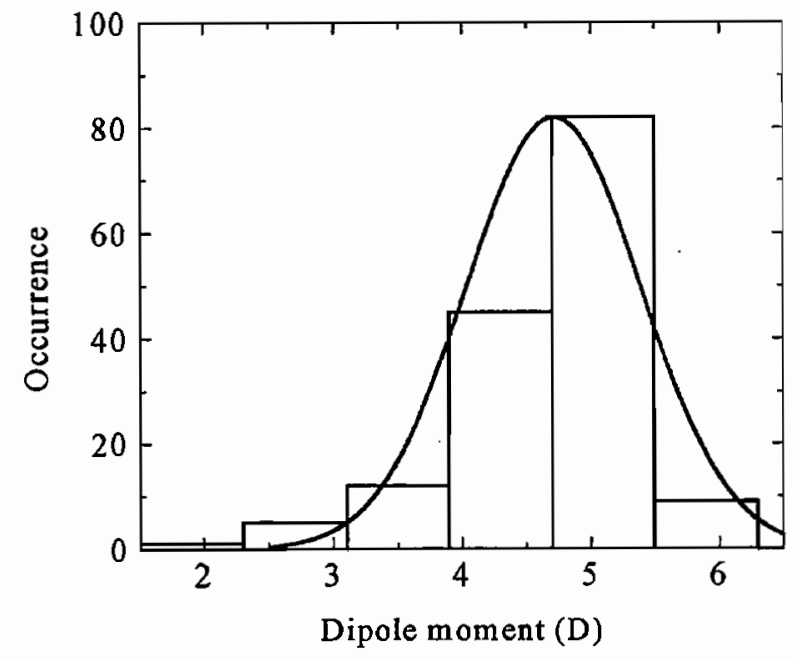

FIG. 6. Distribution of calculated dipole moment values and the normal distribution with $\langle\mu\rangle=4.54 \mathrm{D}$ and $s=0.10 \mathrm{D}$.

consequence of this change in the Rayleigh properties. The calculated polarizabilities for the minimum-energy and thermally disordered systems are summarized in Table II. The mean polarizability of the pyridine-water system is essentially additive, but the anisotropy is more sensitive to the binding. This additivity is not surprising and has been noted before $[18,55,56]$ for geometry-optimized clusters. In the liquid, this additivity is more peculiar because the polarizability becomes a statistical distribution. The mean dipole polarizability is slightly larger due to the distribution of the thermal disorder. The standard deviation $s$ for the liquid reflects the large variation seen in the liquid case. Thus, the final value represented by $\langle\alpha\rangle \pm s$ shows the two information that describe the normal distribution and comprises $68 \%$ of the data. Figure 7 shows the convergence of the calculated mean and anisotropic polarizabilities when the number of configurations $L$ increases up to the maximum $L=155$, used here. The results clearly demonstrate that the average value converges after around 100 quantum-mechanical polarizability calculations. The hydrogen bonds sampled from the MC simulation, and shown previously in Fig. 3, are indeed able to represent the configuration space necessary to give statistically converged results.

The inhomogeneity in the electronic distribution leads to depolarization of the light elastically scattered and this Rayleigh depolarization is obtained from the local dipole polarizabilities. Upon hydrogen-bond formation in the aqueous environment, the depolarization ratios become a distribution

TABLE II. Calculated Rayleigh depolarization ratio $\left(10^{-2}\right)$ of hydrogen-bonded pyridine and water. The results shown for the liquid are average values and the standard deviation in also given.

\begin{tabular}{cccc}
\hline \hline Depolarization & Pyridine & Cluster (1:1) & Liquid (1:1) \\
\hline$\sigma_{p}$ & 2.21 & 2.15 & $1.94 \pm 0.20$ \\
$\sigma_{n}$ & 4.33 & 4.21 & $3.81 \pm 0.38$ \\
$\sigma_{c}$ & 4.53 & 4.40 & $3.96 \pm 0.41$ \\
\hline \hline
\end{tabular}

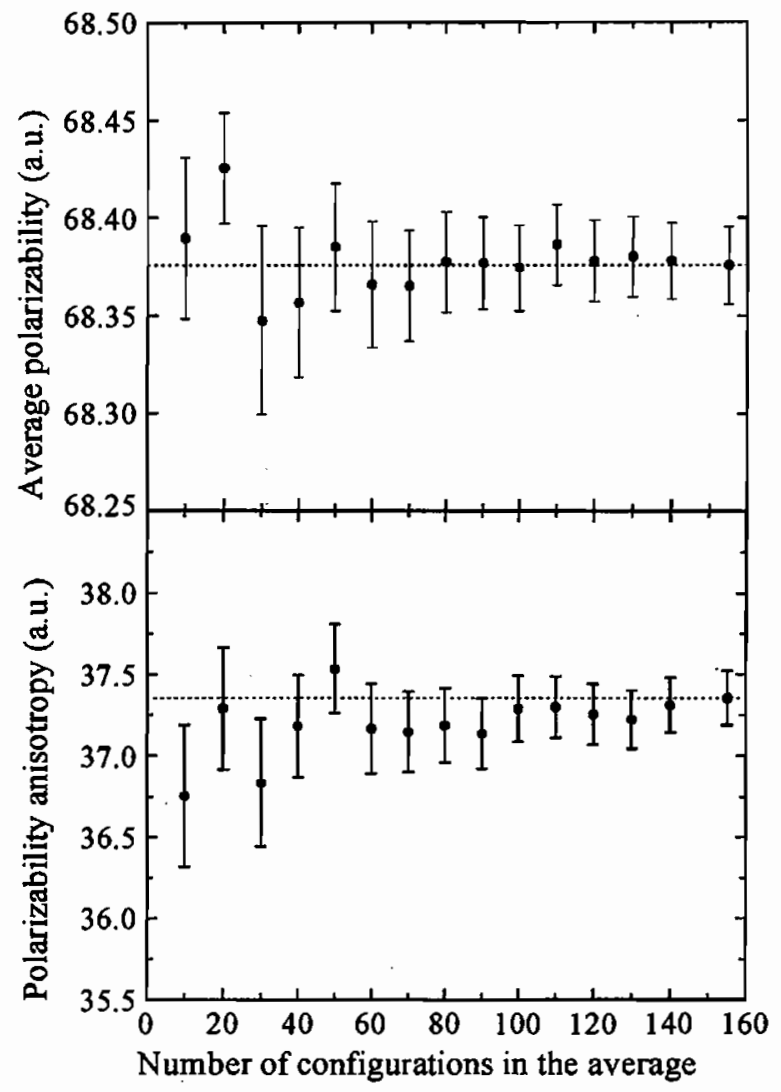

FIG. 7. Convergence of the calculated mean and anisotropic dipole polarizabilities (in atomic units). The statistical error is shown.

with the average value being decreased with respect to the value obtained for the cluster optimized. In the liquid case, these are always smaller than in the cluster-optimized case. A clear distinction between the two cases can be made and it is quite interesting for all polarizations that the reduction in the ratios, going from the optimized to the liquid case, is the same $10 \%$. In general terms, the average result of the depolarization ratios differ by only $10 \%$ from the clusteroptimized case. The thermal motion, however, implies a

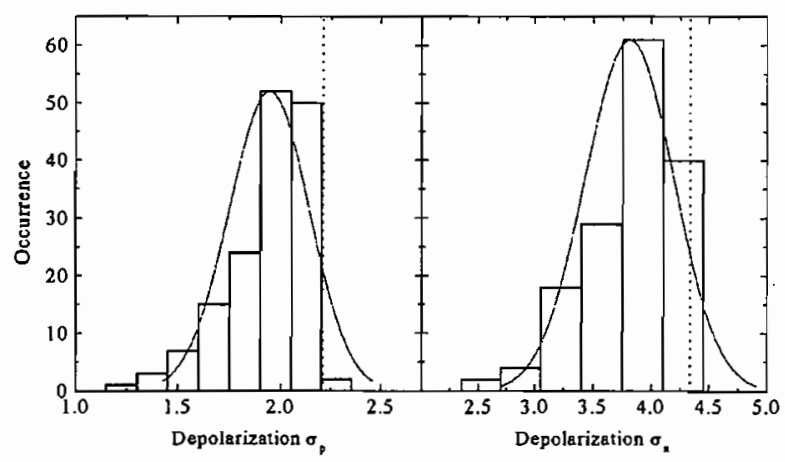

FIG. 8. Histogram showing the distribution of depolarization (dimensionless) in the liquid and comparison with the cluster value (vertical dotted line). 
broadening of the results. Figure 8 shows a comparison between the distribution of depolarization ratios for the disordered liquid structures and the same depolarization for the cluster-optimized case. The calculated values of the depolarization ratios for the minimum-energy case lie outside the half-width of the distribution for the liquid; i.e., they are superior to $85 \%$ of the data points of the normal statistical distribution. Although this is a single-case study, it should be mentioned that similar results have been obtained for other systems, with the depolarization calculated for clusteroptimized hydrogen bond giving values that are higher than those obtained by taking into consideration the thermal distribution of structures. Of course, this could also be extended beyond polarization calculations. As dipole polarizabilities are related to intermolecular forces, the results presented here can also be used for rationalizing the interaction of hydrogen-bonded systems with the outer environment. In this case, the solvent effect in the polarizability has to be properly addressed $[57,58]$. A similar analysis can be made for nuclear-magnetic-resonance chemical shifts [59] and quadrupole coupling constants [60], and, indeed, these can be obtained by using the same theoretical approach. This study is devoted to obtaining quantum mechanical results of liquid systems using statistically converged results.

\section{SUMMARY AND CONCLUSIONS}

Hydrogen bonds are becoming a topic of central interest in chemistry, physics, and biology. Several studies have been performed in recent years, which consider different theoretical and experimental aspects. On the theoretical side, most studies have been performed in clusters and this is indeed of great importance to understand gas phase and even solid state properties. For liquids, however, this is not the proper circumstance, since a liquid has several configurations and cannot be treated by a single structure. Especially, it should not be treated by cluster-optimized structures that represent a minimum-energy configuration, which is artificial for a liquid at room temperature. One of the most important structural aspects of the liquid derives from the thermal disorder that gives the statistical essence of a liquid. In this paper, we have focused on the influence of the thermal disorder in the hydrogen-bond structures that are obtained for the pyridine molecule in an aqueous environment. We chose the dipole moment and dipole polarizability as the probe electronic property, including the anisotropic component of the polarizability that is responsible for the light depolarization. The $a b$ initio quantum mechanical calculations were performed only on the pyridine and the hydrogen-bonded water and the influence of the outer solvent molecules were not considered. Probe calculations indicated that this has only a small influence that is estimated to be less than $10 \%$. Our results for the dipole moment, dipole polarizabilities, and depolarization ratios calculated for the hydrogen-bonded pyridine and water are statistically converged values incorporating the inherent disorder nature of the liquid. Since dipole polarizabilities are related to intermolecular forces, the results presented here can also be used for rationalizing the interaction of hydrogen-bonded systems with the outer environment. Similarly, the dipole moment results show that the disorder affects the local dipole moment. In the liquid environment, the thermal disorder leads to an average dipole moment for the complex that is inferior to that for the cluster optimized. However, in the case studied here, the differences are important but not sizable. The charge transfer from the hydrogenbond acceptor (pyridine) to the hydrogen-bond donor (water) has also been computed. It is found that, on an average, $0.036 e$ is transferred to water. This result is only slightly smaller than that obtained for the minimum-energy cluster $(0.039 e)$. This is indicative that insofar as charge transfer may have a role in the hydrogen bond, in this particular case this role is essentially the same and is not much affected by the thermal disorder. A direct spectroscopic consequence of the dipole polarizability and its anisotropy is the effect of Rayleigh depolarization. Again, the depolarization ratios are given by a distribution, and in the pyridine-water case considered here the standard deviation is about $10 \%$ of the average value. Our results indicate that the average depolarization ratios are systematically decreased in the liquid compared to the optimized cluster for all three polarization cases considered here. The calculated Rayleigh intensities are essentially the same. The depolarization ratios are, however, different for the normal, planar, and circular polarized light; but in all these cases we find a reduction of $10 \%$ in changing from the optimized to the average thermal distribution of the liquid $(1: 1)$ hydrogen bond. Reductions of $20 \%$ have been obtained in other systems under studies in our group. The standard deviation in the present case is also calculated as $\sim 10 \%$ of the average value. This signifies that in the case considered here, the calculated value for the cluster-optimized structure lies in the boundary (see Fig. 8) of $\langle\sigma\rangle+s$. The values lying below $\langle\sigma\rangle+s$ of the distribution of thermal disordered structures, comprising $85 \%$ of the calculated data for the liquid, are smaller than the calculated single value for the cluster-optimized structure. This study quantifies, using $a b$ initio quantum mechanics and statistical analysis, the important aspect of the thermal disorder of the hydrogen bond in a liquid system.

\section{ACKNOWLEDGMENTS}

This work has been partially supported by $\mathrm{CNPq}$ and FAPESP (Brazil).
[1] P. Ball, $\mathrm{H}_{2} \mathrm{O}: \mathrm{A}$ Biography of Water (Orion Publishing, London, 2000)

[2] D. Eisenberg and W. Kauzmann, The Structure and Properties of Water (Clarendon, Oxford, 1969).
[3] F. Franks, Water: A Comprehensive Treatise (Plenum, New York, 1972)

[4] G. A. Jeffrey, An Introduction to Hydrogen Bond (Oxford University Press, Oxford, 1997). 
[5] S. Scheiner, Hydrogen Bonding: A Theoretical Perspective (Oxford University Press, Oxford, 1997).

[6] K. R. Wilson, J. G. Tobin, A. L. Ankudinov, J. J. Rehr, and R. J. Saykally, Phys. Rev. Lett. 85, 4289 (2000).

[7] G. M. Gale, G. Gaillot, F. Hache, N. Lascoux, S. Bratos, and J.-Cl. Leickman, Phys. Rev. Lett. 82, 1068 (1999).

[8] K. Morgenstem and J. Nieminen, Phys. Rev. Lett. 88, 066102 (2002).

[9] J. L. Finney, A. Hallbrucker, I. Kohl, A. K. Soper, and D. T. Bowron, Phys. Rev. Lett. 88, 225503 (2002).

[10] T. S. Zwier, Annu. Rev. Phys. Chem. 47, 205 (1996).

[11] The Chemical Physics of Atomic and Molecular Clusters, edited by G. Scoles (North-Holland, Amsterdam, 1990).

[12] Atomic and Molecular Clusters, edited by E. R. Bernstein (Elsevier, Amsterdam, 1990).

[13] A. D. Buckingham, P. W. Fowler, and J. M. Hutson, Chem. Rev. (Washington, D.C.) 88, 963 (1988)

[14] T. W. Bell, A. B. Khasanov, and M. G. B. Drew, J. Am. Chem. Soc. 124, 14092 (2002).

[15] G. Herzberg, Infrared and Raman Spectra of Polyatomic Molecules (Van Nostrand, Princeton, 1945).

[16] I. L. Fabellinskii, Molecular Scattering of Light (Plenum, New York, 1968).

[17] E. W. Blanch, R. I. Keir, and G. L. D. Ritchie, J. Phys. Chem. A 106, 4257 (2002).

[18] E. E. Fileti, R. Rivelino, and S. Canuto, J. Phys. B 36, 399 (2003).

[19] K. Coutinho and S. Canuto, DICE (Version 2.8) (University of São Paulo, São Paulo, 2000).

[20] H. J. C. Berendsen, J. P. M. Postma, and W. F. van Gunsteren, in Intermolecular Forces, edited by B. Pullman (Reidel, Dordrecht, 1981), p. 331.

[21] W. L. Jorgensen and N. A. McDonald, J. Mol. Struct.: THEOCHEM 424, 145 (1998).

[22] M. P. Allen and D. J. Tildesley, Computer Simulation of Liquids (Oxford University Press, Oxford, 1987).

[23] S. Canuto and K. Coutinho, Adv. Quantum Chem. 28, 90 (1997).

[24] S. Canuto and K. Coutinho, Int. J. Quantum Chem. 77, 192 (2000).

[25] K. Coutinho, S. Canuto, and M. C. Zemer, J. Chem. Phys. 112, 9874 (2000).

[26] K. Coutinho and S. Canuto, J. Chem. Phys. 113, 9132 (2000).

[27] W. R. Rocha, K. Coutinho, W. B. de Almeida, and S. Canuto, Chem. Phys. Lett. 335, 127 (2001).

[28] T. Malaspina, K. Coutinho, and S. Canuto, J. Chem. Phys. 117, $1692(2002)$.

[29] F. H. Stilinger, Adv. Chem. Phys. 31, 1 (1975).

[30] M. Mezei and D. L. Beveridge, J. Chem. Phys. 74, 622 (1981)

[31] W. L. Jorgensen, J. M. Briggs, and M. L. Contreras, J. Phys. Chem. 94, 1683 (1990)

[32] H. Sato and F. Hirata, J. Chem. Phys. 111, 8545 (1999)
[33] R. J. Bartlett J. Phys. Chem. 93, 1697 (1989).

[34] K. Raghavachari, Annu. Rev. Phys. Chem. 42, 615 (1991)

[35] M. J. Frisch et al., GaUSSIAN 98 (Revision A.6) (Gaussian, Inc., Pittsburgh, 1998).

[36] K. Morokuma, Acc. Chem. Res. 10, 294 (1977).

[37] C. E. Dykstra, Chen. Rev. (Washington, D.C.) 93, 2339 (1993).

[38] A. D. Buckingham and P. W. Fowler, J. Chem. Phys. 79, 6426 (1983).

[39] A. J. Stone and A. D. Buckingham, J. Chem. Phys. 107, 1030 (1997).

[40] P. W. Fowler and A. D. Buckingham, Mol. Phys. 50, 1349 (1983).

[41] B. F. King and F. Weinhold, J. Chem. Phys. 103, 333 (1995).

[42] B. F. King, T. C. Farrar, and F. Weinhold, J. Chem. Phys. 103, 348 (1995).

[43] E. D. Isaacs, A. Shukla, P. M. Platzman, D. R. Hamann, B. Barbiellini, and C. A. Tulk, Phys. Rev. Lett. 82, 600 (1999).

[44] T. K. Ghanty, V. N. Staroverov, P. R. Koren, and E. R. Davidson, J. Am. Chem. Soc. 122, 1210 (2000).

[45] J.-H. Guo, Y. Luo, A. Augustsson, J.-E. Rubensson, C. Sathe, H. Agren, H. Siegbahn, and J. Nordgren, Phys. Rev. Lett. 89, $137402(2002)$

[46] G. Comilescu, J.-S. Hu, and A. Bax, J. Am. Chem. Soc. 121, 2949 (1999).

[47] A. J. Dingley and S. Grzesiek, J. Am. Chem. Soc. 120, 8293 (1998).

[48] A. E. Reeds, L. A. Curtiss, and F. Weinhold, Chem. Rev. (Washington, D.C.) 88, 899 (1988).

[49] A. van der Vaart and K. M. Merz, J. Chem. Phys. 116, 7380 (2002).

[50] S. F. Boys and F. Bernardi, Mol. Phys. 19, 553 (1970)

[51] A. D. Buckingham, P. W. Fowler, and A. J. Stone, Int. Rev. Phys. Chem. 5, 107 (1986).

[52] K. D. Bonin and V. Kresin, Electric-dipole Polarizabilities of Atoms, Molecules and Clusters (World Scientific, Singapore, 1997).

[53] V. E. Bazterra, M. C. Caputo, M. B. Ferraro, and P. Fuentealba, J. Chem. Phys. 117, 11158 (2002).

[54] A. Abdurahman, A. Shukla, and G. Seifert, Phys. Rev. B 66, 155423 (2002)

[55] G. Maroulis, J. Chem. Phys. 113, 1813 (2000).

[56] C. E. Dykstra, S.-Y. Liu, and D. J. Malik, J. Mol. Struct.: THEOCHEM 135, 357 (1986).

[57] A. Morita and S. Kato, J. Chem. Phys. 110, 11987 (1999).

[58] L. Jensen, M. Swart, T. Ph. Van Duijnen, and J. G. Snijders, J. Chem. Phys. 117, 3316 (2002).

[59] R. Ludwig, J. A. Bohmann, and T. C. Farrar, J. Chem. Phys. 99, 9681 (1995).

[60] R. Ludwig, F. Weinhold, and T. C. Farrar, J. Chem. Phys. 107, 499 (1997) 


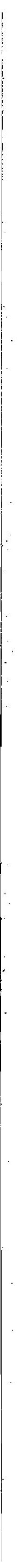




\title{
Is There a Favorite Isomer for Hydrogen-Bonded Methanol in Water?
}

\author{
Eudes E. Fileti ${ }^{1}$, Kaline Coutinho ${ }^{2}$ and Sylvio Canuto ${ }^{1}$ \\ ${ }^{1}$ Instituto de Física, Universidade de São Paulo, \\ CP 66318, 05315-970, São Paulo, SP Brazil. \\ ${ }^{2}$ Universidade de Mogi das Cruzes/CIIB, \\ CP 411, 08701-970, Mogi das Cruzes, SP, Brazil.
}

November 4, 2003

\begin{abstract}
Sequential Monte Carlo/Quantum Mechanical calculations of the interaction energy of hydrogen-bonded methanol in liquid water gives the same result for methanol acting either as the proton donor or the proton acceptor. For the complex-optimized cases methanol acting as the proton acceptor, $\mathrm{CH}_{3} \mathrm{HO} \cdots \mathrm{H}_{2} \mathrm{O}$, is more stable than the proton donor, $\mathrm{CH}_{3} \mathrm{OH} \cdots \mathrm{OH}_{2}$, by $\sim 0.5 \mathrm{kcal} / \mathrm{mol}$. In the case of methanol in liquid water, at room temperature, statistically converged results, using counterpoise corrected MP2/aug-cc-pVDZ calculations, leads to the same binding energy in both cases.
\end{abstract}




\section{Contents}

1 Introduction 3

2 Methods 4

2.1 Monte Carlo Simulation . . . . . . . . . . . . . . 4

2.2 Hydrogen Bonds from Monte Carlo Simulation . . . . . . . . . 5

2.3 Quantum Mechanical Calculations . . . . . . . . . . 8

3 Results 9

3.1 Gas Phase Interaction $\ldots \ldots \ldots \ldots$

3.2 Liquid $(1: 1)$ Interaction . . . . . . . . . . . . . . . . 10

3.3 Statistical Convergence . . . . . . . . . . . . . . 12

4 Final Remarks and Conclusions 12 


\section{Introduction}

Alcohol-water liquids are among the most interesting liquid mixtures[1, 2, 3]. Indeed, alcohol-water exhibits properties that are of great interest in physics, chemistry and biology. To a large extent this is a consequence of the great ability of both water and alcohol to make hydrogen bonds indexhydrogen bond. They are both proton donor and proton acceptor of hydrogen bonds. The methanol-water system can have two hydrogen-bonded structures corresponding to the two possible heterodimers (or isomers) where methanol is a proton acceptor, $\mathrm{CH}_{3} \mathrm{HO} \cdots \mathrm{H}_{2} \mathrm{O}$, or a proton donor, $\mathrm{CH}_{3} \mathrm{OH} \cdots \mathrm{OH}_{2}$, of the hydrogen bond (see figure 1). The existence of these two isomers is easy to realize and the strengths of the two possible interactions are of great interest. In fact they are related to several thermodynamic and physico-chemical properties. For instance, the mixture of methanol and water exhibit an entropy value that is considerably smaller than one should expect $[1,4,5]$. Also there are enormous consequences in the segregation and in the hydrophobic role of the $\mathrm{CH}_{3}$ group leading to fundamental questions regarding the orientational local order $[4,5]$. Methanol-water is one of the simplest examples of the amphoteric relation because both methanol and water can act as proton donor and proton acceptor of hydrogen bonds. The question of which of the two isomers is the more stable is conspicuous. Early theoretical studies have obtained controversial results $[6,7,8,9,10]$ regarding the relative stability of the two isomers. Even experimental results have missed the $\mathrm{CH}_{3} \mathrm{OH} \cdots \mathrm{OH}_{2}$ isomer and obtained only one heterodimer[11]. It was not until very recently that the question has been confidently answered for the gas phase complexes. Detailed microwave rotation-tunneling spectroscopy[12] has set the issue and established that the complex where methanol is the proton acceptor and water is the proton donor, $\mathrm{CH}_{3} \mathrm{HO} \cdots \mathrm{H}_{2} \mathrm{O}$ in figure 1 (left), is the more stable isomer in gas phase. More recent theoretical calculations have indeed confirmed the greater stability of this isomer but obtained a relative stability that is less than $1 \mathrm{kcal} / \mathrm{mol}[13,14]$. Although gas phase results are of interest in their own, it is also clear that the liquid situation may find a broader range of interest for alcohol-water mixtures[15, 16, 17, 18]. Unfortunately, the results obtained for gas phase cannot be directly extrapolated to the liquid situation without a great risk. The hydrogen bonds in a liquid environment certainly do not satisfy a minimum-energy structure. In fact, a liquid is better described by statistical physics and its structure is represented by a great number of possible configurations or molecular arrangements. The thermal 
contribution leads to a decrease of the hydrogen bond interaction $[19,20]$. Hence, the strength of the hydrogen bond formed between methanol and water in gas phase is not the same as in the liquid case. The focus of this present contribution is to clarify this aspect. In fact, we will make an attempt to obtain the relative strength of the two hydrogen-bonded isomers formed between methanol and water in the liquid environment at room temperature. We use Monte Carlo simulation to generate the structure of the liquid composed of methanol in bulk water. Using the structures of the simulation, we identify the hydrogen bonds in the liquid, in both isomeric possibilities, select the configurations and perform ab initio quantum mechanics calculations to obtain the intermolecular strength. These results clarify the relative strengths in the liquid environment and also give a theoretical estimate of the decrease of the hydrogen bond interaction as compared to the gas phase situation.

\section{Methods}

\subsection{Monte Carlo Simulation}

The structure of the liquid is generated by Metropolis Monte Carlo (MC) computer simulation[21], using the DICE Monte Carlo program[22]. The simulations are performed in the canonical $(N V T)$ ensemble with one methanol molecule plus 400 water molecules using the experimental density of water, which at $T=298.15 \mathrm{~K}$ is $0.9966 \mathrm{~g} / \mathrm{cm}^{3}$. The intermolecular interactions are described by the standard Lennard-Jones plus Coulomb potentials. For the water molecules we use the SPC potential[23] and for methanol we use the all-site OPLS-AA potential[24]. Our sequential Monte Carlo/quantum mechanics procedure for generating liquid structure using $\mathrm{MC}$ simulation has been described previously in great detail[19, 20, 25, 26]. The present simulation consisted of an equilibration stage of $2.0 \times 10^{6} \mathrm{MC}$ steps, followed by a long averaging stage of $80.0 \times 10^{6} \mathrm{MC}$ steps, where the equilibrium configurations are generated. Successive configurations generated in the MC simulations, are found to be statistically highly correlated, and will not give important additional information. Therefore we calculate the interval of statistical correlation using the auto-correlation function of the energy[27]. For the simulations presented here, after the calculation of the auto-correlation of the energy we obtain that configurations separated by $4.0 \times 10^{5} \mathrm{MC}$ steps 
are statistically relevant ( $\sim 20 \%$ of statistical correlation). Thus, after the entire simulation, 200 configurations separated by $4.0 \times 10^{5} \mathrm{MC}$ steps were sampled.

\subsection{Hydrogen Bonds from Monte Carlo Simulation}

An important point is the identification of the hydrogen bonds in the structures generated in the Monte Carlo simulation. Hydrogen bonds are normally extracted from computer simulation using the pair-wise radial distribution function[21]. This gives the coordination of water molecules around the solute, but it cannot be assured that all near-neighbor water molecules are indeed hydrogen-bonded. This point has been the subject of previous concern $[19,20,26,27,28]$. The definition of a hydrogen bond in a liquid

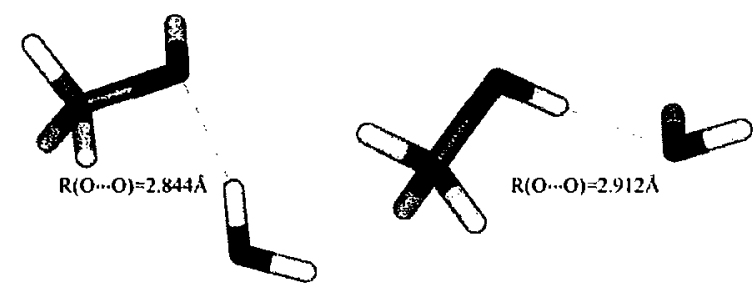

Figure 1: The two isomers of hydrogen-bonded methanol-water.

is not unanimously free from ambiguities. A very efficient procedure however can be obtained using in addition to the geometric, also an energetic criterion[19, 20, 26, 29, 30,31]. Here we identify a hydrogen-bonded structure when the distance $R_{O-O} \leq 3.35 \AA$, the angle $\theta(O-O H) \leq 40^{\circ}$ and the binding energy is larger than $2.5 \mathrm{kcal} / \mathrm{mol}$. These geometric conditions are obtained from the radial and angular distribution functions. For the energetic criterion we look at the pair-wise energy distribution.

First, figure 2 shows the pair-wise radial distribution function between the $\mathrm{O}$ atom of methanol and the $\mathrm{O}$ atom of water. The first peak in this $G_{O-O}(r)$ distribution function starts at $2.45 \AA$ and ends at $3.35 \AA$, with a maximum at $2.75 \AA$. Hydrogen bonds can therefore be located for the distance $R_{O-O} \leq 3.35 \AA$. Similar analysis gives the criterion for the angle $\theta(O-O H) \leq 40^{\circ}$. Figure 3, in turn, identifies the hydrogen bonds for pair-wise methanol-water interaction energy less than $-2.5 \mathrm{kcal} / \mathrm{mol}$. Using these three criteria, in the $200 \mathrm{MC}$ configurations we find 287 hydrogen bonds 


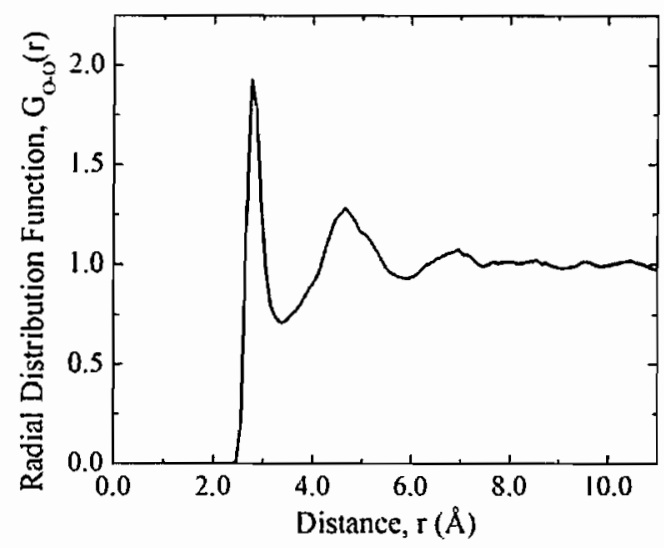

Figure 2: Pairwise radial distribution function between the oxygen atoms of methanol and water.

formed in the $\mathrm{CH}_{3} \mathrm{HO} \cdots \mathrm{H}_{2} \mathrm{O}$ and 160 in the $\mathrm{CH}_{3} \mathrm{OH} \cdots \mathrm{OH}_{2}$ isomers. Table 1 shows the detailed statistics of hydrogen bonds. For the $\mathrm{CH}_{3} \mathrm{HO} \cdots \mathrm{H}_{2} \mathrm{O}$ isomer we find that $7(3.5 \%)$ of the configurations do not form any hydrogen bonds, in 103 (51.5\%) it forms one, and in 86 (43\%) it forms two and in only $4(2 \%)$ it forms three hydrogen bonds. This gives an average of 1.43 hydrogen bond between methanol and water in the $\mathrm{CH}_{3} \mathrm{HO} \cdots \mathrm{H}_{2} \mathrm{O}$ isomer. For the $\mathrm{CH}_{3} \mathrm{OH} \cdots \mathrm{OH}_{2}$ the picture is slightly different and $40(20 \%)$ configurations make no hydrogen bond and the rest, $160(80 \%)$ makes one hydrogen bond, leading to an average of 0.80 hydrogen bond. Because of the

Table 1: Statistics of the hydrogen bonds formed between methanol and water. See text.

\begin{tabular}{ccc}
\hline \hline Number of hydrogen bonds & $\mathrm{CH}_{3} \mathrm{HO} \cdots \mathrm{H}_{2} \mathrm{O}$ & $\overline{\mathrm{CH}_{3} \mathrm{OH} \cdots \mathrm{OH}_{2}}$ \\
\hline 0 & $7(3.5 \%)$ & $40(20.0 \%)$ \\
1 & $103(51.5 \%)$ & $160(80.0 \%)$ \\
2 & $86(43.0 \%)$ & - \\
3 & $4(2.0 \%)$ & - \\
Average & 1.43 & 0.80 \\
\hline
\end{tabular}




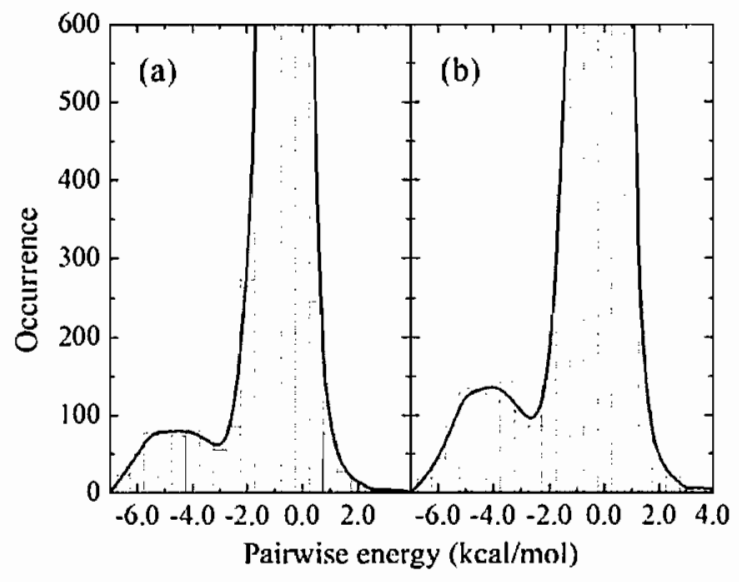

Figure 3: Histogram of the pairwise energy interaction between methanol and water. (a) is the $\mathrm{CH}_{3} \mathrm{OH} \cdots \mathrm{OH}_{2}$ isomer and (b) is the $\mathrm{CH}_{3} \mathrm{HO} \cdots \mathrm{H}_{2} \mathrm{O}$.

great diversity of structures of methanol-water mixture[18] an explanation is needed. The physical situation considered here is methanol in extreme dilution in water. Hence, only one methanol molecule is considered. In a liquid mixture with proper proportion there will also be configurations where two methanol molecules acting as proton donor are hydrogen-bonded to a single water molecule. This, however, will not be present here giving a more simplified picture and a more direct comparison with the (1:1) gas phase result. Thus we will focus in the 103 configurations making one hydrogen bond in the $\mathrm{CH}_{3} \mathrm{HO} \cdots \mathrm{H}_{2} \mathrm{O}$ and 160 configurations in $\mathrm{CH}_{3} \mathrm{OH} \cdots \mathrm{OH}_{2}$. All these (1:1) structures composed of one methanol and one water molecule will be submitted to the quantum mechanical calculations. In fact statistical convergence is obtained before we use all these hydrogen-bonded structures.

Figure 4 shows, in a single picture, the superposition of all these (1:1) hydrogen bond structures in the liquid, for both isomers. It clearly shows the efficiency of the identification and the sampling procedure for obtaining hydrogen bonds formed between methanol and water. Indeed, it can be seen how the configuration space is filled and the water molecules hydrogen bonded to the methanol. The calculated hydrogen bond distance $\mathrm{O}-\mathrm{O}$ in the complex is $2.844 \AA$, for the $\mathrm{CH}_{3} \mathrm{HO} \cdots \mathrm{H}_{2} \mathrm{O}$ isomer and $2.912 \AA$ for the $\mathrm{CH}_{3} \mathrm{OH} \cdots \mathrm{OH}_{2}$ isomer. For comparison, in the (1:1) liquid case, the average 

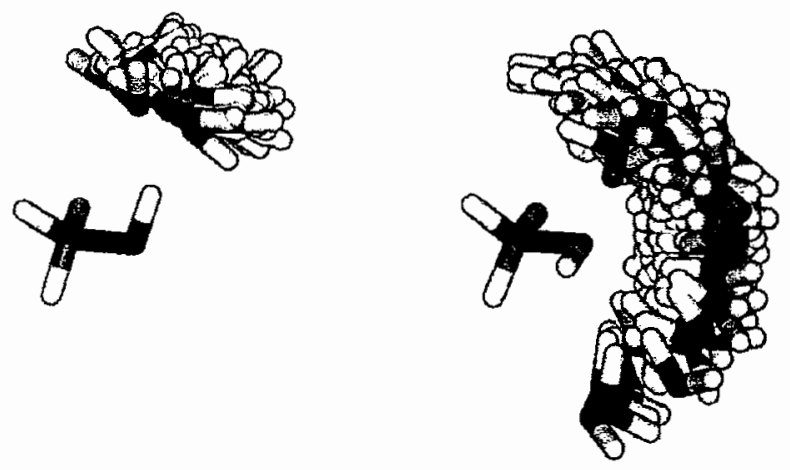

Figure 4: Superposition of configurations of the hydrogen bonds formed by methanol in aqueous solution.

distances are calculated as $2.84 \pm 0.16 \AA$ and $2.84 \pm 0.15 \AA$, respectively.

\subsection{Quantum Mechanical Calculations}

The major interest of this paper is the calculation of the binding energy of methanol in liquid water and a comparison with the result obtained for the optimized (1:1) cluster. All binding energies are obtained using counterpoise correction[32] to basis set superposition error (BSSE), i.e.;

$$
\triangle E_{A B}^{C P}=E_{A B}-E_{(A) B}-E_{A(B)}
$$

where, as usual, $E_{A B}$ is the energy of the complex, $E_{A(B)}$ is the energy of the monomer $A$ obtained with the entire basis set, including the basis set of monomer $B$, and $E_{B(A)}$ is the equivalent for the monomer $B$.

As the appropriate Boltzmann weights are included in the Metropolis Monte Carlo sampling technique the average value of the binding energy, or any other property calculated from the $\mathrm{MC}$ data, is given as a simple average over a chain of size $L$ of energy values:

$$
\langle E\rangle=\frac{1}{L} \sum_{i}^{\mathrm{L}} E_{i}
$$

The quantum mechanical energies and properties are calculated individually for each of the (1:1) structures extracted from the MC simulation of the liquid and for the optimized (1:1) complexes using many-body perturbation theory in second-order with the Moller-Plesset partitioning[33], using the MP2/aug-cc-pVDZ theoretical model, implemented in the Gaussian 98 program [34]. 
Table 2: Calculated binding energies (kcal/mol) of the two hydrogen-bonded methanol-water isomers in gas phase. All present calculations are made using the geometry optimized with MP2/aug-cc-pVDZ. B3LYP stands for the DFT calculations of González et al[13] using the B3LYP/6-311+G(d,p) optimized geometry. ZPE stands for zero point energy difference between the complex and the separate parts using MP2/aug-cc-pVDZ.

\begin{tabular}{cccc}
\hline \hline & & & Relative \\
Method & $\mathrm{CH}_{3} \mathrm{HO} \cdots \mathrm{H}_{2} \mathrm{O}$ & $\mathrm{CH}_{3} \mathrm{OH} \cdots \mathrm{OH}_{2}$ & stability \\
\hline MP2/aug-cc-pVDZ & 5.2 & 4.5 & 0.7 \\
MP3/aug-cc-pVDZ & 4.9 & 4.4 & 0.5 \\
D-MP4/aug-cc-pVDZ & 4.8 & 4.3 & 0.5 \\
DQ-MP4/aug-cc-pVDZ & 4.7 & 4.2 & 0.5 \\
SDQ-MP4/aug-cc-pVDZ & 4.8 & 4.2 & 0.6 \\
MP4/aug-cc-pVDZ & 5.0 & 4.4 & 0.6 \\
CCSD/aug-cc-pVDZ & 4.7 & 4.2 & 0.5 \\
CCSD(T) /aug-cc-pVDZ & 5.0 & 4.5 & 0.5 \\
B3LYP/6-311+G(3df,2p) & 5.9 & 5.2 & 0.7 \\
ZPE & 1.9 & 1.6 & - \\
\hline \hline
\end{tabular}

\section{Results}

\subsection{Gas Phase Interaction}

We first consider the isolated methanol-water system, corresponding to the gas phase physical circumstance. A full geometry optimization is performed for both isomers using the second-order MP2 and the aug-cc-pVDZ basis set. Figure 1 shows the optimized hydrogen bond $\mathrm{O}-\mathrm{O}$ distance in both cases. We can note that the $\mathrm{CH}_{3} \mathrm{HO} \cdots \mathrm{H}_{2} \mathrm{O}$ isomer has a shorter distance indicating a possible stronger bond. The calculated $\mathrm{O}-\mathrm{O}$ hydrogen bond distances of $2.844 \AA$ and $2.912 \AA$ are in good agreement with the previous result[13] of $2.851 \AA$ and $2.901 \AA$. Table 2 shows the calculated results for the binding energy of both isomers after taking into account the basis-set superposition error via counterpoise correction. To analyze the role of electron correlation effects in more detail higher-order calculations, up to the coupled-cluster $\operatorname{CCSD}(\mathrm{T})$ level, were performed in the geometries obtained at the MP2/augcc-pVDZ level. At the MP2 level the $\mathrm{CH}_{3} \mathrm{HO} \cdots \mathrm{H}_{2} \mathrm{O}$ isomer is more stable by $0.7 \mathrm{kcal} / \mathrm{mol}$. This is in good agreement with previous density-functional 
theory calculations by González et al[13] that obtained the same value for the relative stability of this isomer. With all theoretical results shown in table 2 we can see that the $\mathrm{CH}_{3} \mathrm{HO} \cdots \mathrm{H}_{2} \mathrm{O}$ isomer is more stable but the relative stability is less than $1 \mathrm{kcal} / \mathrm{mol}$. In fact at the highest level used here, $\operatorname{CCSD}(\mathrm{T}) /$ aug-cc-pVDZ//MP2/aug-cc-pVDZ we obtain a relative stability of $0.5 \mathrm{kcal} / \mathrm{mol}$. This agreement between MP2 and $\operatorname{CCSD}(\mathrm{T})$ corroborates that MP2/aug-cc-pVDZ is a good theoretical model for obtaining hydrogen bond interaction. If we take into account the zero-point energy correction that is important in the gas phase results, the relative stability decreases to $0.5 \mathrm{kcal} / \mathrm{mol}(\mathrm{MP} 2)$ and $0.2 \mathrm{kcal} / \mathrm{mol}(\mathrm{CCSD}(\mathrm{T}))$. It is clear from these results that high-level ab initio calculations systematically predict the existence of both isomers with the $\mathrm{CH}_{3} \mathrm{HO} \cdots \mathrm{H}_{2} \mathrm{O}$ being the most stable. The relative stability is, however, very small being calculated to be less than $1 \mathrm{kcal} / \mathrm{mol}$ and with the best result indicating a relative stability of the $\mathrm{CH}_{3} \mathrm{HO} \cdots \mathrm{H}_{2} \mathrm{O}$ isomer by only $0.5 \mathrm{kcal} / \mathrm{mol}$.

\subsection{Liquid (1:1) Interaction}

Now we discuss the results obtained using the structures generated by the MC simulation at room temperature. The calculated average binding energies obtained using the (1:1) structures of the MC simulation, sampled according to the statistical correlation, as discussed above, are shown in table 3 . These average results include counterpoise correction to basis set superposition error. The results show that the binding energies are the same within $0.01 \mathrm{kcal} / \mathrm{mol}$ that is much smaller than the standard deviation of the calculations. The $\mathrm{CH}_{3} \mathrm{HO} \cdots \mathrm{H}_{2} \mathrm{O}$ isomer has an average binding energy of $3.05 \pm 1.09 \mathrm{kcal} / \mathrm{mol}$ compared to the value of $3.04 \pm 0.64 \mathrm{kcal} / \mathrm{mol}$ for the $\mathrm{CH}_{3} \mathrm{OH} \cdots \mathrm{OH}_{2}$ isomer. It is clear that in the liquid situation at room temperature these results are similar and favor the conclusion that the two possible isomers are equally probable energetically. The largest standard deviation $(1.09 \mathrm{kcal} / \mathrm{mol}$ vs. $0.64 \mathrm{kcal} / \mathrm{mol})$ obtained for the $\mathrm{CH}_{3} \mathrm{OH} \cdots \mathrm{H}_{2} \mathrm{O}$ isomer is a consequence of the larger structural disorder as can be seen in figure 4. The two distributions of calculated values are shown in figure 5 . Another aspect worth mentioning is the decrease in binding energy for the liquid situation. As a result of the thermal fluctuation and the ensemble of possible configurations in the liquid we can note that the final binding energy is reduced to $60-70 \%$ of the corresponding value for the minimum-energy configuration of the gas phase. Table 3 also gives the calculated dipole moments. 
Table 3: Calculated binding energy $(\mathrm{kcal} / \mathrm{mol})$ of the two isomers of hydrogen-bonded methanol-water obtained with MP2/aug-cc-pVDZ including counterpoise correction to BSSE. Results shown for the liquid are averages. Dipole moments are in Debye and dipole polarizabilities (average and anisotropic) are in a.u. Rayleigh depolarizations ( $\sigma$ for natural, planar and circular polarizations) are dimensionless. Standard deviations are also shown.

\begin{tabular}{ccccc}
\hline \hline & \multicolumn{2}{c}{$\mathrm{CH}_{3} \mathrm{HO} \cdots \mathrm{H}_{2} \mathrm{O}$} & \multicolumn{2}{c}{$\mathrm{CH}_{3} \mathrm{OH} \cdots \mathrm{OH}_{2}$} \\
& liquid & gas & liquid & gas \\
\hline$\Delta \mathrm{E}$ & $3.05 \pm 1.09$ & 5.15 & $3.04 \pm 0.64$ & 4.48 \\
$\mu$ & $3.68 \pm 0.34$ & 2.04 & $3.42 \pm 0.29$ & 2.73 \\
$\alpha$ & $31.45 \pm 0.09$ & 31.19 & $31.27 \pm 0.18$ & 30.67 \\
$\Delta \alpha$ & $5.72 \pm 0.74$ & 5.90 & $5.69 \pm 1.1$ & 5.25 \\
$\sigma_{N}\left(10^{-3}\right)$ & $4.5 \pm 1.1$ & 4.7 & $4.5 \pm 1.8$ & 4.0 \\
$\sigma_{P}\left(10^{-3}\right)$ & $2.2 \pm 0.6$ & 2.4 & $2.3 \pm 0.9$ & 2.0 \\
$\sigma_{C}\left(10^{-3}\right)$ & $4.5 \pm 1.1$ & 4.7 & $4.6 \pm 1.8$ & 4.0 \\
\hline \hline
\end{tabular}

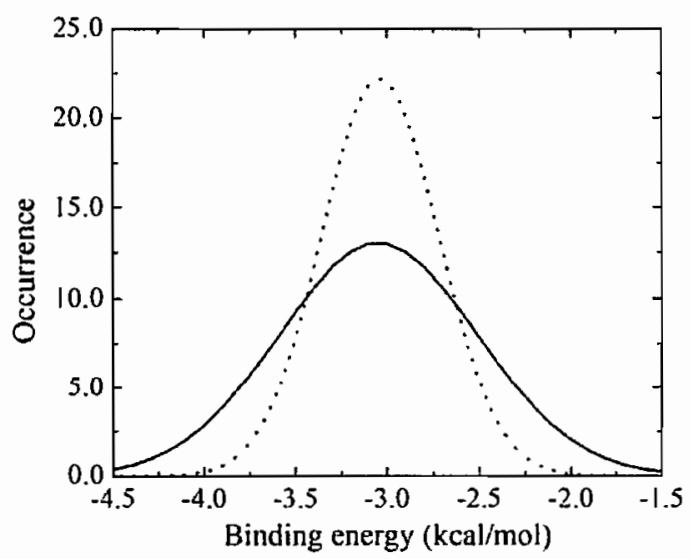

Figure 5: Histogram showing the distribution of binding energies between methanol and water. Full line is for $\mathrm{CH}_{3} \mathrm{HO} \cdots \mathrm{H}_{2} \mathrm{O}$ and dashed line is for $\mathrm{CH}_{3} \mathrm{OH} \cdots \mathrm{OH}_{2}$. 
As it can be seen the average dipole moments for the (1:1) liquid situation is considerably larger than in the (1:1) optimized complex. For completeness, table 3 also gives the average and anisotropic dipole polarizabilities of the (1:1) structures of the liquid as compared to the gas phase situation. The inhomogeneity in the electronic distribution leads to depolarization of the light elastically scattered and this Rayleigh depolarization is obtained from the calculated (1:1) dipole polarizabilities. Upon hydrogen bond formation in the aqueous environment the depolarization ratios become a distribution with the average value being only slightly decreased with respect to the value obtained for the cluster-optimized. The depolarization ratios are essentially the same for both isomers. The table 3 gives the corresponding Rayleigh depolarization ratios for different light polarizations (natural, planar and circular). Rayleigh depolarizations have been analyzed before for the case of pyridine in water with similar results as those found here[20].

\subsection{Statistical Convergence}

The efficient sampling of configurations from the simulation is crucial to ensure fast statistical convergence of the subsequent quantum mechanical calculations. Instead of performing a quantum mechanical calculation on every configuration generated by the MC simulation, as discussed in section 2.1, we used the interval of statistical correlation[27, 35], to select the configurations that are statistically relevant[25]. We have shown previously that performing average over thousands of successive configurations generated in the MC simulation, gives the same result as averaging over only a few statistically uncorrelated configurations[36, 37]. Using the auto-correlation function of the energy is a very efficient way to sample configurations and ensure statistically converged results. Indeed, figure 6 shows the calculated average binding energy for increased number of $(1: 1)$ configurations used in the liquid case. The results are clearly converged demonstrating the efficiency of our sampling procedure and the reliability of our average results.

\section{Final Remarks and Conclusions}

Hydrogen bond is a fundamental interaction to understand the thermodynamics of protic liquids, liquid mixtures and several biological phenomena that can only occur in the liquid environment. Hydrogen bonds between 


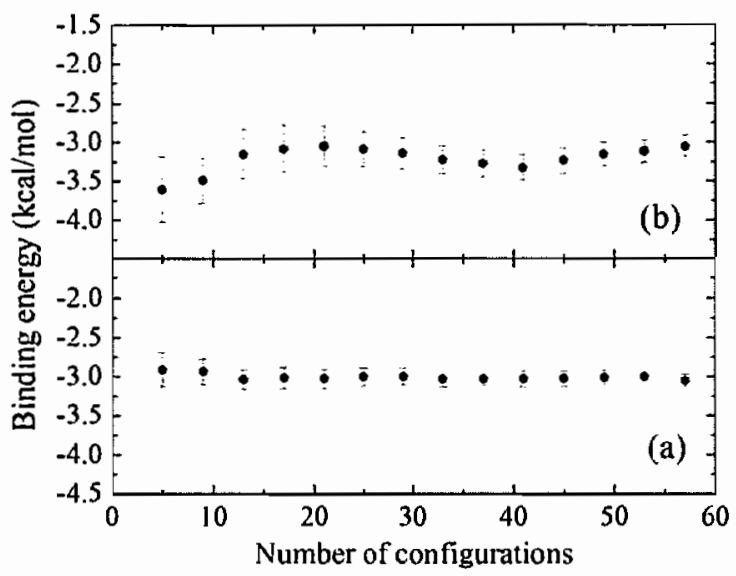

Figure 6: Convergence of the calculated binding energies for hydrogenbonded methanol-water. $(a)$ is $\mathrm{CH}_{3} \mathrm{OH} \cdots \mathrm{OH}_{2}$ and $(b)$ is $\mathrm{CH}_{3} \mathrm{HO} \cdots \mathrm{H}_{2} \mathrm{O}$. Statistical errors are shown.

bio-molecules are perhaps the most significant process regulating functions in living systems. Most understanding of the electronic structure of hydrogen bonds has been derived from studies in optimized complexes. However, the situation found in such clusters is certainly not the same as that in a liquid. Whereas in a cluster the hydrogen bond structure is fixed by a minimum-energy condition, in the liquid environment there are several configurations given by the temperature and the related natural disorder of the liquid. Therefore the hydrogen-bonded site of a solute molecule in aqueous environment experiences a great local thermal disorder. Understanding the nature of hydrogen bonds formed between a solute organic molecule and water is crucial for describing several solvation and bio-molecular processes[38]. One system that is very important is the alcohol-water mixture. Methanolwater is among the simplest of these mixtures and we have focused on the adequate treatment of the two possible isomers. In this study we considered the situation of methanol in water in conditions of extreme dilution: one methanol molecule is surrounded by bulk water. This simplified condition precludes the existence of more diversified cluster formation and makes it easier to compare with the (1:1) gas phase result. Using liquid structures generated by realistic Monte Carlo simulations, we calculated the average 
interaction energy between methanol and water using first principle calculations at the second-order perturbation theory level, MP2/aug-cc-pVDZ, and counterpoise correction to basis set superposition. We find that the statistically converged binding energies of (1:1) complexes decrease to about $2 / 3$ compared to the minimum-energy structures and that in the liquid environment the two isomers have the same average binding energy.

\section{Acknowledgments}

This paper is dedicated to Prof. Osvaldo Goscinski on the occasion of his 65th anniversary. SC, in particular, takes great pride in having been one of his graduate student and to have the opportunity to pay this modest tribute to a dear friend. This work has been partially supported by CNPq, CAPES and FAPESP (Brazil).

\section{References}

[1] F. Franks and J. E. Desnoyers, in Water Science Reviews, vol. 1, F. Franks (ed.) p. 171, Cambridge University Press (1985).

[2] F. Franks and D. J. G. Ives, Q. Rev. 20, 1 (1966).

[3] A. K. Soper and J. L. Finney, Phys. Rev. Lett. 71, 4346 (1993).

[4] S. Dixit, J. Crain, W. C. K. Poon, J. L. Finney and A. K. Soper, Nature 416, 829 (2002).

[5] J. -H. Guo et al. Phys. Rev. Lett. 91, 157401 (2003).

[6] J. E. Del Bene, J. Chem. Phys. 55, 4633 (1971).

[7] Y. C. Tse, M. D. Newton and L. C. Allen, Chem. Phys. Lett. 75, 350 (1980).

[8] G. Bolis, E. Clementi, D. H. Wertz, H. A. Scheraga and C. Tosi, J. Am. Chem. Soc. 105, 355 (1983).

[9] S. Kim, M. S. Jho and H. A. Scheraga, J. Phys. Chem. 92, 7216 (1988). 
[10] N. Bakkas, Y. Bouteiller, A. Loutellier, J. P. Perchard and S. Racine, J. Chem. Phys. 99, 3335 (1993).

[11] F. Huisken and M. Stemmler, Chem. Phys. Lett. 180, 332 (1991).

[12] P. A. Stockman, G. A. Blakee, F. J. Lovas and R. D. Suenram, J. Chem. Phys. 107, 3782 (1997).

[13] L. González, O. Mó and M. Yáñez, J. Chem. Phys. 109, 139 (1998).

[14] E. E. Fileti, R. Rivelino and S. Canuto, J. Phys. B. At. Mol. Opt. Phys. 36, 399 (2003).

[15] J. L. Finney, D. T. Bowron and A. K. Soper, J. Phys. Condens. Matter. 12, A123 (2000)

[16] G. Palinkas, E. Hawlicka and K. Heinzeger, Chem. Phys. 158, 65 (1991).

[17] H. Tanaka and K. Gubbins, J. Chem. Phys. 97, 2626 (1992).

[18] A. Laaksonen, P. G. Kusalik and I. M. Svishchev, J. Phys. Chem. A 101, 5910 (1997).

[19] T. Malaspina, K. Coutinho and S. Canuto, J. Chem. Phys. 117, 1692 (2002).

[20] E. E. Fileti, K. Coutinho, T. Malaspina and S. Canuto, Phys. Rev. E 67, 61504 (2003).

[21] M. P. Allen and D. J. Tildesley, Computer Simulation of Liquids, Oxford University Press, Oxford (1987).

[22] K. Coutinho and S. Canuto, DICE (version 2.8): A general Monte Carlo program for liquid simulation, University of São Paulo (2000).

[23] H. J. C. Berendsen, J. P. M. Postma and W. F. van Gunsteren, in: B. Pullman (ed.), Intermolecular Forces, Reidel, Dordrecht, 1981, p. 331.

[24] W. L. Jorgensen, D. S. Maxwell and J. T. Rives, J. Am. Chem. Soc. 118, 11225 (1996).

[25] K. Coutinho and S. Canuto, J. Mol. Struct. Theochem 632, 235 (2003). 
[26] S. Canuto and K. Coutinho, Int. J. Quantum Chem. 77, 192 (2000).

[27] K. Coutinho, S. Canuto and M. C. Zerner, J. Chem. Phys. 112, 9874 (2000).

[28] H. Sato and F. Hirata, J. Chem. Phys. 111, 8545 (1999).

[29] F. H. Stilinger, Adv. Chem. Phys. 31, 1 (1975).

[30] M. Mezei and D. L. Beveridge, J. Chem. Phys. 74, 622 (1981).

[31] W. L. Jorgensen, J. M. Briggs and M. L. Contreras, J. Phys. Chem. 94, 1683 (1990).

[32] S. F. Boys and F. Bernardi, Mol. Phys. 19, 553 (1970).

[33] R. J. Bartlett J. Phys. Chem. 93, 1697 (1989).

[34] M. J. Frisch, et al. Gaussian 98, Revision A.6, Gaussian, Inc., Pittsburgh PA, 1998.

[35] K. Coutinho and S. Canuto, Adv. Quantum. Chem. 28, 89 (1997).

[36] K. Coutinho, M. J. de Oliveira and S. Canuto, Int. J. Quantum Chem. 66, 249 (1998).

[37] W. R. Rocha, K. Coutinho, W. B. de Almeida and S. Canuto, Chem. Phys. Lett. 335, 127 (2001).

[38] T. W. Bell, A. B. Kkasanov and M. G. B. Drew, J. Am. Chem. Soc. 124, $14092(2002)$. 


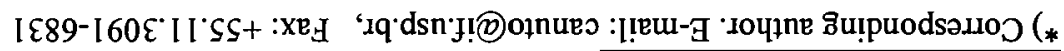

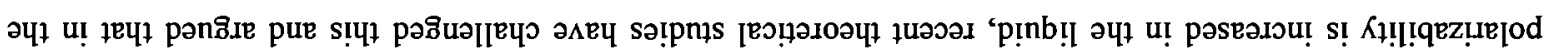

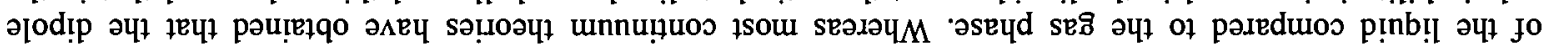

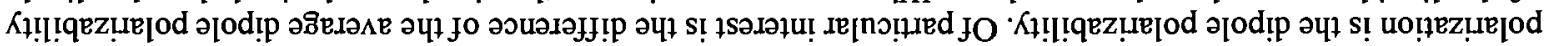

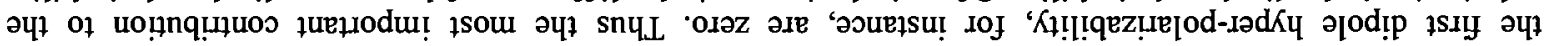

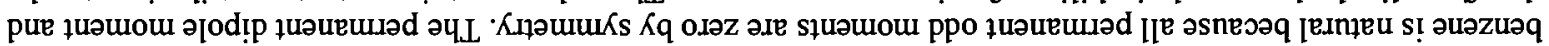

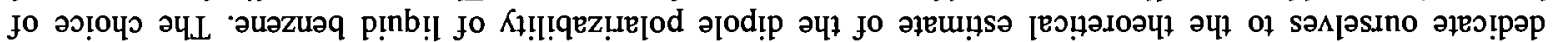

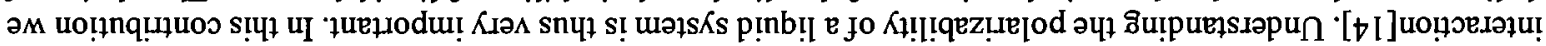

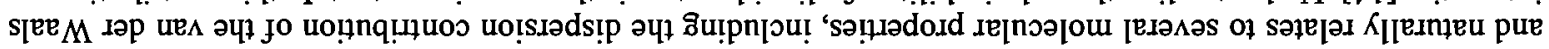

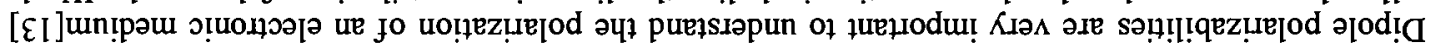

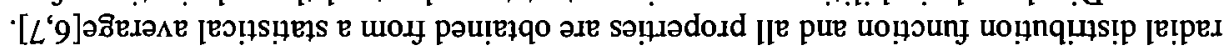

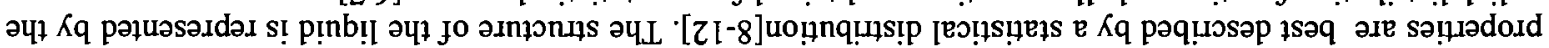

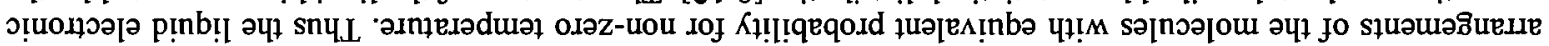

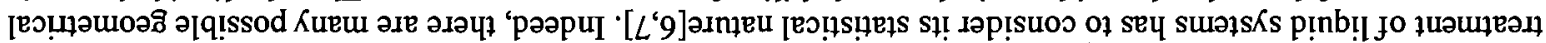

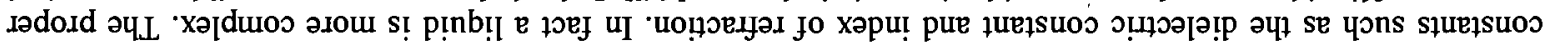

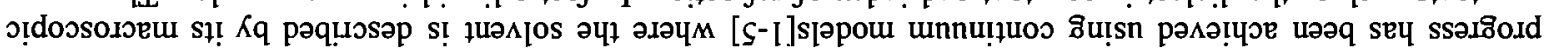

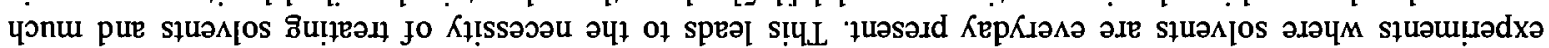

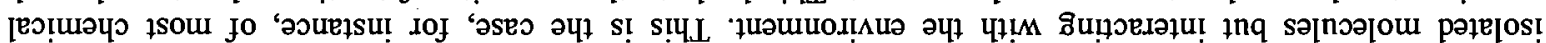

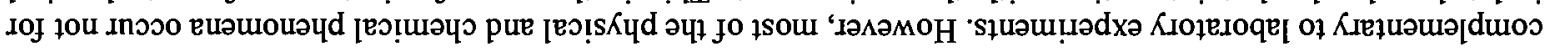

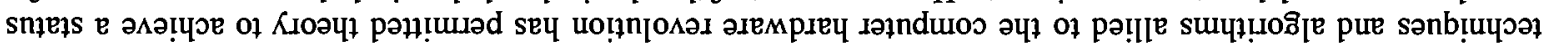

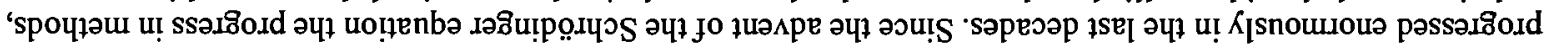

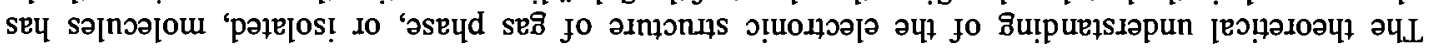

uo!̣onpodpuI 'I

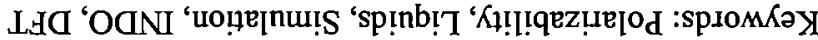

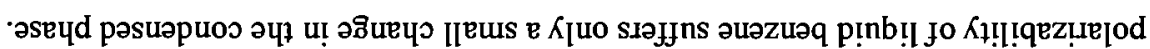

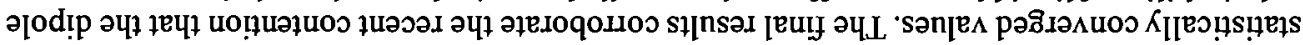

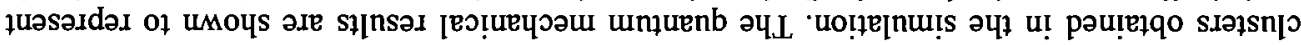

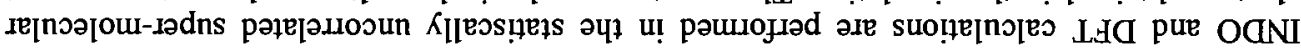

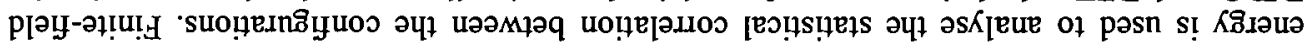

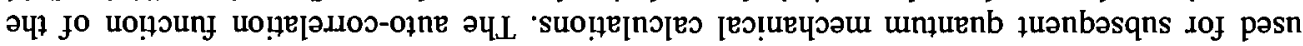

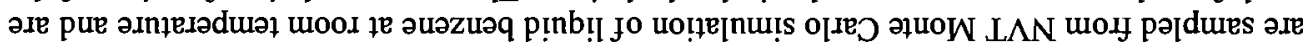
suọ̣e.nn

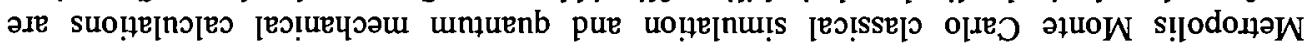

poedusqY

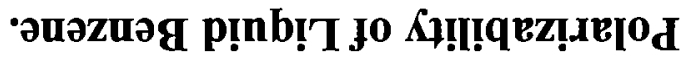

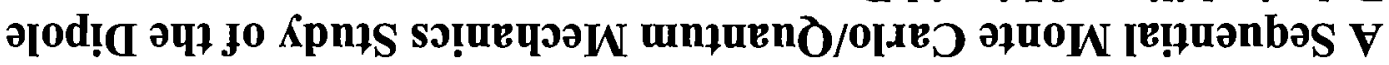


liquid it should not show any appreciable change or be decreased instead[15-17]. The difficulties in obtaining properties of molecular liquid systems are related to the natural uncertainty associated to the complex and disordered liquid phase. In several previous studies it became clear that cluster or even micro-solvation models can not describe in general the liquid properties[18,19]. The proper description of the liquid state needs a statistical procedure and assuring that the statistical properties are converged is necessary for reliable theoretical estimates. In this paper we use the sequential Monte Carlo quantum mechanics (S-MC/QM) methodology[20,21] where we first generate the structure of the liquid using Metropolis Monte Carlo. Next, statistically relevant configurations are separated and submitted to quantum mechanics calculations. Statistically converged results are obtained. Several QM calculations are necessary to obtain the ensemble average that is necessary to characterize the statistical nature of the liquid. This is an approach that is conceptually sound: the liquid system is explicitly considered and a proper statistical ensemble is used. The drawback is that such an approach is demanding computationally. In this present study the dipole polarizability of liquid benzene is obtained using densityfunctional theory (DFT) and the semi-empirical INDO models. However, the absolute accuracy is not the major point of interest here. Instead, we want to compare the dipole polarizability in the condensed liquid phase with that for the gas phase. Recent theoretical estimates point to a slight decrease of the polarizability[15-17] in the condensed medium.

\section{Theoretical Methodology}

\subsection{Monte Carlo Simulation}

Monte Carlo (MC) simulations are made in the Metropolis sampling technique and periodic boundary conditions using the minimum image method in a cubic box[7]. The simulations are performed in the NVT ensemble. The total system consists of 343 benzene molecules at room temperature $(298 \mathrm{~K})$ and density of $0.8990 \mathrm{~g} / \mathrm{cm}^{3}$. The intermolecular interactions are described by the standard Lennard-Jones potential with 2 parameters for each site $i\left(\varepsilon_{\mathrm{i}}\right.$ and $\left.\sigma_{\mathrm{i}}\right)$

$$
U_{a b}=\sum_{i}^{a} \sum_{j}^{b} 4 \varepsilon_{i j}\left[\left(\frac{\sigma_{i j}}{r_{i j}}\right)^{12}-\left(\frac{\sigma_{i j}}{r_{i j}}\right)^{6}\right] .
$$

We use the six-site OPLS[22] parameters and the experimental geometry. These are shown in Table 1. The intermolecular interactions are spherically truncated within a center of mass separation larger than the cutoff radius, $\mathrm{r}_{\mathrm{C}}=18.4 \AA$. Long-range corrections are calculated beyond this cutoff distance. In the simulation the molecules are kept with rigid geometries. The initial configurations are generated randomly, considering the position and orientation of each molecule. A new configuration is generated after randomly attempting to translate in all Cartesian directions and to rotate around a randomly chosen axis. The simulation consists of a thermalization phase of $1.7 \times 10^{6} \mathrm{MC}$ steps, followed by an averaging stage of $17.15 \times 10^{6} \mathrm{MC}$ steps. All Monte Carlo simulations and statistical correlation analysis are performed with the DICE[23] Monte Carlo statistical mechanics program. The great advantage of the sequential procedure is that all the important statistical informa-

Table 1: Geometry (in Å) and parameters of the Lennard-Jones potential of benzene.

\begin{tabular}{cccccc}
\hline Site & $x$ & $y$ & $z$ & $\varepsilon(\mathrm{kcal} / \mathrm{mol})$ & $\sigma(A)$ \\
\hline $\mathrm{C}$ & 0.0000 & 1.4000 & 0.0000 & 0.110 & 3.750 \\
$\mathrm{C}$ & 1.2124 & 0.7000 & 0.0000 & 0.110 & 3.750 \\
$\mathrm{C}$ & 1.2124 & -0.7000 & 0.0000 & 0.110 & 3.750 \\
$\mathrm{C}$ & 0.0000 & -1.4000 & 0.0000 & 0.110 & 3.750 \\
$\mathrm{C}$ & -1.2124 & -0.7000 & 0.0000 & 0.110 & 3.750 \\
$\mathrm{C}$ & -1.2124 & 0.7000 & 0.0000 & 0.110 & 3.750 \\
$\mathrm{H}$ & 0.0000 & 2.4881 & 0.0000 & 0.000 & 0.000 \\
H & 2.1547 & 1.2440 & 0.0000 & 0.000 & 0.000 \\
$\mathrm{H}$ & 2.1547 & -1.2440 & 0.0000 & 0.000 & 0.000 \\
H & 0.0000 & -2.4881 & 0.0000 & 0.000 & 0.000 \\
H & -2.1547 & -1.2440 & 0.0000 & 0.000 & 0.000 \\
H & -2.1547 & 1.2440 & 0.0000 & 0.000 & 0.000 \\
\hline
\end{tabular}


tion is available before running into the QM calculations[24-26]. This considerably reduces the number of supermolecular structures that will be submitted to the quantum mechanical calculations, because the configurations are selected according to their statistical correlation, obtained from the auto-correlation function of the energy $[11,12,24,25]$. Using a correlation step of $2.7 \times 10^{5}$, we separate a total of 62 configurations, with less than $5 \%$ of statistical correlation. These 62 structures are used in the quantum mechanical calculations. The solvation shells were defined from the analysis of the radial distribution function. The first solvation shell comprises a total of 14 benzene molecules. The second shell, a total of 63 benzene molecules. This is of course a very large system for most $a b$ initio methodologies and some compromizing has to be used. We employ both the semi-empirical INDO and the first principle DFT methods.

\subsection{Quantum Mechanics Calculations}

It has been shown that the INDO model gives reasonably good hyper-polarizabilities within the sumover-state (SOS) methodology[29]. However, for the dipole polarizability of ground states all terms of the SOS are positive and lead to slow convergence of the sum procedure. The QM calculations of the dipole polarizabilities are then made using the finite-field approximation[30] in the INDO level. Five different electric fields are applied in each of the three Cartesian orientations.

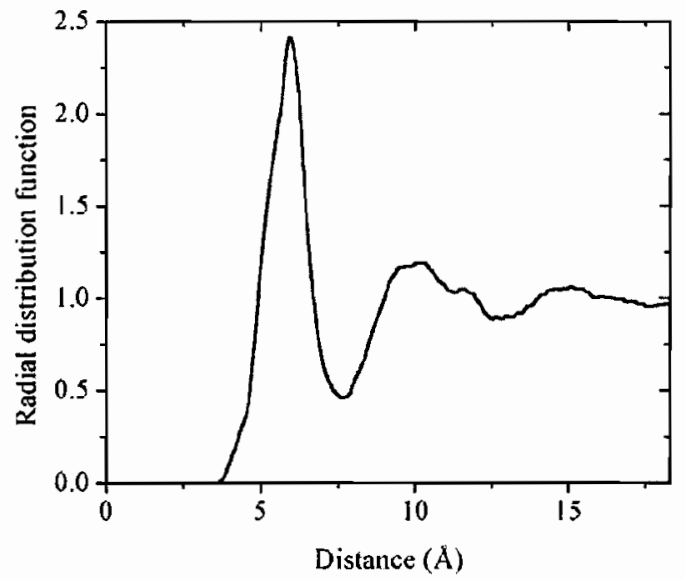

Figure 1: Pair-wise radial distribution function between the center of mass of benzene.

The field values are $\pm 0.0020, \pm 0.0010$ and 0.00 a.u. The dipole polarizabilities reported are the results of a simple average over the QM INDO results for the 62 statistically uncorrelated super-molecular configurations. Five finite electric fields were used for the small (14 benzene molecules) and large ( 28 benzene molecules) super-molecular systems in the three Cartesian components. A total of $1612 \mathrm{QM}$ calculations are performed. To verify the major assumptions of this study we also employ the DFT gradient corrected Becke's three-parameter hybrid exchange-correlation functional combined with the Lee-Yang-Parr correlation term, the so-called B3LYP model [31,32]. The basis set used is the split-valence 6-31G. For the smaller case (14 benzene molecules) this leads to a total of 924 contracted gaussian-type functions. It should be stressed that the calculations for the super-molecular structures generated in the liquid are made using the antisymmetrization of the entire system. For instance, in the case of the smaller system composed of 14 benzene molecules this corresponds to a total of 420 valence electron in the INDO model and 598 electrons in the B3LYP/6-31G case.

\section{Results and discussion}

Figure 1 shows the calculated radial distribution function of the center-of-mass of benzene. A clear first solvation shell ending in $7.5 \AA$ is seen. The second solvation shell ends at $12.9 \AA$. Spherical integration up to these distances give, respectively, 14 and 63 benzene molecules. Between these two minima there is a clear maximum at $10.0 \AA$ and spherical integration of the radial distribution function up to this point gives a number of 
28 benzene molecules in this solvation shell. Even at the semi-empirical INDO level we could not perform the finite-field calculations for the 63 benzene molecules. We have thus limited to the first solvation shell (14 molecules) and the in-between shell with 28 molecules.
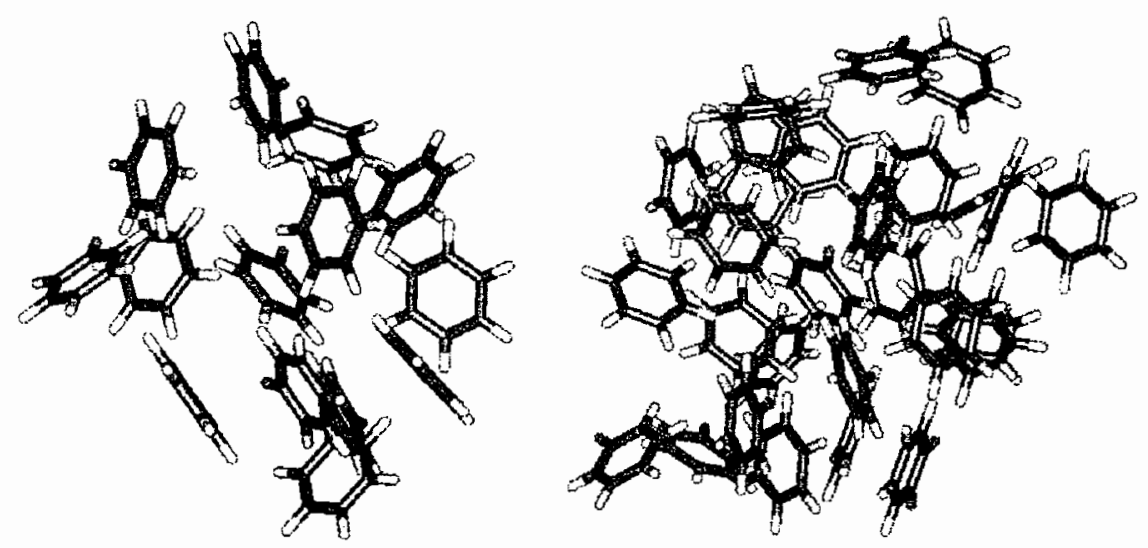

Figure 2: Illustration of two super-molecular configurations (left with 14 benzene molecules and right with 28 benzene molecules) extracted from the MC simulation.

Figure 2 illustrates one of the 62 super-molecular structures composed of 14 and 28 benzene molecules used in the QM calculations. Having defined the size of the super-molecular structures it is now important to establish the number of $\mathrm{QM}$ calculations that have to be performed to obtain the statistical convergence. The answer to this question is obtained from the auto-correlation function of the energy $[11,12,24,25]$. This function, over a chain of size $l$, is defined as

$$
C(i)=\frac{\left\langle E_{j} E_{j+i}\right\rangle_{l-i}-\left\langle E_{j}\right\rangle_{l-i}\left\langle E_{j+i}\right\rangle_{l-i}}{\left\langle E^{2}\right\rangle_{l}-\langle E\rangle_{l}^{2}}
$$

where $i$, means the interval of MC configurations. For markovian processes this is an exponentially decaying function,

$$
C(i)=\sum_{j}^{n} c_{j} e^{-i / \tau_{j}}
$$

The correlation step is

$$
\tau=\int_{0}^{\infty} \mathrm{C}(\mathrm{i}) \mathrm{di} .
$$

Figure 3 shows the calculated auto-correlation function of the energy of liquid benzene. From this and the equation above it can be seen that the correlation step in normalized MC steps is $\sim 40$. A normalized step corresponds here to 343 (the number of benzene molecules) MC steps. In calculating the averages we decided to select structures in an interval of 800 normalized steps corresponding to $2.744 \times 10^{5} \mathrm{MC}$ steps. As the total number of configurations generated is $17.15 \times 10^{6}$ (or 50000 normalized steps), the averages are taken over 62 configurations, with a correlation of less than $5 \%$. These 62 configurations will be subjected to quantum mechanical super-molecular calculations. These calculations are made at the INDO and B3LYP/6-31G levels using the finite field model. The wavefunction is antissymetric over the entire system and the finite field is applied in the entire super-molecular system. The dipole polarization is calculated and therefrom the dipole polarizability is obtained as the linear term of the polarization. Having the dipole polarizability for the entire system composed of $\mathrm{N}$ benzene molecules we obtain the condensed phase result of benzene dividing the resul by 


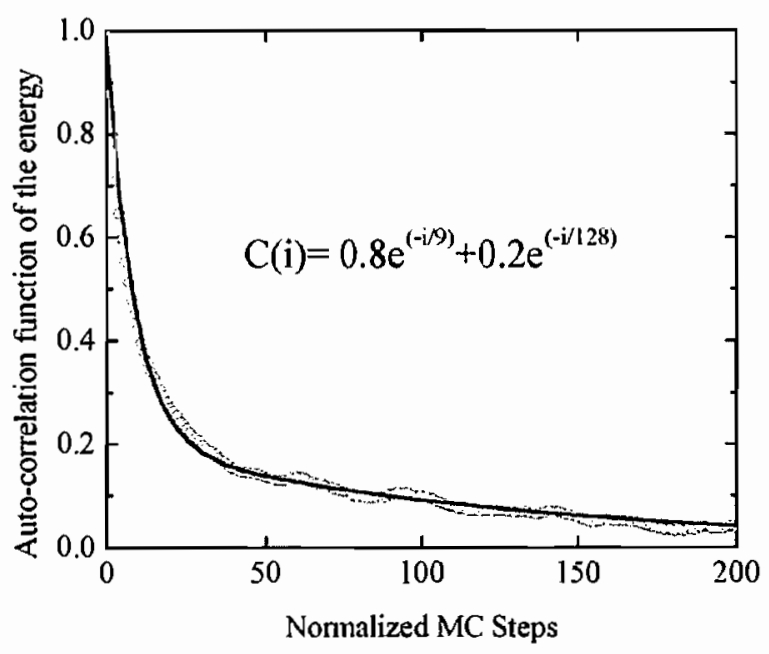

Figure 3: Calculated auto-correlation function of the energy. MC step is normalized to the total number of molecules.

the number $\mathrm{N}$. This gives the polarizability per molecule. An important point is that there are no separated calculations for the solvent. We simply compare the results obtained for the super-molecules with the calulations for the isolated benzene system. The distinction betwee these two results is the influence of the condensation. The use of a properly antysymmetric wavefunction is important to include the exchange interaction between the different benzene molecules in the liquid and also to obtain the intermolecular interactions. The inclusion of the dispersion contribution to the van der Waals interaction is known to require correlation effects and it is likely to be excluded in the INDO calculations. As the DFT method is correlated it is ideally expected to include the dispersion part of the correlation effect. This is not assured however and the proper and explicit inclusion of van der Waals contribution is a central topic in DFT theoretical methodologies. We only emphasize that the use of super-molecular approach with a proper antissimetric wavefunction may include dispersion interaction at a lower level[33]. Indeed, for the benzene molecule the solvatochromic shift upon condensation, that is dictated by the dispersion interaction, is well described using the INDO theoretical methodology used here[34,35].

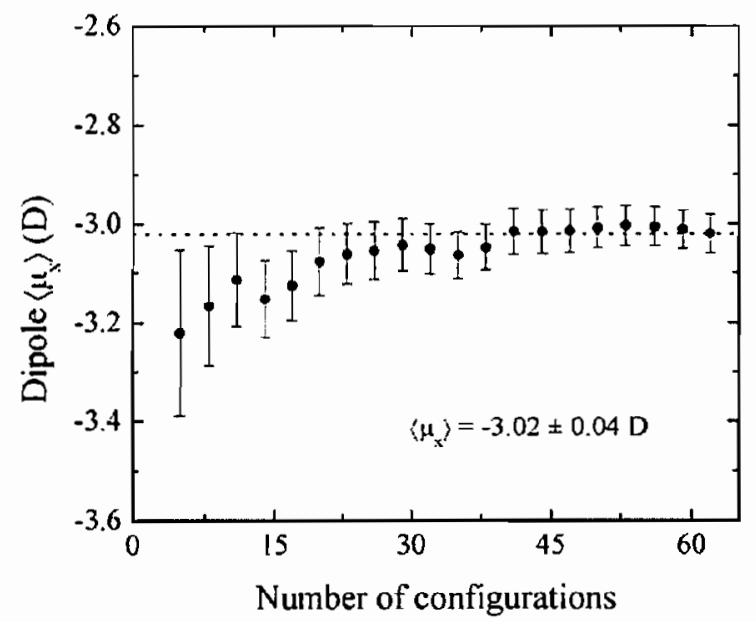

Figure 4: Statistical convergence of the dipole polarization. Bar represents the statistical error. The example corresponds to the finite-field value of 0.002 a.u. in the small (14 benzene molecules) super-molecular configuration. 
In the INDO calculations we use both the super-molecules with 14 and 28 benzene molecules. Figure 4 shows the convergence of the calculated dipole moment of the 14 benzene molecules in the external finite-field of 0.002 a.u. As it can be seen the calculated dipole moment is statistically well converged after $\sim 40$ QM calculations. The same procedure is repeated for all the other electric fields and also for the super-molecular configurations with 28 benzene molecules. Statistical convergence is assured in all cases. Using these results for the finite-fields, the dipole polarizability component is obtained as shown in Figure 5. The numerical results are finally summarized in Table 2.

Table 2: Calculated components of the dipole polarizability (in a.u.) of liquid benzene using finite-field approximation in the INDO and DFT models. $\alpha_{\text {mean }}$ is the statistical average mean dipole polarizability and $\Delta \alpha$ is the statistical average polarizability anisotropy.

\begin{tabular}{lcc}
\hline \hline Model & $\Delta \alpha$ & $\alpha_{\text {mean }}$ \\
\hline INDO & & \\
14 benzene & 2.1 & 42.7 \\
28 benzene & 0.9 & 43.7 \\
& & \\
B3LYP/6-31G & & \\
14 benzene & 12.5 & 55.6 \\
Ref [17] & 36.5 & 63.7 \\
\hline \hline
\end{tabular}

Conversion factor: 1 Debye is 0.3935 a.u.

Calculated mean dipole polarizability for the gas phase is 43.0 a.u. (INDO) and 53.4 a.u. (B3LYP/6-31G). Experimental dipole polarizability for the gas phase value is 69.7 a.u. [37].

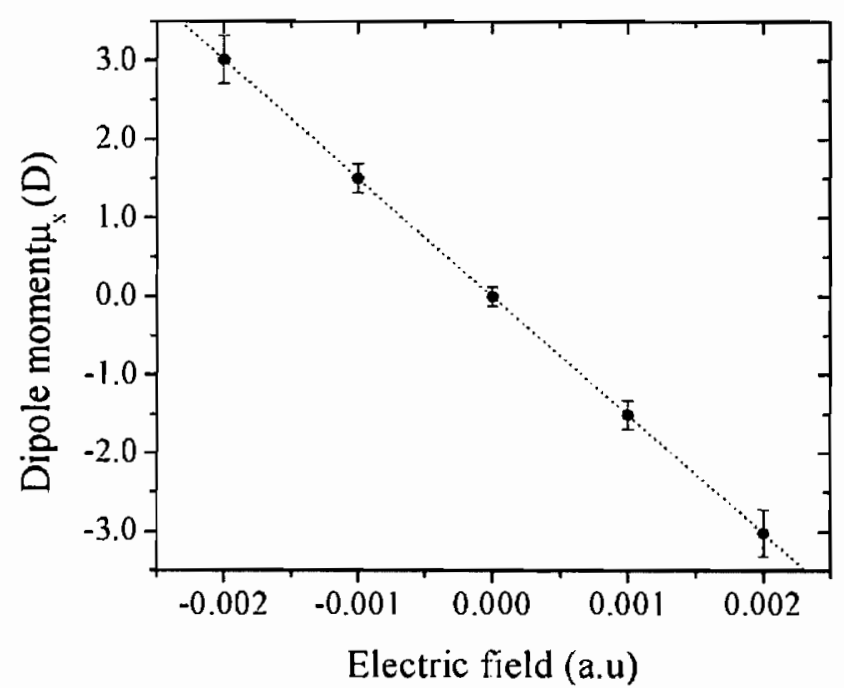

Figure 5: Polarization as a function of the applied field for the small (14 benzene molecules) configuration. Each point shown is the result of a converged statistical average of 62 quantum mechanics calculations (See Figure 4).

As expected the calculated dipole polarizability at the INDO semi-empirical level are not competitive with other numerical estimates. Parkinson and Zerner have considered the possibility of extending these calculations to the random-phase approximation (RPA) level [36]. Our theoretical result for the gas phase is 43.0 a.u, which is equivalent to the RPA result but still too small compared to the experimental result[37] of 69.7 a.u. At this point the absence of more diffuse function is responsible for this decreased value. In the condensed phase this lack is less important. However, in comparison with the condensed phase result we can see the trend that the dipole polarizability assumes essentially the same value. Two aspects are worth noting. First, the emphasis in this present study lies in a realistic representation of the liquid. Hence it is worth noticing that the dipole 
polarizability dipole polarizability of the liquid benzene obtained here is nearly isotropic. For the larger supermolecular system of 28 benzene molecules the anisotropic component of the polarizability is only 0.9 a.u. This is indicative that a reasonable representation of the bulk polarizability is obtained here. Second, it should be pointed out that the polarizability is represented by a statistical distribution. Figure 6 illustrates the distribution of the polarization in the $x$-direction for the field of 0.002 a.u. Although the average value is, in this case, $\left\langle\mu_{>}\right\rangle=-3.08$ $\mathrm{D}$, the distribution of polarization values is reasonably broad.

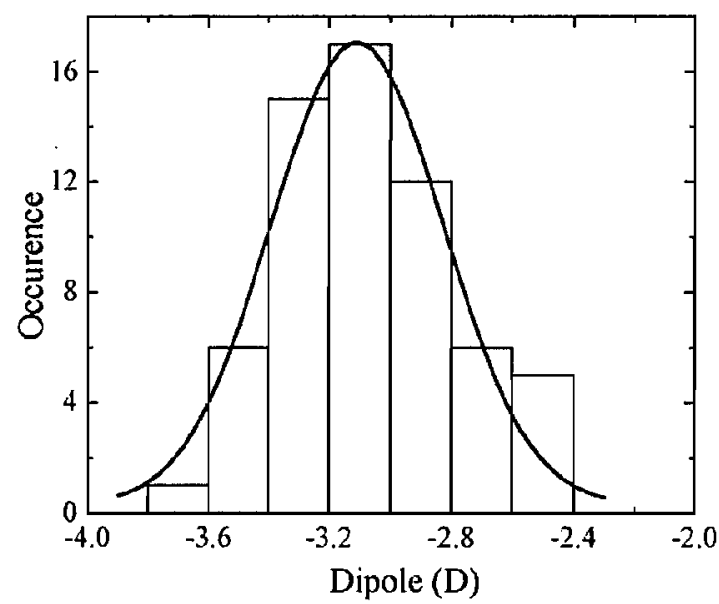

Figure 6: Statistical distribution of calculated dipole moment for the field of 0.002 a.u in the $x$-direction.

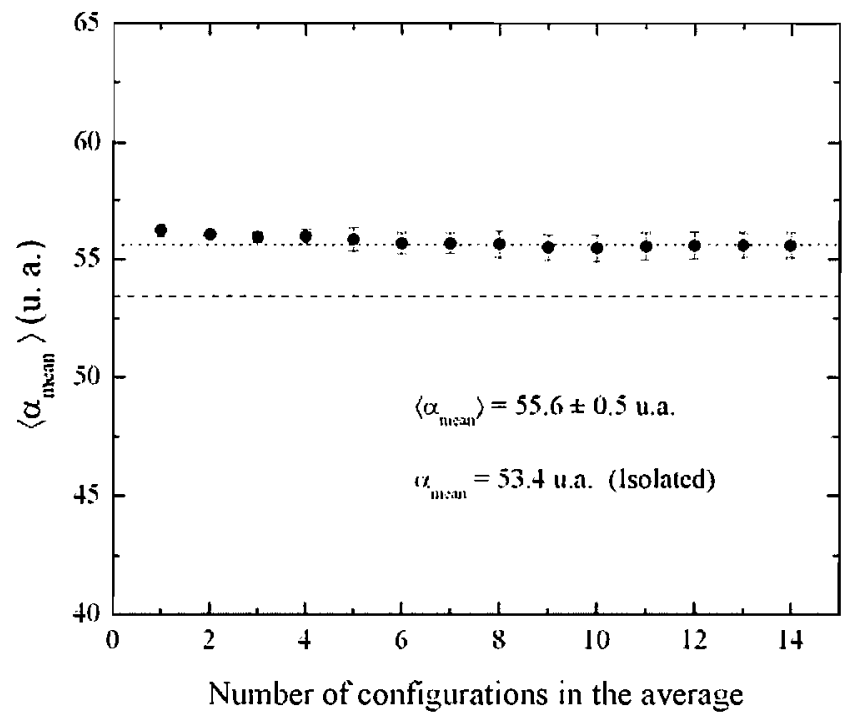

Figure 7: Calculated results for the mean dipole polarizability per benzene molecule for the small (14 benzene molecules) super-molecular configurations using the B3LYP/6-31G theoretical model. Bars represent the standard deviation.

The B3LYP/6-31G calculations for the condensed phase are performed only for the smaller supermolecules composed of 14 benzene molecules. The results for the mean dipole polarizability are shown in Figure 7 and seems to converge to the average of $55.6 \pm 0.5$ a.u. As a comparison the gas phase result obtained for the isolated benzene molecule is 53.4 a.u. It is well known that diffuse functions play an important role in the calculations of dipole polarizabilities. In this present study we are limited to the size of basis function and could only use a relatively small basis without a proper description of the diffuse part of the basis set. Indeed in this study the basis set size for the small cluster of 14 benzene molecules includes nearly one thousand basis function 
and could not be extended any further. Note that the result for the dipole polarizability of a single super-molecule requires, in fact, several single-point calculations for the different finite field values. Because the supermolecules including several benzene molecules are extended compared to the single molecule case, it is expected that the lack of diffuse funstion will be more harmful for the gas phase than the condensed phase. Hence, the difference of $2.2 \pm 0.5$ a.u between the condensed and gas phases results is likely to be slightly overestimated. Again, the first principle DFT calculations, similar to the semi-empirical INDO results, give an average value for the mean polarizability that is essentially the same result as in the gas phase.

As it was first discussed by Jensen et al [17] using time-dependent DFT results the dipole polarizability of condensed phase benzene is slightly decreased compared to the gas phase result by $8 \%$. Morita and Kato [15] have earlier considered the medium (water) perturbation on the dipole polarizabilities of small systems like Ne, $\mathrm{Ar}, \mathrm{CH}_{4}$ and anions like $\mathrm{Cl}^{-}$. Similarly, they conclude that for the case of neutral systems in water there is a decrease in the dipole polarizability between 13 and $18 \%$. For the anion, $\mathrm{Cl}^{-}$, in water the decrease is as much as $37 \%$. van Duijnen et al [38] contends that the dipole polarizability of formaldehyde in water shows no appreciable change and that if polarizability is to change due to medium effect it should be decreased. In line with this result we find that the dipole polarizability of liquid benzene shows no appreciable change and, in fact, using statistically converged result we find the results to be equivalent. .

\section{Conclusion}

Monte Carlo classical simulation is performed to generate the structure of liquid benzene at room temperature. Configurations are sampled using the auto-correlation function of the energy and the structures used in the subsequent quantum mechanical calculations are less than $5 \%$ statistically correlated. INDO finite-field calculations are made in the super-molecular structures including all benzene molecules within $10 \AA$. For each finite-field value the electronic polarization is verified to be statistically converged. As a complement, the quantum mechanical results are performed also at the density-functional B3LYP/6-31G level. The final results indicate that the dipole polarizability of the liquid is equivalent to the gas phase result. This result corroborates the recent contention that the dipole polarizability of liquid benzene suffers only a small change in condensed phase.

Acknowledgments: This work has been partially supported by CNPq and FAPESP (Brazil). Discussions with Dr. K. Coutinho and Dr. R. Rivelino are greatfully acknowledged.

\section{References}

[1] L. Onsager, J Am Chem Soc 58, 1486 (1939).

[2] O. Tapia and O. Goscinski, Molec. Phys. 29, 1653 (1975).

[3] J. L. Rivail and D. Rinaldi, Chem. Phys. 18, 233 (1976).

[4] J. Tomasi and M. Persico, Chem. Rev. 94, 2027 (1994).

[5] M. M. Karelson and M. C. Zerner, J. Phys. Chem. 96, 6949 (1992).

[6] D. M. Heyes, The Liquid State. Applications of Molecular Simulations, John Wiley, (1998)

[7] M. P. Allen and D. J. Tildesley, Computer Simulation of Liquids, Clarendon Press, (1987).

[8] J. T. Blair, K. Krogh-Jespersen and R. M. Levy, J. Am. Chem. Soc. 111, 6948 (1989).

[9] J. Gao, J. Am. Chem. Soc. 116, 9324 (1994).

[10] J. Zeng, N. S. Hush and J. R. Reimers, J. Chem. Phys. 99, 1496 (1993).

[11] K. Coutinho, S. Canuto and M. C. Zerner, Int. J. Quantum Chem. 65, 885 (1997).

[12] K. Coutinho and S. Canuto, Adv. Quantum Chem. 28, 89 (1997).

[13] A. D. Buckingham, Adv. Chem. Phys. 12, 107 (1967); D. M. Bishop, Adv. Quantum Chem. 25, 1 (1994).

[14] A. J. Stone, The Theory of Intermolecular Forces, Clarendon Press, (1996).

[15] A. Morita and S. Kato, J. Chem. Phys. 110, 11987 (1999).

[16] P. Th. van Duijnen, A. H. De Vries, M. Swart and F. Grozema, J. Chem. Phys. 117, 8442 (2002).

[17] L. Jensen, M. Swart, P. Th. van Duijnen and J. G. Snijders, J. Chem. Phys. 117, 3316 (2002).

[18] K. Coutinho, R. C. Guedes, B. J. Costa Cabral and S. Canuto, Chem. Phys. Lett. 369, 345 (2003).

[19] K. Coutinho and S. Canuto, J. Chem. Phys. 113, 9132 (2000).

[20] S. Canuto, K. Coutinho and D. Trzresniak, Adv. Quantum Chem. 41, 161 (2002). 
[21] T. Malaspina, K. Coutinho and S. Canuto, J. Chem. Phys. 117 (2002).

[22] W. L. Jorgensen, J. D. Madura, C. J. Swenson, J. Amer. Chem. Soc. 106, 6638 (1984).

[23] K. Coutinho and S. Canuto; DICE: A Monte Carlo program for molecular liquid simulation, University of São Paulo, (1997).

[24] K. Coutinho, M. J. Oliveira and S. Canuto, Int. J. Quantum Chem. 66, 249 (1998)

[25] K. Coutinho, S. Canuto and M. C. Zerner, J. Chem. Phys., 112, 9874 (2000).

[26] S. Canuto and K. Coutinho, Int. J. Quantum Chem. 77, 192 (2000).

[27] J. Ridley and M. C. Zerner, Theor. Chim. Acta, 32, 111 (1973).

[28] M. C. Zerner; INDO-UF: A semi-empirical program package of the University of Florida, Gainesville, FL 32611 .

[29] S. Di Bella, T. J. Marks and M. A. Ratner, J. Am. Chem. Soc. 116, 4440 (1994).

[30] H. D. Cohen and C. C. J. Roothaan, J. Chem. Phys. 43, 34 (1965); I. Cernusak, G. H. F. Diercksen and A. J. Sadlej, Phys. Rev. A, 33, 814 (1986); G. Maroulis, J. Phys. B: At. Mol. Opt. Phys. 34, 3727 (2001).

[31] A. D. Becke, Phys. Rev. A 38, 3098 (1988)

[32] C. Lee, W. Yang, and R. G. Parr, Phys. Rev. B 37, 785 (1988).

[33] S. Canuto, K. Coutinho and M. C. Zerner, J. Chem. Phys. 112, 7293 (2000).

[34] K. Coutinho, S. Canuto and M. C. Zerner, J. Chem. Phys. 112, 9874 (2000).

[35] K. Coutinho, S. Canuto and M. C. Zerner, Int. J. Quantum Chem. 65, 885 (1997).

[36] W. A. Parkinson and M. C. Zerner, Chem. Phys. Lett. 139, 563 (1987).

[37] D. R. Lide, Handbook of Chemistry and Physics, $73^{\text {rd }}$ edition, CRC-Press, Boca Raton, 1992-1993.

[38] P. van Duijnen, M. Swart and F. Grozema, in ACS Symposium Series, edited by J. Gao and M. A. Thompson (ACS, Washington, D.C.), vol. 712, 220 (1998). 


\title{
Isotropic and anisotropic chemical shifts in liquid water: A QM/MM study
}

\author{
Eudes E. Fileti, H. C. Georg, K. Coutinho e Sylvio Canuto* \\ Instituto de Física, Universidade de São Paulo, CP 66318, 05315-970, São Paulo, SP, Brazil. \\ *) Corresponding author. E-mail: canuto@if.usp.br, Fax: +55.11.3091-6831.
}

\begin{abstract}
We present a sequential Simulation/DFT study of the gas-liquid chemical shifts of water. Extensive quantum chemical calculations using density functional theory have been performed for structures of liquid water generated by Monte Carlo and Molecular Dynamic simulations. The dependence of the chemical shifts on the empirical potential (SPC, TIPS, FERG) used in the simulations, the cluster size $(5,9,13,17$ and 24 molecules in each cluster) and the functional chosen for the ab initio calculation (B, B3 and G96 combined with LYP, P86 and PW91, beyond of B97-1, MPW1PW91 and PBE1PBE) was analyzed. The converged and BSSE corrected results are in good agreement with experimental results, showing that a simple empirical potential associated to an appropriate functional is able to describe the chemical shifts.
\end{abstract}

\section{Introduction}

Nowadays calculations of the chemical shielding can reproduce with accuracy the chemical environment of the nuclei in a molecule. The advances in computational resources and the improvement in the theoretical methods provide important refinements to estimate the chemical shielding, such as inclusion of the electron correlation effects and the possibility of studying systems more complex than isolated molecules or small clusters. Presently the determination of the chemical shifts for nuclei in proteins, solids and liquids through current methodologies ${ }^{1-5}$ are very convincing.

An important category of systems whose electronic structure can be investigated through NMR calculations are the solvated systems. A solvated molecule experiments the effect of the interaction with its vicinity, such as in hydrogen bonds ${ }^{6,7}$. Several theoretical models were proposed to describe the solvent effect on chemical shielding ${ }^{8-14}$. The main branches are the selfconsistent reaction field methods (SCRF) ${ }^{15,16}$ where the solute is put inside a spherical cavity in a polarizable medium represented by its dielectric constant; and the rigid clusters approximation, where some solvent molecules are considered explicitly in order to describe the solvation shells of the sulute ${ }^{10,17}$. It was shown that the former method does not work in determining the chemical shift and the latter, though it can serve as a rough approximation, does not serve as a model to the liquid phase ${ }^{18}$ since the system is fixed by an equilibrium condition, and consequently not describing the thermal disorder that characterizes a liquid system.

Chesnut and Rusiloski ${ }^{18}$ have proposed a more realistic model to describe the solvent effects on the chemical shifts of the atoms of a molecule in liquid water. In their model some configurations are extracted from the simulations and undergo quantum calculations. Because of a bad description of the solvation shells and the computational limitations, the results presented considerable deviations from the expected value, although they have shown a superior qualitative agreement with 
the results obtained with SCRF and rigid cluster approximation. Two years after the publishing of that work, Malkin and co-worker(s?) ${ }^{13}$ had shown in a study about the isotropic chemical shift, that improving the description of the solvation shells and the sampling of the configurations submitted to quantum calculations, they could find better values to gas-liquid chemical shift. In fact such results are in better agreement with the expected values than the results of the Chesnut and Rusiloski.

The SCRF, rigid cluster approximation and Malkin sampling methods, before mentioned, were compared by Cheeseman e co-workers ${ }^{19}$. In that work the authors verified that the continuum method fails even in the reproduction of the sign of the isotropic chemical shift and that the discrete approximation is more reliable. They also verified that the rigid cluster approximation, in the case of $\left(\mathrm{H}_{2} \mathrm{O}\right)_{5}$ provided results near to that obtained by the average over the structure from simulations. However the best agreement between the experimental and theoretical values was given by the Malkin sampling method ${ }^{13}$, that represented the chemical shift as a distribution of values around an average obtained from quantum calculations and no more by an absolute value obtained by a single calculation. Nevertheless none of these works made used of a rigorous statistical treatment to obtain converged averages. Recent results ${ }^{20-24}$ showed that a minimum number of configurations must be taken into account to obtain a statically converged average.

In this work we propose to revisit the study of the chemical shift on liquid water through sequential simulation/DFT study and analyze how different functionals describe the chemical shielding in both gas and liquid phase. Others aspects will be approached, such as the dependence with the potential used in the simulations, the effects of molecular vibrations, the dependence with the selected clusters size. Additionally, we will also analyze the results obtained to anisotropic chemical shielding in liquid phase, for which theoretical results are scarce. An important fact is that our results can be compared to the recently proposed absolute scale for chemical shielding of the oxygen atom ${ }^{25}$ as well as the new experimental values determined for the hydrogen atom ${ }^{26}$

\section{Theoretical Details}

2.1 Absolute chemical shielding and chemical shift

The absolute chemical shielding is an orientation dependent property, that is, it depends on the orientation of the molecule in relation to the applied magnetic field. Thus the chemical shielding can be described by a second rank non-symmetric Cartesian tensor, $\sigma$, in which nine independent values specify the orientation of the shielding in relation to the coordinate system. Thus we have ${ }^{27,28}$ :

$$
\vec{\sigma}=\left(\begin{array}{lll}
\sigma_{11} & \sigma_{12} & \sigma_{13} \\
\sigma_{21} & \sigma_{22} & \sigma_{23} \\
\sigma_{31} & \sigma_{32} & \sigma_{33}
\end{array}\right) \text {. }
$$

In conventional NMR experiments is very difficult to determine all the components of the chemical shielding, thus only the symmetric part of the shielding is determined, then we define the isotropic chemical shielding, $\sigma^{i s o}$, given by the trace of the tensor, i. $e^{27,28}$ :

$$
\sigma^{i s o}=\frac{1}{3}\left(\sigma_{11}+\sigma_{22}+\sigma_{33}\right) .
$$

In many cases, is it enough to analyze this property to compare with the experimental results, however important provided information are lost. Thus we introduce the anisotropic chemical shielding $\sigma^{\text {anis }}$ expressed by:

$$
\begin{aligned}
& \sigma^{a n i s}=\sigma_{33}-\frac{1}{2}\left(\sigma_{11}+\sigma_{22}\right) \\
& \operatorname{com} \sigma_{11}<\sigma_{22}<\sigma_{33} .
\end{aligned}
$$

The isotropic and anisotropic gas-liquid chemical shifts are determined by the $X$ atom as being:

and

$$
\delta(X)^{i s o}=\sigma(X)_{\text {liq }}^{i s o}-\sigma(X)_{g a s}^{i s o}
$$

$$
\delta(X)^{a n i s}=\sigma(X)_{l i q}^{a n i s}-\sigma(X)_{g a s}^{a n i s}
$$

Is it suitable to comment here that in experimental NMR spectra a standard compound is chosen as a reference, thus the chemical shift is taken as the difference between the shielding of the interest atom and the corresponding atom in the reference compound. In the case of theoretical calculations, to compare with the experimental result, the theoretical magnetic shielding must be subtracted from the shielding in the reference compound (both obtained at the same theoretical level). In the differences given by the expressions (4) and (5), the reference values cancel out, therefore the chemical shifts here are referred simply as the difference between the shielding of the atom in the liquid phase and the shielding of the atom in the gas phase.

\subsection{Simulations and Statistical Analysis}

Monte Carlo and Molecular Dynamic simulations were performed to generate the configurations of the liquid. Rigid and flexible water models were 
Table 1: Parameters of the potentials used in the simulations intermolecular interactions.

\begin{tabular}{cccccc}
\hline Constants & SPC & TIPS & FERG & DP & Unity \\
\hline$l_{0}$ & 1.00 & 0.96 & 1.00 & 0.96 & $\AA$ \\
$\theta_{0}$ & 109.5 & 104.5 & 109.5 & 104.5 & degree \\
$A$ & -- & -- & 650 & 580 & $\mathrm{Mcal} \AA^{6} / \mathrm{mol}$ \\
$C$ & -- & -- & -625.47 & -525.00 & $\mathrm{Kcal} \AA^{12} / \mathrm{mol}$ \\
$q(H)$ & -- & -- & 0.413 & 0.400 & $e$ \\
$K_{q}$ & -- & -- & 547.5 & 529.6 & $\mathrm{Kcal} / \mathrm{mol} / \AA^{2}$ \\
$K_{c}$ & -- & -- & -1.65 & 0.00 & $\mathrm{Kcal} / \mathrm{mol} / \AA^{3}$ \\
$K_{\theta}$ & -- & -- & 49.9 & 34.1 & $\mathrm{Kcal} / \mathrm{mol}^{2} / \mathrm{rad}^{2}$ \\
\hline
\end{tabular}

used to describe the inter and intramolecular interactions. We used two rigid potentials, $\operatorname{SPC}^{29} \mathrm{e}$ TIPS $^{30}$, and two flexible potentials: the Ferguson potential $^{31}$ (FERG) that is based on SPC potential and the Dang-Pettitt ${ }^{32}$ potential (DP) which is based on the TIPS potential. The general potential form is given by:

$$
\begin{aligned}
& U=\sum_{i<j} \frac{A_{i j}}{r_{i j}^{12}}+\frac{C_{i j}}{r^{6}}+\frac{q_{i} q_{j}}{r_{i j}}+ \\
& +\sum_{l i g} K_{q}\left(l-l_{0}\right)^{2}+K_{q} K_{c}\left(l-l_{0}\right)^{3}+ \\
& +\sum_{a n g} K_{\theta}\left(\theta-\theta_{0}\right)^{2}
\end{aligned}
$$

where the first sum is the traditional Lennard-Jones plus Coulomb potential that describe the

The two other summations are the intramolecular part of the potential that describes the stretching of the $\mathrm{O}-\mathrm{H}$ bond represented by $l$ (the FERG potential has a cubic contribution to the stretching) and the $\mathrm{HOH}$ angle deformation represented by $\theta$. The values of these parameters are given in Table 1 .

One notices that, for large $N$, the standard deviation converges to a constant value whereas the statistical error tends to zero. In this way the final value of the shielding will be represented by the distribution $\langle\sigma\rangle \pm s$ that describes the Gaussian distribution and comprising $68 \%$ of the values

The simulations with rigid water molecules were performed by employing the Monte Carlo Metropolis method as implemented in the program Dice $^{33}$. The production simulations were carried out for $5 \cdot 10^{7}$ steps at a temperature of $298 \mathrm{~K}$, in NVT ensemble with 500 water molecules. In the case of flexible molecules we used the Molecular Dynamics method through the GROMACS program $^{34,35}$. For both the gas phase and the liquid phase we performed simulations of 1 ns with a time step of $0.25 \mathrm{fs}$ in a temperature of $298 \mathrm{~K}$. The MD simulations were performed in the NVT ensemble with 500 water molecules.

Since the configurations obtained from the simulations obey the Boltzmann statistic, the average of the magnetic shielding or any otherproperty are given through a simple averaging over the number of configurations used, $N$, that is:

$$
\langle\sigma\rangle=\frac{1}{N} \sum_{i}^{N} \sigma_{i}
$$

It is known that non-correlated values of $\sigma_{i}$ yield a normal distribution with standard deviation, $s$, given by:

$$
s=\sqrt{\frac{N}{N-1}\left[\left\langle\sigma^{2}\right\rangle-\langle\sigma\rangle^{2}\right]}
$$

and a statistical error, $\Delta$, given simply by:

$$
\Delta=\frac{s}{\sqrt{N-1}}
$$

The structures selected to quantum calculations were taken with an interval of $5 \cdot 10^{4}$ Monte Carlo steps and 10 ps in Molecular Dynamics simulations. This procedure leads to uncorrelated configurations for both techniques.

\subsection{Quantum Mechanical Calculations}

Once the density functional theory (DFT) has been successfully applied to several problems in quantum chemistry, particularly in the determination of the chemical shifts ${ }^{2-5,13,14}$, we use it in this work to describe the isotropic and anisotropic chemical shifts in liquid water. As a first approach, we have employed the hybrid functional B3LYP ${ }^{36,37}$ with the purpose of studying the convergence with the cluster size. The 6- 
$311++G(2 d, 2 p)$ basis set was used to calculate the shielding of the reference molecule, given that it is accepted that the $6-311++G(d, p)$ basis set is enough to provide results in considerably good agreement with the experimental results ${ }^{19,38}$. To evaluate the cluster size effect on the magnetic shielding, we used the $6-311++G(2 d, 2 p)$ basis set to the first solvation shell $(1+4$ molecules $)$ while for molecules beyond the four first neighbor we used the $3-21 \mathrm{G}$ basis set. In order to observe the dependence of the chemical shifts with the functional employed, we used several other functionals. The GIAO method ${ }^{38-40}$ was chosen to treat the gauge invariance problem. All quantum calculations were performed through the Gaussian 03 program $^{41}$.

\section{Results and discussions}

\subsection{Absolute magnetic shielding of the gas- phase}

Previous to discuss the results obtained for the chemical shift for the molecule in liquid is necessary to discuss the absolute magnetic shieldings obtained for the isolated (rigid and flexible) molecule. Table 2 shows the values of the isotropic and anisotropic shieldings for the atoms of the isolated water molecule, in rigid geometry and for the 100 geometries generated by the flexible potential models in gas phase, obtained by Molecular Dynamics simulations. In addition we carried out calculations on B3LYP/6$311++\mathrm{G}(2 \mathrm{~d}, 2 \mathrm{p})$ optimized geometry (designated in Table 2 by OPT) to serve as reference to the geometries obtained by the simulations.

Table 2: Isotropic, $\sigma^{\text {iso }}$, and anisotropic, $\sigma^{\text {anis }}$, absolute magnetic shielding for the water atoms in rigid and flexible geometry. Values in ppm obtained at B3LYP/6-311++G(2d,2p) level. OPT stands for the values obtained for the B3LYP/6-311++G(2d,2p) optimized geometry. Uncertainties are the standard deviations of the averages obtained with 100 configurations.

\begin{tabular}{|c|c|c|c|c|c|}
\hline Rigid & $\sigma^{\text {iso }}\left({ }^{17} \mathrm{O}\right)$ & $\sigma^{\text {iso }}\left({ }^{1} H\right)$ & Flexible & $\sigma^{\text {iso }}\left({ }^{17} \mathrm{O}\right)$ & $\sigma^{\text {iso }}\left({ }^{1} \mathrm{H}\right)$ \\
\hline SPC & 301.61 & 29.52 & FERG & $299.94 \pm 10.59$ & $29.46 \pm 0.67$ \\
\hline TIPS & 325.30 & 31.36 & DP & $324.92 \pm 9.23$ & $31.37 \pm 0.70$ \\
\hline Opt & 324.69 & 31.27 & & & \\
\hline Exp & $323.6^{\mathrm{a}}$ & $30.05^{\mathrm{b}}$ & Exp & $323.6^{\mathrm{a}}$ & $30.05^{b}$ \\
\hline Rigid & $\sigma^{\text {anis }}\left({ }^{17} \mathrm{O}\right)$ & $\sigma^{\text {anis }}\left({ }^{l} H\right)$ & Flexible & $\sigma^{\text {anis }}\left({ }^{17} \mathrm{O}\right)$ & $\sigma^{\text {anis }}\left({ }^{1} H\right)$ \\
\hline $\mathrm{SPC}$ & 55.20 & 16.96 & FERG & $58.74 \pm 3.72$ & $16.87 \pm 0.87$ \\
\hline TIPS & 54.14 & 19.07 & DP & $55.88 \pm 2.53$ & $19.08 \pm 0.95$ \\
\hline Opt & 54.31 & 19.02 & & & \\
\hline Vaara et $\mathrm{al}^{\mathrm{c}}$ & 46.97 & 19.1 & Vaara et $\mathrm{al}^{\mathrm{c}}$ & 46.97 & 19.1 \\
\hline
\end{tabular}

We see that all values obtained for rigid SPC geometry, as well as the configurations produced by FERG potential (based on SPC geometry) are not in agreement with the experimental value. The oxygen atom, for instance, presented a difference in the isotropic shielding of $\sim 22 \mathrm{ppm}$ from its experimental value of the 323.6 $\mathrm{ppm}^{25}$. For the anisotropic shielding the larger sensitivity occurred to hydrogen atoms for which the SPC and FERG potentials provided a difference of $\sim 2 \mathrm{ppm}$. These differences are due the fact the SPC geometry is very different from that found experimentally (see Table 1). On the other hand, the values for the TIPS potential (based in experimental geometry), as well as the DP potential (based, in its turn, in the TIPS geometry), presented satisfactory values for the magnetic shielding of the atoms in both the fixed and flexible (vibrating) molecules. In the case of the oxygen atom of the TIPS molecule the percent deviation from the experimental result was $\sim 0.5 \%$. For hydrogen atoms, obtaining accurate values for the isotropic shielding is computationally expensive. A value of $30.9 \mathrm{ppm}^{42}$ was obtained in $\operatorname{CCSD}(\mathrm{T})$ level, however the best theoretical estimative for this value, $30.2 \mathrm{ppm}$, was achieved using an elaborated RASSACF model ${ }^{43}$. Our values naturally are not so precise, presenting a deviation of $\sim 4 \%$ from the experimental value, but are in good agreement with other theoretical values from recent literature in which a MP2/6-311++G(2d,2p) calculation has found $31.02 \mathrm{ppm}^{44}$. 
Table 3: Isotropic, $\sigma^{\text {iso }}$, and anisotropic, $\sigma^{\text {anis }}$, absolute magnetic shielding for the reference water molecule in the presence of the first solvation shell. Values in ppm obtained at B3LYP/6-311++G(2d,2p) level. Uncertainties are the standard deviations of the averages obtained with 100 configurations.

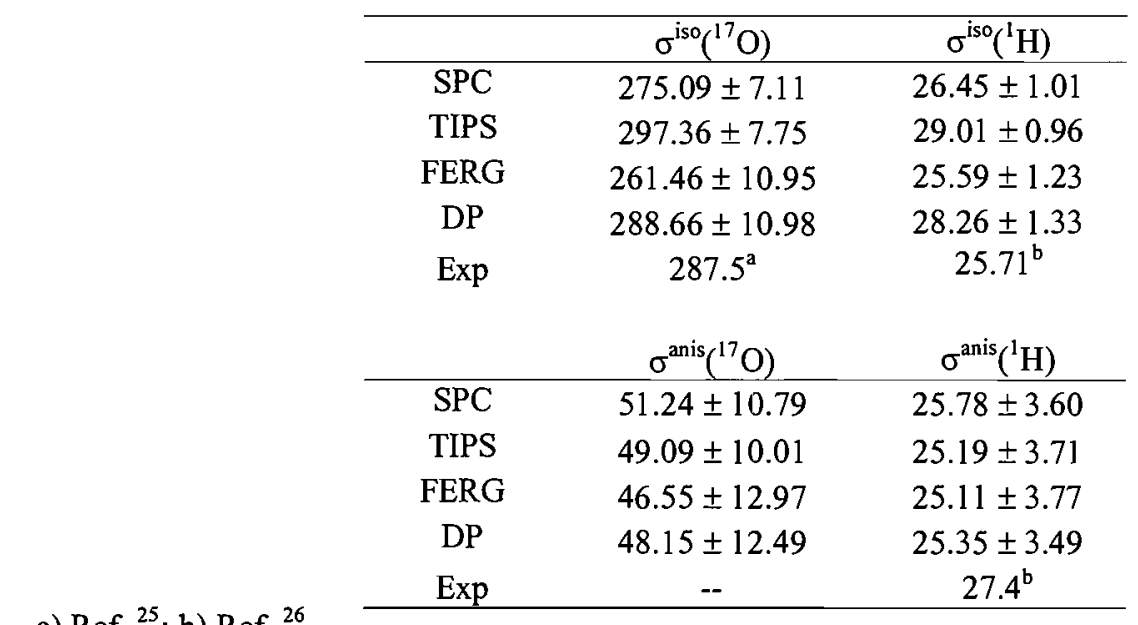

a) $\operatorname{Ref.}^{25}$; b) Ref. ${ }^{26}$

There is no experimental result for the anisotropic shielding in gas-phase, hence Table 2 presents the most accepted theoretical results. Taking this value as reference we observe that our values for the SPC and FERG geometries do not present good agreement. For the FERG potential we obtained $16.87 \pm 0.87 \mathrm{ppm}$ for $\sigma^{\text {anis }}\left({ }^{1} \mathrm{H}\right)$ while the reference values is $19.1 \pm 0.1 \mathrm{ppm}^{43}$. The TIPS and DP models, in their turn, showed better agreement; $19.07 \mathrm{ppm}$ (TIPS) and $19.08 \pm 0.95$ ppm (DP). In the case of the oxygen atom, $\sigma^{\text {anis }}\left({ }^{17} \mathrm{O}\right)$ was calculated in high level RASSCF as being $46.97 \mathrm{ppm}^{43}$ and in MP2/6-311++G(2d,2p) level as being $46.05 \mathrm{ppm}^{44}$, however the value obtained here is $55.88 \pm 2.53 \mathrm{ppm}$, suggesting that the electron correlation must be important to characterize this property. The difference between the values for rigid and flexible molecules reveals the importance of considering the intramolecular vibrations. Such vibrations insert a fluctuation in the values and the property is described no more by an absolute value but by a distribution. Finally we can observe that the values presented in Table 2 to TIPS geometry are very similar to that values obtained for the optimized isolated molecule, indicating the similarity between the two geometries.

\subsection{Absolute chemical shielding of the liquid-phase} For a more appropriate description of a liquid phase system many aspects must be considered. First of all, the model employed to describe the liquid can not be optimized, given that in a liquid the molecules undergoes deformations due to interactions with its neighbour, in a way that there is not an equilibrium condition, although it is a good approximation for the gas-phase ${ }^{45}$.

Figure 1: Superposition of the 100 possible configurations for the first solvation shell (1 solute +4 solvent) of the liquid water simulated by Molecular Dynamics.

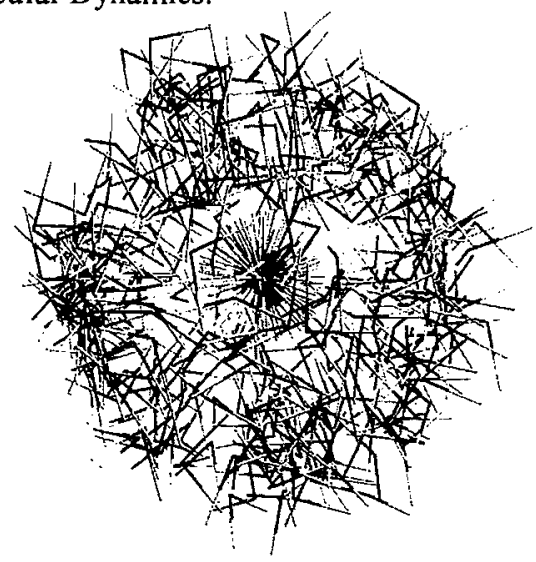

Secondly, it turns out to be more and more important to consider the solvent molecules explicitly, since fundamental interactions such as hydrogen bonds must be well described. Finally, it must be taken into account a minimum number of solvent molecules to describe the liquid environment around the solute molecule. For the liquid water it is known that five molecules (1 solute +4 solvent) determine the first solvation shell of the liquid ${ }^{46}$.

As seen, we will consider in this work, as being the better description of the liquid phase, that one which provides a distribution of values 
obtained from several configurations taken from computer simulations. In this way we certify that the effect of thermal disorder will be included as well as the intrinsic statistical character of the liquid phase.

Figure 1 illustrates the superposition of 100 configurations selected from simulations with the first solvation shell of liquid water. The central molecule has its oxygen atom fixed. We can see that the neighboring molecules fill all the configurational space. In the same way we can see that the solvent molecules are uniformly distributed around the reference molecule. The magnetic shieldings for the reference water molecule, calculated in B3LYP/6-311+ $\mathrm{G}(2 \mathrm{~d}, 2 \mathrm{p})$ are shown in Table 3. As the hydrogen atoms have the same chemical environment, its shieldings tend to the same value, thus the reported values in Table 3 refers to the average of the shieldings of the two hydrogen atoms (see Figure 2).

Figure 2: Convergence of average isotropic chemical shielding, $\sigma^{\text {iso }}$, for the two hydrogen atoms of the reference water molecule in liquid water (potential DP). Black balls stand for the the average shielding of the two hydrogen atoms.

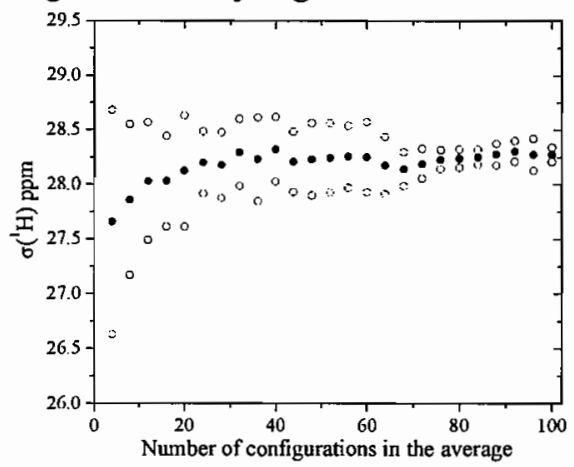

The presented values in Table 3 are not directly comparable to experimental value since they contain basis set superposition error, however they can be used to another analysis. One can observe, for instance, that the standard deviations of the shieldings for the flexible potentials are larger than the deviations for the corresponding rigid potential due to inclusion of vibrational contribution. The rigid potentials presented values systematically larger than the values presented by the corresponding flexible potential. For instance, the chemical shielding for the TIPS oxygen atom is $297.36 \pm 7.75 \mathrm{ppm}$ while for the DP oxygen atom is $288.66 \pm 10.98 \mathrm{ppm}$. The difference between these averages, that in this example is $\sim 9 \mathrm{ppm}$, can be attributed to vibrational effects. Figure 3 presents the statistical convergence for the calculated average shieldings of the FERG and DP configurations. We can see that the averages achieve convergence with approximately 50 configurations. It is also important to notice in Table 3 that the isotropic shielding suffers a larger effect due to the choice of potential than the anisotropic shielding. The sensitivity of the shieldings with the potential is more evident in the graphics of Figure 3. Given that we have already discussed the results for chemical shielding, we can now discuss the gas-liquid chemical shifts. Two fundamental aspects not discussed so far will be taken into account in the next sections. The first is the convergence of the shielding with the cluster size. It is known that only the first solvation shell is not enough to reproduce the experimental results ${ }^{18}$ and that, in order to have a good description of the magnetic shielding in the liquid phase, it is necessary more than four molecules in the first solvation shell ${ }^{13}$

Figure 3: Convergence of average isotropic, $\sigma^{\text {iso }}$, and anisotropic, $\sigma^{\text {anis }}$, shielding for the atoms of the reference molecule in first solvation shell of liquid water. Black balls stand for the averages obtained with DP potential and white balls with FERG potential. The vertical bars represent the statistical errors.

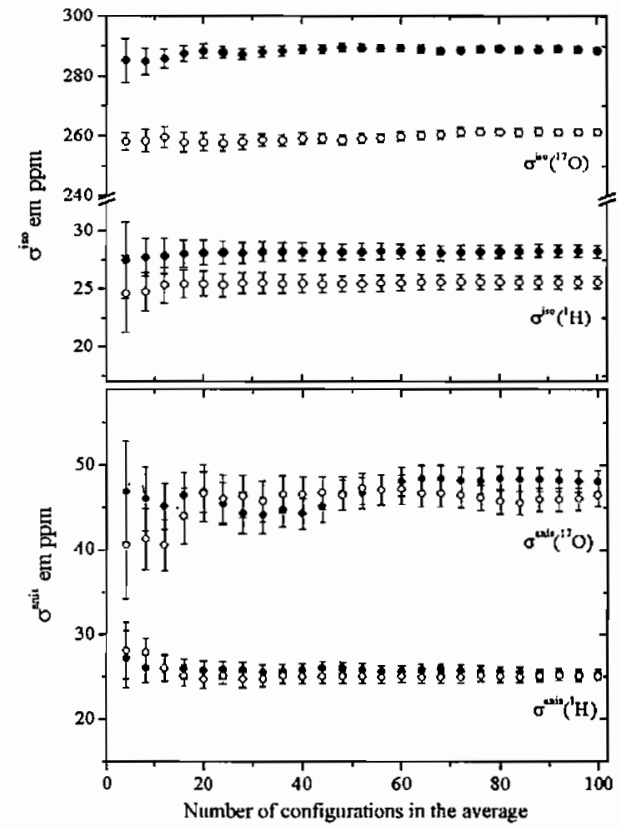


Table 4: Comparison between isotropic, $\sigma^{\text {iso }}$, and anisotropic, $\sigma^{\text {anis }}$, absolute magnetic shielding for balanced and locally dense basis sets. Balanced stands for $6-311+\mathrm{G}(2 \mathrm{~d}, 2 \mathrm{p})$ basis set and dense stands for a combination of 6$311+\mathrm{G}(2 \mathrm{~d}, 2 \mathrm{p})$ and 3-21G (see text). Values in ppm obtained at B3LYP level for the structures generated by DP potential. Uncertainties are the standard deviations of the averages obtained over 100 configurations.

\begin{tabular}{|c|c|c|c|c|}
\hline & \multicolumn{2}{|c|}{$\sigma^{\text {iso }}\left({ }^{17} \mathrm{O}\right)$} & \multicolumn{2}{|c|}{$\sigma^{\text {iso }}\left({ }^{1} \mathrm{H}\right)$} \\
\hline & 5 & 9 & 5 & 9 \\
\hline Balanced & $288.66 \pm 10.98$ & $282.29 \pm 10.20$ & $28.26 \pm 1.33$ & $28.04 \pm 1.32$ \\
\hline \multirow[t]{3}{*}{ Dense } & $290.77 \pm 10.48$ & $281.61 \pm 11.31$ & $28.22 \pm 1.49$ & $28.23 \pm 1.26$ \\
\hline & \multicolumn{2}{|c|}{$\sigma^{\text {anis }}\left({ }^{17} \mathrm{O}\right)$} & \multicolumn{2}{|c|}{$\sigma^{\text {anis }}\left({ }^{1} H\right)$} \\
\hline & 5 & 9 & 5 & 9 \\
\hline Balanced & $48.15 \pm 12.49$ & $42.60 \pm 13.09$ & $25.35 \pm 3.49$ & $25.05 \pm 2.96$ \\
\hline Dense & $46.82 \pm 12.37$ & $44.50 \pm 11.88$ & $25.93 \pm 3.64$ & $24.71 \pm 3.13$ \\
\hline
\end{tabular}

Table 5: Dependence of the isotropic, $\delta^{\text {iso }}$, and anisotropic, $\delta^{\text {anis }}$, chemical shifts on the cluster size. Uncorrected (without $\mathrm{CP}$ ) and corrected (with $\mathrm{CP}$ ) values in ppm. The structures were generated with the DP potential and the quantum calculations were performed at B3LYP level. Uncertainties are the standard deviations.

\begin{tabular}{|c|c|c|c|c|}
\hline & \multicolumn{2}{|c|}{ without CP } & \multicolumn{2}{|c|}{ with $\mathrm{CP}$} \\
\hline & $\delta^{\text {iso }}\left({ }^{17} \mathrm{O}\right)$ & $\delta^{\text {iso }}\left({ }^{1} \mathrm{H}\right)$ & $\delta^{\text {iso }}\left({ }^{17} \mathrm{O}\right)$ & $\delta^{\text {iso }}\left({ }^{1} \mathrm{H}\right)$ \\
\hline 1 & 0.0 & 0.0 & 0.0 & 0.0 \\
\hline 5 & $-36.25 \pm 13.15$ & $-3.11 \pm 1.36$ & $-29.49 \pm 8.33$ & $-2.77 \pm 1.02$ \\
\hline 9 & $-43.31 \pm 13.52$ & $-3.14 \pm 1.28$ & $-36.61 \pm 7.67$ & $-2.88 \pm 0.92$ \\
\hline 13 & $-44.32 \pm 15.59$ & $-3.22 \pm 1.40$ & $-38.10 \pm 7.37$ & $-2.91 \pm 0.98$ \\
\hline 17 & $-44.54 \pm 11.77$ & $-3.29 \pm 1.39$ & $-38.12 \pm 7.95$ & $-2.99 \pm 1.01$ \\
\hline 24 & $-44.32 \pm 11.79$ & $-3.47 \pm 1.42$ & $-38.11 \pm 7.92$ & $-3.12 \pm 0.99$ \\
\hline \multirow[t]{2}{*}{$\operatorname{Exp}$} & -36.1 & -4.26 & -36.1 & -4.26 \\
\hline & $\delta^{\text {anis }}\left({ }^{17} \mathrm{O}\right)$ & $\delta^{\text {anis }}\left({ }^{l} H\right)$ & $\delta^{\text {anis }}\left({ }^{17} \mathrm{O}\right)$ & $\delta^{\text {anis }}\left({ }^{1} \mathrm{H}\right)$ \\
\hline 1 & 0.0 & 0.0 & 0.0 & 0.0 \\
\hline 5 & $-7.74 \pm 12.74$ & $6.27 \pm 3.85$ & $-5.96 \pm 10.73$ & $7.08 \pm 3.78$ \\
\hline 9 & $-11.28 \pm 12.12$ & $5.82 \pm 3.72$ & $-10.99 \pm 11.01$ & $6.93 \pm 3.28$ \\
\hline 13 & $-13.78 \pm 13.02$ & $5.83 \pm 3.20$ & $-11.94 \pm 10.54$ & $6.59 \pm 3.35$ \\
\hline 17 & $-14.27 \pm 13.01$ & $5.75 \pm 3.31$ & $-12.57 \pm 10.13$ & $6.62 \pm 3.22$ \\
\hline 24 & $-14.55 \pm 13.22$ & $6.03 \pm 3.22$ & $-12.69 \pm 10.78$ & $6.78 \pm 3.40$ \\
\hline
\end{tabular}

The second aspect to be considered is the basis set superposition error (BSSE). Since our study involves super molecular quantum calculations, the BSSE correction is essential for the reliability of the results. Thus we used the counterpoise correction ${ }^{47}$, calculating the chemical shift using the reference magnetic shielding calculated in the presence of the basis functions of the solvent molecules.

In the next analysis, we will consider only the structures generated by the DP potential since this potential described better the magnetic shielding for both liquid and gas phases. It is important to mention that, though the DP potential is an empirical potential it has described such properties quite well, however a similar study suggest that an appropriate description is only possible with $a b$ inito potentials ${ }^{13}$.

3.4 Locally dense basis set

As the computational cost increase very much with the number of molecules in the cluster, it is important to try to describe the system as cheapest as possible. Then, for the solvent water molecules description we used the expedient employed by Chesnut and co-workers ${ }^{48-50}$, in which the reference water molecule is treated by a relatively large basis set on the atoms of interest and a considerably smaller basis set in the other atoms of system. These procedures, that drastically reduce the computational effort, provide good results when compared with the conventional approximation of balanced basis. 
Figure 4: Cluster sizes used in the average calculations.
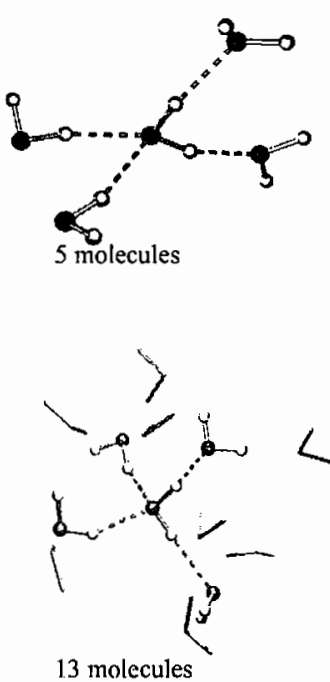
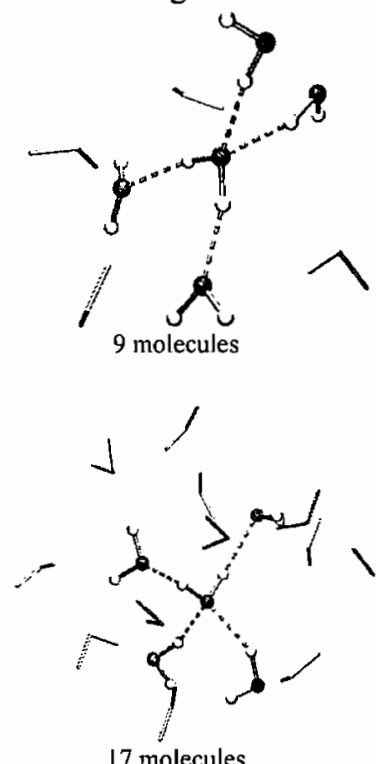

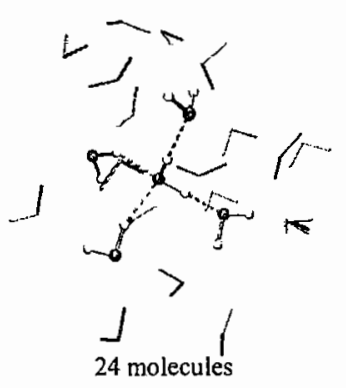

In other study, on the first coordination shell of the geometrical structure of the ice, $\left(\mathrm{H}_{2} \mathrm{O}\right)_{17}{ }^{51}$, two basis set were employed: the $6-311 \mathrm{G}(\mathrm{d}, \mathrm{p})$ to the whole cluster; and the locally dense 6-311G(d,p) basis set (describing the central molecule) combined with the 4-31G basis set (describing its neighbors). The results they found were practically identical showing the validity of this approximation. In this work we carried out a test to have insights about the magnitude of the effects on the simulations structures. Table 4 presents the obtained values to isotropic and anisotropic shieldings for two different cluster sizes extracted from simulations, with 5 and 9 water molecules. For the pentamer we used the $6-311++G(2 d, 2 p)$ basis set to describe the whole system (Balanced) and, in sequence, we used the $6-311++G(2 d, 2 p)$ to describe the central molecule and the $3-21 \mathrm{G}$ to describe its neighbors (Dense). We observed that the difference between the two treatments was substantial only two oxygen atoms. For both $\sigma^{\text {iso }}(\mathrm{O})$ and $\sigma^{\text {anis }}(\mathrm{O})$ the difference is significant, $\sim 2$ ppm, suggesting that describing the pentamer with the large basis set only on the central molecule is not sufficient. Thus we performed the same analysis for a large cluster size, with 9 molecules. Now we considered, on the one hand, the balanced basis set in all nine molecules and, on the other hand, the molecules of the first solvation shell described by a $6-311+G(2 d, 2 p)$ basis set and the other molecules described by a 3$21 \mathrm{G}$ basis set. Now, the difference for $\sigma^{\text {iso }}(\mathrm{O})$ was smaller than $0.7 \mathrm{ppm}$ whereas the difference for $\sigma^{\text {anis }}(\mathrm{O})$ was $\sim 1 \mathrm{ppm}$. We consider these differences as acceptable since this procedure has permitted a great reduction of the computational cost that allowed a detailed study of the bigger clusters. Based in this analysis, our study on the effects of the larger solvation shells will be performed with the $6-311++G(2 d, 2 p) / 3-21 G$ locally dense basis set. 


\subsection{Chemical shift gas-liquid}

3.5.1Dependence with the cluster size and BSSE

For some properties the first solvation shell of the liquid water its enough to obtain a good description of the solven $t^{46}$. However, to the magnetic shielding it is necessary to go beyond, so to have a converged value in relation to the number of solvent molecules. In this section we will examine this effect varying the cluster size and observing the value of the chemical shielding of the reference water molecule. Figure 4 presents a configuration of liquid for each different size. In each snapshot the first solvation shell is emphasized, indicating that all the five molecules are described with 6$311++\mathrm{G}(2 \mathrm{~d}, 2 \mathrm{p})$. In the other clusters, of $9,13,17$ and 24 molecules, the molecules beyond the first shell are described by the 3-21G basis set.

As we have seen in Figure 3, the values for both isotropic and anisotropic shielding have a converged average after approximately 40 configurations. Therefore for the clusters of 13,17 and 24 molecules we take the average over 50 configurations.

Table 6: Dependence of the parallel, $\delta_{/ /}$, and perpendicular, $\delta_{\perp}$, components of the isotropic chemical shift (in $\mathrm{ppm}$ ) on the cluster size. Uncorrected (without $\mathrm{CP}$ ) and corrected (with $\mathrm{CP}$ ) values in ppm. The structures were generated with the DP potential and the quantum calculations were performed at the B3LYP level. Uncertainties are the standard deviations.

\begin{tabular}{|c|c|c|c|c|}
\hline & \multicolumn{2}{|c|}{ without $\mathrm{CP}$} & \multicolumn{2}{|c|}{ with CP } \\
\hline & $\delta_{/ /}\left({ }^{17} \mathrm{O}\right)$ & $\delta_{/}\left({ }^{1} \mathrm{H}\right)$ & $\delta /\left({ }^{17} \mathrm{O}\right)$ & $\delta_{/ /}\left({ }^{1} \mathrm{H}\right)$ \\
\hline 1 & 0.0 & 0.0 & 0.0 & 0.0 \\
\hline 5 & $-41.41 \pm 16.69$ & $1.07 \pm 2.25$ & $-33.46 \pm 13.04$ & $1.95 \pm 1.73$ \\
\hline 9 & $-50.90 \pm 16.68$ & $0.74 \pm 2.26$ & $-43.94 \pm 12.94$ & $1.75 \pm 1.63$ \\
\hline 13 & $-53.50 \pm 14.37$ & $0.66 \pm 1.81$ & $-46.06 \pm 12.32$ & $1.48 \pm 1.57$ \\
\hline 17 & $-54.05 \pm 14.47$ & $0.54 \pm 1.88$ & $-46.50 \pm 12.63$ & $1.42 \pm 1.71$ \\
\hline 24 & $-54.02 \pm 14.67$ & $0.55 \pm 1.79$ & $-46.57 \pm 15.90$ & $1.35 \pm 1.57$ \\
\hline & $\delta_{\perp}\left({ }^{17} \mathrm{O}\right)$ & $\delta_{\perp}\left({ }^{\mathrm{l}} \mathrm{H}\right)$ & $\delta_{1}\left({ }^{17} \mathrm{O}\right)$ & $\delta_{\perp}\left({ }^{1} \mathrm{H}\right)$ \\
\hline 1 & 0.0 & 0.0 & 0.0 & 0.0 \\
\hline 5 & $-33.67 \pm 13.20$ & $-5.20 \pm 2.28$ & $-27.50 \pm 7.58$ & $-5.13 \pm 2.20$ \\
\hline 9 & $-39.52 \pm 13.56$ & $-5.08 \pm 2.07$ & $-32.95 \pm 6.69$ & $-5.19 \pm 1.87$ \\
\hline 13 & $-39.72 \pm 12.44$ & $-5.17 \pm 2.17$ & $-34.12 \pm 6.52$ & $-5.11 \pm 1.99$ \\
\hline 17 & $-39.78 \pm 12.63$ & $-5.21 \pm 2.19$ & $-33.93 \pm 6.54$ & $-5.20 \pm 2.26$ \\
\hline 24 & $-39.48 \pm 12.61$ & $-5.48 \pm 2.21$ & $-33.88 \pm 7.03$ & $-5.42 \pm 2.02$ \\
\hline
\end{tabular}

Table 5 presents the uncorrected (without CP) and corrected (with CP) values for the isotropic, $\delta^{\text {iso }}$, and anisotropic, $\delta^{\text {anis }}$, chemical shift of the central water molecule. We observed that BSSE correction is fundamental for a good description of the magnetic shielding of the oxygen atom and consequently of its chemical shift. For the configurations of size 9 clusters for instance, the BSSE is $\sim 6 \mathrm{ppm}$. For the hydrogen atom this error is only $\sim 0.3 \mathrm{ppm}$. For the anisotropic chemical shift the BSSE is smaller, reaching less than $2 \mathrm{ppm}$ for the oxygen atom and $1 \mathrm{ppm}$ for the hydrogen atoms. We also observe, from Table 5, that the chemical shift has its value converged only for clusters that contain more than 13 water molecules (see Figure 5). For these clusters we see that the average chemical shift is $38.10 \pm 7.37 \mathrm{ppm}$, comparable with the experimental value of $36.1 \mathrm{ppm}$. For the hydrogen atoms we have obtained an average of
$2.91 \pm 0.98 \mathrm{ppm}$, that possibly would be better if we could employ a superior quantum method that describes better the shielding in both the gas and liquid phase.

These values, corrected against BSSE and calculated with the DP potential, can be directly compared with the value of Malkin ${ }^{13}$ who has obtained $\delta^{\text {iso }}\left({ }^{17} \mathrm{O}\right)=-44.8+2.3 \mathrm{ppm}$ and $\delta^{\text {iso }}\left({ }^{1} \mathrm{H}\right)=$ $2.8 \pm 0.3 \mathrm{ppm}$. We see that regarding the oxygen chemical shift there is a difference of $\sim 7 \mathrm{ppm}$ while for the hydrogen atoms this difference is $\sim 0.1 \mathrm{ppm}$. Other remarkable difference is related to standard deviations, that in the case of Malkin was found to be smaller by a factor of 3 . These differences probably are attributed to a small number of configurations (only 10) that was used by Malkin in the calculation of the average. 
Table 7: Averages of the chemical shifts (in ppm) obtained for the clusters with 13 water molecules calculated with several functionals. Uncertainties are the standard deviations.

\begin{tabular}{ccccc}
\hline & $\delta^{\text {iso }}\left({ }^{17} \mathrm{O}\right)$ & $\delta^{\text {iso }}\left({ }^{1} \mathrm{H}\right)$ & $\delta^{\text {anis }}\left({ }^{17} \mathrm{O}\right)$ & $\delta^{\text {anis }}\left({ }^{1} \mathrm{H}\right)$ \\
\hline BLYP & $-43.10 \pm 7.93$ & $-2.98 \pm 1.04$ & $-11.50 \pm 10.28$ & $6.44 \pm 3.16$ \\
B3LYP & $-38.10 \pm 7.37$ & $-2.91 \pm 0.98$ & $-11.94 \pm 10.54$ & $6.59 \pm 3.35$ \\
G96LYP & $-40.49 \pm 8.00$ & $-3.04 \pm 1.01$ & $-12.28 \pm 10.93$ & $6.60 \pm 3.40$ \\
BP86 & $-42.68 \pm 7.91$ & $-3.04 \pm 1.00$ & $-11.85 \pm 10.88$ & $6.44 \pm 3.33$ \\
B3P86 & $-36.96 \pm 7.30$ & $-2.94 \pm 0.98$ & $-12.19 \pm 10.41$ & $6.41 \pm 3.33$ \\
G96P86 & $-39.87 \pm 7.78$ & $-3.08 \pm 0.99$ & $-12.25 \pm 10.66$ & $6.64 \pm 3.34$ \\
& & & & \\
BPW91 & $-40.35 \pm 7.70$ & $-3.03 \pm 1.00$ & $-11.58 \pm 10.74$ & $6.48 \pm 3.32$ \\
B3PW91 & $-35.86 \pm 7.23$ & $-2.93 \pm 0.99$ & $-11.90 \pm 10.45$ & $6.55 \pm 3.32$ \\
G96PW91 & $-37.53 \pm 7.64$ & $-3.06 \pm 1.00$ & $-11.96 \pm 10.62$ & $6.59 \pm 3.31$ \\
& & & & \\
MPW1PW91 & $-35.86 \pm 7.15$ & $-2.90 \pm 0.98$ & $-11.66 \pm 10.36$ & $6.53 \pm 3.31$ \\
PBE1PBE & $-36.14 \pm 7.13$ & $-2.90 \pm 0.97$ & $-11.76 \pm 10.29$ & $6.60 \pm 3.34$ \\
B971 & $-36.29 \pm 7.14$ & $-2.92 \pm 0.98$ & $-11.91 \pm 10.28$ & $6.61 \pm 3.34$ \\
Exp & -36.1 & -4.26 & & \\
\hline
\end{tabular}

a) $\operatorname{Ref}^{25}$; b) $\operatorname{Ref.}^{26}$

Figure 5: Convergence of the average isotropic chemical shift, $\delta^{\text {iso }}$, with cluster size. Each point at the figure represents an average over 50 B3LYPcalculations with locally dense basis set, except for the size 5 and 9 clusters for which we performed 100 calculations

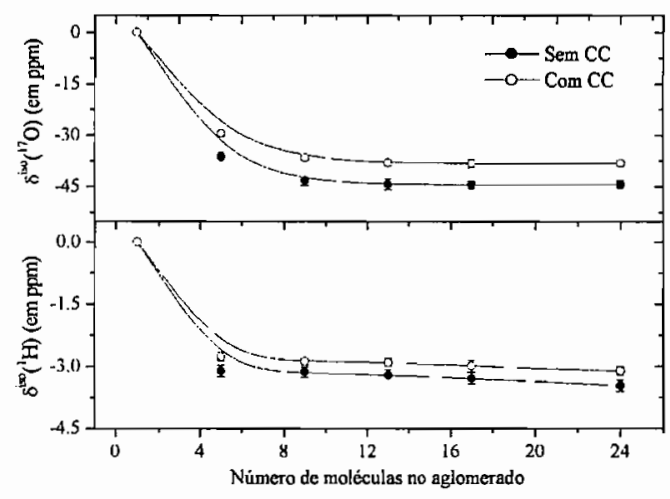

Figure 6: Convergence of the average anisotropic chemical shift, $\delta^{\text {anis }}$, with cluster size. Each point at the figure represents an average over $50 \mathrm{~B} 3 \mathrm{LYP}$ calculations with locally dense basis set, except for the size 5 and 9 clusters for which we performed 100 calculations.

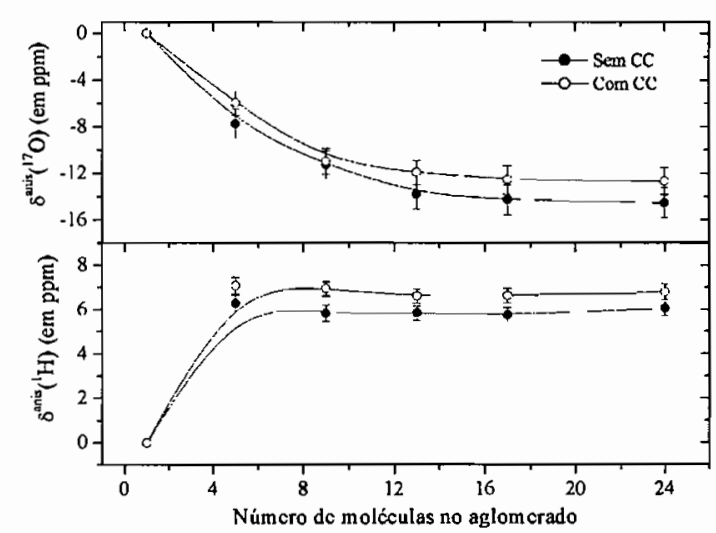


Figure 7: Average of the parallel, $\delta_{/ /}$, and perpendicular, $\delta_{\perp}$, components of the isotropic chemical shift for the hydrogen atom. Each point at the figure stand for an average over 50 B3LYP calculations with locally dense basis set, except for the clusters of size 5 and 9 for which we performed 100 calculations.

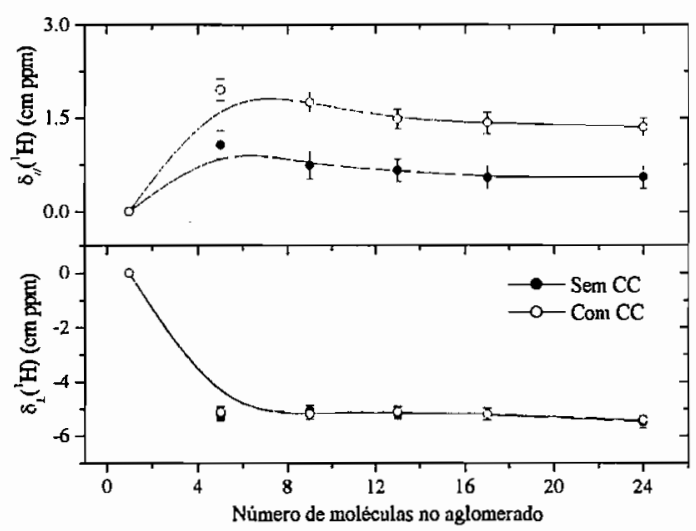

Table 5 presents, in addition, the values of anisotropic chemical shift, for which there is theoretical results only at rigid cluster approximation $^{51}$ which, as seen, fails at describing the isotropic chemical shift. We can observe that this shift to oxygen atom decreases with the increasing number of neighbour molecules whereas for the hydrogen atom the oppose occurs (see Figure 5). This effect was observed before in water dimer $^{40}$ and discussed in the light of experimental results ${ }^{26}$ and its main cause is attributed to induced currents in the proton acceptor oxygen atom ${ }^{40}$.

Table 6 presents the chemical shifts of the components of the chemical shift tensor that are parallel, $\delta_{/ /}$, and perpendicular, $\delta_{\perp}$, to the symmetry axis of the tensor, that in its turn, is nearly parallel to the hydrogen bond axis. Those components can be obtained from the linear combinations of the $\sigma^{\text {iso }}$ and $\sigma^{\text {anis }}$, given by:

$$
\begin{aligned}
& \sigma_{1 /}=\sigma^{i s o}+\frac{2}{3} \sigma^{a n i s} \\
& \text { and } \\
& \sigma_{\perp}=\sigma^{i s o}-\frac{1}{3} \sigma^{a n i s}
\end{aligned}
$$

We see that the values for the oxygen atom obey the same tendency, that is, both parallel and perpendicular components always decrease their intensity with the increasing number of solvent molecules in the cluster. These values also converge for clusters of size 13 , being $\delta / /\left({ }^{17} \mathrm{O}\right)=-46.06 \pm$
$12.32 \mathrm{ppm}$ and $\delta_{\perp}\left({ }^{17} \mathrm{O}\right)=-34.12 \pm 6.52 \mathrm{ppm}$ the BSSE corrected values. As for the values of the hydrogen atoms, we observed that the chemical shifts $\delta_{/ /}\left({ }^{1} \mathrm{H}\right)$ and $\delta_{\perp}\left({ }^{1} \mathrm{H}\right)$ showed opposite tendency, the converged value of the former being $1.48 \pm 1.57$ ppm and of the latter $-5.11 \pm 1.99 \mathrm{ppm}$, both corrected against BSSE. Figure 7 shows the behavior for the two chemical shifts when the number of solvent molecule increases.

\subsubsection{Dependence with the functional}

An important factor to the description of the chemical shift by the DFT method is the choice of the functional. Several works has been explored the use of functionals as well as suggested improvements to applications of the DFT in chemical shieldings calculations ${ }^{52-54}$. In this section we will explore the behavior of the isotropic and anisotropic chemical shifts. For that we employed a large series of functionals. The $\mathrm{B}^{55}, \mathrm{B3}^{36}$ e $\mathrm{G} 96^{56}$ exchange functionals were used in combination with the $\mathrm{P}^{56} 6^{57}$, LYP ${ }^{37}$, PW91 ${ }^{58}$ correlation functionals. We think it is interesting also to consider the functionals PBE1PBE ${ }^{59}$, MPW1PW9 ${ }^{60}$ and B97-1 ${ }^{61}$ in such analysis.

As we have seen in the previous sections, the shielding averages are well converged with 13 molecules. So in this analysis we are using this cluster size to calculate the averages. The values for the isotropic chemical shift are presented in Table 7. The chemical shift values varies with the functional in a range of $7.24 \mathrm{ppm}$ for the oxygen atom, the larger value being the one obtained with the BLYP functional, $-43.10 \mathrm{ppm}$, and the smaller value obtained with the B3PW91 functional, -35.86 ppm. For the hydrogen atoms we observed a range of $0.18 \mathrm{ppm}$ the larger value obtained with the G96P86 functional and the smaller value obtained with the MPW1PW91 and PBE1PBE functionals. We noticed that the choice of exchange functional is fundamental for a good description of the isotropic chemical shift. It can be observed, for instance, by comparing the obtained values with the functionals which have B, B3 and G96 as the exchange functional, for which the difference reaches $5 \mathrm{ppm}$ for isotropic chemical shift of the oxygen atom (which is the case of BLYP and B3LYP functionals). That shows a relative superiority of the B3 functional. In all the cases, the values obtained with the functional G96 were intermediate to the values obtained with the $B$ and B3 functional.

We can also compare the quality of the correlation functionals. We see that with the same exchange functional (B, B3 or G96) the PW91 was the one that presented the best values for $\delta^{\text {iso }}\left({ }^{17} \mathrm{O}\right)$. For $\delta^{\text {iso }}\left({ }^{1} \mathrm{H}\right)$ the values obtained with P86 showed a 
slightly superior quality than PW91 correlation functional. Using of the LYP correlation functional we obtained the larger values for $\delta^{\text {iso }}\left({ }^{17} \mathrm{O}\right)$ and the smaller values for $\delta^{\text {iso }}\left({ }^{1} \mathrm{H}\right)$. In a recent study on the determination of the chemical shifts for 105 molecules in gas phase, it was observed that the B3LYP, B3P86 and B3PW91 presented, essentially, the same performance. However in the present work we observed that the B3PW91 presents a smaller percent deviation from the experimental value $(0.7 \%)$ than the B3LYP $(5.5 \%)$ and B3P86 (2.4\%) functionals.

The MPW1PW91 and PBE1PBE functionals have already been successfully employed in the determination of the chemical shift $^{14}$ (ref-PBE). Here they have been shown again to be good models to gas-liquid chemical shifts, presenting for the $\delta^{\text {iso }}\left({ }^{17} \mathrm{O}\right)$ a percent deviation smaller than $0.7 \%$ in relation to the experimental value.

Finally we have obtained the value for the anisotropic chemical shift, for both oxygen an hydrogen atoms, showing to be less sensitive to the employed functional, comprised a small range of $0.75 \mathrm{ppm}$ for $\delta^{\text {anis }}\left({ }^{17} \mathrm{O}\right)$ and $0.23 \mathrm{ppm}$ for $\delta^{\text {anis }}\left({ }^{1} \mathrm{H}\right)$.

\section{Conclusions}

In this work we have studied the chemical shifts in the liquid water through the sequential Simulation/DFT methodology. The liquid water was simulated via Monte Carlo and Molecular Dynamic methods with four different potentials. Two of them without intramolecular terms (SCP and TIPS) and two with intramolecular terms (FERG and DP). Uncorrelated structures were selected and used in the DFT calculations of the absolute magnetic shielding and of the isotropic and anisotropic chemical shifts. Statistically converged averages were obtained for these properties.

In a first analysis we studied the dependence of the chemical shielding with the potential employed at the production of the structures of the liquid. Through of this initial study, carried out in B3LYP/6-311++G(2d,2p) level, we have verified that the rigid potentials are not appropriate for the description of the chemical shift, showing the necessity to consider the vibrational effects in the study of the liquid and gas phase. We also verified that the FERG potential, though it has reproduced relatively well the chemical shift, does not provide a good description for the absolute shielding. Then, we considered in the following analysis only the DP potential which reproduced in a satisfactory way both the absolute shieldings and the chemical shifts.

To study the convergence of the averages calculated in relation to cluster size we analyzed clusters containing 5,9,13,17 and 24 molecules. The expedient of locally dense basis set was used to perform the calculations. In this sense, the reference molecule and the first solvation shell around it were treated with the $6-311++\mathrm{G}(2 \mathrm{~d}, 2 \mathrm{p})$ basis set while the other molecules in the cluster were treated with the $3-21 \mathrm{G}$ basis set. We observed that the difference between the obtained results with the conventional method, where all molecules are described with the larger basis set and the method of locally dense basis set, was small, being less than $1 \mathrm{ppm}$ for the isotropic chemical shift for oxygen atom in the cluster with 9 molecules and the computational demand was drastically reduced.

For each cluster size we obtained the isotropic and anisotropic chemical shifts, with and without BSSE correction, represented by averages over 50 configurations, except for clusters of size 5 and 9 for which we used 100 configurations in the average. We verified that the isotropic chemical shift for the oxygen atom only achieve acceptable concordance when the cluster had 13 molecules and the BSSE was corrected. We observed that while the BSSE correction, that was $\sim 6 \mathrm{ppm}$, has improved the value for oxygen atom, it has worsened the value for the hydrogen atom. For the anisotropic chemical shift error was smaller, less than $2 \mathrm{ppm}$ for the oxygen atom and $1 \mathrm{ppm}$ for the hydrogen atoms. Thus, with the B3LYP functional, we obtained the values of $38.10 \pm 7.37 \mathrm{ppm}$ and $2.91 \pm 0.98 \mathrm{ppm}$ as being the better description for the isotropic chemical shifts for the oxygen and hydrogen atoms respectively. These values not only are reasonable, but also presented a percent deviation of $5 \%$ from the experimental value, giving us a motivation to analyze the dependence of the chemical shift with the functional.

For this analysis we considered 12 different functionals, and we verified that the range of values is $7.24 \mathrm{ppm}$ for the oxygen atom, the larger value being that obtained with BLYP functional and the smaller value obtained with the B3PW91 functional. We noticed that the choice of exchange functional is fundamental to the description of the chemical shifts, the shifts varying up to $5 \mathrm{ppm}$ between the $\mathrm{B}$ and $\mathrm{B} 3$ exchange functionals. We also noticed that the values obtained with the G96 functionals produced intermediate results between the $\mathrm{B}$ and $\mathrm{B} 3$ results, the $\mathrm{B} 3$ functional producing the best values. The MPW1PW91, PBE1PBE and B971 functionals presented values for $\delta^{\text {iso }}\left({ }^{17} \mathrm{O}\right)$ in excellent agreement with experimental values, all of them with deviations smaller than $0.7 \%$. We verified that the anisotropic chemical shift was less sensitive to the employed functional, comprised in a range of $0.75 \mathrm{ppm}$ for $\delta^{\text {anis }}\left({ }^{17} \mathrm{O}\right)$.

Acknowledgments: This work has been partially supported by CNPq and FAPESP (Brazil). 


\section{Reference List}

1. Krauss M, Olsen L, Antony J \& Hemmingsen L. J. Chem. Phys. B 106, 9446 (2002).

2. Krishnamurty $\mathrm{S}$, Heine $\mathrm{T} \&$ Goursot A. $J$. Chem. Phys. B 107, 5728 (2003).

3. Zhou P, Li G, Shao Z, Pan X \& Yu T. $J$. Chem. Phys. B 105, 12469 (2001).

4. Consentino U et al. J. Am. Chem. Soc. 124, 4901 (2001).

5. Dong S, Ida R \& Wa G. J. Chem. Phys. A 104, 11194 (2000).

6. Scheiner S. Hydrogen Bonding: A Theoretical Perspective. Oxford Press, Oxford (1999).

7. Jeffrey G A. Introduction to Hydrogen Bond. Oxford Press, Oxford (1997).

8. Yamazaki T, Sato H \& Hirata F. J. Chem. Phys 115, 8949 (2001).

9. Sebastiani D \& Rothlisberger U. J. Phys. Chem. B 108, 2807 (2004).

10. Jackowski K \& Barszczewicz A. J. Mol. Struct. 431, 47 (1998).

11. Nymand T, Astrand P O \& Mikkelsen K V. J. Chem. Phys. B 101, 4105 (1997).

12. Cui Q \& Karplus M. J. Chem. Phys. B 104, 3721 (2000).

13. Malkin V G, Malkina O L, Steinebrunner G \& Huber H. Chem. Eur. J2, 452 (1996).

14. Mennucci B, Martínez J M \& Tomasi J. $J$. Chem. Phys. A 105, 7287 (2001).

15. Kirkwood J G. J. Chem. Phys 2, 351 (1934).

16. Onsager L. J. Am. Chem. Soc. 58, 1486 (1936).

17. Jackowski K. Chem. Phys. Lett. 194, 167 (1992).
18. Chesnut D B \& Rusiloski B E. J. Mol. Struct. 314, 19 (1994)

19. Cheeseman J R, Trucks G W, Keith T A \& Frisch M J. J. Chem. Phys 104, 5497 (1996).

20. Fileti E E, Coutinho K, Malaspina $T$ \& Canuto S. Phys. Rev. E 67, 61504 (2003).

21. Canuto S, Coutinho K \& Trzresniak D. $A d v$. Quantum Chem. 41, 161 (2002).

22. Malaspina T, Coutinho $\mathrm{K} \&$ Canuto S. $J$. Chem. Phys 117, 1692 (2002).

23. Coutinho K \& Canuto S. J. Chem. Phys 113, $9132(2000)$

24. Coutinho K, Canuto S \& Zerner M C. $J$. Chem. Phys 112, 9874 (2000).

25. Wasylishen R E \& Bryce D L. J. Chem. Phys 117, 10061 (2002).

26. Modig K \& Halle B. J. Am. Chem. Soc. 124, 12031 (2002).

27. Pople J A, Schneider W G \& Bernstein H J. High-resolution nuclear magnetic resonance. McGraw-Hill, New York (1959).

28. Slichter C P. Principles of magnetic resonance. Harper and Row, New York (1963)

29. Berendsen H J C, Postma J P M, van Gunsteren W F \& Hermans J. Intermolecular Forces. Pullman B (ed.), pp. 331 (Reidel, Dordrecht,20041).

30. Jorgensen W L. J. Am. Chem. Soc. 103, 335 (1981)

31. Ferguson D M. J. Comp. Chem. 16, 501 (1995)

32. Dang L X \& Pettit B M. J. Phys. Chem 91, 3349 (1987).

33. Coutinho K \& Canuto S. DICE: Um Programa para Simulação Computacional de Líquidos Moleculares Utilizando o Método Monte Carlo. 1997. 
34. Berendsen H J C, van der Spoel D \& van Drunen R. Comp. Phys. Comm. 91, 43 (1995).

35. Lindahl E, Hess,B. \& van der Spoel D. $J$. Mol. Mod. 7, 306 (2001).

36. Becke A D. J. Chem. Phys 98, 5648 (1993).

37. Lee C, Yang W \& Par R G. Phys. Rev. B 37, 785 (1988).

38. Wolinski K, Hinton J F \& Pulay P. J. Am. Chem. Soc. 112, 8251 (1990).

39. Ditchfield R. Mol. Phys 27, 789 (1974).

40. Ditchfield R. J. Chem. Phys 65, 3123 (1976).

41. Frisch M J \& et al. Gaussian 98. 1998 \& Gaussian 03. 2003.

42. Gauss J \& Stanton J F. J. Chem. Phys 104, 2574 (1996).

43. Vaara J, Lounilla J, Ruud K \& Helgaker T. J. Chem. Phys 109, 8388 (1998).

44. Karadakov P. J. Mol. Struct. 602, 293 (2002).

45. Hehre W J, Radom L, Schleyer P v R \& Pople J A. Ab Initio Molecular Orbital Theory. John Wiley, New York (1986).

46. Eisenberg D \& Kauzmann W. The structure and properties of water. Oxford University Press, London (1969).

47. Boys,S.F. \& Bernardi,F. Mol. Phys 19, 553 (2004).
48. Chesnut D B \& Moore K D. J. Comp. Chem. 10, 648 (1989).

49. Chesnut D B \& Phung C G. Chem. Phys. Lett. 183, 505 (1991).

50. Chesnut D B \& Rusiloski B E. J. Phys. Chem 97, 2839 (1993).

51. Hinton J F, Guthrie P, Pulay P \& Wolinski K. J. Am. Chem. Soc. 114, 1604 (1992).

52. Allen M J, Keal T W \& Tozer D J. Chem. Phys. Lett. 380, 70 (2003).

53. Wilson P J \& Tozer D J. Chem. Phys. Lett. 337, 341 (2001).

54. Wilson P J, Amos R D \& Handy N C. Chem. Phys. Lett. 312, 475 (1999).

55. Becke A D. Phys. Rev. A 38, 3098 (1988).

56. Gill P M W. Mol. Phys 89, 433 (1996).

57. Perdew J P. Phys. Rev. B 33, 8822 (1986).

58. Perdew J P et al. Phys. Rev. B 46, 1992 (1992).

59. Perdew J P, Burke K \& Emzerhof M. Phys. Rev. Lett. 78, 1396 (1997).

60. Adamo C \& Barone V. J. Chem. Phys 108, 664 (1998).

61. Hamprecht F A, Cohen A J, Tozer D J \& Handy N C. J. Chem. Phys 109, 6264 (1998)

62. Hindman J C. J. Chem. Phys 44, 4582 (1966). 


\section{Lista de Tabelas}

4.1 Geometria otimizada do complexo $\mathrm{CH}_{3} \mathrm{CN} \cdots \mathrm{H}_{2} \mathrm{O}$ em comparação com as moléculas isoladas. Os índices dos átomos estão indicados na Figura 4.1a. Distâncias em $\AA$, ângulos em grau, constantes rotacionais em GHz e momentos de dipolo em debye . . . . . . . . . . . . . . 37

4.2 Freqüências vibracionais do complexo $\mathrm{CH}_{3} \mathrm{CN} \cdots \mathrm{H}_{2} \mathrm{O}$ e das moléculas isoladas, determinadas com os modelos MP2.

Todas as freqüências em $\mathrm{cm}^{-1}$. a) Ref. [121] e b) Ref. [122] . . . . . . 39

4.3 Freqüências vibracionais do complexo $\mathrm{CH}_{3} \mathrm{CN} \cdots \mathrm{H}_{2} \mathrm{O}$ e das moléculas isoladas, determinadas com os modelos DFT.

Todas as freqüências em $\mathrm{cm}^{-1}$. a) Ref. [121] e b) Ref. [122] . . . . . . 40

4.4 Energias de ligação calculadas (kcal/mol) e os efeitos da correlação eletrônica no complexo $\mathrm{CH}_{3} \mathrm{CN} \cdots \mathrm{H}_{2} \mathrm{O}$. Todos os resultados são obtidos usando geometrias otimizadas em nível MP2 (funçōes base indicadas na tabela) e corrigidos contra BSSE . . . . . . . . . . . . . . . 4 4

4.5 Polarizabilidades de dipolo média, $\alpha$, e anisotrópica, $\Delta \alpha$, calculadas (em ua) e taxa de despolarização Rayleigh $\mathrm{CH}_{3} \mathrm{CN}$ e $\mathrm{CH}_{3} \mathrm{CN} \cdots \mathrm{H}_{2} \mathrm{O}$. Todos os cálculos foram realizados no nível MP2/aug-cc-pVDZ e nas correspondentes geometrias otimizadas. a) $O$ valor experimental para a polarizabilidade de dipolo da água é 9.80ua. No caso da acetonitrila tem-se dois valores reportados 29.72ua e 30.27ua, Ref. [118] . . . . . . . . . . . . . . 43

4.6 Atividades Raman $A_{p}$ (em ua) e a taxa de despolarização para a luz planopolarizada para $\mathrm{CH}_{3} \mathrm{CN}$ e $\mathrm{CH}_{3} \mathrm{CN} \cdots \mathrm{H}_{2} \mathrm{O}$. Todos os cálculos foram realizados no nível MP2/aug-cc-pVDZ nas correspondentes geometrias otimizadas . 44 
5.1 Polarizabilidades médias, polarizabilidades de interação e polarizabilidades anisotrópicas (em ua), calculadas com o método MP2/aug-cc-pVDZ. Fator de conversão para a polarizabilidade médias: 1 ua $=0.148 \AA^{3}$. a)Polarizabilidades experimentais estāo avaliadas somente para as moléculas isoladas [118] . . . 51

5.2 Taxas de despolarização para diferentes tipos de luz incidente calculadas em termos das polarizabilidades médias e anisotrópicas. Todos valores foram obtidos em nível MP2/aug-cc-pVDZ . . . . . . . . . . . . 53

5.3 Intensidades Rayleigh (em $10^{4} \mathrm{ua}$ ) calculadas em termos das polarizabilidades de dipolo e anisotrópica. Valores em parênteses correspondem ao fator de aumento da intensidade após a complexação com água. Todos os valores foram calculados em nível MP2/aug-cc-pVDZ . . . . . . . . . . 53

5.4 Polarizabilidades média e anisotrópica (em ua) e taxas de despolarização Rayleigh. Todos os valores foram determinados em nível MP2/aug-cc-pVDZ

5.5 Intensidade Rayleigh (em $10^{4}$ ua) calculadas em termos das polarizabilidades médias e anisotrópica. Valores em parênteses correspondem ao fator de aumento da intensidade após a complexação com a água. Todos os valores foram calculados em nível MP2/aug-cc-pVDZ. $I_{A}, I_{B}$ e $I_{C}$ são as constantes rotacionais dadas em $\mathrm{GHz}$. . . . . . . . . . . . . . 56

6.1 Valores das blindagens magnéticas isotrópicas, $\sigma^{i s o}$, anisotrópicas, $\sigma^{\text {anis }}$ dos átomos nas moléculas de metanol e água (em ppm) determinadas em três níveis teóricos. Na quarta coluna são apresentados os resultados experimentais para $\sigma^{i s o}$ e outros resultados teóricos para $\sigma^{\text {anis }}$. a) Resultado de fase líquida convertido para escala absoluta citado por Kitzinger [196]; b) Ref. [197]; c) Ref. [198]; d) Ref. [199]; e) Ref. [200]; f) Ref. [201]; g) Ref. [194]; h) Calculado para o grupo metil na molécula de metilformato Ref. [202]; i)

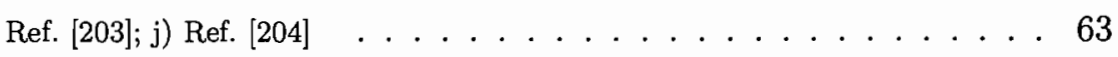

6.2 Variação nas cargas atômicas de Mulliken (em unidade elementar) sobre os átomos dos complexos $\mathrm{CH}_{3} \mathrm{HO} \cdots \mathrm{H}_{2} \mathrm{O}$ e $\mathrm{CH}_{3} \mathrm{OH} \cdots \mathrm{OH}_{2} \ldots . . . .66$ 
6.3 Valores dos deslocamentos químicos isotrópicos, $\delta^{i s o}$, e anisotrópicos, $\delta^{\text {anis }}$ para o complexo $\mathrm{CH}_{3} \mathrm{HO} \cdots \mathrm{H}_{2} \mathrm{O}$ (em ppm) determinados em três níveis teóricos. Os asteriscos indicam os átomos que estão diretamente envolvidos na ligação de hidrogênio. sCC indica resultados sem correção e cCC com correçāo counterpoise . . . . . . . . . . . . . . . 67

6.4 Valores dos deslocamentos químicos isotrópicos, $\delta^{i s o}$, e anisotrópicos, $\delta^{a n i s}$ para o complexo $\mathrm{CH}_{3} \mathrm{OH} \cdots \mathrm{OH}_{2}$ (em ppm) determinados em três níveis teóricos. Os asteriscos indicam os átomos que estão diretamente envolvidos na ligação de hidrogênio. sCC indica resultados sem correção e cCC com correção counterpoise . . . . . . . . . . . . . . . . .

6.5 Valores das componentes paralela $\left(\delta_{/ /}\right)$e perpendiculares $\left(\delta_{\perp}\right)$ da blindagem magnética isotrópica (em ppm) em três níveis teóricos e seus respectivos valores experimentais. Asteriscos indicam os átomos que estāo diretamente envolvidos na ligação de hidrogênio. Resultados sem correção counterpoise . 72

7.1 Distâncias Ro...o e Ro...H em $\AA$, momento de dipolo em Debye e constantes rotacionais em $\mathrm{GHz}$ para os monômeros, dímeros e heterodímeros. Todos os resultados foram obtidos usando as geometrias otimizadas em nível MP2/aug-cc-pVDZ .................. 81

7.2 Energias total (em hartree) e relativa (em $\mathrm{kcal} / \mathrm{mol}$ ) dos heterodímeros de etanol (trans e gauche) e água. As letras em maiúsculo, DA, indicam as moléculas doadora e aceitadora de próton respectivamente. $\mathrm{E}_{g}$ indica a molécula de etanol na sua forma gauche. Todos os resultados foram obtidos usando as geometrias otimizadas em nível MP2/aug-cc-pVDZ. $\triangle Z P E$ representa a diferença na energia de ponto zero entre o complexo e as partes separadas obtida usando MP2/aug-cc-pVDZ . . . . . . . . . . . 84 
7.3 Energias de ligação corrigidas contra BSSE em $\mathrm{kcal} / \mathrm{mol}$ dos complexos. As letras em maiúsculo, DA, indicam as moléculas doadora e aceitadora de próton respectivamente. Todos os resultados foram obtidos usando as geometrias otimizadas em nível MP2/aug-cc-pVDZ. $\triangle Z P E$ representa a diferença na energia de ponto zero entre o complexo e as partes separadas obtida usando MP2/aug-cc-pVDZ . . . . . . . . . . . . . . 85

8.1 Momento de dipolo e polarizabilidades do sistema piridina-água. Os resultados mostrados para o líquido são os valores médios com os respectivos desvios padrão. Modelo vetorial assume uma soma vetorial simples dos momentos de dipolo das moléculas separadas. . . . . . . . . . . . . . .

8.2 Taxa de despolarização Rayleigh $\left(10^{-2}\right)$ do complexo de piridina-água. Os resultados mostrados para o líquido são os valores médios com os respectivos desvios padrão. . . . . . . . . . . . . . . . . 100

9.1 Estatística das ligações de hidrogênio formadas entre metanol e água . . . . 108

9.2 Energias de ligação $(\mathrm{kcal} / \mathrm{mol})$ dos dois isômeros de metanol-água calculada em fase gasosa. Todos os cálculos apresentados foram realizados com a base aug-cc-pVDZ usando a geometria otimizada com MP2/aug-cc-pVDZ. B3LYP se refere a cálculos DFT de González et. al. [160] usando uma geometria otimizada com B3LYP/6-311+G(d,p) . ZPE se refere à diferença da energia de ponto zero entre o complexo e as partes separadas usando MP2/aug-cc-pVDZ ..................... 11

9.3 Valores médios da energia de ligação ( $\mathrm{kcal} / \mathrm{mol}$ ) em fase líquida dos dois isômeros de metanol-água obtidos com MP2/aug-cc-pVDZ incluindo correção para BSSE. Os momentos de dipolo estão em Debye e as polarizabilidades (média e anisotrópica) estão em ua. Despolarizações Rayleigh ( $\sigma$ para polarização natural, planar e circular) são adimensionais. Os desvios padrão também são mostrados . . . . . . . . . . . . . . . . . . 112

10.1 Geometria (em $\AA$ ) e parâmetros do potencial do benzeno. . . . . . . . . 116 
10.2 Polarizabilidade de dipolo calculada para o líquido de benzeno (em ua) usando a aproximação de campo finito com os métodos INDO e DFT. $\langle\bar{\alpha}\rangle$ é a média estatística da polarizabilidade de dipolo média e $\Delta \alpha$ é a a média estatística da polarizabilidade anisotrópica. O valor de $\bar{\alpha}$ calculado para a fase gasosa é 43.0ua (INDO) e 53.4ua (DFT) . . . . . . . . . . . . . 123

11.1 Parâmetros dos potenciais utilizados . . . . . . . . . . . . . 130

11.2 Blindagem isotrópica, $\sigma^{i s o}$, e anisotrópica, $\sigma^{a n i s}$, para os átomos da molécula de água em geometria rígida e em geometria flexível. Valores em ppm obtidos em nível B3LYP/6-311++G(2d,2p). OPT designa os valores para a geometria otimizada em nível B3LYP $/ 6-311++\mathrm{G}(2 \mathrm{~d}, 2 \mathrm{p})$. As incertezas são os desvios padrão da média obtida sobre 100 configurações a) Ref. [201]; b) Ref. [199]; c) Ref. [204] . . . . . . . . . . . . . . . . 132

11.3 Blindagem isotrópica, $\sigma^{i s o}$, e anisotrópica, $\sigma^{a n i s}$, para os átomos da molécula de água de referência da primeira camada de solvatação. Valores em ppm obtidos em nível B3LYP/6-311++G(2d,2p). OPT designa os valores para a geometria otimizada em nível B3LYP/6-311++G(2d,2p). As incertezas são os desvios padrão da média obtida sobre 100 configurações. a) Ref. [201]; b) Ref. [280] . . . . . . . . . . . . . . . . 134

11.4 Dependência da blindagem magnética isotrópica e anisotrópica com o uso de bases localmente densas. Balanceada se refere a base $6-311++G(2 d, 2 p)$ e densa se refere à combinação $6-311++G(2 d, 2 p)$ e 3-21G (veja texto). Valores em ppm obtidos em nível B3LYP para estruturas geradas com o potencial DP. As incertezas são os desvios padrão da média obtida sobre 100 confi-

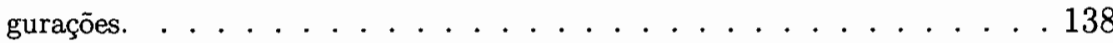

11.5 Dependência dos deslocamentos químicos isotrópico, $\delta^{i s o}$, e anisotrópico, $\delta^{\mathbf{a n i s}}$, com o tamanho do aglomerado. Valores em ppm não corrigidos (sCC) e corrigidos (cCC) contra BSSE. As estruturas usadas nas médias foram geradas com o potencial DP e os cálculos quânticos foram realizados em nível B3LYP/6-311++G(2d,2p) . . . . . . . . . . . . 139 
11.6 Dependência das componentes paralela, $\delta_{/ /}$, perpendicular $\delta_{\perp}$ do tensor deslocamento químico isotrópico com o tamanho do aglomerado. Valores em ppm não corrigidos (sCC) e corrigidos (cCC) contra BSSE através da correção. As estruturas usadas nas médias foram geradas com o potencial DP e os cálculos quânticos foram realizados em nível B3LYP. As incertezas são os desvios padrāo da média . . . . . . . . . . . . . . . . . . 143

11.7 Valores médios em ppm para os deslocamento químicos obtidos para aglomerados com 13 moléculas de água com vários funcionais diferentes. As incertezas são os desvios padrão da média. Ref. [201]; b) Ref. [280] . . . . . 145 


\section{Lista de Figuras}

3.1 Energia eletrônica (incluindo a repulsão nuclear) em função da distância $R$ para o estado ligado de um sistema . . . . . . . . . . . . . . . 21

4.1 Estruturas geométricas do complexo acetonitrila-água . . . . . . . . . . 34

5.1 Estruturas otimizadas dos complexos: $\mathrm{CH}_{3} \mathrm{CN} \cdots \mathrm{H}_{2} \mathrm{O}, \mathrm{HCHO} \cdots \mathrm{H}_{2} \mathrm{O}, \mathrm{CH}_{3} \mathrm{HO} \cdots \mathrm{H}_{2} \mathrm{O}$, $\mathrm{HCOOH} \cdots \mathrm{OH}_{2}, \mathrm{H}_{2} \mathrm{O} \cdots \mathrm{H}_{2} \mathrm{O}(1)$ e $\left(\mathrm{CH}_{3}\right)_{2} \mathrm{CO} \cdots \mathrm{H}_{2} \mathrm{O}$. Os comprimentos das ligações de hidrogênio são dados em $\AA$, e foram obtidos em nível MP2/augcc-pVDZ ......................... 50

5.2 Estruturas dos complexos cianeto de hidrogênio-água e metanol-água. Os comprimentos das ligações de hidrogênio são dados em $\AA$, e foram obtidos em nível MP2/aug-cc-pVDZ . . . . . . . . . . . . . . . 55

6.1 Deslocamento químico isotrópico e anisotrópico para o complexo $\mathrm{CH}_{3} \mathrm{OH} \cdots \mathrm{OH}_{2}$ em três níveis teóricos. Resultados corrigidos contra BSSE . . . . . . . . . 70

6.2 Deslocamento químico isotrópico e anisotrópico para o complexo $\mathrm{CH}_{3} \mathrm{HO} \cdots \mathrm{H}_{2} \mathrm{O}$ em três níveis teóricos. Resultados corrigidos contra BSSE . . . . . . . . . 71

7.1 Estruturas otimizadas em nível MP2/aug-cc-pVDZ para os dímeros de água (WW), metanol (MM) e etanol (EE). As distâncias Ro...o são mostradas .

7.2 Estruturas otimizadas em nível MP2/aug-cc-pVDZ para os heterodímeros envolvendo etanol gauche e água $\left(\mathbf{E}_{g} \mathbf{W}\right.$ e $\left.\mathbf{W} \mathbf{E}_{g}\right)$. A convenção usada indica moléculas doadora e aceitadora de próton respectivamente (DA). As distâncias Ro..o sāo mostradas . . . . . . . . . . . . . . 80 
7.3 Estruturas otimizadas em nível MP2/aug-cc-pVDZ para os heterodímeros envolvendo metanol e água. (MW e WM); etanol e água (EW e WE); e metanol e etanol (ME e EM). A convenção usada indica moléculas doadora e aceitadora de próton respectivamente (DA). As distâncias Ro... o são mostradas 80

7.4 Estabilidades relativas dos sistemas homogêneos e misturados . . . . . . . 88

8.1 Função de distribuição radial entre o átomo de nitrogênio da molécula de piridina e o átomo de hidrogênio das moléculas de água . . . . . . . 995

8.2 Histograma de energias de interação de pares entre as moléculas de piridina

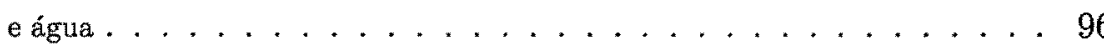

8.3 Superposição de configuraçōes das ligações de hidrogênio formadas pela piridina em solução aquosa . . . . . . . . . . . . . . . . 996

8.4 A estrutura do complexo otimizado de piridina-água . . . . . . . . . . 96

8.5 Transferência de carga (em unidade elementar) da molécula de piridina para a molécula de água em comparação com o valor para o complexo otimizado

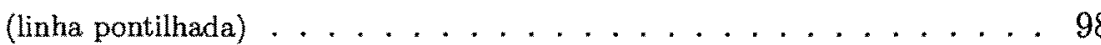

8.6 Distribuição dos valores dos momentos de dipolo calculados e a distribuição normal com $(\mu)=4.71 \mathrm{D}$ e $\delta=0.68 \mathrm{D} \ldots \ldots 100$

8.7 Convergência da média calculada da polarizabilidade de dipolo média . . . . 101

8.8 Histograma mostrando a distribuição da taxa de despolarização no líquido em comparação com o valor para o complexo otimizado (linha pontilhada) . 102

9.1 Função de distribuição radial de pares entre os átomos de oxigênio do metanol

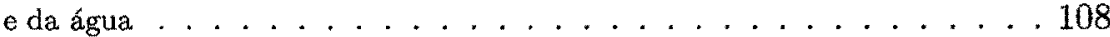

9.2 Histograma das energias de interação de pares entre metanol e água. (a) se refere ao isômero $\mathrm{CH}_{3} \mathrm{OH} \cdots \mathrm{OH}_{2}$ e (b) ao isômero $\mathrm{CH}_{3} \mathrm{HO} \cdots \mathrm{H}_{2} \mathrm{O} \ldots 109$

9.3 Superposição das configurações das ligações de hidrogênio formadas pelo metanol em solução aquosa . . . . . . . . . . . . . . 110 
9.4 Convergência das energias de ligação para o complexo metanol-água. (a) se refere ao isômero $\mathrm{CH}_{3} \mathrm{OH} \cdots \mathrm{OH}_{2}$ e (b) ao isômero $\mathrm{CH}_{3} \mathrm{HO} \cdots \mathrm{H}_{2} \mathrm{O}$. Os erros estatisticos são mostrados . . . . . . . . . . . . . . 113

9.5 Histograma mostrando a distribuiçäo das energias de ligaçäo entre metanol e água. $\mathrm{A}$ linha cheia se refere ao isômero $\mathrm{CH}_{3} \mathrm{HO} \cdots \mathrm{H}_{2} \mathrm{O}$ e a linha pontilhada ao isômero $\mathrm{CH}_{3} \mathrm{OH} \ldots \mathrm{OH}_{2} \ldots \ldots \ldots . \ldots . \ldots 114$

10.1 Função de distribuição radial de pares entre os centros de massa das moléculas

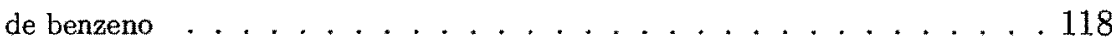

10.2 Ilustração das duas configurações supermoleculares, em cima com 14 moléculas e em baixo com 28 moléculas . . . . . . . . . . . . . . . . . 119

10.3 Função de autocorrelação da energia O passo MCM é normalizado ao número total de moléculas . . . . . . . . . . . . . . 120

10.4 Convergência estatística da polarização de dipolo. As barras representam o erro estatístico. O exemplo corresponde ao campo finito de intensidade 0.002 ua aplicado na menor supermolécula ao longo da direção $x \ldots 121$

10.5 Momento de dipolo induzido como função do campo elétrico aplicado. Cada ponto mostrado é o resultado convergido de uma média estatística de 62 cálculos de mecânica quântica (veja Figura 10.4) . . . . . . . . . . 122

10.6 Distribuição estatística do momento de dipolo calculado com o campo de intensidade 0.002 ua ao longo da direção $x \ldots \ldots$. . . . . . . . . . 124

10.7 Resultados calculados para a polarizabilidade de dipolo média por molécula de benzeno para a menor supermolécula usando o modelo B3LYP/6-31G , . 124

11.1 Convergência da média da blindagem isotrópica, $\sigma^{i s o}$, para os dois átomos de hidrogênio da molécula de referência da primeira camada de solvatação do líquido de água (potencial DP). A curva de bolas cheias representa a convergência para a média da blindagem dos dois hidrogẽnios . . . . . . . 135 
11.2 Convergência da média da blindagem isotrópica, $\sigma^{i s o}$, e anisotrópica, $\sigma^{\text {anis }}$, para os átomos da molécula da primeira camada de solvatação do líquido de água. As bolas cheias representam a convergência dos resultados obtidos com o potencial DP e as vazias para o potencial FERG. As barras verticais

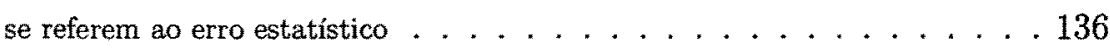

11.3 Tamanhos de aglomerados usados . . . . . . . . . . . . . . . 140

11.4 Convergência do deslocamento químico isotrópico, $\delta^{i s o}$, com o número de moléculas nos aglomerados usados no cálculo da média. Cada ponto no gráfico se refere a uma média sobre 50 cálculos B3LYP com base localmente densas, exceto para os aglomerados com 5 e 9 moléculas para os quais foram realizados 100 cálculos quânticos . . . . . . . . . . . . . . 141

11.5 Convergência do deslocamento químico anisotrópico, $\delta^{\text {anis }}$, com o número de moléculas nos aglomerados usados no cálculo da média. Cada ponto no gráfico se refere a uma média sobre 50 cálculos B3LYP com base localmente densa, exceto para os aglomerados com 5 e 9 moléculas para os quais foram realizados 100 cálculos quânticos. . . . . . . . . . . . 142

11.6 Convergência das componentes paralela, $\delta_{/ /}$, e perpendiculares, $\delta_{1}$, do deslocamento químico isotrópico do átomo de hidrogênio. Cada ponto no gráfico se refere a uma média sobre 50 cálculos B3LYP com base localmente densa, exceto para os aglomerados com 5 e 9 moléculas para os quais foram realizados 100 cálculos quânticos . . . . . . . . . . . . . . . . 144

B.1 Representação em coordenadas polares da intensidade de emissão de radiação por um momento de dipolo oscilante . . . . . . . . . . . . . . 208

B.2 Espalhamento Raman a ângulos retos a partir da direçāo do feixe incidente, mostrando as componentes polarizadas . . . . . . . . . . . . . 209 